\title{
WestVirginiaUniversity
}

THE RESEARCH REPOSITORY @ WVU

Graduate Theses, Dissertations, and Problem Reports

2010

\section{Live load distribution factors for exterior girders in steel I-girder bridges}

\author{
Gregory K. Michaelson \\ West Virginia University
}

Follow this and additional works at: https://researchrepository.wvu.edu/etd

\section{Recommended Citation}

Michaelson, Gregory K., "Live load distribution factors for exterior girders in steel l-girder bridges" (2010). Graduate Theses, Dissertations, and Problem Reports. 4632.

https://researchrepository.wvu.edu/etd/4632

This Thesis is protected by copyright and/or related rights. It has been brought to you by the The Research Repository @ WVU with permission from the rights-holder(s). You are free to use this Thesis in any way that is permitted by the copyright and related rights legislation that applies to your use. For other uses you must obtain permission from the rights-holder(s) directly, unless additional rights are indicated by a Creative Commons license in the record and/ or on the work itself. This Thesis has been accepted for inclusion in WVU Graduate Theses, Dissertations, and Problem Reports collection by an authorized administrator of The Research Repository @ WVU. For more information, please contact researchrepository@mail.wvu.edu. 


\title{
LIVE LOAD DISTRIBUTION FACTORS FOR EXTERIOR GIRDERS IN STEEL I-GIRDER BRIDGES
}

\author{
Gregory K. Michaelson \\ Thesis submitted to the \\ College of Engineering and Mineral Resources \\ at West Virginia University \\ in partial fulfillment of the requirements \\ for the degree of \\ Master of Science \\ in \\ Civil and Environmental Engineering
}

Karl E. Barth, Ph.D., Chair

Udaya B. Halabe, Ph.D.

Hema J. Siriwardane, Ph.D.

Department of Civil and Environmental Engineering

Morgantown, West Virginia

2010

Keywords: steel bridge, LRFD, live load distribution, finite element modeling, parametric study 


\begin{abstract}
LIVE LOAD DISTRIBUTION FACTORS FOR EXTERIOR GIRDERS IN STEEL I-GIRDER BRIDGES
\end{abstract}

\title{
Gregory K. Michaelson
}

In lieu of a complex three-dimensional analysis, live load distribution factors (also referred to as girder distribution factors or wheel load distribution factors) are commonly employed by bridge engineers to simplify the analysis of a bridge system. Specifically, instead of looking at the bridge system as a whole, these factors allow for a designer or analyst to consider bridge girders individually by determining the maximum number of wheels (or lanes) that may act on a given girder.

The development of the relatively new distribution factors for beam-and-slab bridges incorporated in the current AASHTO LRFD Specifications are primarily the result of NCHRP Report 12-26. This report, however, does not take into account the different live load responses of interior and exterior girders. Numerous research studies have shown that the distribution of live load in a bridge system differs between interior girders and exterior girders.

The current AASHTO specifications employ three methods to determine the distribution to exterior girders: a statical based procedure called the lever rule, a rigid body rotation procedure called special analysis, and an empirical equation that calculates an adjustment factor that is applied to the interior girder distribution factor. While several studies have shown that for many cases these methods do not accurately predict the load in the exterior girder little work is available to actually evaluate the distribution of live load to exterior girders.

Therefore, the goal of this research is to develop new expressions for the distribution of live load to the exterior girders of steel slab-on-beam bridges. To accomplish this, a commercial finite element software package (Abaqus) is employed. The finite element modeling technique used in this project is first compared with physical data from the August 2002 field test of the Missouri Bridge A6101. Once validated, this modeling technique is then used in a sensitivity study to determine the effect of key parameters on exterior girder live load distribution. Subsequently, a parametric matrix employing these key parameters is developed and analyzed. Data correlation techniques are then used to relate the parameters which were varied throughout the course of this study to develop empirical equations for live load distribution factors. 


\section{ACKNOWLEDGMENTS}

The author would like to thank the following:

1. Dr. Karl E. Barth, for both the opportunity to pursue a Master of Science as well as his invaluable guidance and direction. His encouragement and support throughout this project, and graduate school altogether, was greatly appreciated.

2. Dr. Udaya B. Halabe, and Dr. Hema J. Siriwardane, for their participation on this thesis' graduate advisory committee.

3. Rebecca Dale, for her love and support. Without these, this thesis would not have been possible.

4. Scott Morgan, for always being there to bounce ideas off of, tolerating me for a year and a half, and doing a great job both welcoming me and introducing me to West Virginia University.

5. The crew of ESB-B11, for making the graduate student experience a much more enjoyable one than it would have been without them.

Special thanks also go to Dr. Abelardo Garza at Dassault Systèmes Simulia for his advice regarding some alternative finite element modeling techniques. His tips regarding FEA saved me countless hours modeling the bridges in my study, and his assistance is greatly appreciated.

Funding for this research was provided by the Jack H. Samples Distinguished Professorship in Structural Engineering at West Virginia University and is greatly appreciated. 


\section{TABle of Contents}

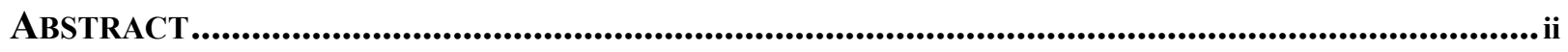

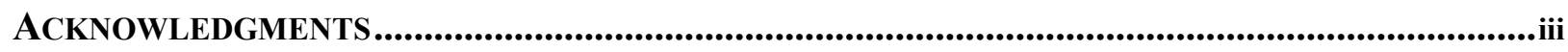

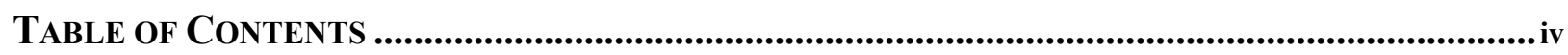

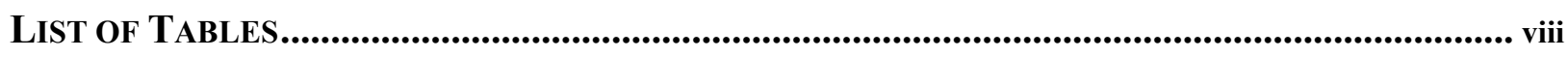

LIST OF FIGURES

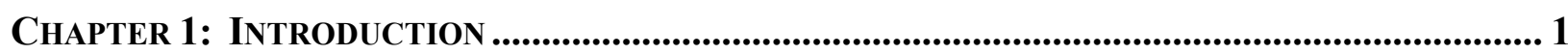

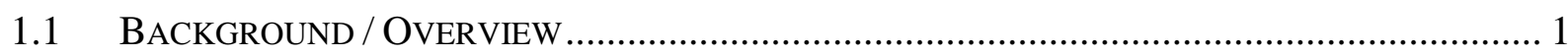

1.2 PROJECT SCOPE \& OBJECTIVES ............................................................................ 2

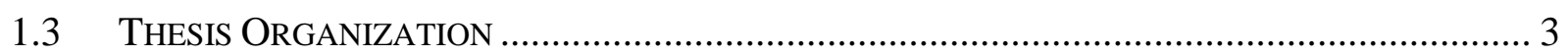

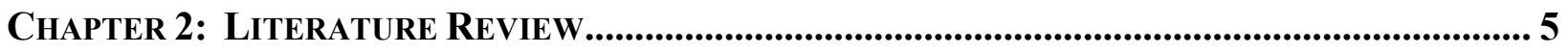

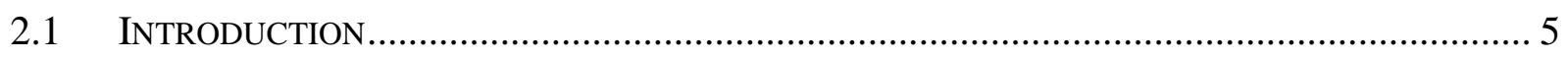

2.2 HistoricAl DeVElopment OF AASHTO Live LOAD DistribUtion FACTORS ............. 5

2.2.1 AASHTO Standard Specifications ............................................................... 5

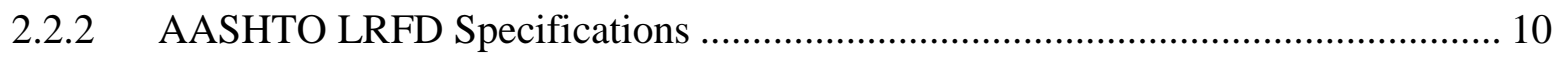

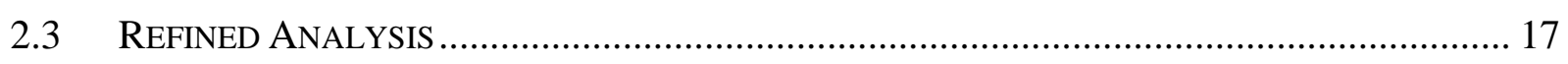

2.3.1 Simplified Computer Analysis....................................................................... 17

2.3.2 Detailed Computer Analysis ........................................................................... 18

2.4 Studies Evaluating CurRent Live LoAd Distribution Factors......................... 19

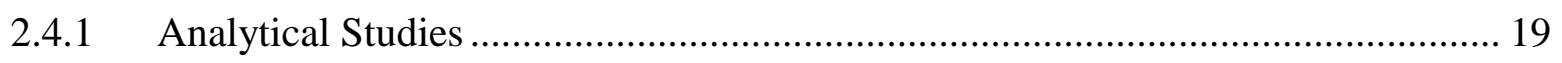

2.4.2 Field Studies....................................................................................... 22

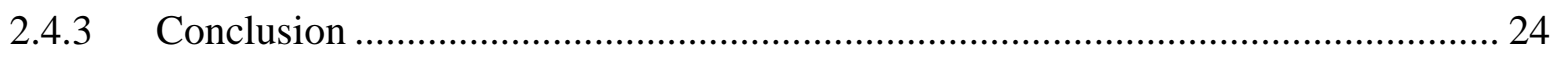

2.5 INFLUENCE OF VARIOUS PARAMETERS ON LIVE LOAD DiSTRIBUTION ........................... 25

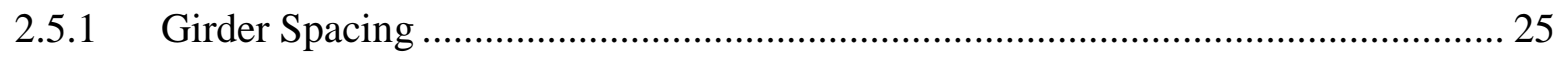

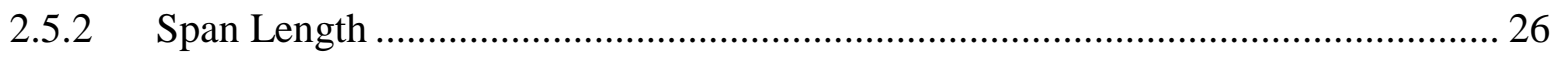

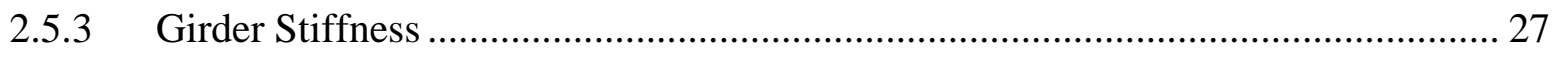

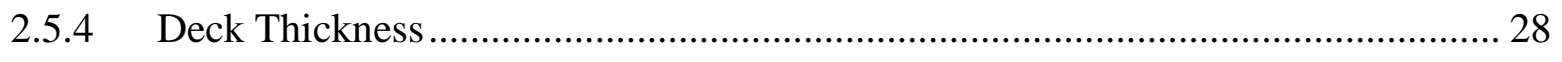

2.5.5 Girder Location and Number of Girders........................................................ 29

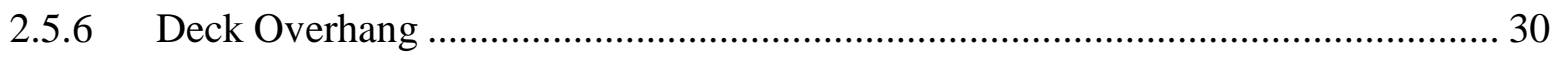

2.5.7 Continuity (Support) Conditions................................................................... 30

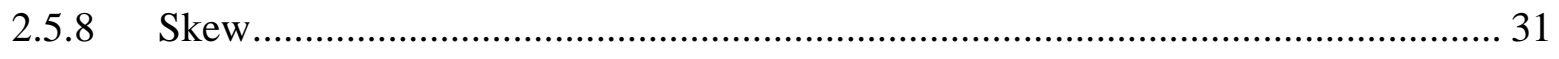

2.5.9 Cross-Frame Characteristics ....................................................................... 31 


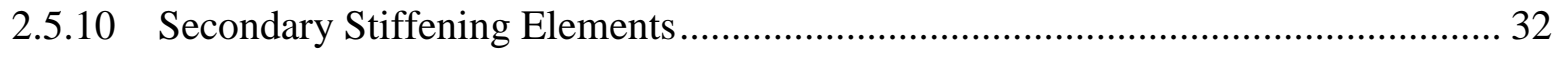

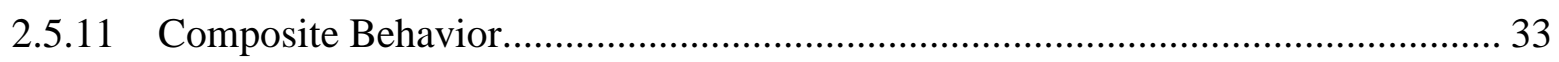

2.6 Live LoAd Distribution in Foreign Highway Bridge Codes................................... 33

2.6.1 Ontario Highway Bridge Design Code ………………........................................... 33

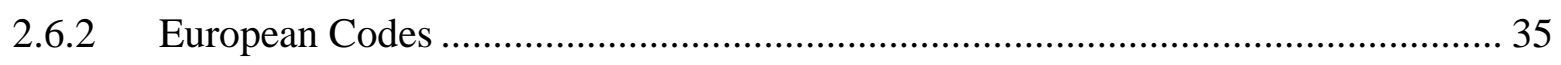

2.6.3 Australian Bridge Code................................................................................. 35

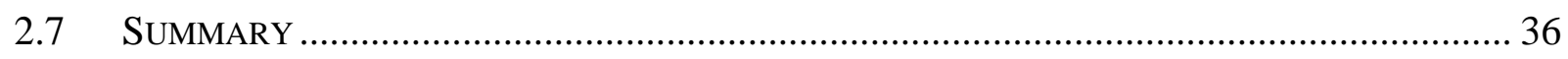

CHAPTER 3: AASHTO LRFD DISTRIBUTION FACTORS FOR EXTERIOR GIRDERS ................... 37

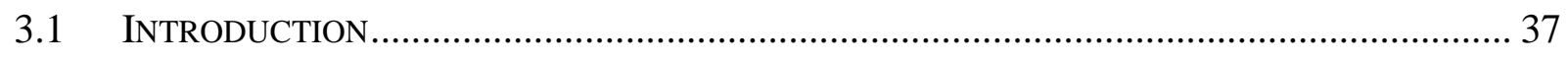

3.2 CURRENT AASHTO EXTERIOR GIRDER DistRIBUTION FACTORS .................................. 37

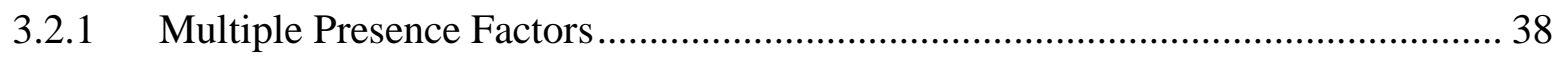

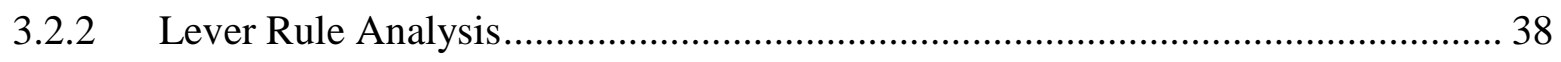

3.2.3 Modified Interior Girder Distribution Factors ...................................................... 39

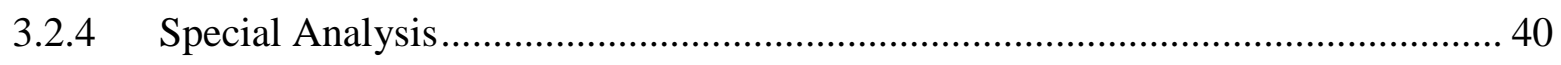

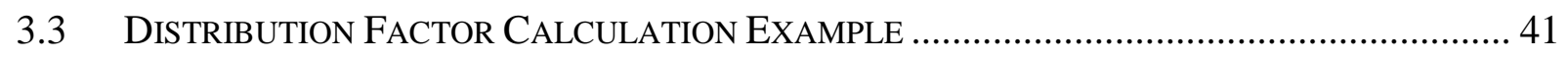

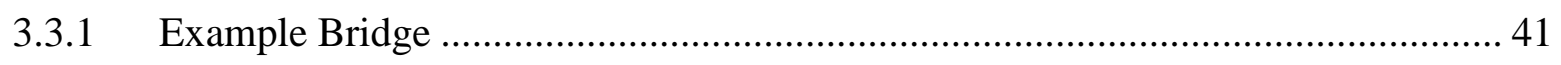

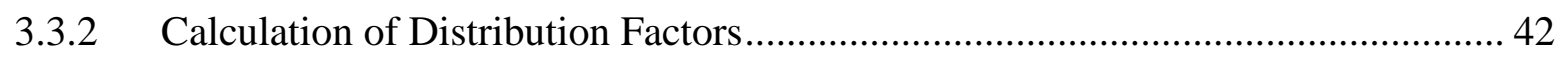

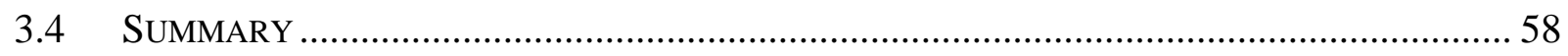

Chapter 4: Finite Element Modeling Techniques and Analytical Computation of

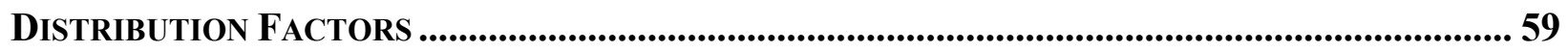

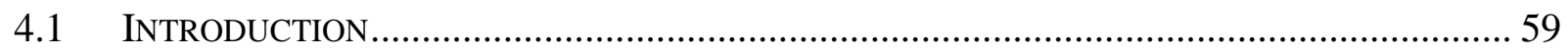

4.2 Finite Element Modeling TechniQues................................................................ 59

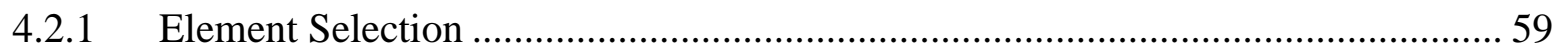

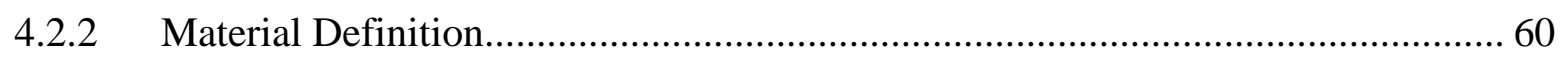

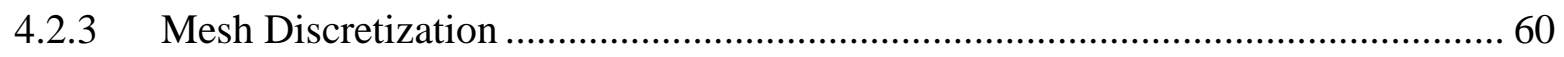

4.2.4 Boundary Conditions and Multiple-Point Constraints........................................... 61

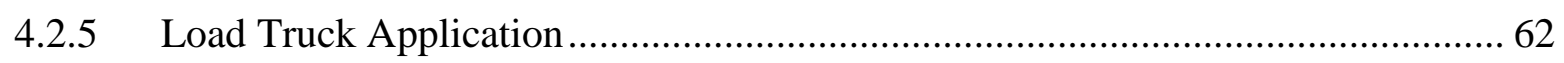

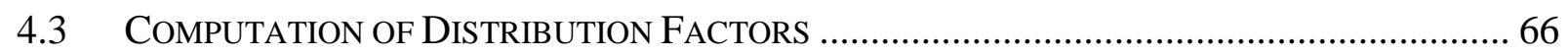

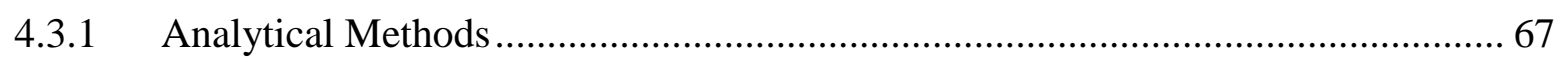

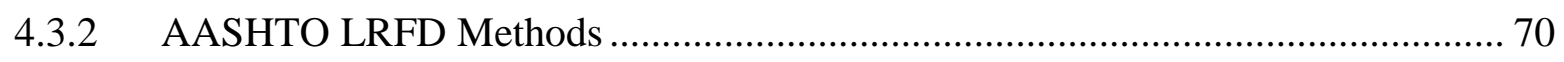

4.4 Benchmark ANALYSIS: Missouri Bridge A6101 ……............................................. 70

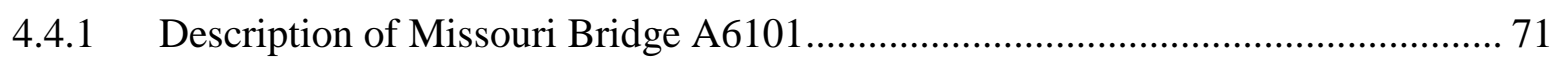

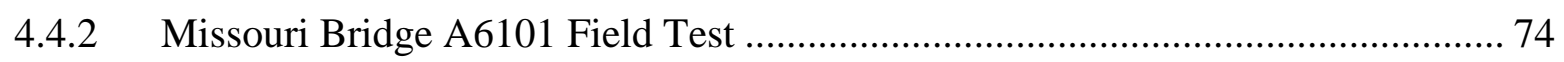

4.4.3 Missouri Bridge A6101 Finite Element Model ......................................................... 77 


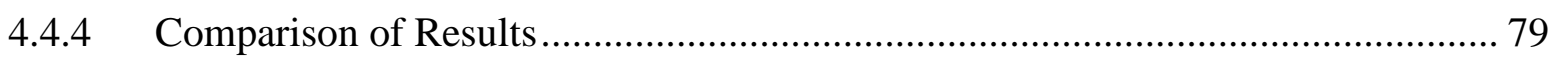

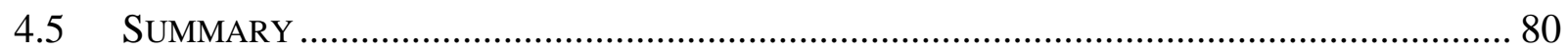

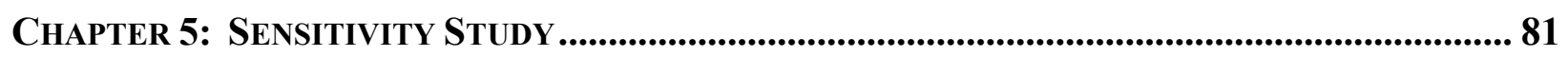

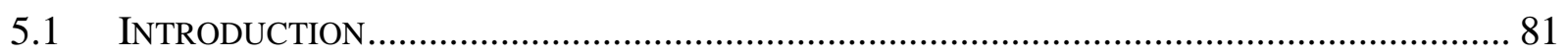

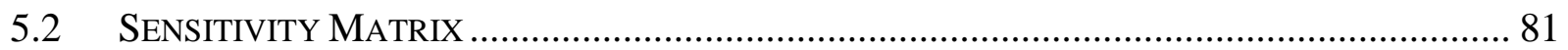

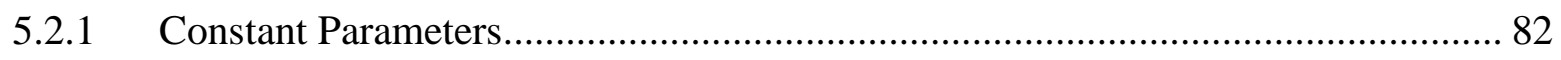

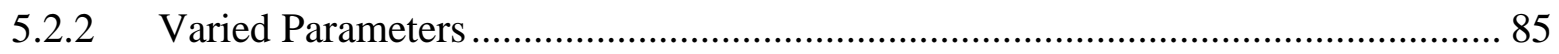

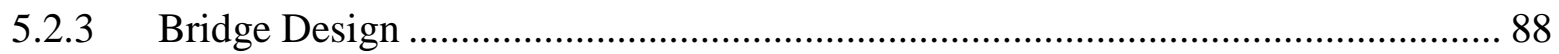

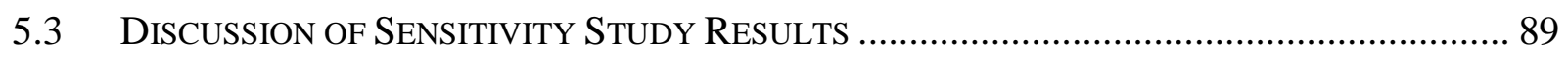

5.3.1 Comparison with AASHTO LRFD Distribution Factors …………………............. 90

5.3.2 Influence of Girder Spacing / Number of Beams ................................................. 91

5.3.3 Influence of Span Length / Girder Stiffness ........................................................... 93

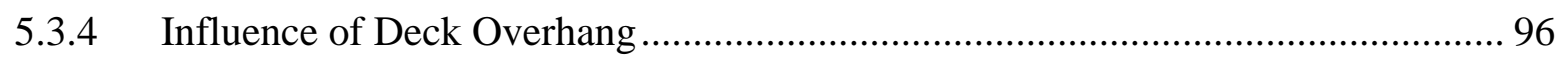

5.3.5 Influence of Barrier Presence.................................................................................. 98

5.3.6 Influence of Cross-Frame Stiffness ................................................................... 100

5.3.7 Influence of Unbraced Length ............................................................................... 103

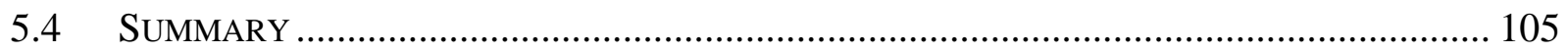

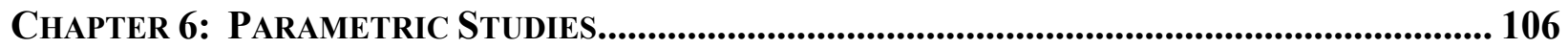

6.1 INTRODUCTION .......................................................................................... 106

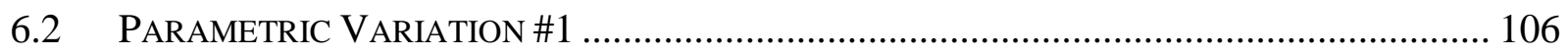

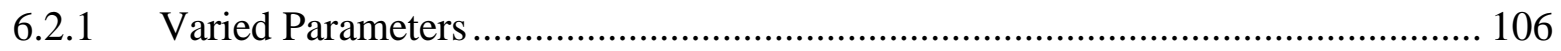

6.2.2 Discussion of Parametric Variation \#1 Results .................................................... 107

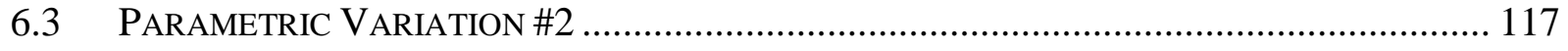

6.3.1 Determination of Key Parameters................................................................... 118

6.3.2 Discussion of Parametric Variation \#2 Results ................................................... 121

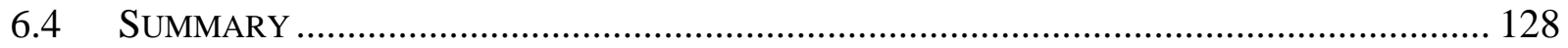

ChAPTER 7: DEVElopMent OF MODIFIEd EXTERIOR Girder Distribution FACTORS .... 129

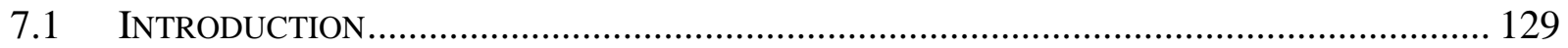

7.2 DeVELOPMENT OF PRoposed Equations ……….................................................... 129

7.2.1 Selection of Analytical Computation Technique................................................... 129

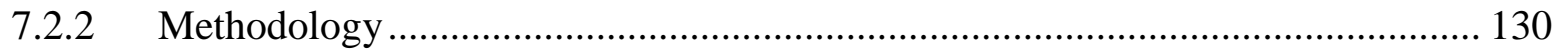

7.2.3 Proposed Equations......................................................................................... 131

7.3 COMPARISON OF PROPOSED EQUATIONS ................................................................ 132

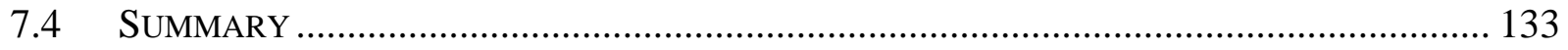


CHAPTER 8: SUMMARY AND CONCLUDING REMARKS................................................................ 134

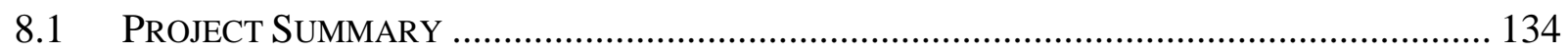

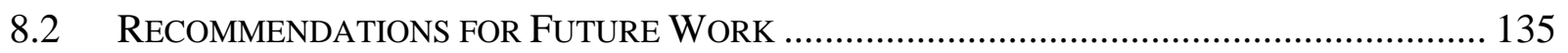

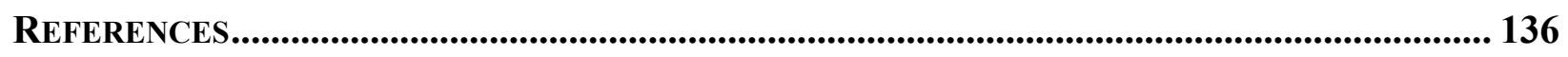

APPENDIX A: SENSITIVITY MATRIX RESUlTS ............................................................................ 139

APPENDIX B: PARAMETRIC VARIATION \#1 RESUlTS .................................................................. 157

APPENDIX C: PARAMETRIC VARIATION \#2 RESULTS .............................................................. 182

APPENDIX D: COMPARISON OF PROPOSED EQUATIONS .............................................................. 194 


\section{LIST OF TABLES}

Table 2.1: Live Load Distribution Factors from the AASHTO Standard Specifications ............. 7

Table 2.2: Parametric Values Used in Derivation of Distribution Factors ............................... 13

Table 3.1: AASHTO Multiple Presence Factors ................................................................ 38

Table 3.2: Multiple-Loaded-Lane Correction Factors for Exterior Beam Distribution Factors.. 39

Table 3.3: Example Bridge Girder Dimensions.................................................................. 42

Table 3.4: Example Bridge Section Properties ................................................................. 44

Table 3.5: Example Bridge "x" Distances .......................................................................... 55

Table 3.6: Example Bridge "e" Distances........................................................................... 55

Table 3.7: Example Bridge Distribution Factors …............................................................. 57

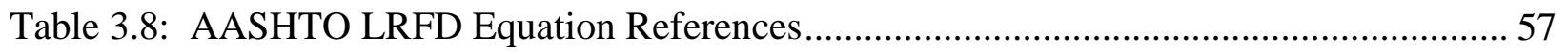

Table 4.1: Missouri Bridge A6101 Truck Run Positions ..................................................... 77

Table 4.2: Missouri Bridge A6101 Finite Element Model Verification .................................... 79

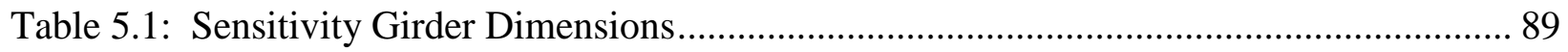

Table 6.1: Parametric Variation \#2 Girder Dimensions ..................................................... 121 


\section{LIST OF FIGURES}

Figure 2.1: Notational Model for Applying Lever Rule to Three-Girder Bridges ...................... 8

Figure 2.2: Statistical Comparison of Analytical Distribution Factors with a: AASHTO Standard Equations and b: Derived Equations (Moment, Interior Girder, Multiple Lanes Loaded)........... 15

Figure 3.1: Example Bridge Cross-Section ..................................................................... 41

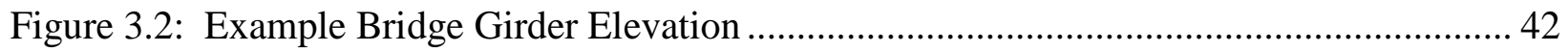

Figure 3.3: Example Bridge Lever Rule Truck Placement ...................................................... 50

Figure 3.4: Example Bridge Special Analysis Truck Placement ........................................... 54

Figure 4.1: Mesh Discretization for Concrete Deck ......................................................... 61

Figure 4.2: Abaqus Screen Capture of Sensitivity Bridge Model .......................................... 62

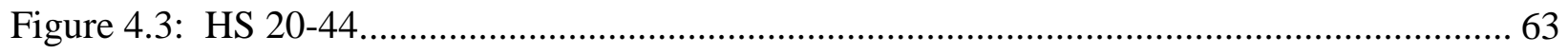

Figure 4.4: Schematic of Nodal Distribution of Point Loads ............................................... 66

Figure 4.5: Elevation View of Missouri A6101 Bridge (Wu, 2003) ....................................... 71

Figure 4.6: Missouri Bridge A6101 Cross-Section................................................................ 72

Figure 4.7: Missouri Bridge A6101 Girder Elevation ...................................................... 72

Figure 4.8: Missouri Bridge A6101 Framing Plan .............................................................. 72

Figure 4.9: Missouri Bridge A6101 Cross-Frames ............................................................. 73

Figure 4.10: Missouri Bridge A6101 Barrier................................................................... 74

Figure 4.11: Missouri Bridge A6101 Load Truck (Wu, 2003).............................................. 76

Figure 4.12: Missouri Bridge A6101 Truck Run Schematic .................................................. 77

Figure 4.13: Abaqus Screen Capture of Missouri Bridge A6101 Model ................................ 78

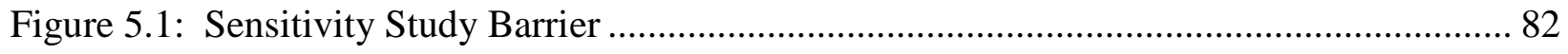

Figure 5.2: Sensitivity Matrix End Cross-Frame ............................................................ 84

Figure 5.3: Sensitivity Matrix Interior Cross-Frame ......................................................... 84

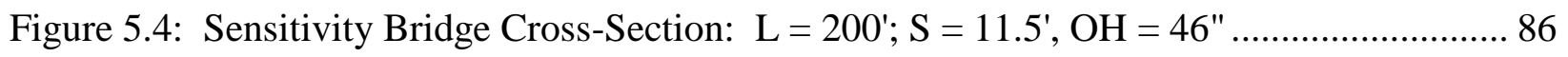

Figure 5.5: Sensitivity Bridge Cross-Section: L = 200'; S = 11.5', OH = 69" ........................ 86

Figure 5.6: Sensitivity Bridge Cross-Section: L = 200'; S = 8.625', OH = 46" ...................... 87

Figure 5.7: Sensitivity Bridge Cross-Section: $\mathrm{L}=200$ '; $\mathrm{S}=8.625$ ', $\mathrm{OH}=69$ "...................... 87

Figure 5.8: 100-Foot Girder Elevation for Sensitivity Study .............................................. 88

Figure 5.9: 200-Foot Girder Elevation for Sensitivity Study ............................................... 88 
Figure 5.10: Comparison of AASHTO and FEA Distribution Factors 90

Figure 5.11: Comparison of the Effect of Girder Spacing / Number of Beams with a: one lane loaded, b: two lanes loaded, and c: three lanes loaded 92

Figure 5.12: Comparison of the Effect of Span Length / Girder Stiffness with a: one lane loaded, b: two lanes loaded, and c: three lanes loaded. 95

Figure 5.13: Comparison of the Effect of Deck Overhang with a: one lane loaded, b: two lanes loaded, and c: three lanes loaded 97

Figure 5.14: Comparison of the Effect of Barrier Presence with a: one lane loaded, b: two lanes loaded, and c: three lanes loaded 100

Figure 5.15: Comparison of the Effect of Cross-Frame Stiffness with a: one lane loaded, b: two lanes loaded, and c: three lanes loaded 102

Figure 5.16: Comparison of the Effect of Unbraced Length with a: one lane loaded, b: two lanes loaded, and c: three lanes loaded 104

Figure 6.1: Comparison of the Effect of Girder Stiffness with a: one lane loaded, b: two lanes loaded, and c: three lanes loaded 109

Figure 6.2: Comparison of the Effect of Span Length with a: one lane loaded, b: two lanes loaded, and c: three lanes loaded 111

Figure 6.3: Comparison of the Effect of Girder Spacing with a: one lane loaded, b: two lanes loaded, and c: three lanes loaded 114

Figure 6.4: Comparison of the Effect of the Number of Beams with a: one lane loaded, b: two lanes loaded, and c: three lanes loaded 116

Figure 6.5: 100-Foot Girder Elevation for Parametric Variation \#2 ..................................... 121

Figure 6.6: Remaining Girder Elevations for Parametric Variation \#2 ................................. 121

Figure 6.7: Comparison of the Influence of Girder Spacing with a: FEA \#1, b: FEA \#2 ......... 123

Figure 6.8: Comparison of the Influence of Span Length with a: FEA \#1, b: FEA \#2 ............. 124

Figure 6.9: Comparison of the Influence of Deck Overhang with a: FEA \#1, b: FEA \#2 ........ 126

Figure 6.10: Comparison of the Influence of Number of Beams with a: FEA \#1, b: FEA \#2 .. 127 


\section{CHAPTER 1: INTRODUCTION}

\subsection{BACKGROUND / OVERVIEW}

In lieu of a complex three-dimensional analysis, live load distribution factors (also referred to as girder distribution factors or wheel load distribution factors) are commonly employed by bridge engineers to simplify the analysis of a bridge system. Specifically, instead of looking at the bridge system as a whole, these factors allow for a designer or analyst to consider bridge girders individually by determining the maximum number of wheels (or lanes) that may act on a given girder. The current AASHTO LRFD Specifications give relatively simple, empirical equations for determination of said distribution factors, based on the type of superstructure and cross section, the number of loaded design lanes, and whether interior or exterior beams are being analyzed.

The development of the relatively new LRFD distribution factors for beam-and-slab bridges is the result of NCHRP Report 12-26 (Nutt, Schamber, \& Zokaie, 1988). This report, however, does not take into account the different live load responses of interior and exterior girders. Numerous researchers have stated that the distribution of live load in a bridge system differs between interior girders and exterior girders. Walker (1987) and Zokaie (2000) found that girder location, i.e. interior vs. exterior, has an influence on live load distribution and that edge girders are more sensitive to truck placement than interior girders.

However, as of today, there is a considerable lack of research in the distribution of live loads to exterior girders. Currently, the methods presented in the AASHTO LRFD Specifications for the determination of exterior girder live load distribution are based off of much older techniques that have been in place since the adoption of the first edition of the AASHO Specifications in the 1930s (American Association of State Highway Officials, 1931). Therefore, there is a definite need to develop more accurate distribution factors for exterior girders in steel I-girder bridges. 


\subsection{Project Scope \& ObJectives}

The focus of this project is to develop more accurate expressions for live load distribution factors for exterior girders in steel I-girder bridges. Specifically, this is accomplished in the following manner.

- A literature review focused on determining the effect of certain parameters on live load distribution was conducted. Particular attention was paid to NCHRP Report 12-26 (Nutt, Schamber, \& Zokaie, 1988), the report whose work resulted in the development of the empirical distribution factors which are still incorporated in the current AASHTO LRFD Specifications.

- A highly accurate finite element modeling technique (which would be later used to determine live load distribution factors) was then assessed by comparing results from this technique with physical load test data from the 2002 testing of Missouri Bridge A6101 (Wu, 2003).

- A sensitivity matrix was developed to determine the influence of certain parameters on exterior girder live load distribution. These bridges were then analyzed (with the aforementioned modeling technique) using a commercial finite element software package (Dassault Systèmes, 2009), and live load distribution factors were calculated from the finite element results.

- Once the results of the sensitivity study were analyzed, key parameters which were determined to have the most significant impact on exterior girder live load distribution were expanded to encapsulate a wider range of bridges. This expanded parametric matrix was then analyzed using the aforementioned technique, and live load distribution factors were calculated from the finite element results.

- Finally, the results of the parametric study were used in with a commercial data correlation software tool (Oakdale Engineering, 2008) to develop empirical distribution factors for exterior girders. 


\subsection{Thesis Organization}

A brief overview of the organization of this thesis is as follows:

- Chapter 2:

o This chapter summarizes previous live load distribution factor research that led to the formulation of the equations currently the AASHTO Specifications. In addition, a brief overview of distribution factors for other countries is presented.

- Chapter 3:

o This chapter outlines the procedures for determining live load distribution factors for exterior girders in steel I-girder bridges according to AASHTO LRFD Specifications.

- $\quad$ Chapter 4:

o This chapter outlines the finite element modeling techniques used for this research project. Also, presented in this chapter are the methods used to calculate distribution factors from finite element models. Finally, a benchmark analysis of the Missouri Bridge A6101, which was used to verify the validity of the modeling techniques presented herein, is discussed.

- Chapter 5:

o This chapter describes a matrix of bridges analyzed with a commercial finite element software package (Dassault Systèmes, 2009) in order to determine the sensitivity of certain parameters on the exterior girder live load. A description of the matrix is provided, along with both the constant and varied parameters. Finally, the results of this study are discussed, highlighting specifically the influence of the parameters varied on exterior girder live load distribution. 
- Chapter 6:

o This chapter describes expansions to the matrix discussed in Chapter 5 in order to fully encapsulate the effect of key parameters on the live load distribution to exterior steel I-girders. Results of this study are also discussed, highlighting the influence of these parameters on exterior girder live load distribution.

- $\quad$ Chapter 7:

o This chapter describes the data correlation techniques used to develop empirical equations for exterior girder live load distribution factors. Also, comparisons of the equations and the results from the finite element models are presented.

- $\quad$ Chapter 8:

o This chapter provides a summary of the scope of work conducted for this study and highlights the key findings. Lastly, this chapter provides suggestions for future efforts in this area.

In addition to these chapters, the following appendices are included:

- Appendix A:

o This appendix summarizes the results of the sensitivity study discussed in Chapter 5.

- Appendix B:

o This appendix summarizes the results of the first parametric variation discussed in Chapter 6.

- Appendix C:

o This appendix summarizes the results of the second parametric variation discussed in Chapter 6.

- Appendix D:

o This appendix summarizes comparisons between the equations proposed in Chapter 7 and the results of the studies presented in Chapters 5 and 6. 


\section{CHAPTER 2: LITERATURE REVIEW}

\subsection{INTRODUCTION}

The purpose of this chapter is to discuss previous research efforts related to live load distribution in bridge systems. The primary focus is on beam-and-slab bridges, although consideration is also given to other bridge types. A brief history of American practice is described, and a discussion regarding the accuracy of these procedures is also presented. An overview of refined analysis methods is presented as well. Also included is an overview of the findings of several researchers who have investigated the effects of various parameters on live load distribution. In addition, the parameters affecting live load distribution are summarized and reviewed. Lastly, a summary of live load distribution practices in selected foreign countries is provided.

\subsection{Historical Development of AASHTO Live LoAd Distribution Factors}

Since their first appearance in the first edition of the AASHO Standard Specifications (American Association of State Highway Officials, 1931), live load distribution factors have been incorporated into American bridge codes. The current AASHTO Standard Specifications for Highway Bridges (American Association of State Highway and Transportation Officials, 1996) still include these original distribution factors with relatively minor modifications. In 1994, AASHTO adopted the LRFD Bridge Design Specifications, which contain a new form of distribution factors that represented the first major change to these equations since 1931. Presented in this section are descriptions of the distribution factors in both codes of practice and the historical development behind them.

\subsubsection{AASHTO Standard Specifications}

Although the provisions of the AASHTO Standard Specifications (along with the new AASHTO LRFD Specifications) allow for more detailed analyses of bridge systems (for more 
discussion on these analysis methods, see Section 2.3), the use of simplified methods to determine bridge load response were also permitted and almost always employed. These simplified methods involved the use of wheel load distribution factors. Specifically, these factors will be used in conjunction with a line-girder analysis to determine the maximum number of wheels that would be resisted by a given girder. The majority of the empirical equations for these distribution factors are in the following form.

$$
\begin{aligned}
& g=\frac{S}{D} \\
& \text { where: } g=\text { distribution factor } \\
& S \text { = center-to-center girder spacing (feet) } \\
& D=\text { a constant varying with the bridge type and } \\
& \text { number of loaded lanes }
\end{aligned}
$$

These types of formulas, which are dependent on bridge type, are generally valid for girder spacings up to a specified maximum value. Table 2.1 presents the distribution factors in the AASHTO Standard Specifications, organized based on deck type. 


\begin{tabular}{|c|c|c|}
\hline Kind of Floor & $\begin{array}{l}\text { Bridge Designed for } \\
\text { One Traffic Lane } \\
\end{array}$ & $\begin{array}{c}\text { Bridge Designed for } \\
\text { Two or More Traffic } \\
\text { Lanes } \\
\end{array}$ \\
\hline \multicolumn{3}{|l|}{ Timber: } \\
\hline Plank & $\mathrm{S} / 4.0$ & S/3.75 \\
\hline $\begin{array}{l}\text { Nail Laminated 4" thick or } \\
\text { multiple layer floors over } \\
\text { 5” thick }\end{array}$ & $\mathrm{S} / 4.5$ & $\mathrm{~S} / 4.0$ \\
\hline $\begin{array}{l}\text { Nail laminated 6” thick or } \\
\text { more }\end{array}$ & $\begin{array}{l}\text { S/5.0 (If S exceeds 5' } \\
\text { use Lever Rule) }\end{array}$ & $\begin{array}{l}\text { S/4.25 (If S exceeds } \\
\text { 6.5' use Lever Rule) }\end{array}$ \\
\hline $\begin{array}{l}\text { Glued laminated panels on } \\
\text { glued laminated stringers: } \\
\text { 4” thick } \\
\text { 6” or more thick }\end{array}$ & $\begin{array}{l}\mathrm{S} / 4.5 \\
\mathrm{~S} / 5.25\end{array}$ & $\begin{array}{l}S / 4.0 \\
S / 4.5\end{array}$ \\
\hline $\begin{array}{l}\text { Glued laminated panels on } \\
\text { steel stringers: } \\
\text { 4” thick } \\
\text { 6” or more thick }\end{array}$ & $\begin{array}{l}\text { S/4.5 } \\
\text { S/5.25 (If S exceeds } \\
\text { 5.5' use Lever Rule) }\end{array}$ & $\begin{array}{l}\text { S/4.0 } \\
\text { S/4.5 (If S exceeds 7, } \\
\text { use Lever Rule) }\end{array}$ \\
\hline $\begin{array}{l}\text { Concrete: } \\
\text { On steel I-beam stringers } \\
\text { and prestressed concrete } \\
\text { girders }\end{array}$ & $\begin{array}{l}\text { S/7.0 (If S exceeds 10' } \\
\text { use Lever Rule) }\end{array}$ & $\begin{array}{l}\text { S/5.5 (If S exceeds 14' } \\
\text { use Lever Rule) }\end{array}$ \\
\hline On concrete T-beams & $\begin{array}{l}\text { S/6.5 (If S exceeds 6' } \\
\text { use Lever Rule) }\end{array}$ & $\begin{array}{l}\text { S/6.0 (If S exceeds 10’ } \\
\text { use Lever Rule) }\end{array}$ \\
\hline On timber stringers & $\begin{array}{l}\text { S/6.0 (If S exceeds 6' } \\
\text { use Lever Rule }\end{array}$ & $\begin{array}{l}\text { S/5.0 (If S exceeds 10' } \\
\text { use Lever Rule) }\end{array}$ \\
\hline On concrete box girders & $\begin{array}{l}\text { S/8.0 (If S exceeds 12' } \\
\text { use Lever Rule) }\end{array}$ & $\begin{array}{l}\text { S/7.0 (If S exceeds 14' } \\
\text { use Lever Rule) }\end{array}$ \\
\hline On steel box girders & See Article 10.39.2 & \\
\hline $\begin{array}{l}\text { On prestressed concrete } \\
\text { spread box beams }\end{array}$ & See Article 3.28 & \\
\hline \multicolumn{3}{|l|}{ Steel Grid } \\
\hline Less than 4" thick & $\mathrm{S} / 4.5$ & $\mathrm{~S} / 4.0$ \\
\hline 4” thick or more & $\begin{array}{l}\text { S/6.0 (If S exceeds 6' } \\
\text { use Lever Rule) }\end{array}$ & $\begin{array}{l}\text { S/5.0 (If S exceeds } \\
10.5 \text { ' use Lever Rule) }\end{array}$ \\
\hline $\begin{array}{l}\text { Steel Bridge Corrugated } \\
\text { Plank (2” minimum depth) }\end{array}$ & S/5.5 & $\mathrm{S} / 4.5$ \\
\hline
\end{tabular}

Table 2.1: Live Load Distribution Factors from the AASHTO Standard Specifications 
For situations where the center-to-center girder spacing exceeds these limits, the distribution factor may be calculated by assuming the slab to act as a beam that is simply supported by the girders. This method is commonly referred to as the Lever Rule. A visual depiction of the Lever Rule for a three-girder bridge is presented in Figure 2.1. It should be noted that the Lever Rule is still in use in the current edition of the AASHTO LRFD Specifications (American Association of State Highway and Transportation Officials, 2010) for certain loading conditions.

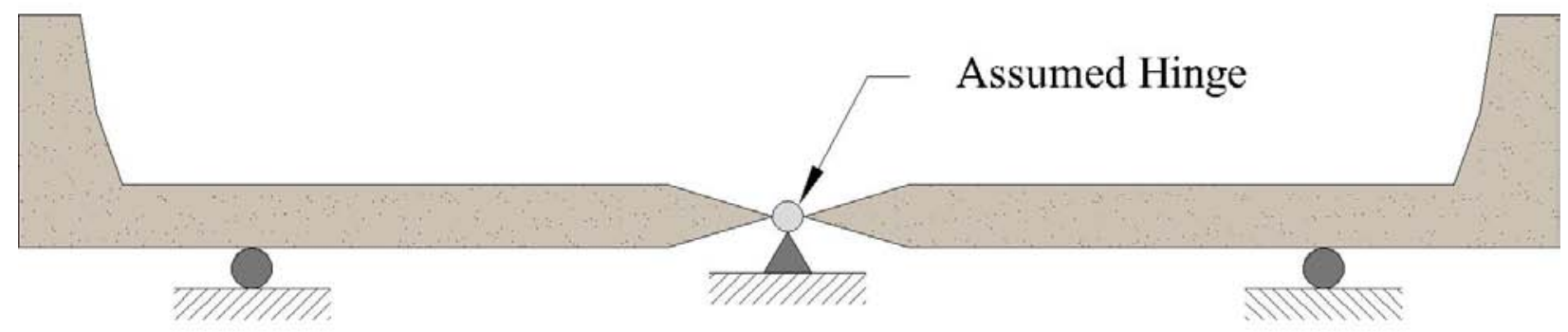

Figure 2.1: Notational Model for Applying Lever Rule to Three-Girder Bridges

Also, slightly more complex equations are present in the AASHTO Standard Specifications for precast multibeam bridges (AASHTO Article 3.23.4), spread box girder bridges (Article 3.28), and steel box girder bridges (Article 10.39.2). For these equations, the distribution factors are not a function of just girder spacing. Other aspects are taken into consideration, such as the number of traffic lanes, the number of girders, the span length, and the overall deck width.

The current distribution factor in the AASHTO Standard Specifications for composite steel I-beam bridges with two or more traffic lanes (S/5.5, see Table 2.1) was developed by Newmark and Seiss (1943). This distribution factor was derived by considering a portion of the slab to act as a beam on an elastic foundation (where the stiffness of the beams were approximated as elastic supports), and then using moment distribution methods to determine the beam response. The following general expression for " $D$ ” from Equation 2-1 was suggested for interior girders (Newmark \& Siess, 1942): 
$D=4.42+0.42 \frac{L}{10 \sqrt{H}}$

Equation 2-2

where: $D$ = constant used in Equation 2-1

$L=$ span length (feet)

$H=\frac{E_{b} I_{b}}{L E I}$

$E_{b}=$ modulus of elasticity of the beam material

$I_{b}=$ moment of inertia of the beam cross-section

$E=$ modulus of elasticity of the slab material

$I=$ moment of inertia of the slab cross-section

(per unit width)

By substituting properties typical of steel I-girder bridges into this equation, the distribution factor was further simplified to the current form of "S/5.5" (Newmark \& Seiss, 1943). The accuracy of this distribution factor was also verified experimentally using one-fourth scale straight bridges (Newmark, Siess, \& Penman, 1946) as well as one-fourth scale skewed bridges (Newmark, Siess, \& Peckham, 1948).

It should be noted that while this expression has been applied to a wide range of bridges, the bridges considered in developing this distribution factor were of a much more limited scope. Specifically, Newmark and Siess considered only simply-supported bridges, with span lengths ranging from 20 to 80 feet. The girder spacing of the bridges used to develop this distribution factor ranged from 5 to 8 feet, while today the equation is considered valid for girder spacings up to 14 feet. Also, at the time the $\mathrm{S} / 5.5$ factor was developed, the standard design lane was 10 feet wide, while today 12-foot design lanes are customary.

Throughout the years, there have been numerous studies related to load distribution of vehicular loads. As the results of these studies have been presented, the empirical equations given in the Standard Specifications had often been changed in order to reflect the findings of this research with the goal of improved accuracy. Unfortunately, this had led to some inconsistencies in the manner in which distribution factors are calculated. Sanders (1984) 
summarized these conflicts and shortcomings as follows:

- Most of said distribution factors were developed by considering a limited set of parameters:
o Floor type
o Beam type
o Girder spacing, etc.

- The format of these distribution factors varies even within bridges of similar construction:

o Steel I-girders

o Composite box beams

o Precast multibeams

o Spread box beams

- A non-uniform consideration of reduction of load intensity is present.

- Also, there are random changes in the number and position of traffic lanes in these factors.

- Finally, there are varying levels of research for different types of distribution factors.

The Sanders report finally introduces the study conducted by Imbsen and Associates, Inc. (Nutt, Schamber, \& Zokaie, 1988). This study, NCHRP Project 12-26, becomes the basis for a unified set of distribution factors to be incorporated in the updated AASHTO LRFD Specifications.

\subsubsection{AASHTO LRFD Specifications}

The beam-and-slab bridge live load distribution factors for interior girders contained in the current AASHTO Load and Resistance Factor Design (LRFD) Bridge Design Specifications were developed in the late 1980s by Imbsen and Associates, Inc. (Nutt, Schamber, \& Zokaie, 1988) as a component of the National Cooperative Highway Research Program Project 12-26, following the recommendations of the 1984 Sanders report. This study, focusing on the development of new distribution factors, was initiated by a desire to improve the accuracy of the 
distribution factors currently in the AASHTO Standard Specifications, which at the time, had only undergone minor changes since 1931.

One of the initial phases of this project was to perform a series of sensitivity studies to assess the effect of certain parameters on the distribution of loads on bridges. These studies, however, should not be considered to be a true parametric study as an "average" reinforced concrete T-beam bridge was chosen where only one parameter at a time was varied. The original layout of the average T-beam section consisted of the following parameters.

- 5 beams spaced at 7.77 feet.

- A slab thickness of 6.95 inches.

- A beam moment of inertia of $65960 \mathrm{in}^{4}$.

- A cross-sectional area of $596 \mathrm{in}^{2}$.

- An eccentricity (between the centroids of the beam and the deck) of 22.1 inches.

Although these studies consisted on reinforced concrete T-beam bridges only, the authors state that the studies reveal parameter sensitivity for all types of beam-and-slab bridges since the critical parameters for beam-and-slab bridges are the same and only their values, or magnitudes, will change. After an evaluation of detailed analysis methods (see Section 2.3.2), including grillage of beams, orthotropic plate modeling, concentrically and eccentrically stiffened plate modeling, and folded plate modeling, the programs GENDEK-5 (eccentrically stiffened plate modeling) and CURVBRG (grillage analogy modeling) were used for these studies. From these two methods, only the GENDEK-5 results reported by the authors.

For this series of studies, the following set of parameters was chosen (for a detailed discussion of these parameters, see Section 2.5):

- Girder spacing / number of girders

- Span length

- Girder stiffness

- Slab thickness

- Number of loaded lanes

- Deck overhang

- Skew

- Load configuration 
- Support condition

- End diaphragms

It should be noted that the investigated parameters indicated that beam-and-slab bridges were treated generically by simply altering the relevant geometric and stiffness parameters. However, as the authors state, there is a significant difference between the response of a generic beam-and-slab bridge and other major bridge types, such as box girders and precast multibeam bridges. The effects of other secondary stiffening elements, such as curbs and parapets, interior diaphragms, and horizontal curvature were not considered in this sensitivity study.

After conducting the sensitivity analysis, it was determined that some of these parameters did not have a significant effect of live load distribution on bridge systems. Results showed that the number of girders had a negligible effect on load distribution when the number of girders exceeded five (for more discussion on this parameter, see Section 2.5.5). Therefore, for this parametric study, all bridges were modeled with six girders. In addition, since the AASHTO Standard Specifications permitted moment from three loaded lanes to be reduced by 90 percent, it was found that two loaded lanes resulted in the largest developed moment; this value was fixed in the subsequent parametric study. Also, according to the author, the effect of varying overhang was not considered (a parameter which greatly affects the live load distribution on exterior girders), and a constant value of 54 inches was used. For skew, it was found that skew does in fact have an effect on load distribution (for more discussion on this parameter, see Section 2.5.8). However, this effect was handled separately in the development of skew correction factors.

Therefore, only four variables were considered and used in the subsequent parametric study: girder spacing, span length, girder stiffness, and slab thickness. From a database of 350 existing bridges from 10 states, a set of parametric values were determined. These values are listed in Table 2.2. It should be noted that all bridges were loaded with the AASHTO HS20 design truck. 


\begin{tabular}{|c|ccccc|}
\hline Parameter & \multicolumn{5}{|c|}{ Parametric Values } \\
\hline \hline Girder Spacing (ft) & 3.5 & 5.0 & $7.5^{*}$ & 10.0 & 16.0 \\
Span Length (ft) & 20.0 & & $64.0^{*}$ & 130.0 & 200.0 \\
I + Ae ${ }^{2}$ in $\left.^{4}\right)$ & 10,000 & 50,000 & $560,000^{*}$ & $3,000,000$ & $7,000,000$ \\
Slab Thickness (in) & 4.0 & & $7.25^{*}$ & & 12.0 \\
\hline
\end{tabular}

* Average Bridge Parameters

\section{Table 2.2: Parametric Values Used in Derivation of Distribution Factors}

From this parametric study, a new set of empirical equations for wheel load distribution factors were derived. Equation 2-3 and Equation 2-4 are the resulting equations for the distribution factors of live load moment for interior beams for one lane loaded and 2 lanes loaded, respectively. These formulas were later included in the AASHTO LRFD Specifications and are as follows:

$$
\begin{aligned}
& g=0.1+\left(\frac{S}{4^{\prime}}\right)^{0.4}\left(\frac{S}{L}\right)^{0.3}\left(\frac{I+A e^{2}}{L t_{s}^{3}}\right)^{0.1} \\
& g=0.15+\left(\frac{S}{3^{\prime}}\right)^{0.6}\left(\frac{S}{L}\right)^{0.2}\left(\frac{I+A e^{2}}{L t_{s}^{3}}\right)^{0.1}
\end{aligned}
$$

where: $g$ = distribution factor

$$
S \text { = girder spacing }
$$

$L=$ span length

$I=$ transformed gross moment of inertia of the girder only in terms of equivalent slab material

$A=$ transformed gross area of the girder only in terms of equivalent slab material $e=$ distance the from neutral axis of the girder to the middle surface of the slab (eccentricity) $t_{s}=$ slab thickness 
In addition, similar equations for the distribution of shear forces in interior girders as well as the previously mentioned skew correction factors were also developed. These factors were then incorporated into the AASHTO LRFD Specifications.

To evaluate the accuracy of these equations, Imbsen and Associates, Inc. used two different methods (Nutt, Schamber, \& Zokaie, 1988). For the first method of evaluation, a database of 30 representative beam-and-slab bridges, consisting of ten T-beam bridges, nine prestressed concrete I-girders, and eleven steel I-girder bridges, from different states was compiled. These bridges were chosen to include a broad range of parameters. Models of these bridges were created using the aforementioned GENDEK-5. The GENDEK-5 analyses were then compared with the derived equations. The resulting distribution factors were compared with the AASHTO Standard distribution factors as well as the results from the report's derived equations. The comparison can be seen visually between the analysis results and the results of Equation 2-4 in Figure 2.2, where the plot of approximate vs. accurate values has been displayed. The solid lines on these graphs represent a perfect correlation between these two distribution factors. From these figures, it can be clearly seen that not only does the AASHTO Standard equations incorrectly predict the actual distribution of live load, but that the predictions from the derived equations have attained relative accuracy. Also, the standard deviation of the ratios between the analytical results and the result of Equation 2-4 was found to be 0.038 ; the authors attribute the differences to the simplifications in the derivation of the report's equations and to the effects of some parameters such as girder torsional inertia, bridge width, etc. that were not considered in their derivation. Similar plots for other distribution factors are also provided in NCHRP Report 12-26. 


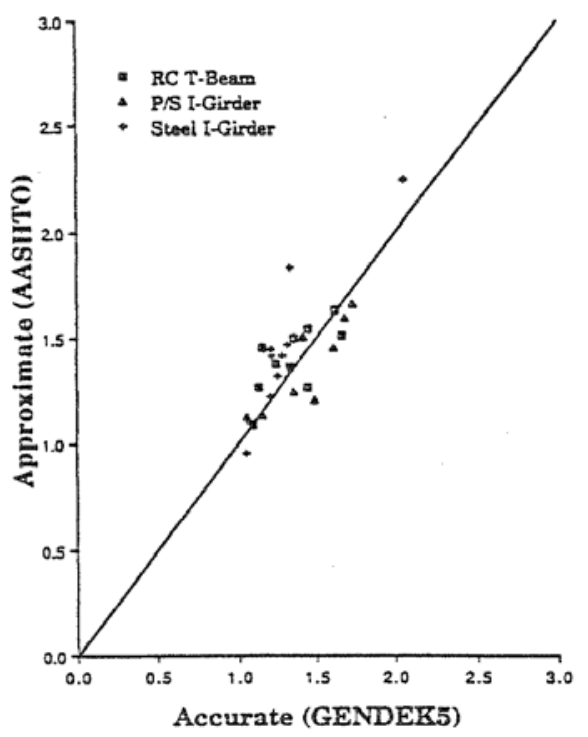

(a)

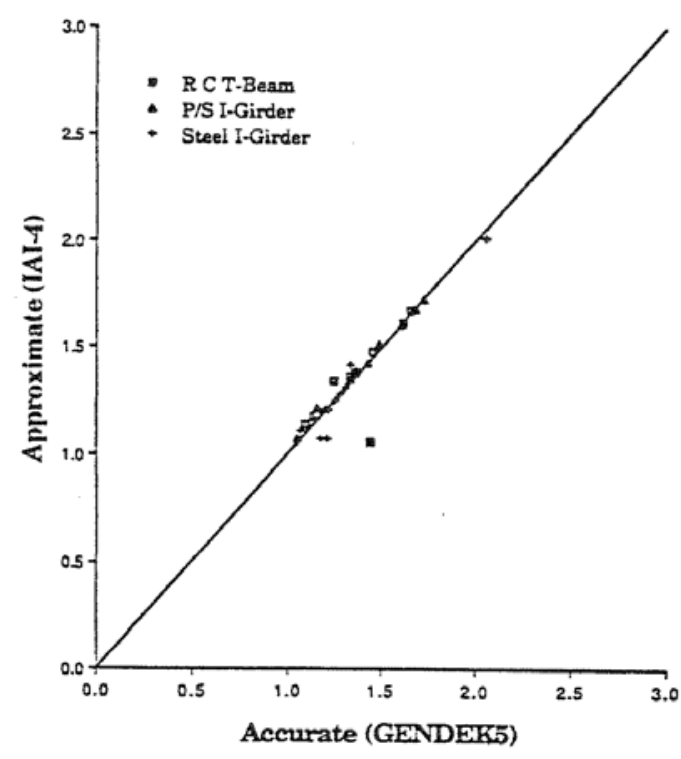

(b)

Figure 2.2: Statistical Comparison of Analytical Distribution Factors with a: AASHTO Standard Equations and b: Derived Equations (Moment, Interior Girder, Multiple Lanes Loaded)

For the second method of evaluation, a larger database of 304 bridges (67 T-beams, 89 prestressed concrete I-girders, and 148 steel I-girder bridges) was compiled. These bridges were then analyzed using a multidimensional space interpolation (MSI) approach. This method was used by the authors for the larger database of bridges because it achieved fairly accurate results (although not as accurate as the GENDEK-5 analyses) while being less computationally demanding. Comparisons similar to the comparison between the GENDEK-5 analysis and the derived equations were then generated for the MSI analysis. For this second method of evaluation, the ratios between Equation 2-4 and the MSI approach have a mean of 1.029 and a standard deviation of 0.034 . This translates to Equation 2-4 being 2.9\% overly conservative; similarly, Equation 2-3 was found to be $4.1 \%$ overly conservative. It should be noted that, respectively, AASHTO equations yielded an overly conservative estimate of $7.4 \%$ and $41.6 \%$. Also, for the shear distribution factors suggested in the report, results stated that the derived equations yielded an overly conservative estimate of roughly $3 \%$.

As of today, forms of these equations are still present in the current AASHTO LRFD Specifications. There are, however, three major differences between the equations currently in the code and the ones in the Imbsen and Associates, Inc. report. The first major difference is the 
incorporation of multiple presence factors into the distribution factors. Multiple presence factors account for the probability of coincident loadings on a bridge system. It should be noted that these multiple presence factors differ from the ones in the AASHTO Standard Specifications. The second major difference is that the distribution factors in the AASHTO Standard Specifications are in terms of wheel loads while the AASHTO LRFD distribution factors are in terms of vehicle lanes. This is resolved by dividing the distribution factor by two. The third major difference will be discussed after the derivation.

For example, the derivation of the distribution factor for moment for one lane loaded is presented below. Note that the multiple presence factor, " $\mathrm{m}_{1}$ " for one lane loaded is 1.20.

$$
\begin{aligned}
g & =\frac{m_{1}}{2}\left[0.1+\left(\frac{S}{4^{\prime}}\right)^{0.4}\left(\frac{S}{L}\right)^{0.3}\left(\frac{I+A e^{2}}{L t_{s}{ }^{3}}\right)^{0.1}\right] \\
& =\frac{1.20}{2}\left[0.1+\left(\frac{S}{4^{\prime}}\right)^{0.4}\left(\frac{S}{L}\right)^{0.3}\left(\frac{I+A e^{2}}{L t_{s}{ }^{3}}\right)^{0.1}\right] \\
& =0.6\left[0.1+\left(\frac{S}{4^{\prime}}\right)^{0.4}\left(\frac{S}{L}\right)^{0.3}\left(\frac{I+A e^{2}}{L t_{s}{ }^{3}}\right)^{0.1}\right] \\
& =0.06+0.6\left(\frac{S}{4^{\prime}}\right)^{0.4}\left(\frac{S}{L}\right)^{0.3}\left(\frac{I+A e^{2}}{L t_{s}{ }^{3}}\right)^{0.1} \\
& =0.06+\left(0.6 \frac{1}{0.4}\right)^{0.4}\left(\frac{S}{4^{\prime}}\right)^{0.4}\left(\frac{S}{L}\right)^{0.3}\left(\frac{I+A e^{2}}{L t_{s}{ }^{3}}\right)^{0.1} \\
& =0.06+(0.2789)^{0.4}\left(\frac{S}{4^{\prime}}\right)^{0.4}\left(\frac{S}{L}\right)^{0.3}\left(\frac{I+A e^{2}}{L t_{s}{ }^{3}}\right)^{0.1} \\
& =0.06+\left(\frac{1}{3.5861}\right)^{0.4}\left(\frac{S}{4^{\prime}}\right)^{0.4}\left(\frac{S}{L}\right)^{0.3}\left(\frac{I+A e^{2}}{L t_{s}{ }^{3}}\right)^{0.1} \\
& =0.06+\left(\frac{S}{14.3444^{\prime}}\right)^{0.4}\left(\frac{S}{L}\right)^{0.3}\left(\frac{I+A e^{2}}{L t_{s}{ }^{3}}\right)^{0.1}
\end{aligned}
$$

Defining $K_{g}=I+A e^{2}$ and including a factor of 12 to convert " $L$ " to inches in the last term:

$$
g \approx 0.06+\left(\frac{S}{14^{\prime}}\right)^{0.4}\left(\frac{S}{L}\right)^{0.3}\left(\frac{K_{g}}{12.0 L t_{s}{ }^{3}}\right)^{0.1}
$$


As mentioned earlier, there is another major difference between this formula and the formula presented in the code. While they appear similar, there is a discrepancy between this definition of " $K_{g}$ " and the definition of " $K_{g}$ " present in the current AASHTO LRFD Specifications (American Association of State Highway and Transportation Officials, 2010). This difference is the inclusion of the modular ratio parameter, " $n$ ". Originally, as stated before, the parametric study performed in NCHRP 12-26 (Nutt, Schamber, \& Zokaie, 1988) consisted of using a reinforced concrete bridge where the elastic moduli of both the deck and the beams of the same. This " $n "$ value accounts for the differences between the moduli of elasticity of the deck and beam.

Similar derivations have been performed for the other distribution factors derived in the Imbsen and Associates, Inc. report and have been recorded into the AASHTO LRFD Specifications. The results from the Imbsen and Assocuates, Inc. study have been subsequently evaluated by numerous analytical and field studies (see Section 2.4). While it has been shown that the AASHTO LRFD Specifications are more accurate in predicting bridge load distribution than the AASHTO Standard Specifications, results from these studies also indicate that the current distribution factors are still somewhat too conservative.

\subsection{REFINED ANALYSIS}

While the use of the empirical equations described above are the most common method of determining live load distribution on bridge systems, both the AASHTO Standard and LRFD Specifications also allow the use of more refined analysis techniques to determine live load response. Specifically, two other methods with increasing complexity and reliability are given.

\subsubsection{Simplified Computer Analysis}

The first level of refined analysis permitted in the AASHTO Specifications is to utilize computer aided techniques in order to determine appropriate wheel load distribution factors. Specifically, computer programs have been developed that simplify bridge behavior using influence surface or influence section concepts are then used to determine distribution factors. Some specific examples of such programs that have generated reliable results are the programs 
SALOD (which is applicable for beam-and-slab bridges) and LANELL (which is for concrete box girder bridges) (Nutt, Schamber, \& Zokaie, 1988).

\subsubsection{Detailed Computer Analysis}

For bridges with characteristics not addressed by the other two methods of analysis (either using the empirical equations previously referenced or employing a simplified computer analysis), detailed computer analysis may be used. In these situations, the actual forces occurring in the superstructure are calculated and the use of distribution factors is not necessary. It should be noted that is the responsibility of the designer or engineer to determine the most critical location for the application of live loads.

There are many examples of detailed analytical techniques, such as a finite element analysis software package, that can be used for nearly any bridge type. The AASHTO LRFD Specifications has certain guidelines regarding the use of refined methods of analysis. For example, AASHTO LRFD Specifications state that unless otherwise specified, flexural and torsional deformation of the deck shall be considered in an analysis but vertical shear deformation may be neglected (American Association of State Highway and Transportation Officials, 2010). Also, for beam-and-slab bridges, the aspect ratio of finite elements and grid panels should not exceed 5.0. For further, more detailed guidelines, the reader is referred to the AASHTO LRFD Specifications, Article 4.6.3.

There are also other methods are applicable for specific bridges, such as the finite difference method, the finite strip method, and series or harmonic methods. The grillage analogy and the rib-stiffened plate models have also been found to be accurate for beam-and-slab bridges. The rib-stiffened plate model has also provided accurate results for spread box beams. In addition, a folded plate model can be used to analyze concrete box girders with reliable results. For further reference regarding details for these analysis techniques, see NCHRP Report 12-26 (Nutt, Schamber, \& Zokaie, 1988). 


\subsection{Studies Evaluating CurRent Live LoAd Distribution Factors}

Research has been conducted by several investigators focused on examining the accuracy of the current AASHTO distribution factors. These efforts have included both analytical studies using finite element analysis and field studies of existing bridges. This section will summarize these efforts.

\subsubsection{Analytical Studies}

Many analytical studies conducted by various researchers have shown that, in general, both the current AASHTO Standard Specifications and LRFD Specifications are overly conservative regarding live load distribution. Research efforts have largely been focused on the accuracy of these Specifications with respect to variation of one or more specific parameters. A summary of selected studies will be presented herein.

Hays et al. (1986) and Mabsout et al. (1999) have both investigated the accuracy of the Specifications compared to varying span lengths. Hays et al. performed their analysis using the computer program SALOD, which uses an influence surface concept, and verified the computer results with the field testing of eight bridges. To determine the values of the distribution factors for the comparison study, Hays et al. divided the maximum midspan girder moment by half of the simple beam moment due to one of the vehicles. Mabsout et al. performed their analytical studies using the commercial finite element program SAP90, where the concrete slab was modeled as quadrilateral shell elements and the girders were modeled as space frame members. Mabsout et al. determined the distribution factors in the same manner as Hays et al. A similar range of span lengths was investigated in both studies, varying from 30 to 120 feet. Hays et al. have compared the results of their analytical study to distribution factors resulting from the Standard Specifications and the Ontario Highway Bridge Design Code (OHBDC, see Section 2.6.1); the LRFD Specifications were not yet published at the time of this study.

Results published by Hays et al. show that the Standard Specifications are not conservative for interior girders with span lengths less than 60 feet. They also demonstrate that while the OHBDC is somewhat conservative, it is very accurate in capturing the nonlinear relationship of decreasing distribution factor with increasing span length. Mabsout et al. 
obtained similar results from their analytical studies. They state that the Standard Specifications are less conservative than the LRFD Specifications for span lengths up to 60 feet and girder spacing up to 6 feet. However, as span length and girder spacing increase, the Standard Specifications become more conservative. Mabsout et al. also found that the LRFD equations well represent the finite element results.

Khaleel and Itani (1990) have examined the effects of skew for beam-and-slab bridges. This research considered finite element models of 112 continuous-span bridges, with span lengths ranging from 80 to 120 feet and girder spacings from 6 to 9 feet. Skew angles from 0 to 60 degrees were evaluated. Results of this research were compared to distribution factors obtained from expressions given in the AASHTO Standard Specifications, which do not account for the effects of skew. Therefore, as would be expected, Khaleel and Itani found a wide discrepancy between their analytical results and the distribution factors obtained from the Specifications. Specifically, in some cases the design moment was underestimated by $6 \%$, while for other situations the moment was over-predicted by $40 \%$. As a result, a skew correction factor to be used with the Standard Specifications was proposed by the authors.

Other researchers have investigated the accuracy of the current distribution factors for bridges with varying degrees of skew. One such study was that of Arockiasamy et al. (1997). This research was accomplished by performing finite element modeling using ANSYS 5.2, coupled with field tests in order to verify the accuracy of the analytical model. The authors investigated angles of skew ranging from 0 to 60 degrees and concluded that the LRFD code is accurate in capturing the effects of skew for beam-and-slab bridges, particularly for skew angles in excess of 30 degrees. Arockiasamy et al. also state that the LRFD equations overestimate the effect of slab thickness.

It should be stated that the method used to calculate distribution factors in the Arockiasamy et al. report differs somewhat from the method used in the two previously mentioned papers. The formula used to calculate the distribution factors is as follows: 


$$
g_{i \theta}=\frac{n \varepsilon_{i \theta}}{\left(\sum_{j=1}^{k} \varepsilon_{j} W_{j}\right)_{\theta=0}}
$$

where: $g_{i}=$ distribution factor for the "i'th" girder

$\mathcal{E}_{i}=$ bottom flange strain at the "i'th" girder

$W_{i}=$ ratio of the section modulus of the "j’th"

girder to the section modulus of a typical

interior girder

$k=$ number of girders

$n=$ number of wheel lines of applied loading

$\theta=$ skew

This particular equation is used because the methods used to calculate the distribution factors in the aforementioned papers assume that the sum of internal moments should be equal to the externally applied moment. This assumption is not realistic, however, for skewed bridges. To correct this, the ratio is set to be between the maximum girder moment obtained from finite element analysis and the moment in the bridge idealized as a one-dimensional beam subject to one set of wheels. If the skew is zero, then this equation will yield the same results as the methods mentioned in the two aforementioned papers.

In analytical studies by Shahawy and Huang (2001), the focus was on the accuracy of the LRFD equations as a function of span length, girder spacing, width of deck overhang, and deck thickness. This research was conducted using finite element models with span lengths ranging from 50 to 120 feet, girder spacings from 4 to 10 feet, deck overhangs from 6 inches to 5 feet, and deck thickness ranging from 6 to 9 inches. The authors found that results from the LRFD equations can have up to $30 \%$ error for some situations, particularly when girder spacing exceeds 8 feet and deck overhang exceeds 3 feet.

Analytical studies conducted by Barr et al. (2001) investigated the accuracy of the LRFD distribution factors while varying several parameters. Although the study focused on distribution in prestressed concrete girder bridges, the varied parameters included skew, simply supported versus continuous spans, the presence of interior and end diaphragms, and the presence of haunches. Models were created using SAP2000. Results of this work indicate that for models similar to those used in developing the LRFD equations (simple-spans, without haunches, 
interior diaphragms, or end diaphragms), the equations are reliable and are $6 \%$ conservative on average. However, when these additional parameters are included in the model, the distribution factors given by the specifications are up to $28 \%$ conservative. Specifically, the authors found that:

1. Including the presence of haunches and end diaphragms significantly reduced the distribution factors.

2. The effects of including intermediate diaphragms in the model were negligible.

3. The effects of continuity increased the distribution factor in some cases and decreased it in others.

In addition, these researchers also found the effects of skew to be reasonably approximated by the LRFD equations. Also, the OHBDC procedures (see Section 2.6.1) were shown to capture the effects of skew with high precision. However, these specifications are only valid for angles of skew not exceeding 20 degrees.

\subsubsection{Field Studies}

A field study by Fu et al. (1996) to determine the effect of live load on beam-and-slab bridges considered four steel I-girder systems, comparing actual distribution factors to the AASHTO LRFD equations. For three of the bridges that were not skewed, using methods similar to those in the aforementioned reports (Hays, Sessions, \& Berry, 1986) (Mabsout, Tarhini, Frederick, \& Kesserwan, 1999), the equations were found to be anywhere from $7 \%$ to $42 \%$ conservative. However, it is also noteworthy that results from the LRFD equations were $13 \%$ unconservative for the skewed bridge.

Field-testing of two simply supported, steel I-girder bridges was performed by Kim and Nowak (1997). These tests differed from most load tests in this field of research in that the strain data was collected from daily traffic loads as well as from calibrated truck loads. After filtering the measured strain records with a lowpass digital filter to remove the dynamic components, thereby obtaining the equivalent static strain, the following formula was used to obtain the girder distribution factor (it should be noted that if the skew in Equation 2-5 is set to zero, it will yield the same results as this equation): 


$$
g_{i}=\frac{M_{i}}{\sum_{j=1}^{k} M_{j}}=\frac{E S_{i} \varepsilon_{i}}{\sum_{j=1}^{k} E S_{j} \varepsilon_{j}}=\frac{\frac{S_{i}}{S_{l}} \varepsilon_{i}}{\sum_{j=1}^{k} \frac{S_{j}}{S_{l}} \varepsilon_{j}}=\frac{\varepsilon_{i} w_{i}}{\sum_{j=1}^{k} \varepsilon_{j} w_{j}}
$$

where: $g_{i}=$ distribution factor for the "i'th" girder

$$
\begin{aligned}
& M_{i}=\text { bending moment at the "i'th" girder } \\
& E=\text { modulus of elasticity } \\
& S_{i}=\text { section modulus of the "i'th" girder } \\
& S_{I}=\text { typical interior section modulus } \\
& \mathcal{E}_{i}=\text { bottom flange static strain at the "i'th" girder } \\
& W_{i}=\text { ratio of the section modulus of the "i'th" } \\
& \quad \text { girder to the section modulus of a typical } \\
& \quad \text { interior girder } \\
& k=\text { number of girders }
\end{aligned}
$$

It was shown that the LRFD distribution factors overestimated the actual distribution by $28 \%$ and $19 \%$ in the two bridges tested. Furthermore, the distribution factors obtained from the Standard Specifications were $16 \%$ and $24 \%$ greater than the actual distribution factors that resulted from field testing. Also, one other important fact that can be derived from this study is that the results from both separate analyses showed that interior girder distribution factors were consistently larger than exterior girder distribution factors (for moment, two lane loaded).

Additional field-testing of seventeen steel I-girder bridges was conducted by Eom and Nowak (2001). Actual distribution factors obtained from the field tests were lower than those given by the AASHTO Specifications in all cases. It was found that the Standard Specifications were very conservative for short spans with small girder spacings, and even more conservative for other situations. Also, the LRFD distribution factors were found to be more accurate than those from the Standard Specifications, although were still considered to be too conservative. Finite element models were also created of these seventeen bridges. As a result of these efforts, it was shown that models created using simply supported boundary conditions overestimate the strain in the girders, and as a result overestimate the distribution factors. The reason for this is that although the bridges considered in the field-testing were designed to be simply supported, corrosion had caused the supports to be more rigid. It was found that better correlation could be 
obtained between the field-testing and analytical models by including a stiffness coefficient at the supports in order to account for this corrosion.

In 2009, Cross et al. performed a study to determine the validity of AASHTO LRFD shear distribution factors used in bridge design (Cross, Vaughn, Panahshahi, Petermeier, Siow, \& Domagalski, 2009). Twelve interstate bridges were instrumented on their beam webs with three stain gauge rosette installed on each beam to measure shear stresses caused by static, slowmoving, and dynamic load tests. Finite element models using SAP2000 were also generated to verify both the experimental study and the validity of the LRFD shear distribution factors. The study showed that the LRFD distribution factors closely approximate the shear distribution factors determined by both the finite element modeling and testing.

\subsubsection{Conclusion}

Two main conclusions can be reached from the results of the analytical and field studies presented in this section. First, there is a need to develop improved live load distribution factors. The relatively recent adoption of the AASHTO LRFD specifications has resulted in enhanced accuracy for bridges having geometries similar to those considered in developing the equations. However, for bridges with span lengths, girder spacings, etc. outside of these ranges, overly conservative results are often obtained.

Second, a very common trend with many of the discussed analytical and field studies is that, while the parameters of girder spacing, span length, skew, continuity, etc. have been investigated thoroughly, the differing behavior of interior girders vs. exterior girders has not been adequately investigated. As of now, a substantial lack of research is present on the live load response of exterior girders in beam-and-slab bridges.

Therefore, there is a need to develop more comprehensive distribution factors that will provide a more accurate approximation of live load response and maintain simplicity of use. Section 2.5 describes the effect of some parameters that may be considered in developing these new expressions. 


\subsection{Influence OF VARIOUS PARAMETERS ON Live LoAd Distribution}

Several previous researchers (Newmark \& Siess, 1942) (Newmark, 1949) (Walker, 1987) (Nutt, Schamber, \& Zokaie, 1988) (Tarhini \& Frederick, 1992) (Kim \& Nowak, 1997) (Mabsout, Tarhini, Frederick, \& Tayar, 1997) (Mabsout, Tarhini, Frederick, \& Kobrosly, 1997) (Eom \& Nowak, 2001) have investigated the effect of numerous parameters on live load distribution in slab-and-beam bridges. Two of the most comprehensive parameter studies were conducted by Nutt et al. (1988) as part of NCHRP Report 12-26 (see Section 2.2.2) and Tarhini and Frederick (1992). For discussion of NCHRP Report 12-26, see Section 2.2.2.

Research conducted by Tarhini and Frederick (1992) focused on steel I-girder bridges with concrete slabs. Similar to the procedure of Nutt et al., a typical bridge design was selected; then one parameter was varied within practical ranges while all other characteristics of the design were held constant. Finite element analysis was employed in this research using the analysis program ICES STRUDL II. The concrete slab was modeled using isotropic, eight-node brick elements. The girders were modeled using shell elements and the cross bracing was modeled as space truss members.

As a result of these research efforts, girder spacing, span length, and girder stiffness have been determined to be the most significant parameters affecting the distribution characteristics of bridges. However, numerous other parameters have also been considered. Some of these variables have been found to have a negligible effect on live load distribution, while some disagreement exists regarding the influence of others.

\subsubsection{Girder Spacing}

Since early work by Newmark (1938), girder spacing has been considered to be the most influential parameter affecting live load distribution. Newmark and Siess (1942) originally developed simple, empirical equations expressing distribution factors as a function of transverse spacing of beams, span length, and beam stiffness relative to the stiffness of the slab. In later

research (Newmark, 1949), the effects of span length and beam stiffness on live load distribution were neglected, and the distribution factors were expressed as a linear function of girder spacing 
only. These relationships are still incorporated in the AASHTO Standard Specifications with minimal changes since their adoption.

However, even though girder spacing directly influences live load distribution, it has been shown through analytical studies that the "S/D" factor consistently overestimates the actual live load distribution factors. Sensitivity studies presented in NCHRP Report 12-26 (Nutt, Schamber, \& Zokaie, 1988) and analytical studies by Tarhini and Frederick (1992) show that while girder spacing has a significant effect on live load distribution, the relationship is not linear as implied by the "S/D" method (but closer to an exponential relationship), and thus does not correlate well with the AASHTO Standard Specifications. Tarhini and Fredrick proposed a different formula for distribution factors as a function of span length and girder spacing as an alternative to the "S/5.5” formula present in the AASHTO Standard Specifications.

\subsubsection{Span Length}

Nutt et al. (1988) determined that a nonlinear relationship existed between span length and girder distribution factors. This relationship was most significant for moment in interior girders (shear for interior girders was also evaluated in this study).

Tarhini and Frederick (1992) also observed a nonlinear (quadratic) relationship between span length and the girder distribution factor. In this study, the quadratic increase in the distribution factor with increasing span length is due to the potentiality for an increased number of vehicles present on a longer bridge. As a result of this finding they proposed the following relationship be used to compute distribution factors:

$$
g=0.00013 L^{2}-0.021 L+1.25 \sqrt{S}-\frac{(S+7)}{10}
$$

where: $g=$ distribution factor

$L=$ span length (feet)

$S=$ girder spacing (feet) 


\subsubsection{Girder Stiffness}

Newmark and Siess (1942) expressed the amount of live load distributed to an individual bridge girder in terms of the relative stiffness of the girder compared to the stiffness of the slab, expressed by the dimensionless parameter $\mathrm{H}$, where

$$
\begin{aligned}
& H=\frac{E_{b} I_{b}}{a E I} \\
& \text { where: } E_{b}=\text { modulus of elasticity of the beam material } \\
& \qquad \begin{aligned}
I_{b} & =\text { moment of inertia of the beam cross-section } \\
E & =\text { modulus of elasticity of the slab material } \\
I & =\text { moment of inertia of the slab cross-section } \\
& \text { (per unit width) } \\
a & =\text { span length }
\end{aligned}
\end{aligned}
$$

Results demonstrated that the relative stiffness (as defined by the parameter " $H$ ”) had a small effect on live load distribution. Consequently, early efforts by Newmark and Siess (1942) express the distribution factor as a function of this stiffness parameter, but later literature (Newmark, 1949) states that the range of “ $H$ ” for a particular type of bridge is small enough that this variable can usually be neglected.

Tarhini \& Frederick (1992) also found girder stiffness to have a small, but negligible effect on live load distribution. For example, they studied the effects of relatively large changes in the moment of inertia of the cross section such as doubling the cross-sectional area of the girder and altering the thickness of the slab. These changes resulted in approximately a 5\% difference compared to the original design, which the authors considered to be insignificant.

Nutt et al. (1988) defined girder stiffness by the parameter “ $K_{g}$ ” as follows. 


$$
K_{g}=I+A e^{2}
$$

where: $I=$ transformed gross moment of inertia of the

= girder only in terms of equivalent slab

$=$ material

$A=$ transformed gross area of the girder only in

terms of equivalent slab material

$e=$ distance the from neutral axis of the girder to

the middle surface of the slab (eccentricity)

In order to confirm that this was an acceptable means of quantifying girder stiffness, individual values of moment of inertia, area and eccentricity were varied, while maintaining a constant value of " $K_{g}$ ”. It was observed that varying individual parameters was relatively inconsequential and that there was only a $1.5 \%$ difference obtained due to varying these individual parameters if “ $K_{g}$ ” was held constant.

By defining girder stiffness in this manner, Nutt et al. (1988) found there was a significant relationship between girder stiffness and live load distribution. However, the effect of increasing girder stiffness was to increase the distribution factor, while the effect of increasing span length was to decrease the distribution factor. Thus, because girders used in longer spans typically have larger stiffness values, the overall effect of these two parameters will be reduced. The effects of varying torsional stiffness were also evaluated in this study with results showing this parameter has only a relatively small impact on girder distribution factors (3\% difference).

\subsubsection{Deck Thickness}

Conflicting information exists regarding the effect of the thickness of concrete decks on live load distribution. Newmark (1949) states that deck thickness will affect wheel load distribution, as deck thickness will have a direct influence on the relative stiffness. Although, in research by Tarhini \& Frederick (1992), bridges having a slab thickness ranging from 5.5 to 11.5 inches were analyzed and it was found that these changes had a negligible effect on live load distribution. 
Nutt et al. (1988) also considered the effect of this parameter to be small (10\% difference between bridges with 6 and 9 inch slabs). Nonetheless, they did include this parameter in the recommended distribution factor equations contained in NCHRP Report 12-26.

\subsubsection{Girder Location and Number of Girders}

Girder location, i.e. interior vs. exterior, was found to have an influence on live load distribution factors by Walker (1987). In this study actual distribution factors were obtained using a grid model with plate elements. These distribution factors were then used to calculate an equivalent value of " $D$ " (as used in Equation 2-1) that would have produced the same distribution factor. Results demonstrated that the S/D factors overestimate actual distribution to a lesser extent in exterior girders. Furthermore, for bridges with five equally spaced girders, the calculated value of " $\mathrm{D}$ " is greater for the center girder than the value for the first interior girder.

A study by Zokaie (2000), following up on NCHRP Report 12-26 (Nutt, Schamber, \& Zokaie, 1988) states that edge girders are more sensitive to truck placement than interior girders. Therefore, either the lever rule or a correction factor could be used. A combination of these two methods is incorporated into the LRFD Specifications; the lever rule is used for cases involving one traffic lane and a correction factor, which is a function of the transverse distance between the exterior girder and the curb, is used for two or more traffic lanes.

Also, according to NCHRP Report 12-26, the number of girders was considered as a parameter for determining wheel load distribution in their sensitivity study. In these studies, the number of loaded lanes was kept at two as simultaneous loading on more lanes was unlikely. Also, according to the authors, the effect of three of more lanes being loaded simultaneously is relatively small as the distance between the girder in question and the farthest loaded lane increases. From the results of their sensitivity study, it was found that the number of girders did not have a significant effect on load distribution for a bridge with five or more girders. Only with four-girder bridges was a slight decrease in moment observed. This was also observed in three-girder systems, however for this case, there was only space for one loaded lane. For their parametric study, a constant value of six girders and two loaded lanes was used throughout. 


\subsubsection{Deck Overhang}

Deck overhang has been shown to have a linear effect on live load distribution to the exterior girder (Nutt, Schamber, \& Zokaie, 1988). This effect has been incorporated into the LRFD Specifications (American Association of State Highway and Transportation Officials, 2010) in the form of a correction factor to be applied to exterior girders when two or more design lanes are considered. Currently, this correction factor is applied to the distribution factors for moment to interior girders (see Chapter 3 for more details). The effect of the width of deck overhang on the interior girder is considered negligible.

\subsubsection{Continuity (Support) Conditions}

Nutt et al. (1988) also examined the difference in distribution factors between simple span and two-span continuous bridges in which all other parameters were the same. The twospan bridges that were analyzed had two equal length spans (where the length of each span was equal to the total length of the corresponding simply-supported bridge), five girders, and were not skewed. The results showed that the distribution factors obtained for the two-span bridges were 1 to $11 \%$ higher than the distribution factors that resulted for the corresponding simple-span bridges. By examining the average increase in distribution factor between two-span continuous and simply- supported bridges, Nutt et al. (1988) recommended that a constant correction factor of 1.04 be applied to distribution factors obtained for shear, and similarly, a distribution factor of 1.10 be used for all bending moments.

Later research by Zokaie (2000) states that there is a 5\% difference between positive moments and 10\% difference between negative moments for continuous versus simple span bridges. However, it is assumed that moment redistribution will cancel this effect and no correction factor is recommended (or included) for use in the AASHTO LRFD Specifications. The formulas for distribution factors are therefore considered to be directly applicable to continuous span bridges and it is recommended that the average length of the adjacent spans be used in the formulas. 


\subsubsection{Skew}

Nutt et al. (1988) observed that skew did affect live load distribution. Specifically, increasing skew tends to decrease the wheel load distribution for moment and increase the shear distributed to the obtuse corner of the bridge. In addition, they found this to be a nonlinear effect and also state that this effect will be greater for increasing skew. As a result of their sensitivity studies, two correction factors for skewed bridges (to be applied to the distribution factors obtained for a non-skewed bridge with identical geometry) were developed; one suggested correction factor is to be used for moment and the second is to be applied to the distribution factor for shear in the obtuse corner of the bridge. These correction factors are a function of girder spacing, span length, slab thickness, transformed moment of inertia of the girder, transformed area of the girder, girder eccentricity, and skew angle.

\subsubsection{Cross-Frame Characteristics}

Walker (1987) investigated the effect of diaphragms using a grid with plate elements to generate influence surfaces. Models were created with typical cross bracing spaced at 25 feet and similar models were created with no diaphragms. Results of these efforts showed that for a load applied near the curb, the difference between the two types of models (with and without diaphragms) was negligible. Although, it was also observed that for a load transversely centered, the discrepancy between the two models is more pronounced.

Also, Tarhini and Frederick (1992) have studied the effect of cross frames on live load distribution to a limited degree. Their results from analytical studies indicated that using various configurations of the most common types of channel diaphragm cross bracing had little effect on wheel load distribution.

Field studies by Kim and Nowak (1997) indicated that relatively widely spaced diaphragms lead to more uniform girder distribution factors between girders, although no information is provided regarding a relationship between increasing or decreasing distribution with cross frame spacing. 
Nutt et al. (1988) state that cross bracing can have an important role in live load distribution. However, they give two reasons for not considering this parameter in their sensitivity studies:

1. The effect of interior cross frames decreases as the number or loaded lanes increases.

2. The effect of these members is difficult to predict, as many field studies have shown diaphragms to be less effective than predicted in design.

\subsubsection{Secondary Stiffening Elements}

Secondary stiffening elements (such as sidewalks, parapets, and railings) have also been studied to determine the effect these members have on live load distribution. However, results of these efforts have been largely inconclusive. Mabsout et al. (1997) studied the effects of sidewalks and railings placed on one or both sides of a bridge using the finite element program SAP90. From these studies, a clear pattern of bridge behavior was not evident from adding these members.

Conversely, another research report by Mabsout et al. (1997) indicates a more distinct relationship between the presence of sidewalks and railings and girder distribution factors. Results for various combinations of sidewalk and/or railing on one or both sides of the bridge were compared with distribution factors obtained from current LFD and LRFD Specifications. In summary, depending on the combination and location of stiffening elements added (sidewalk and/or railing, one or both sides of the bridge), the researchers found that the current LRFD girder distribution factors are 9 to 30\% higher than those obtained in the finite element studies.

Nutt et al. (1988) point out that while secondary stiffening elements do affect live load distribution, considering these members (such as curbs and parapets) in design may be unconservative. For example, if the bridge were widened subsequent to its original design, the curbs and parapets would be removed. Therefore, the enhanced distribution as a result of these

elements would be lost, and girders designed to take advantage of this behavior may become overstressed. 


\subsubsection{Composite Behavior}

Based on analytical results, Tarhini \& Frederick (1992) found the effect of composite vs. noncomposite construction to have a negligible effect on wheel load distribution in I-girder bridges. The difference in girder distribution factors for composite vs. non-composite bridges was roughly 6 percent for a short span bridge spanning 35 feet and 1.5 percent for a relatively long span bridge spanning 119 feet.

\subsection{Live LoAd Distribution In Foreign HighWAY BRIDGe CODES}

The purpose of this section is to give a brief overview of the approaches used by some foreign countries to distribute live loads due to vehicular traffic to individual bridge girders. It was found that the Ontario specifications use an enhanced form of the AASHTO S/D factors. However, the majority of European countries and Australia utilize more refined analysis techniques.

\subsubsection{Ontario Highway Bridge Design Code}

The Ontario Highway Bridge Design Code (Ministry of Transportation, 1991) uses the same concept of distributing a certain number of lines of wheels to an individual girder, as is typically used in bridge design in the United States. Also, similar to the current AASHTO Standard Specifications, these load fractions are given in the following form. 
$g=\frac{S}{D_{d}}$

where: $g=$ load fraction

$$
\begin{aligned}
S= & \text { center-to-center girder spacing (meters) } \\
= & \text { spacing of webs in voided slabs or cellular } \\
& \text { structures (meters) } \\
= & 1 \mathrm{~m} \text { for solid slabs and transversely } \\
& \text { prestressed laminated wood bridges } \\
D_{d}= & \text { load distribution factor modified for design } \\
& \text { or evaluation }
\end{aligned}
$$

The OHDBC prescribes a unique approach for determination of " $D_{d}$ " that is based on the research of Bakht and Moses (1988) and Bakht and Jaeger (1990). Furthermore, " $\mathrm{D}_{\mathrm{d}}$ ” varies based on the limit state of interest (the same value is used for ultimate and serviceability limit states with a slightly different value used for the fatigue limit state) and for moment versus shear.

For example, the appropriate value of " $D_{d}$ " for calculation of the distribution factor to be applied to bending moments for the ultimate and serviceability limit states is

$$
D_{d}=D\left[1+\frac{\mu C_{f}}{100}\right]
$$

where: $D=$ load distribution factor (determined from

tables in the code)

$$
C_{f}=\text { correction factor to adjust “ } D \text { ” for }
$$

longitudinal moment and shear

(determined from tables in the code)

$$
\begin{aligned}
& \mu=\frac{W_{e}-3.3 \mathrm{~m}}{0.6 \mathrm{~m}} \\
& W_{e}=\text { width of a design lane (meters) }
\end{aligned}
$$

"D” and " $\mathrm{C}_{\mathrm{f}}$ ”, as stated above, are determined from tables and are a function of the type of bridge, class of highway, number of design lanes, girder location (interior vs. exterior), and span length. A similar expression for " $\mathrm{D}_{\mathrm{d}}$ ” is given for bending moment in the fatigue limit state 
with the exception that an additional parameter " $\mathrm{C}_{\mathrm{e}}$ " is included. This variable is also given in tables and is a function of span length and the number of design lanes. " $\mathrm{D}_{\mathrm{d}}$ " values for shear are presented in tables as well; these values are dependent on the bridge type and number of design lanes only.

\subsubsection{European Codes}

According to Nutt et al. (1988), the bridge design codes used n many European countries generally do not specify simplified analysis methods to determine the effect of wheel loads on bridges. Detailed analysis methods are more commonly used. Nutt et al. also state that when simplified methods are used, they tend to be those developed within the country. Specific countries mentioned include Great Britain, France, and Germany. Also, in many of the aforementioned cases, the local codes reference these methods.

\subsubsection{Australian Bridge Code}

Similar to the practices of most European countries, the Australian Bridge Design Code (Austroads, 1996) does not incorporate distribution factors for live load. Instead, the number of design lanes is determined based on roadway width, then these lanes are positioned to give the maximum load effect as a result of refined analysis methods. "Multiple lane modification factors" are incorporated into the code (similar to AASHTO multiple presence factors) which reduce the load applied to each lane as the number of design lanes increases. 


\subsection{SUMMARY}

Current AASHTO LRFD Specifications provide for simplified methods to determine the forces transferred to individual bridge girders by the use of live load distribution factors. While these factors are relatively accurate for bridges with certain geometries and parameters, the equations have been shown to be overly conservative for a wide range of bridges.

It has also been shown that many of the analytical and field-based research endeavors into the area of live load distribution on beam-and-slab bridge systems, while considering many parameters relating to the behavior of a bridge system as a whole, have not explicitly investigated the differences between interior girder behavior and exterior girder behavior. By evaluating the influence of additional parameters that may affect live load distribution and possibly reviewing the distribution methods used in foreign codes of practice, distribution factors that are more accurate for a larger scope of bridges may be developed. 


\section{CHAPTER 3: AASHTO LRFD DISTRIBUTION FACTORS FOR EXTERIOR GIRDERS}

\subsection{INTRODUCTION}

The current edition of the AASHTO LRFD Bridge Design Specifications (American Association of State Highway and Transportation Officials, 2010) lists live load distribution factors in Section 4.6.2.2. Generally, the distribution factors presented in this Section are discretized based on deck superstructure type, force effect investigated (i.e. moment or shear), the number of design lanes loaded, and interior vs. exterior behavior.

The following chapter outlines the procedures for calculating live load distribution factors for exterior girders in steel I-girder bridges according to the current edition of the AASHTO Specifications. Also included in this chapter is a brief example illustrating the use of these specifications.

\subsection{CURRENT AASHTO EXTERIOR GIRDER DiSTRIBUtION FACTORS}

The Imbsen and Associates, Inc. study (Nutt, Schamber, \& Zokaie, 1988) became the basis for the distribution factors present for slab-on-beam bridges in the AASHTO LRFD Specifications (American Association of State Highway and Transportation Officials, 2010). However, as the authors of that study state, the derived wheel load distribution factors were developed to be adequate only for design of interior girders. Therefore, the distribution factors from NCHRP Report 12-26 are used only for distribution of load to interior girders.

For exterior girder live load distribution, much more approximate methods are presented in the AASHTO LRFD Specifications. The following section summarizes the methods behind the calculation of AASHTO LRFD distribution factors for exterior girders in steel I-girders as well as a brief discussion regarding multiple presence factors. 


\subsubsection{Multiple Presence Factors}

In short, multiple presence factors are intended to account for the probability of coincident truck loadings on bridges. These factors are presented in Table 3.6.1.1.2-1 of the current AASHTO LRFD Specifications. It should be noted that the multiple presence factors have been already included in the approximate equations for distribution factors for interior girders presented in Section 4.6.2.2 for both single and multiple lanes loaded. Only when applying the Lever Rule or Special Analysis should multiple presence factors be used.

The multiple presence factors specified by the AASHTO Specifications are presented in Table 3.1.

\begin{tabular}{|c|c|}
\hline Number of Loaded Lanes & Multiple Presence Factor, $\mathbf{m}_{\mathbf{i}}$ \\
\hline \hline 1 & $\mathrm{~m}_{1}=1.20$ \\
2 & $\mathrm{~m}_{2}=1.00$ \\
3 & $\mathrm{~m}_{3}=0.85$ \\
$>3$ & $\mathrm{~m}_{>3}=0.65$ \\
\hline
\end{tabular}

Table 3.1: AASHTO Multiple Presence Factors

\subsubsection{Lever Rule Analysis}

To determine the live load distribution of moment and shear in exterior beams for one lane loaded scenarios, the AASHTO Specifications state in Table 4.6.2.2.2d-1 that the Lever Rule shall be employed. As stated in Section 2.2.1, the slab is to be treated as a beam that is simply supported by the girders. An internal hinge is assumed at the interior girder directly beside the exterior girder. Next, a design vehicle is placed on the bridge. According to AASHTO Section 3.6.1.3.1, for the design of all bridge components other than the deck overhang, the design vehicle is to be positioned transversely such that the center of any wheel load is not closer than 2.0 feet from the edge of the design lane. Therefore, to produce the extreme force effect in the exterior girder, the truck is placed as close to the edge of the bridge as possible, i.e. 2 feet from the barrier or curb. To determine the distribution factor, moments are summed at the assumed hinged to determine the percentage of load resisted by the exterior 
girder. The resulting percentage is used for both moment and shear in exterior girders for one lane loaded.

To compute the actual distribution factor, the obtained percentage is then multiplied by the appropriate multiple presence factor. As previously stated in Section 3.2.1, for one loaded lane, the appropriate multiple presence factor is 1.20. Therefore, to obtain the moment and shear exterior girder distribution factor for one loaded lane, the obtained percentage is multiplied by 1.20 .

\subsubsection{Modified Interior Girder Distribution Factors}

To obtain the live load distribution of moment and shear in exterior beams for two or more lanes loaded, the use of correction factors, similar to the use of correction factors for skew, is adopted in the AASHTO LRFD Specifications. These correction factors, " $e$ " are applied to the distribution factors for interior girders. The correction factors are presented in Table 3.2. For these factors, the distance " $d_{e}$ ", which is the horizontal distance from the centerline of the exterior web of an exterior beam at deck level to the interior edge of the curb or traffic barrier, is taken as positive if the exterior web is inboard of the interior face of the traffic railing (but must be less than or equal to 5.5 feet) and negative if it is outboard of the curb or traffic barrier (but must be greater than or equal to 1.0 feet).

\begin{tabular}{|l|c|}
\hline Correction Factor for Moment & $e=0.77+\frac{d_{e}}{9.1}$ \\
\hline Correction Factor for Shear & $e=0.6+\frac{d_{e}}{10}$ \\
\hline
\end{tabular}

Table 3.2: Multiple-Loaded-Lane Correction Factors for Exterior Beam Distribution Factors 


\subsubsection{Special Analysis}

Along with NCHRP Report 12-26 the provisions of the AASHTO LRFD Specifications clearly state that the development of the distribution factors presented did not consider the effect of diaphragms or cross-frames. Therefore, the AASHTO Specifications outline in Section C4.6.2.2.2d an additional investigation for bridges with steel beams, cast-in-place concrete Tbeams, and precast concrete I-sections or bulb-T sections. This procedure is the same as the conventional approximation for loads on piles. One other important fact to mention regarding Special Analysis is that the AASHTO LRFD Specifications specifically state that this additional investigation is recommended until research provides a better solution.

$$
\begin{aligned}
& R=\frac{N_{L}}{N_{b}}+\frac{X_{e x t} \sum_{N_{L}} e}{\sum_{N_{b}} x^{2}} \\
& \text { where: } R=\text { reaction on exterior beams (in lanes) } \\
& N_{L}=\text { number of loaded lanes under consideration } \\
& N_{b}=\text { number of beams or girders } \\
& X_{\text {ext }}=\text { horizontal distance from the center of } \\
& \text { gravity of the pattern of girders to the } \\
& \text { exterior girder (feet) } \\
& e=\text { eccentricity of a design truck or a design lane } \\
& \text { load from the center of gravity of the pattern } \\
& \text { of girders to each girder (feet) } \\
& x=\text { horizontal distance from the center of } \\
& \text { gravity of the pattern of girders to each } \\
& \text { girder (feet) }
\end{aligned}
$$

When applying Special Analysis, the process is iterated for as many design vehicles can fit onto the bridge cross-section. Also, it is the responsibility of the designer or analyst to apply the appropriate multiple presence factors to the derived reactions. 


\subsection{Distribution FACTOR CAlCulation EXAMPLE}

The following section presents example calculations of exterior girder distribution factors for a typical steel I-girder bridge according to current AASHTO Specifications (American Association of State Highway and Transportation Officials, 2010). This is meant to give the reader a better understanding of the procedures mentioned in Section 3.2.

\subsubsection{Example Bridge}

The following hypothetical bridge will serve as the basis for the calculation of AASHTO LRFD live load distribution factors in this example. For this example, a 100-foot, simple-span steel girder bridge, synonymous with the type of bridge focused in this effort, will be used. The beams, which are welded plate girders, are topped with a 10-inch-thick reinforced concrete slab (using concrete with a 4-ksi compressive strength) with a 0.5 inch integral wearing surface (which is an extra sacrificial layer of concrete that is removed to provide a smooth driving surface). Typical Jersey-style barriers are employed, as well as a 2 inch haunch. The bridge has 3 equal girder spacings of 11.5 feet and has 46-inch overhangs. A cross-section of this bridge and girder elevation are shown in Figure 3.1 and Figure 3.2, respectively. The girder dimensions are shown in Table 3.3.

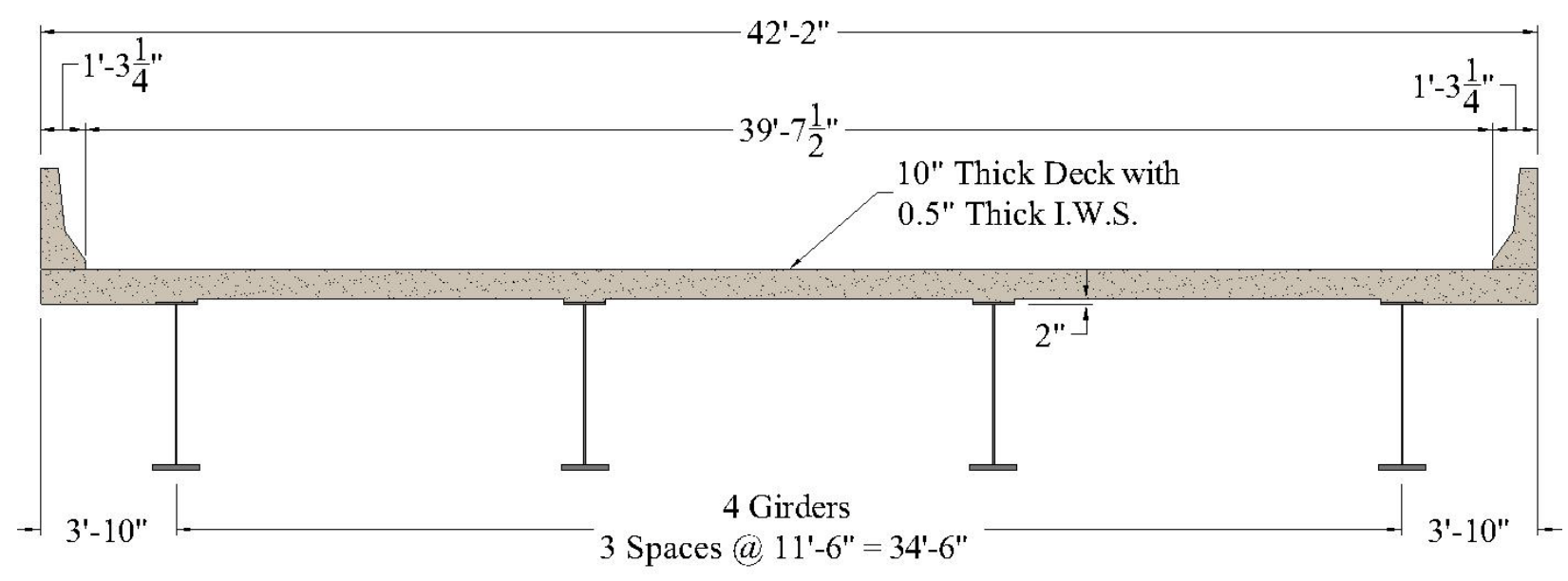

Figure 3.1: Example Bridge Cross-Section 


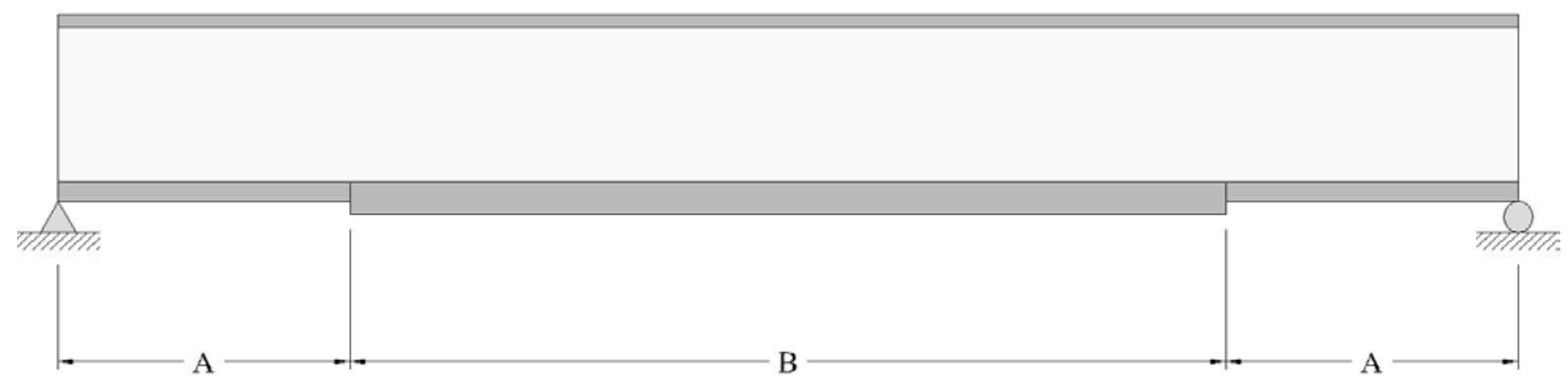

Figure 3.2: Example Bridge Girder Elevation

\begin{tabular}{|c|c|c|c|c|c|c|c|c|c|}
\hline \multicolumn{2}{|c|}{ Top Flange } & \multicolumn{4}{c|}{ Bottom Flange (A) } & \multicolumn{3}{c|}{ Bottom Flange (B) } & \multicolumn{2}{c|}{ Web } \\
\hline$b_{t f}($ in $)$ & $t_{t f}($ in) & $b_{b f}($ in) & $t_{b f}($ in $)$ & $L_{b f}(f t)$ & $b_{b f}($ in $)$ & $t_{b f}($ in $)$ & $L_{b f}(f t)$ & $d_{w}($ in $)$ & $t_{w}($ in $)$ \\
\hline \hline 14 & 0.9375 & 16 & 0.8125 & 20 & 16 & 1.625 & 60 & 54 & 0.5625 \\
\hline
\end{tabular}

Table 3.3: Example Bridge Girder Dimensions

\subsubsection{Calculation of Distribution Factors}

As previously stated, these procedures are listed in Section 4.6.2.2 of the AASHTO LRFD Specifications. These distribution factors are discretized based on deck superstructure type, the respective force effect being investigated, and the number of lanes loaded. The different types of deck superstructures, or cross-sections, are presented in Table 4.6.2.2.1-1. For steel beams with cast-in-place concrete slab decks, this is regarded as a type "a” cross-section. Therefore, throughout this calculation, all AASHTO formulas cited will correspond with a type “a” cross-section.

It is also important to note that the AASHTO distribution factors are only applicable for a certain range of parameters. These parameters vary for each distribution factor. For clarification, it will be shown that, for each expression, this example bridge falls within all of these ranges of applicability.

AASHTO Specifications also specify that if a given bridge has a particular skew (whose limit varies depending on the type of cross-section and force effect being investigated), all resulting distribution factors must be modified by multiplying them by the appropriate skew 
correction factor. Therefore, it should be noted that since this bridge is not skewed, no skew correction factors will need to be applied to the resulting distribution factors.

Furthermore, at the end of this example, all of the equations used in this example are related to their respective locations within the AASHTO LRFD Specifications. These AASHTO LRFD equation references are listed in Table 3.8.

\subsubsection{Longitudinal Stiffness Parameter}

The first step in determining live load distribution factors is to determine the longitudinal stiffness parameter, “ $K_{g}$ ”. As previously stated, while this term is not explicitly represented in the exterior girder distribution factor expressions, it is necessary (as will be shown) for the calculation of the exterior girder distribution factors. “ $K_{g}$ ” is determined as follows.

$$
\begin{aligned}
& K_{g}=n\left(I+A e_{g}{ }^{2}\right) \\
& \text { where: } K_{g}=\text { longitudinal stiffness parameter }\left(\mathrm{in}^{4}\right) \\
& n=\text { modular ratio } \\
& I=\text { moment of inertia of noncomposite } \\
& \text { beam (in in }{ }^{4} \text { ) } \\
& A=\text { area of noncomposite beam }\left(\mathrm{in}^{2}\right) \\
& e_{g}=\text { distance between the centers of gravity of the } \\
& \text { basic beam and deck (in) }
\end{aligned}
$$

The modular ratio, “ $n$ ”, referenced in the previous equation is determined as follows.

$$
n=\frac{E_{B}}{E_{D}}
$$

Equation 3-3

where: $n=$ modular ratio

$$
\begin{aligned}
& E_{B}=\text { modulus of elasticity of beam material (ksi) } \\
& E_{D}=\text { modulus of elasticity of deck material (ksi) }
\end{aligned}
$$

Table 3.4 lists the calculations of the area and moment of inertia of the plate girder. For clarity, the " $y$ " values are distances from the individual component centroids to the bottom of the 
girder. These are used to calculate the composite centroid of the entire girder. On the other hand, the "d" values are distances from the individual component centroids to the composite centroid of the entire girder. These distances are used in conjunction with the parallel-axis theorem to determine the composite moment of inertia of the entire girder.

\begin{tabular}{||l|c|c|c|c|c|c||}
\hline \multicolumn{1}{|c|}{ Section } & $\begin{array}{c}\text { area, } A \\
\left(\mathrm{in}^{2}\right)\end{array}$ & $\begin{array}{c}\text { centroid, } y \\
\text { (in) }\end{array}$ & $\begin{array}{c}\text { Ay } \\
\left(\mathrm{in}^{3}\right)\end{array}$ & $\begin{array}{c}I_{o} \\
\left(\mathrm{in}^{4}\right)\end{array}$ & $\begin{array}{c}d \\
(\mathrm{in})\end{array}$ & $\begin{array}{c}I_{N A} \\
\left(\mathrm{in}^{4}\right)\end{array}$ \\
\hline top flange & 13.13 & 56.09 & 736.23 & 0.96 & -32.69 & 14023 \\
\hline web & 30.38 & 28.63 & 869.48 & 7381.13 & -5.22 & 8208 \\
\hline bottom flange & 26.00 & 0.81 & 21.13 & 5.72 & 22.60 & 13280 \\
\hline $\mathbf{\Sigma}=$ & $\mathbf{6 9 . 5 0}$ & & $\mathbf{1 6 2 6 . 8 4}$ & & & $\mathbf{3 5 5 1 1}$ \\
\hline
\end{tabular}

Table 3.4: Example Bridge Section Properties

Therefore, for this plate girder:

$$
\begin{aligned}
& A=69.50 \text { in }^{2} \\
& I=35511 \text { in }^{4}
\end{aligned}
$$

Next, the moduli of elasticity of the respective materials must be determined. According to AASHTO Section 6.4.1, the modulus of elasticity for steel may be assumed to be $29000 \mathrm{ksi}$. However, for normal weight concrete, the modulus of elasticity must be calculated using the following formula.

$$
E_{c}=1820 \sqrt{f_{c}{ }^{\prime}}
$$

where: $E_{c}=$ modulus of elasticity of concrete (ksi)

$$
f_{c}^{\prime}=\text { compressive strength of concrete (ksi) }
$$

Taking the compressive strength of concrete to be $4 \mathrm{ksi}$ (as stated earlier) the modulus of elasticity of concrete is as follows.

$$
E_{c}=1820 \sqrt{f_{c}^{\prime}}=1820 \sqrt{(4 \mathrm{ksi})}=3640 \mathrm{ksi}
$$


Therefore, the modular ratio is as follows.

$$
n=\frac{E_{B}}{E_{D}}=\frac{E_{s}}{E_{c}}=\frac{29000 \mathrm{ksi}}{3640 \mathrm{ksi}}=7.97 \approx 8
$$

As stated in the previous expression, for simplicity, the modular ratio may be taken to be 8 in all of the following equations.

One note that should be discussed before the calculation of " $e_{g}$ ” is the calculation of " $t_{s}$," which is the effective thickness of the slab. The effective thickness of the slab is determined by subtracting the integral wearing surface thickness from the thickness of the slab as it is cast. For this example, the deck was cast at 10 inches with a 0.5-inch-thick integral wearing surface. This equates to a " $t_{s}$ " value of 9.5 inches.

Next, “ $e_{g}$ ” must be calculated. As previously stated, “ $e_{g}$ ” distance between the centers of gravity of the basic beam and deck. Since the centroid of the beam has already been calculated in Table 3.4 and the centroid of the slab is simply located at its center, this value can be easily calculated as follows.

$$
\begin{aligned}
e_{g} & =t_{b f}+d_{w}+\text { haunch }+\frac{t_{s}}{2}-\frac{\sum A x}{\sum A} \\
& =0.8125 \mathrm{in}+54 \mathrm{in}+2 \mathrm{in}+\frac{9.5 \mathrm{in}}{2}-\frac{1626.84 \mathrm{in}^{3}}{69.50 \mathrm{in}^{2}} \\
& =38.97 \mathrm{in}
\end{aligned}
$$

Therefore, “ $K_{g}$ ” can be calculated as follows.

$$
\begin{aligned}
K_{g} & =n\left(I+A e_{g}^{2}\right) \\
& =8\left[35511 \mathrm{in}^{4}+\left(69.50 \mathrm{in}^{2}\right)(38.97 \mathrm{in})^{2}\right] \\
& =1,128,344 \mathrm{in}^{4}
\end{aligned}
$$




\subsubsection{Interior Girder Distribution Factors- One Lane Loaded}

Next, the distribution factors for interior girders must be calculated. As previously stated, although the goal of this calculation example is to show the calculation of only the exterior girder distribution factors, the interior girder distribution factors are necessary for the determination of the modified distribution factors discussed in Section 3.2.3.

The previously discussed AASHTO distribution factors are organized in Section 4.6.2.2 of the Specifications in a series of tables based on the force effect being investigated, interior vs. exterior girder behavior, etc.. One of the important tables in the beginning of this section, Table 4.6.2.2.1-1, distinguishes what values are to be used for " $L$ " in these equations. For this example, the bridge consists of only one span, and, therefore, only positive moment is to be investigated. Therefore, according to this Table, " $L$ " is to be taken as the length of the span for which the respective force effect is being investigated, or 100 feet.

Furthermore, it should be noted that, since these equations are empirical, the units used for the values necessary in these equations must remain consistent with those specified in the Specifications, which are specifically listed at the beginning of Section 4.6.2.2. Therefore, all of the values necessary for the equations used in this example are made consistent with the specified units. The results of all of these empirical equations will be in terms of the number of design lanes that should be applied.

First, the distribution factors for interior girders with one lane loaded will be calculated first. The formulas for these distribution factors are located in Table 4.6.2.2.2b-1 and Table 4.6.2.2.3a-1, respectively, and are as follows. 
$g_{M_{\text {int }}}=0.06+\left(\frac{S}{14}\right)^{0.4}\left(\frac{S}{L}\right)^{0.3}\left(\frac{K_{g}}{12.0 L t_{s}^{3}}\right)^{0.1}$

$g_{V_{\text {int }} t_{1}}=0.36+\frac{S}{25.0}$

where: $g=$ distribution factor

$$
\begin{aligned}
S & =\text { girder spacing } \\
& =11.5 \text { feet } \\
L & =\text { span length } \\
& =100 \text { feet } \\
K_{g} & =\text { longitudinal stiffness parameter } \\
& =1,128,344 \text { in }^{4} \\
t_{S} & =\text { effective slab thickness } \\
& =9.5 \text { inches }
\end{aligned}
$$

For these formulas, there are certain ranges of applicability within which these formulas are valid. For the equation for moment distribution, these ranges are

- $3.5 \mathrm{ft} \leq S \leq 16.0 \mathrm{ft}$

- 4.5 in $\leq t_{s} \leq 12.0$ in

- $20 \mathrm{ft} \leq L \leq 240 \mathrm{ft}$

- $N_{b} \geq 4$

- 10,000 in $^{4} \leq K_{g} \leq 7,000,000$ in $^{4}$

For the equation for shear distribution, these ranges are

- $\quad 6.0 \mathrm{ft} \leq S \leq 13.0 \mathrm{ft}$

- $20 \mathrm{ft} \leq L \leq 240 \mathrm{ft}$

- 4.5 in $\leq t_{s} \leq 12.0$ in

- $N_{b} \geq 4$ 
It can be clearly seen that this example bridge meets all the requirements of the said ranges of applicability. Therefore, these distribution factors can be calculated as follows.

$$
\begin{aligned}
g_{\text {int }_{1}} & =0.06+\left(\frac{11.5}{14}\right)^{0.4}\left(\frac{11.5}{100}\right)^{0.3}\left[\frac{1,128,344}{12.0(100)(9.5)^{3}}\right]^{0.1} \\
& =0.548 \text { lanes } \\
g_{\text {int }_{1}} & =0.36+\frac{11.5}{25.0} \\
& =0.820 \text { lanes }
\end{aligned}
$$

\subsubsection{Interior Girder Distribution Factors- Two or More Lanes Loaded}

Next, the distribution factors for interior girders with two or more lanes loaded will be calculated. The formulas for these distribution factors are located in Table 4.6.2.2.2b-1 and Table 4.6.2.2.3a-1, and are as follows:

$$
\begin{array}{rl}
g_{\text {int } 2_{2}} & 0.075+\left(\frac{S}{9.5}\right)^{0.6}\left(\frac{S}{L}\right)^{0.2}\left(\frac{K_{g}}{12.0 L t_{s}^{3}}\right)^{0.1} \\
g_{V_{\text {int }_{2}}=} & 0.2+\frac{S}{12}-\left(\frac{S}{35}\right)^{2.0} \\
\text { where: } g & =\text { distribution factor } \\
S & =\text { girder spacing } \\
& =11.5 \text { feet } \\
L & =\text { span length } \\
& =100 \text { feet } \\
K_{g} & =\text { longitudinal stiffness parameter } \\
& =1,128,344 \text { in } \\
& \\
t_{S} & =\text { effective slab thickness } \\
& =9.5 \text { inches }
\end{array}
$$


The same ranges of applicability for these distribution factors are the same as those for the distribution factors listed in the Section 3.3.2.2. Therefore, this bridge obviously meets those limits as well, and the distribution factors are as follows.

$$
\begin{aligned}
g_{\text {int }_{2}} & =0.075+\left(\frac{11.5}{9.5}\right)^{0.6}\left(\frac{11.5}{100}\right)^{0.2}\left[\frac{1,128,344}{12.0(100)(9.5)^{3}}\right]^{0.1} \\
& =0.809 \text { lanes } \\
g_{V_{\text {int }_{2}}} & =0.2+\frac{11.5}{12}-\left(\frac{11.5}{35}\right)^{2.0} \\
& =1.050 \text { lanes }
\end{aligned}
$$

\subsubsection{Exterior Girder Distribution Factors- One Lane Loaded (Lever Rule Analysis)}

As previously stated, to determine the live load distribution of moment and shear in exterior beams for one lane loaded scenarios, the AASHTO Specifications state in Table 4.6.2.2.2d-1 that the Lever Rule shall be employed. As the specifications state, the only requirement for the applicability of the Lever Rule (for both moment and shear distribution) is that " $d_{e}$ " is between -1.0 feet and 5.5 feet. " $d_{e}$ " is defined as the horizontal distance from the centerline of the exterior web of an exterior beam at deck level to the interior edge of the curb or traffic barrier. For this bridge, “ $d_{e}$ ” will simply be equal to the width of the overhang minus the width of the barrier, which is 2.563 feet. Therefore, the Lever Rule is applicable for this bridge.

A diagram showing the placement of the truck for the Lever Rule is shown in Figure 3.3. The left side of the diagram shown the HS20-44 placed on the bridge, whereas the right shows the dimensions relating to this truck placement. For more details regarding the rules of truck placement and Lever Rule Analysis in general, see Section 3.2.2. 


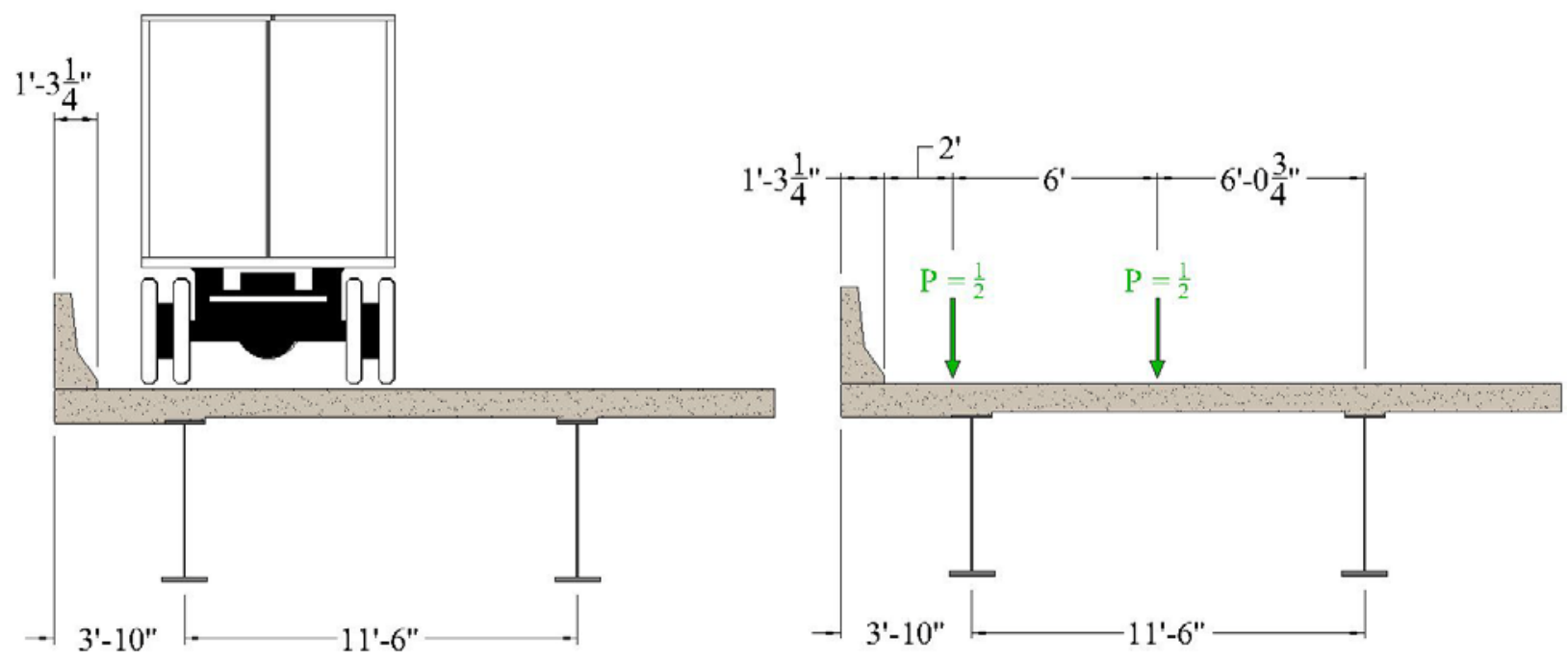

Figure 3.3: Example Bridge Lever Rule Truck Placement

Since the Lever Rule is used to determine the percentage of truck distributed to each girder, the wheel loads are taken to be equal to 0.5; i.e. half of the truck load on one side of the truck and the other half of the load on the other side of the truck.

Next, moments are summed about the interior girder to determine the vertical reaction at the exterior girder.

$$
\begin{aligned}
& \text { Lever Rule Analysis }=\frac{1}{11.5 \mathrm{ft}}\left[\frac{1}{2}(6.0625 \mathrm{ft}+6 \mathrm{ft})+\frac{1}{2}(6.0625 \mathrm{ft})\right] \\
& \text { Lever Rule Analysis }=0.788 \text { lanes }
\end{aligned}
$$

To obtain the live load distribution factors for both moment and shear, the appropriate multiple presence factor needs to be applied. For one lane load scenarios, this factor equals 1.20. Therefore, the distribution factors are as follows.

$$
\begin{aligned}
g_{M_{\text {ext }_{1}}=g_{V_{\text {ext }}}} & =m_{1}(\text { L.R.A. }) \\
& =1.20(0.788 \text { lanes }) \\
& =0.946 \text { lanes }
\end{aligned}
$$




\subsubsection{Exterior Girder Distribution Factors- Two or More Lanes Loaded}

Next, the distribution factors for exterior girders with two or more lanes loaded will be calculated. The formulas for these distribution factors are located in Table 4.6.2.2.2d-1 and Table 4.6.2.2.3a-1, and are as follows:

$$
\begin{aligned}
& g=e g_{\text {interior }} \\
& \quad e_{M}=0.77+\frac{d_{e}}{9.1} \\
& g=e g_{\text {interior }} \\
& e_{V}=0.6+\frac{d_{e}}{10}
\end{aligned}
$$

where: $g$ = exterior girder distribution factor

$g_{\text {interior }}=$ interior girder distribution factor

$d_{e}=$ the horizontal distance from the centerline

of the exterior web of an exterior beam at

deck level to the interior edge of the curb or

traffic barrier

For these formulas, the interior girder distribution factors will be taken as the maximum of the two factors that resulted from the empirical equations demonstrated in Section 3.3.2.2 and Section 3.3.2.3. " $d e$ " for these equations, the width of the overhang minus the width of the barrier, was calculated in the previous section, and is equal to 2.563 feet.

Furthermore, for these equations, the same range of applicability ( $-1.0 \mathrm{ft} \leq d_{e} \leq 5.5 \mathrm{ft}$ ) for the distribution factors listed in Section 3.3.2.4 also applies to these distribution factors. Therefore, this bridge obviously meets those limits as well. Also, for this particular class of distribution factors only (exterior girders, two or more lanes loaded), the code also specifies that if the bridge fails to meet this requirement, the Lever Rule may be applied if the bridge has three girders. However, since this bridge meets the previously stated range of applicability, the formulas listed in this section may be applied. 
Therefore, the calculation of these distribution factors is as follows.

$$
\begin{aligned}
& e_{M}=0.77+\frac{d_{e}}{9.1} \\
& =0.77+\frac{2.563}{9.1} \\
& =1.052 \\
& \therefore g_{M_{\text {ext }} 2}=e_{M} \max \left[\begin{array}{l}
g_{M_{\text {int }_{1}}} \\
g_{M_{\text {int }_{2}}}
\end{array}\right] \\
& =1.052 \max \left[\begin{array}{l}
0.548 \text { lanes } \\
0.809 \text { lanes }
\end{array}\right] \\
& =1.052 \text { (0.809 lanes) } \\
& =0.851 \text { lanes } \\
& e_{V}=0.6+\frac{d_{e}}{10} \\
& =0.6+\frac{2.563}{10} \\
& =0.856 \\
& \therefore g_{V_{\text {ext }_{2}}}=e_{V} \max \left[\begin{array}{l}
g_{V_{\text {int }_{1}}} \\
g_{V_{\text {int }_{2}}}
\end{array}\right] \\
& =0.856 \max \left[\begin{array}{l}
0.820 \text { lanes } \\
1.050 \text { lanes }
\end{array}\right] \\
& =0.856 \text { (1.050 lanes) } \\
& =0.899 \text { lanes }
\end{aligned}
$$




\subsubsection{6 $\underline{\text { Special Analysis }}$}

As previously stated, the AASHTO Specifications outline in Section C4.6.2.2.2d an additional investigation for bridges with steel beams, cast-in-place concrete T-beams, and precast concrete I-sections or bulb-T sections. The formula for special analysis is listed in this section and is as follows.

$$
\begin{aligned}
& R=\frac{N_{L}}{N_{b}}+\frac{X_{e x t} \sum_{N_{L}} e}{\sum_{N_{b}} x^{2}} \\
& \text { where: } R=\text { reaction on exterior beams (in lanes) } \\
& N_{L}=\text { number of loaded lanes under consideration } \\
& N_{b}=\text { number of beams or girders } \\
& X_{e x t}=\text { horizontal distance from the center of } \\
& \quad \text { gravity of the pattern of girders to the } \\
& \quad \text { exterior girder (feet) } \\
& e= \text { eccentricity of a design truck or a design lane } \\
& \text { load from the center of gravity of the pattern } \\
& \text { of girders to each girder (feet) } \\
& x= \text { horizontal distance from the center of } \\
& \text { gravity of the pattern of girders to each } \\
& \text { girder (feet) }
\end{aligned}
$$

For Special Analysis, the total number of design lanes is taken to be the integer part of the ratio " $w / 12.0$ " where " $w$ " is the clear roadway width in feet between curbs and/or barriers. As can be seen in Figure 3.1, the clear roadway width for this example bridge is 39 feet and 7.5 inches. This translates to a total of 3 design lanes that can fit onto this bridge. Therefore, Special Analysis will generate 3 distribution factors that will be applicable to both moment and shear on exterior girders.

Figure 3.4 shows the transverse truck placement on the example bridge for Special Analysis. The upper portion of the diagram shown the HS20-44 placed on the bridge, whereas the lower portion shows the dimensions relating to this truck placement. Also, these diagrams 
show labels for the girders which will be used later for the calculation of determination of girder eccentricities.
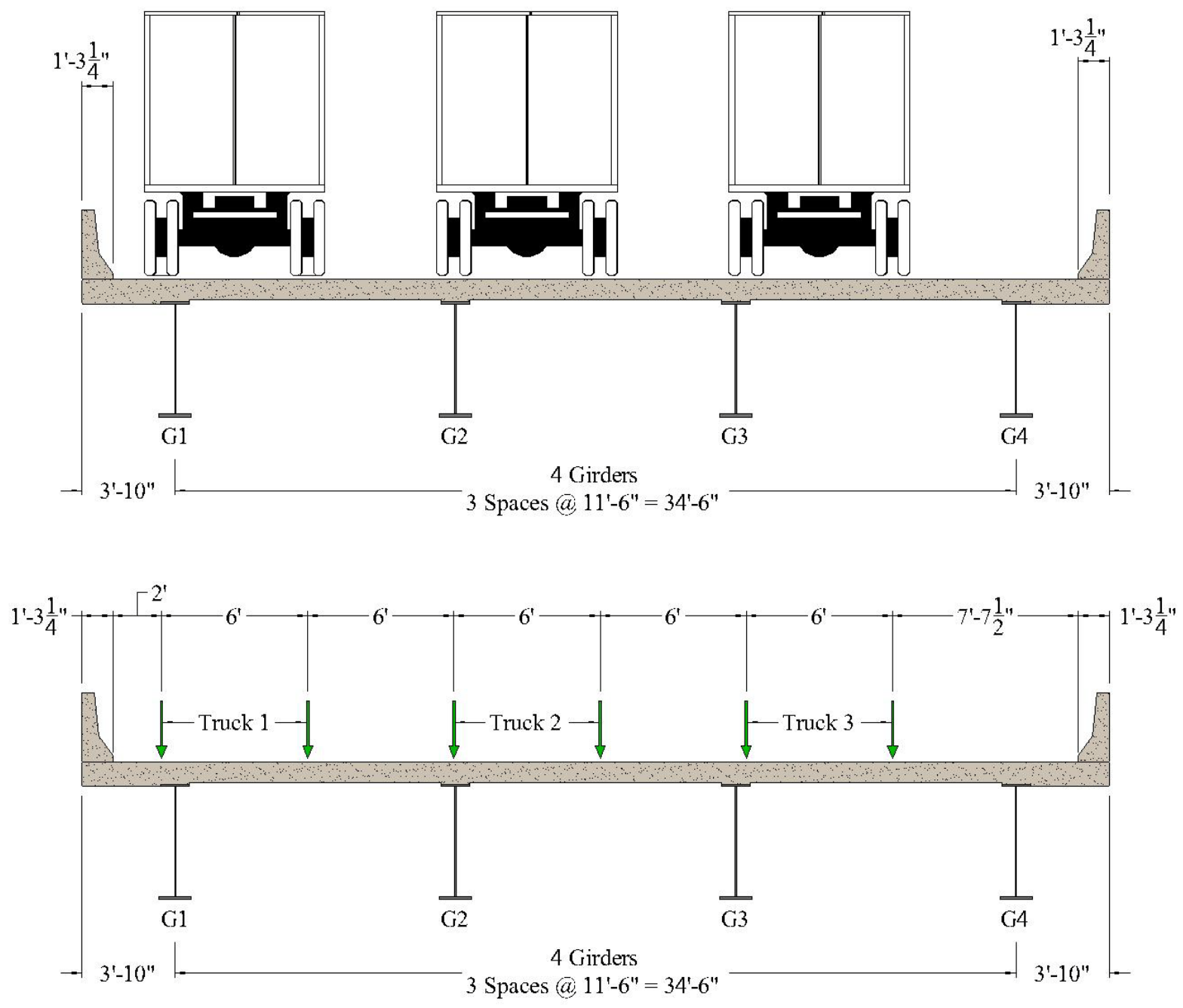

Figure 3.4: Example Bridge Special Analysis Truck Placement

To begin Special Analysis, “ $N_{b}$ ” and “ $X_{\text {ext }}$ need to be determined. “ $N_{b}$ ” is simply the number of girders, which for this example bridge, is 4 . " $X_{\text {ext }}$ " is the horizontal distance from the center of gravity of the pattern of girders to the exterior girder. For this bridge, this is simply half the width between the two exterior girders, or 17.25 feet. 
Next, the horizontal distances from the centers-of-gravity of the pattern of girders to each girder, or the " $x$ " distances in AASHTO Eq. C4.6.2.2.2d-1, and their squares are shown in Table 3.5.

\begin{tabular}{|c|c|c|}
\hline Girder & $\mathbf{x}(\mathbf{f t})$ & $\left.\mathbf{x}^{2} \mathbf{( f t}^{\mathbf{2}}\right)$ \\
\hline G1 & 17.25 & 297.5625 \\
G2 & 5.75 & 33.0625 \\
G3 & -5.75 & 33.0625 \\
G4 & -17.25 & 297.5625 \\
\hline \multicolumn{3}{|c|}{$\sum_{N_{b}} x^{2}=$} \\
\end{tabular}

Table 3.5: Example Bridge " $x "$ Distances

Next, the eccentricities of each lane from the center-of-gravity of the pattern of girders, or the " $e$ " distances in AASHTO Eq. C4.6.2.2.2d-1 need to be determined. These distances are shown in Table 3.6.

\begin{tabular}{|c|c|c|}
\hline Lane & $\mathbf{e}(\mathbf{f t})$ & $\sum_{\mathbf{N}_{\mathbf{L}}} \mathbf{e}(\mathbf{f t})$ \\
\hline \hline Truck-1 & 14.8125 & $=14.8125$ \\
Truck-2 & 2.8125 & $=14.8125+2.8125=17.625$ \\
Truck-3 & -9.1875 & $=14.8125+2.8125-9.1875=8.4375$ \\
\hline
\end{tabular}

Table 3.6: Example Bridge "e" Distances 
Therefore, the reactions according to Special Analysis can now be calculated and are as follows. As stated earlier, there will be three reactions calculated as there are a maximum of three lanes applied to this bridge.

$$
\begin{aligned}
& R_{1}=\frac{1}{4}+\frac{(17.25 \mathrm{ft})(14.8125 \mathrm{ft})}{\left(661.25 \mathrm{ft}^{2}\right)}=0.636 \text { lanes } \\
& R_{2}=\frac{2}{4}+\frac{(17.25 \mathrm{ft})(17.625 \mathrm{ft})}{\left(661.25 \mathrm{ft}^{2}\right)}=0.960 \text { lanes } \\
& R_{3}=\frac{3}{4}+\frac{(17.25 \mathrm{ft})(8.4375 \mathrm{ft})}{\left(661.25 \mathrm{ft}^{2}\right)}=0.970 \text { lanes }
\end{aligned}
$$

To obtain the live load distribution factors, these reactions must be multiplied by the appropriate multiple presence factors. Therefore, these distribution factors are as follows.

$$
\begin{aligned}
& g_{M_{\text {ext }_{1}}}=g_{V_{\text {ext }_{1}}}=m_{1}\left(R_{1}\right)=1.20(0.636 \text { lanes })=0.764 \text { lanes } \\
& g_{M_{\text {ext }_{2}}}=g_{V_{\text {ext }_{2}}}=m_{2}\left(R_{2}\right)=1.00(0.960 \text { lanes })=0.960 \text { lanes } \\
& g_{M_{\text {ext }_{3}}}=g_{V_{\text {ext }_{3}}}=m_{3}\left(R_{3}\right)=0.85(0.970 \text { lanes })=0.825 \text { lanes }
\end{aligned}
$$

\subsubsection{Distribution Factor Summary}

Table 3.7 summarizes the distribution factors calculated in this example. From this summary, it can be shown that moment is controlled by Special Analysis. For shear, the distribution of live load to interior girders with two or more lanes loaded controls.

These distribution factors would then be used in conjunction with a line-girder analysis to determine the maximum live load moment and shear for which this bridge will need to withstand. For most standard bridge designs, an influence-line approach will be used to generate the maximum moments and shears at tenth points along the span, creating live load moment and shear envelopes. These moments and shears would then be multiplied by the controlling distribution factors to generate the distributed live load moments and shears that would then be used for the evaluation of the bridge according to LRFD limit states. 


\begin{tabular}{|l|c|c|c|}
\hline \multirow{2}{*}{$\begin{array}{c}\text { Distribution Factor } \\
\text { Category }\end{array}$} & $\begin{array}{c}\text { Number of } \\
\text { Lanes Loaded }\end{array}$ & \multicolumn{2}{c|}{ Distribution Factors (by girder type) } \\
\cline { 3 - 4 } & 1 & Interior Girders & Exterior Girders \\
\hline \hline \multirow{2}{*}{ Moment } & 2 or more & 0.548 & 0.946 \\
\cline { 2 - 4 } & 1 & 0.809 & 0.851 \\
\hline \multirow{2}{*}{ Shear } & 2 or more & 1.050 & 0.946 \\
\cline { 2 - 4 } & 1 & & 0.899 \\
\hline \multirow{3}{*}{ Special Analysis } & 2 & & 0.764 \\
\cline { 2 - 4 } & 3 & & 0.960 \\
\cline { 2 - 4 } & & & 0.825 \\
\hline
\end{tabular}

Table 3.7: Example Bridge Distribution Factors

Also, for the reader's convenience, Table 3.8 has been provided. Throughout this chapter, equations have been used that come directly from the AASHTO LRFD Specifications (American Association of State Highway and Transportation Officials, 2010). Table 3.8 provides the AASHTO reference for each equation that has been presented in this chapter.

\begin{tabular}{|c|c|}
\hline Chapter 3 Equation Reference & AASHTO LRFD Equation Reference \\
\hline \hline Equation 3-1 & Equation C4.6.2.2.2d-1 \\
\hline Equation 3-2 & Equation 4.6.2.2.1-1 \\
\hline Equation 3-3 & Equation 4.6.2.2.1-2 \\
\hline Equation 3-4 & Equation C5.4.2.4-1 \\
\hline Equation 3-5 & Found in Table 4.6.2.2.2b-1 \\
\hline Equation 3-6 & Found in Table 4.6.2.2.3a-1 \\
\hline Equation 3-7 & Found in Table 4.6.2.2.2b-1 \\
\hline Equation 3-8 & Found in Table 4.6.2.2.3a-1 \\
\hline Equation 3-9 & Found in Table 4.6.2.2.2d-1 \\
\hline Equation 3-10 & Found in Table 4.6.2.2.3b-1 \\
\hline Equation 3-11 & Equation C4.6.2.2.2d-1 \\
\hline
\end{tabular}

Table 3.8: AASHTO LRFD Equation References 


\subsection{SUMMARY}

The preceding chapter outlined the procedures for calculating live load distribution factors for exterior girders in steel I-girder bridges according to the current edition of the AASHTO LRFD Specifications. Also, included in this chapter was a brief example demonstrating how the calculations behind these AASHTO distribution factors are done.

One important point that becomes clear after reviewing AASHTO live load distribution methods is that the procedures for determining exterior girder distribution factors are more cumbersome than the refined formulas for interior girder distribution factors. Since the previously mentioned Imbsen and Associates, Inc. study (Nutt, Schamber, \& Zokaie, 1988) did not differentiate between the behaviors of interior versus exterior girders and only evaluated live load distribution for a typical interior girder, their formulas are only reported for interior girder distribution in the AASHTO Specifications.

Therefore, it should be clear that a more refined method of determining live load distribution to exterior girders in steel I-girder bridges should be developed to increase both the reliability and economy of future steel slab-on-beam bridges. 


\section{ChAPTER 4: Finite Element MOdeling TeChNiQues AND Analytical COMPUTATION OF Distribution Factors}

\subsection{INTRODUCTION}

The following chapter outlines the finite element modeling techniques used for this research project. Specifically, details such as element selections, material definitions, mesh discretizations, boundary conditions used, and load applications are discussed. Also, presented in this chapter are the methods used to calculate distribution factors from finite element models and the ideologies behind their implementation. Finally, a benchmark analysis of Missouri Bridge A6101, which was used to verify the validity of the modeling techniques presented herein, is presented. The methods presented in this chapter are further employed in the sensitivity and parametric studies presented in subsequent chapters.

\subsection{Finite Element Modeling TeChNiQUeS}

To determine the influence of certain parameters in the distribution of live load to the exterior girder of steel I-girder bridges, the bridges were modeled and analyzed using the commercial finite element software package Abaqus/CAE (Dassault Systèmes, 2009). Contained in this section is a description of the modeling techniques used to accurately capture steel girder bridge behavior and how these techniques were implemented using Abaqus software.

\subsubsection{Element Selection}

Element selection for these finite element models included a 4-node, doubly-curved, finite-membrane-strain, general-purpose shell with reduced integration (known in the Abaqus/Standard User's Manual as an S4R element) and a 2-node linear beam in space (known in the Abaqus/Standard User's Manual as a B31 element). S4R elements were used to simulate the concrete deck, the girder webs, and the girder flanges; B31 elements were used to simulate 
the cross-frame members and the concrete barriers. To model the composite action between both the girders and the deck as well as between the deck and the barriers, node-to-node multiple point constraints were used such that the degrees of freedom between nodes WERE restrained (these constraints are known in the Abaqus/Standard User’s Manual as an MPC Beam).

\subsubsection{Material Definition}

The incorporation of nonlinear behavior would create difficulties in predicting live load distribution since strain values would be somewhat unpredictable once stresses breached the yield point. Therefore, all materials were only modeled as linear, elastic, isotropic mediums. It should also be noted that the maximum stress values for both the steel and concrete in all of the models once analyzed were found to be well below the yield stress for steel or the compressive strength of concrete, respectively, indicating that the modeling of the materials as linear elastic mediums was sound. This conclusion has also been made by other researchers. Eom and Nowak (2001) concluded, after testing 17 steel I-girder bridges in Michigan, that the observed response of these bridges under the application of live load was linear throughout their study. The relevant material properties (i.e. the respective moduli of elasticity and the Poisson's ratios) were defined with the same values as those specified in Section 5.2.1.

\subsubsection{Mesh Discretization}

AASHTO LRFD Section 4.6.3.3 (American Association of State Highway and Transportation Officials, 2010) describes certain guidelines that should be adhered to with modeling beam-slab bridges. For example, the aspect ratio of finite elements should not exceed 5.0. Also, for finite element analyses involving plate and beam elements, it is preferable to maintain the relative vertical distances between various elements.

The mesh discretization for the finite element models was designed both to attain accurate results as well as to adhere with AASHTO LRFD specifications. For the bridges in the sensitivity / parametric matrix discussed in Chapters 5 and 6, mesh discretization of the girders consisted of four elements along the flanges and approximately 8-14 elements along the web. This is due to the differing web depths between the different girder designs used in this study. 
For the deck, the mesh was discretized such that elements were approximately 8 to 10 inches long transversely except for at the end of the deck, where the mesh was discretized such that the elements at the end of the deck ended where the centroid of the barrier occurred. This was done so that MPC beams would be assigned such that the composite action between the deck and the barrier would occur at the centroid of the B31 barrier element. Figure 4.1 illustrates this discretization scheme.

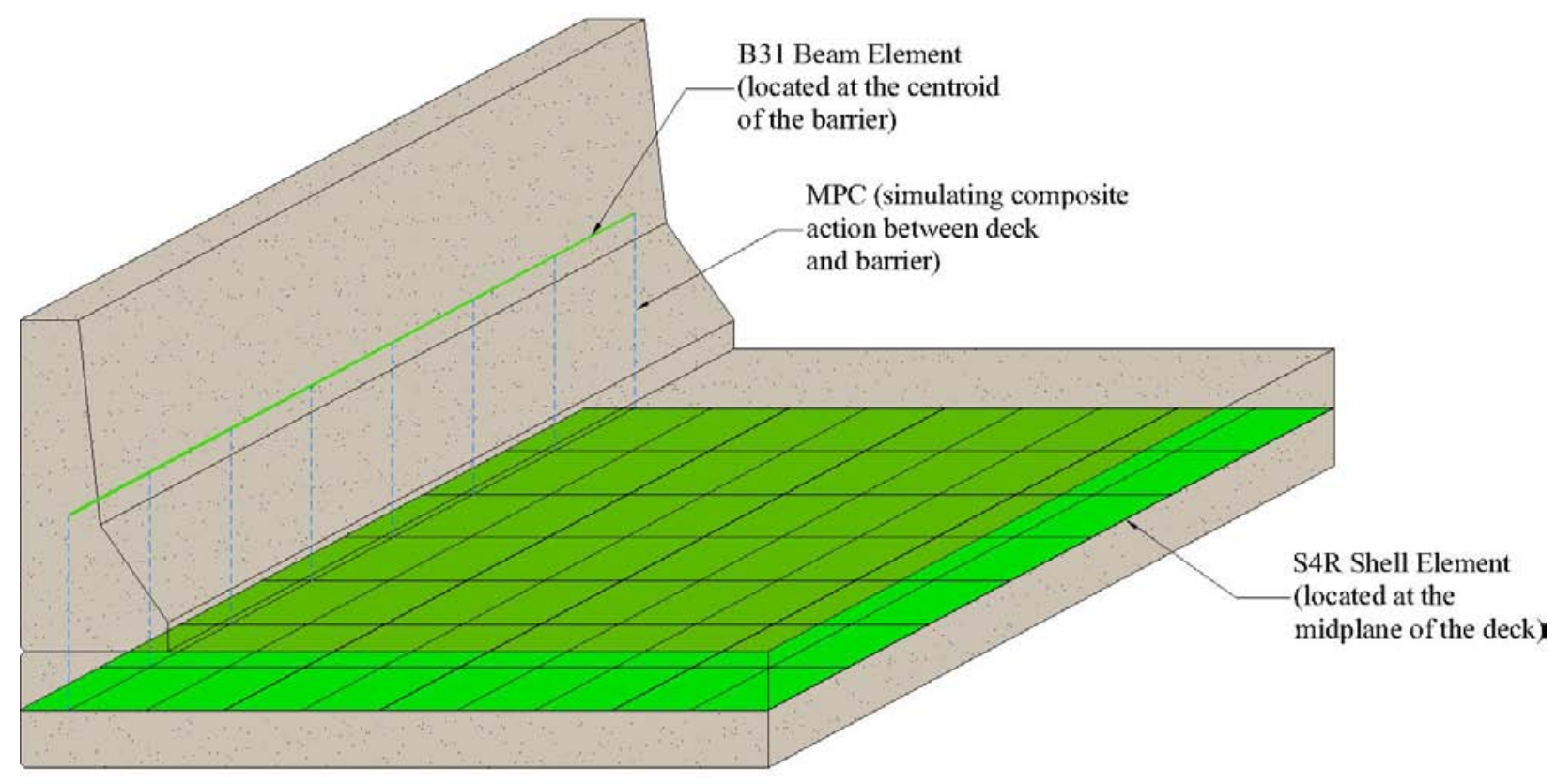

Figure 4.1: Mesh Discretization for Concrete Deck

As for discretization along the longitudinal axis, all elements were discretized to be one foot long, i.e. one element per foot of span length. This scheme of discretization ensured that all of the AASHTO specifications were met as well as that the results that were attained were accurate.

\subsubsection{Boundary Conditions and Multiple-Point Constraints}

Boundary conditions on the models represented common "hinge-roller" conditions. Also, as is common with bridge construction, the girder ends were also restrained from lateral 
movement as well. These boundary conditions were placed on the nodes along the edges of the bottom flange of each girder.

An image of one of the finite element models in the sensitivity / parametric matrix discussed in Chapters 5 and 6 (specifically the control run of the bridge with a span length 100 feet, an 11.5-foot girder spacing, a 25-foot unbraced length, and a 46 inch overhang) is shown in Figure 4.2. The image shows the boundary conditions (in orange) as well as the mesh discretization. For purposes of clarity, the MPC Beams have been removed from the model; however the wire features where the MPC Beams are assigned remain showing.

It should be noted that this bridge is that this is the same bridge analyzed in the distribution factor calculation example in Section 3.3.

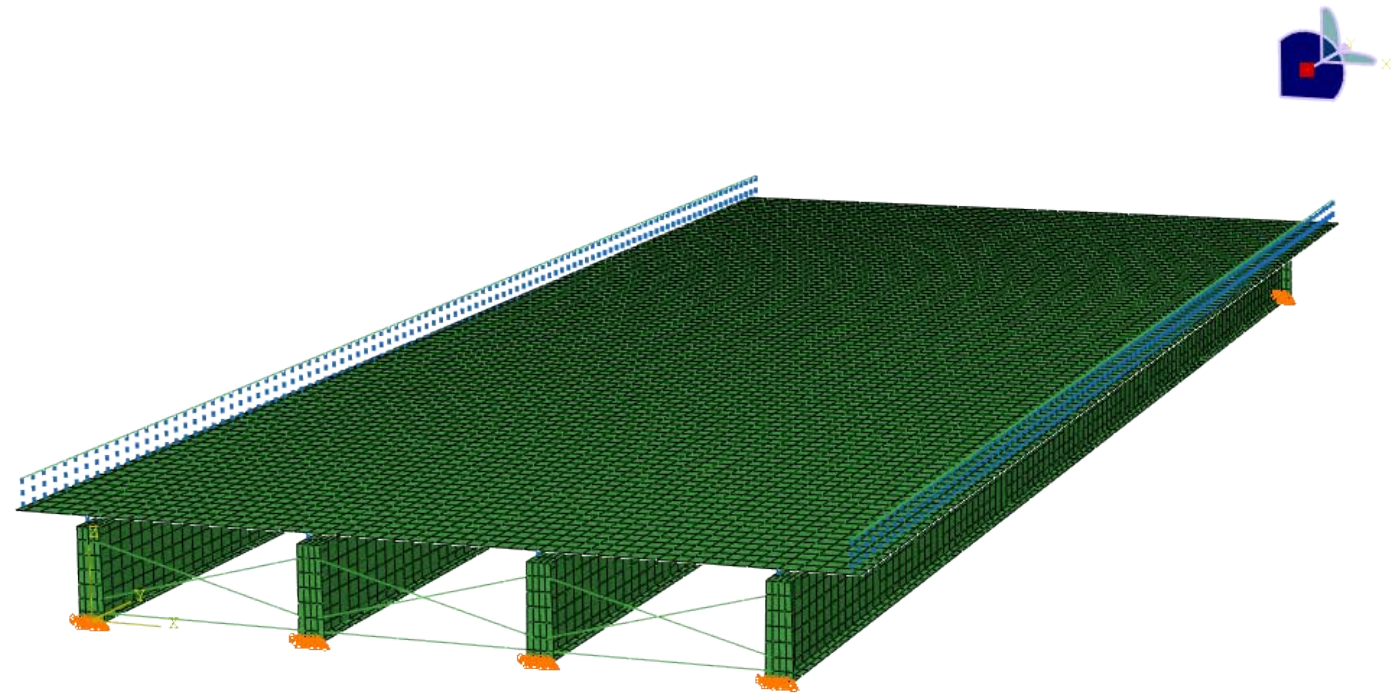

Figure 4.2: Abaqus Screen Capture of Sensitivity Bridge Model

\subsubsection{Load Truck Application}

Once the bridges were modeled in Abaqus, the bridges were loaded with the AASHTO LRFD specified design truck to determine the distribution of this truck to the exterior girders. This section will both give a brief description of the design truck as well as the methodology behind loading the truck on the finite element models. 


\subsubsection{Description of HL-93 Loading}

The HL-93, or the vehicular live loading on the roadways of bridges, is defined in Section 3.6.1.2 of the AASHTO LRFD Specifications (American Association of State Highway and Transportation Officials, 2010). Specifically, the HL-93 consists of a combination of the following:

- The design lane load: a uniformly distributed load of 0.64 kips per longitudinal foot of the bridge.

- $\quad$ The design truck (commonly referred to as HS 20-44) as described in Figure 4.3 or the design tandem, which consists of a pair of 25.0-kip axles spaced 4.0 feet apart (note that the transverse spacing of the wheels in the tandem is 6 feet, which is the same spacing as those on the HS20-44).

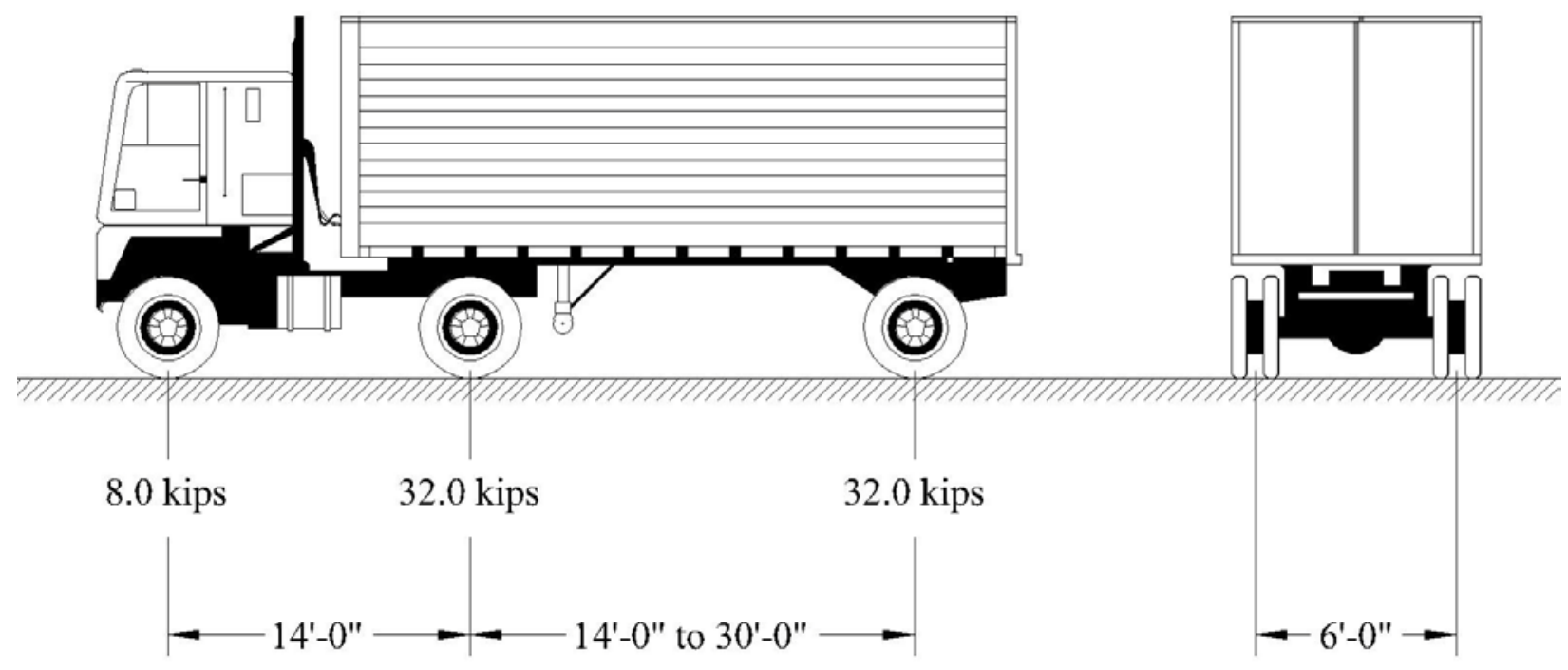

Figure 4.3: HS 20-44

\subsubsection{Placement of AASHTO Truck Loading}

In general, design trucks are to be placed on a given bridge in order to produce the maximum force effect that is being investigated. However, AASHTO Specifications outline 
certain rules regarding the placement of live loads on bridges. These rules as they pertain to simply-supported steel I-girder bridges can be summarized as follows (each "rule" is accompanied by its corresponding AASHTO Section reference):

- 3.6.1.1.1: The number of design lanes is taken to be the integer part of the quotient of the clear roadway width and 12 feet (as the width of the design lane is 12 feet). For roadway widths between 20.0 feet and 24.0 feet, there shall be two design lanes, each half of the clear roadway width.

- 3.6.1.1.2: As shown in Figure 4.3, the rear axle spacing shall be varied between 14 feet and 30 feet in order to produce extreme force effects.

- 3.6.1.3.1: Each design truck shall be placed transversely within its design lane, which has a transverse width of 10 feet.

- 3.6.1.3.1: The design truck shall be placed such that the center of the wheel is no closer than 2 feet from the edge of the design lane.

Since the target of this sensitivity study is to determine the effect of live load distribution to exterior girders, the design trucks were placed laterally as close to the edge of the bridge as possible. For one-lane-loaded scenarios, this equated to placing the truck 2 feet from the edge of the barrier. For multiple lane loadings, according to the previously specified rules, the design trucks were laterally placed 4 feet apart. Also, for each bridge modeled, the total number of trucks applied was equal to the number design lanes permitted by AASHTO Section 3.6.1.1.1, as expected.

As for longitudinal placement of the bridges, according to McCormac (2007):

"Maximum moment in a beam loaded with a moving series of concentrated loads usually will occur at the load nearest the center of gravity of the loads on the beam when the center of gravity of the loads on the beam is the same distance on one side of the centerline of the beam as the load nearest the center of gravity of the loads is on the other side. 
This theory of influence lines was used to place the trucks longitudinally along the bridge models. It should be noted that, after a brief investigation, the maximum moment on simplespan beams was determined to occur when rear axle spacing was at its minimum specified value of 14 feet.

\subsubsection{Finite Element Model Loading}

Once the load truck placement position was determined, the wheel point loads on the elements were linearly distributed to the neighboring nodes. A schematic of this loading is shown in Figure 4.4. Also, Equation 4-1 through Equation 4-4 describe the nodal loads shown in Figure 4.4.

According to AASHTO LRFD Section 4.6.3.3.1, nodal loads shall be statically equivalent to the actual loads being applied (American Association of State Highway and Transportation Officials, 2010). It can be easily shown that the equations corresponding to Figure 4.4, once summed, will equal the applied point load. 


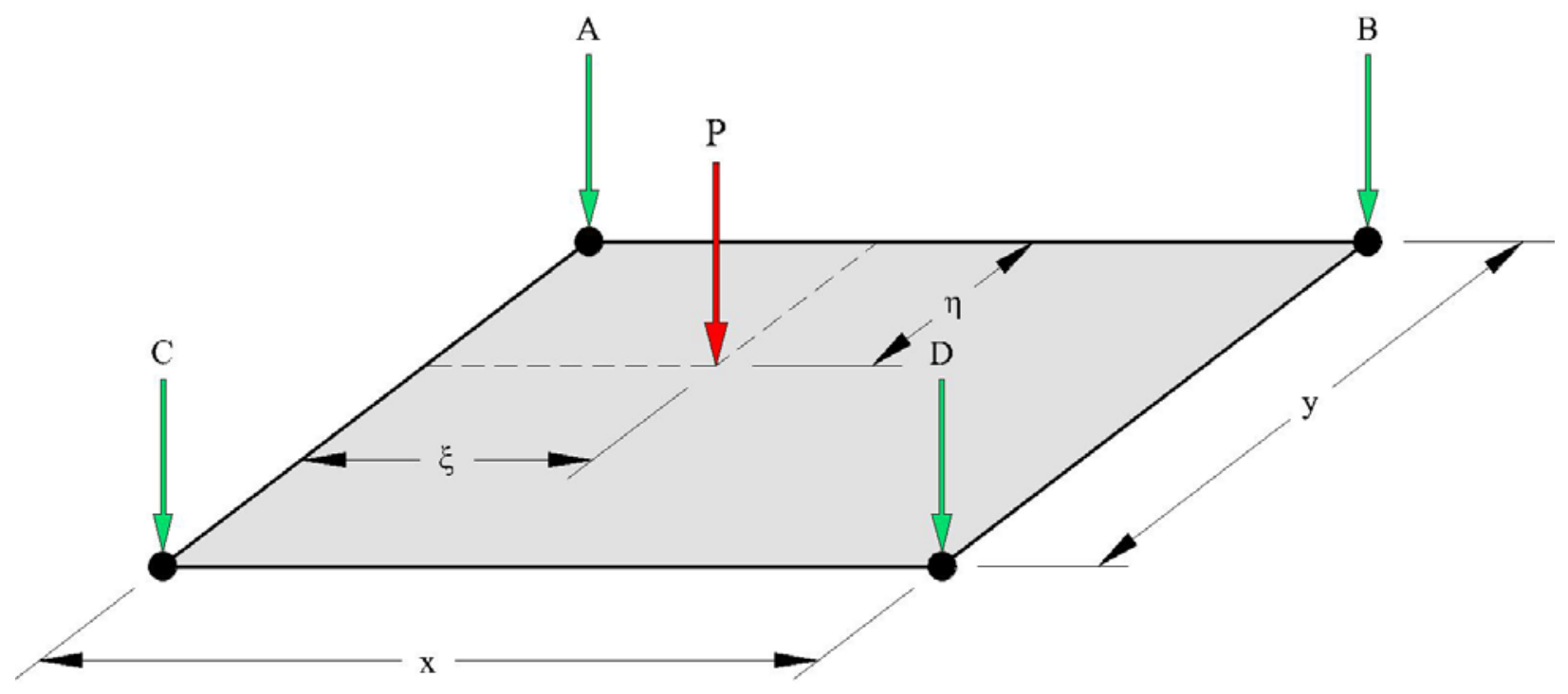

Figure 4.4: Schematic of Nodal Distribution of Point Loads

$$
\begin{aligned}
& A=P\left(1-\frac{\xi}{x}\right)\left(1-\frac{\eta}{y}\right) \\
& B=P\left(\frac{\xi}{x}\right)\left(1-\frac{\eta}{y}\right) \\
& C=P\left(1-\frac{\xi}{x}\right)\left(\frac{\eta}{y}\right) \\
& D=P\left(\frac{\xi}{x}\right)\left(\frac{\eta}{y}\right)
\end{aligned}
$$

Equation 4-2

Equation 4-3

\section{Equation 4-4}

where: loads $P, A, B, C$, and $D$ and distances $x, y, \xi$, and $\eta$ are defined in Figure 4.4 .

\subsection{COMPUTATION OF DISTRIBUTION FACTORS}

Using data from the analysis of the finite element models, distribution factors were calculated and then compared against those calculated using current AASHTO LRFD methods: the lever rule, special analysis, etc. This section describes the methods behind the calculation of those factors. 


\subsubsection{Analytical Methods}

When calculating distribution factors from finite element data, there are two main philosophies present. The first is dividing the moment in the beam in question by the sum of the moments in all the beams. This method will be referred to hereafter as the Stallings/Yoo method, as it is presented in their research (Stallings \& Yoo, 1993). The second is diving the moment in the beam in question by the moment obtained from line-girder analysis, using the same loads as present on the finite element model. This method will be referred to hereafter as the Tarhini/Frederick method, as it is presented in their research (Tarhini \& Frederick, 1992).

\subsubsection{Stallings/Yoo Method}

As previously described, the Stallings/Yoo method is as follows:

$$
g_{i}=\frac{M_{i}}{\sum_{j=1}^{k} M_{j}}
$$

where: $g_{i}=$ distribution factor for the "i'th" girder

$M_{i}=$ bending moment at the "i'th" girder

$k=$ number of girders

To derive the distribution factors from the finite element model, the authors use the following derivation from the theory of mechanics of materials: 


$$
g_{i}=\frac{M_{i}}{\sum_{j=1}^{k} M_{j}}=\frac{E S_{i} \varepsilon_{i}}{\sum_{j=1}^{k} E S_{j} \varepsilon_{j}}=\frac{\frac{S_{i}}{S_{l}} \varepsilon_{i}}{\sum_{j=1}^{k} \frac{S_{j}}{S_{l}} \varepsilon_{j}}=\frac{\varepsilon_{i} w_{i}}{\sum_{j=1}^{k} \varepsilon_{j} w_{j}}
$$

where: $g_{i}=$ distribution factor for the "i'th" girder

$$
\begin{aligned}
& M_{i}=\text { bending moment at the "i'th" girder } \\
& E=\text { modulus of elasticity } \\
& S_{i}=\text { section modulus of the "i'th" girder } \\
& S_{l}=\text { typical interior section modulus } \\
& \mathcal{E}_{i}=\text { bottom flange static strain at the "i'th" girder } \\
& W_{i}=\text { ratio of the section modulus of the "i'th" } \\
& \quad \text { girder to the section modulus of a typical } \\
& \quad \text { interior girder } \\
& k=\text { number of girders }
\end{aligned}
$$

It was determined, after investigation of the bridges in the sensitivity matrix, that the section moduli of both the interior girders and the exterior girders are essentially identical. Therefore, the section moduli ratios presented in Equation 4-6 can be taken as unity.

This method works very well for situations where the bridge in question is only loaded on one design lane. However, for bridges with multiple design lanes loaded, this method by itself proves invalid. Since this method is basically a normalization technique (or determining the percentage of distribution to each girder) the sum of the distribution factors of all girders will equal one instead of the number of trucks applied. Therefore, synonymous with research by Eom and Nowak (2001), the resulting distribution factors are multiplied by the number of trucks applied to obtain relevant distribution factor values. 
$g_{i}=\frac{n \varepsilon_{i}}{\sum_{j=1}^{k} \varepsilon_{j}}$

where: $g_{i}=$ distribution factor for the "i'th" girder

$M_{i}=$ bending moment at the "i'th" girder

$\mathcal{E}_{i}=$ bottom flange static strain at the "i'th" girder

$k=$ number of girders

$n=$ number of applied design trucks

\subsubsection{Tarhini/Frederick Method}

As previously described, the Tarhini/Frederick method is as follows:

$g_{i}=\frac{M_{i}^{F E A}}{M_{i}^{L G A}}$

Equation 4-8

where: $g_{i}=$ distribution factor for the "i'th" girder

$$
\begin{aligned}
M_{i}^{F E A}= & \text { bending moment at the "i'th" girder } \\
& \text { found with finite element data } \\
M_{i}^{L G A}= & \text { bending moment at the "i'th" girder } \\
& \text { found from line-girder analysis }
\end{aligned}
$$

To incorporate the same data set that is used for the Stallings/Yoo method, synonymous with the derivation presented in Equation 4-6 (neglecting the section moduli ratios has they have already been shown to be negligible), the following method is presented: 
$g_{i}=\frac{M_{i}^{F E A}}{M_{i}{ }^{L G A}}=\frac{E S_{j} \varepsilon_{i}{ }^{F E A}}{E S_{j} \varepsilon_{i}{ }^{L G A}}=\frac{\varepsilon_{i}{ }^{F E A}}{\varepsilon_{i}{ }^{L G A}}$

Equation 4-9

where: $g_{i}=$ distribution factor for the "i'th" girder

$M_{i}^{F E A}=$ bending moment at the "i'th" girder

found with finite element data

$M_{i}^{L G A}=$ bending moment at the “i'th" girder

found from line-girder analysis

$E=$ modulus of elasticity

$S_{I}=$ typical section modulus

$\varepsilon_{i}^{F E A}=$ bending moment at the “i'th" girder

found with finite element data

$\mathcal{E}_{i}^{L G A}=$ bending moment at the "i'th" girder

found from line-girder analysis

It should be noted that, since finite element strains are being directly compared with the strains derived from line-girder analysis, no "n” factor, as shown in Equation 4-7, is necessary.

\subsubsection{AASHTO LRFD Methods}

Once the distribution factors were obtained analytically from finite element data, these values were then compared with the distribution factors obtained from AASHTO methods. These methods are identical to the methods that were presented in Section 3.2 and demonstrated in Section 3.3.

\subsection{Benchmark Analysis: Missouri Bridge A6101}

To verify the validity of the finite element modeling technique presented in this chapter, physical load test data from the field testing of Missouri Bridge A6101 performed in August of 2002 (Wu, 2003) was compared against the results of a finite element model of the bridge using the previously described modeling technique. Contained herein is a brief description of this 
bridge and its field testing as well as the comparison of the finite element data and the field test data.

\subsubsection{Description of Missouri Bridge A6101}

Missouri Bridge A6101 is located on Route 224 over the relocated Route 13 in Lafayette County, Missouri. Figure 4.5 shows an elevation view of this bridge.

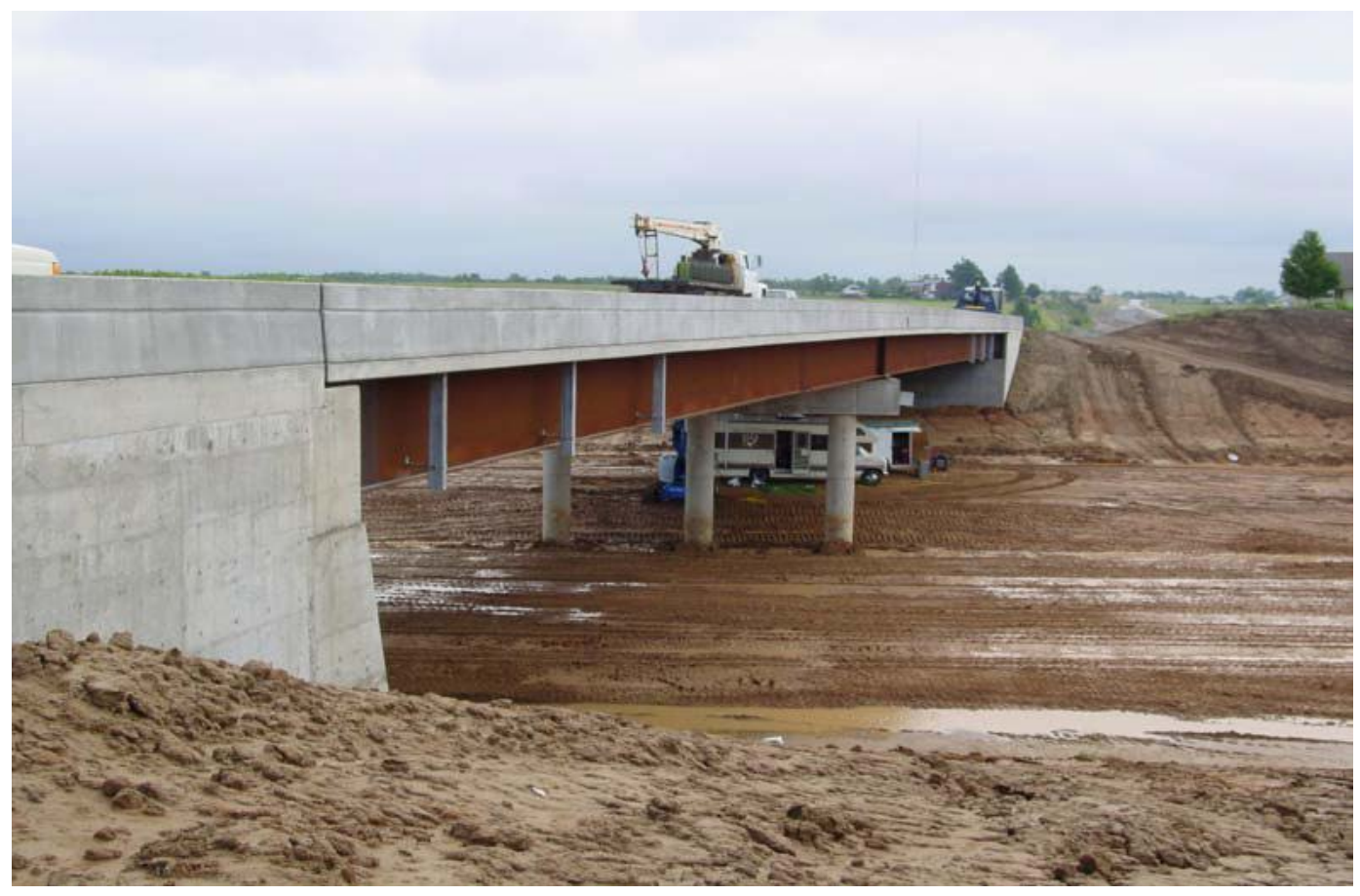

Figure 4.5: Elevation View of Missouri A6101 Bridge (Wu, 2003)

The design calculations and dimensions presented in the plans for Missouri Bridge A6101 are in metric units. For the reader's convenience, the parameters specific both to the bridge's general layout and the finite element model discussed in Section 4.4.3 have been converted to U.S.C.S. units. A cross-sectional view of the bridge can be seen in Figure 4.6 and an elevation view of the girder, indicating both plate sizes and the yield stress of different girder elements, can be seen in Figure 4.7. Also, the bridge's framing plan can be seen in Figure 4.8. It should be noted that in Figure 4.8, the girders are numbered one through five; this numbering scheme will be referred to later in Section 4.4.4. 


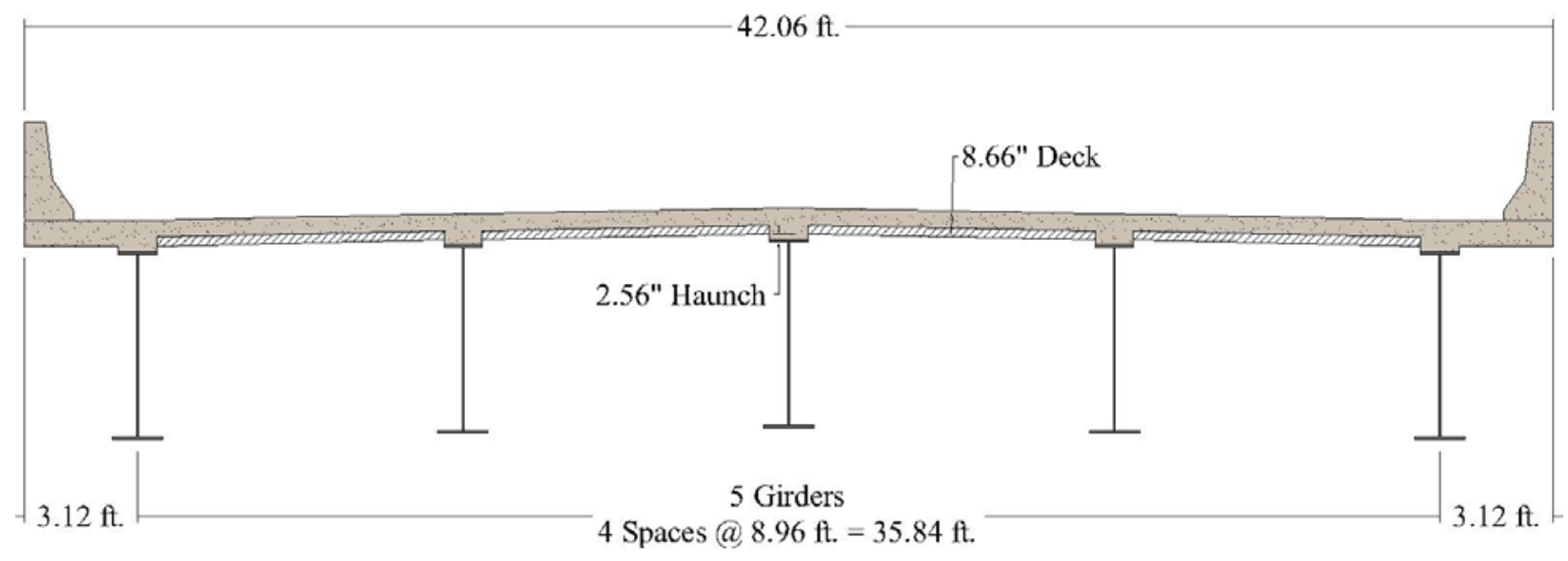

Figure 4.6: Missouri Bridge A6101 Cross-Section

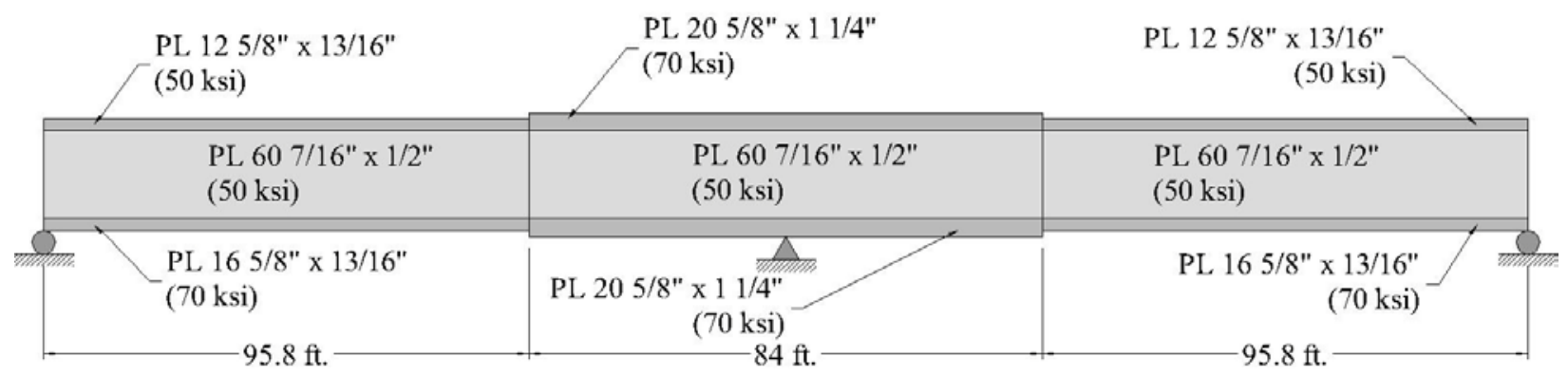

Figure 4.7: Missouri Bridge A6101 Girder Elevation

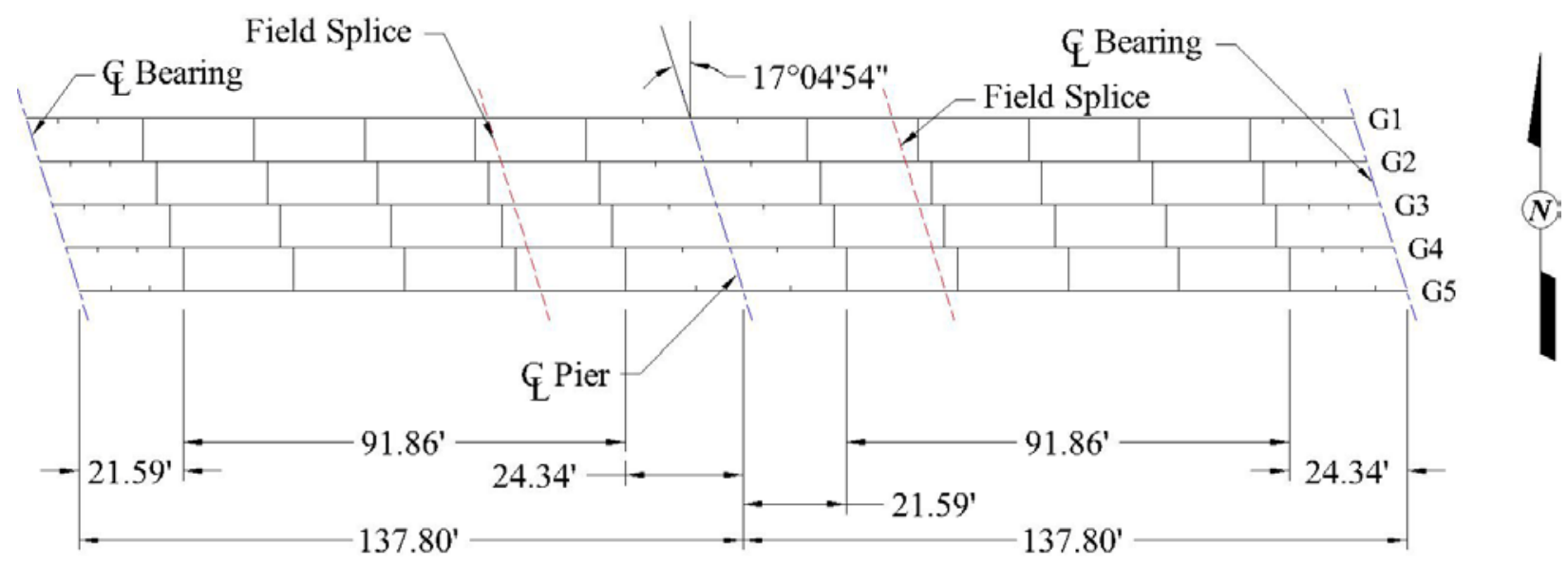

Figure 4.8: Missouri Bridge A6101 Framing Plan 
Figure 4.9 shows the details of Missouri Bridge A6101's cross-frames. As shown, the left half of this figure, or Parts (A) and (B), details the positive bending region of the bridge whereas the right half, Parts (C) and (D) details the negative bending region. Part (A) of the figure is the bridge's cross-frame at the two end supports; it consists of a C15×33.9 channel used as the upper chord, L3 $\times 3 \times 5 / 16$ angles used as the diagonal chords, and a $L 5 \times 5 \times 5 / 16$ angle used as the lower chord. Parts (B) and (C) of the figure show the bridge's intermediate cross-frames. Part (B) details the positive bending region's cross-frames while Part (C) details the negative bending region's cross-frames. These consist of $L 4 \times 4 \times 5 / 16$ angles used for the upper and lower chords and $\mathrm{L} 3 \times 3 \times 5 / 16$ angles used as the diagonal chords. Part (D) of the figure details the bridges cross-frame at the pier region, which consists of $L 5 \times 5 \times 5 / 16$ angles used for the upper and lower chords and $\mathrm{L} 3 \times 3 \times 5 / 16$ angles used as the diagonal chords.

Also, detailed in Figure 4.10 are the bridge's concrete barrier and its respective measurements.

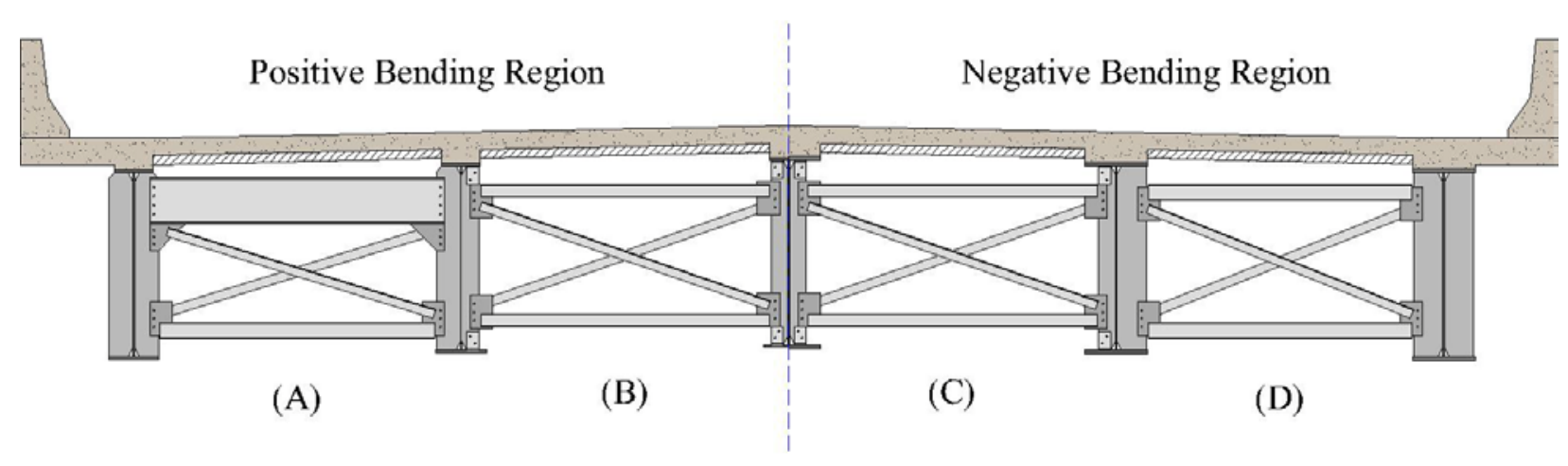

Figure 4.9: Missouri Bridge A6101 Cross-Frames 


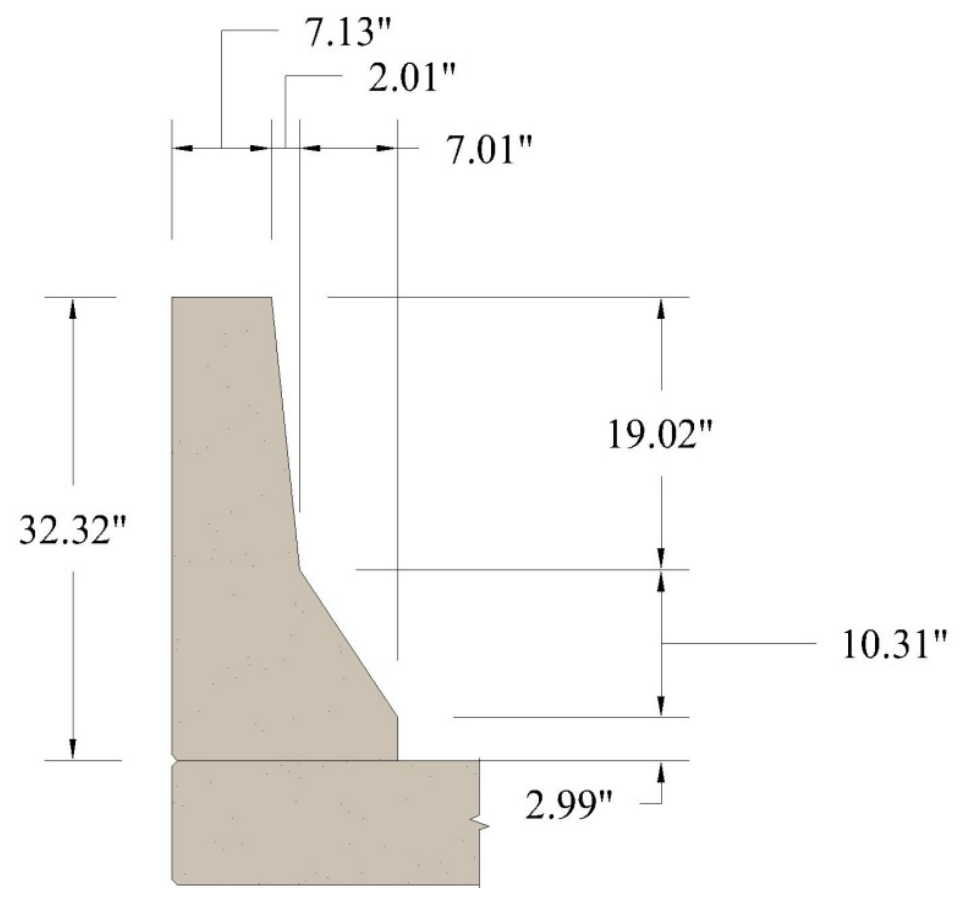

Figure 4.10: Missouri Bridge A6101 Barrier

\subsubsection{Missouri Bridge A6101 Field Test}

On August 20, 2002, field testing of Missouri Bridge A6101, a new 2-span continuous high-performance steel (HPS) bridge, was conducted by the University of Missouri-Columbia and West Virginia University in cooperation with the Missouri Department of Transportation (MoDOT) (Wu, 2003) (Davis, 2003). The field test team consisted of seven people: from the University of Missouri, Professor Michael G. Barker, technicians C.H. Cassil and Richard Oberto, and graduate students Justin Davis and Everett Oesch; from West Virginia University, Professor Karl Barth and graduate student Haiyong Wu.

Presented herein is a description of the instrumentation used during the load test, the load truck used, and static load testing procedure. For a more detailed description regarding this field test, including background on its parent project, the reader is referred to the dissertation of Haiyong Wu (2003) or the thesis of Justin Davis (2003). 


\subsubsection{Instrumentation}

The bridge was instrumented on the day of field testing to measure deflection values, girder strains and bridge vibrations. For the purposes of verifying the finite element modeling technique presented in this Chapter, only the instruments pertaining to measuring deflection values are discussed.

Two different devices for measuring vertical displacements were employed during this field test. The first was a set of string potentiometers, or "string pots", placed directly below the 4/10 point of each girder, or 55.1 feet from the east bearing. These were used in lieu of conventional linear variable differential transformers (or LVDTs) due to the height of the girder from the ground. However, after interpreting the data from the string pots after the field test, the team concluded that the string pots were malfunctioning during the field test and any data derived from these was were not used.

The second device was a laser deflection system developed by the Civil Engineering Department at the University of Missouri-Columbia. This device worked by placing a laser instrument on a tripod at a reasonable distance from the bridge. The laser was aimed at a deflection device attached to Girder 2 (from Figure 4.8) at the 4/10 point, which acted as a reference point as the bridge deflected.

Relative deflections were measured and recorded for Girder 2 during the field test. After subsequent analysis by the field test team, it was determined that the laser deflection device performed very well. However, after the eighth truck run, the laser device stopped taking measurements. This was reasonable, as the laser needed to be precisely aimed at the deflection device on the girder. As can be seen from Figure 4.5, conditions on the ground on the day of field testing were quite muddy; this could have possibly caused the tripod to go out of a level position and, therefore, cause measurements to cease. Therefore, as will be shown in Section 4.4.4, the measured laser deflection values cease at Truck Run 8.

\subsubsection{2 $\underline{\text { Load Truck }}$}

The vehicle used to load the bridge was a 1984 Freighliner block and brick truck owned

by the Civil Engineering Department of the University of Missouri (Davis, 2003). Steel blocks 
were used to load the test truck to increase its weight for the load testing. After the static deflection testing procedure (discussed in Section 4.4.2.3) was completed, weighing pads were used to determine the truck's individual wheel weights. A photograph of the load truck is shown in Figure 4.11, along with pertinent truck dimensions and each wheel's individual weights.
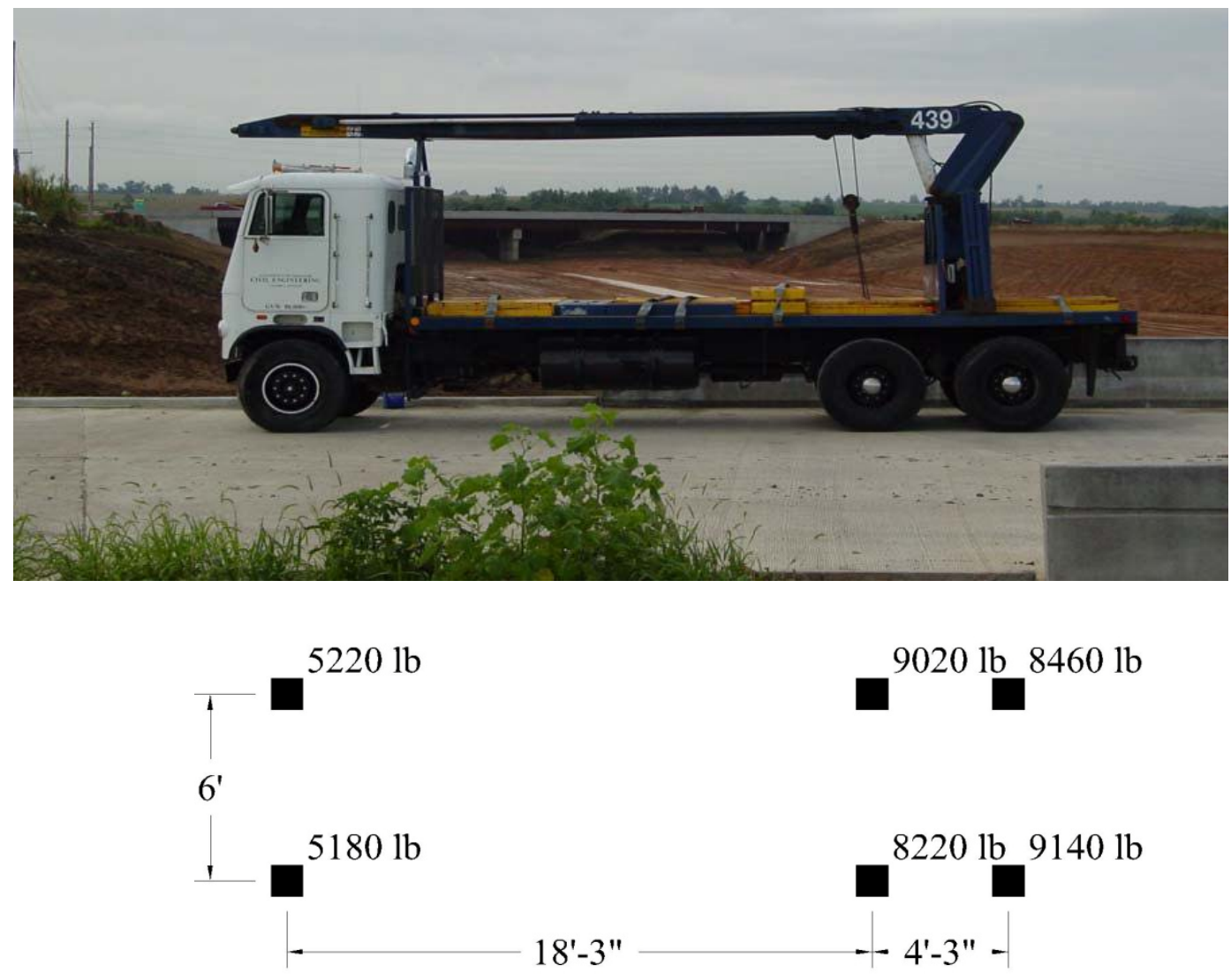

Figure 4.11: Missouri Bridge A6101 Load Truck (Wu, 2003)

\subsubsection{Truck Runs}

To obtain deflection values that were as close to being analytically static as possible, the load truck was run across the bridge as slow as possible to reduce impact. For each run, the truck began on the east approach, traveled completely across the bridge, then made the same pass in reverse back to the east side. This process was completed twelve times. For each run, the truck maintained a constant distance transversely across the bridge. These distances are illustrated in Figure 4.12 and tabulated in Table 4.1. 


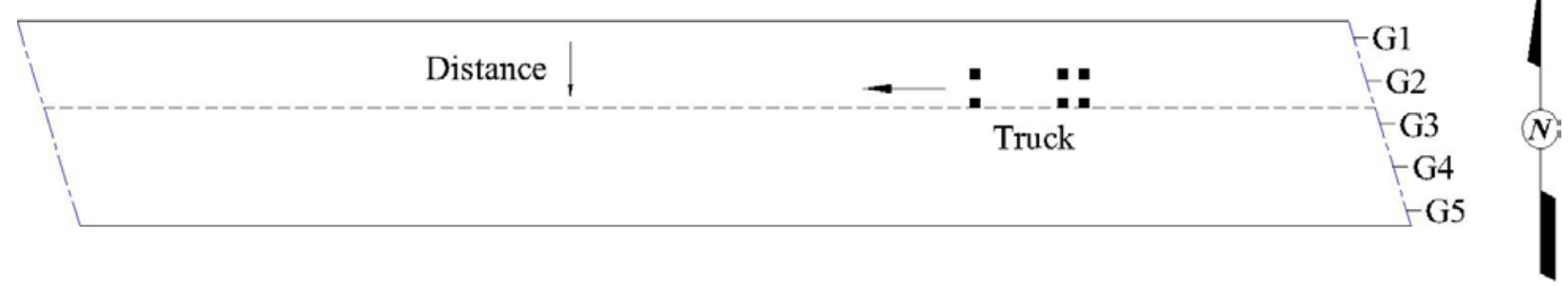

Figure 4.12: Missouri Bridge A6101 Truck Run Schematic

\begin{tabular}{|c|c|}
\hline $\begin{array}{c}\text { Distance from Center of Driver's Side Wheel to Curb } \\
\text { Truck Run }\end{array}$ & Distance (in) \\
\hline \hline 1 & 84.00 \\
2 & 128.75 \\
3 & 188.25 \\
4 & 204.00 \\
5 & 236.25 \\
6 & 248.75 \\
7 & 295.75 \\
8 & 308.25 \\
9 & 340.50 \\
10 & 356.25 \\
11 & 415.75 \\
12 & Face of S. Parapet \\
\hline
\end{tabular}

Table 4.1: Missouri Bridge A6101 Truck Run Positions

\subsubsection{Missouri Bridge A6101 Finite Element Model}

A finite element model, synonymous with the techniques presented in Section 4.2 was prepared to mirror the field test of Missouri Bridge A6101 discussed in Section 4.4.2. With only a few exceptions, these previously described techniques were completely replicated in order to verify their validity. These exceptions can be described as follows. 
- Mesh discretization along the longitudinal axis of the bridge was not equal to one element per foot along the entire span. This was due to the non-ideal conditions of the bridge (including skew and staggered cross-frames). Mesh disretization was in fact kept smaller (one element per 9 to 10 inches) in order to maintain accuracy.

- The AASHTO HL-93 loading (discussed in Section 4.2.5.1) was not applied to the bridge. Instead, the load truck (discussed in Section 4.4.2.2) from the field test was applied to the finite element model. Also, the transverse truck locations specified in Table 4.1 were replicated.

o It should be noted that the longitudinal truck placement rules discussed in Section 4.2.5.2 were also followed as these rules can also be employed to determine maximum moment / deflection response.

An image of this finite element model can be seen in Figure 4.13. As with Figure 4.2, for the purposes of clarity, the MPC Beams have been removed from the model; however the wire features where the MPC Beams are assigned remain showing.

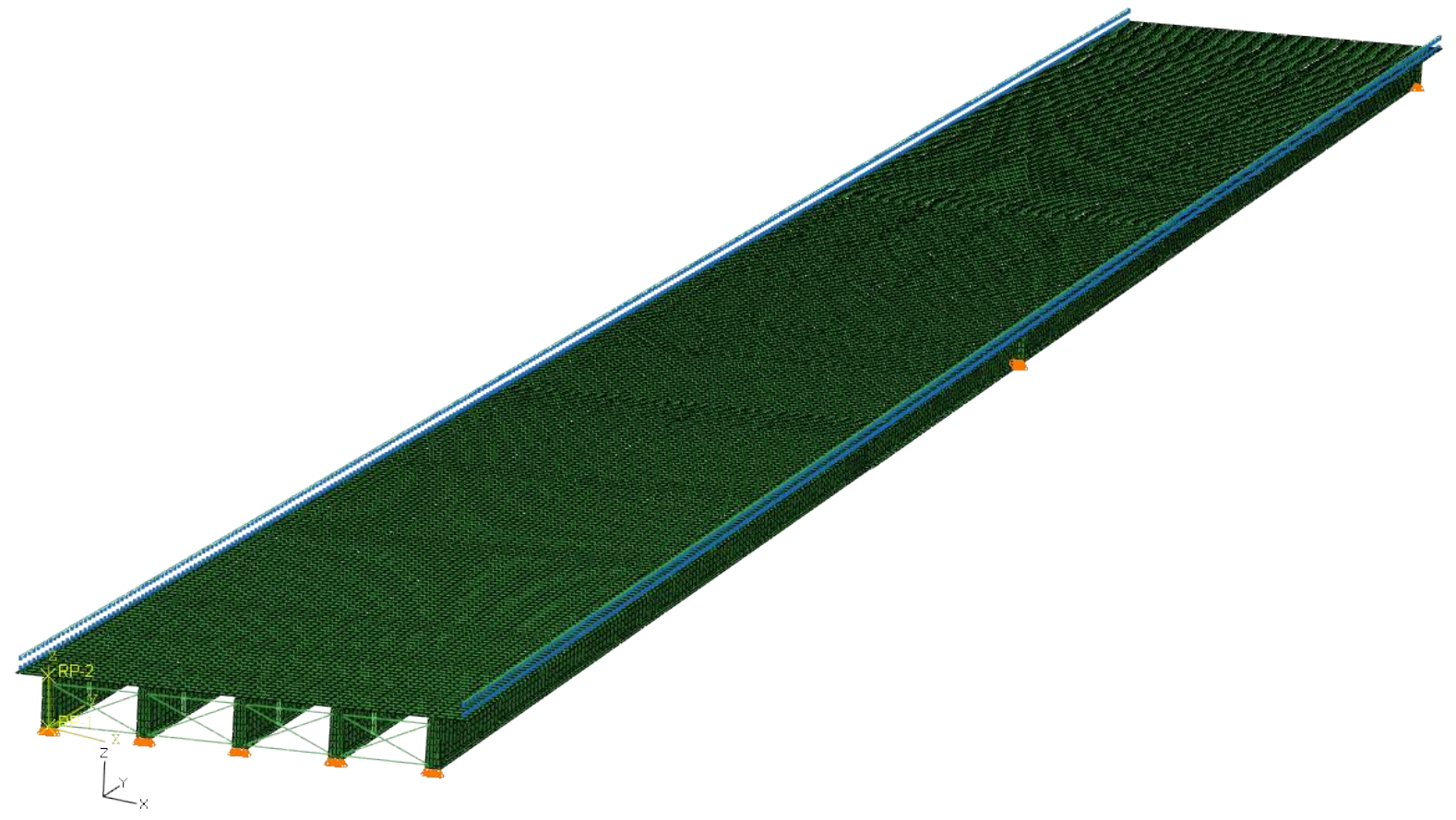

Figure 4.13: Abaqus Screen Capture of Missouri Bridge A6101 Model 


\subsubsection{Comparison of Results}

Presented in Table 4.2 is a comparison of both the physical data from the field test of Missouri Bridge A6101 along with the data from the bridge's finite element model. Specifically, from the field test, only the laser deflection values have been reported as they were determined by the test team to be the most accurate; from the finite element model, only vertical deflections on Girder 2 (from Figure 4.8) at the 4/10 point were reported for each run as these values directly compare with the field test data.

It can be easily seen that the finite element model was very accurate in predicting girder deflections. The largest absolute difference in values is only 0.03 inches, equivalent to a $10 \%$ difference. It should be noted that, while percent differences have been reported, they can be somewhat deceptive as differences of a fraction of an inch can represent somewhat large percent differences.

\begin{tabular}{|c|c|c|c|c|}
\hline \multicolumn{7}{|c|}{ Girder 2 Test Data Comparis ons (in) } \\
\hline Truck Location & $\begin{array}{c}\text { Measured Laser } \\
\text { Deflection }\end{array}$ & $\begin{array}{c}\text { Abaqus FEA } \\
\text { Deflection }\end{array}$ & $\begin{array}{c}\text { Absolute } \\
\text { Diffe re nce }\end{array}$ & $\begin{array}{c}\text { Absolute Percent } \\
\text { Diffe rence }\end{array}$ \\
\hline \hline Run 1 & -0.310 & -0.284 & 0.026 & $8.40 \%$ \\
Run 2 & -0.308 & -0.285 & 0.023 & $7.45 \%$ \\
Run 3 & -0.300 & -0.269 & 0.031 & $10.46 \%$ \\
Run 4 & -0.271 & -0.261 & 0.010 & $3.80 \%$ \\
Run 5 & -0.243 & -0.240 & 0.003 & $1.04 \%$ \\
Run 6 & -0.230 & -0.232 & 0.002 & $0.78 \%$ \\
Run 7 & -0.209 & -0.198 & 0.011 & $5.45 \%$ \\
Run 8 & -0.190 & -0.188 & 0.002 & - \\
Run 9 & - & -0.166 & - & - \\
Run 10 & - & -0.155 & - & - \\
Run 11 & - & -0.115 & - & - \\
\hline Average & - & -0.087 & 0.013 & - \\
\hline Maximum (in magnitude) & -0.310 & -0.245 & 0.031 & $5.06 \%$ \\
\hline Minimum (in magnitude) & -0.190 & -0.285 & 0.002 & $10.46 \%$ \\
\hline
\end{tabular}

Table 4.2: Missouri Bridge A6101 Finite Element Model Verification 


\subsection{SUMMARY}

The preceding chapter outlined the finite element modeling techniques used for this research project. Specifically, details such as element selections, material definitions, mesh discretizations, boundary conditions used, and load applications were discussed. Also, presented in this chapter were the methods used to calculate distribution factors from finite element models and the ideologies behind their implementation.

Finally, a benchmark analysis of Missouri Bridge A6101, which was used to verify the validity of these modeling techniques, was presented. From this benchmark analysis, it can be seen that this finite element modeling technique is quite accurate in predicting bridge system behavior and girder response. 


\section{ChaPTER 5: SEnSiTIVITY STUdY}

\section{$5.1 \quad$ INTRODUCTION}

The following chapter describes a matrix of bridges analyzed with a commercial finite element software package in order to determine the sensitivity of certain parameters on the live load distribution to the exterior girders of steel I-girder bridges. Specifically, the chapter will discuss the bridges modeled along with their respective constant and varied parameters. Also, a description of the procedures used to develop the parametric bridges is presented. Finally, the results of the sensitivity study are discussed, highlighting specifically the influence of the varied parameters and comparing results with AASHTO LRFD Specifications predictions.

\subsection{SenSitivity MATRIX}

A total of 64 bridges were modeled in this sensitivity matrix in order to determine the effect of certain parameters on exterior girder live load distribution. This section describes the constant and varied parameters. Many of the constant parameters, specifically material properties (which are discussed in more detail in Section 5.2.1) are based on guidelines in the current AASHTO LRFD Bridge Design Specifications (American Association of State Highway and Transportation Officials, 2010). 


\subsubsection{Constant Parameters}

The following parameters were kept constant in the sensitivity matrix:

- The total slab thickness of all the bridges in the sensitivity matrix was kept at 10 inches. With a constant integral wearing surface of 0.5 inches, this yielded a constant effective slab thickness of 9.5 inches throughout the matrix.

- A constant haunch of 2 inches was used for all girders.

- A constant width of 34.5 feet between exterior girders was maintained throughout the sensitivity matrix.

- The same New Jersey style barrier was used throughout. The dimensions are presented in Figure 5.1. It should be noted however that presence of the barrier is one of the parameters varied (which is discussed in more detail in Section 5.2.2)

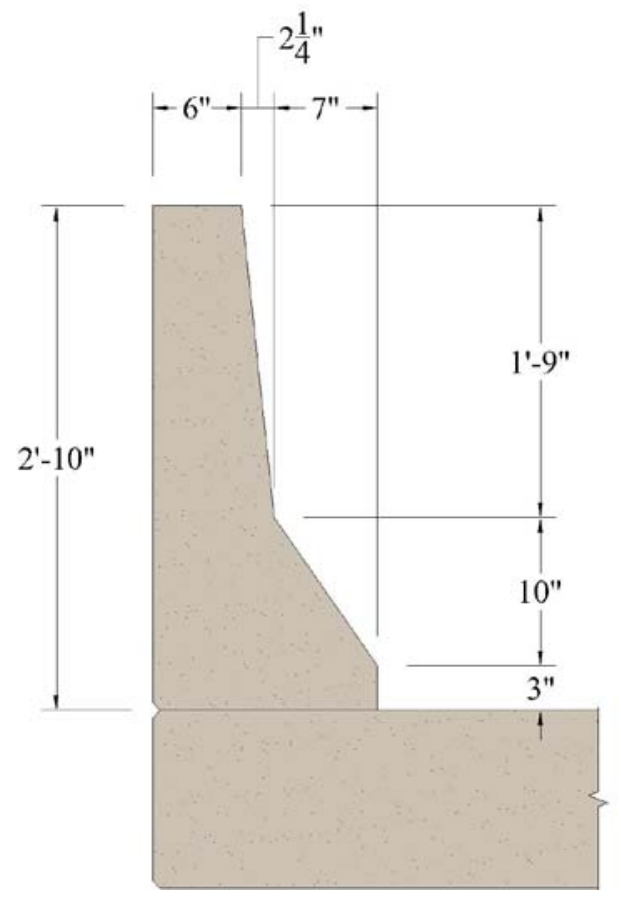

Figure 5.1: Sensitivity Study Barrier

- Normal weight concrete was used throughout. In accordance with AASHTO LRFD Table 3.5.1-1, this equates to a unit weight of 0.145 kips per cubic foot. 
Also, in accordance with the same table, the unit weight of steel was taken to be 0.490 kips per cubic foot.

- The following material properties were also employed:

o For reinforced concrete, which was taken to have a compressive strength of $4.0 \mathrm{ksi}$, according to the previsions of AASHTO LRFD Section 5.4.2.4, the modulus of elasticity of concrete was determined to be $3640 \mathrm{ksi}$. Also, according to AASHTO LRFD Section 5.4.2.5, Poisson's ratio was taken to be 0.2 .

o For steel, which was taken to have a yield strength of $50 \mathrm{ksi}$, according to the previsions of AASHTO LRFD Section 6.4.1, the modulus of elasticity of steel was taken to be 29000 ksi. Also, Poisson's ratio was taken to be 0.3 .

- All of the bridges investigated were simply supported.

o As summarized in Section 2.5.7, continuity conditions were found by multiple researchers to have little effect on live load distribution.

- Finally, the same styles of both end cross-frames and intermediate cross-frames remained the same. These styles are shown in Figure 5.2 and Figure 3.3, respectively.

o Other miscellaneous details, such as the horizontal length of the corner clip of stiffeners and connection plates (1.5 inches) and the width of interior cross-frame connection plates (6 inches), remained the same. 


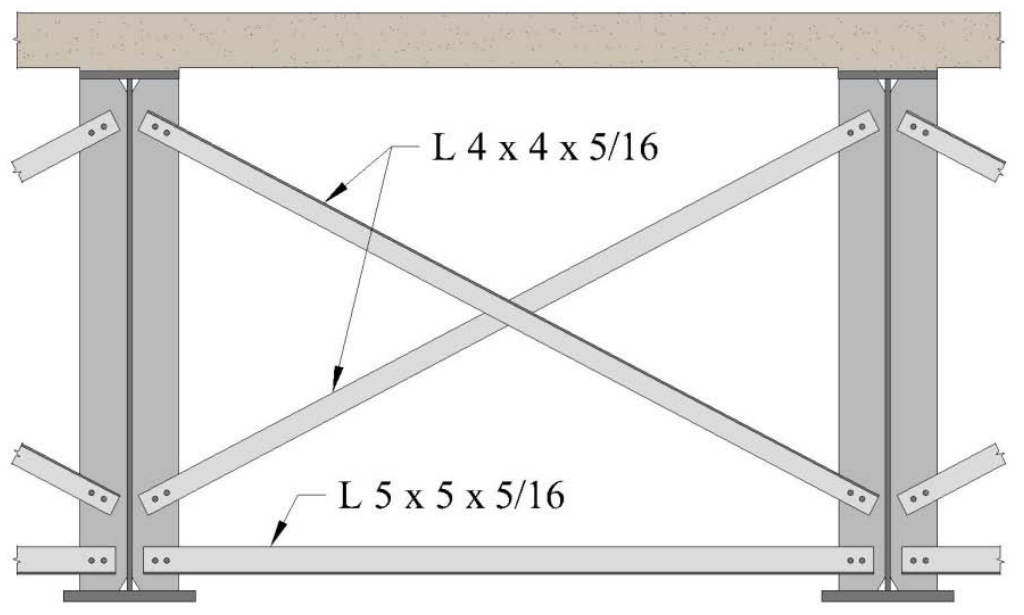

Figure 5.2: Sensitivity Matrix End Cross-Frame

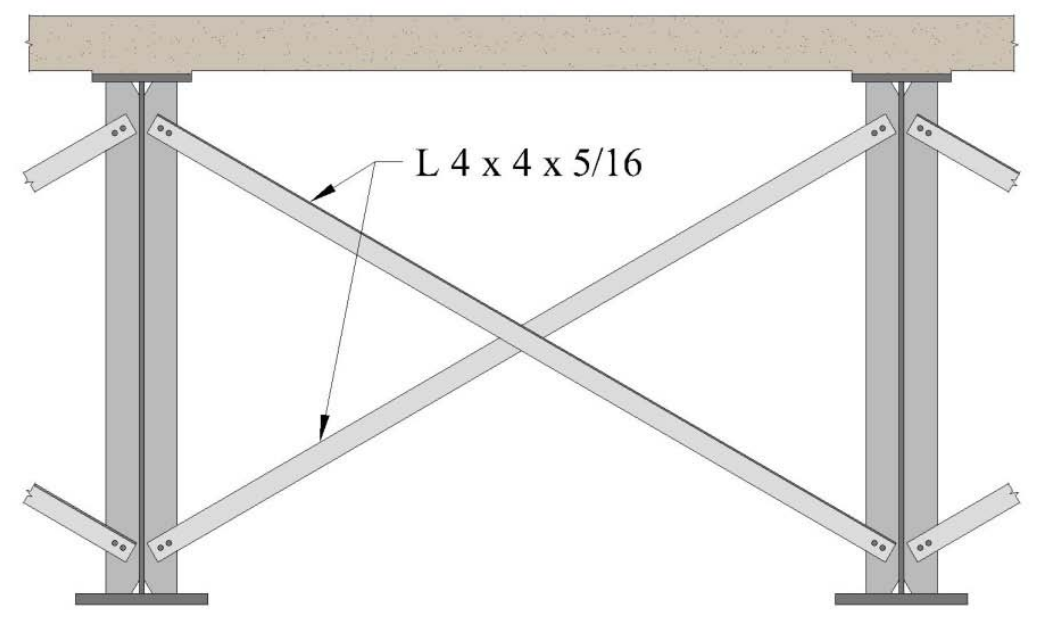

Figure 5.3: Sensitivity Matrix Interior Cross-Frame 


\subsubsection{Varied Parameters}

The following parameters were varied throughout the sensitivity matrix and investigated to determine their respective effect on exterior girder live load distribution:

- Two span lengths: 100 feet and 200 feet.

- Two girder layouts: four girders spaced at 11.5 feet on center and five girders spaced at 8.625 feet on center.

- Two cross-frame spacings, or unbraced lengths: 20 feet, and 25 feet.

- Two deck overhangs (measured from the centerline of the exterior girder web to the end of the deck): 46 inches and 69 inches.

This constitutes a total of 16 bridges. Of these bridges, four iterations of each bridge were developed, totaling 64 bridges. These iterations can be described as:

- The bridge with no alterations.

- The bridge with no barrier present.

- The bridge with no cross-frames present.

- The bridge with all of the cross-frames scaled to twice their given size.

Figure 5.4 through Figure 5.7 show representative cross-sections of the bridges described with no alterations. 


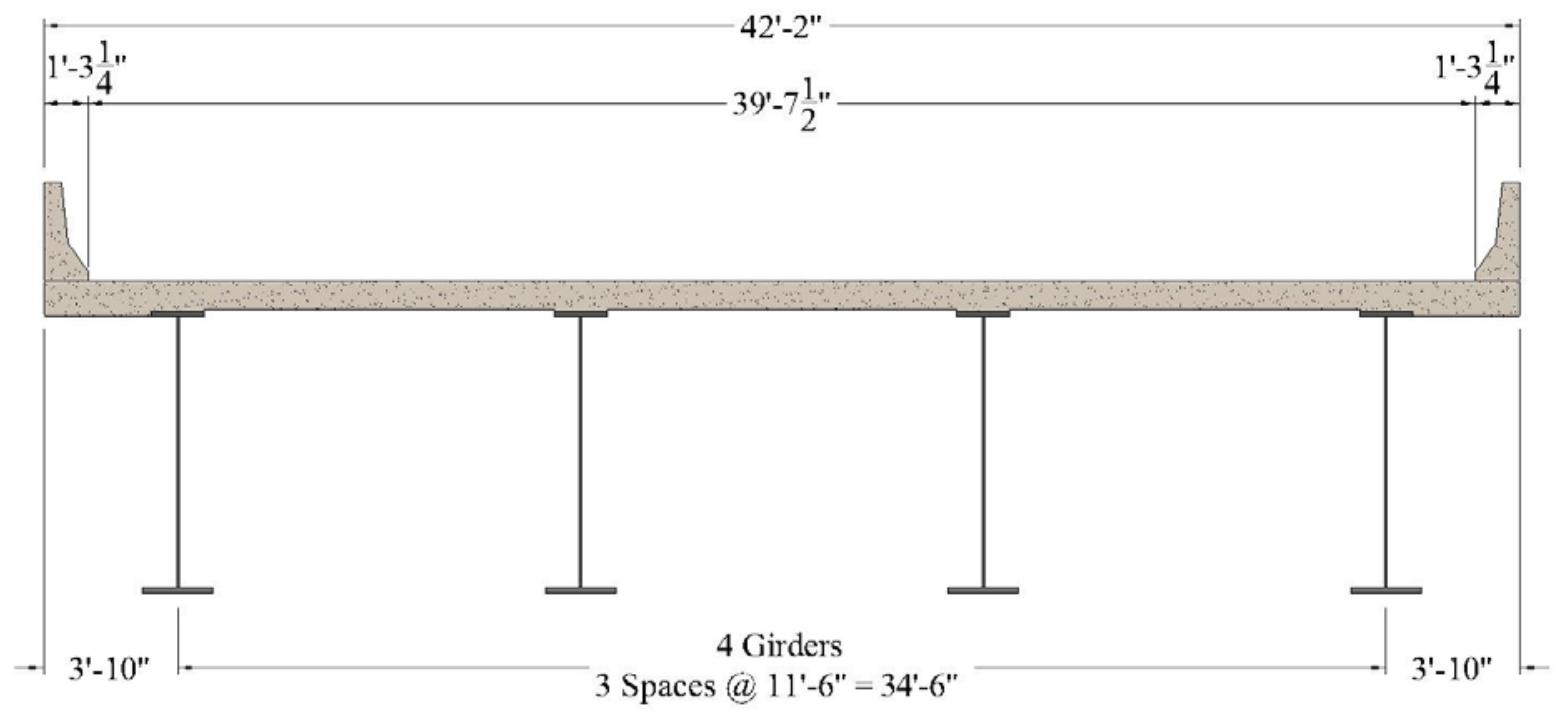

Figure 5.4: Sensitivity Bridge Cross-Section: $L=200^{\prime} ; S=11.5$ ', $\mathrm{OH}=46^{\prime \prime}$

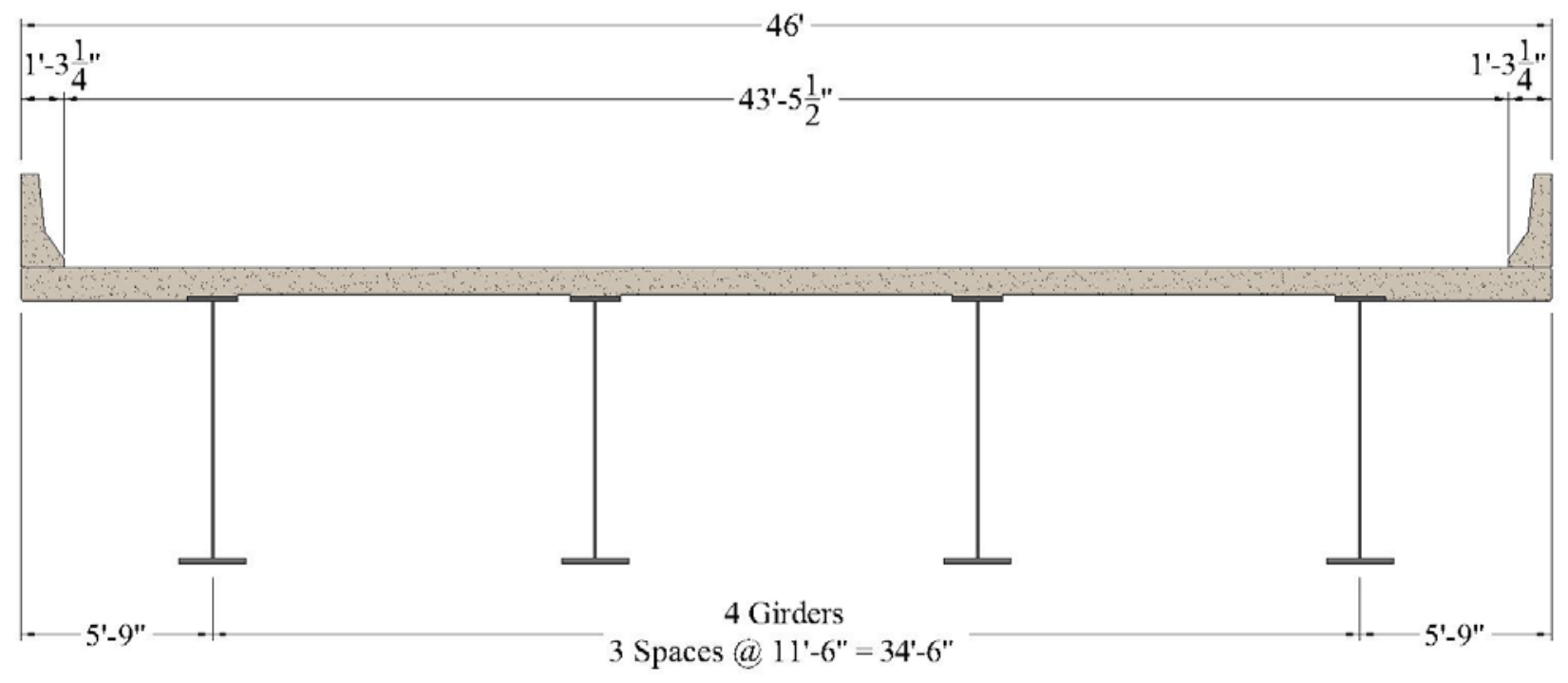

Figure 5.5: Sensitivity Bridge Cross-Section: $L=200^{\prime} ; S=11.5$ ', $\mathrm{OH}=69^{\prime \prime}$ 


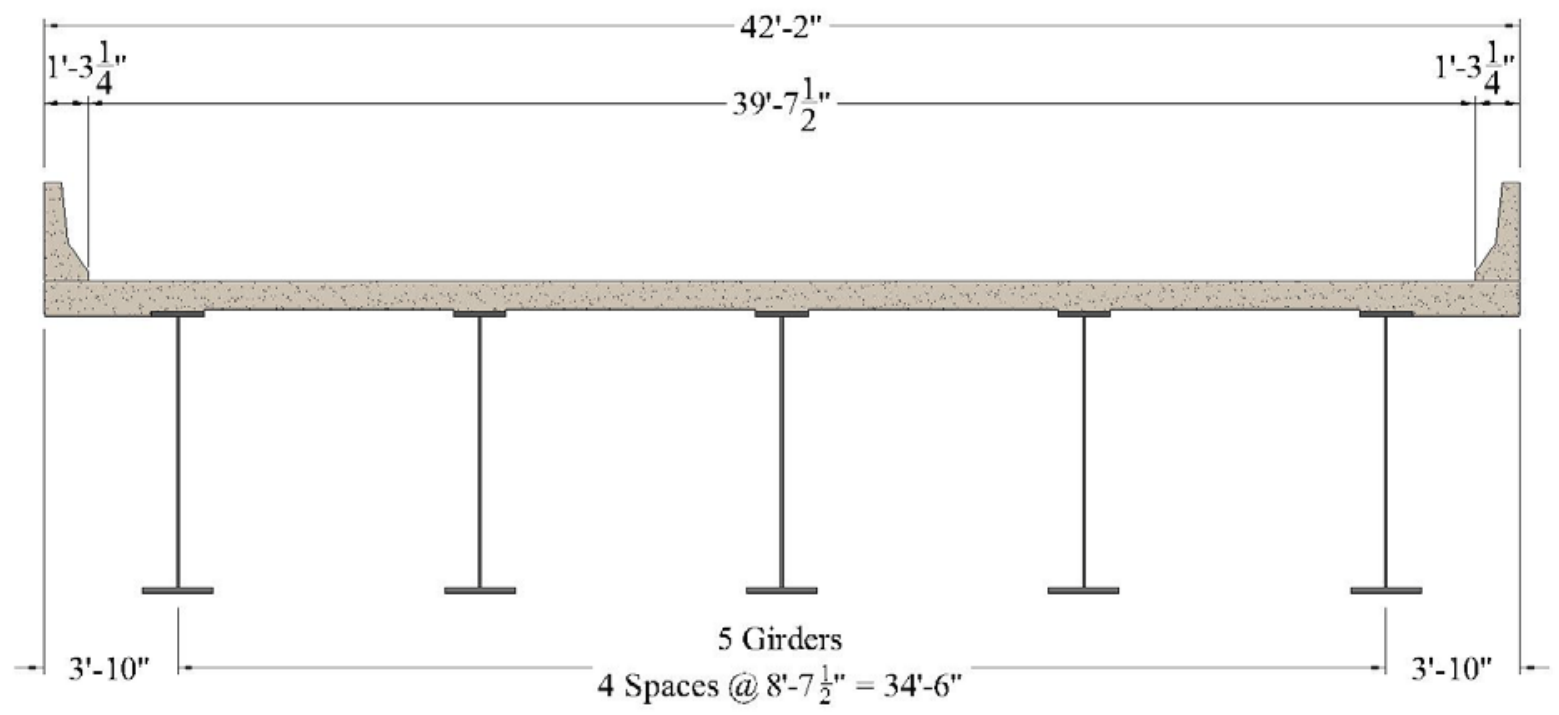

Figure 5.6: Sensitivity Bridge Cross-Section: $L=200$ '; $S=8.625$ ', $\mathrm{OH}=46^{\prime \prime}$

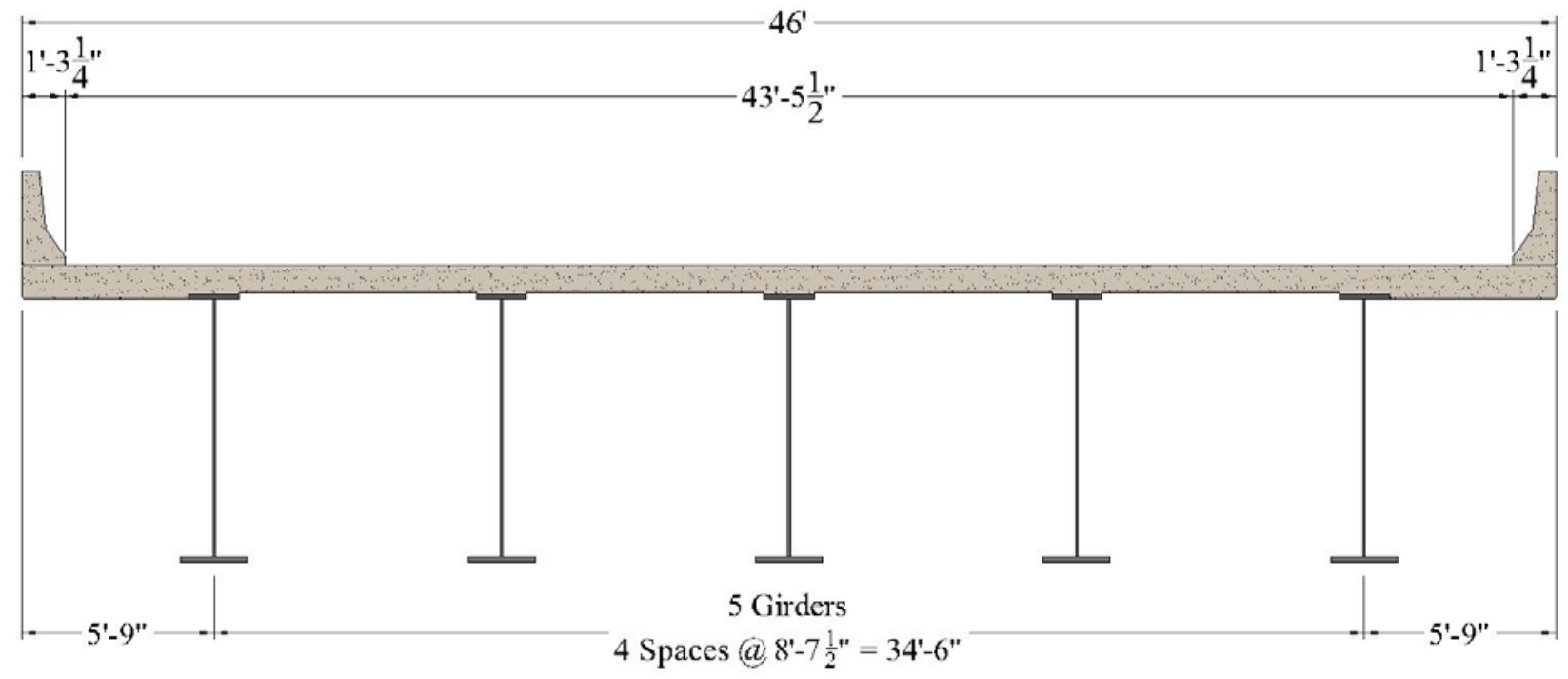

Figure 5.7: Sensitivity Bridge Cross-Section: $L=200^{\prime} ; S=8.625$ ', $\mathrm{OH}=69^{\prime \prime}$ 


\subsubsection{Bridge Design}

The bridges used in this study were designed according to current AASHTO LRFD Specifications (American Association of State Highway and Transportation Officials, 2010) and checked with MDX Software, Version 6.5 (MDX Software, Inc., 2009). For a given span length, the bridges were designed for the most conservative scenario, i.e. longest unbraced length, longest overhang, least number of girders, etc. Figure 5.8 and Figure 5.9, along with Table 5.1, show elevations and plate size information for the 100-foot and 200-foot span girders, respectively. It may be noted that Figure 5.8 illustrates the 100 -foot with a section transition whereas the 200-foot girder, shown in Figure 5.9, has a constant cross-section. This is due to the fact that the initial trial girder for the 100-foot cross-section was obtained from AISI's "ShortSpan Steel Bridges” package (American Iron and Steel Institute, 1998). As studies showed that there was virtually no influence from changes in girder stiffness along the span, the constant cross-section was used for simplicity in analysis for the 200-foot span girder.

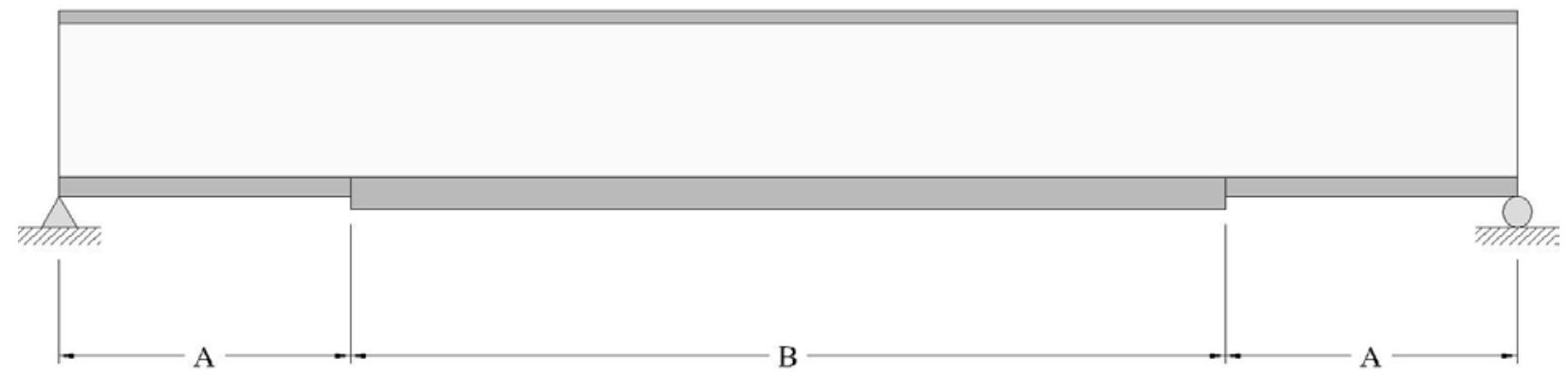

Figure 5.8: 100-Foot Girder Elevation for Sensitivity Study

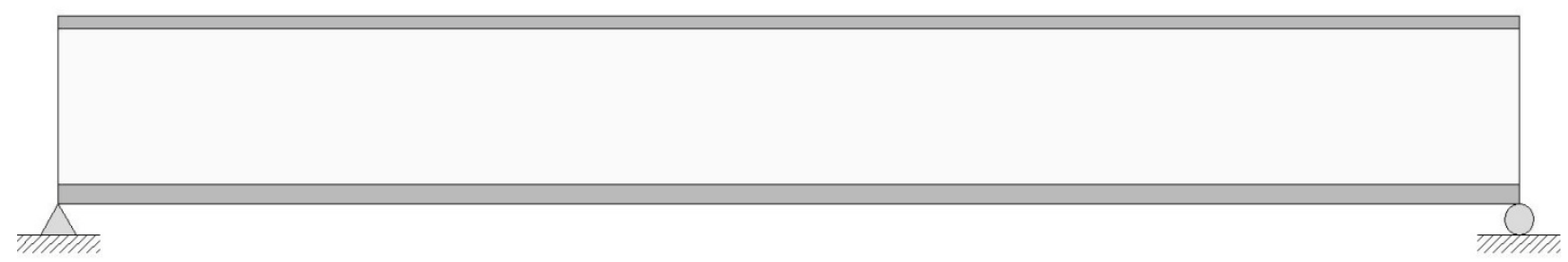

Figure 5.9: 200-Foot Girder Elevation for Sensitivity Study 


\begin{tabular}{|c|c|c|c|c|c|c|c|c|c|c|c|c|}
\hline \multirow{2}{*}{ L (ft) } & \multicolumn{2}{|c|}{ Top Flange } & \multicolumn{3}{|c|}{ Bottom Flange (A) } & \multicolumn{3}{|c|}{ Bottom Flange (B) } & \multicolumn{2}{|c|}{ Web } & \multicolumn{2}{|c|}{ Stiffeners } \\
\hline & $b_{t f}$ (in) & $t_{t f}$ (in) & $b_{b f}(i n)$ & $t_{b f}$ (in) & $L_{b f}(f t)$ & $b_{b f}$ (in) & $t_{b f}$ (in) & $L_{b f}(f t)$ & $d_{w}$ (in) & $t_{w}(i n)$ & $t_{b r g}$ (in) & $t_{\text {int }}$ (in) \\
\hline 100 & 14 & 0.9375 & 16 & 0.8125 & 20 & 16 & 1.625 & 60 & 54 & 0.5625 & 0.75 & 0.5 \\
\hline 200 & 18 & 1.375 & 24 & 2 & 200 & -- & -- & -- & 93 & 0.875 & 1 & 0.5 \\
\hline
\end{tabular}

\section{Table 5.1: Sensitivity Girder Dimensions}

\subsection{Discussion OF SENSITIVITy StUdy RESUlts}

Since the tabulated results of the sensitivity study are too large to be included in this chapter, Appendix A has been provided for the reader's convenience. This appendix summarizes the effect of each varied parameter in tabular form.

Discussed in this section will be the general trends of the results of the sensitivity study, highlighting specifically the effect of the varied parameters on the effect of exterior girder live load distribution. In the graphs and discussion presented in this section, "FEA \#1" refers to the Stallings/Yoo method described in Section 4.3.1.1 and "FEA \#2" refers to the Tarhini/Frederick method described in Section 4.3.1.2. Also, for the sake of continuity, many of the graphs presented in this section will be related to the example bridge discussed in Section 3.3.1. 


\subsubsection{Comparison with AASHTO LRFD Distribution Factors}

Generally, as has been found in previous studies (see Chapter 2), the distribution factors obtained from the finite element modeling were significantly lower than those obtained from AASHTO LRFD methods. Figure 5.10 shows a comparison of the two types of distribution factors for the bridge discussed in Section 3.3.1. It should be noted that for the AASHTO Lever Rule results, only one-lane-loaded scenarios are reported as, when applying the Lever Rule, there is usually only room for one truck. Similarly, for the AASHTO modified distribution factors, only multiple-lane-loaded scenarios are reported.

For the sensitivity matrix as a whole, one lane loaded distribution factors are (averaged from the two analytical methods) 82\% lower than the Lever Rule and Special Analysis factors; for multiple lane loading scenarios, the FEA distribution factors are an average 10.1\% lower than the AASHTO modified distribution factors and those obtained from Special Analysis.

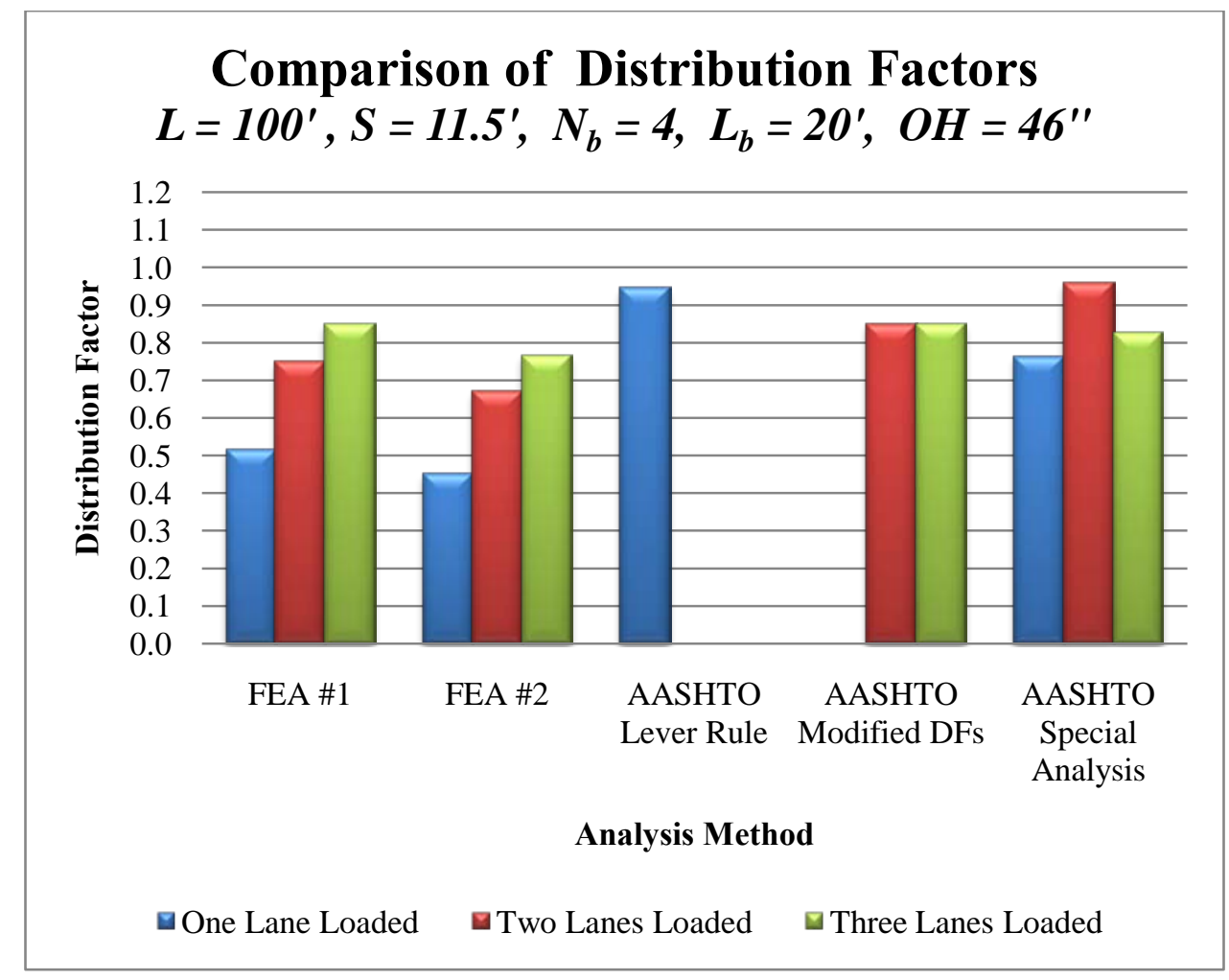

Figure 5.10: Comparison of AASHTO and FEA Distribution Factors 


\subsubsection{Influence of Girder Spacing / Number of Beams}

Figure 5.11 shows the comparison of these two variables on the example bridge described in Section 3.3.1 and its counterpart bridge in the matrix (with a girder spacing of 8.625 feet). This figure is split into three components for clarity, each component representing the number of lanes loaded (i.e. one graph for one-lane-loaded, another for two-lane-loaded scenarios, etc.)

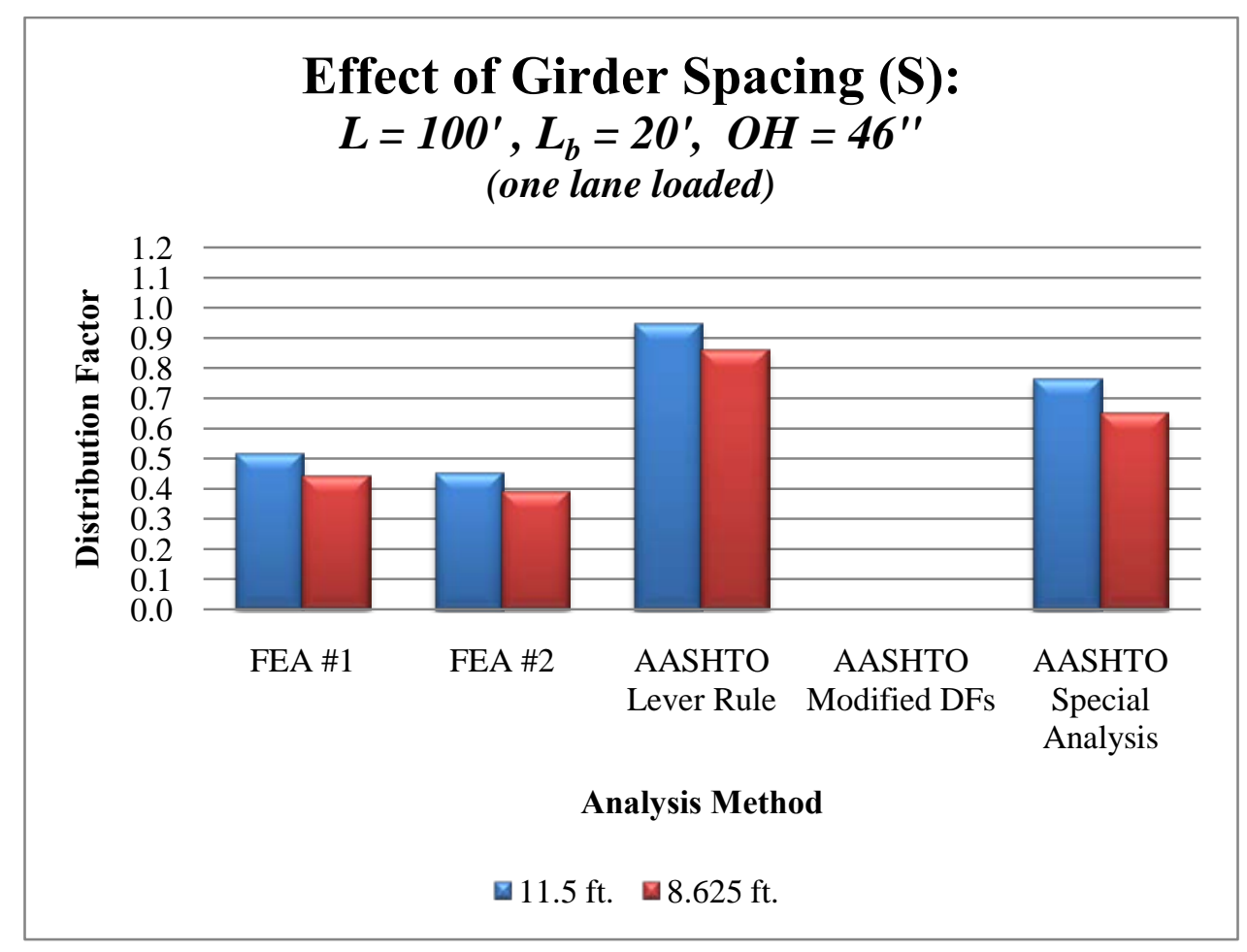

(a) 


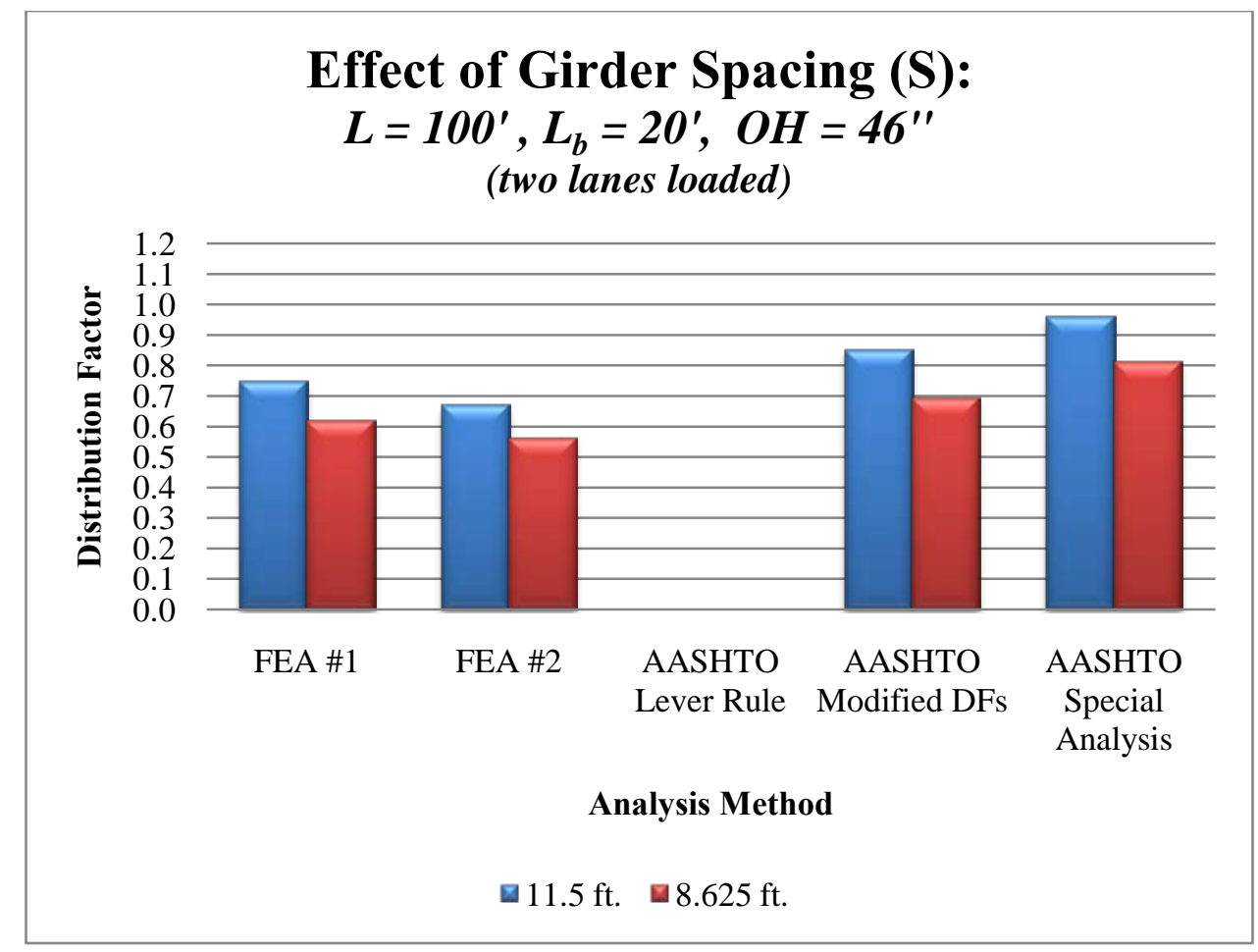

(b)

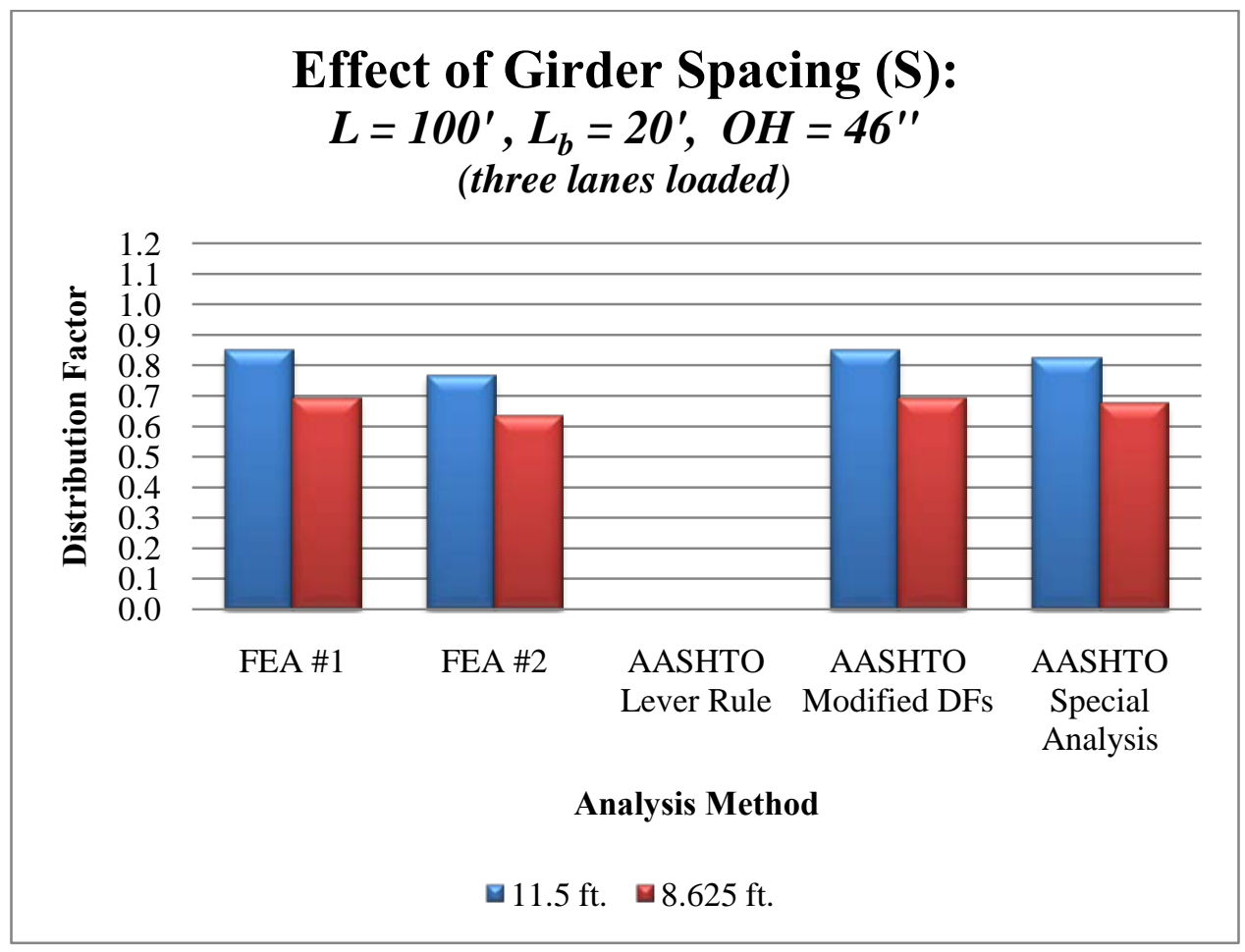

(c)

Figure 5.11: Comparison of the Effect of Girder Spacing / Number of Beams with a: one lane loaded, b: two lanes loaded, and c: three lanes loaded 
As expected, the girder spacing has a significant effect on exterior girder live load distribution. For the sensitivity matrix as a whole, distribution factors for bridges with an 11.5foot girder spacing are about 15\% higher than those with an 8.625-foot spacing. This is based on averaging the FEA \#1 and FEA \#2 as well as all lane loading scenarios. However, this comparison is somewhat difficult to make for this data since another parameter of interest (the number of beams in a bridge) is varied as well when the girder spacing is changed; for a girder spacing of 11.5 feet, four girders are used whereas for a girder spacing of 8.625 feet, five girders are used. This potential influencing factor with Parametric Variation \#1 (described in Section 6.2). However, one other interesting conclusion that can be made from this data is that girder spacing / number of beams does seem to have a greater effect as the number of lanes being loaded increases.

\subsubsection{Influence of Span Length / Girder Stiffness}

Figure 5.12 shows the comparison of the two different span lengths used in this study on the example bridge described in Section 3.3.1 and its counterpart bridge in the matrix (with a span length of 200 feet). Similar to Figure 5.11, this figure is split into three components for clarity, each component representing the number of lanes loaded. 


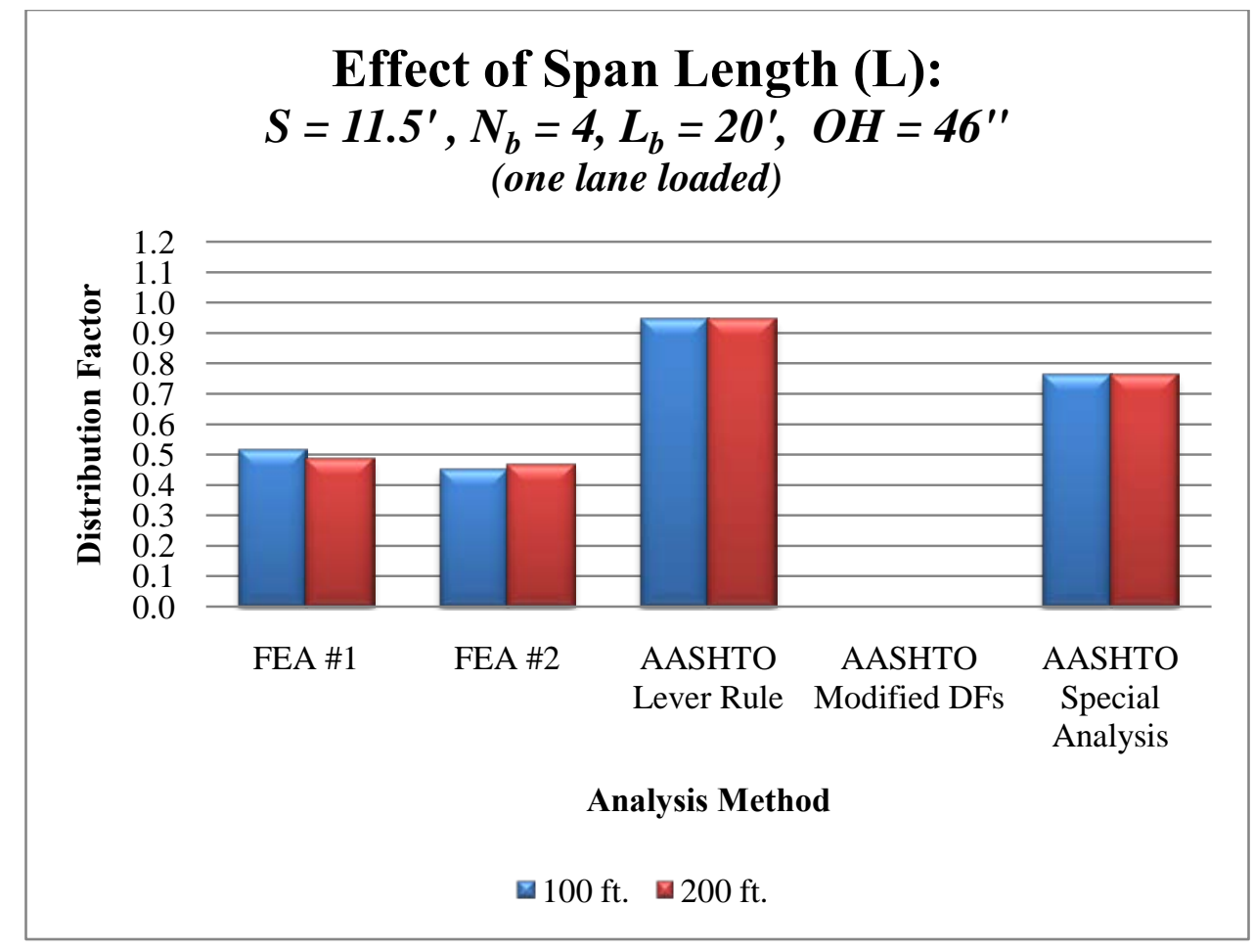

(a)

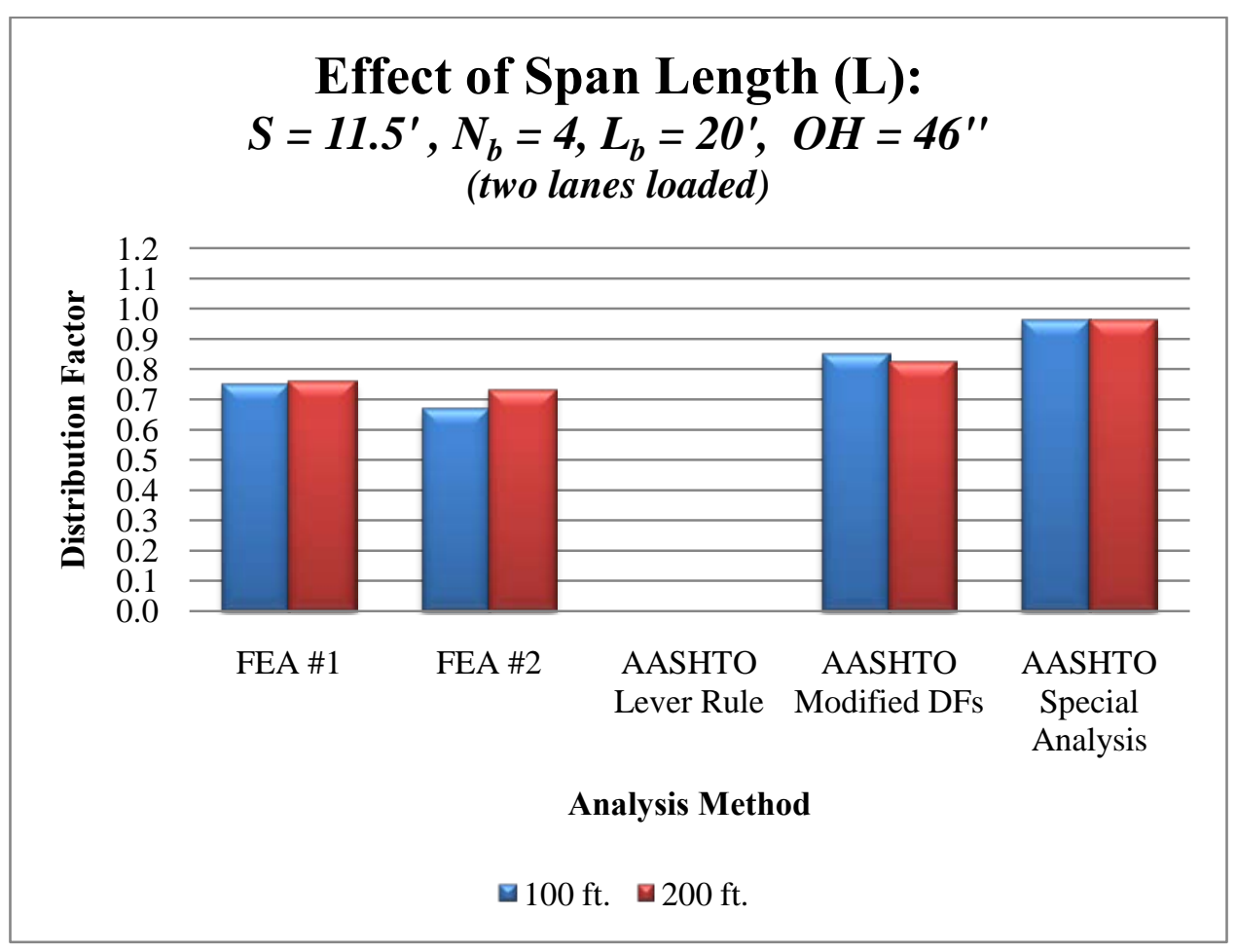

(b) 


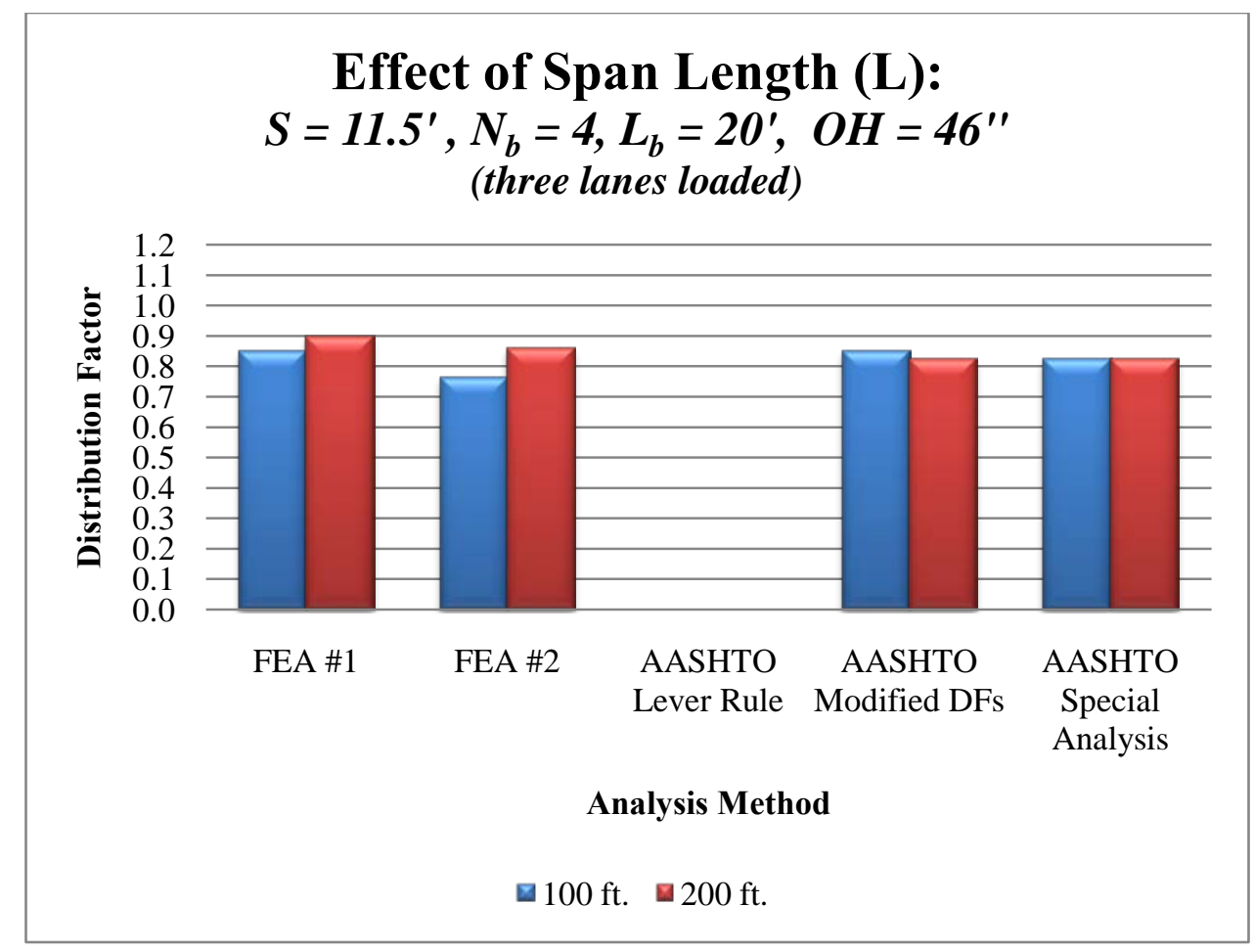

(c)

Figure 5.12: Comparison of the Effect of Span Length / Girder Stiffness with a: one lane loaded, $b$ : two lanes loaded, and c: three lanes loaded

From these graphs, it appears that span length has a somewhat negligible effect on exterior girder live load distribution. However, this evaluation is somewhat difficult to make for this data since another parameter of interest (the girder stiffness) is varied as well when the span length is changed. This difficulty is handled with Parametric Variation \#1 (discussed in Section 6.2). However, one other interesting conclusion that can be made from this data is that span length / girder stiffness does seem to have a greater effect as the number of lanes being loaded increases, especially with the results obtained from FEA \#2. 


\subsubsection{Influence of Deck Overhang}

Figure 5.13 shows the comparison of the two deck overhangs used in this study on the example bridge described in Section 3.3.1 and its counterpart bridge in the matrix (with a deck overhang of 69 inches). This comparison is also shown for all lane loadings used in this study. Similar to Figure 5.11 and Figure 5.12, this figure is split into three components for clarity, each component representing the number of lanes loaded.

As expected, the width of the deck overhang has a significant effect on exterior girder live load distribution. For the sensitivity matrix as a whole, distribution factors for bridges with a 69 inch deck overhang are about 11\% higher than those with a 46 inch deck overhang.

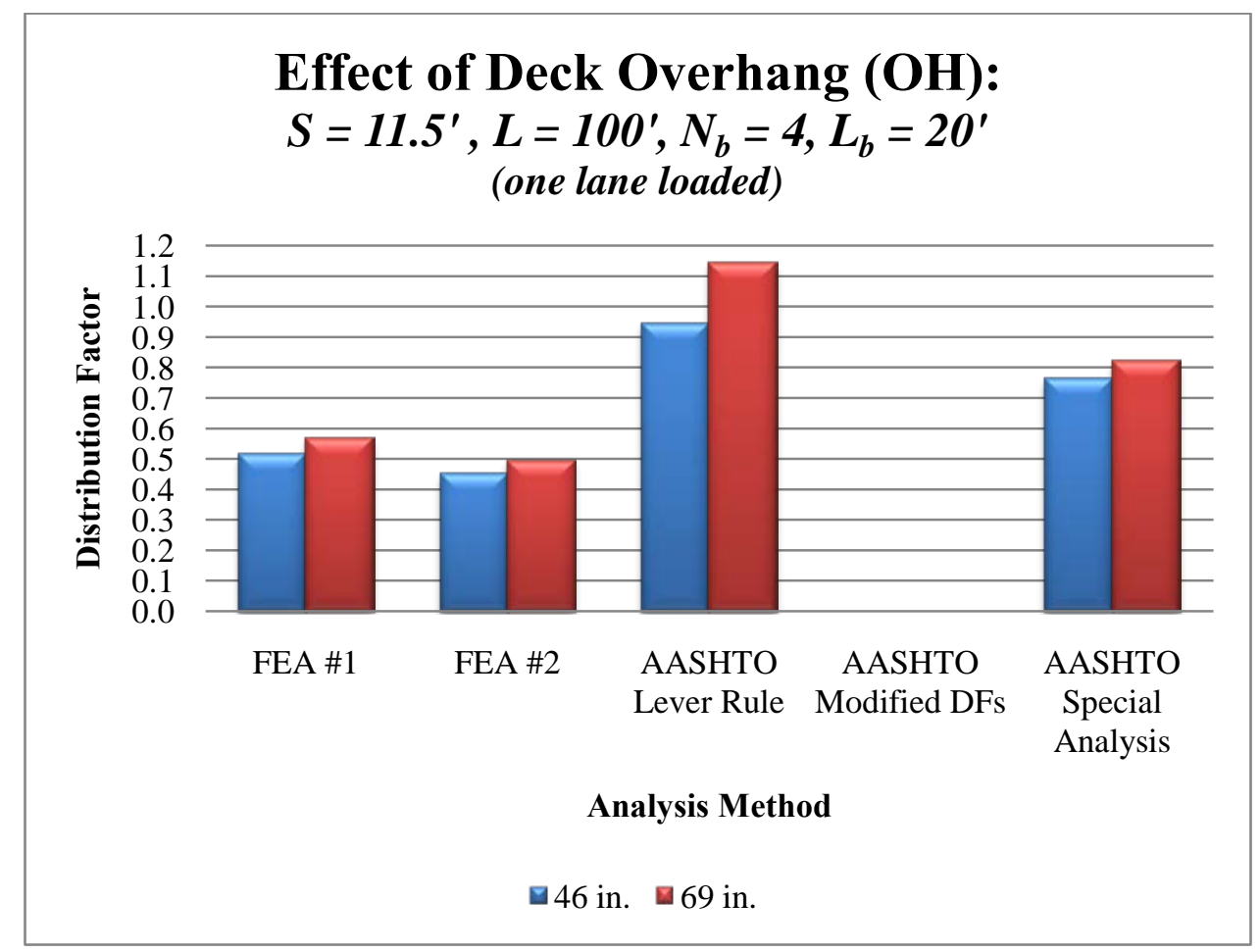

(a) 


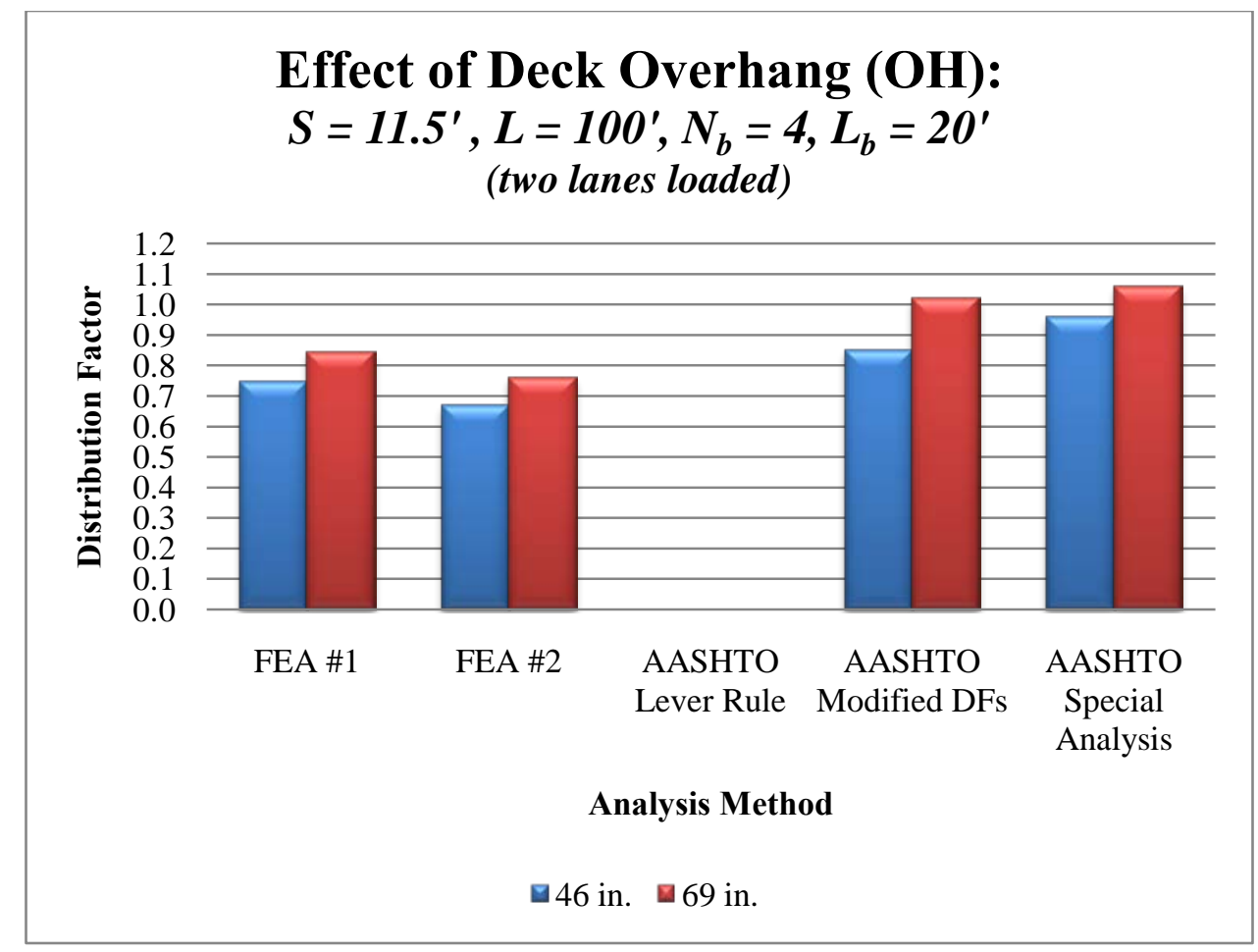

(b)

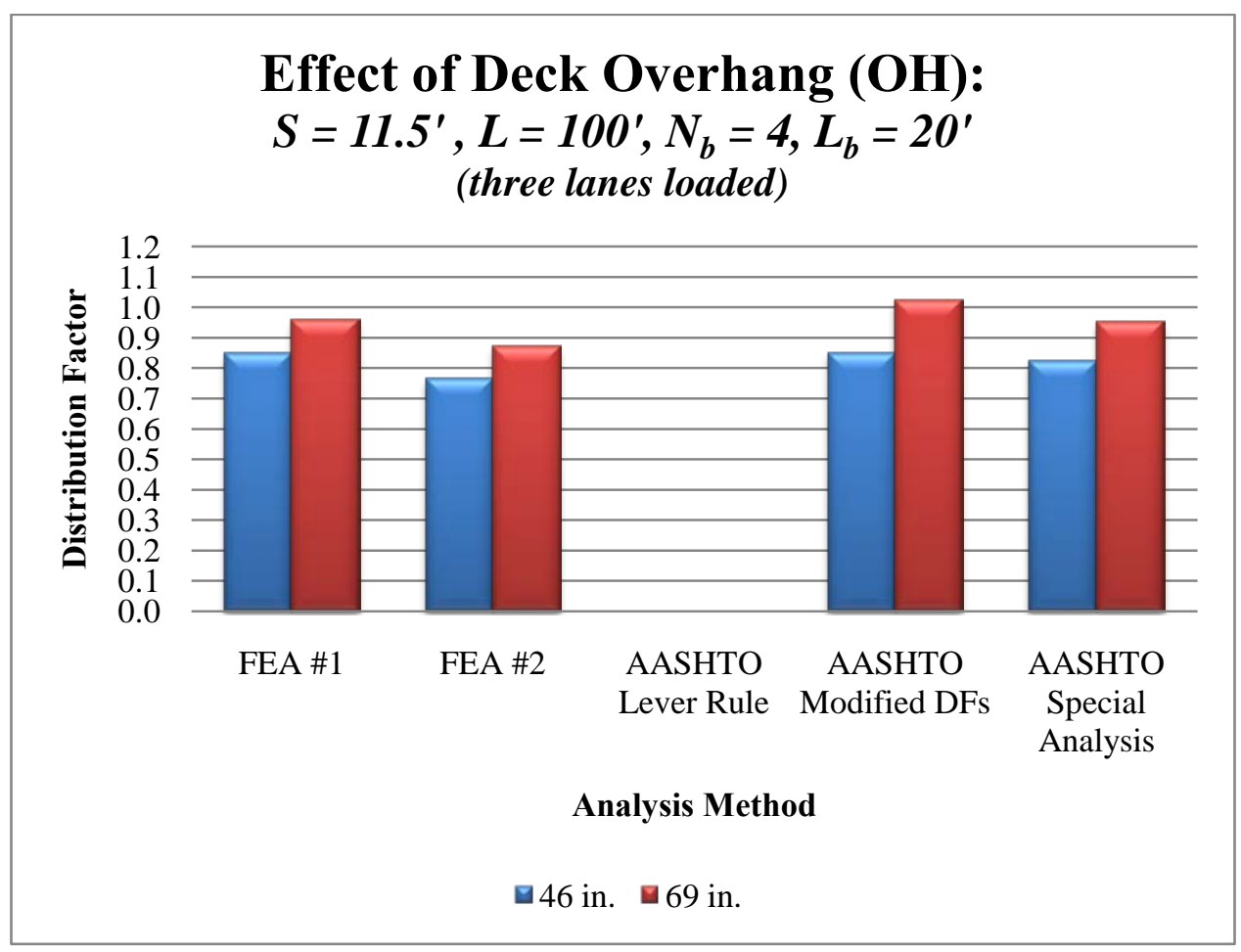

(c)

Figure 5.13: Comparison of the Effect of Deck Overhang with a: one lane loaded, b: two lanes loaded, and c: three lanes loaded 


\subsubsection{Influence of Barrier Presence}

Figure 5.14 shows the comparison of the two deck overhangs used in this study on the example bridge described in Section 3.3.1 and its counterpart bridge in the matrix (i.e. this bridge with no barrier). This comparison is also shown for all lane loadings used in this study. Similar to the previous figures in this section, this figure is split into three components for clarity, each component representing the number of lanes loaded.

An interesting observation that can be made from these results is how different the effect is interpreted using FEA \#1 and FEA \#2. FEA \#2 shows roughly a 12\% higher distribution factor for bridges without barriers than those with barriers whereas FEA \#1 shows roughly a 5\% higher distribution factor. This is most likely a result of the methodologies behind FEA \#1 and FEA \#2. FEA \#1 simply expresses the percentage of load among the total load in only the girders whereas FEA \#2 directly compares the load in the girder to the load from line-girder analysis. Another interesting observation that can be made is that, while the finite element modeling shows a distinct influence of barrier presence, because the AASHTO distribution factors do not account for barrier presence, these factors remain constant. 


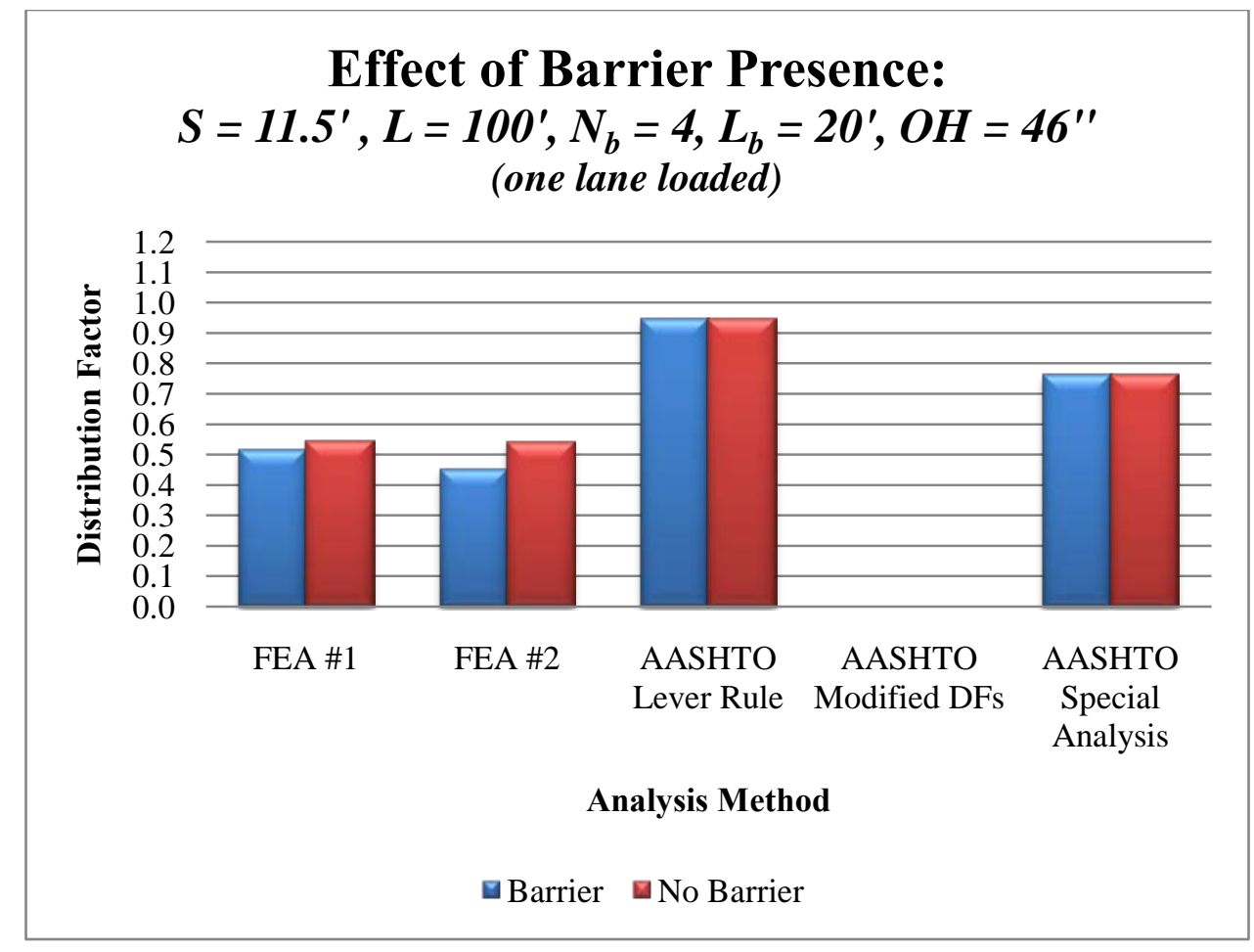

(a)

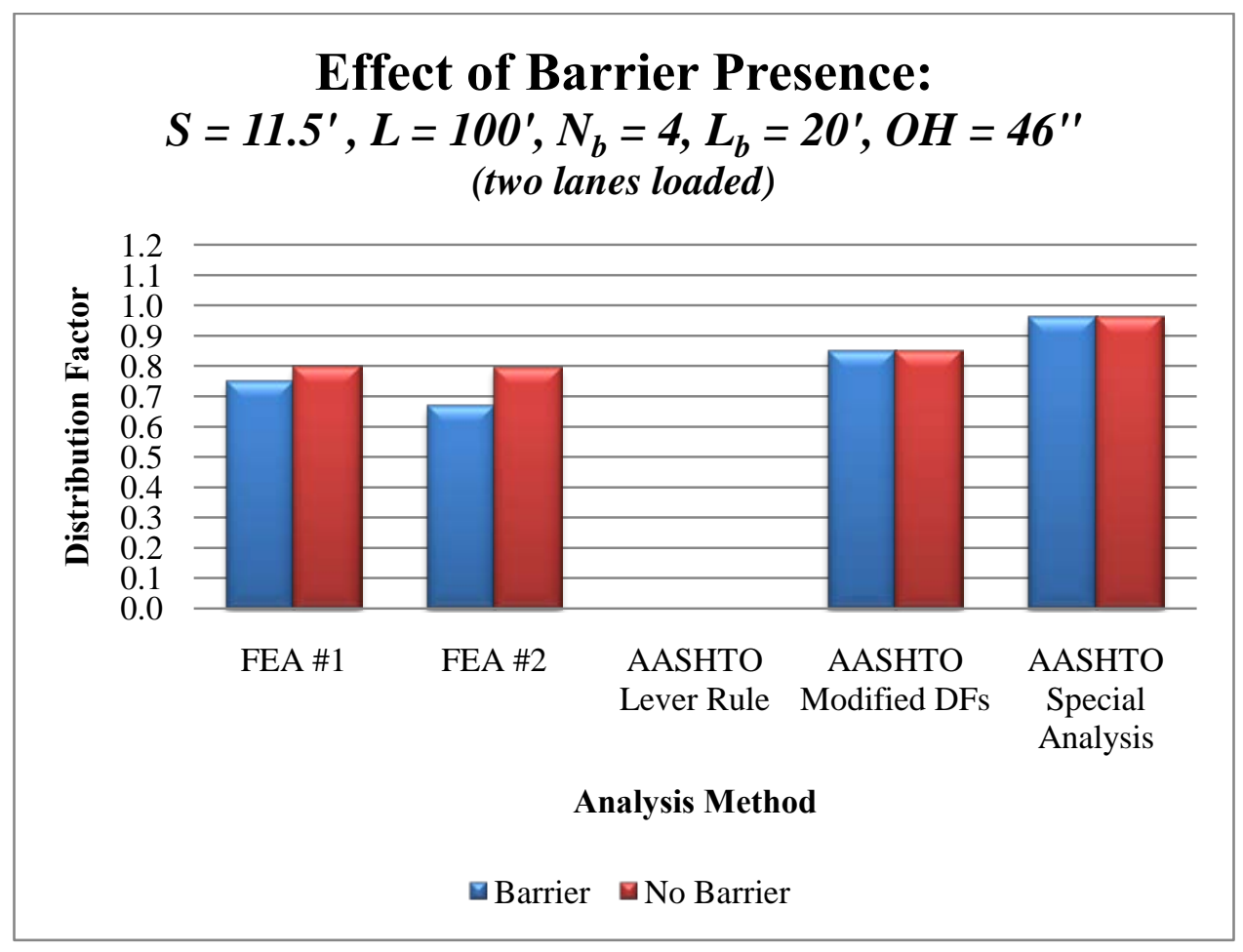

(b) 


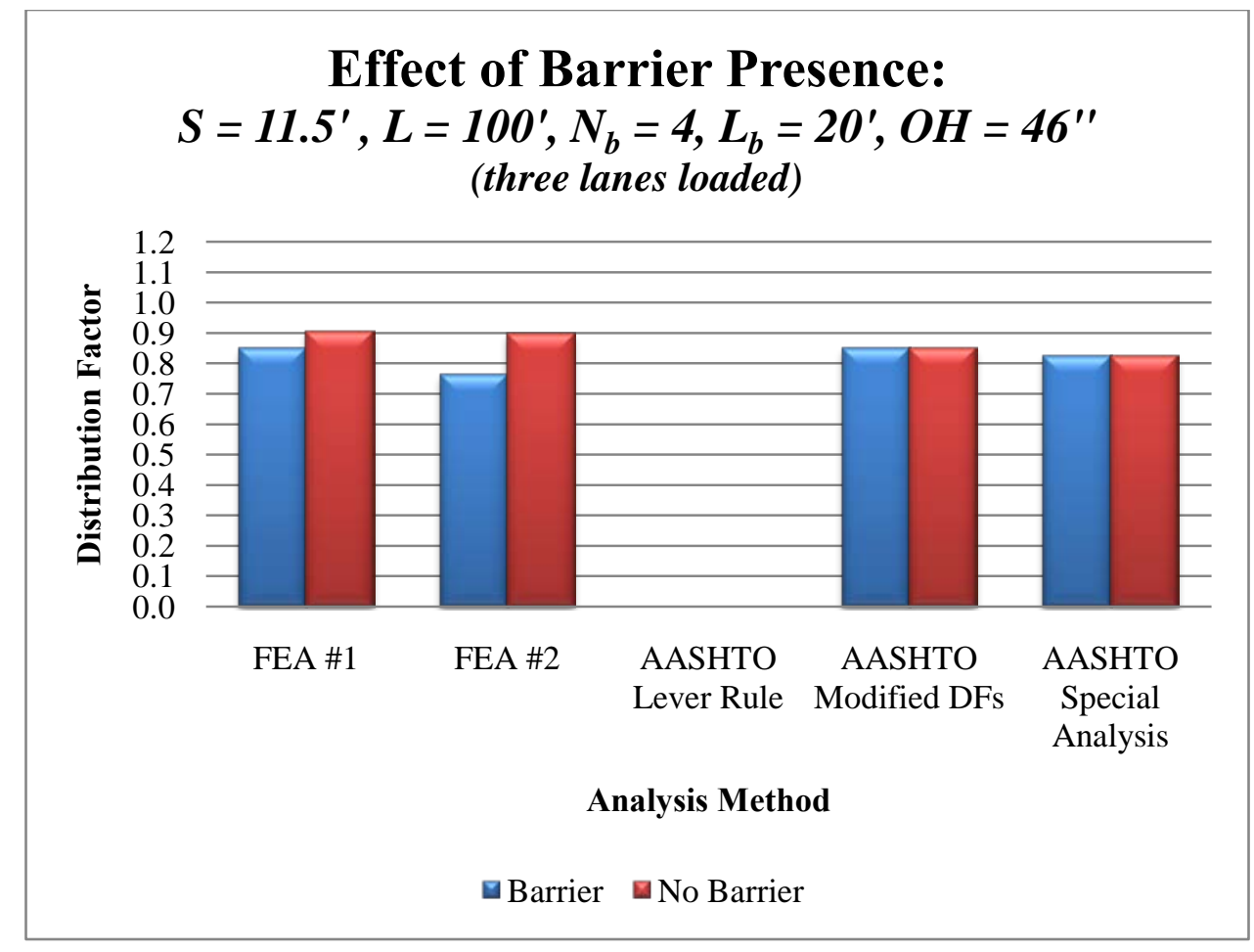

(c)

Figure 5.14: Comparison of the Effect of Barrier Presence with a: one lane loaded, b: two lanes loaded, and $c$ : three lanes loaded

\subsubsection{Influence of Cross-Frame Stiffness}

Figure 5.15 shows the comparison of the different cross-frame stiffness values used in this study on the example bridge described in Section 3.3.1 and its counterpart bridge in the matrix (i.e. this bridge with varying cross-frame stiffness values). This comparison is also shown for all lane loadings used in this study. Similar to the previous figures in this section, this figure is split into three components for clarity, each component representing the number of lanes loaded.

Also, as with the effect of barrier presence discussed in Section 5.3.5, while the finite element modeling shows an influence of cross-frame stiffness, because the AASHTO distribution factors do not account cross-frame stiffness, these factors remain constant. 


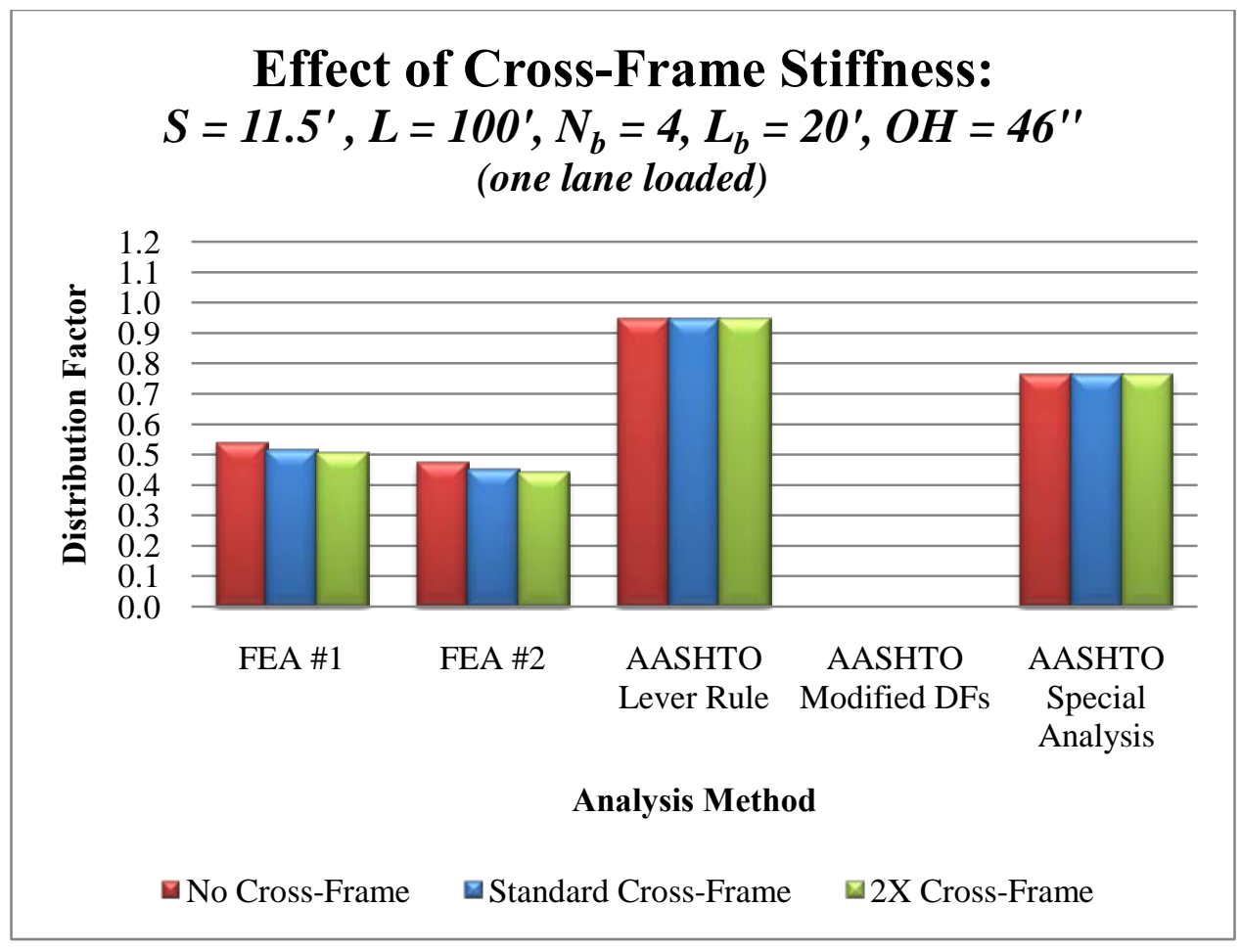

(a)

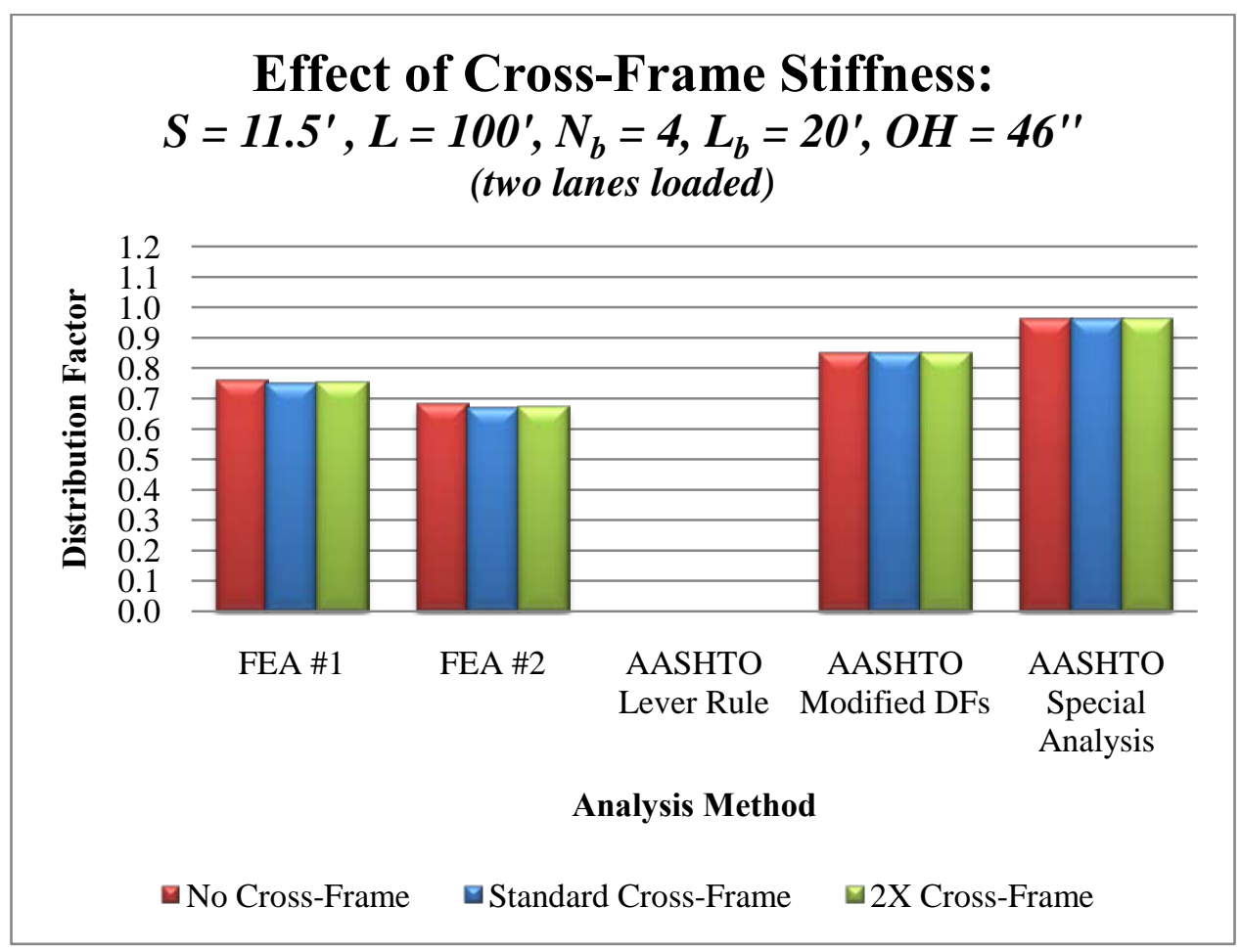

(b) 


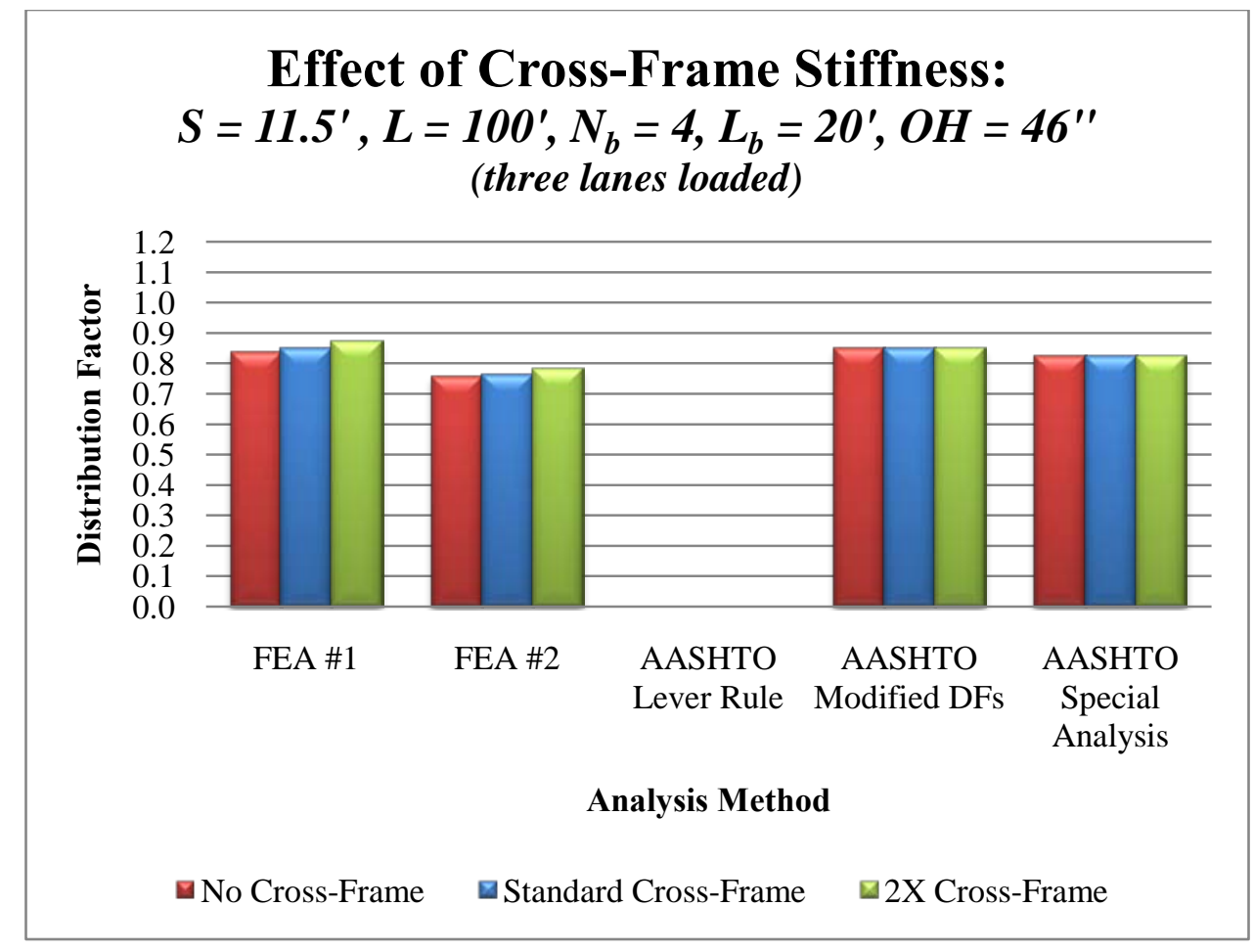

(c)

Figure 5.15: Comparison of the Effect of Cross-Frame Stiffness with a: one lane loaded, b: two lanes loaded, and c: three lanes loaded

While cross-frame stiffness does present an influence to exterior girder live load distribution, it is important to analyze the parameters varied for these results as well. For this comparison, three different cross-frame variations were used:

- The standard cross-frames described in Figure 5.2 and Figure 5.3

- These cross-frames scaled to twice their designed size.

- No cross-frames.

These double-scale cross-frames would constitute a very conservative design whereas a bridge with no cross-frames would constitute an inadequate design as However, all support cross-frames are required to distribute lateral loads (such as wind, centrifugal forces, seismic forces, etc.) from the superstructure to the substructure.. Therefore, the small difference between these values would suggest that cross-frame stiffness has a negligible effect on exterior girder live load distribution. 


\subsubsection{Influence of Unbraced Length}

Figure 5.16 shows the comparison of the different unbraced lengths used in this study on the example bridge described in Section 3.3.1 (i.e. this bridge with unbraced lengths of 20 feet and 25 feet). This comparison is also shown for all lane loadings used in this study. Similar to the previous figures in this section, this figure is split into three components for clarity, each component representing the number of lanes loaded.

As can be seen from the figures, the effect of unbraced length is negligible. While the variations of the values of unbraced lengths are small, according to the Steel Bridge Design Handbook, Chapter 13: Design for Constructability (National Steel Bridge Alliance) reasonable cross-frame spacing is on the order of 20 to 30 feet. Originally, the AASHTO LRFD Specifications set a maximum limit of 25 feet for cross-frame spacing, however this was removed to allow the designer to select reasonable cross-frame spacings if they could be demonstrated to provide sufficient lateral bracing. Therefore, for span lengths of 100 feet and 200 feet, $L_{b}$ values of 20 feet and 25 feet can be deemed reasonable.

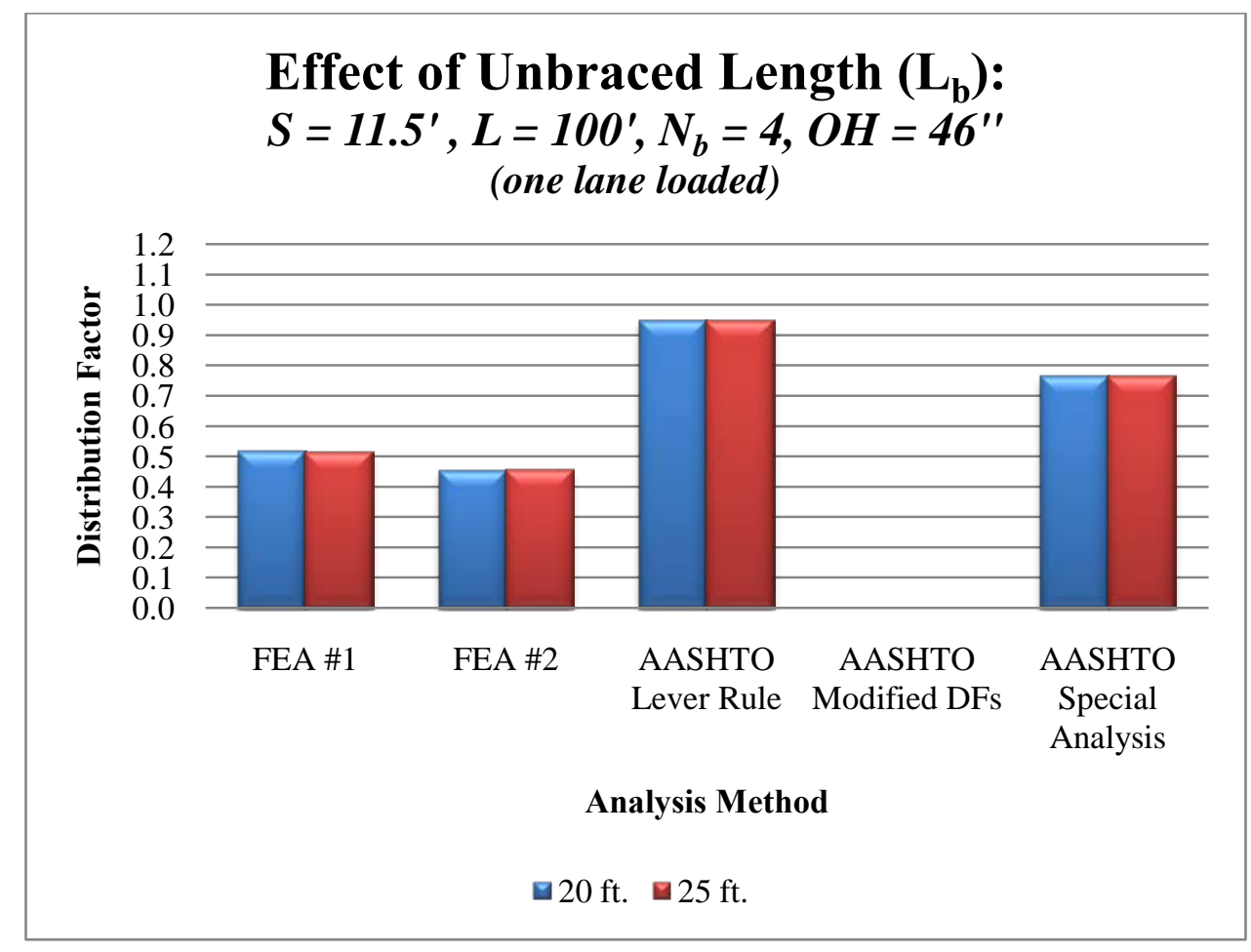

(a) 


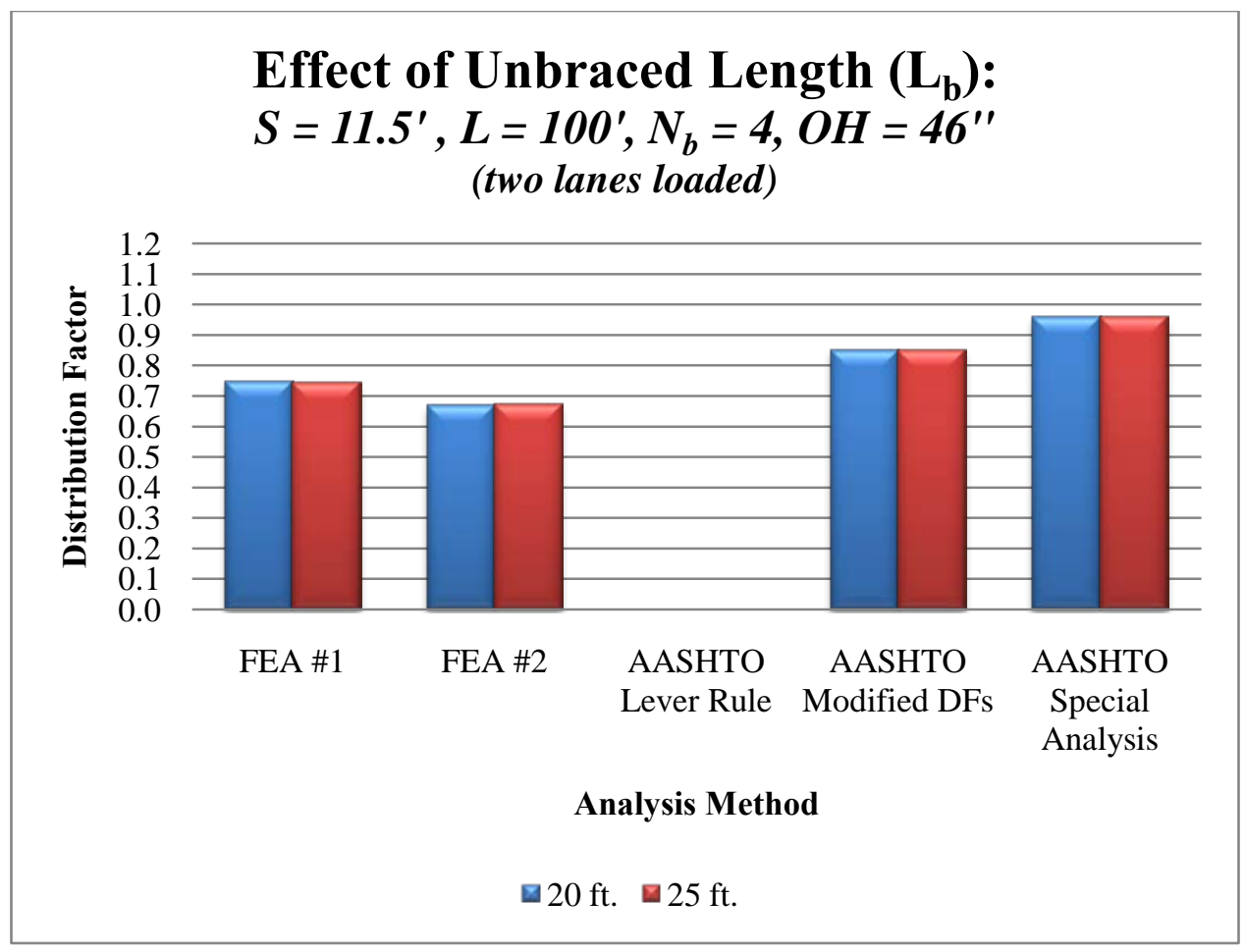

(b)

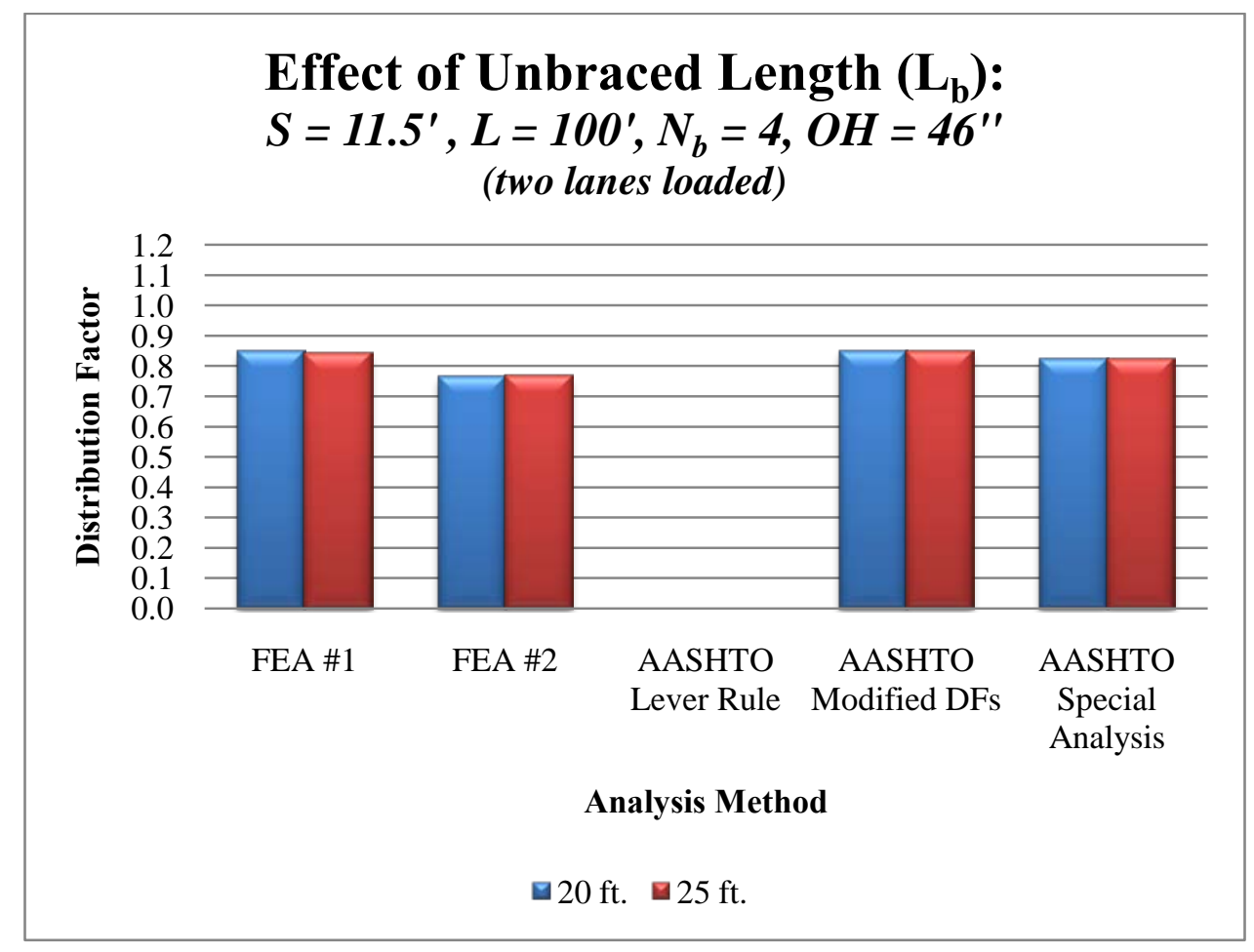

(c)

Figure 5.16: Comparison of the Effect of Unbraced Length with a: one lane loaded, b: two lanes loaded, and $c$ : three lanes loaded 


\subsection{SUMMARY}

The preceding chapter described a matrix of bridges analyzed with a finite element software package in order to determine the sensitivity of certain parameters on the live load distribution to the exterior girders of steel I-girder bridges. From this study, the following parameters were found to influence exterior girder live load distribution:

- Girder spacing / number of beams appeared to have a significant impact. However, as both variables were varied simultaneously, further investigation is required to assess the effect of each of these parameters.

- Span length / girder stiffness appeared to have a somewhat negligible effect. However, as with girder spacing / number of beams, both variables were varied simultaneously. Therefore, further investigation is required to assess the effect of each of these parameters.

- Deck overhang was found to have a significant impact.

- Barrier presence was found to have a definite impact.

- Cross-frame stiffness was found to have a somewhat negligible effect.

- Unbraced lengths were found to have a somewhat negligible effect.

From the data shown in Appendix A (along with the discussions presented in this chapter) while good correlations between the effect of varied parameters have been found, it is clear that more investigation is necessary to adequately assess exterior girder live load distribution. Two parametric matrices (denoted Parametric Variation \#1 and Parametric Variation \#2) are formulated based on the results of this sensitivity study. These formulations, as well as their subsequent analysis and discussions are presented in Chapter 6. 


\section{Chapter 6: Parametric Studies}

\subsection{INTRODUCTION}

The following chapter describes two matrices of bridges analyzed with a commercial finite element software package in order to effect of key parameters on the live load distribution to the exterior girders of steel I-girder bridges. These matrices were developed from an assessment of the results of the sensitivity study to further investigate these parameters that were found to have the most influence on exterior girder load distribution. Finally, the results of the parametric variations are discussed, specifically highlighting the influence of the varied parameters and comparing results with AASHTO LRFD Specifications predictions.

\subsection{PARAMETRIC VARIATION \#1}

The sensitivity matrix of 64 bridges discussed in Chapter 5 was expanded to 128 bridges in order to more accurately assess the effects of certain key parameters on exterior girder live load distribution. These bridges employed the same constant parameters discussed in Section 5.2.1. Discussed in this section are the specific parameters varied in this section as well as their respective influences. It should be noted that this matrix will be referred to hereafter as Parametric Variation \#1.

\subsubsection{Varied Parameters}

As discussed in Section 5.3, while the sensitivity study provided accurate inferences between some of the varied parameters, further assessment of an extended range of variations of some key variables was required. 
The following parametric variations were developed:

- To assess the effect of girder spacing and number of beams, 2 additional iterations were formed, hence resulting in the number of bridges in the matrix $(64 \times 2=$ 128). The resulting iterations were as follows:

0 4 beams spaced at 8.625 feet

o 5 beams spaced at 8.625 feet

o 4 beams spaced at 11.5 feet

o 5 beams spaced at 11.5 feet

- To assess the effect of span length and girder stiffness, all of the bridges in this matrix, for both 100-foot and 200-foot spans, were modeled using the same girder dimensions, specifically the girder design for a 200-foot span length (presented in 5.2.3). While this girder is obviously conservative for a 100 -foot span length, it is definitely a more reasonable avenue than using the girder design for a 100 -foot span length throughout as significant overstressing (and deterioration of results) may occur for 200-foot spans.

o The results for the 100-foot spans were then directly compared to the 200foot spans as the only varied parameter in this instance will be the span length.

o Also, the 100-foot span bridges in this matrix meeting the following two parameters can be directly related to comparable bridges previously analyzed in the sensitivity study in Chapter 5 to compare girder stiffness:

- 5 beams spaced at 8.625 feet

- 4 beams spaced at 11.5 feet

\subsubsection{Discussion of Parametric Variation \#1 Results}

Since the tabulated results of Parametric Variation \#1 are too large to be included in this chapter, Appendix B has been provided for the reader's convenience. This appendix summarizes the effect of each varied parameter in tabular form.

Discussed in this section will be the general trends of the results of Parametric Variation \#1, highlighting specifically the effect of the varied parameters on exterior girder live load 
distribution. As with the discussion in Section 5.3, in the graphs and discussion presented in this section, "FEA \#1" will refer to the Stallings/Yoo method discussed in Section 4.3.1.1 and "FEA \#2” will refer to the Tarhini/Frederick method discussed in Section 4.3.1.2. Also, as with the discussion in Section 5.3, many of the graphs presented in this section will be related to the example bridge discussed in Section 3.3.1.

\subsubsection{Influence of the Effect of Girder Stiffness}

Using data obtained from the sensitivity study discussed in Chapter 5 and Parametric Variation \#1, direct comparisons can be made to ascertain the effect of girder stiffness on exterior girder live load distribution. Figure 6.1 compares the girder stiffness values used in this study on the example bridge described in Section 3.3.1 and its counterpart bridge in Parametric Variation \#1 (i.e. this bridge with the girder designed for 200 -foot spans). This comparison is also shown for all lane loadings used in this study. Similar to previous figures, this figure is split into three components, each component representing the number of lanes loaded.

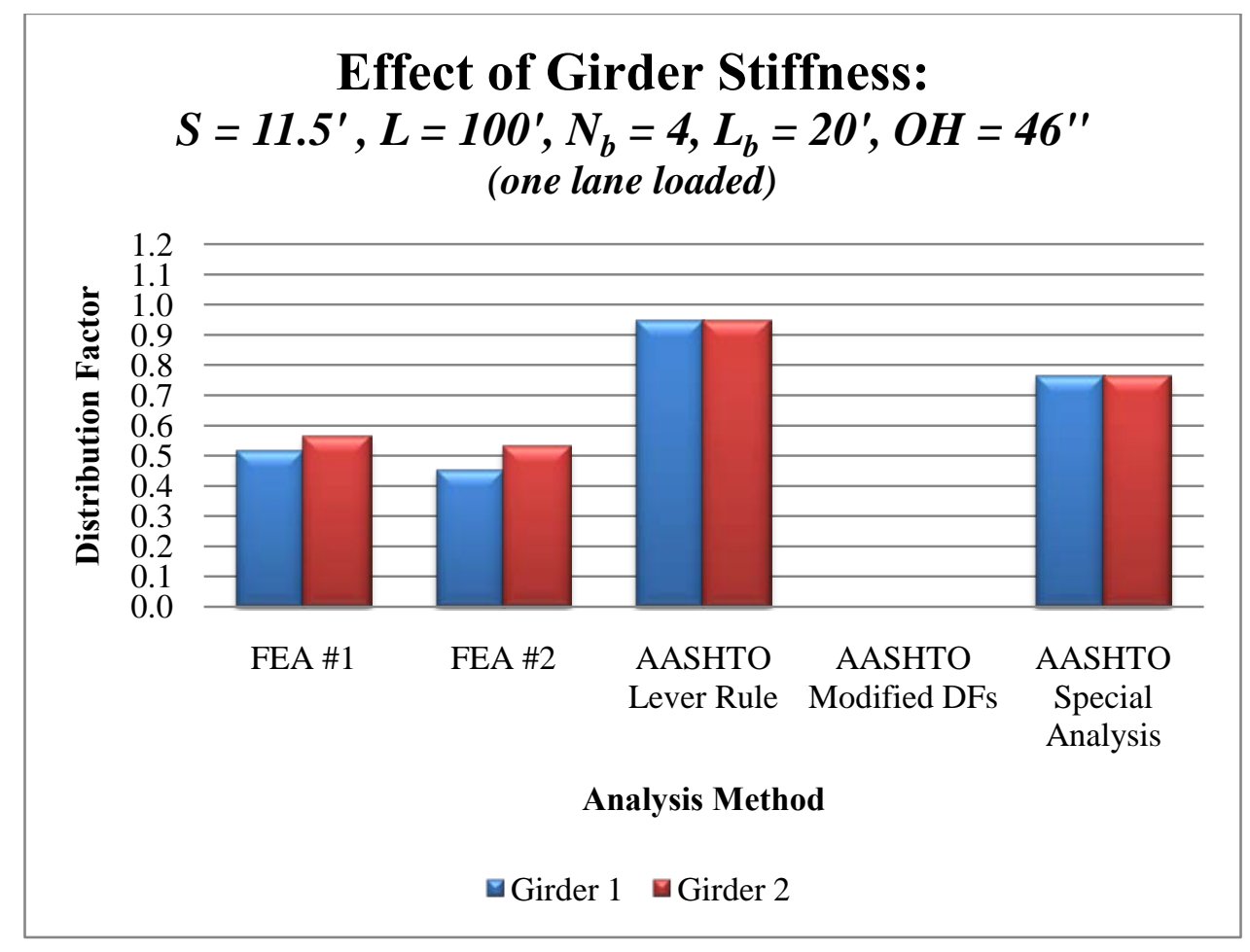

(a) 


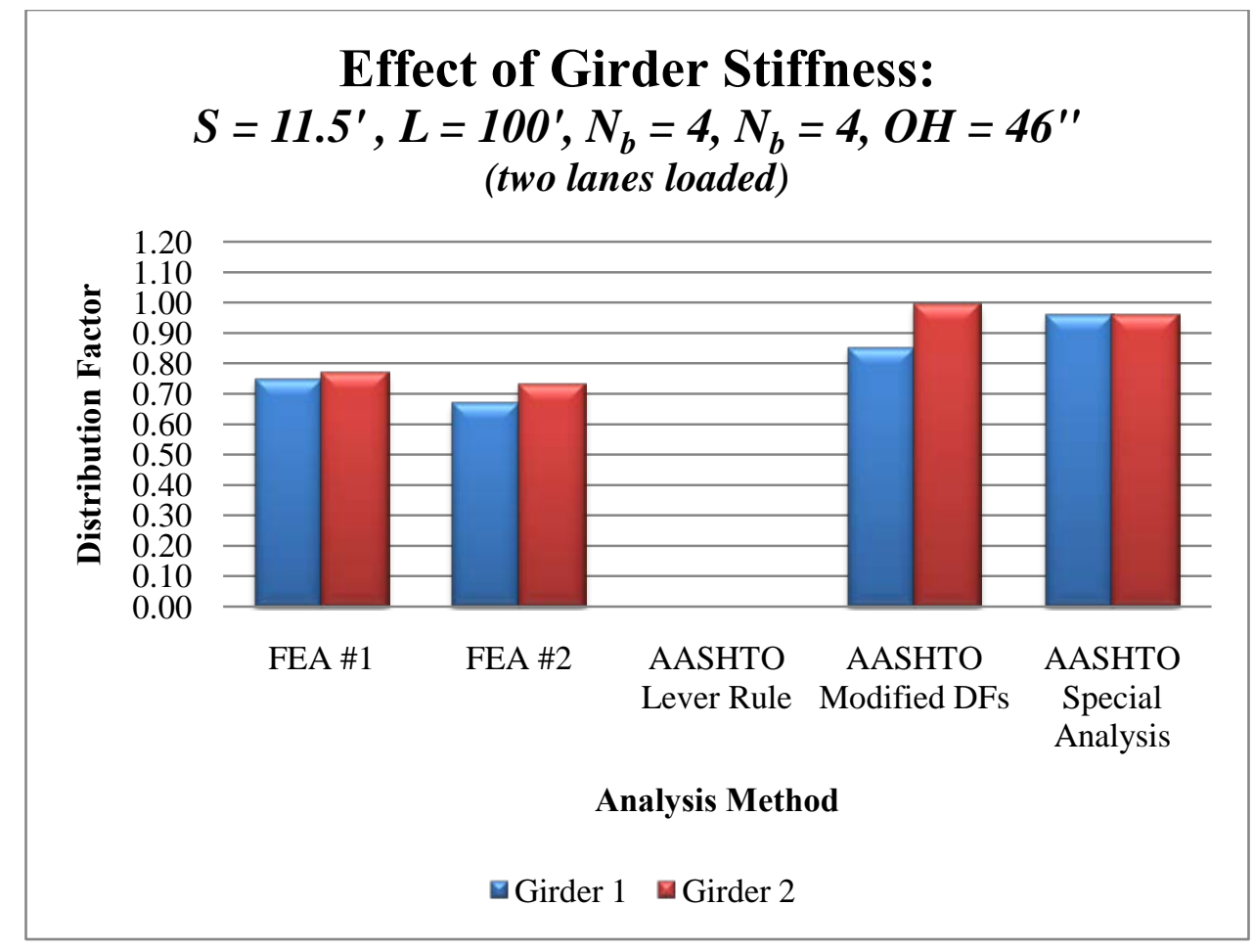

(b)

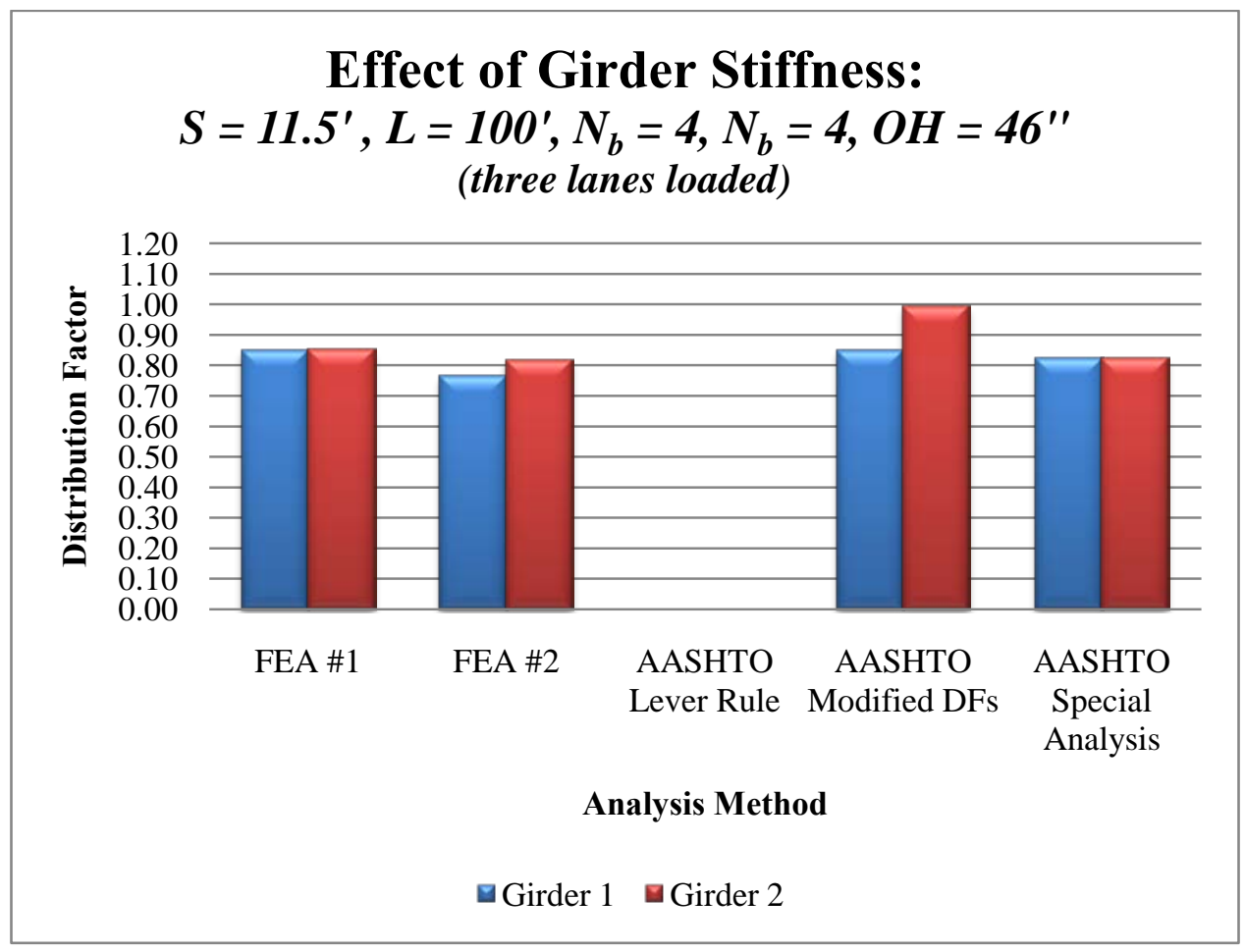

(c)

Figure 6.1: Comparison of the Effect of Girder Stiffness with a: one lane loaded, b: two lanes loaded, and c: three lanes loaded 
While girder stiffness does present an influence to exterior girder live load distribution, it is important to analyze the parameters varied for these results as well. For this comparison, two different girders were used, termed in Figure 6.1 as Girders 1 and 2. Girder 1 represents the optimum design for a 100-foot span length; Girder 2, on the other hand, represents the optimum design for a 200-foot span length. For a span length of 100 feet, Girder 2 would be a very conservative design. Therefore, the small difference between these values would suggest that girder stiffness has a negligible effect on exterior girder live load distribution.

\subsubsection{Influence of the Effect of Span Length}

Figure 6.2 shows the comparison of the two different span lengths used in Parametric Variation on the example bridge described in Section 3.3.1 and its counterpart bridge in the matrix (with a span length of 200 feet).

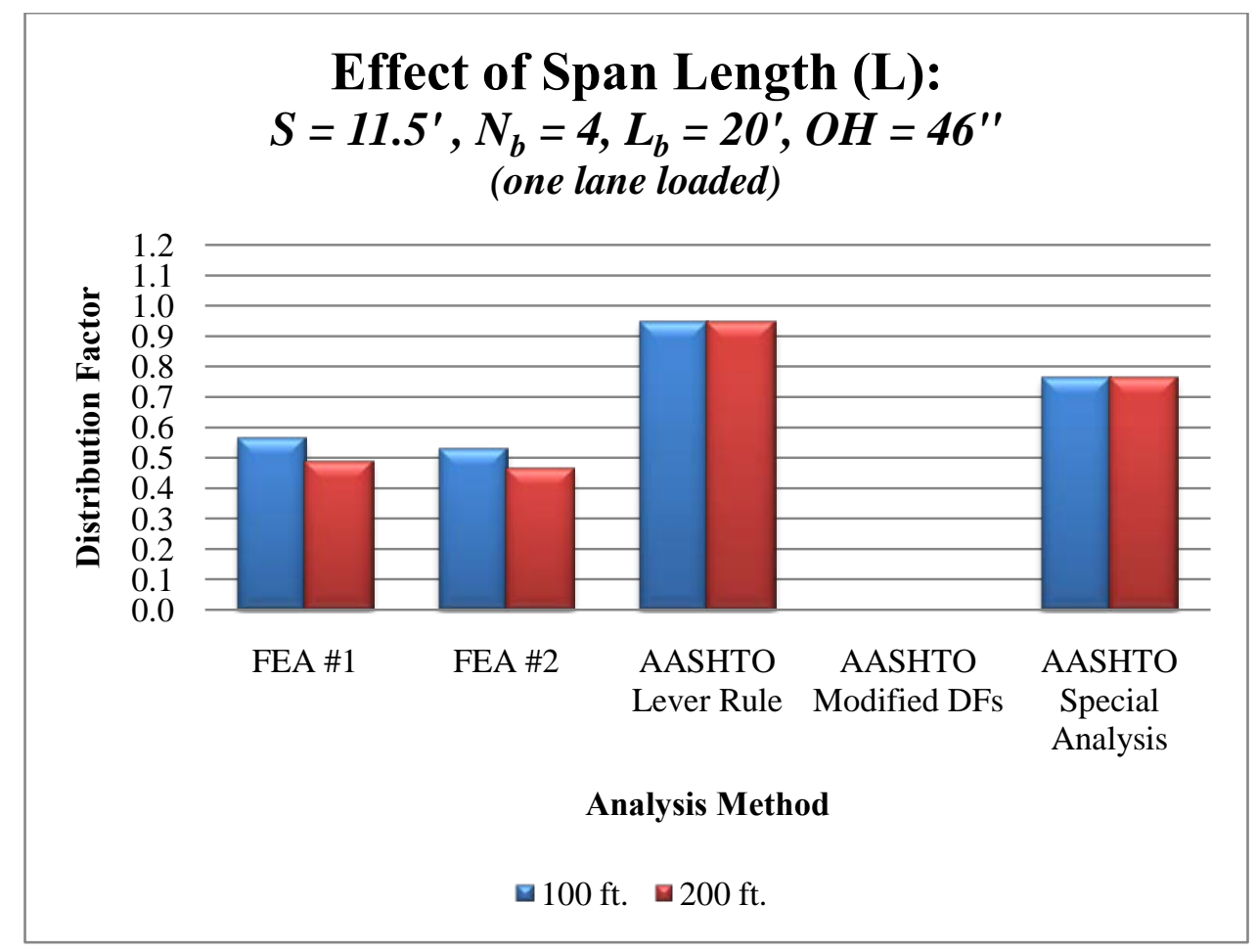

(a) 


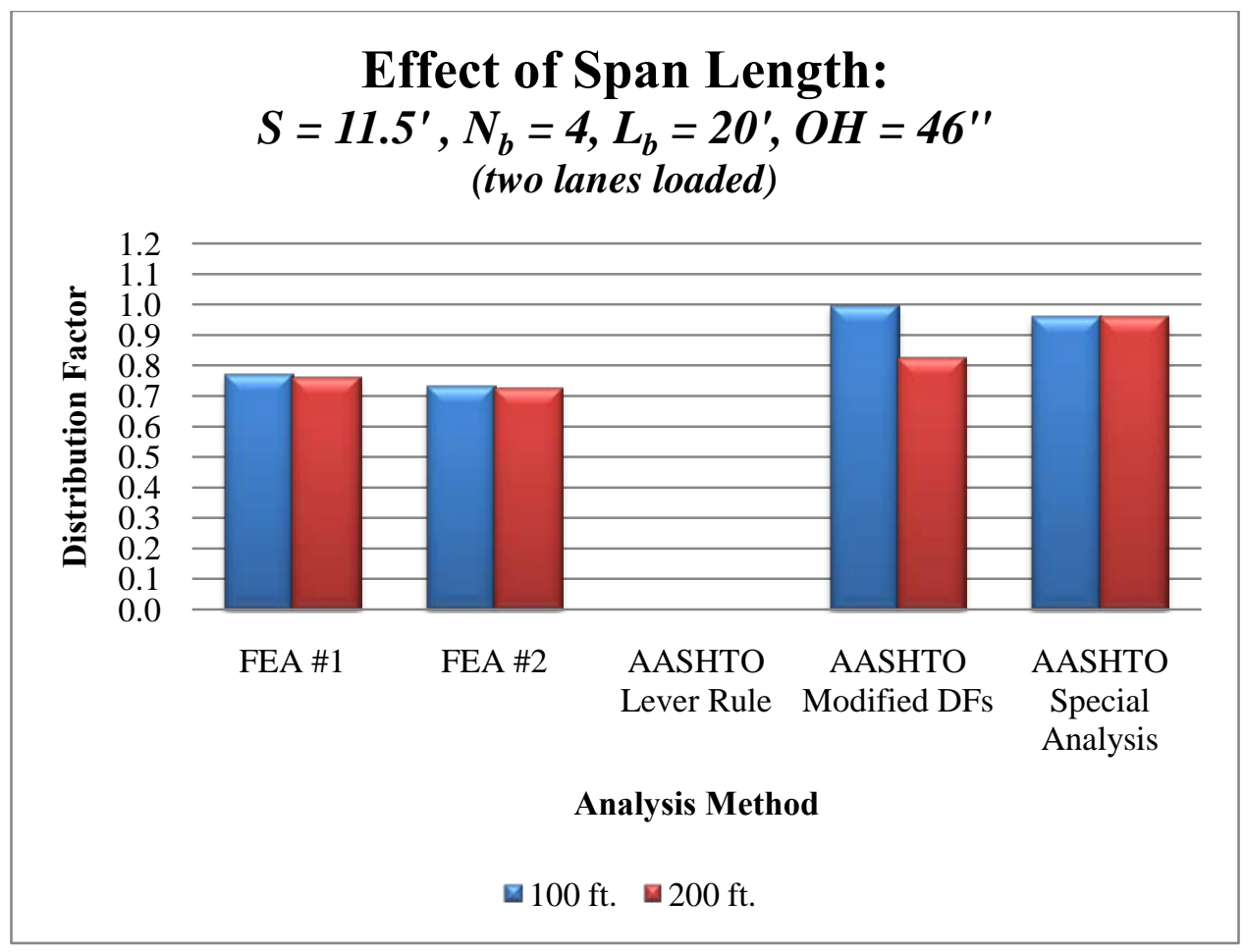

(b)

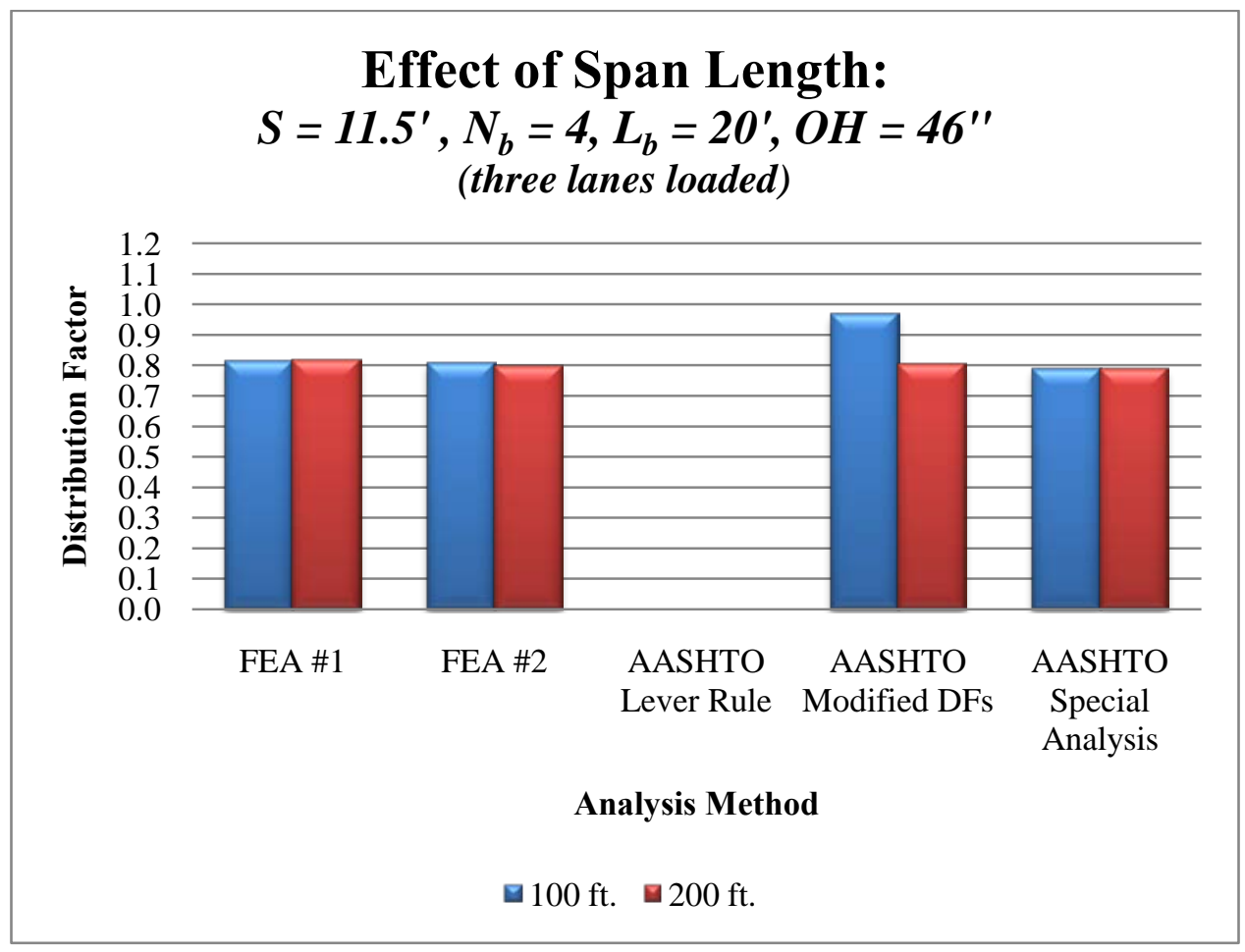

(c)

Figure 6.2: Comparison of the Effect of Span Length with a: one lane loaded, b: two lanes loaded, and c: three lanes loaded 
As previously stated in Section 5.3.3, the evaluation of span length in the sensitivity study was somewhat difficult to make since another parameter of interest (the girder stiffness) was varied as well when the span length was changed. This difficulty was handled with Parametric Variation \#1.

As has been found by other researchers (see Section 2.5.2), span length has a rather significant effect on exterior girder live load distribution. For Parametric Variation \#1 as a whole, distribution factors for bridges with a 100-foot span length are about $16 \%$ higher than those with a 200-foot span length. This is based on averaging the FEA \#1 and FEA \#2 for onelane-loaded scenarios.

However, for situations with multiple lanes loaded, the influence of span length was found to decrease. For two-lane-loaded scenarios, distribution factors for bridges with a 100foot span length are about 4\% higher than those with a 200-foot span length; for three-lane loaded scenarios, the effect is negligible. Nonetheless, span length was found to have an impact on exterior girder live load distribution, and was considered when developing Parametric Variation \#2 (described in Section 6.3).

\subsubsection{Influence of the Effect of Girder Spacing}

Figure 6.3 shows the comparison of the two different girder spacings used in Parametric Variation \#1 on the example bridge described in Section 3.3.1 and its counterpart bridge in the matrix (with a girder spacing of 8.625 feet).

As expected, the girder spacing has a significant effect on exterior girder live load distribution. For Parametric Variation \#1 as a whole, distribution factors for bridges with an 11.5-foot girder spacing are about 13\% higher than those with an 8.625-foot girder spacing. This percentage averages FEA \#1 and FEA \#2 for all lane loading scenarios. Previously, in Section 5.3.2, this comparison was somewhat difficult to make for this data since another parameter of interest (the number of beams in a bridge) was varied as well when the girder spacing is changed; for a girder spacing of 11.5 feet, four girders are used whereas for a girder spacing of 8.625 feet, five girders are used. However, this difficulty was handled with Parametric Variation \#1 by including the iterations of both the number of beams and the girder spacing. Therefore, it can be concluded that girder spacing does indeed have a significant effect on exterior girder live 
load distribution, and was considered when developing Parametric Variation \#2 (described in Section 6.3)

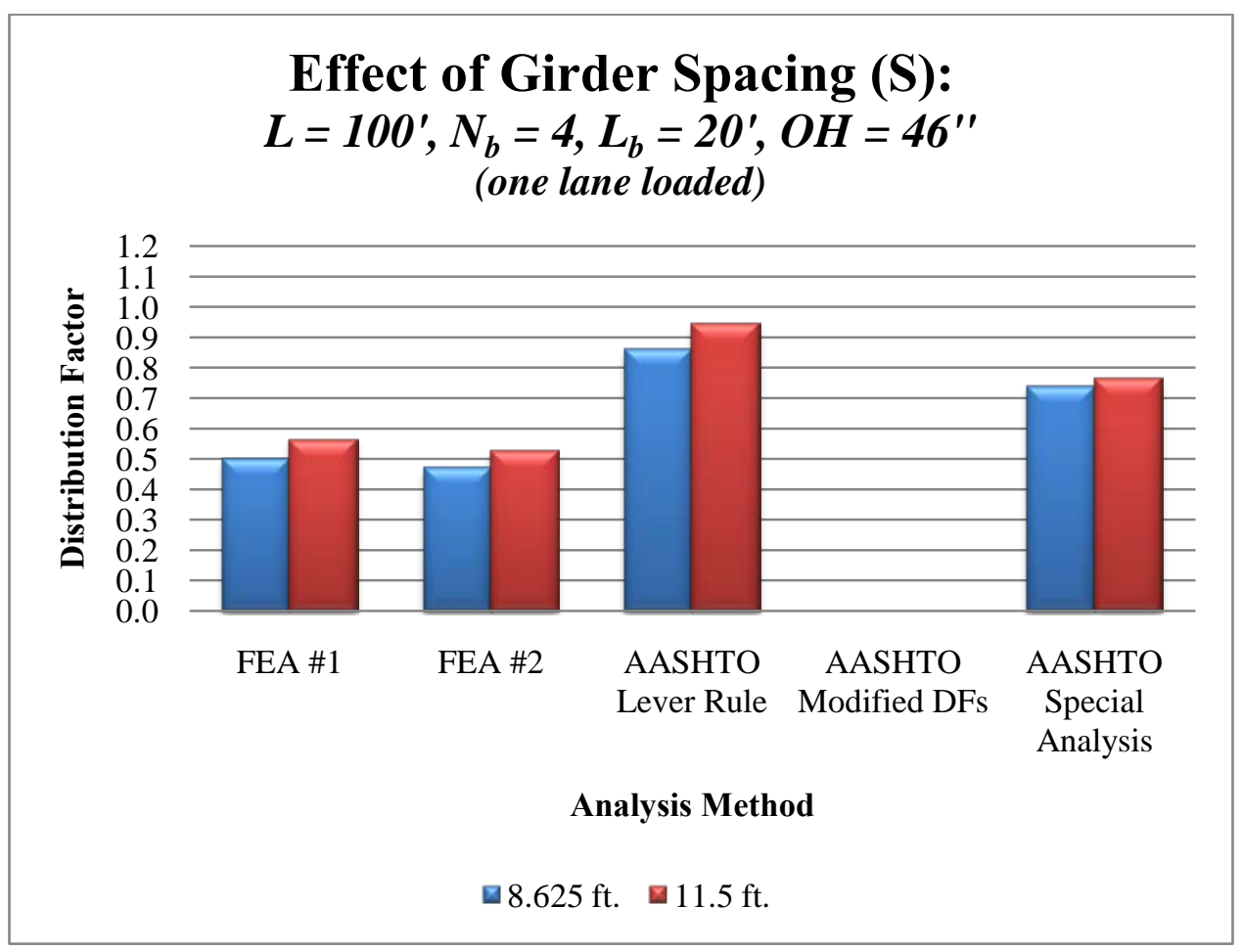

(a) 


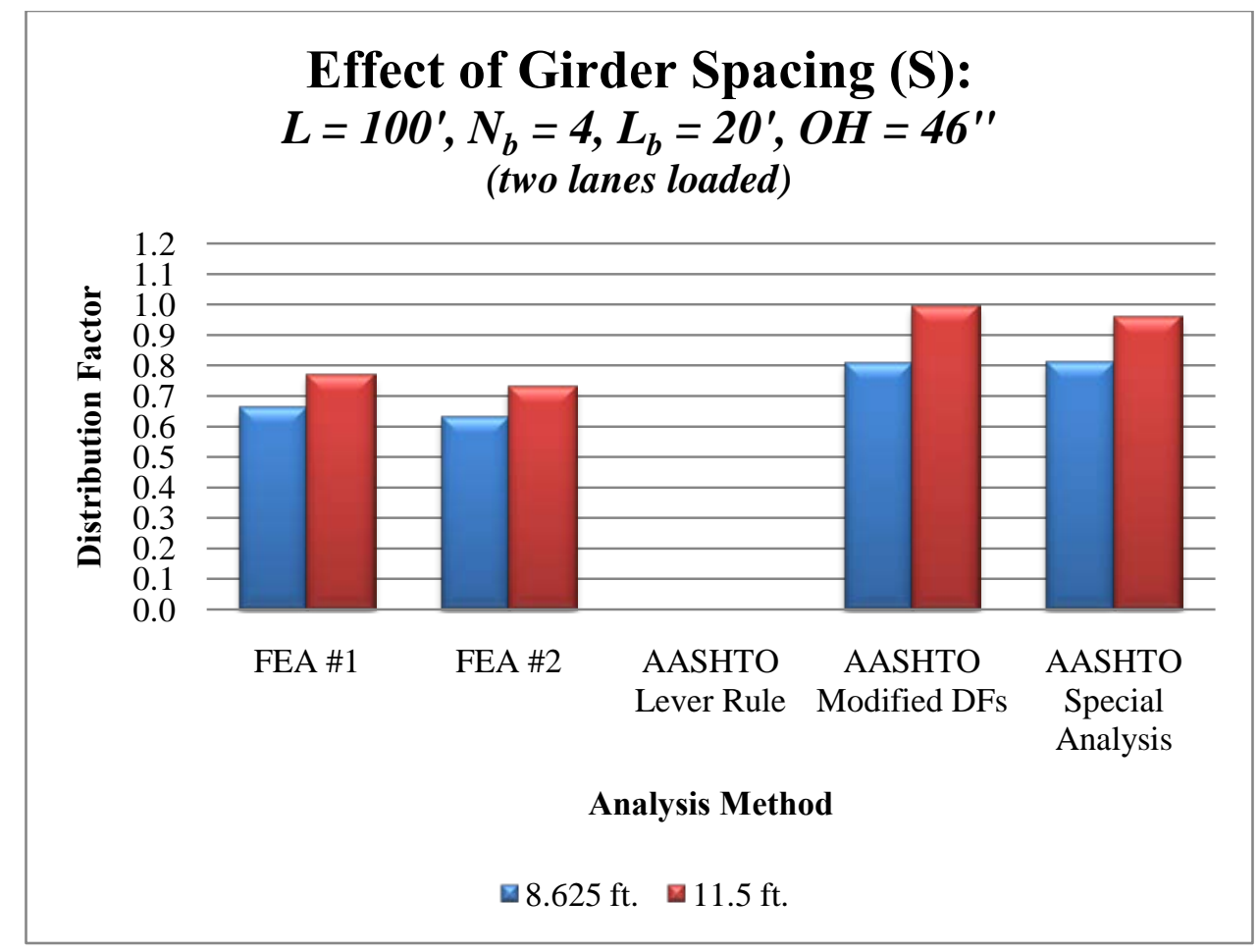

(b)

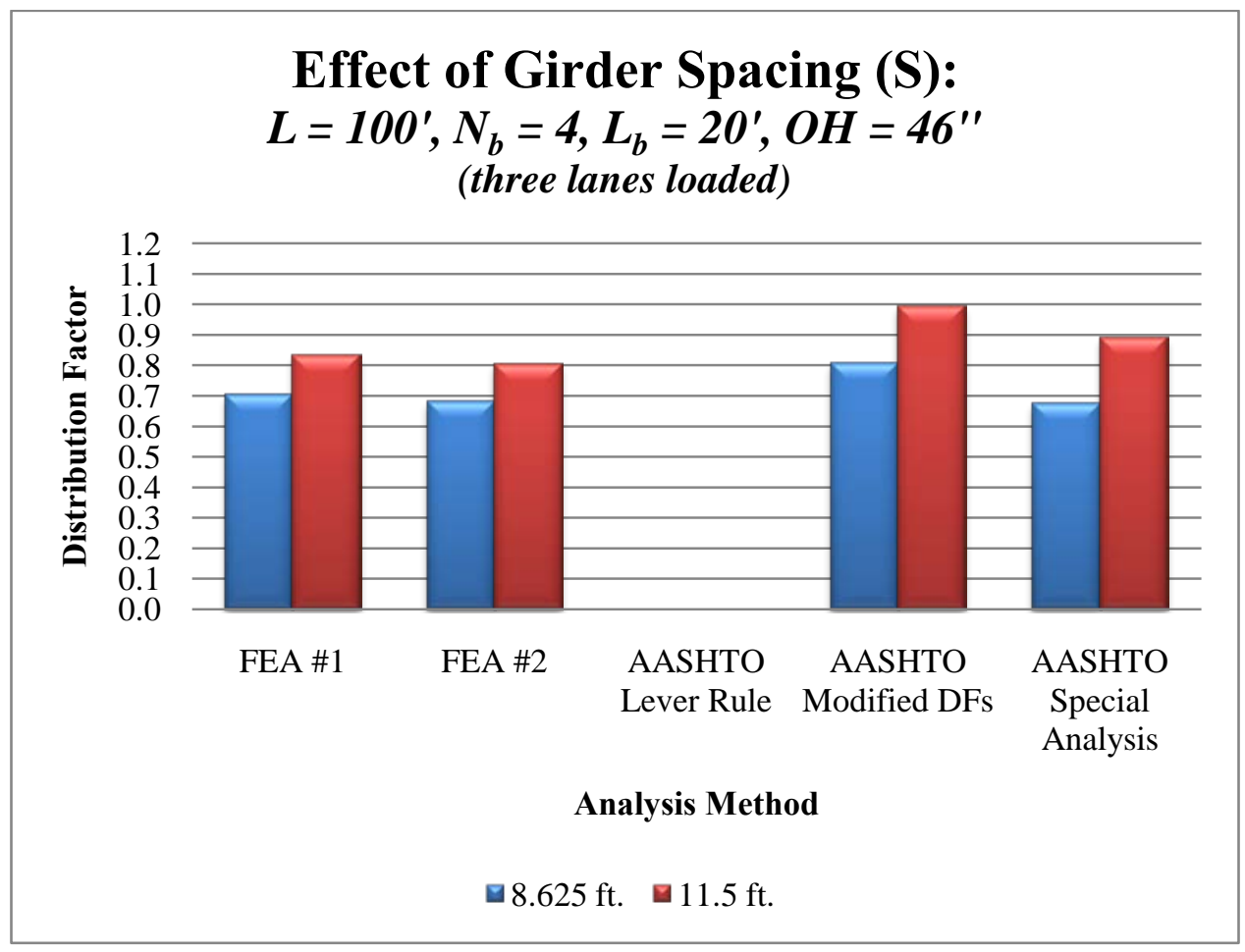

(c)

Figure 6.3: Comparison of the Effect of Girder Spacing with a: one lane loaded, b: two lanes loaded, and c: three lanes loaded 


\subsubsection{Influence of the Effect of the Number of Beams}

Figure 6.4 shows the comparison of the two different cross-section configurations used in Parametric Variation \#1 on the example bridge described in Section 3.3.1 and its counterpart bridge in the matrix (with 5 beams).

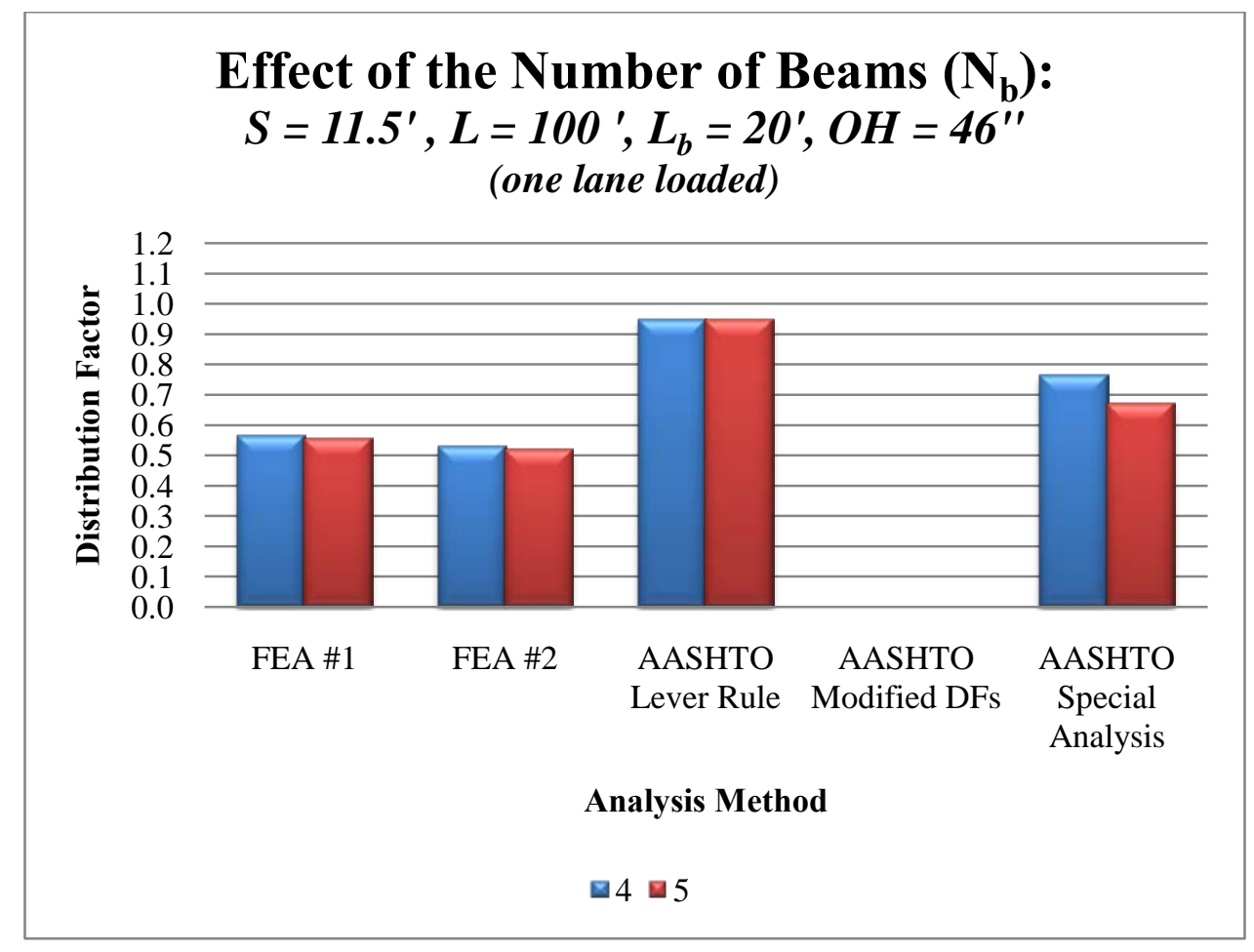

(a) 


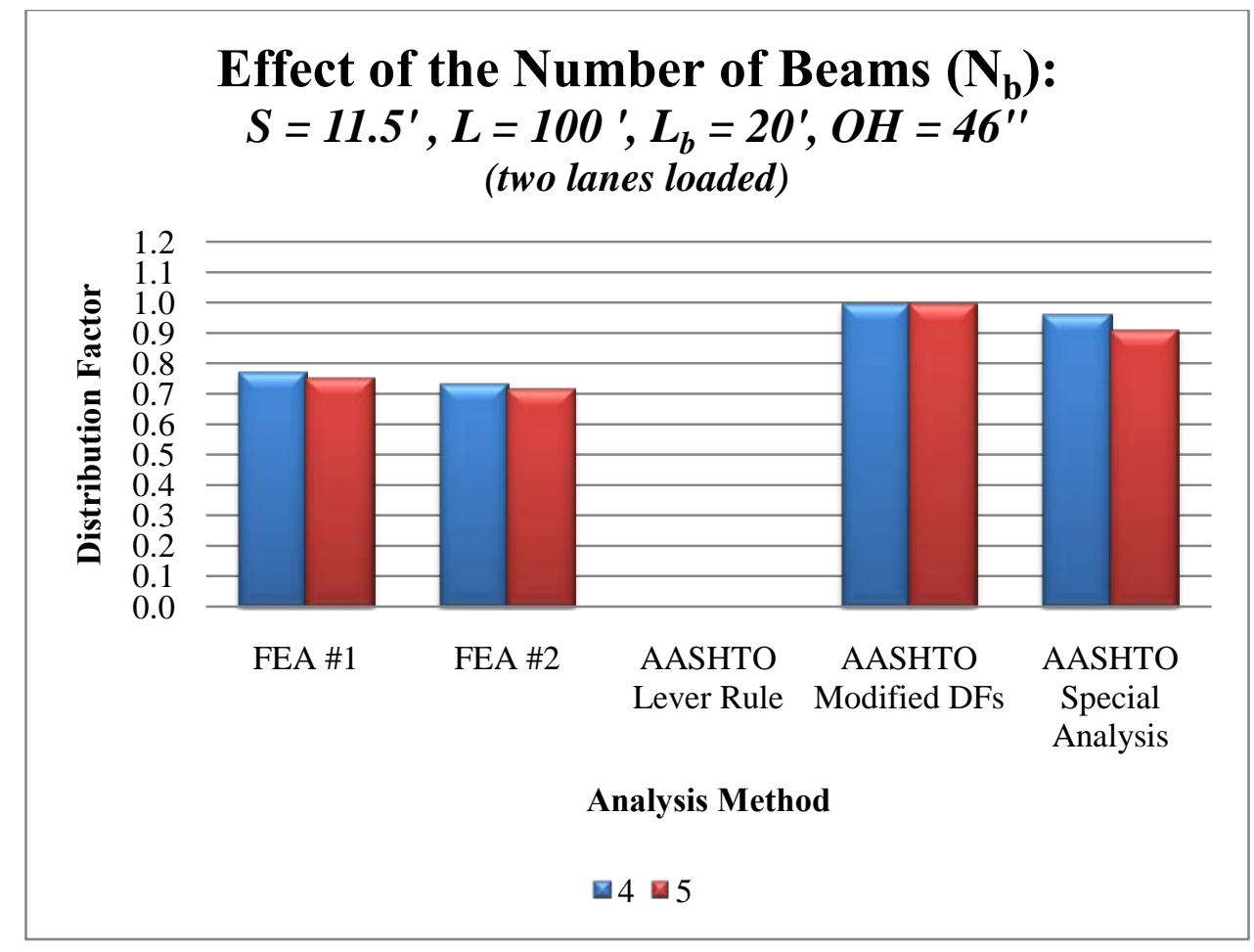

(b)

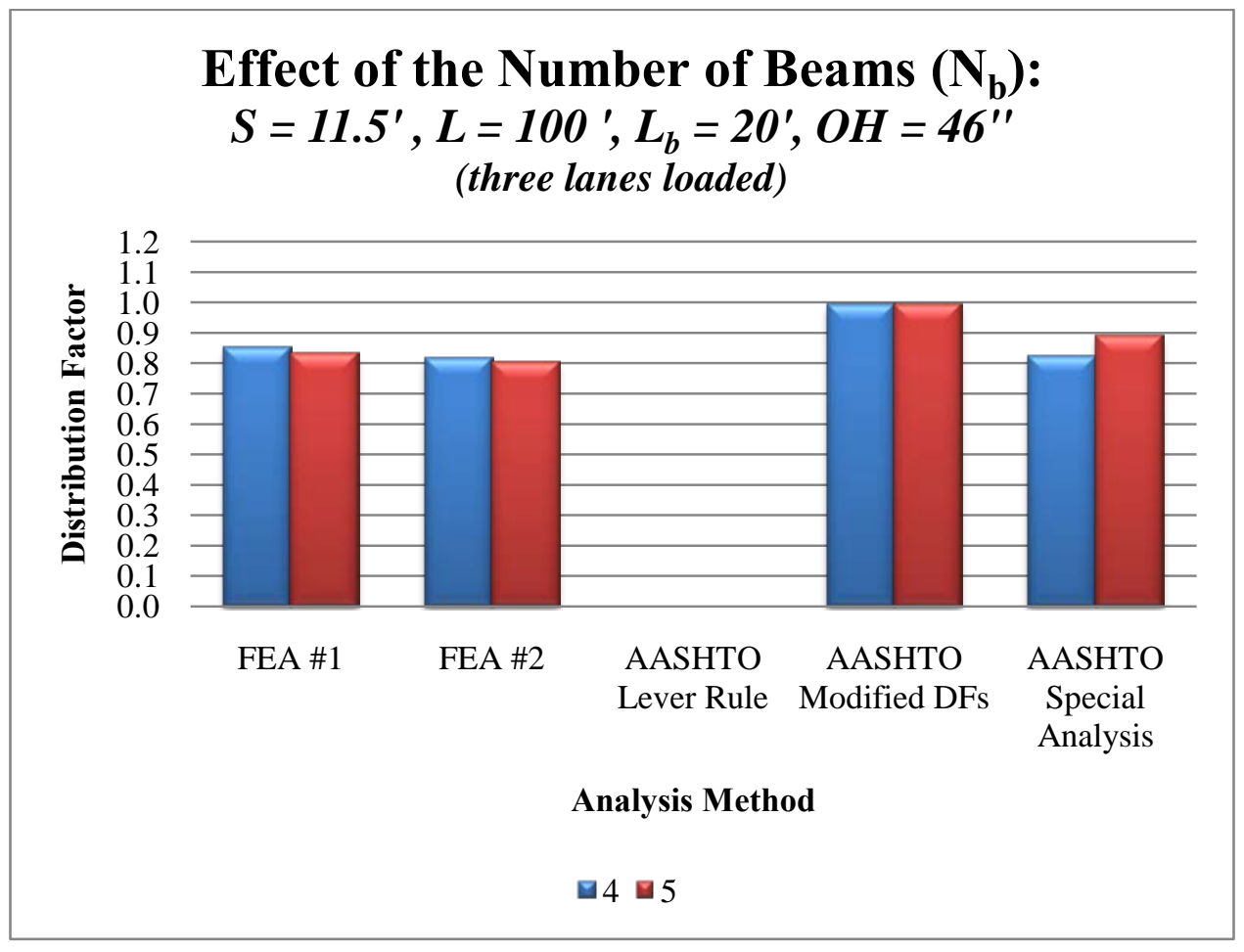

(c)

Figure 6.4: Comparison of the Effect of the Number of Beams with a: one lane loaded, b: two lanes loaded, and c: three lanes loaded 
As previously stated in Section 5.3.2, the evaluation of the number of beams in the sensitivity study was somewhat difficult to make since another parameter of interest (the girder spacing) was varied as well when the number of beams was changed. This difficulty was handled with Parametric Variation \#1.

As can be seen from Figure 6.4, the number of beams seems to have a somewhat minor effect on exterior girder live load distribution. For Parametric Variation \#1 as a whole, distribution factors for bridges with 4 beams are about $4 \%$ higher than those with 5 beams. This is based on averaging the FEA \#1 and FEA \#2 for one-lane-loaded scenarios. For two-laneloaded scenarios, distribution factors for bridges with 4 beams are also about $5 \%$ higher than those with 5 beams; for three-lane loaded scenarios, however, the effect is negligible. However, these averaged percentages for the effect of the number of beams should not be exclusively considered when determining the impact of the number of beams; for some of the bridges in Parametric Variation \#1, the effect of number of beams reaches as high as $10 \%$. Therefore, to fully encapsulate exterior girder live load distribution, the effect of the number of beams was considered when developing Parametric Variation \#2 (described in Section 6.3).

\subsection{PARAMETRIC VARIATION \#2}

Using the results of the sensitivity study discussed in Chapter 5 and Parametric Variation \#1 discussed in Section 6.2, the parameters found to be most influential were determined, and final parametric matrix (denoted as Parametric Variation \#2 hereafter) was developed. Discussed in this section is the development of this matrix as well as the results from its analysis. It should be noted that since this matrix was developed to fully encapsulate the effect of critical parameters, these results will be used to develop empirical relationships for exterior girder live load distribution. 


\subsubsection{Determination of Key Parameters}

After analyzing the results of the sensitivity discussed in Chapter 5 and Parametric Variation \#1 discussed in Section 6.2, the following parameters were determined to be the most crucial to exterior girder live load distribution.

- Girder spacing $(S)$

- Span length $(L)$

- Width of Overhang $(\mathrm{OH})$

- Number of Beams $\left(N_{b}\right)$

To fully encapsulate the effect of these parameters, 96 bridges were developed in the following manner:

- Four different girder spacings were employed.

$$
\begin{array}{ll}
\text { ○ } & S=7.1875 \text { feet } \\
\text { o } & S=8.625 \text { feet } \\
\text { o } & S=10.0625 \text { feet } \\
\text { o } & S=11.5 \text { feet }
\end{array}
$$

- For each of these girder spacings, 3 different overhang widths were used. It should be noted that, according to the Steel Bridge Design Handbook, Chapter 8: Stringer Bridges (National Steel Bridge Alliance), refined analyses of steel girder bridges have shown that forces in the exterior and interior girders will be reasonably balanced when the deck overhang is approximately $30 \%$ to $32 \%$ of the girder spacing. Therefore, to fully encapsulate the effect of deck overhang while maintaining reasonable values, the following overhangs widths were used.
○ $O H=20 \% S$
○ $O H=25 \% S$
○ $O H=33 \% S$ 
- Four different span lengths were employed. As with the girder spacings used, these values basically split the difference of the two values used in the sensitivity study and Parametric Variation \#1.

$$
\begin{array}{ll}
\text { o } & L=100 \text { feet } \\
\text { o } & L=150 \text { feet } \\
\text { o } & L=200 \text { feet } \\
\text { o } & L=250 \text { feet }
\end{array}
$$

- Two different values for the number of beams, or $N_{b}$, were used.

$$
\begin{array}{ll}
\text { ○ } & N_{b}=4 \\
\text { ○ } & N_{b}=5
\end{array}
$$

The following parameters were found to have little effect on exterior girder live load distribution and were kept constant (a description as to why these parameters were kept constant is included as well).

- Girder stiffness.

o Section 6.2.2.1 discusses the effect of girder stiffness on exterior girder live load distribution. It was determined that, while the girders used for this comparison did prove to have some effect, not only was this effect very minor, but the difference between the stiffness values of the two girders was very large. Therefore, for each respective span length, an optimum girder was designed and used throughout.

- The presence of a barrier.

o Section 5.3.5 discusses the effect of barrier presence on exterior girder live load distribution. While barrier presence was shown to have an effect, it would be very uncommon to design and erect a steel slab-on-beam bridge without a concrete parapet. Therefore, all bridges in Parametric Variation \#2 were designed and modeled with a constant barrier. The barrier used for this matrix was the same one as the barrier used for the sensitivity study and Parametric Variation \#1, and is illustrated in Figure 5.1.

- Cross-frame stiffness.

o Section 5.3.6 discusses the effect of cross-frame stiffness on exterior girder live load distribution. Not only was cross-frame stiffness was 
shown to have a very little effect, but the difference between the stiffness values of the respective cross-frames was very large. Also, it would be very uncommon to design and erect a steel slab-on-beam bridge without an adequate cross-frame. Therefore, the same cross-frame designs were used throughout Parametric Variation \#2. These designs that were the same ones that were used in the sensitivity study and Parametric Variation \#1 were used for Parametric Variation \#2, and are illustrated in Figure 5.2 and Figure 5.3.

- Unbraced length.

o Section 5.3.7 discusses the effect of unbraced length on exterior girder live load distribution. As was discussed, the effect of unbraced length is negligible. Therefore, a constant unbraced length was used through Parametric Variation \#2. According to the Steel Bridge Design Handbook, Chapter 13: Design for Constructability (National Steel Bridge Alliance) reasonable cross-frame spacing is on the order of 20 to 30 feet. Therefore, the constant value used for unbraced length was 25 feet.

- Other parameters that were kept constant in the sensitivity study and Parametric Variation \#1 (discussed in Section 5.2.1) were also kept constant in Parametric Variation \#2. These parameters included barrier type, slab thickness, and material properties.

As stated above, for each respective span length, an optimum girder was designed and used throughout. To ensure that results from the finite element modeling of Parametric Variation \#2 were reasonable, the bridges were designed according to current AASHTO LRFD Specifications (American Association of State Highway and Transportation Officials, 2010) and checked with MDX Software, Version 6.5 (MDX Software, Inc., 2009). To ensure that the bridge designs would encompass the whole of the sensitivity matrix, the bridges for each span length were designed for the worst case scenarios, i.e. longest overhang and least number of girders. A brief summary of the girder designs are presented in Figure 6.5, Figure 6.6, and Table 6.1. 


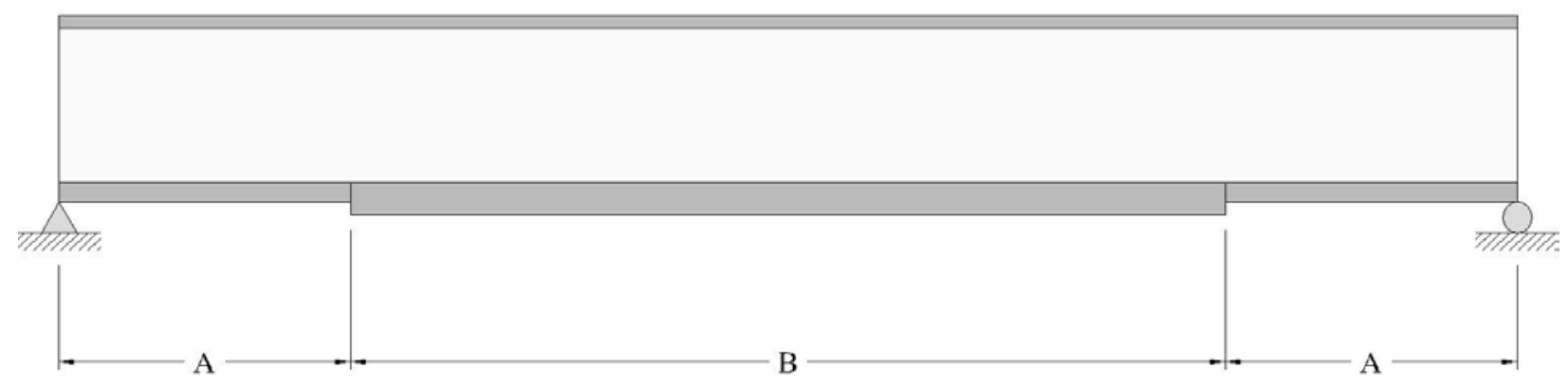

Figure 6.5: 100-Foot Girder Elevation for Parametric Variation \#2

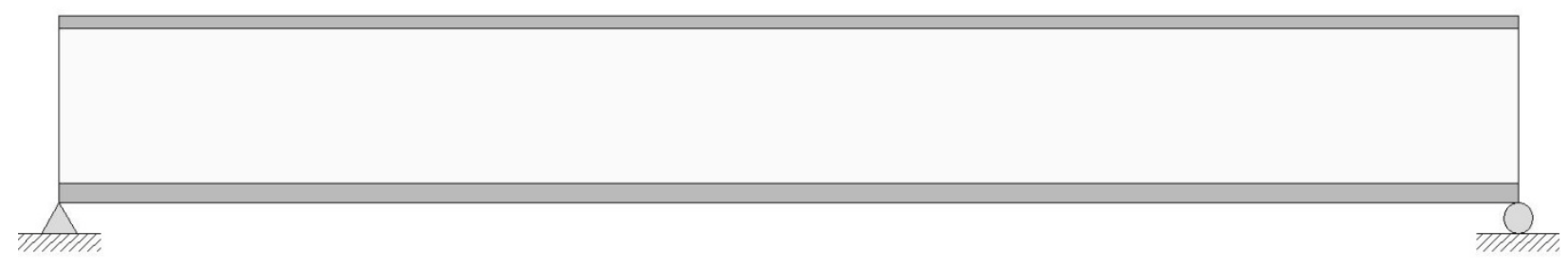

Figure 6.6: Remaining Girder Elevations for Parametric Variation \#2

\begin{tabular}{|c|c|c|c|c|c|c|c|c|c|c|c|c|}
\hline \multirow{2}{*}{ L (ft) } & \multicolumn{2}{|c|}{ Top Flange } & \multicolumn{3}{|c|}{ Bottom Flange (A) } & \multicolumn{3}{|c|}{ Bottom Flange (B) } & \multicolumn{2}{|c|}{ Web } & \multicolumn{2}{|c|}{ Stiffeners } \\
\hline & $b_{t f}$ (in) & $t_{t f}$ (in) & $b_{b f}$ (in) & $t_{b f}$ (in) & $L_{b f}(f t)$ & $b_{b f}(\mathrm{in})$ & $t_{b f}($ in $)$ & $L_{b f}(f t)$ & $d_{w}($ in) & $t_{w}($ in $)$ & $t_{\text {brg }}$ (in) & $t_{\text {int (in) }}$ \\
\hline 100 & 14 & 0.9375 & 16 & 0.8125 & 20 & 16 & 1.625 & 60 & 54 & 0.5625 & 0.75 & 0.5 \\
\hline 150 & 16 & 1 & 18 & 1.625 & 150 & -- & -- & -- & 72 & 0.75 & 0.875 & 0.5 \\
\hline 200 & 18 & 1.375 & 24 & 2 & 200 & -- & -- & -- & 93 & 0.875 & 1 & 0.5 \\
\hline 250 & 20 & 1.375 & 28 & 2 & 250 & -- & -- & -- & 120 & 1 & 1 & 0.5 \\
\hline
\end{tabular}

Table 6.1: Parametric Variation \#2 Girder Dimensions

\subsubsection{Discussion of Parametric Variation \#2 Results}

Since the tabulated results of Parametric Variation \#2 are too large to be included in this chapter, Appendix C has been provided for the reader's convenience. This appendix summarizes the effect of each varied parameter in tabular form.

Discussed in this section will be the general trends of the results of Parametric Variation \#2, As with the discussions in Section 5.3 and Section 6.2, in the graphs and discussion presented in this section, "FEA \#1" will refer to the Stallings/Yoo method discussed in Section 4.3.1.1 and “FEA \#2" will refer to the Tarhini/Frederick method discussed in Section 4.3.1.2. All AASHTO methods presented will already have multiple presence factors appropriately applied. 


\subsubsection{Influence of the Effect of Girder Spacing}

Figure 6.7 shows the comparison of the different girder spacings used in Parametric Variation \#2. In this figure, each curve represents the number of lanes loaded, and each data point represents the average value obtained for all the bridges in matrix that exhibit a given girder spacing. This figure is also split into two components, each component representing a different analytical computation technique (FEA \#1 and FEA \#2, respectively).

As expected, the girder spacing has the same effect here as it did for the sensitivity matrix in Chapter 5 and Parametric Variation \#1 in Section 6.2. This influence of girder spacing has also been found by numerous other researchers (see Section 2.5.1).

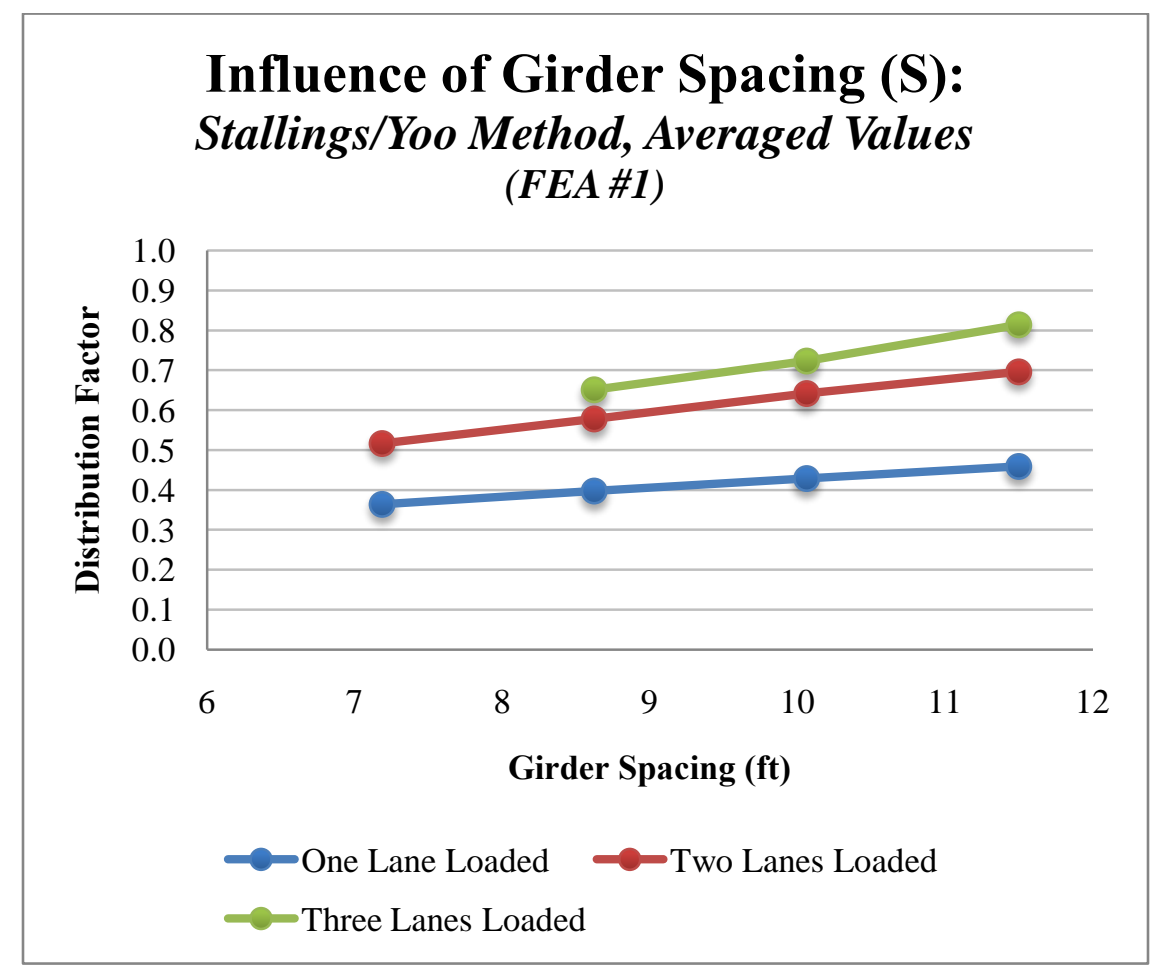

(a) 


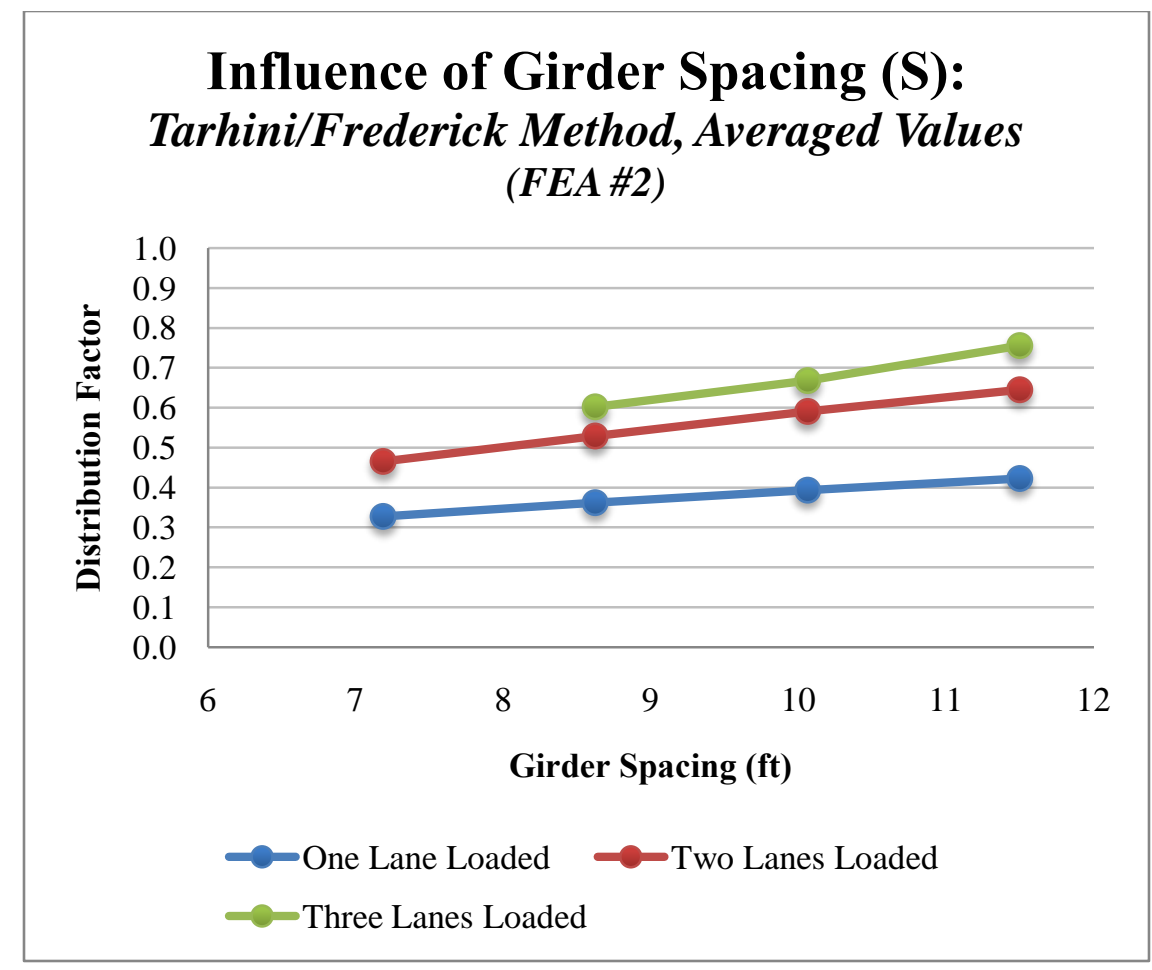

(b)

Figure 6.7: Comparison of the Influence of Girder Spacing with a: FEA \#1, b: FEA \#2

\subsubsection{Influence of the Effect of Span Length}

Figure 6.8 shows the comparison of the different span lengths used in Parametric Variation \#2. In this figure, similar to Figure 6.7, each curve represents the number of lanes loaded, and each data point represents the average value obtained for all the bridges in matrix that exhibit a given span length. This figure is also split into two components, each component representing a different analytical computation technique (FEA \#1 and FEA \#2, respectively).

As expected, the span length has the same effect here as it did for the sensitivity matrix in Chapter 5 and Parametric Variation \#1 in Section 6.2. Another interesting observation about the influence of span length is its obvious nonlinear effect. This nonlinear relationship has also been found by Tarhini and Frederick (1992), and, using the method presented in their research (FEA \#2), this nonlinear relationship is quite clear. 


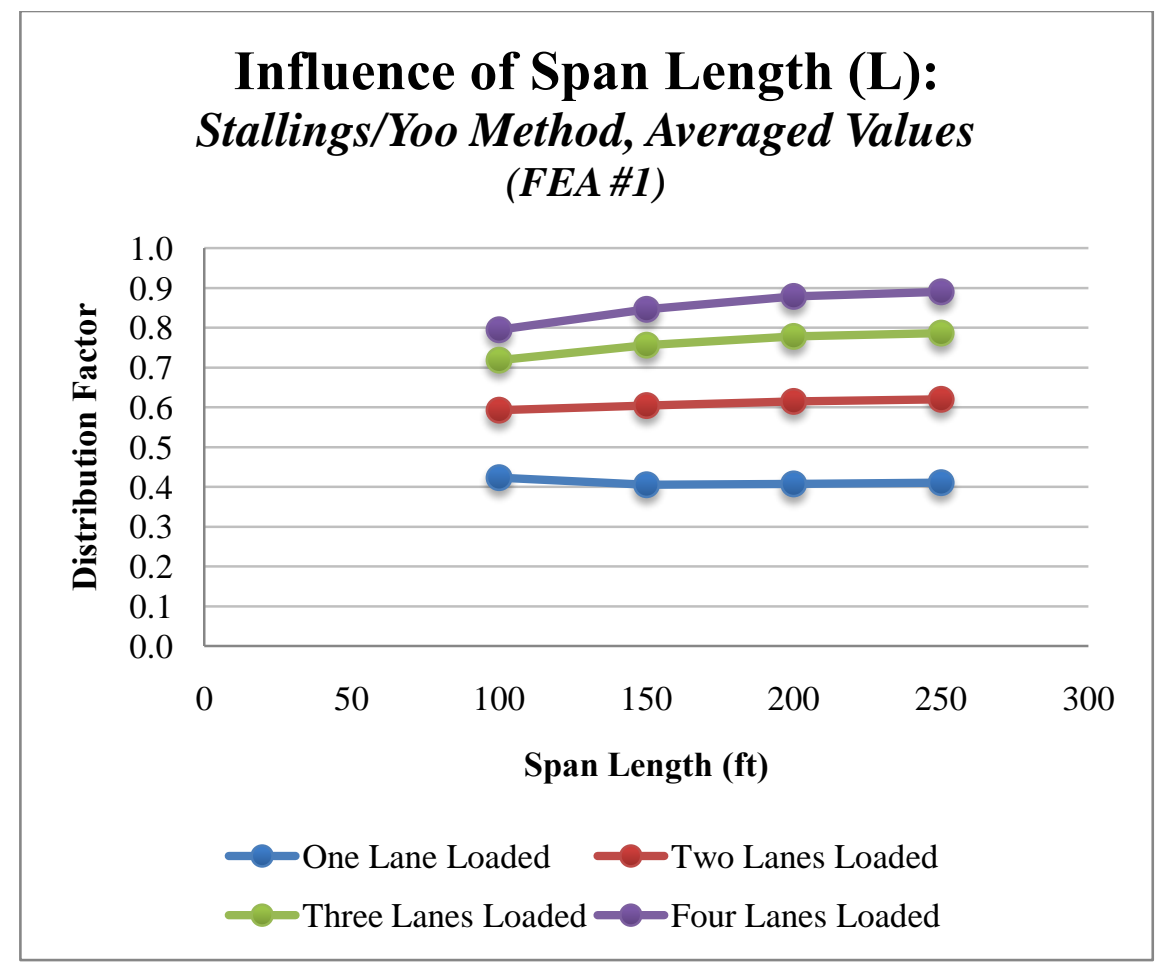

(a)

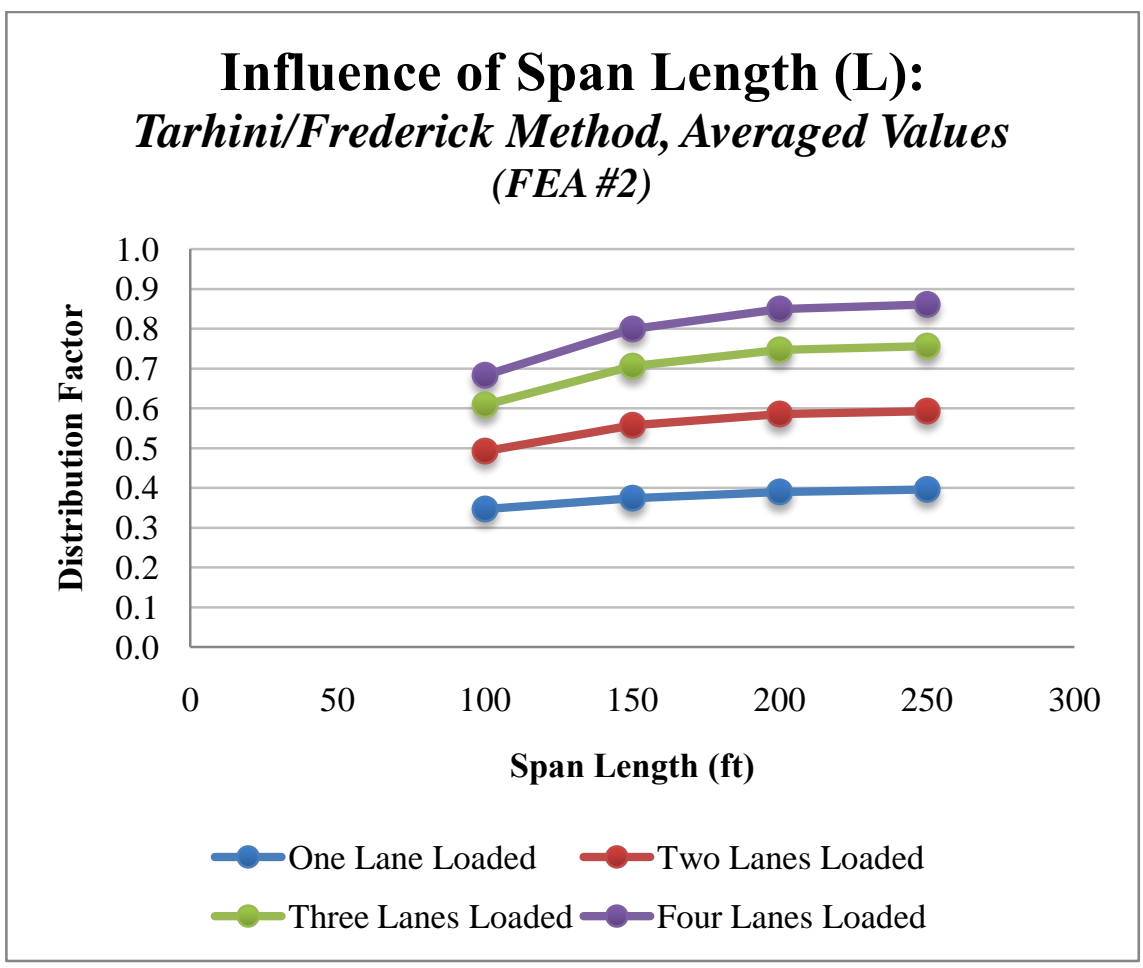

(b)

Figure 6.8: Comparison of the Influence of Span Length with a: FEA \#1, b: FEA \#2 


\subsubsection{Influence of the Effect of Deck Overhang}

Figure 6.9 shows the comparison of the different deck overhangs used in Parametric Variation \#2. In this figure, each curve represents the number of lanes loaded, and each data point represents the average value obtained for all the bridges in matrix that exhibit a given deck overhang. This figure is also split into two components, each component representing a different analytical computation technique (FEA \#1 and FEA \#2, respectively).

As expected, the width of the deck overhang has the same effect as it did for the sensitivity matrix in Chapter 5 and Parametric Variation \#1 in Section 6.2. However, it should be noted that, for Parametric Variation \#2, instead of defining constant values for deck overhang widths, values were defined as percentages of girder spacing. Therefore, Figure 6.9 summarizes a total twelve different overhangs. Furthermore, as stated in Section 2.5.6, NCHRP 12-26 (Nutt, Schamber, \& Zokaie, 1988) found in their sensitivity study that the width of deck overhang had a linear effect on live load distribution to exterior girders, which is nearly the same conclusion that can be drawn from these results.

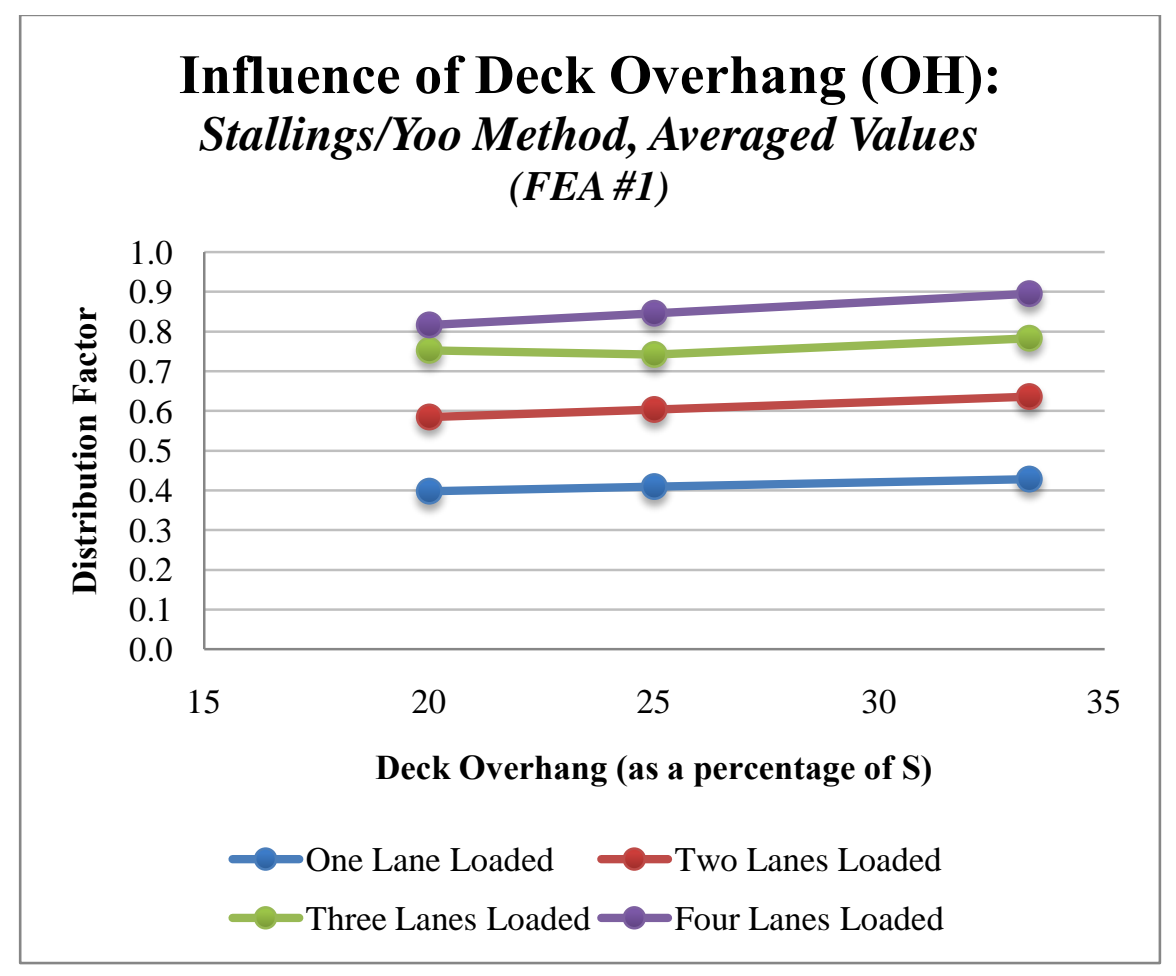

(a) 


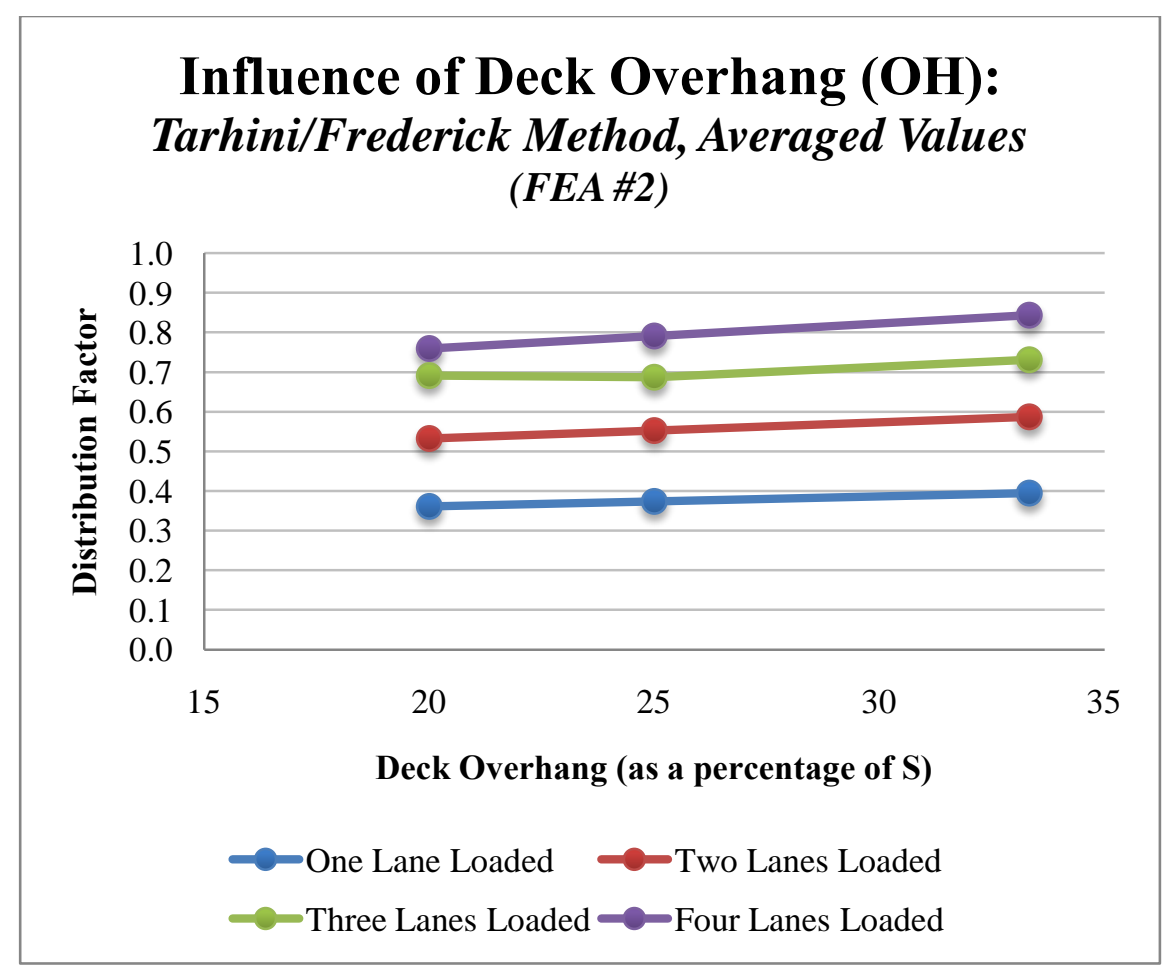

(b)

Figure 6.9: Comparison of the Influence of Deck Overhang with a: FEA \#1, b: FEA \#2

\subsubsection{Influence of the Effect of the Number of Beams}

Figure 6.10 shows the comparison of the two different beam configurations (or the number of beams used) used in Parametric Variation \#2. In this figure, each curve represents the number of lanes loaded, and each data point represents the average value obtained for all the bridges in matrix that exhibit a given beam configurations. This figure is also split into two components, each component representing a different analytical computation technique (FEA \#1 and FEA \#2, respectively).

As expected, the number of beams has the same effect as it did for the sensitivity matrix in Chapter 5 and Parametric Variation \#1 in Section 6.2. Also, it should be noted that, since this figure displays trends for the entirety of Parametric Variation \#2, it is more apparent here that the number of beams has a considerable impact on exterior girder live load distribution than it did in Section 6.2.2.4 as only percent differences were reported. 


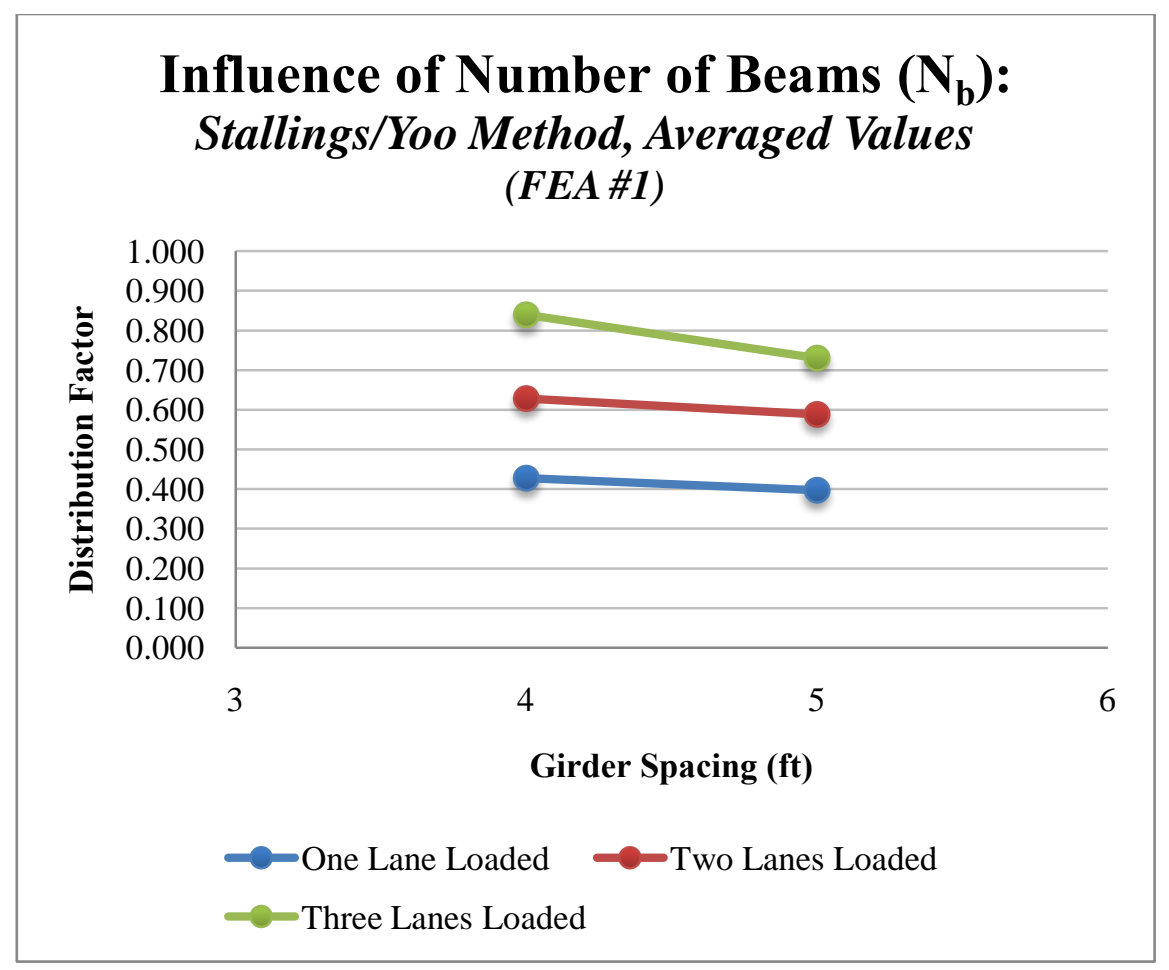

(a)

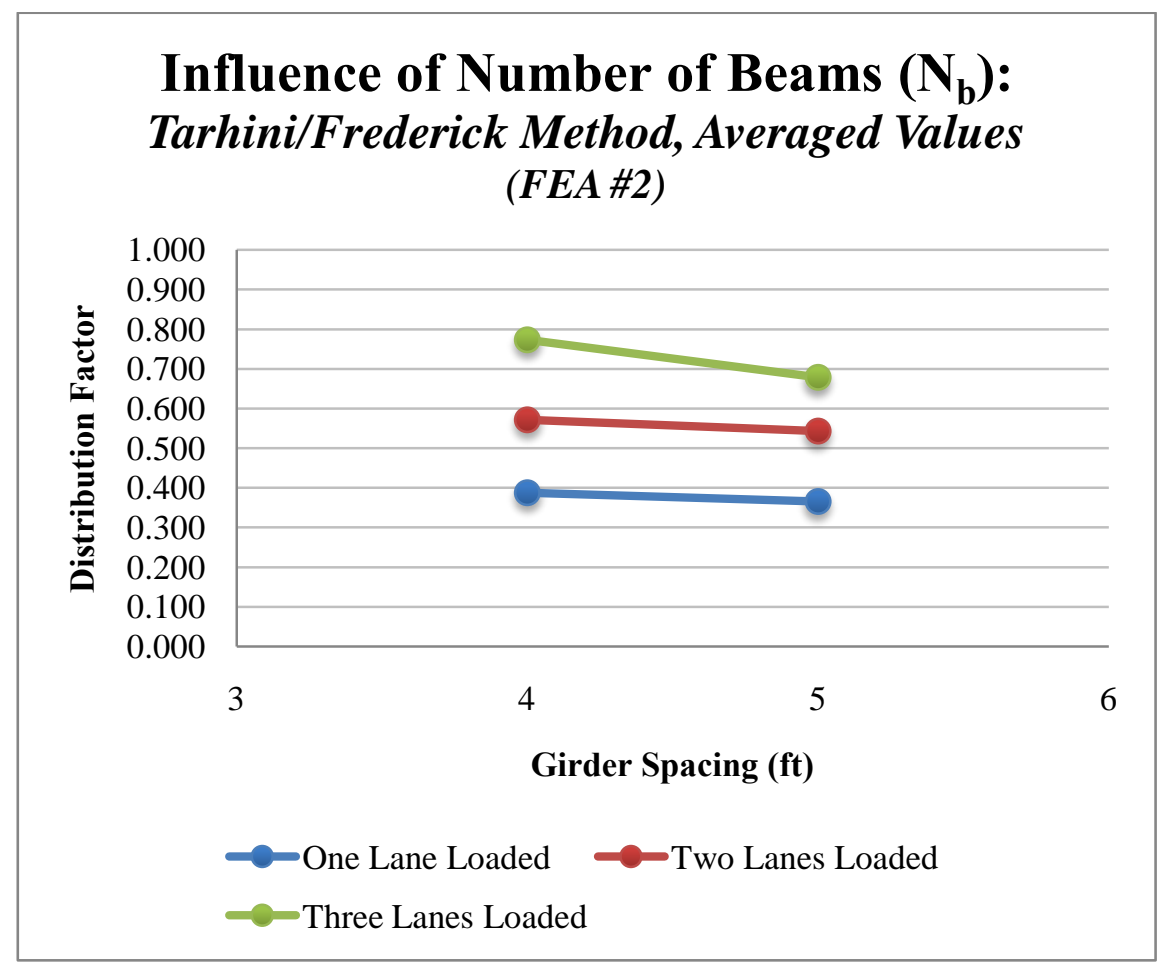

(b)

Figure 6.10: Comparison of the Influence of Number of Beams with a: FEA \#1, b: FEA \#2 


\subsection{SUMMARY}

The preceding chapter describes two matrices of bridges analyzed with a commercial finite element software package in order to study the effect of key parameters on the live load distribution to the exterior girders of steel I-girder bridges. These matrices were formulated based on the results of the sensitivity study in Chapter 5. The main targets of these parametric studies were:

- To isolate and fully encapsulate various parameters to determine their effect on exterior girder live load distribution.

o This was accomplished with Parametric Variation \#1.

- To develop a data set that captures the effect of key parameters on exterior girder live load distribution in order to develop empirical relationships for distribution factors.

o This was accomplished with Parametric Variation \#2.

Using the results from Parametric Variation \#2, empirical equations can be derived to predict exterior girder live load distribution factors for steel I-girders. The methodologies behind these derivations, along with the proposed equations, are presented in Chapter 7. 


\section{Chapter 7: DeVElopMent OF MOdified EXTERIOR Girder DISTRIBUTION FACTORS}

\subsection{INTRODUCTION}

The following chapter describes the methodologies used in developing empirical equations for exterior girder live load distribution factors for steel I-girder bridges. Specifically, a commercial data correlation software package was used to relate the results obtained from Parametric Variation \#2 (described in Section 6.3) with its critical parameters. Finally, the proposed equations are presented, highlighting specifically the degree of correlation with the data from Parametric Variation \#2.

\subsection{Development of Proposed Equations}

DataFit 9.0.59, a commercial data correlation software package (Oakdale Engineering, 2008), was used to develop empirical equations for exterior girder live load distribution factors for steel I-girder bridges. DataFit is a data analysis tool that incorporates both multivariable capabilities as well as linear and nonlinear curve fitting. Discussed here will be the methodologies used in employing this software as well of the derivation of the proposed equations.

\subsubsection{Selection of Analytical Computation Technique}

As described in Section 4.3, two different analytical methods were used to calculate distribution factors for the sensitivity study in Chapter 5 and parametric studies described in Chapter 6. The Stallings/Yoo method calculates distribution factors for a typical girder by dividing its maximum bending strain by the sum of maximum bending strains in all of the girders. The Tarhini/Frederick method, on the other hand, calculates distribution factors for a 
typical girder by dividing its maximum bending strain by the maximum bending strain obtained from line-girder analysis.

Throughout the course of the sensitivity and parametric studies previously described, it was found that, while the two methods generated very similar values, the Stallings/Yoo method generally yielded more conservative results than the Tarhini/Frederick method. Therefore, for the derivation of empirical equations, data obtained from the Stallings/Yoo was employed.

\subsubsection{Methodology}

As previously stated, DataFit incorporates both multivariable capabilities as well as linear and nonlinear curve fitting to derive the most accurate equation for a random data set. However, for an equation with more than two independent variables, the curve fitting process becomes much more complex, and DataFit by default attempts to map any such equation as a linear function in $\mathbb{R}^{n}$ space, where " $n$ " is the number of independent variables. Therefore, in an attempt to capture the possible nonlinearity of some of the independent variables for Parametric Variation \#2, the following method, adopted from the dissertation of Bin Zou (2008), was employed.

- All of the independent variables were input as the natural logarithms of selected parameters into DataFit.

- The dependent variable was input into DataFit as the natural logarithm of the distribution factors obtained from Parametric Variation \#2.

o In addition, all of these distribution factors were multiplied by the appropriate multiple presence factor (described in Section 3.2.1) to generate equations adherent to AASHTO LRFD Specifications (American Association of State Highway and Transportation Officials, 2010).

- The properties of logarithms were used to transform the equation output from DataFit as the product of the independent variables.

Mathematically, this last step can be described as follows. For this derivation, " $g$ " represents the dependent variable (in this case, the distribution factor), " $\mathrm{c}_{\mathrm{i}}$ " represents the correlation constants that DataFit will generate, and " $\mathrm{x}_{\mathrm{i}}$ " represents the independent variables. 


$$
\begin{gathered}
\ln (g)=\ln \left(c_{0}\right)+c_{1} \ln \left(x_{1}\right)+c_{2} \ln \left(x_{2}\right)+c_{3} \ln \left(x_{3}\right)+c_{4} \ln \left(x_{4}\right) \\
\ln (g)=\ln \left(c_{0}\right)+\ln \left(x_{1}{ }^{c_{1}}\right)+\ln \left(x_{2}{ }^{c_{2}}\right)+\ln \left(x_{3}{ }^{c_{3}}\right)+\ln \left(x_{4}{ }^{c_{4}}\right) \\
\ln (g)=\ln \left[\left(c_{0}\right)\left(x_{1}{ }^{c_{1}}\right)\left(x_{1}{ }^{c_{1}}\right)\left(x_{2}{ }^{c_{2}}\right)\left(x_{3}{ }^{c_{3}}\right)\left(x_{4}{ }^{c_{4}}\right)\right] \\
g=c_{0}\left(x_{1}{ }^{c_{1}}\right)\left(x_{1}{ }^{c_{1}}\right)\left(x_{2}{ }^{c_{2}}\right)\left(x_{3}{ }^{c_{3}}\right)\left(x_{4}{ }^{c_{4}}\right)
\end{gathered}
$$

\subsubsection{Proposed Equations}

Using the parameters varied in Parametric Variation \#2 (girder spacing, span length, deck overhang, and the number of beams), multiple combinations of these parameters were tested to determine the combination of independent variables that produced the most accurate equations. The accuracy of these equations was measured by $\mathrm{R}^{2}$, which is known as the coefficient of multiple determination. $\mathrm{R}^{2}$ measures the proportion of variation in the dependent variable that is explained by the proposed equation. For example, if $\mathrm{R}^{2}=0.95$, then $95 \%$ of the variation in the dependent variable is explained by the proposed equation. A value of $\mathrm{R}^{2}=1.0$ means that the curve passes through every independent data point whereas a value of $\mathrm{R}^{2}=0.0$ means that the proposed equation does not describe the data any better than a horizontal line passing through the average of the data points.

Therefore, after performing tests of multiple combinations of these key parameters, the following equations are proposed for one-lane-loaded scenarios and multiple-lanes-loaded scenarios.

$$
\begin{aligned}
& g=0.382(S)^{0.464}(S / L)^{-0.115}(O H / L)^{0.145}\left(N_{b}\right)^{-0.328} \\
& g=0.199(S)^{0.710}(S / L)^{-0.222}(O H / L)^{0.164}\left(N_{b}\right)^{-0.272}
\end{aligned}
$$

where: $g=$ distribution factor

$S=$ girder spacing (in feet)

$L=$ span length (in feet)

$\mathrm{OH}=$ deck overhang (in feet)

$N_{b}=$ number of beams 
These combinations of independent proved to exhibit good correlation between the key parameters identified for Parametric Variation \#2 and the resulting distribution factors. For Equation $7-1$, the resulting $\mathrm{R}^{2}$ value was 0.970 ; for Equation $7-2$, the resulting $\mathrm{R}^{2}$ value was 0.990. These $\mathrm{R}^{2}$ indicate that these equations are fairly accurate in determining exterior girder live load distribution.

It should be noted that, for virtually every bridge in Parametric Variation \#2, once the appropriate multiple presence factors were applied, multiple-lane-loaded scenarios yielded the largest distribution factors. Therefore, Equation 7-2 was derived using the maximum multiplelane-loaded distribution factor from each bridge.

Furthermore, when analyzing steel I-girder bridges, it is necessary to accurately determine the amount of live load distribution of one design truck. This is mainly because it is this live load that is checked against the fatigue limit state capacity of various details (American Association of State Highway and Transportation Officials, 2010). Therefore, Equation 7-1 was also derived to assist bridge engineers in accurately evaluating one-lane-loaded scenarios.

\subsection{Comparison of Proposed Equations}

Since the tabulated comparisons of these proposed equations are somewhat large, Appendix D has been provided for the reader's convenience. This appendix summarizes the comparison of each equation against the results obtained from Parametric Variation \#2. 


\subsection{SUMMARY}

The preceding chapter described the methodologies used in employing a commercial data correlation software package to develop empirical equations for exterior girder live load distribution factors. Correlation coefficients (or $\mathrm{R}^{2}$ values) demonstrate that the equations proposed in this chapter correlate well with the results of Parametric Variation \#2.

It should be noted, however, that these equations should only be applied within the ranges and parameters for Parametric Variation \#2 defined in Section 6.3.1. For these equations to be applied to a wider range of bridges, they should be tested against refined analyses (such as the techniques presented in Section 4.2) of said bridges to assess their validity. These and other suggestions for future work, along with a summary of this project, are presented in Chapter 8. 


\section{CHAPTER 8: SUMMARY AND CONCLUDING REMARKS}

\subsection{Project SUMmary}

The focus of this project was to develop more accurate expressions for live load distribution factors for exterior girders in steel I-girder bridges. As stated in Section 1.2, the objectives and scope of this project was as follows.

- A literature review focused on determining the effect of certain parameters on live load distribution was conducted.

- A highly accurate finite element modeling technique (later used to determine live load distribution factors) was assessed by comparing results from this technique with physical load test data from the 2002 testing of Missouri Bridge A6101.

- A sensitivity matrix was developed and analyzed using the aforementioned technique to determine the influence of certain parameters on exterior girder live load distribution.

- Key parameters that were identified that have the most significant impact on exterior girder live load distribution were expanded to encapsulate a wider range of bridges. This expanded parametric matrix was then analyzed to determine exterior girder live load distribution factors.

- Finally, the results of the parametric study were used in conjunction with a commercial data correlation software tool (Oakdale Engineering, 2008) to develop empirical distribution factors for exterior girders. 


\subsection{RECOMMENDATIONS FOR FUTURE WORK}

The author recommends the following tasks for future work and/or expansions to this project.

- Expand the parametric matrices presented in this project to include more parameters to verify the proposed empirical equations.

- Use more physical load test data to verify the validity of these equations.

- Investigate different modeling techniques and compare with physical test data to assess the validity of different methods. Examples of these methods may be:

o Grillage analogies

o Eccentrically-stiffened plate models

o Models using higher-order elements

- Investigate other parameters to determine their effect on exterior girder live load distribution. These parameters may include:

o Skew

o Different barrier types

o Slab thickness

o The presence of sidewalks

o Continuity / support conditions

- Conduct a sensitivity study to determine parameters affecting the distribution of live load shear to exterior girders. Then, develop a parametric matrix to assess the effect of these parameters and derive similar equations exterior girder live load shear distribution factors in steel slab-on-beam bridges. 


\section{REFERENCES}

American Association of State Highway and Transportation Officials. (2010). AASHTO LRFD Bridge Design Specifications, Fifth Edition. Washington, DC: AASHTO.

American Association of State Highway and Transportation Officials. (1996). AASHTO Standard Specifications for Highway Bridges, Sixteenth Edition. Washington, DC: AASHTO.

American Association of State Highway Officials. (1931). AASHO Standard Specifications for Highway Bridges, First Edition. Washington, DC: 1931.

American Iron and Steel Institute. (1998). Short Span Steel Bridges: Plans and Software. Washington, DC: AISI Publicatons No. TSC-98A.

Arockiasamy, M., Amer, A., \& Bell, N. B. (1997). Load Distribution on Highway Bridges Based on Field Test Data: Phase II. Boca Raton, FL: Florida Department of Transportation.

Austroads. (1996). Australian Bridge Design Code. Sydney: Australasian Railway Association.

Bakht, B., \& Jaeger, L. G. (1990). Bridge Evaluation for Multipresence of Vehicles. ASCE Journal of Structural Engineering , 603-618.

Bakht, B., \& Moses, F. (1988). Lateral Distribution Factors for Highway Bridges. ASCE Journal of Structural Engineering , 1785-1803.

Barr, P. J., Eberhard, M. O., \& Stanton, J. F. (2001). Live-Load Distribution Factors in Prestressed Concrete Girder Bridges. ASCE Journal of Structural Engineering , 298-306.

Cross, B., Vaughn, B., Panahshahi, N., Petermeier, D., Siow, Y. S., \& Domagalski, T. (2009). Analytical and Experimental Investigation of Bridge Girder Shear Distribution Factors. ASCE Journal of Bridge Engineering , 154-163.

Dassault Systèmes. (2009). Abaqus/CAE Users Manual (Version 6.9). Providence, RI: Dassault Systèmes Simulia Corp.

Davis, J. M. (2003). Serviceability Field Testing of Hybrid HPS Bridge A6101. Columbia, MO: University of Missouri - Columbia.

Eom, J., \& Nowak, A. S. (2001). Live Load Distribution for Steel Girder Bridges. ASCE Journal of Bridge Engineering , 489-497.

Fu, C. C., Elhelbawey, M., Sahin, M. A., \& Schelling, D. R. (1996). Lateral Distribution Factor from Bridge Field Testing. ASCE Journal of Structural Engineering , 1106-1109. 
Hays, C. O., Sessions, L. M., \& Berry, A. J. (1986). Further Studies on Lateral Load Distribution Using a Finite Element Method. Transporation Research Record 1072 , 6-14.

Khaleel, M. A., \& Itani, R. Y. (1990). Live-Load Moments for Continuous Skew Bridges. ASCE Journal of Structural Engineering , 2361-2373.

Kim, S., \& Nowak, A. S. (1997). Load Distribution and Impact Factors for I-Girders. ASCE Journal of Bridge Engineering , 97-104.

Mabsout, M. E., Tarhini, K. M., Frederick, G. R., \& Kesserwan, A. (1999). Effect of Multilanes on Wheel Load Distribution in Steel Girder Bridges. ASCE Journal of Bridge Engineering , 99-106.

Mabsout, M. E., Tarhini, K. M., Frederick, G. R., \& Kobrosly, M. (1997). Influence of Sidewalks and Railings on Wheel Load Distribution in Steel Girder Bridges. ASCE Journal of Bridge Engineering , 88-96.

Mabsout, M. E., Tarhini, K. M., Frederick, G. R., \& Tayar, C. (1997). Finite-Element Analysis of Steel Girder Bridges. ASCE Journal of Bridge Engineering , 83-87.

McCormac, J. C. (2007). Structural Analysis: Using Classical and Matrix Methods (Fourth Edition). Hoboken, NJ: John Wiley \& Sons, Inc.

MDX Software, Inc. (2009). MDX Version 6.5 Users Manual. MDX Curved \& Straight Steel Bridge Design \& Rating Software: MDX Software, Inc.

Ministry of Transportation. (1991). Ontario Highway Bridge Design Code, Quality and Standards Division. Toronto: Quality and Standards Division.

National Steel Bridge Alliance. Steel Bridge Design Handbook, Chapter 13: Design for Constructability. Chicago, IL: National Steel Bridge Alliance.

National Steel Bridge Alliance. Steel Bridge Design Handbook, Chapter 8: Stringer Bridges. Chicago, IL: National Steel Bridge Alliance.

Newmark, N. M. (1938). A Distribution Procedure for the Analysis of Slabs Continuous over Flexible Girders. University of Illinois, Engineering Experiment Station Bullettin No. 304 , 7-118.

Newmark, N. M. (1949). Design of I-Beam Bridges. Transportation ASC, Vol. 114 , 997-1022.

Newmark, N. M., \& Seiss, C. P. (1943). Design of Slab and Stringer Bridges. Public Roads, Vol. 23:7, 157-166. 
Newmark, N. M., \& Siess, C. P. (1942). Moments in I-beam Bridges. University of Illinois, Engineering Experiment Station Bulletin No. 336, Volume XXXIX , 1-148.

Newmark, N. M., Siess, C. P., \& Peckham, W. M. (1948). Studies of Slab and Beam Highway Bridges, Part 2: Tests of Simple-Span Skew I-Beam Bridges. University of Illinois, Engineering Experiment Station Bulletin No. 375 , 1-61.

Newmark, N. M., Siess, C. P., \& Penman, R. R. (1946). Studies of Slab and Beam Highway Bridges, Part 1: Tests of Simple-Span Right I-Beam Bridges. University of Illinois, Engineering Experiment Station Bulletin No. 363 , 1-130.

Nutt, R. V., Schamber, R. A., \& Zokaie, T. (1988). NCHRP 12-26: Distribution of Wheel Loads on Highway Bridges. Final Report for National Cooperative Highway Research Program.

Oakdale Engineering. (2008). DataFit 9.0.59. Oakdale, PA: Oakdale Engineering.

Sanders, W. W. (1984). NCHRP Synthesis of Highway Practice 111: Distribution of Wheel Loads on Highway Bridges. Washington DC: Transportation Research Board.

Shahawy, M., \& Huang, D. (2001). Analytical and Field Investigation of Lateral Load Distribution in Concrete Slab-On-Girder Bridges. ACI Structural Journal , 590-599.

Stallings, J. M., \& Yoo, C. H. (1993). Tests and Ratings of Short-Span Steel Bridges. ASCE Journal of Structural Engineering , 2150-2168.

Tarhini, K. M., \& Frederick, G. R. (1992). Wheel Load Distribution in I-Girder Highway Bridges. ASCE Journal of Structural Engineering , 118 (5), 1285-1294.

Walker, W. H. (1987). Lateral Load Distribution in Multi-girder Bridges. AISC Engineering Journal , 21-28.

Wu, H. (2003). Influence of Live-Load Deflections on Superstructure Performance of Slab on Steel Stringer Bridges. Morgantown, WV: West Virginia University.

Zokaie, T. (2000). AASHTO-LRFD Live Load Distribution Specifications. ASCE Journal of Bridge Engineering , 131-138.

Zou, B. (2008). Design Guidelines for FRP Honeycomb Sandwick Bridge Decks. Morgantown, WV: West Virginia University. 


\section{APPENDiX A: SEnSitivity MATRiX Results}

The following appendix lists in tabular form the distribution factors calculated from the finite element models of the sensitivity matrix discussed in Chapter 5. For the reader's convenience, this data has been organized such that each table is focused on the influence of a single parameter on exterior girder live load distribution. These tables are then further discretized based on the number of lanes loaded.

Also, AASHTO LRFD distribution factors have been calculated and presented along with the analytically computed distribution factors. It should be noted that, where these tables are discretized based on the number of lanes loaded as well as the investigated parameters, the reader will find that some of the columns in these tables have been left blank. This is due to the applicability of AASHTO distribution factors on respective loading scenarios. For example, according to the AASHTO Specifications, for steel slab-on-beam bridges, the Lever Rule is only to be applied to situations where one design lane is loaded. Therefore, in these tables, for situations with two or more design lanes loaded, the reader will find the columns associated with the Lever Rule blank.

In these tables, the following nomenclature is used.

- $\mathrm{S}=$ girder spacing (feet)

- $\mathrm{L}=$ span length (feet)

- $\mathrm{N}_{\mathrm{b}}=$ number of beams

- $\mathrm{L}_{\mathrm{b}}=$ unbraced length (feet)

- $\mathrm{OH}=$ overhang width (inches)

Also, references are made to the different types of girders used in the sensitivity matrix. For these tables, "G1" represents the girder that was designed and implemented for the bridges with a 100-foot span length whereas "G2" represents the girder that was designed and implemented for the 200-foot-span bridges. 


\begin{tabular}{|c|c|c|c|c|c|c|c|c|c|c|c|c|c|c|}
\hline \multicolumn{12}{|c|}{$\begin{array}{c}\text { Comparis on of the Effect of Girder Spacing }(\mathbf{S}) \text { and Number of Girders }\left(\mathbf{N}_{\mathbf{b}}\right) \\
\text { (bending moment, one lane loaded) }\end{array}$} & \multicolumn{3}{|c|}{$\begin{array}{c}\text { For } S=8.625^{\prime}, N_{b}=5 \\
\text { For } S=11.5^{\prime}, N_{b}=4\end{array}$} \\
\hline \multirow{2}{*}{\multicolumn{5}{|c|}{ Constant Parameters }} & \multicolumn{10}{|c|}{ Exterior Girder Dis tribution Factors (organized by method and varied parameters) } \\
\hline & & & & & \multicolumn{2}{|c|}{ Stallings/Yoo } & \multicolumn{2}{|c|}{ Tarhini/Fre de rick } & \multicolumn{2}{|c|}{ Lever Rule } & \multicolumn{2}{|c|}{ AASHTO Mod. } & \multicolumn{2}{|c|}{ Spe cial Analys is } \\
\hline Girder & $\mathbf{L}(\mathbf{f t})$ & $\mathbf{L}_{\mathbf{b}}(\mathbf{f t})$ & $\mathbf{O H}$ (in) & Iteration & $8.625^{\prime}$ & 11.5' & 8.625 & $11.5^{\prime}$ & $8.625^{\prime}$ & $11.5^{\prime}$ & $8.625^{\prime}$ & 11.5' & $8.625^{\prime}$ & 11.5' \\
\hline \multirow{4}{*}{ G1 } & \multirow{4}{*}{100} & \multirow{4}{*}{20} & \multirow{4}{*}{46} & CONTROL & 0.441 & 0.515 & 0.391 & 0.451 & 0.861 & 0.946 & & & 0.652 & 0.764 \\
\hline & & & & 2x Cross-Frames & 0.430 & 0.504 & 0.382 & 0.442 & 0.861 & 0.946 & & & 0.652 & 0.764 \\
\hline & & & & No Barrier & 0.470 & 0.543 & 0.471 & 0.542 & 0.861 & 0.946 & & & 0.652 & 0.764 \\
\hline & & & & No Cross-Frames & 0.466 & 0.540 & 0.412 & 0.472 & 0.861 & 0.946 & & & 0.652 & 0.764 \\
\hline \multirow{4}{*}{ G1 } & \multirow{4}{*}{100} & \multirow{4}{*}{20} & \multirow{4}{*}{69} & CONTROL & 0.495 & 0.568 & 0.438 & 0.496 & 1.128 & 1.146 & & & 0.706 & 0.824 \\
\hline & & & & 2x Cross-Frames & 0.477 & 0.550 & 0.424 & 0.483 & 1.128 & 1.146 & & & 0.706 & 0.824 \\
\hline & & & & No Barrier & 0.531 & 0.602 & 0.536 & 0.605 & 1.128 & 1.146 & & & 0.706 & 0.824 \\
\hline & & & & No Cross-Frames & 0.529 & 0.601 & 0.465 & 0.523 & 1.128 & 1.146 & & & 0.706 & 0.824 \\
\hline \multirow{4}{*}{ G1 } & \multirow{4}{*}{100} & \multirow{4}{*}{25} & \multirow{4}{*}{46} & CONTROL & 0.436 & 0.511 & 0.393 & 0.454 & 0.861 & 0.946 & & & 0.652 & 0.764 \\
\hline & & & & 2x Cross-Frames & 0.423 & 0.498 & 0.384 & 0.444 & 0.861 & 0.946 & & & 0.652 & 0.764 \\
\hline & & & & No Barrier & 0.464 & 0.538 & 0.473 & 0.544 & 0.861 & 0.946 & & & 0.652 & 0.764 \\
\hline & & & & No Cross-Frames & 0.463 & 0.536 & 0.413 & 0.474 & 0.861 & 0.946 & & & 0.652 & 0.764 \\
\hline \multirow{4}{*}{ G1 } & \multirow{4}{*}{100} & \multirow{4}{*}{25} & & CONTROL & 0.488 & 0.563 & 0.439 & 0.498 & 1.128 & 1.146 & & & 0.706 & 0.824 \\
\hline & & & 69 & 2x Cross-Frames & 0.466 & 0.542 & 0.424 & 0.484 & 1.128 & 1.146 & & & 0.706 & 0.824 \\
\hline & & & & No Barrier & 0.522 & 0.595 & 0.537 & 0.607 & 1.128 & 1.146 & & & 0.706 & 0.824 \\
\hline & & & & No Cross-Frames & 0.525 & 0.598 & 0.466 & 0.525 & 1.128 & 1.146 & & & 0.706 & 0.824 \\
\hline & & & & CONTROL & 0.413 & 0.486 & 0.401 & 0.468 & 0.861 & 0.946 & & & 0.652 & 0.764 \\
\hline G2 & 200 & 20 & 46 & 2x Cross-Frames & 0.402 & 0.477 & 0.393 & 0.460 & 0.861 & 0.946 & & & 0.652 & 0.764 \\
\hline & & & & No Barrier & 0.426 & 0.499 & 0.437 & 0.507 & 0.861 & 0.946 & & & 0.652 & 0.764 \\
\hline & & & & No Cross-Frames & 0.440 & 0.513 & 0.424 & 0.491 & 0.861 & 0.946 & & & 0.652 & 0.764 \\
\hline & & & & CONTROL & 0.453 & 0.525 & 0.445 & 0.509 & 1.128 & 1.146 & & & 0.706 & 0.824 \\
\hline G2 & 200 & 20 & 69 & 2x Cross-Frames & 0.434 & 0.510 & 0.431 & 0.497 & 1.128 & 1.146 & & & 0.706 & 0.824 \\
\hline & & & & No Barrier & 0.469 & 0.542 & 0.488 & 0.556 & 1.128 & 1.146 & & & 0.706 & 0.824 \\
\hline & & & & No Cross-Frames & 0.495 & 0.566 & 0.479 & 0.543 & 1.128 & 1.146 & & & 0.706 & 0.824 \\
\hline & & & & CONTROL & 0.414 & 0.487 & 0.402 & 0.469 & 0.861 & 0.946 & & & 0.652 & 0.764 \\
\hline G2 & 200 & 25 & 46 & 2x Cross-Frames & 0.403 & 0.477 & 0.394 & 0.461 & 0.861 & 0.946 & & & 0.652 & 0.764 \\
\hline$G 2$ & & 20 & 40 & No Barrier & 0.427 & 0.500 & 0.438 & 0.508 & 0.861 & 0.946 & & & 0.652 & 0.764 \\
\hline & & & & No Cross-Frames & 0.440 & 0.513 & 0.424 & 0.491 & 0.861 & 0.946 & & & 0.652 & 0.764 \\
\hline & & & & CONTROL & 0.454 & 0.526 & 0.447 & 0.511 & 1.128 & 1.146 & & & 0.706 & 0.824 \\
\hline G2 & 200 & 25 & 69 & 2x Cross-Frames & 0.435 & 0.510 & 0.433 & 0.498 & 1.128 & 1.146 & & & 0.706 & 0.824 \\
\hline & & 20 & 09 & No Barrier & 0.471 & 0.544 & 0.491 & 0.558 & 1.128 & 1.146 & & & 0.706 & 0.824 \\
\hline & & & & No Cross-Frames & 0.495 & 0.566 & 0.479 & 0.543 & 1.128 & 1.146 & & & 0.706 & 0.824 \\
\hline
\end{tabular}




\begin{tabular}{|c|c|c|c|c|c|c|c|c|c|c|c|c|c|c|}
\hline \multicolumn{12}{|c|}{$\begin{array}{l}\text { Comparis on of the Effect of Girder Spacing (S) and Number of Girde rs }\left(\mathbf{N}_{\mathbf{b}}\right) \\
\text { (bending moment, two lanes loaded) }\end{array}$} & \multicolumn{3}{|c|}{$\begin{array}{c}\text { For } S=8.625 \mathrm{ft}, N_{b}=5 \\
\text { For } S=11.5 \mathrm{ft}, N_{b}=4\end{array}$} \\
\hline \multirow{2}{*}{\multicolumn{5}{|c|}{ Constant Parameters }} & \multicolumn{10}{|c|}{ Exterior Girder D is tribution Factors (organized by method and varied parame te rs) } \\
\hline & & & & & \multicolumn{2}{|c|}{ Stallings/Yoo } & \multicolumn{2}{|c|}{ Tarhini/Frede rick } & \multicolumn{2}{|c|}{ Lever Rule } & \multicolumn{2}{|c|}{ AASHTO Mod. } & \multicolumn{2}{|c|}{ Special Analys is } \\
\hline Girder & L (ft) & $\mathbf{L}_{\mathbf{b}}(\mathbf{f t})$ & $\mathbf{O H}$ (in) & Ite ration & 8.625' & $11.5^{\prime}$ & $8.625^{\prime}$ & $11.5^{\prime}$ & $8.625^{\prime}$ & $11.5^{\prime}$ & $8.625^{\prime}$ & $11.5^{\prime}$ & $8.625^{\prime}$ & $11.5^{\prime}$ \\
\hline G1 & 100 & 20 & 46 & $\begin{array}{c}\text { CONTROL } \\
\text { 2x Cross-Frames } \\
\text { No Barrier } \\
\text { No Cross-Frames } \\
\end{array}$ & $\begin{array}{l}0.620 \\
0.625 \\
0.669 \\
0.630 \\
\end{array}$ & $\begin{array}{l}0.749 \\
0.754 \\
0.799 \\
0.760 \\
\end{array}$ & $\begin{array}{l}0.562 \\
0.565 \\
0.669 \\
0.572 \\
\end{array}$ & $\begin{array}{l}0.671 \\
0.673 \\
0.794 \\
0.682 \\
\end{array}$ & & & $\begin{array}{l}0.692 \\
0.692 \\
0.692 \\
0.692 \\
\end{array}$ & $\begin{array}{l}0.851 \\
0.851 \\
0.851 \\
0.851 \\
\end{array}$ & $\begin{array}{l}0.809 \\
0.809 \\
0.809 \\
0.809 \\
\end{array}$ & $\begin{array}{l}0.960 \\
0.960 \\
0.960 \\
0.960 \\
\end{array}$ \\
\hline G1 & 100 & 20 & 69 & $\begin{array}{c}\text { CONTROL } \\
\text { 2x Cross-Frames } \\
\text { No Barrier } \\
\text { No Cross-Frames } \\
\end{array}$ & $\begin{array}{l}0.708 \\
0.704 \\
0.769 \\
0.732 \\
\end{array}$ & $\begin{array}{l}0.843 \\
0.838 \\
0.903 \\
0.867 \\
\end{array}$ & $\begin{array}{l}0.645 \\
0.641 \\
0.775 \\
0.667 \\
\end{array}$ & $\begin{array}{l}0.759 \\
0.753 \\
0.904 \\
0.781 \\
\end{array}$ & & & $\begin{array}{l}0.831 \\
0.831 \\
0.831 \\
0.831 \\
\end{array}$ & $\begin{array}{l}1.022 \\
1.022 \\
1.022 \\
1.022 \\
\end{array}$ & $\begin{array}{l}0.898 \\
0.898 \\
0.898 \\
0.898 \\
\end{array}$ & $\begin{array}{l}1.060 \\
1.060 \\
1.060 \\
1.060 \\
\end{array}$ \\
\hline G1 & 100 & 25 & 46 & $\begin{array}{c}\text { CONTROL } \\
\text { 2x Cross-Frames } \\
\text { No Barrier } \\
\text { No Cross-Frames } \\
\end{array}$ & $\begin{array}{l}0.616 \\
0.625 \\
0.664 \\
0.624 \\
\end{array}$ & $\begin{array}{l}0.744 \\
0.752 \\
0.794 \\
0.753 \\
\end{array}$ & $\begin{array}{l}0.565 \\
0.570 \\
0.673 \\
0.575 \\
\end{array}$ & $\begin{array}{l}0.673 \\
0.677 \\
0.799 \\
0.685 \\
\end{array}$ & & & $\begin{array}{l}0.692 \\
0.692 \\
0.692 \\
0.692 \\
\end{array}$ & $\begin{array}{l}0.851 \\
0.851 \\
0.851 \\
0.851 \\
\end{array}$ & $\begin{array}{l}0.809 \\
0.809 \\
0.809 \\
0.809 \\
\end{array}$ & $\begin{array}{l}0.960 \\
0.960 \\
0.960 \\
0.960 \\
\end{array}$ \\
\hline G1 & 100 & 25 & 69 & $\begin{array}{c}\text { CONTROL } \\
\text { 2x Cross-Frames } \\
\text { No Barrier } \\
\text { No Cross-Frames } \\
\end{array}$ & $\begin{array}{l}0.703 \\
0.701 \\
0.762 \\
0.725 \\
\end{array}$ & $\begin{array}{l}0.838 \\
0.835 \\
0.896 \\
0.860 \\
\end{array}$ & $\begin{array}{l}0.649 \\
0.646 \\
0.778 \\
0.670 \\
\end{array}$ & $\begin{array}{l}0.763 \\
0.758 \\
0.908 \\
0.785 \\
\end{array}$ & & & $\begin{array}{l}0.831 \\
0.831 \\
0.831 \\
0.831 \\
\end{array}$ & $\begin{array}{l}1.022 \\
1.022 \\
1.022 \\
1.022 \\
\end{array}$ & $\begin{array}{l}0.898 \\
0.898 \\
0.898 \\
0.898 \\
\end{array}$ & $\begin{array}{l}1.060 \\
1.060 \\
1.060 \\
1.060 \\
\end{array}$ \\
\hline G2 & 200 & 20 & 46 & $\begin{array}{c}\text { CONTROL } \\
\text { 2x Cross-Frames } \\
\text { No Barrier } \\
\text { No Cross-Frames } \\
\end{array}$ & $\begin{array}{l}0.628 \\
0.634 \\
0.647 \\
0.629 \\
\end{array}$ & $\begin{array}{l}0.759 \\
0.766 \\
0.778 \\
0.758 \\
\end{array}$ & $\begin{array}{l}0.608 \\
0.612 \\
0.657 \\
0.610\end{array}$ & $\begin{array}{l}0.729 \\
0.734 \\
0.785 \\
0.731\end{array}$ & & & $\begin{array}{l}0.670 \\
0.670 \\
0.670 \\
0.670\end{array}$ & $\begin{array}{l}0.823 \\
0.823 \\
0.823 \\
0.823\end{array}$ & $\begin{array}{l}0.809 \\
0.809 \\
0.809 \\
0.809\end{array}$ & $\begin{array}{l}0.960 \\
0.960 \\
0.960 \\
0.960\end{array}$ \\
\hline G2 & 200 & 20 & 69 & $\begin{array}{c}\text { CONTROL } \\
\text { 2x Cross-Frames } \\
\text { No Barrier } \\
\text { No Cross-Frames } \\
\end{array}$ & $\begin{array}{l}0.698 \\
0.695 \\
0.722 \\
0.718 \\
\end{array}$ & $\begin{array}{l}0.834 \\
0.832 \\
0.857 \\
0.852 \\
\end{array}$ & $\begin{array}{l}0.685 \\
0.682 \\
0.743 \\
0.704 \\
\end{array}$ & $\begin{array}{l}0.809 \\
0.807 \\
0.874 \\
0.827 \\
\end{array}$ & & & $\begin{array}{l}0.804 \\
0.804 \\
0.804 \\
0.804 \\
\end{array}$ & $\begin{array}{l}0.988 \\
0.988 \\
0.988 \\
0.988 \\
\end{array}$ & $\begin{array}{l}0.898 \\
0.898 \\
0.898 \\
0.898 \\
\end{array}$ & $\begin{array}{l}1.060 \\
1.060 \\
1.060 \\
1.060 \\
\end{array}$ \\
\hline G2 & 200 & 25 & 46 & $\begin{array}{c}\text { CONTROL } \\
\text { 2x Cross-Frames } \\
\text { No Barrier } \\
\text { No Cross-Frames } \\
\end{array}$ & $\begin{array}{l}0.627 \\
0.634 \\
0.646 \\
0.629 \\
\end{array}$ & $\begin{array}{l}0.758 \\
0.765 \\
0.777 \\
0.758 \\
\end{array}$ & $\begin{array}{l}0.607 \\
0.612 \\
0.656 \\
0.611 \\
\end{array}$ & $\begin{array}{l}0.727 \\
0.733 \\
0.784 \\
0.731 \\
\end{array}$ & & & $\begin{array}{l}0.670 \\
0.670 \\
0.670 \\
0.670\end{array}$ & $\begin{array}{l}0.823 \\
0.823 \\
0.823 \\
0.823\end{array}$ & $\begin{array}{l}0.809 \\
0.809 \\
0.809 \\
0.809\end{array}$ & $\begin{array}{l}0.960 \\
0.960 \\
0.960 \\
0.960\end{array}$ \\
\hline G2 & 200 & 25 & 69 & $\begin{array}{c}\text { CONTROL } \\
\text { 2x Cross-Frames } \\
\text { No Barrier } \\
\text { No Cross-Frames }\end{array}$ & $\begin{array}{l}0.698 \\
0.695 \\
0.722 \\
0.718\end{array}$ & $\begin{array}{l}0.833 \\
0.832 \\
0.857 \\
0.852 \\
\end{array}$ & $\begin{array}{l}0.685 \\
0.682 \\
0.744 \\
0.704\end{array}$ & $\begin{array}{l}0.809 \\
0.807 \\
0.874 \\
0.828 \\
\end{array}$ & & & $\begin{array}{l}0.804 \\
0.804 \\
0.804 \\
0.804\end{array}$ & $\begin{array}{l}0.988 \\
0.988 \\
0.988 \\
0.988\end{array}$ & $\begin{array}{l}0.898 \\
0.898 \\
0.898 \\
0.898\end{array}$ & $\begin{array}{l}1.060 \\
1.060 \\
1.060 \\
1.060\end{array}$ \\
\hline
\end{tabular}




\begin{tabular}{|c|c|c|c|c|c|c|c|c|c|c|c|c|c|c|}
\hline \multirow{2}{*}{\multicolumn{12}{|c|}{$\begin{array}{l}\text { Comparis on of the Effect of Girder Spacing }(\mathbf{S}) \text { and Number of Girde rs }\left(\mathbf{N}_{\mathbf{b}}\right) \\
\text { (bending moment, three lanes loaded) }\end{array}$}} & \multirow{2}{*}{\multicolumn{3}{|c|}{$\begin{array}{c}\text { For } S=8.625 \mathrm{ft}, \mathrm{N}_{\mathrm{b}}=5 \\
\text { For } S=11.5 \mathrm{ft}, \mathrm{N}_{\mathrm{b}}=4\end{array}$}} \\
\hline & & & & & & & & & & & & & & \\
\hline \multirow{2}{*}{\multicolumn{5}{|c|}{ Cons tant Parameters }} & \multicolumn{10}{|c|}{ Exterior Girder D is tribution Factors (organized by method and varied parame te rs) } \\
\hline & & & & & \multicolumn{2}{|c|}{ Stallings/Yoo } & \multicolumn{2}{|c|}{ Tarhini/Fre de rick } & \multicolumn{2}{|c|}{ Lever Rule } & \multicolumn{2}{|c|}{ AASHTO Mod. } & \multicolumn{2}{|c|}{ Spe cial Analys is } \\
\hline Girder & L (ft) & $\mathbf{L}_{\mathbf{b}}$ (ft) & OH (in) & Ite ration & 8.625' & 11.5' & $8.625 '$ & 11.5' & $8.625^{\prime}$ & 11.5' & 8.625' & 11.5' & 8.625 & 11.5' \\
\hline \multirow{4}{*}{ G1 } & \multirow{4}{*}{100} & \multirow{4}{*}{20} & \multirow{4}{*}{46} & CONTROL & 0.692 & 0.849 & 0.632 & 0.765 & & & 0.692 & 0.851 & 0.676 & 0.825 \\
\hline & & & & 2x Cross-Frames & 0.713 & 0.871 & 0.648 & 0.782 & & & 0.692 & 0.851 & 0.676 & 0.825 \\
\hline & & & & No Barrier & 0.746 & 0.905 & 0.745 & 0.899 & & & 0.692 & 0.851 & 0.676 & 0.825 \\
\hline & & & & No Cross-Frames & 0.681 & $\mathbf{0 . 8 3 7}$ & 0.624 & 0.757 & & & 0.692 & 0.851 & 0.676 & 0.825 \\
\hline \multirow{4}{*}{ G1 } & \multirow{4}{*}{100} & \multirow{4}{*}{20} & \multirow{4}{*}{69} & CONTROL & 0.792 & 0.958 & 0.731 & 0.872 & & & 0.831 & 1.022 & 0.790 & 0.952 \\
\hline & & & & 2x Cross-Frames & 0.805 & 0.972 & 0.740 & 0.882 & & & 0.831 & 1.022 & 0.790 & 0.952 \\
\hline & & & & No Barrier & 0.863 & 1.031 & 0.869 & 1.031 & & & 0.831 & 1.022 & 0.790 & 0.952 \\
\hline & & & & No Cross-Frames & 0.793 & 0.959 & 0.735 & 0.876 & & & 0.831 & 1.022 & 0.790 & 0.952 \\
\hline \multirow{4}{*}{ G1 } & \multirow{4}{*}{100} & \multirow{4}{*}{25} & \multirow{4}{*}{46} & CONTROL & 0.688 & 0.843 & 0.634 & 0.767 & & & 0.692 & 0.851 & 0.676 & 0.825 \\
\hline & & & & 2x Cross-Frames & 0.714 & 0.870 & 0.652 & 0.785 & & & 0.692 & 0.851 & 0.676 & 0.825 \\
\hline & & & & No Barrier & 0.741 & 0.899 & 0.748 & 0.903 & & & 0.692 & 0.851 & 0.676 & 0.825 \\
\hline & & & & No Cross-Frames & 0.674 & 0.829 & 0.627 & 0.761 & & & 0.692 & 0.851 & 0.676 & 0.825 \\
\hline \multirow{4}{*}{ G1 } & \multirow{4}{*}{100} & & & CONTROL & 0.786 & 0.952 & 0.734 & 0.876 & & & 0.831 & 1.022 & 0.790 & 0.952 \\
\hline & & 25 & 69 & 2x Cross-Frames & 0.805 & 0.971 & 0.746 & 0.887 & & & 0.831 & 1.022 & 0.790 & 0.952 \\
\hline & & 25 & 69 & No Barrier & 0.856 & 1.023 & 0.872 & 1.035 & & & 0.831 & 1.022 & 0.790 & 0.952 \\
\hline & & & & No Cross-Frames & 0.785 & 0.950 & 0.738 & 0.881 & & & 0.831 & 1.022 & 0.790 & 0.952 \\
\hline & & & & CONTROL & 0.732 & 0.898 & 0.707 & 0.861 & & & 0.670 & 0.823 & 0.676 & 0.825 \\
\hline G) & 200 & 20 & 46 & 2x Cross-Frames & 0.750 & 0.917 & 0.721 & 0.877 & & & 0.670 & 0.823 & 0.676 & 0.825 \\
\hline GL & 200 & 20 & 46 & No Barrier & 0.749 & 0.915 & 0.759 & 0.922 & & & 0.670 & 0.823 & 0.676 & 0.825 \\
\hline & & & & No Cross-Frames & 0.709 & 0.868 & 0.690 & 0.838 & & & 0.670 & 0.823 & 0.676 & 0.825 \\
\hline & & & & CONTROL & 0.820 & 0.993 & 0.803 & 0.964 & & & 0.804 & 0.988 & 0.790 & 0.952 \\
\hline G? & 200 & 20 & 69 & 2x Cross-Frames & 0.831 & 1.007 & 0.812 & 0.974 & & & 0.804 & 0.988 & 0.790 & 0.952 \\
\hline GL & 200 & 20 & 69 & No Barrier & 0.845 & 1.018 & 0.866 & 1.035 & & & 0.804 & 0.988 & 0.790 & 0.952 \\
\hline & & & & No Cross-Frames & 0.812 & 0.979 & 0.800 & 0.955 & & & 0.804 & 0.988 & 0.790 & 0.952 \\
\hline & & & & CONTROL & 0.730 & 0.895 & 0.705 & 0.858 & & & 0.670 & 0.823 & 0.676 & 0.825 \\
\hline G2 & 200 & 25 & 46 & 2x Cross-Frames & 0.748 & 0.915 & 0.719 & 0.874 & & & 0.670 & 0.823 & 0.676 & 0.825 \\
\hline GL & 200 & 25 & 46 & No Barrier & 0.748 & 0.913 & 0.757 & 0.919 & & & 0.670 & 0.823 & 0.676 & 0.825 \\
\hline & & & & No Cross-Frames & 0.709 & 0.868 & 0.690 & 0.839 & & & 0.670 & 0.823 & 0.676 & 0.825 \\
\hline & & & & CONTROL & 0.818 & 0.991 & 0.802 & 0.961 & & & 0.804 & 0.988 & 0.790 & 0.952 \\
\hline G? & 200 & 25 & 69 & 2x Cross-Frames & 0.830 & 1.006 & 0.810 & 0.972 & & & 0.804 & 0.988 & 0.790 & 0.952 \\
\hline $\mathrm{G} 2$ & 200 & 25 & 69 & No Barrier & 0.843 & 1.016 & 0.865 & 1.033 & & & 0.804 & 0.988 & 0.790 & 0.952 \\
\hline & & & & No Cross-Frames & 0.812 & 0.979 & 0.800 & 0.955 & & & 0.804 & 0.988 & 0.790 & 0.952 \\
\hline
\end{tabular}




\begin{tabular}{|c|c|c|c|c|c|c|c|c|c|c|c|c|c|c|}
\hline \multicolumn{12}{|c|}{$\begin{array}{l}\text { Comparis on of the Effect of Span Length (L) and Girder Stiffiness } \\
\text { (bending moment, one lane loaded) }\end{array}$} & \multicolumn{3}{|c|}{ 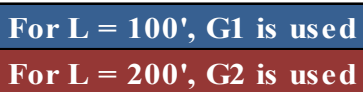 } \\
\hline \multirow{2}{*}{\multicolumn{5}{|c|}{ Constant Parameters }} & \multicolumn{10}{|c|}{ Exterior Girder D is tribution Factors (organized by method and varied parame ters) } \\
\hline & & & & & \multicolumn{2}{|c|}{ Stallings/Yoo } & \multicolumn{2}{|c|}{ Tarhini/Fre de rick } & \multicolumn{2}{|c|}{ Lever Rule } & \multicolumn{2}{|c|}{ AASHTO Mod. } & \multicolumn{2}{|c|}{ Spe cial Analys is } \\
\hline S (ft) & $\mathbf{N}_{\mathbf{b}}$ & $\mathbf{L}_{\mathrm{b}}$ (ft) & OH (in) & Ite ration & $100^{\prime}$ & $200^{\prime}$ & $100^{\prime}$ & 2001 & $100^{\prime}$ & $200^{\prime}$ & $100^{\prime}$ & $200^{\prime}$ & $100^{\prime}$ & $200^{\prime}$ \\
\hline 8.625 & 5 & 20 & 46 & $\begin{array}{c}\text { CONTROL } \\
\text { 2x Cross-Frames } \\
\text { No Barrier } \\
\text { No Cross-Frames }\end{array}$ & $\begin{array}{l}0.441 \\
0.430 \\
0.470 \\
0.466 \\
\end{array}$ & $\begin{array}{l}0.413 \\
0.402 \\
0.426 \\
0.440 \\
\end{array}$ & $\begin{array}{l}0.391 \\
0.382 \\
0.471 \\
0.412\end{array}$ & $\begin{array}{l}0.401 \\
0.393 \\
0.437 \\
0.424\end{array}$ & $\begin{array}{l}0.861 \\
0.861 \\
0.861 \\
0.861\end{array}$ & $\begin{array}{l}0.861 \\
0.861 \\
0.861 \\
0.861\end{array}$ & & & $\begin{array}{l}0.652 \\
0.652 \\
0.652 \\
0.652\end{array}$ & $\begin{array}{l}0.652 \\
0.652 \\
0.652 \\
0.652\end{array}$ \\
\hline 8.625 & 5 & 20 & 69 & $\begin{array}{c}\text { CONTROL } \\
\text { 2x Cross-Frames } \\
\text { No Barrier } \\
\text { No Cross-Frames }\end{array}$ & $\begin{array}{l}0.495 \\
0.477 \\
0.531 \\
0.529\end{array}$ & $\begin{array}{l}0.453 \\
0.434 \\
0.469 \\
0.495\end{array}$ & $\begin{array}{l}0.438 \\
0.424 \\
0.536 \\
0.465\end{array}$ & $\begin{array}{l}0.445 \\
0.431 \\
0.488 \\
0.479\end{array}$ & $\begin{array}{l}1.128 \\
1.128 \\
1.128 \\
1.128\end{array}$ & $\begin{array}{l}1.128 \\
1.128 \\
1.128 \\
1.128\end{array}$ & & & $\begin{array}{l}0.706 \\
0.706 \\
0.706 \\
0.706\end{array}$ & $\begin{array}{l}0.706 \\
0.706 \\
0.706 \\
0.706\end{array}$ \\
\hline 8.625 & 5 & 25 & 46 & $\begin{array}{c}\text { CONTROL } \\
\text { 2x Cross-Frames } \\
\text { No Barrier } \\
\text { No Cross-Frames }\end{array}$ & $\begin{array}{l}0.436 \\
0.423 \\
0.464 \\
0.463\end{array}$ & $\begin{array}{l}0.414 \\
0.403 \\
0.427 \\
0.440\end{array}$ & $\begin{array}{l}0.393 \\
0.384 \\
0.473 \\
0.413 \\
\end{array}$ & $\begin{array}{l}0.402 \\
0.394 \\
0.438 \\
0.424 \\
\end{array}$ & $\begin{array}{l}0.861 \\
0.861 \\
0.861 \\
0.861\end{array}$ & $\begin{array}{l}0.861 \\
0.861 \\
0.861 \\
0.861\end{array}$ & & & $\begin{array}{l}0.652 \\
0.652 \\
0.652 \\
0.652\end{array}$ & $\begin{array}{l}0.652 \\
0.652 \\
0.652 \\
0.652\end{array}$ \\
\hline 8.625 & 5 & 25 & 69 & $\begin{array}{c}\text { CONTROL } \\
\text { 2x Cross-Frames } \\
\text { No Barrier } \\
\text { No Cross-Frames }\end{array}$ & $\begin{array}{l}0.488 \\
0.466 \\
0.522 \\
0.525\end{array}$ & $\begin{array}{l}0.454 \\
0.435 \\
0.471 \\
0.495\end{array}$ & $\begin{array}{l}0.439 \\
0.424 \\
0.537 \\
0.466\end{array}$ & $\begin{array}{l}0.447 \\
0.433 \\
0.491 \\
0.479\end{array}$ & $\begin{array}{l}1.128 \\
1.128 \\
1.128 \\
1.128\end{array}$ & $\begin{array}{l}1.128 \\
1.128 \\
1.128 \\
1.128\end{array}$ & & & $\begin{array}{l}0.706 \\
0.706 \\
0.706 \\
0.706\end{array}$ & $\begin{array}{l}0.706 \\
0.706 \\
0.706 \\
0.706\end{array}$ \\
\hline 11.5 & 4 & 20 & 46 & $\begin{array}{c}\text { CONTROL } \\
\text { 2x Cross-Frames } \\
\text { No Barrier } \\
\text { No Cross-Frames }\end{array}$ & $\begin{array}{l}0.515 \\
0.504 \\
0.543 \\
0.540\end{array}$ & $\begin{array}{l}0.486 \\
0.477 \\
0.499 \\
0.513\end{array}$ & $\begin{array}{l}0.451 \\
0.442 \\
0.542 \\
0.472\end{array}$ & $\begin{array}{l}0.468 \\
0.460 \\
0.507 \\
0.491\end{array}$ & $\begin{array}{l}0.946 \\
0.946 \\
0.946 \\
0.946\end{array}$ & $\begin{array}{l}0.946 \\
0.946 \\
0.946 \\
0.946\end{array}$ & & & $\begin{array}{l}0.764 \\
0.764 \\
0.764 \\
0.764\end{array}$ & $\begin{array}{l}0.764 \\
0.764 \\
0.764 \\
0.764\end{array}$ \\
\hline 11.5 & 4 & 20 & 69 & $\begin{array}{c}\text { CONTROL } \\
\text { 2x Cross-Frames } \\
\text { No Barrier } \\
\text { No Cross-Frames } \\
\end{array}$ & $\begin{array}{l}0.568 \\
0.550 \\
0.602 \\
0.601 \\
\end{array}$ & $\begin{array}{l}0.525 \\
0.510 \\
0.542 \\
0.566 \\
\end{array}$ & $\begin{array}{l}0.496 \\
0.483 \\
0.605 \\
0.523 \\
\end{array}$ & $\begin{array}{l}0.509 \\
0.497 \\
0.556 \\
0.543 \\
\end{array}$ & $\begin{array}{l}1.146 \\
1.146 \\
1.146 \\
1.146 \\
\end{array}$ & $\begin{array}{l}1.146 \\
1.146 \\
1.146 \\
1.146 \\
\end{array}$ & & & $\begin{array}{l}0.824 \\
0.824 \\
0.824 \\
0.824 \\
\end{array}$ & $\begin{array}{l}0.824 \\
0.824 \\
0.824 \\
0.824 \\
\end{array}$ \\
\hline 11.5 & 4 & 25 & 46 & $\begin{array}{c}\text { CONTROL } \\
\text { 2x Cross-Frames } \\
\text { No Barrier } \\
\text { No Cross-Frames }\end{array}$ & $\begin{array}{l}0.511 \\
0.498 \\
0.538 \\
0.536\end{array}$ & $\begin{array}{l}0.487 \\
0.477 \\
0.500 \\
0.513\end{array}$ & $\begin{array}{l}0.454 \\
0.444 \\
0.544 \\
0.474\end{array}$ & $\begin{array}{l}0.469 \\
0.461 \\
0.508 \\
0.491\end{array}$ & $\begin{array}{l}0.946 \\
0.946 \\
0.946 \\
0.946\end{array}$ & $\begin{array}{l}0.946 \\
0.946 \\
0.946 \\
0.946\end{array}$ & & & $\begin{array}{l}0.764 \\
0.764 \\
0.764 \\
0.764\end{array}$ & $\begin{array}{l}0.764 \\
0.764 \\
0.764 \\
0.764\end{array}$ \\
\hline 11.5 & 4 & 25 & 69 & $\begin{array}{c}\text { CONTROL } \\
\text { 2x Cross-Frames } \\
\text { No Barrier } \\
\text { No Cross-Frames }\end{array}$ & $\begin{array}{l}0.563 \\
0.542 \\
0.595 \\
0.598\end{array}$ & $\begin{array}{l}0.526 \\
0.510 \\
0.544 \\
0.566\end{array}$ & $\begin{array}{l}0.498 \\
0.484 \\
0.607 \\
0.525 \\
\end{array}$ & $\begin{array}{l}0.511 \\
0.498 \\
0.558 \\
0.543 \\
\end{array}$ & $\begin{array}{l}1.146 \\
1.146 \\
1.146 \\
1.146\end{array}$ & $\begin{array}{l}1.146 \\
1.146 \\
1.146 \\
1.146\end{array}$ & & & $\begin{array}{l}0.824 \\
0.824 \\
0.824 \\
0.824\end{array}$ & $\begin{array}{l}0.824 \\
0.824 \\
0.824 \\
0.824\end{array}$ \\
\hline
\end{tabular}




\begin{tabular}{|c|c|c|c|c|c|c|c|c|c|c|c|c|c|c|}
\hline \multicolumn{12}{|c|}{$\begin{array}{c}\text { Comparis on of the Effect of Span Length (L) and Girder Stiffiness } \\
\text { (bending moment, two lanes loaded) }\end{array}$} & \multicolumn{3}{|c|}{$\begin{array}{l}\text { For } L=100^{\prime}, G 1 \text { is used } \\
\text { For } L=200^{\circ}, G 2 \text { is used }\end{array}$} \\
\hline \multirow{2}{*}{\multicolumn{5}{|c|}{ Constant Parameters }} & \multicolumn{10}{|c|}{ Exterior Girder D is tribution Factors (organized by method and varied parame ters) } \\
\hline & & & & & \multicolumn{2}{|c|}{ Stallings/Yoo } & \multicolumn{2}{|c|}{ Tarhini/Fre de rick } & \multicolumn{2}{|c|}{ Lever Rule } & \multicolumn{2}{|c|}{ AASHTO Mod. } & \multicolumn{2}{|c|}{ Spe cial Analys is } \\
\hline S (ft) & $\mathbf{N}_{\mathbf{b}}$ & $\mathbf{L}_{\mathbf{b}}(\mathbf{f t})$ & OH (in) & Iteration & 100' & $200^{\prime}$ & $100^{\prime}$ & 200' & $100^{\prime}$ & 200' & $100 '$ & $200^{\prime}$ & $100^{\prime}$ & $200^{\prime}$ \\
\hline 8.625 & 5 & 20 & 46 & $\begin{array}{c}\text { CONTROL } \\
\text { 2x Cross-Frames } \\
\text { No Barrier } \\
\text { No Cross-Frames }\end{array}$ & $\begin{array}{l}0.620 \\
0.625 \\
0.669 \\
0.630\end{array}$ & $\begin{array}{l}0.628 \\
0.634 \\
0.647 \\
0.629\end{array}$ & $\begin{array}{l}0.562 \\
0.565 \\
0.669 \\
0.572\end{array}$ & $\begin{array}{l}0.608 \\
0.612 \\
0.657 \\
0.610\end{array}$ & & & $\begin{array}{l}0.692 \\
0.692 \\
0.692 \\
0.692\end{array}$ & $\begin{array}{l}0.670 \\
0.670 \\
0.670 \\
0.670\end{array}$ & $\begin{array}{l}0.809 \\
0.809 \\
0.809 \\
0.809\end{array}$ & $\begin{array}{l}0.809 \\
0.809 \\
0.809 \\
0.809\end{array}$ \\
\hline 8.625 & 5 & 20 & 69 & $\begin{array}{c}\text { CONTROL } \\
\text { 2x Cross-Frames } \\
\text { No Barrier } \\
\text { No Cross-Frames } \\
\end{array}$ & $\begin{array}{l}0.708 \\
0.704 \\
0.769 \\
0.732 \\
\end{array}$ & $\begin{array}{l}0.698 \\
0.695 \\
0.722 \\
0.718 \\
\end{array}$ & $\begin{array}{l}0.645 \\
0.641 \\
0.775 \\
0.667 \\
\end{array}$ & $\begin{array}{l}0.685 \\
0.682 \\
0.743 \\
0.704 \\
\end{array}$ & & & $\begin{array}{l}0.831 \\
0.831 \\
0.831 \\
0.831 \\
\end{array}$ & $\begin{array}{l}0.804 \\
0.804 \\
0.804 \\
0.804 \\
\end{array}$ & $\begin{array}{l}0.898 \\
0.898 \\
0.898 \\
0.898 \\
\end{array}$ & $\begin{array}{l}0.898 \\
0.898 \\
0.898 \\
0.898 \\
\end{array}$ \\
\hline 8.625 & 5 & 25 & 46 & $\begin{array}{c}\text { CONTROL } \\
\text { 2x Cross-Frames } \\
\text { No Barrier } \\
\text { No Cross-Frames } \\
\end{array}$ & $\begin{array}{l}0.616 \\
0.625 \\
0.664 \\
0.624 \\
\end{array}$ & $\begin{array}{l}0.627 \\
0.634 \\
0.646 \\
0.629 \\
\end{array}$ & $\begin{array}{l}0.565 \\
0.570 \\
0.673 \\
0.575 \\
\end{array}$ & $\begin{array}{l}0.607 \\
0.612 \\
0.656 \\
0.611 \\
\end{array}$ & & & $\begin{array}{l}0.692 \\
0.692 \\
0.692 \\
0.692 \\
\end{array}$ & $\begin{array}{l}0.670 \\
0.670 \\
0.670 \\
0.670 \\
\end{array}$ & $\begin{array}{l}0.809 \\
0.809 \\
0.809 \\
0.809 \\
\end{array}$ & $\begin{array}{l}0.809 \\
0.809 \\
0.809 \\
0.809 \\
\end{array}$ \\
\hline 8.625 & 5 & 25 & 69 & $\begin{array}{c}\text { CONTROL } \\
\text { 2x Cross-Frames } \\
\text { No Barrier } \\
\text { No Cross-Frames } \\
\end{array}$ & $\begin{array}{l}0.703 \\
0.701 \\
0.762 \\
0.725 \\
\end{array}$ & $\begin{array}{l}0.698 \\
0.695 \\
0.722 \\
0.718 \\
\end{array}$ & $\begin{array}{l}0.649 \\
0.646 \\
0.778 \\
0.670 \\
\end{array}$ & $\begin{array}{l}0.685 \\
0.682 \\
0.744 \\
0.704 \\
\end{array}$ & & & $\begin{array}{l}0.831 \\
0.831 \\
0.831 \\
0.831 \\
\end{array}$ & $\begin{array}{l}0.804 \\
0.804 \\
0.804 \\
0.804 \\
\end{array}$ & $\begin{array}{l}0.898 \\
0.898 \\
0.898 \\
0.898 \\
\end{array}$ & $\begin{array}{l}0.898 \\
0.898 \\
0.898 \\
0.898 \\
\end{array}$ \\
\hline 11.5 & 4 & 20 & 46 & $\begin{array}{c}\text { CONTROL } \\
\text { 2x Cross-Frames } \\
\text { No Barrier } \\
\text { No Cross-Frames } \\
\end{array}$ & $\begin{array}{l}0.749 \\
0.754 \\
0.799 \\
0.760 \\
\end{array}$ & $\begin{array}{l}0.759 \\
0.766 \\
0.778 \\
0.758 \\
\end{array}$ & $\begin{array}{l}0.671 \\
0.673 \\
0.794 \\
0.682 \\
\end{array}$ & $\begin{array}{l}0.729 \\
0.734 \\
0.785 \\
0.731 \\
\end{array}$ & & & $\begin{array}{l}0.851 \\
0.851 \\
0.851 \\
0.851 \\
\end{array}$ & $\begin{array}{l}0.823 \\
0.823 \\
0.823 \\
0.823 \\
\end{array}$ & $\begin{array}{l}0.960 \\
0.960 \\
0.960 \\
0.960 \\
\end{array}$ & $\begin{array}{l}0.960 \\
0.960 \\
0.960 \\
0.960 \\
\end{array}$ \\
\hline 11.5 & 4 & 20 & 69 & $\begin{array}{c}\text { CONTROL } \\
\text { 2x Cross-Frames } \\
\text { No Barrier } \\
\text { No Cross-Frames } \\
\end{array}$ & $\begin{array}{l}0.843 \\
0.838 \\
0.903 \\
0.867 \\
\end{array}$ & $\begin{array}{l}0.834 \\
0.832 \\
0.857 \\
0.852 \\
\end{array}$ & $\begin{array}{l}0.759 \\
0.753 \\
0.904 \\
0.781 \\
\end{array}$ & $\begin{array}{l}0.809 \\
0.807 \\
0.874 \\
0.827 \\
\end{array}$ & & & \begin{tabular}{l|}
1.022 \\
1.022 \\
1.022 \\
1.022 \\
\end{tabular} & $\begin{array}{l}0.988 \\
0.988 \\
0.988 \\
0.988 \\
\end{array}$ & $\begin{array}{l}1.060 \\
1.060 \\
1.060 \\
1.060 \\
\end{array}$ & $\begin{array}{l}1.060 \\
1.060 \\
1.060 \\
1.060 \\
\end{array}$ \\
\hline 11.5 & 4 & 25 & 46 & $\begin{array}{c}\text { CONTROL } \\
\text { 2x Cross-Frames } \\
\text { No Barrier } \\
\text { No Cross-Frames }\end{array}$ & $\begin{array}{l}0.744 \\
0.752 \\
0.794 \\
0.753\end{array}$ & $\begin{array}{l}0.758 \\
0.765 \\
0.777 \\
0.758\end{array}$ & $\begin{array}{l}0.673 \\
0.677 \\
0.799 \\
0.685\end{array}$ & $\begin{array}{l}0.727 \\
0.733 \\
0.784 \\
0.731 \\
\end{array}$ & & & $\begin{array}{l}0.851 \\
0.851 \\
0.851 \\
0.851\end{array}$ & $\begin{array}{l}0.823 \\
0.823 \\
0.823 \\
0.823\end{array}$ & $\begin{array}{l}0.960 \\
0.960 \\
0.960 \\
0.960\end{array}$ & $\begin{array}{l}0.960 \\
0.960 \\
0.960 \\
0.960\end{array}$ \\
\hline 11.5 & 4 & 25 & 69 & $\begin{array}{c}\text { CONTROL } \\
\text { 2x Cross-Frames } \\
\text { No Barrier } \\
\text { No Cross-Frames }\end{array}$ & $\begin{array}{l}0.838 \\
0.835 \\
0.896 \\
0.860\end{array}$ & $\begin{array}{l}0.833 \\
0.832 \\
0.857 \\
0.852\end{array}$ & $\begin{array}{l}0.763 \\
0.758 \\
0.908 \\
0.785 \\
\end{array}$ & $\begin{array}{l}0.809 \\
0.807 \\
0.874 \\
0.828 \\
\end{array}$ & & & $\begin{array}{l}1.022 \\
1.022 \\
1.022 \\
1.022 \\
\end{array}$ & $\begin{array}{l}0.988 \\
0.988 \\
0.988 \\
0.988\end{array}$ & $\begin{array}{l}1.060 \\
1.060 \\
1.060 \\
1.060\end{array}$ & $\begin{array}{l}1.060 \\
1.060 \\
1.060 \\
1.060\end{array}$ \\
\hline
\end{tabular}




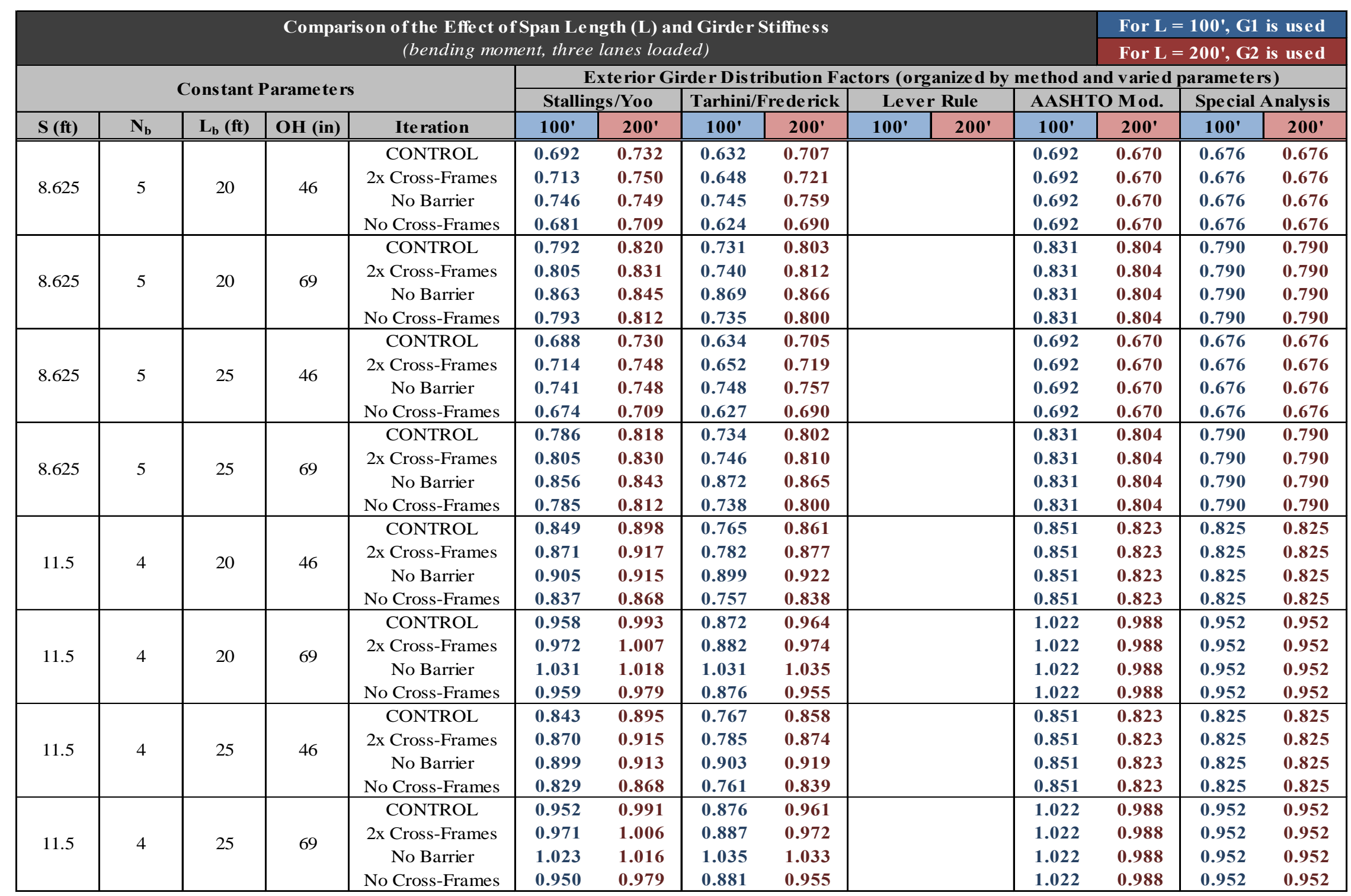




\begin{tabular}{|c|c|c|c|c|c|c|c|c|c|c|c|c|c|c|c|}
\hline \multicolumn{16}{|c|}{$\begin{array}{l}\text { Comparis on of the Effect of Unbraced Le ngth }\left(\mathrm{L}_{\mathbf{b}}\right) \\
\text { (bending moment, one lane loaded) }\end{array}$} \\
\hline \multirow{2}{*}{\multicolumn{6}{|c|}{ Cons tant Parameters }} & \multicolumn{10}{|c|}{ Exte rior Girder Dis tribution Factors (organized by method and varied parame te rs) } \\
\hline & & & & & & \multicolumn{2}{|c|}{ Stallings/Yoo } & \multicolumn{2}{|c|}{ Tarhini/Fre derick } & \multicolumn{2}{|c|}{ Lever Rule } & \multicolumn{2}{|c|}{ AASHTO Mod. } & \multicolumn{2}{|c|}{ Special Analys is } \\
\hline Girder & L (ft) & S (ft) & $\mathbf{N}_{\mathbf{b}}$ & OH (in) & Iteration & $20^{\prime}$ & $25^{\prime}$ & $20^{\prime}$ & $25^{\prime}$ & $20^{\prime}$ & $25^{\prime}$ & $20^{\prime}$ & $25^{\prime}$ & $20^{\prime}$ & $25^{\prime}$ \\
\hline \multirow{4}{*}{ G1 } & \multirow{4}{*}{100} & \multirow{4}{*}{8.625} & \multirow{4}{*}{5} & \multirow{4}{*}{46} & CONTROL & 0.441 & 0.436 & 0.391 & 0.393 & 0.861 & $\overline{0.861}$ & & & 0.652 & 0.652 \\
\hline & & & & & 2x Cross-Frames & 0.430 & 0.423 & 0.382 & 0.384 & 0.861 & 0.861 & & & 0.652 & 0.652 \\
\hline & & & & & No Barrier & 0.470 & 0.464 & 0.471 & 0.473 & 0.861 & 0.861 & & & 0.652 & 0.652 \\
\hline & & & & & No Cross-Frames & 0.466 & 0.463 & 0.412 & 0.413 & 0.861 & 0.861 & & & 0.652 & 0.652 \\
\hline \multirow{4}{*}{ G1 } & \multirow{4}{*}{100} & \multirow{4}{*}{8.625} & \multirow{4}{*}{5} & \multirow{4}{*}{69} & CONTROL & 0.495 & 0.488 & 0.438 & 0.439 & 1.128 & 1.128 & & & 0.706 & 0.706 \\
\hline & & & & & 2x Cross-Frames & 0.477 & 0.466 & 0.424 & 0.424 & 1.128 & 1.128 & & & 0.706 & 0.706 \\
\hline & & & & & No Barrier & 0.531 & 0.522 & 0.536 & 0.537 & 1.128 & 1.128 & & & 0.706 & 0.706 \\
\hline & & & & & No Cross-Frames & 0.529 & 0.525 & 0.465 & 0.466 & 1.128 & 1.128 & & & 0.706 & 0.706 \\
\hline \multirow{4}{*}{ G1 } & \multirow{4}{*}{100} & \multirow{4}{*}{11.5} & \multirow{4}{*}{4} & \multirow{4}{*}{46} & CONTROL & 0.515 & 0.511 & 0.451 & 0.454 & 0.946 & 0.946 & & & 0.764 & 0.764 \\
\hline & & & & & 2x Cross-Frames & 0.504 & 0.498 & 0.442 & 0.444 & 0.946 & 0.946 & & & 0.764 & 0.764 \\
\hline & & & & & No Barrier & 0.543 & 0.538 & 0.542 & 0.544 & 0.946 & 0.946 & & & 0.764 & 0.764 \\
\hline & & & & & No Cross-Frames & 0.540 & 0.536 & 0.472 & 0.474 & 0.946 & 0.946 & & & 0.764 & 0.764 \\
\hline & & & & & CONTROL & 0.568 & 0.563 & 0.496 & 0.498 & 1.146 & 1.146 & & & 0.824 & 0.824 \\
\hline G1 & 100 & 11.5 & 4 & 69 & 2x Cross-Frames & 0.550 & 0.542 & 0.483 & 0.484 & 1.146 & 1.146 & & & 0.824 & 0.824 \\
\hline GI & 100 & 11.5 & 4 & 69 & No Barrier & 0.602 & 0.595 & 0.605 & 0.607 & 1.146 & 1.146 & & & 0.824 & 0.824 \\
\hline & & & & & No Cross-Frames & 0.601 & 0.598 & 0.523 & 0.525 & 1.146 & 1.146 & & & 0.824 & 0.824 \\
\hline & & & & & CONTROL & 0.413 & 0.414 & 0.401 & 0.402 & 0.861 & 0.861 & & & 0.652 & 0.652 \\
\hline & & & & & 2x Cross-Frames & 0.402 & 0.403 & 0.393 & 0.394 & 0.861 & 0.861 & & & 0.652 & 0.652 \\
\hline G2 & 200 & 8.625 & 5 & 46 & No Barrier & 0.426 & 0.427 & 0.437 & 0.438 & 0.861 & 0.861 & & & 0.652 & 0.652 \\
\hline & & & & & No Cross-Frames & 0.440 & 0.440 & 0.424 & 0.424 & 0.861 & 0.861 & & & 0.652 & 0.652 \\
\hline & & & & & CONTROL & 0.453 & 0.454 & 0.445 & 0.447 & 1.128 & 1.128 & & & 0.706 & 0.706 \\
\hline (C) & & & & & 2x Cross-Frames & 0.434 & 0.435 & 0.431 & 0.433 & 1.128 & 1.128 & & & 0.706 & 0.706 \\
\hline G2 & 200 & 8.625 & 5 & 69 & No Barrier & 0.469 & 0.471 & 0.488 & 0.491 & 1.128 & 1.128 & & & 0.706 & 0.706 \\
\hline & & & & & No Cross-Frames & 0.495 & 0.495 & 0.479 & 0.479 & 1.128 & 1.128 & & & 0.706 & 0.706 \\
\hline & & & & & CONTROL & 0.486 & 0.487 & 0.468 & 0.469 & 0.946 & 0.946 & & & 0.764 & 0.764 \\
\hline G2 & & & & & 2x Cross-Frames & 0.477 & 0.477 & 0.460 & 0.461 & 0.946 & 0.946 & & & 0.764 & 0.764 \\
\hline G2 & 200 & 11.5 & 4 & 46 & No Barrier & 0.499 & 0.500 & 0.507 & 0.508 & 0.946 & 0.946 & & & 0.764 & 0.764 \\
\hline & & & & & No Cross-Frames & 0.513 & 0.513 & 0.491 & 0.491 & 0.946 & 0.946 & & & 0.764 & 0.764 \\
\hline & & & & & CONTROL & 0.525 & 0.526 & 0.509 & 0.511 & 1.146 & 1.146 & & & 0.824 & 0.824 \\
\hline G) & 200 & 115 & 4 & 69 & 2x Cross-Frames & 0.510 & 0.510 & 0.497 & 0.498 & 1.146 & 1.146 & & & 0.824 & 0.824 \\
\hline G2 & 200 & 11.5 & 4 & 69 & No Barrier & 0.542 & 0.544 & 0.556 & 0.558 & 1.146 & 1.146 & & & 0.824 & 0.824 \\
\hline & & & & & No Cross-Frames & 0.566 & 0.566 & 0.543 & 0.543 & 1.146 & 1.146 & & & 0.824 & 0.824 \\
\hline
\end{tabular}




\begin{tabular}{|c|c|c|c|c|c|c|c|c|c|c|c|c|c|c|c|}
\hline \multicolumn{16}{|c|}{$\begin{array}{l}\text { Comparis on of the Effect of Unbrace d Length }\left(\mathbf{L}_{\mathbf{b}}\right) \\
\text { (bending moment, two lanes loaded) }\end{array}$} \\
\hline \multirow{2}{*}{\multicolumn{6}{|c|}{ Cons tant Parameters }} & \multicolumn{10}{|c|}{ Exte rior Girder Dis tribution Factors (organized by method and varied parame te rs) } \\
\hline & & & & & & \multicolumn{2}{|c|}{ Stallings/Yoo } & \multicolumn{2}{|c|}{ Tarhini/Fre derick } & \multicolumn{2}{|c|}{ Lever Rule } & \multicolumn{2}{|c|}{ AASHTO Mod. } & \multicolumn{2}{|c|}{ Special Analys is } \\
\hline Girder & L (ft) & S (ft) & $\mathbf{N}_{\mathbf{b}}$ & OH (in) & Iteration & $20^{\prime}$ & $25^{\prime}$ & $20^{\prime}$ & $25^{\prime}$ & $20^{\prime}$ & $25^{\prime}$ & $20^{\prime}$ & $25^{\prime}$ & $20^{\prime}$ & $25^{\prime}$ \\
\hline \multirow{4}{*}{ G1 } & \multirow{4}{*}{100} & \multirow{4}{*}{8.625} & \multirow{4}{*}{5} & \multirow{4}{*}{46} & CONTROL & 0.620 & 0.616 & 0.562 & 0.565 & & & 0.692 & 0.692 & 0.809 & 0.809 \\
\hline & & & & & 2x Cross-Frames & 0.625 & 0.625 & 0.565 & 0.570 & & & 0.692 & 0.692 & 0.809 & 0.809 \\
\hline & & & & & No Barrier & 0.669 & 0.664 & 0.669 & 0.673 & & & 0.692 & 0.692 & 0.809 & 0.809 \\
\hline & & & & & No Cross-Frames & 0.630 & 0.624 & 0.572 & 0.575 & & & 0.692 & 0.692 & 0.809 & 0.809 \\
\hline \multirow{4}{*}{ G1 } & \multirow{4}{*}{100} & \multirow{4}{*}{8.625} & \multirow{4}{*}{5} & \multirow{4}{*}{69} & CONTROL & 0.708 & 0.703 & 0.645 & 0.649 & & & 0.831 & 0.831 & 0.898 & 0.898 \\
\hline & & & & & 2x Cross-Frames & 0.704 & 0.701 & 0.641 & 0.646 & & & 0.831 & 0.831 & 0.898 & 0.898 \\
\hline & & & & & No Barrier & 0.769 & 0.762 & 0.775 & 0.778 & & & 0.831 & 0.831 & 0.898 & 0.898 \\
\hline & & & & & No Cross-Frames & 0.732 & 0.725 & 0.667 & 0.670 & & & 0.831 & 0.831 & 0.898 & 0.898 \\
\hline \multirow{4}{*}{ G1 } & \multirow{4}{*}{100} & \multirow{4}{*}{11.5} & \multirow{4}{*}{4} & \multirow{4}{*}{46} & CONTROL & 0.749 & 0.744 & 0.671 & 0.673 & & & 0.851 & 0.851 & 0.960 & 0.960 \\
\hline & & & & & 2x Cross-Frames & 0.754 & 0.752 & 0.673 & 0.677 & & & 0.851 & 0.851 & 0.960 & 0.960 \\
\hline & & & & & No Barrier & 0.799 & 0.794 & 0.794 & 0.799 & & & 0.851 & 0.851 & 0.960 & 0.960 \\
\hline & & & & & No Cross-Frames & 0.760 & 0.753 & 0.682 & 0.685 & & & 0.851 & 0.851 & 0.960 & 0.960 \\
\hline & & & & & CONTROL & 0.843 & 0.838 & 0.759 & 0.763 & & & 1.022 & 1.022 & 1.060 & 1.060 \\
\hline G1 & 100 & 11.5 & 4 & 69 & 2x Cross-Frames & 0.838 & 0.835 & 0.753 & 0.758 & & & 1.022 & 1.022 & 1.060 & 1.060 \\
\hline GI & 100 & 11.5 & 4 & 69 & No Barrier & 0.903 & 0.896 & 0.904 & 0.908 & & & 1.022 & 1.022 & 1.060 & 1.060 \\
\hline & & & & & No Cross-Frames & 0.867 & 0.860 & 0.781 & 0.785 & & & 1.022 & 1.022 & 1.060 & 1.060 \\
\hline & & & & & CONTROL & 0.628 & 0.627 & 0.608 & 0.607 & & & 0.670 & 0.670 & 0.809 & 0.809 \\
\hline & & & & & 2x Cross-Frames & 0.634 & 0.634 & 0.612 & 0.612 & & & 0.670 & 0.670 & 0.809 & 0.809 \\
\hline G2 & 200 & 8.625 & 5 & 46 & No Barrier & 0.647 & 0.646 & 0.657 & 0.656 & & & 0.670 & 0.670 & 0.809 & 0.809 \\
\hline & & & & & No Cross-Frames & 0.629 & 0.629 & 0.610 & 0.611 & & & 0.670 & 0.670 & 0.809 & 0.809 \\
\hline & & & & & CONTROL & 0.698 & 0.698 & 0.685 & 0.685 & & & 0.804 & 0.804 & 0.898 & 0.898 \\
\hline (C) & & & & & 2x Cross-Frames & 0.695 & 0.695 & 0.682 & 0.682 & & & 0.804 & 0.804 & 0.898 & 0.898 \\
\hline G2 & 200 & 8.625 & 5 & 69 & No Barrier & 0.722 & 0.722 & 0.743 & 0.744 & & & 0.804 & 0.804 & 0.898 & 0.898 \\
\hline & & & & & No Cross-Frames & 0.718 & 0.718 & 0.704 & 0.704 & & & 0.804 & 0.804 & 0.898 & 0.898 \\
\hline & & & & & CONTROL & 0.759 & 0.758 & 0.729 & 0.727 & & & 0.823 & 0.823 & 0.960 & 0.960 \\
\hline & & & & & 2x Cross-Frames & 0.766 & 0.765 & 0.734 & 0.733 & & & 0.823 & 0.823 & 0.960 & 0.960 \\
\hline G2 & 200 & 11.5 & 4 & 46 & No Barrier & 0.778 & 0.777 & 0.785 & 0.784 & & & 0.823 & 0.823 & 0.960 & 0.960 \\
\hline & & & & & No Cross-Frames & 0.758 & 0.758 & 0.731 & 0.731 & & & 0.823 & 0.823 & 0.960 & 0.960 \\
\hline & & & & & CONTROL & 0.834 & 0.833 & 0.809 & 0.809 & & & 0.988 & 0.988 & 1.060 & 1.060 \\
\hline$G_{2}$ & 200 & 115 & 4 & 69 & 2x Cross-Frames & 0.832 & 0.832 & 0.807 & 0.807 & & & 0.988 & 0.988 & 1.060 & 1.060 \\
\hline G2 & 200 & 11.5 & 4 & 69 & No Barrier & 0.857 & 0.857 & 0.874 & 0.874 & & & 0.988 & 0.988 & 1.060 & 1.060 \\
\hline & & & & & No Cross-Frames & 0.852 & 0.852 & 0.827 & 0.828 & & & 0.988 & 0.988 & 1.060 & 1.060 \\
\hline
\end{tabular}




\begin{tabular}{|c|c|c|c|c|c|c|c|c|c|c|c|c|c|c|c|}
\hline \multicolumn{16}{|c|}{$\begin{array}{l}\text { Comparis on of the Effect of Unbraced Length }\left(\mathbf{L}_{\mathbf{b}}\right) \\
\text { (bending moment, three lanes loaded) }\end{array}$} \\
\hline \multirow{2}{*}{\multicolumn{6}{|c|}{ Cons tant Parameters }} & \multicolumn{10}{|c|}{ Exte rior Girder Dis tribution Factors (organized by method and varied parame te rs) } \\
\hline & & & & & & \multicolumn{2}{|c|}{ Stallings/Yoo } & \multicolumn{2}{|c|}{ Tarhini/Fre derick } & \multicolumn{2}{|c|}{ Lever Rule } & \multicolumn{2}{|c|}{ AASHTO Mod. } & \multicolumn{2}{|c|}{ Special Analys is } \\
\hline Girder & L (ft) & S (ft) & $\mathbf{N}_{\mathbf{b}}$ & OH (in) & Iteration & $20^{\prime}$ & $25^{\prime}$ & $20^{\prime}$ & $25^{\prime}$ & $20^{\prime}$ & $25^{\prime}$ & $20^{\prime}$ & $25^{\prime}$ & $20^{\prime}$ & $25^{\prime}$ \\
\hline \multirow{4}{*}{ G1 } & \multirow{4}{*}{100} & \multirow{4}{*}{8.625} & \multirow{4}{*}{5} & \multirow{4}{*}{46} & CONTROL & 0.692 & 0.688 & 0.632 & 0.634 & & & 0.692 & 0.692 & 0.676 & 0.676 \\
\hline & & & & & 2x Cross-Frames & 0.713 & 0.714 & 0.648 & 0.652 & & & 0.692 & 0.692 & 0.676 & 0.676 \\
\hline & & & & & No Barrier & 0.746 & 0.741 & 0.745 & 0.748 & & & 0.692 & 0.692 & 0.676 & 0.676 \\
\hline & & & & & No Cross-Frames & 0.681 & 0.674 & 0.624 & 0.627 & & & 0.692 & 0.692 & 0.676 & 0.676 \\
\hline \multirow{4}{*}{ G1 } & \multirow{4}{*}{100} & \multirow{4}{*}{8.625} & \multirow{4}{*}{5} & \multirow{4}{*}{69} & CONTROL & 0.792 & 0.786 & 0.731 & 0.734 & & & 0.831 & 0.831 & 0.790 & 0.790 \\
\hline & & & & & 2x Cross-Frames & 0.805 & 0.805 & 0.740 & 0.746 & & & 0.831 & 0.831 & 0.790 & 0.790 \\
\hline & & & & & No Barrier & 0.863 & 0.856 & 0.869 & 0.872 & & & 0.831 & 0.831 & 0.790 & 0.790 \\
\hline & & & & & No Cross-Frames & 0.793 & 0.785 & 0.735 & 0.738 & & & 0.831 & 0.831 & 0.790 & 0.790 \\
\hline \multirow{4}{*}{ G1 } & \multirow{4}{*}{100} & \multirow{4}{*}{11.5} & \multirow{4}{*}{4} & \multirow{4}{*}{46} & CONTROL & 0.849 & 0.843 & 0.765 & 0.767 & & & 0.851 & 0.851 & 0.825 & 0.825 \\
\hline & & & & & 2x Cross-Frames & 0.871 & 0.870 & 0.782 & 0.785 & & & 0.851 & 0.851 & 0.825 & 0.825 \\
\hline & & & & & No Barrier & 0.905 & 0.899 & 0.899 & 0.903 & & & 0.851 & 0.851 & 0.825 & 0.825 \\
\hline & & & & & No Cross-Frames & 0.837 & 0.829 & 0.757 & 0.761 & & & 0.851 & 0.851 & 0.825 & 0.825 \\
\hline & & & & & CONTROL & 0.958 & 0.952 & 0.872 & 0.876 & & & 1.022 & 1.022 & 0.952 & 0.952 \\
\hline G1 & 100 & 115 & 4 & 69 & 2x Cross-Frames & 0.972 & 0.971 & 0.882 & 0.887 & & & 1.022 & 1.022 & 0.952 & 0.952 \\
\hline GI & 100 & 11.5 & 4 & 69 & No Barrier & 1.031 & 1.023 & 1.031 & 1.035 & & & 1.022 & 1.022 & 0.952 & 0.952 \\
\hline & & & & & No Cross-Frames & 0.959 & 0.950 & 0.876 & 0.881 & & & 1.022 & 1.022 & 0.952 & 0.952 \\
\hline & & & & & CONTROL & 0.732 & 0.730 & 0.707 & 0.705 & & & 0.670 & 0.670 & 0.676 & 0.676 \\
\hline & & & & & 2x Cross-Frames & 0.750 & 0.748 & 0.721 & 0.719 & & & 0.670 & 0.670 & 0.676 & 0.676 \\
\hline G2 & 200 & 8.625 & 5 & 46 & No Barrier & 0.749 & 0.748 & 0.759 & 0.757 & & & 0.670 & 0.670 & 0.676 & 0.676 \\
\hline & & & & & No Cross-Frames & 0.709 & 0.709 & 0.690 & 0.690 & & & 0.670 & 0.670 & 0.676 & 0.676 \\
\hline & & & & & CONTROL & 0.820 & 0.818 & 0.803 & 0.802 & & & 0.804 & 0.804 & 0.790 & 0.790 \\
\hline & & & & & 2x Cross-Frames & 0.831 & 0.830 & 0.812 & 0.810 & & & 0.804 & 0.804 & 0.790 & 0.790 \\
\hline G2 & 200 & 8.625 & 5 & 69 & No Barrier & 0.845 & 0.843 & 0.866 & 0.865 & & & 0.804 & 0.804 & 0.790 & 0.790 \\
\hline & & & & & No Cross-Frames & 0.812 & 0.812 & 0.800 & 0.800 & & & 0.804 & 0.804 & 0.790 & 0.790 \\
\hline & & & & & CONTROL & 0.898 & 0.895 & 0.861 & 0.858 & & & 0.823 & 0.823 & 0.825 & 0.825 \\
\hline & & & & & 2x Cross-Frames & 0.917 & 0.915 & 0.877 & 0.874 & & & 0.823 & 0.823 & 0.825 & 0.825 \\
\hline G2 & 200 & 11.5 & 4 & 46 & No Barrier & 0.915 & 0.913 & 0.922 & 0.919 & & & 0.823 & 0.823 & 0.825 & 0.825 \\
\hline & & & & & No Cross-Frames & 0.868 & 0.868 & 0.838 & 0.839 & & & 0.823 & 0.823 & 0.825 & 0.825 \\
\hline & & & & & CONTROL & 0.993 & 0.991 & 0.964 & 0.961 & & & 0.988 & 0.988 & 0.952 & 0.952 \\
\hline G2 & 200 & 115 & 4 & 69 & 2x Cross-Frames & 1.007 & 1.006 & 0.974 & 0.972 & & & 0.988 & 0.988 & 0.952 & 0.952 \\
\hline G2 & 200 & 11.5 & 4 & 69 & No Barrier & 1.018 & 1.016 & 1.035 & 1.033 & & & 0.988 & 0.988 & 0.952 & 0.952 \\
\hline & & & & & No Cross-Frames & 0.979 & 0.979 & 0.955 & 0.955 & & & 0.988 & 0.988 & 0.952 & 0.952 \\
\hline
\end{tabular}




\begin{tabular}{|c|c|c|c|c|c|c|c|c|c|c|c|c|c|c|c|}
\hline \multicolumn{16}{|c|}{$\begin{array}{l}\text { Comparis on of the Effect of Overhang Width }(\mathrm{OH}) \\
\text { (bending moment, one lane loaded) }\end{array}$} \\
\hline \multirow{2}{*}{\multicolumn{6}{|c|}{ Cons tant Parameters }} & \multicolumn{10}{|c|}{ Exterior Girder Dis tribution Factors (organized by method and varied parame te rs) } \\
\hline & & & & & & \multicolumn{2}{|c|}{ Stallings/Yoo } & \multicolumn{2}{|c|}{ Tarhini/Fre derick } & \multicolumn{2}{|c|}{ Lever Rule } & \multicolumn{2}{|c|}{ AASHTO Mod. } & \multicolumn{2}{|c|}{ Special Analys is } \\
\hline Girder & L (ft) & S (ft) & $\mathbf{N}_{\mathbf{b}}$ & $\mathbf{L}_{\mathbf{b}}(\mathbf{f t})$ & Iteration & $46 "$ & 69" & $46 "$ & 69" & 46" & 69" & 46" & $69 "$ & $46 "$ & $69^{\prime \prime}$ \\
\hline \multirow{4}{*}{ G1 } & \multirow{4}{*}{100} & \multirow{4}{*}{8.625} & \multirow{4}{*}{5} & \multirow{4}{*}{20} & CONTROL & 0.441 & 0.495 & 0.391 & 0.438 & $\overline{0.861}$ & 1.128 & & & 0.652 & 0.706 \\
\hline & & & & & 2x Cross-Frames & 0.430 & 0.477 & 0.382 & 0.424 & 0.861 & 1.128 & & & 0.652 & 0.706 \\
\hline & & & & & No Barrier & 0.470 & 0.531 & 0.471 & 0.536 & 0.861 & 1.128 & & & 0.652 & 0.706 \\
\hline & & & & & No Cross-Frames & 0.466 & 0.529 & 0.412 & 0.465 & 0.861 & 1.128 & & & 0.652 & 0.706 \\
\hline \multirow{4}{*}{ G1 } & \multirow{4}{*}{100} & \multirow{4}{*}{8.625} & \multirow{4}{*}{5} & \multirow{4}{*}{25} & CONTROL & 0.436 & 0.488 & 0.393 & 0.439 & 0.861 & 1.128 & & & 0.652 & 0.706 \\
\hline & & & & & 2x Cross-Frames & 0.423 & 0.466 & 0.384 & 0.424 & 0.861 & 1.128 & & & 0.652 & 0.706 \\
\hline & & & & & No Barrier & 0.464 & 0.522 & 0.473 & 0.537 & 0.861 & 1.128 & & & 0.652 & 0.706 \\
\hline & & & & & No Cross-Frames & 0.463 & 0.525 & 0.413 & 0.466 & 0.861 & 1.128 & & & 0.652 & 0.706 \\
\hline \multirow{4}{*}{ G1 } & \multirow{4}{*}{100} & \multirow{4}{*}{11.5} & \multirow{4}{*}{4} & \multirow{4}{*}{20} & CONTROL & 0.515 & 0.568 & 0.451 & 0.496 & 0.946 & 1.146 & & & 0.764 & 0.824 \\
\hline & & & & & 2x Cross-Frames & 0.504 & 0.550 & 0.442 & 0.483 & 0.946 & 1.146 & & & 0.764 & 0.824 \\
\hline & & & & & No Barrier & 0.543 & 0.602 & 0.542 & 0.605 & 0.946 & 1.146 & & & 0.764 & 0.824 \\
\hline & & & & & No Cross-Frames & 0.540 & 0.601 & 0.472 & 0.523 & 0.946 & 1.146 & & & 0.764 & 0.824 \\
\hline & & & & & CONTROL & 0.511 & 0.563 & 0.454 & 0.498 & 0.946 & 1.146 & & & 0.764 & 0.824 \\
\hline G1 & 100 & 11.5 & 4 & 25 & 2x Cross-Frames & 0.498 & 0.542 & 0.444 & 0.484 & 0.946 & 1.146 & & & 0.764 & 0.824 \\
\hline GI & 100 & 11.5 & 4 & 25 & No Barrier & 0.538 & 0.595 & 0.544 & 0.607 & 0.946 & 1.146 & & & 0.764 & 0.824 \\
\hline & & & & & No Cross-Frames & 0.536 & 0.598 & 0.474 & 0.525 & 0.946 & 1.146 & & & 0.764 & 0.824 \\
\hline & & & & & CONTROL & 0.413 & 0.453 & 0.401 & 0.445 & 0.861 & 1.128 & & & 0.652 & 0.706 \\
\hline & & & & & 2x Cross-Frames & 0.402 & 0.434 & 0.393 & 0.431 & 0.861 & 1.128 & & & 0.652 & 0.706 \\
\hline G2 & 200 & 8.625 & 5 & 20 & No Barrier & 0.426 & 0.469 & 0.437 & 0.488 & 0.861 & 1.128 & & & 0.652 & 0.706 \\
\hline & & & & & No Cross-Frames & 0.440 & 0.495 & 0.424 & 0.479 & 0.861 & 1.128 & & & 0.652 & 0.706 \\
\hline & & & & & CONTROL & 0.414 & 0.454 & 0.402 & 0.447 & 0.861 & 1.128 & & & 0.652 & $\overline{0.706}$ \\
\hline & & & & & 2x Cross-Frames & 0.403 & 0.435 & 0.394 & 0.433 & 0.861 & 1.128 & & & 0.652 & 0.706 \\
\hline G2 & 200 & 8.625 & 5 & 25 & No Barrier & 0.427 & 0.471 & 0.438 & 0.491 & 0.861 & 1.128 & & & 0.652 & 0.706 \\
\hline & & & & & No Cross-Frames & 0.440 & 0.495 & 0.424 & 0.479 & 0.861 & 1.128 & & & 0.652 & 0.706 \\
\hline & & & & & CONTROL & 0.486 & 0.525 & 0.468 & 0.509 & 0.946 & 1.146 & & & 0.764 & 0.824 \\
\hline G2 & & & & & 2x Cross-Frames & 0.477 & 0.510 & 0.460 & 0.497 & 0.946 & 1.146 & & & 0.764 & 0.824 \\
\hline G2 & 200 & 11.5 & 4 & 20 & No Barrier & 0.499 & 0.542 & 0.507 & 0.556 & 0.946 & 1.146 & & & 0.764 & 0.824 \\
\hline & & & & & No Cross-Frames & 0.513 & 0.566 & 0.491 & 0.543 & 0.946 & 1.146 & & & 0.764 & 0.824 \\
\hline & & & & & CONTROL & 0.487 & 0.526 & 0.469 & 0.511 & 0.946 & 1.146 & & & 0.764 & 0.824 \\
\hline$G_{2}$ & 200 & 115 & 4 & 25 & 2x Cross-Frames & 0.477 & 0.510 & 0.461 & 0.498 & 0.946 & 1.146 & & & 0.764 & 0.824 \\
\hline G2 & 200 & 11.5 & 4 & 25 & No Barrier & 0.500 & 0.544 & 0.508 & 0.558 & 0.946 & 1.146 & & & 0.764 & 0.824 \\
\hline & & & & & No Cross-Frames & 0.513 & 0.566 & 0.491 & 0.543 & 0.946 & 1.146 & & & 0.764 & 0.824 \\
\hline
\end{tabular}




\begin{tabular}{|c|c|c|c|c|c|c|c|c|c|c|c|c|c|c|c|}
\hline \multicolumn{16}{|c|}{$\begin{array}{l}\text { Comparis on of the Effect of Overhang Width }(\mathbf{O H}) \\
\text { (bending moment, two lanes loaded) }\end{array}$} \\
\hline \multirow{2}{*}{\multicolumn{6}{|c|}{ Cons tant Parameters }} & \multicolumn{10}{|c|}{ Exterior Girder Dis tribution Factors (organized by method and varied parame te rs) } \\
\hline & & & & & & \multicolumn{2}{|c|}{ Stallings/Yoo } & \multicolumn{2}{|c|}{ Tarhini/Fre derick } & \multicolumn{2}{|c|}{ Lever Rule } & \multicolumn{2}{|c|}{ AASHTO Mod. } & \multicolumn{2}{|c|}{ Special Analys is } \\
\hline Girder & L (ft) & S (ft) & $\mathbf{N}_{\mathbf{b}}$ & $\mathbf{L}_{\mathbf{b}}(\mathbf{f t})$ & Iteration & $46 "$ & 69" & $46 "$ & 69" & 46" & 69" & $46 "$ & $69 "$ & $46 "$ & $69^{\prime \prime}$ \\
\hline \multirow{4}{*}{ G1 } & \multirow{4}{*}{100} & \multirow{4}{*}{8.625} & \multirow{4}{*}{5} & \multirow{4}{*}{20} & CONTROL & 0.620 & 0.708 & 0.562 & 0.645 & & & 0.692 & 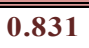 & 0.809 & 0.898 \\
\hline & & & & & 2x Cross-Frames & 0.625 & 0.704 & 0.565 & 0.641 & & & 0.692 & 0.831 & 0.809 & 0.898 \\
\hline & & & & & No Barrier & 0.669 & 0.769 & 0.669 & 0.775 & & & 0.692 & 0.831 & 0.809 & 0.898 \\
\hline & & & & & No Cross-Frames & 0.630 & 0.732 & 0.572 & 0.667 & & & 0.692 & 0.831 & 0.809 & 0.898 \\
\hline \multirow{4}{*}{ G1 } & \multirow{4}{*}{100} & \multirow{4}{*}{8.625} & \multirow{4}{*}{5} & \multirow{4}{*}{25} & CONTROL & 0.616 & 0.703 & 0.565 & 0.649 & & & 0.692 & 0.831 & 0.809 & 0.898 \\
\hline & & & & & 2x Cross-Frames & 0.625 & 0.701 & 0.570 & 0.646 & & & 0.692 & 0.831 & 0.809 & 0.898 \\
\hline & & & & & No Barrier & 0.664 & 0.762 & 0.673 & 0.778 & & & 0.692 & 0.831 & 0.809 & 0.898 \\
\hline & & & & & No Cross-Frames & 0.624 & 0.725 & 0.575 & 0.670 & & & 0.692 & 0.831 & 0.809 & 0.898 \\
\hline \multirow{4}{*}{ G1 } & \multirow{4}{*}{100} & \multirow{4}{*}{11.5} & \multirow{4}{*}{4} & \multirow{4}{*}{20} & CONTROL & 0.749 & 0.843 & 0.671 & 0.759 & & & 0.851 & 1.022 & 0.960 & 1.060 \\
\hline & & & & & 2x Cross-Frames & 0.754 & 0.838 & 0.673 & 0.753 & & & 0.851 & 1.022 & 0.960 & 1.060 \\
\hline & & & & & No Barrier & 0.799 & 0.903 & 0.794 & 0.904 & & & 0.851 & 1.022 & 0.960 & 1.060 \\
\hline & & & & & No Cross-Frames & 0.760 & 0.867 & 0.682 & 0.781 & & & 0.851 & 1.022 & 0.960 & 1.060 \\
\hline & & & & & CONTROL & 0.744 & 0.838 & 0.673 & 0.763 & & & 0.851 & 1.022 & 0.960 & 1.060 \\
\hline G1 & 100 & 11.5 & 4 & 25 & 2x Cross-Frames & 0.752 & 0.835 & 0.677 & 0.758 & & & 0.851 & 1.022 & 0.960 & 1.060 \\
\hline GI & 100 & 11.5 & 4 & 25 & No Barrier & 0.794 & 0.896 & 0.799 & 0.908 & & & 0.851 & 1.022 & 0.960 & 1.060 \\
\hline & & & & & No Cross-Frames & 0.753 & 0.860 & 0.685 & 0.785 & & & 0.851 & 1.022 & 0.960 & 1.060 \\
\hline & & & & & CONTROL & 0.628 & 0.698 & 0.608 & 0.685 & & & 0.670 & 0.804 & 0.809 & 0.898 \\
\hline & & & & & 2x Cross-Frames & 0.634 & 0.695 & 0.612 & 0.682 & & & 0.670 & 0.804 & 0.809 & 0.898 \\
\hline G2 & 200 & 8.625 & 5 & 20 & No Barrier & 0.647 & 0.722 & 0.657 & 0.743 & & & 0.670 & 0.804 & 0.809 & 0.898 \\
\hline & & & & & No Cross-Frames & 0.629 & 0.718 & 0.610 & 0.704 & & & 0.670 & 0.804 & 0.809 & 0.898 \\
\hline & & & & & CONTROL & 0.627 & 0.698 & 0.607 & 0.685 & & & 0.670 & 0.804 & 0.809 & 0.898 \\
\hline & & & & & 2x Cross-Frames & 0.634 & 0.695 & 0.612 & 0.682 & & & 0.670 & 0.804 & 0.809 & 0.898 \\
\hline G2 & 200 & 8.625 & 5 & 25 & No Barrier & 0.646 & 0.722 & 0.656 & 0.744 & & & 0.670 & 0.804 & 0.809 & 0.898 \\
\hline & & & & & No Cross-Frames & 0.629 & 0.718 & 0.611 & 0.704 & & & 0.670 & 0.804 & 0.809 & 0.898 \\
\hline & & & & & CONTROL & 0.759 & 0.834 & 0.729 & 0.809 & & & 0.823 & 0.988 & 0.960 & 1.060 \\
\hline & & & & & 2x Cross-Frames & 0.766 & 0.832 & 0.734 & 0.807 & & & 0.823 & 0.988 & 0.960 & 1.060 \\
\hline G2 & 200 & 11.5 & 4 & 20 & No Barrier & 0.778 & 0.857 & 0.785 & 0.874 & & & 0.823 & 0.988 & 0.960 & 1.060 \\
\hline & & & & & No Cross-Frames & 0.758 & 0.852 & 0.731 & 0.827 & & & 0.823 & 0.988 & 0.960 & 1.060 \\
\hline & & & & & CONTROL & 0.758 & 0.833 & 0.727 & 0.809 & & & 0.823 & 0.988 & 0.960 & 1.060 \\
\hline C? & 200 & 115 & 4 & 25 & 2x Cross-Frames & 0.765 & 0.832 & 0.733 & 0.807 & & & 0.823 & 0.988 & 0.960 & 1.060 \\
\hline G2 & 200 & 11.5 & 4 & 25 & No Barrier & 0.777 & 0.857 & 0.784 & 0.874 & & & 0.823 & 0.988 & 0.960 & 1.060 \\
\hline & & & & & No Cross-Frames & 0.758 & 0.852 & 0.731 & 0.828 & & & 0.823 & 0.988 & 0.960 & 1.060 \\
\hline
\end{tabular}




\begin{tabular}{|c|c|c|c|c|c|c|c|c|c|c|c|c|c|c|c|}
\hline \multicolumn{16}{|c|}{$\begin{array}{l}\text { Comparis on of the Effect of Overhang Width }(\mathbf{O H}) \\
\text { (bending moment, three lanes loaded) }\end{array}$} \\
\hline \multirow{2}{*}{\multicolumn{6}{|c|}{ Constant Parameters }} & \multicolumn{10}{|c|}{ Exte rior Girder Dis tribution Factors (organized by me thod and $v$ aried parame te rs) } \\
\hline & & & & & & \multicolumn{2}{|c|}{ Stallings/Yoo } & \multicolumn{2}{|c|}{ Tarhini/Fre derick } & \multicolumn{2}{|c|}{ Lever Rule } & \multicolumn{2}{|c|}{ AASHTO Mod. } & \multicolumn{2}{|c|}{ Special Analys is } \\
\hline Girder & $\mathbf{L}(\mathbf{f t})$ & S (ft) & $\mathbf{N}_{\mathbf{b}}$ & $\mathbf{L}_{\mathbf{b}}(\mathrm{ft})$ & Iteration & $46 "$ & $69 "$ & $46 "$ & 69" & 46" & 69" & $46 "$ & $69 "$ & $46 "$ & $69 "$ \\
\hline \multirow{4}{*}{ G1 } & \multirow{4}{*}{100} & \multirow{4}{*}{8.625} & \multirow{4}{*}{5} & \multirow{4}{*}{20} & CONTROL & 0.692 & 0.792 & 0.632 & 0.731 & & & 0.692 & 0.831 & 0.676 & 0.790 \\
\hline & & & & & 2x Cross-Frames & 0.713 & 0.805 & 0.648 & 0.740 & & & 0.692 & 0.831 & 0.676 & 0.790 \\
\hline & & & & & No Barrier & 0.746 & 0.863 & 0.745 & 0.869 & & & 0.692 & 0.831 & 0.676 & 0.790 \\
\hline & & & & & No Cross-Frames & 0.681 & 0.793 & 0.624 & 0.735 & & & 0.692 & 0.831 & 0.676 & 0.790 \\
\hline \multirow{4}{*}{ G1 } & \multirow{4}{*}{100} & \multirow{4}{*}{8.625} & \multirow{4}{*}{5} & \multirow{4}{*}{25} & CONTROL & 0.688 & 0.786 & 0.634 & 0.734 & & & 0.692 & 0.831 & 0.676 & 0.790 \\
\hline & & & & & 2x Cross-Frames & 0.714 & 0.805 & 0.652 & 0.746 & & & 0.692 & 0.831 & 0.676 & 0.790 \\
\hline & & & & & No Barrier & 0.741 & 0.856 & 0.748 & 0.872 & & & 0.692 & 0.831 & 0.676 & 0.790 \\
\hline & & & & & No Cross-Frames & 0.674 & 0.785 & 0.627 & 0.738 & & & 0.692 & 0.831 & 0.676 & 0.790 \\
\hline \multirow{4}{*}{ G1 } & \multirow{4}{*}{100} & \multirow{4}{*}{11.5} & \multirow{4}{*}{4} & \multirow{4}{*}{20} & CONTROL & 0.849 & 0.958 & 0.765 & 0.872 & & & 0.851 & 1.022 & 0.825 & 0.952 \\
\hline & & & & & 2x Cross-Frames & 0.871 & 0.972 & 0.782 & 0.882 & & & 0.851 & 1.022 & 0.825 & 0.952 \\
\hline & & & & & No Barrier & 0.905 & 1.031 & 0.899 & 1.031 & & & 0.851 & 1.022 & 0.825 & 0.952 \\
\hline & & & & & No Cross-Frames & 0.837 & 0.959 & 0.757 & 0.876 & & & 0.851 & 1.022 & 0.825 & 0.952 \\
\hline & & & & & CONTROL & 0.843 & 0.952 & 0.767 & 0.876 & & & 0.851 & 1.022 & 0.825 & 0.952 \\
\hline G1 & 100 & 115 & 4 & 25 & 2x Cross-Frames & 0.870 & 0.971 & 0.785 & 0.887 & & & 0.851 & 1.022 & 0.825 & 0.952 \\
\hline GI & 100 & 11.5 & 4 & 25 & No Barrier & 0.899 & 1.023 & 0.903 & 1.035 & & & 0.851 & 1.022 & 0.825 & 0.952 \\
\hline & & & & & No Cross-Frames & 0.829 & 0.950 & 0.761 & 0.881 & & & 0.851 & 1.022 & 0.825 & 0.952 \\
\hline & & & & & CONTROL & 0.732 & 0.820 & 0.707 & 0.803 & & & 0.670 & 0.804 & 0.676 & 0.790 \\
\hline & & & & & 2x Cross-Frames & 0.750 & 0.831 & 0.721 & 0.812 & & & 0.670 & 0.804 & 0.676 & 0.790 \\
\hline G2 & 200 & 8.625 & 5 & 20 & No Barrier & 0.749 & 0.845 & 0.759 & 0.866 & & & 0.670 & 0.804 & 0.676 & 0.790 \\
\hline & & & & & No Cross-Frames & 0.709 & 0.812 & 0.690 & 0.800 & & & 0.670 & 0.804 & 0.676 & 0.790 \\
\hline & & & & & CONTROL & 0.730 & 0.818 & 0.705 & 0.802 & & & 0.670 & 0.804 & 0.676 & 0.790 \\
\hline & & & & 25 & 2x Cross-Frames & 0.748 & 0.830 & 0.719 & 0.810 & & & 0.670 & 0.804 & 0.676 & 0.790 \\
\hline G2 & 200 & 8.625 & 5 & 25 & No Barrier & 0.748 & 0.843 & 0.757 & 0.865 & & & 0.670 & 0.804 & 0.676 & 0.790 \\
\hline & & & & & No Cross-Frames & 0.709 & 0.812 & 0.690 & 0.800 & & & 0.670 & 0.804 & 0.676 & 0.790 \\
\hline & & & & & CONTROL & 0.898 & 0.993 & 0.861 & 0.964 & & & 0.823 & 0.988 & 0.825 & 0.952 \\
\hline & 200 & & & 20 & 2x Cross-Frames & 0.917 & 1.007 & 0.877 & 0.974 & & & 0.823 & 0.988 & 0.825 & 0.952 \\
\hline G2 & 200 & 11.5 & 4 & 20 & No Barrier & 0.915 & 1.018 & 0.922 & 1.035 & & & 0.823 & 0.988 & 0.825 & 0.952 \\
\hline & & & & & No Cross-Frames & 0.868 & 0.979 & 0.838 & 0.955 & & & 0.823 & 0.988 & 0.825 & 0.952 \\
\hline & & & & & CONTROL & 0.895 & 0.991 & 0.858 & 0.961 & & & 0.823 & 0.988 & 0.825 & 0.952 \\
\hline G2 & 200 & 115 & 4 & 25 & 2x Cross-Frames & 0.915 & 1.006 & 0.874 & 0.972 & & & 0.823 & 0.988 & 0.825 & 0.952 \\
\hline GL & 200 & 11.5 & 4 & 25 & No Barrier & 0.913 & 1.016 & 0.919 & 1.033 & & & 0.823 & 0.988 & 0.825 & 0.952 \\
\hline & & & & & No Cross-Frames & 0.868 & 0.979 & 0.839 & 0.955 & & & 0.823 & 0.988 & 0.825 & 0.952 \\
\hline
\end{tabular}




\begin{tabular}{|c|c|c|c|c|c|c|c|c|c|c|c|c|c|c|c|}
\hline \multirow{2}{*}{\multicolumn{12}{|c|}{$\begin{array}{l}\text { Comparis on of the Effect of } \mathbf{B} \text { arrier Presence / B arrier Stiffiness } \\
\text { (bending moment, one lane loaded) }\end{array}$}} & \multirow{2}{*}{\multicolumn{4}{|c|}{$\frac{100 \% \text { Represents Full Scale Barrier }}{0 \% \text { Represents No Barrier }}$}} \\
\hline & & & & & & & & & & & & & & & \\
\hline \multirow{2}{*}{\multicolumn{6}{|c|}{ Constant Parameters }} & \multicolumn{10}{|c|}{ Exterior Girde $r$ Dis tribution Factors (organize d by method and $v$ aried parame ters) } \\
\hline & & & & & & \multicolumn{2}{|c|}{ Stallings/Yoo } & \multicolumn{2}{|c|}{ Tarhini/Frederick } & \multicolumn{2}{|c|}{ Lever Rule } & \multicolumn{2}{|c|}{ AASHTO Mod. } & \multicolumn{2}{|c|}{ Spe cial Analys is } \\
\hline Girder & $\mathbf{L}(\mathbf{f t})$ & S (ft) & $\mathbf{N}_{\mathbf{b}}$ & $\mathbf{L}_{\mathbf{b}}(\mathbf{f t})$ & OH (in) & $100 \%$ & $\mathbf{0 \%}$ & $100 \%$ & $\mathbf{0 \%}$ & $100 \%$ & $\mathbf{0 \%}$ & $100 \%$ & $0 \%$ & $100 \%$ & 0\% \\
\hline G1 & 100 & 8.625 & 5 & 20 & 46 & 0.441 & 0.470 & 0.391 & 0.471 & 0.861 & 0.861 & & & 0.652 & 0.652 \\
\hline G1 & 100 & 8.625 & 5 & 20 & 69 & 0.495 & 0.531 & 0.438 & 0.536 & 1.128 & 1.128 & & & 0.706 & 0.706 \\
\hline G1 & 100 & 8.625 & 5 & 20 & 46 & 0.436 & 0.464 & 0.393 & 0.473 & 0.861 & 0.861 & & & 0.652 & 0.652 \\
\hline G1 & 100 & 8.625 & 5 & 20 & 69 & 0.488 & 0.522 & 0.439 & 0.537 & 1.128 & 1.128 & & & 0.706 & 0.706 \\
\hline G1 & 100 & 8.625 & 5 & 20 & 46 & 0.515 & 0.543 & 0.451 & 0.542 & 0.946 & 0.946 & & & 0.764 & 0.764 \\
\hline G1 & 100 & 8.625 & 5 & 20 & 69 & 0.568 & 0.602 & 0.496 & 0.605 & 1.146 & 1.146 & & & 0.824 & 0.824 \\
\hline G1 & 100 & 8.625 & 5 & 20 & 46 & 0.511 & 0.538 & 0.454 & 0.544 & 0.946 & 0.946 & & & 0.764 & 0.764 \\
\hline G1 & 100 & 8.625 & 5 & 20 & 69 & 0.563 & 0.595 & 0.498 & 0.607 & 1.146 & 1.146 & & & 0.824 & 0.824 \\
\hline G2 & 200 & 8.625 & 5 & 20 & 46 & 0.413 & 0.426 & 0.401 & 0.437 & 0.861 & 0.861 & & & 0.652 & 0.652 \\
\hline G2 & 200 & 8.625 & 5 & 20 & 69 & 0.453 & 0.469 & 0.445 & 0.488 & 1.128 & 1.128 & & & 0.706 & 0.706 \\
\hline G2 & 200 & 8.625 & 5 & 20 & 46 & 0.414 & 0.427 & 0.402 & 0.438 & 0.861 & 0.861 & & & 0.652 & 0.652 \\
\hline G2 & 200 & 8.625 & 5 & 20 & 69 & 0.454 & 0.471 & 0.447 & 0.491 & 1.128 & 1.128 & & & 0.706 & 0.706 \\
\hline G2 & 200 & 8.625 & 5 & 20 & 46 & 0.486 & 0.499 & 0.468 & 0.507 & 0.946 & 0.946 & & & 0.764 & 0.764 \\
\hline G2 & 200 & 8.625 & 5 & 20 & 69 & 0.525 & 0.542 & 0.509 & 0.556 & 1.146 & 1.146 & & & 0.824 & 0.824 \\
\hline G2 & 200 & 8.625 & 5 & 20 & 46 & 0.487 & 0.500 & 0.469 & 0.508 & 0.946 & 0.946 & & & 0.764 & 0.764 \\
\hline G2 & 200 & 8.625 & 5 & 20 & 69 & 0.526 & 0.544 & 0.511 & 0.558 & 1.146 & 1.146 & & & 0.824 & 0.824 \\
\hline
\end{tabular}




\begin{tabular}{|c|c|c|c|c|c|c|c|c|c|c|c|c|c|c|c|}
\hline \multirow{2}{*}{\multicolumn{12}{|c|}{$\begin{array}{c}\text { Comparis on of the Effect of B arrier Prese nce / B arrier Stifiness } \\
\text { (bending moment, two lanes loaded) }\end{array}$}} & \multirow{2}{*}{\multicolumn{4}{|c|}{$\frac{100 \% \text { Represents Full Scale Barrier }}{0 \% \text { Represents No Barrier }}$}} \\
\hline & & & & & & & & & & & & & & & \\
\hline \multirow{2}{*}{\multicolumn{6}{|c|}{ Constant Parameters }} & \multicolumn{10}{|c|}{ Exterior Girder Dis tribution Factors (organized by method and $v$ aried parame ters) } \\
\hline & & & & & & \multicolumn{2}{|c|}{ Stallings/Yoo } & \multicolumn{2}{|c|}{ Tarhini/Frederick } & \multicolumn{2}{|c|}{ Lever Rule } & \multicolumn{2}{|c|}{ AASHTO Mod. } & \multicolumn{2}{|c|}{ Spe cial Analys is } \\
\hline Girder & L (ft) & $\mathbf{S}(\mathbf{f t})$ & $\mathbf{N}_{\mathbf{b}}$ & $\mathbf{L}_{\mathbf{b}}(\mathbf{f t})$ & OH (in) & $100 \%$ & $\mathbf{0 \%}$ & $100 \%$ & $\mathbf{0 \%}$ & $100 \%$ & $\mathbf{0 \%}$ & $100 \%$ & 0\% & $100 \%$ & 0\% \\
\hline G1 & 100 & 8.625 & 5 & 20 & 46 & 0.620 & 0.669 & 0.562 & 0.669 & & & 0.692 & 0.692 & 0.809 & 0.809 \\
\hline G1 & 100 & 8.625 & 5 & 20 & 69 & 0.708 & 0.769 & 0.645 & 0.775 & & & 0.831 & 0.831 & 0.898 & 0.898 \\
\hline G1 & 100 & 8.625 & 5 & 20 & 46 & 0.616 & 0.664 & 0.565 & 0.673 & & & 0.692 & 0.692 & 0.809 & 0.809 \\
\hline G1 & 100 & 8.625 & 5 & 20 & 69 & 0.703 & 0.762 & 0.649 & 0.778 & & & 0.831 & 0.831 & 0.898 & 0.898 \\
\hline G1 & 100 & 8.625 & 5 & 20 & 46 & 0.749 & 0.799 & 0.671 & 0.794 & & & 0.851 & 0.851 & 0.960 & 0.960 \\
\hline G1 & 100 & 8.625 & 5 & 20 & 69 & 0.843 & 0.903 & 0.759 & 0.904 & & & 1.022 & 1.022 & 1.060 & 1.060 \\
\hline G1 & 100 & 8.625 & 5 & 20 & 46 & 0.744 & 0.794 & 0.673 & 0.799 & & & 0.851 & 0.851 & 0.960 & 0.960 \\
\hline G1 & 100 & 8.625 & 5 & 20 & 69 & 0.838 & 0.896 & 0.763 & 0.908 & & & 1.022 & 1.022 & 1.060 & 1.060 \\
\hline G2 & 200 & 8.625 & 5 & 20 & 46 & 0.628 & 0.647 & 0.608 & 0.657 & & & 0.670 & 0.670 & 0.809 & 0.809 \\
\hline G2 & 200 & 8.625 & 5 & 20 & 69 & 0.698 & 0.722 & 0.685 & 0.743 & & & 0.804 & 0.804 & 0.898 & 0.898 \\
\hline G2 & 200 & 8.625 & 5 & 20 & 46 & 0.627 & 0.646 & 0.607 & 0.656 & & & 0.670 & 0.670 & 0.809 & 0.809 \\
\hline G2 & 200 & 8.625 & 5 & 20 & 69 & 0.698 & 0.722 & 0.685 & 0.744 & & & 0.804 & 0.804 & 0.898 & 0.898 \\
\hline G2 & 200 & 8.625 & 5 & 20 & 46 & 0.759 & 0.778 & 0.729 & 0.785 & & & 0.823 & 0.823 & 0.960 & 0.960 \\
\hline G2 & 200 & 8.625 & 5 & 20 & 69 & 0.834 & 0.857 & 0.809 & 0.874 & & & 0.988 & 0.988 & 1.060 & 1.060 \\
\hline G2 & 200 & 8.625 & 5 & 20 & 46 & 0.758 & 0.777 & 0.727 & 0.784 & & & 0.823 & 0.823 & 0.960 & 0.960 \\
\hline G2 & 200 & 8.625 & 5 & 20 & 69 & 0.833 & 0.857 & 0.809 & 0.874 & & & 0.988 & 0.988 & 1.060 & 1.060 \\
\hline
\end{tabular}




\begin{tabular}{|c|c|c|c|c|c|c|c|c|c|c|c|c|c|c|c|}
\hline \multirow{2}{*}{\multicolumn{12}{|c|}{$\begin{array}{c}\text { Comparis on of the Effect of } \mathbf{B} \text { arrier Pres e nce / B arrie r Stiffiness } \\
\text { (bending moment, three lanes loaded) }\end{array}$}} & \multirow{2}{*}{\multicolumn{4}{|c|}{$\frac{100 \% \text { Represents Full Scale Barrier }}{0 \% \text { Represents No Barrier }}$}} \\
\hline & & & & & & & & & & & & & & & \\
\hline \multirow{2}{*}{\multicolumn{6}{|c|}{ Cons tant Parameters }} & \multicolumn{10}{|c|}{ Exte rior Girder D is tribution Factors (organized by method and varied parame ters) } \\
\hline & & & & & & \multicolumn{2}{|c|}{ Stallings/Yoo } & \multicolumn{2}{|c|}{ Tarhini/Fre de rick } & \multicolumn{2}{|c|}{ Lever Rule } & \multicolumn{2}{|c|}{ AASHTO Mod. } & \multicolumn{2}{|c|}{ Spe cial Analys is } \\
\hline Girder & $\mathbf{L}(\mathbf{f t})$ & S (ft) & $\mathbf{N}_{\mathbf{b}}$ & $\mathbf{L}_{\mathbf{b}}$ (ft) & OH (in) & $100 \%$ & $\mathbf{0 \%}$ & $100 \%$ & $\mathbf{0 \%}$ & $100 \%$ & $\mathbf{0 \%}$ & $100 \%$ & 0\% & $100 \%$ & $0 \%$ \\
\hline G1 & 100 & 8.625 & $\overline{5}$ & 20 & 46 & $\overline{0.692}$ & 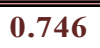 & 0.632 & 0.745 & & & 0.692 & $\overline{0.692}$ & $\overline{0.676}$ & 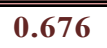 \\
\hline G1 & 100 & 8.625 & 5 & 20 & 69 & 0.792 & 0.863 & 0.731 & 0.869 & & & 0.831 & 0.831 & 0.790 & 0.790 \\
\hline G1 & 100 & 8.625 & 5 & 20 & 46 & 0.688 & 0.741 & 0.634 & 0.748 & & & 0.692 & 0.692 & 0.676 & 0.676 \\
\hline G1 & 100 & 8.625 & 5 & 20 & 69 & 0.786 & 0.856 & 0.734 & 0.872 & & & 0.831 & 0.831 & 0.790 & 0.790 \\
\hline G1 & 100 & 8.625 & 5 & 20 & 46 & 0.849 & 0.905 & 0.765 & 0.899 & & & 0.851 & 0.851 & 0.825 & 0.825 \\
\hline G1 & 100 & 8.625 & 5 & 20 & 69 & 0.958 & 1.031 & 0.872 & 1.031 & & & 1.022 & 1.022 & 0.952 & 0.952 \\
\hline G1 & 100 & 8.625 & 5 & 20 & 46 & 0.843 & 0.899 & 0.767 & 0.903 & & & 0.851 & 0.851 & 0.825 & 0.825 \\
\hline G1 & 100 & 8.625 & 5 & 20 & 69 & 0.952 & 1.023 & 0.876 & 1.035 & & & 1.022 & 1.022 & 0.952 & 0.952 \\
\hline G2 & 200 & 8.625 & 5 & 20 & 46 & 0.732 & 0.749 & 0.707 & 0.759 & & & 0.670 & 0.670 & 0.676 & 0.676 \\
\hline G2 & 200 & 8.625 & 5 & 20 & 69 & 0.820 & 0.845 & 0.803 & 0.866 & & & 0.804 & 0.804 & 0.790 & 0.790 \\
\hline G2 & 200 & 8.625 & 5 & 20 & 46 & 0.730 & 0.748 & 0.705 & 0.757 & & & 0.670 & 0.670 & 0.676 & 0.676 \\
\hline G2 & 200 & 8.625 & 5 & 20 & 69 & 0.818 & 0.843 & 0.802 & 0.865 & & & 0.804 & 0.804 & 0.790 & 0.790 \\
\hline G2 & 200 & 8.625 & 5 & 20 & 46 & 0.898 & 0.915 & 0.861 & 0.922 & & & 0.823 & 0.823 & 0.825 & 0.825 \\
\hline G2 & 200 & 8.625 & 5 & 20 & 69 & 0.993 & 1.018 & 0.964 & 1.035 & & & 0.988 & 0.988 & 0.952 & 0.952 \\
\hline G2 & 200 & 8.625 & 5 & 20 & 46 & 0.895 & 0.913 & 0.858 & 0.919 & & & 0.823 & 0.823 & 0.825 & 0.825 \\
\hline G2 & 200 & 8.625 & 5 & 20 & 69 & 0.991 & 1.016 & 0.961 & 1.033 & & & 0.988 & 0.988 & 0.952 & 0.952 \\
\hline
\end{tabular}




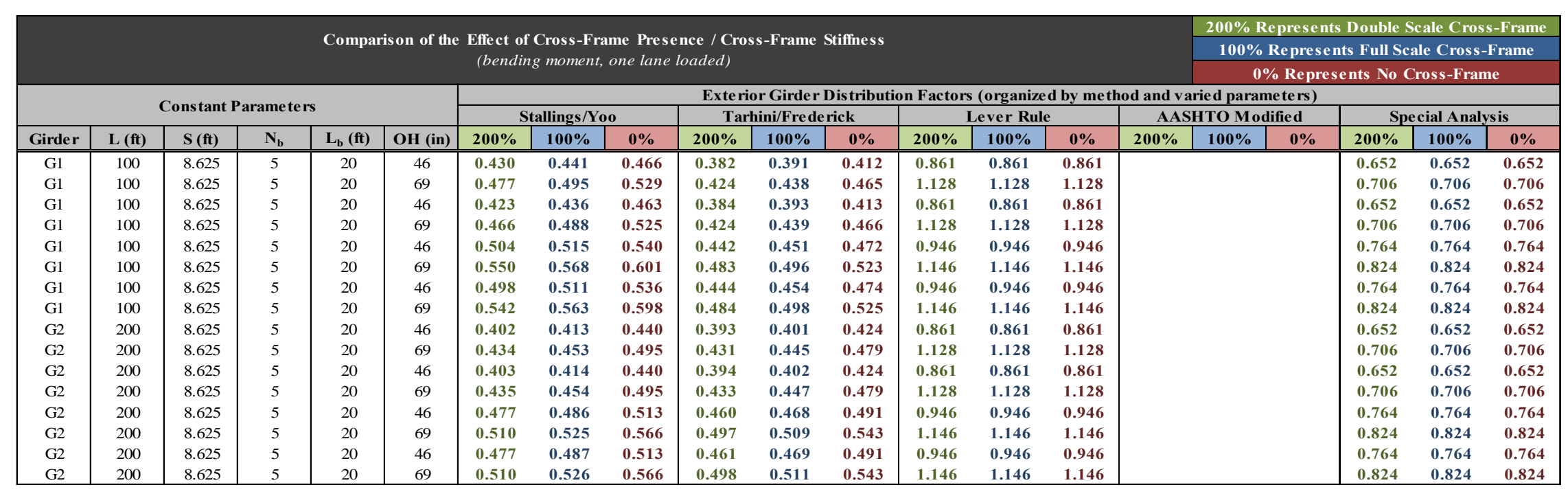

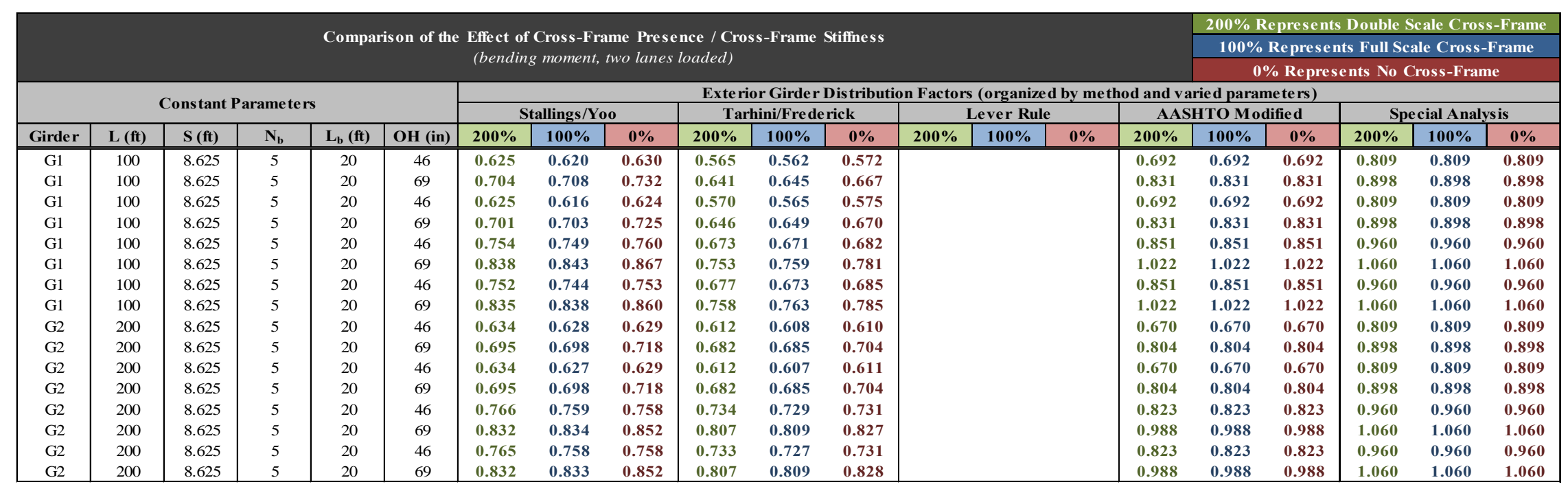




\begin{tabular}{|c|c|c|c|c|c|c|c|c|c|c|c|c|c|c|c|c|c|c|c|c|}
\hline & & & & Compa & son of the & $\begin{array}{l}\text { Effect o } \\
\text { (bendin }\end{array}$ & Cross-Fr & $\begin{array}{l}\text { ne Pres } \\
\text { ree lane }\end{array}$ & loaded) & -Frame & iffiness & & & & & \multicolumn{5}{|c|}{$\begin{array}{c}200 \% \text { Represents Double Scale Cross-Frame } \\
\text { 100\% Represents Full Scale Cross-Frame } \\
0 \% \text { Represents No Cross-Frame }\end{array}$} \\
\hline \multirow{2}{*}{\multicolumn{6}{|c|}{ Constant Parameters }} & \multirow{2}{*}{\multicolumn{15}{|c|}{ 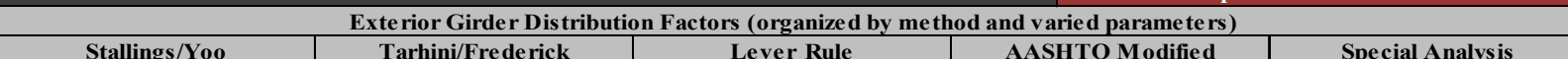 }} \\
\hline & & & & & & \multicolumn{3}{|c|}{ Stallings/Yoo } & & & & & & Lever Rule & \multicolumn{3}{|c|}{ AASHTO Modified } & \multicolumn{3}{|c|}{ Special Analys is } \\
\hline Girder & L (ft) & $S$ (ft) & $\mathbf{N}_{\mathrm{b}}$ & $L_{b}(\mathrm{ft})$ & OH (in) & $200 \%$ & $100 \%$ & $0 \%$ & $200 \%$ & $100 \%$ & $0 \%$ & $200 \%$ & $100 \%$ & $0 \%$ & $200 \%$ & $100 \%$ & $0 \%$ & $200 \%$ & $100 \%$ & $0 \%$ \\
\hline $\begin{array}{c}\text { G1 } \\
\end{array}$ & 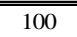 & 8.625 & 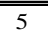 & 20 & 446 & 0.713 & 0.6992 & 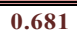 & 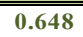 & 0.632 & 0.624 & & & & 0.692 & 0.6992 & $\overline{0.692}$ & 0.676 & 0.676 & 0.676 \\
\hline G1 & 100 & 8.625 & 5 & 20 & 69 & 0.805 & 0.792 & 0.793 & 0.740 & 0.731 & 0.735 & & & & 0.831 & 0.831 & 0.831 & 0.790 & 0.790 & 0.790 \\
\hline G1 & 100 & 8.625 & 5 & 20 & 46 & 0.714 & 0.688 & 0.674 & 0.652 & 0.634 & 0.627 & & & & 0.692 & 0.692 & 0.692 & 0.676 & 0.676 & 0.676 \\
\hline G1 & 100 & 8.625 & 5 & 20 & 69 & 0.805 & 0.786 & 0.785 & 0.746 & 0.734 & 0.738 & & & & 0.831 & 0.831 & 0.831 & 0.790 & 0.790 & 0.790 \\
\hline G1 & 100 & 8.625 & 5 & 20 & 46 & 0.871 & 0.849 & 0.837 & 0.782 & 0.765 & 0.757 & & & & 0.851 & 0.851 & 0.851 & 0.825 & 0.825 & 0.825 \\
\hline G1 & 100 & 8.625 & 5 & 20 & 69 & 0.972 & 0.958 & 0.959 & 0.882 & 0.872 & 0.876 & & & & 1.022 & 1.022 & 1.022 & 0.952 & 0.952 & 0.952 \\
\hline G1 & 100 & 8.625 & 5 & 20 & 46 & 0.870 & 0.843 & 0.829 & 0.785 & 0.767 & 0.761 & & & & 0.851 & 0.851 & 0.851 & 0.825 & 0.825 & 0.825 \\
\hline G1 & 100 & 8.625 & 5 & 20 & 69 & 0.971 & 0.952 & 0.950 & 0.887 & 0.876 & 0.881 & & & & 1.022 & 1.022 & 1.022 & 0.952 & 0.952 & 0.952 \\
\hline G2 & 200 & 8.625 & 5 & 20 & 46 & 0.750 & 0.732 & 0.709 & 0.721 & 0.707 & 0.690 & & & & 0.670 & 0.670 & 0.670 & 0.676 & 0.676 & 0.676 \\
\hline G2 & 200 & 8.625 & 5 & 20 & 69 & 0.831 & 0.820 & 0.812 & 0.812 & 0.803 & 0.800 & & & & 0.804 & 0.804 & 0.804 & 0.790 & 0.790 & 0.790 \\
\hline G2 & 200 & 8.625 & 5 & 20 & 46 & 0.748 & 0.730 & 0.709 & 0.719 & 0.705 & 0.690 & & & & 0.670 & 0.670 & 0.670 & 0.676 & 0.676 & 0.676 \\
\hline G2 & 200 & 8.625 & 5 & 20 & 69 & 0.830 & 0.818 & 0.812 & 0.810 & 0.802 & 0.800 & & & & 0.804 & 0.804 & 0.804 & 0.790 & 0.790 & 0.790 \\
\hline G2 & 200 & 8.625 & 5 & 20 & 46 & 0.917 & 0.898 & 0.868 & 0.877 & 0.861 & 0.838 & & & & 0.823 & 0.823 & 0.823 & 0.825 & 0.825 & 0.825 \\
\hline G2 & 200 & 8.625 & 5 & 20 & 69 & 1.007 & 0.993 & 0.979 & 0.974 & 0.964 & 0.955 & & & & 0.988 & 0.988 & 0.988 & 0.952 & 0.952 & 0.952 \\
\hline G2 & 200 & 8.625 & 5 & 20 & 46 & 0.915 & 0.895 & 0.868 & 0.874 & 0.858 & 0.839 & & & & 0.823 & 0.823 & 0.823 & 0.825 & 0.825 & 0.825 \\
\hline G2 & 200 & 8.625 & 5 & 20 & 69 & 1.006 & 0.991 & 0.979 & 0.972 & 0.961 & 0.955 & & & & 0.988 & 0.988 & 0.988 & 0.952 & 0.952 & 0.952 \\
\hline
\end{tabular}




\section{APPENDiX B: PARAMETRIC VARIATION \#1 Results}

The following appendix lists in tabular form the distribution factors calculated from the finite element models of Parametric Variation \#1 discussed in Section 6.2. For the reader's convenience, this data has been organized such that each table is focused on the influence of a single parameter on exterior girder live load distribution. These tables are then further discretized based on the number of lanes loaded.

These tables follow the same format as the ones listed in Appendix A. In these tables, the following nomenclature is used.

- $\quad \mathrm{S}=$ girder spacing (feet)

- $\quad \mathrm{L}=$ span length (feet)

- $\mathrm{N}_{\mathrm{b}}=$ number of beams

- $\quad \mathrm{L}_{\mathrm{b}}=$ unbraced length (feet)

- $\mathrm{OH}=$ overhang width (inches)

Also, references are made to the different types of girders used in the sensitivity matrix. For these tables, “G1" represents the girder that was designed and implemented for the bridges with a 100-foot span length whereas "G2" represents the girder that was designed and implemented for the 200-foot-span bridges. However, for the majority of this matrix, as discussed in Section 6.2, most of these bridges were modeled with G2.

In addition to the parameters investigated in this variation, the matrix also encompassed the parameters investigated in the sensitivity study discussed in Chapter 5. Therefore, for the reader's convenience, comparisons between these parameters (cross-frame stiffness, unbraced length, etc.) have also been provided. 


\begin{tabular}{|c|c|c|c|c|c|c|c|c|c|c|c|c|c|c|c|}
\hline \multicolumn{16}{|c|}{$\begin{array}{l}\text { Comparis on of the Effect of Girder Stiffiness } \\
\text { (bending moment, one lane loaded) }\end{array}$} \\
\hline \multirow{2}{*}{\multicolumn{6}{|c|}{ Cons tant Parameters }} & \multicolumn{10}{|c|}{ Dis tribution Factors (organized by method and varied parameters) } \\
\hline & & & & & & \multicolumn{2}{|c|}{ Stallings/Yoo } & \multicolumn{2}{|c|}{ Tarhini/Fre de rick } & \multicolumn{2}{|c|}{ Lever Rule } & \multicolumn{2}{|c|}{ AASHTO Mod. } & \multicolumn{2}{|c|}{ Spe cial Analys is } \\
\hline L (ft) & $\mathbf{S}(\mathbf{f t})$ & $\mathbf{N}_{\mathbf{b}}$ & $\mathbf{L}_{\mathrm{b}}(\mathbf{f t})$ & OH (in) & Iteration & G1 & G2 & G1 & G2 & G1 & G2 & G1 & G2 & G1 & G2 \\
\hline \multirow{4}{*}{100} & \multirow{4}{*}{8.625} & \multirow{4}{*}{5} & \multirow{4}{*}{20} & \multirow{4}{*}{46} & CONTROL & 0.441 & 0.488 & 0.391 & 0.461 & 0.861 & 0.861 & & & 0.652 & 0.652 \\
\hline & & & & & 2x Cross-Frames & 0.430 & 0.467 & 0.382 & 0.442 & 0.861 & 0.861 & & & 0.652 & 0.652 \\
\hline & & & & & No Barrier & 0.470 & 0.506 & 0.471 & 0.506 & 0.861 & 0.861 & & & 0.652 & 0.652 \\
\hline & & & & & No Cross-Frames & 0.466 & 0.532 & 0.412 & 0.502 & 0.861 & 0.861 & & & 0.652 & 0.652 \\
\hline \multirow{4}{*}{100} & \multirow{4}{*}{8.625} & \multirow{4}{*}{5} & \multirow{4}{*}{20} & \multirow{4}{*}{69} & CONTROL & 0.495 & 0.567 & 0.438 & 0.536 & 1.128 & 1.128 & & & 0.706 & 0.706 \\
\hline & & & & & 2x Cross-Frames & 0.477 & 0.533 & 0.424 & 0.506 & 1.128 & 1.128 & & & 0.706 & 0.706 \\
\hline & & & & & No Barrier & 0.531 & 0.591 & 0.536 & 0.596 & 1.128 & 1.128 & & & 0.706 & 0.706 \\
\hline & & & & & No Cross-Frames & 0.529 & 0.627 & 0.465 & 0.592 & 1.128 & 1.128 & & & 0.706 & 0.706 \\
\hline \multirow{4}{*}{100} & \multirow{4}{*}{8.625} & \multirow{4}{*}{5} & \multirow{4}{*}{25} & \multirow{4}{*}{46} & CONTROL & 0.436 & 0.479 & 0.393 & 0.464 & 0.861 & 0.861 & & & 0.652 & 0.652 \\
\hline & & & & & 2x Cross-Frames & 0.423 & 0.454 & 0.384 & 0.445 & 0.861 & 0.861 & & & 0.652 & 0.652 \\
\hline & & & & & No Barrier & 0.464 & 0.496 & 0.473 & 0.508 & 0.861 & 0.861 & & & 0.652 & 0.652 \\
\hline & & & & & No Cross-Frames & 0.463 & 0.527 & 0.413 & 0.504 & 0.861 & 0.861 & & & 0.652 & 0.652 \\
\hline & & & & & CONTROL & 0.488 & 0.552 & 0.439 & 0.538 & 1.128 & 1.128 & & & 0.706 & 0.706 \\
\hline & & & & & 2x Cross-Frames & 0.466 & 0.508 & 0.424 & 0.506 & 1.128 & 1.128 & & & 0.706 & 0.706 \\
\hline 100 & 8.625 & 5 & 25 & 69 & No Barrier & 0.522 & 0.574 & 0.537 & 0.597 & 1.128 & 1.128 & & & 0.706 & 0.706 \\
\hline & & & & & No Cross-Frames & 0.525 & 0.622 & 0.466 & 0.593 & 1.128 & 1.128 & & & 0.706 & 0.706 \\
\hline & & & & & CONTROL & 0.515 & 0.563 & 0.451 & 0.530 & 0.946 & 0.946 & & & 0.764 & 0.764 \\
\hline 100 & 115 & 4 & 20 & 46 & 2x Cross-Frames & 0.504 & 0.540 & 0.442 & 0.509 & 0.946 & 0.946 & & & 0.764 & 0.764 \\
\hline 100 & 11.5 & 4 & 20 & 46 & No Barrier & 0.543 & 0.580 & 0.542 & 0.577 & 0.946 & 0.946 & & & 0.764 & 0.764 \\
\hline & & & & & No Cross-Frames & 0.540 & 0.611 & 0.472 & 0.575 & 0.946 & 0.946 & & & 0.764 & 0.764 \\
\hline & & & & & CONTROL & 0.568 & 0.635 & 0.496 & 0.598 & 1.146 & 1.146 & & & 0.824 & 0.824 \\
\hline 100 & 115 & 4 & 20 & 60 & 2x Cross-Frames & 0.550 & 0.600 & 0.483 & 0.566 & 1.146 & 1.146 & & & 0.824 & 0.824 \\
\hline 100 & 11.5 & & & & No Barrier & 0.602 & 0.657 & 0.605 & 0.660 & 1.146 & 1.146 & & & 0.824 & 0.824 \\
\hline & & & & & No Cross-Frames & 0.601 & 0.699 & 0.523 & 0.656 & 1.146 & 1.146 & & & 0.824 & 0.824 \\
\hline & & & & & CONTROL & 0.511 & 0.556 & 0.454 & 0.534 & 0.946 & 0.946 & & & 0.764 & 0.764 \\
\hline & & & & & 2x Cross-Frames & 0.498 & 0.530 & 0.444 & 0.513 & 0.946 & 0.946 & & & 0.764 & 0.764 \\
\hline 100 & 11.5 & 4 & 25 & 46 & No Barrier & 0.538 & 0.572 & 0.544 & 0.581 & 0.946 & 0.946 & & & 0.764 & 0.764 \\
\hline & & & & & No Cross-Frames & 0.536 & 0.606 & 0.474 & 0.578 & 0.946 & 0.946 & & & 0.764 & 0.764 \\
\hline & & & & & CONTROL & 0.563 & 0.625 & 0.498 & 0.601 & 1.146 & 1.146 & & & 0.824 & 0.824 \\
\hline 100 & 115 & 4 & 25 & 60 & 2x Cross-Frames & 0.542 & 0.583 & 0.484 & 0.569 & 1.146 & 1.146 & & & 0.824 & 0.824 \\
\hline 100 & 11.5 & 4 & 25 & 69 & No Barrier & 0.595 & 0.645 & 0.607 & 0.662 & 1.146 & 1.146 & & & 0.824 & 0.824 \\
\hline & & & & & No Cross-Frames & 0.598 & 0.695 & 0.525 & 0.659 & 1.146 & 1.146 & & & 0.824 & 0.824 \\
\hline
\end{tabular}




\begin{tabular}{|c|c|c|c|c|c|c|c|c|c|c|c|c|c|c|c|}
\hline \multicolumn{16}{|c|}{$\begin{array}{l}\text { Comparis on of the Effect of Girder Stiffiness } \\
\text { (bending moment, two lanes loaded) }\end{array}$} \\
\hline \multirow{2}{*}{\multicolumn{6}{|c|}{ Constant Parameters }} & \multicolumn{10}{|c|}{ Distribution Factors (organized by method and varied parame ters) } \\
\hline & & & & & & \multicolumn{2}{|c|}{ Stallings/Yoo } & \multicolumn{2}{|c|}{ Tarhini/Frederick } & \multicolumn{2}{|c|}{ Lever Rule } & \multicolumn{2}{|c|}{ AASHTO Mod. } & \multicolumn{2}{|c|}{ Special Analys is } \\
\hline L (ft) & $\mathbf{S}(\mathbf{f t})$ & $\mathbf{N}_{\mathbf{b}}$ & $\mathbf{L}_{\mathbf{b}}(\mathbf{f t})$ & OH (in) & Iteration & G1 & G2 & G1 & G2 & G1 & G2 & G1 & G2 & G1 & G2 \\
\hline \multirow{4}{*}{100} & \multirow{4}{*}{8.625} & \multirow{4}{*}{5} & \multirow{4}{*}{20} & \multirow{4}{*}{46} & CONTROL & 0.620 & 0.639 & 0.562 & 0.612 & & & 0.692 & 0.807 & 0.809 & 0.809 \\
\hline & & & & & 2x Cross-Frames & 0.625 & 0.643 & 0.565 & 0.616 & & & 0.692 & 0.807 & 0.809 & 0.809 \\
\hline & & & & & No Barrier & 0.669 & 0.671 & 0.669 & 0.672 & & & 0.692 & 0.807 & 0.809 & 0.809 \\
\hline & & & & & No Cross-Frames & 0.630 & 0.666 & 0.572 & 0.639 & & & 0.692 & 0.807 & 0.809 & 0.809 \\
\hline \multirow{4}{*}{100} & \multirow{4}{*}{8.625} & \multirow{4}{*}{5} & \multirow{4}{*}{20} & \multirow{4}{*}{69} & CONTROL & 0.708 & 0.752 & 0.645 & 0.723 & & & 0.831 & 0.968 & 0.898 & 0.898 \\
\hline & & & & & 2x Cross-Frames & 0.704 & 0.742 & 0.641 & 0.713 & & & 0.831 & 0.968 & 0.898 & 0.898 \\
\hline & & & & & No Barrier & 0.769 & 0.795 & 0.775 & 0.800 & & & 0.831 & 0.968 & 0.898 & 0.898 \\
\hline & & & & & No Cross-Frames & 0.732 & 0.799 & 0.667 & 0.769 & & & 0.831 & 0.968 & 0.898 & 0.898 \\
\hline \multirow{4}{*}{100} & \multirow{4}{*}{8.625} & \multirow{4}{*}{5} & \multirow{4}{*}{25} & \multirow{4}{*}{46} & CONTROL & 0.616 & 0.634 & 0.565 & 0.616 & & & 0.692 & 0.807 & 0.809 & 0.809 \\
\hline & & & & & 2x Cross-Frames & 0.625 & 0.644 & 0.570 & 0.621 & & & 0.692 & 0.807 & 0.809 & 0.809 \\
\hline & & & & & No Barrier & 0.664 & 0.665 & 0.673 & 0.675 & & & 0.692 & 0.807 & 0.809 & 0.809 \\
\hline & & & & & No Cross-Frames & 0.624 & 0.657 & 0.575 & 0.643 & & & 0.692 & 0.807 & 0.809 & 0.809 \\
\hline & & & & & CONTROL & 0.703 & 0.743 & 0.649 & 0.727 & & & 0.831 & 0.968 & 0.898 & 0.898 \\
\hline & & & & & 2x Cross-Frames & 0.701 & 0.735 & 0.646 & 0.718 & & & 0.831 & 0.968 & 0.898 & 0.898 \\
\hline 100 & 8.625 & 5 & 25 & 69 & No Barrier & 0.762 & 0.784 & 0.778 & 0.802 & & & 0.831 & 0.968 & 0.898 & 0.898 \\
\hline & & & & & No Cross-Frames & 0.725 & 0.789 & 0.670 & 0.772 & & & 0.831 & 0.968 & 0.898 & 0.898 \\
\hline & & & & & CONTROL & 0.749 & 0.769 & 0.671 & 0.729 & & & 0.851 & 0.995 & 0.960 & 0.960 \\
\hline & & & & & 2x Cross-Frames & 0.754 & 0.774 & 0.673 & 0.733 & & & 0.851 & 0.995 & 0.960 & 0.960 \\
\hline 100 & 11.5 & 4 & 20 & 46 & No Barrier & 0.799 & 0.801 & 0.794 & 0.793 & & & 0.851 & 0.995 & 0.960 & 0.960 \\
\hline & & & & & No Cross-Frames & 0.760 & 0.796 & 0.682 & 0.755 & & & 0.851 & 0.995 & 0.960 & 0.960 \\
\hline & & & & & CONTROL & 0.843 & 0.888 & 0.759 & 0.844 & & & 1.022 & 1.194 & 1.060 & 1.060 \\
\hline & & & & & 2x Cross-Frames & 0.838 & 0.876 & 0.753 & 0.833 & & & 1.022 & 1.194 & 1.060 & 1.060 \\
\hline 100 & 11.5 & 4 & 20 & 69 & No Barrier & 0.903 & 0.928 & 0.904 & 0.923 & & & 1.022 & 1.194 & 1.060 & 1.060 \\
\hline & & & & & No Cross-Frames & 0.867 & 0.937 & 0.781 & 0.891 & & & 1.022 & 1.194 & 1.060 & 1.060 \\
\hline & & & & & CONTROL & 0.744 & 0.765 & 0.673 & 0.734 & & & 0.851 & 0.995 & 0.960 & 0.960 \\
\hline 100 & 11.5 & 4 & 25 & 46 & 2x Cross-Frames & 0.752 & 0.776 & 0.677 & 0.738 & & & 0.851 & 0.995 & 0.960 & 0.960 \\
\hline 100 & 11.5 & 4 & 25 & 40 & No Barrier & 0.794 & 0.796 & 0.799 & 0.798 & & & 0.851 & 0.995 & 0.960 & 0.960 \\
\hline & & & & & No Cross-Frames & 0.753 & 0.787 & 0.685 & 0.761 & & & 0.851 & 0.995 & 0.960 & 0.960 \\
\hline & & & & & CONTROL & 0.838 & 0.881 & 0.763 & 0.849 & & & 1.022 & 1.194 & 1.060 & 1.060 \\
\hline 100 & 11.5 & 4 & 25 & 69 & 2x Cross-Frames & 0.835 & 0.873 & 0.758 & 0.839 & & & 1.022 & 1.194 & 1.060 & 1.060 \\
\hline 100 & 11.5 & 4 & 25 & 69 & No Barrier & 0.896 & 0.919 & 0.908 & 0.928 & & & 1.022 & 1.194 & 1.060 & 1.060 \\
\hline & & & & & No Cross-Frames & 0.860 & 0.926 & 0.785 & 0.896 & & & 1.022 & 1.194 & 1.060 & 1.060 \\
\hline
\end{tabular}




\begin{tabular}{|c|c|c|c|c|c|c|c|c|c|c|c|c|c|c|c|}
\hline \multicolumn{16}{|c|}{$\begin{array}{l}\text { Comparis on of the Effect of Girder Stiffiness } \\
\text { (bending moment, three lanes loaded) }\end{array}$} \\
\hline \multirow{2}{*}{\multicolumn{6}{|c|}{ Constant Parameters }} & \multicolumn{10}{|c|}{ Distribution Factors (organized by method and varied parame ters) } \\
\hline & & & & & & \multicolumn{2}{|c|}{ Stallings/Yoo } & \multicolumn{2}{|c|}{ Tarhini/Frederick } & \multicolumn{2}{|c|}{ Lever Rule } & \multicolumn{2}{|c|}{ AASHTO Mod. } & \multicolumn{2}{|c|}{ Special Analys is } \\
\hline L (ft) & $\mathbf{S}(\mathbf{f t})$ & $\mathbf{N}_{\mathbf{b}}$ & $\mathbf{L}_{\mathbf{b}}(\mathbf{f t})$ & OH (in) & Ite ration & G1 & G2 & G1 & G2 & G1 & G2 & G1 & G2 & G1 & G2 \\
\hline \multirow{4}{*}{100} & \multirow{4}{*}{8.625} & \multirow{4}{*}{5} & \multirow{4}{*}{20} & \multirow{4}{*}{46} & CONTROL & 0.692 & 0.702 & 0.632 & 0.681 & & & 0.692 & 0.807 & 0.676 & 0.676 \\
\hline & & & & & 2x Cross-Frames & 0.713 & 0.717 & 0.648 & 0.694 & & & 0.692 & 0.807 & 0.676 & 0.676 \\
\hline & & & & & No Barrier & 0.746 & 0.734 & 0.745 & 0.741 & & & 0.692 & 0.807 & 0.676 & 0.676 \\
\hline & & & & & No Cross-Frames & 0.681 & 0.707 & 0.624 & 0.686 & & & 0.692 & 0.807 & 0.676 & 0.676 \\
\hline \multirow{4}{*}{100} & \multirow{4}{*}{8.625} & \multirow{4}{*}{5} & \multirow{4}{*}{20} & \multirow{4}{*}{69} & CONTROL & 0.792 & 0.823 & 0.731 & 0.804 & & & 0.831 & 0.968 & 0.790 & 0.790 \\
\hline & & & & & 2x Cross-Frames & 0.805 & 0.827 & 0.740 & 0.807 & & & 0.831 & 0.968 & 0.790 & 0.790 \\
\hline & & & & & No Barrier & 0.863 & 0.870 & 0.869 & 0.884 & & & 0.831 & 0.968 & 0.790 & 0.790 \\
\hline & & & & & No Cross-Frames & 0.793 & 0.849 & 0.735 & 0.830 & & & 0.831 & 0.968 & 0.790 & 0.790 \\
\hline \multirow{4}{*}{100} & \multirow{4}{*}{8.625} & \multirow{4}{*}{5} & \multirow{4}{*}{25} & \multirow{4}{*}{46} & CONTROL & 0.688 & 0.697 & 0.634 & 0.684 & & & 0.692 & 0.807 & 0.676 & 0.676 \\
\hline & & & & & 2x Cross-Frames & 0.714 & 0.718 & 0.652 & 0.698 & & & 0.692 & 0.807 & 0.676 & 0.676 \\
\hline & & & & & No Barrier & 0.741 & 0.727 & 0.748 & 0.744 & & & 0.692 & 0.807 & 0.676 & 0.676 \\
\hline & & & & & No Cross-Frames & 0.674 & 0.697 & 0.627 & 0.691 & & & 0.692 & 0.807 & 0.676 & 0.676 \\
\hline & & & & & CONTROL & 0.786 & 0.815 & 0.734 & 0.807 & & & 0.831 & 0.968 & 0.790 & 0.790 \\
\hline 100 & 8.625 & 5 & 25 & 69 & 2x Cross-Frames & 0.805 & 0.824 & 0.746 & 0.810 & & & 0.831 & 0.968 & 0.790 & 0.790 \\
\hline 100 & 8.025 & 5 & 25 & 69 & No Barrier & 0.856 & 0.859 & 0.872 & 0.886 & & & 0.831 & 0.968 & 0.790 & 0.790 \\
\hline & & & & & No Cross-Frames & 0.785 & $\mathbf{0 . 8 3 7}$ & 0.738 & 0.834 & & & 0.831 & 0.968 & 0.790 & 0.790 \\
\hline & & & & & CONTROL & 0.849 & 0.853 & 0.765 & 0.818 & & & 0.851 & 0.995 & 0.825 & 0.825 \\
\hline & & & & & 2x Cross-Frames & 0.871 & 0.874 & 0.782 & 0.838 & & & 0.851 & 0.995 & 0.825 & 0.825 \\
\hline 100 & 11.5 & 4 & 20 & 46 & No Barrier & 0.905 & 0.883 & 0.899 & 0.883 & & & 0.851 & 0.995 & 0.825 & 0.825 \\
\hline & & & & & No Cross-Frames & 0.837 & 0.849 & 0.757 & 0.815 & & & 0.851 & 0.995 & 0.825 & 0.825 \\
\hline & & & & & CONTROL & 0.958 & 0.983 & 0.872 & 0.949 & & & 1.022 & 1.194 & 0.952 & 0.952 \\
\hline & & & & & 2x Cross-Frames & 0.972 & 0.992 & 0.882 & 0.957 & & & 1.022 & 1.194 & 0.952 & 0.952 \\
\hline 100 & 11.5 & 4 & 20 & 69 & No Barrier & 1.031 & 1.028 & 1.031 & 1.033 & & & 1.022 & 1.194 & 0.952 & 0.952 \\
\hline & & & & & No Cross-Frames & 0.959 & 1.001 & 0.876 & 0.968 & & & 1.022 & 1.194 & 0.952 & 0.952 \\
\hline & & & & & CONTROL & 0.843 & 0.847 & 0.767 & 0.822 & & & 0.851 & 0.995 & 0.825 & 0.825 \\
\hline 100 & 11.5 & 4 & 25 & 46 & 2x Cross-Frames & 0.870 & 0.874 & 0.785 & 0.842 & & & 0.851 & 0.995 & 0.825 & 0.825 \\
\hline 100 & 11.5 & 4 & 25 & 40 & No Barrier & 0.899 & 0.876 & 0.903 & 0.887 & & & 0.851 & 0.995 & 0.825 & 0.825 \\
\hline & & & & & No Cross-Frames & 0.829 & 0.839 & 0.761 & 0.821 & & & 0.851 & 0.995 & 0.825 & 0.825 \\
\hline & & & & & CONTROL & 0.952 & 0.975 & 0.876 & 0.954 & & & 1.022 & 1.194 & 0.952 & 0.952 \\
\hline 100 & 11.5 & 4 & 25 & 69 & 2x Cross-Frames & 0.971 & 0.990 & 0.887 & 0.962 & & & 1.022 & 1.194 & 0.952 & 0.952 \\
\hline 100 & 11.5 & 4 & 25 & 69 & No Barrier & 1.023 & 1.018 & 1.035 & 1.036 & & & 1.022 & 1.194 & 0.952 & 0.952 \\
\hline & & & & & No Cross-Frames & 0.950 & 0.988 & 0.881 & 0.974 & & & 1.022 & 1.194 & 0.952 & 0.952 \\
\hline
\end{tabular}




\begin{tabular}{|c|c|c|c|c|c|c|c|c|c|c|c|c|c|c|c|}
\hline \multicolumn{16}{|c|}{$\begin{array}{l}\text { Comparis on of the Effect of Girder Spacing (S) } \\
\text { (bending moment, one lane loaded) }\end{array}$} \\
\hline \multirow{2}{*}{\multicolumn{6}{|c|}{ Constant Parameters }} & \multicolumn{10}{|c|}{ Dis tribution Factors (organized by me thod and varied parame ters) } \\
\hline & & & & & & \multicolumn{2}{|c|}{ Stallings / Yoo } & \multicolumn{2}{|c|}{ Tarhini / Frede rick } & \multicolumn{2}{|c|}{ Lever Rule } & \multicolumn{2}{|c|}{ AASHTO Mod. } & Special & nalys is \\
\hline Girder & $L(f t)$ & $\mathbf{N}_{\mathrm{b}}$ & $\mathbf{L}_{\mathrm{b}}$ (ft) & OH (in) & Iteration & $8.625^{\prime}$ & $11.5^{\prime}$ & $8.625^{\prime}$ & $11.5^{\prime}$ & $8.625^{\prime}$ & 11.5' & $8.625^{\prime}$ & 11.5 & $8.625^{\prime}$ & 11.5' \\
\hline & & & & & CONTROL & 0.502 & 0.563 & 0.472 & 0.527 & 0.861 & 0.946 & & & 0.738 & 0.764 \\
\hline & 100 & & 30 & & 2x Cross-Frames & 0.489 & 0.540 & 0.459 & 0.506 & 0.861 & 0.946 & & & 0.738 & 0.764 \\
\hline G2 & 100 & 4 & 20 & 46 & No Barrier & 0.521 & 0.580 & 0.521 & 0.574 & 0.861 & 0.946 & & & 0.738 & 0.764 \\
\hline & & & & & No Cross-Frames & 0.540 & 0.611 & 0.507 & 0.572 & 0.861 & 0.946 & & & 0.738 & 0.764 \\
\hline & & & & & CONTROL & 0.581 & 0.635 & 0.544 & 0.593 & 1.128 & 1.146 & & & 0.818 & 0.824 \\
\hline & & & 30 & 60 & 2x Cross-Frames & 0.555 & 0.600 & 0.521 & 0.561 & 1.128 & 1.146 & & & 0.818 & 0.824 \\
\hline G2 & 100 & 4 & 20 & 69 & No Barrier & 0.606 & 0.657 & 0.608 & 0.654 & 1.128 & 1.146 & & & 0.818 & 0.824 \\
\hline & & & & & No Cross-Frames & 0.637 & 0.699 & 0.595 & 0.651 & 1.128 & 1.146 & & & 0.818 & 0.824 \\
\hline & & & & & CONTROL & 0.495 & 0.556 & 0.474 & 0.531 & 0.861 & 0.946 & & & 0.738 & 0.764 \\
\hline $\mathrm{G}^{2}$ & 100 & 4 & 25 & & 2x Cross-Frames & 0.479 & 0.530 & 0.462 & 0.510 & 0.861 & 0.946 & & & 0.738 & 0.764 \\
\hline G2 & 100 & 4 & 25 & 46 & No Barrier & 0.512 & 0.572 & 0.523 & 0.578 & 0.861 & 0.946 & & & 0.738 & 0.764 \\
\hline & & & & & No Cross-Frames & 0.535 & 0.606 & 0.509 & 0.575 & 0.861 & 0.946 & & & 0.738 & 0.764 \\
\hline & & & & & CONTROL & 0.568 & 0.625 & 0.545 & 0.596 & 1.128 & 1.146 & & & 0.818 & 0.824 \\
\hline$G 2$ & 100 & 4 & 25 & & 2x Cross-Frames & 0.534 & 0.583 & 0.521 & 0.564 & 1.128 & 1.146 & & & 0.818 & 0.824 \\
\hline G2 & 100 & 4 & 25 & 69 & No Barrier & 0.590 & 0.645 & 0.609 & 0.657 & 1.128 & 1.146 & & & 0.818 & 0.824 \\
\hline & & & & & No Cross-Frames & 0.632 & 0.695 & 0.596 & 0.653 & 1.128 & 1.146 & & & 0.818 & 0.824 \\
\hline & & & & & CONTROL & 0.488 & 0.553 & 0.461 & 0.519 & 0.861 & 0.946 & & & 0.652 & 0.669 \\
\hline & & & & & 2x Cross-Frames & 0.467 & 0.525 & 0.442 & 0.494 & 0.861 & 0.946 & & & 0.652 & 0.669 \\
\hline G2 & 100 & 5 & 20 & 46 & No Barrier & 0.506 & 0.568 & 0.506 & 0.562 & 0.861 & 0.946 & & & 0.652 & 0.669 \\
\hline & & & & & No Cross-Frames & 0.532 & 0.600 & 0.502 & 0.563 & 0.861 & 0.946 & & & 0.652 & 0.669 \\
\hline & & & & & CONTROL & 0.567 & 0.626 & 0.533 & 0.585 & 1.128 & 1.146 & & & 0.706 & 0.709 \\
\hline 80 & 100 & 5 & 20 & 69 & 2x Cross-Frames & 0.533 & 0.586 & 0.503 & 0.549 & 1.128 & 1.146 & & & 0.706 & 0.709 \\
\hline G2 & 100 & 5 & 20 & 69 & No Barrier & 0.591 & 0.646 & 0.593 & 0.642 & 1.128 & 1.146 & & & 0.706 & 0.709 \\
\hline & & & & & No Cross-Frames & 0.627 & 0.687 & 0.589 & 0.640 & 1.128 & 1.146 & & & 0.706 & 0.709 \\
\hline & & & & & CONTROL & 0.479 & 0.545 & 0.464 & 0.523 & 0.861 & 0.946 & & & 0.652 & 0.669 \\
\hline 40 & 100 & 5 & 25 & 46 & 2x Cross-Frames & 0.454 & 0.513 & 0.445 & 0.498 & 0.861 & 0.946 & & & 0.652 & 0.669 \\
\hline G2 & 100 & 5 & 25 & 46 & No Barrier & 0.496 & 0.559 & 0.508 & 0.566 & 0.861 & 0.946 & & & 0.652 & 0.669 \\
\hline & & & & & No Cross-Frames & 0.527 & 0.595 & 0.504 & 0.566 & 0.861 & 0.946 & & & 0.652 & 0.669 \\
\hline & & & & & CONTROL & 0.552 & 0.614 & 0.535 & 0.588 & 1.128 & 1.146 & & & 0.706 & 0.709 \\
\hline$e^{2}$ & 100 & 5 & 25 & 69 & 2x Cross-Frames & 0.508 & 0.566 & 0.504 & 0.552 & 1.128 & 1.146 & & & 0.706 & 0.709 \\
\hline & & & 25 & & No Barrier & 0.574 & 0.633 & 0.594 & 0.645 & 1.128 & 1.146 & & & 0.706 & 0.709 \\
\hline & & & & & No Cross-Frames & 0.622 & 0.682 & 0.590 & 0.643 & 1.128 & 1.146 & & & 0.706 & 0.709 \\
\hline & & & & & CONTROL & 0.451 & 0.486 & 0.432 & 0.465 & 0.861 & 0.946 & & & 0.738 & 0.764 \\
\hline G2 & 200 & 4 & 20 & 46 & 2x Cross-Frames & 0.447 & 0.477 & 0.429 & 0.458 & 0.861 & 0.946 & & & 0.738 & 0.764 \\
\hline & & & & 46 & No Barrier & 0.466 & 0.499 & 0.475 & 0.504 & 0.861 & 0.946 & & & 0.738 & 0.764 \\
\hline & & & & & No Cross-Frames & 0.466 & 0.513 & 0.445 & 0.488 & 0.861 & 0.946 & & & 0.738 & 0.764 \\
\hline & & & & & CONTROL & 0.495 & 0.525 & 0.477 & 0.505 & 1.128 & 1.146 & & & 0.818 & 0.824 \\
\hline$G_{2}$ & 200 & 4 & 20 & 69 & 2x Cross-Frames & 0.485 & 0.510 & 0.470 & 0.493 & 1.128 & 1.146 & & & 0.818 & 0.824 \\
\hline & & & & 69 & No Barrier & 0.514 & 0.542 & 0.528 & 0.552 & 1.128 & 1.146 & & & 0.818 & 0.824 \\
\hline & & & & & No Cross-Frames & 0.520 & 0.566 & 0.497 & 0.538 & 1.128 & 1.146 & & & 0.818 & 0.824 \\
\hline & & & & & CONTROL & 0.451 & 0.487 & 0.432 & 0.466 & 0.861 & 0.946 & & & 0.738 & 0.764 \\
\hline $\mathrm{G}^{2}$ & 200 & 4 & 25 & 46 & 2x Cross-Frames & 0.446 & 0.477 & 0.429 & 0.459 & 0.861 & 0.946 & & & 0.738 & 0.764 \\
\hline G2 & 200 & 4 & 25 & 46 & No Barrier & 0.465 & 0.500 & 0.474 & 0.505 & 0.861 & 0.946 & & & 0.738 & 0.764 \\
\hline & & & & & No Cross-Frames & 0.464 & 0.513 & 0.443 & 0.488 & 0.861 & 0.946 & & & 0.738 & 0.764 \\
\hline & & & & & CONTROL & 0.496 & 0.526 & 0.478 & 0.506 & 1.128 & 1.146 & & & 0.818 & 0.824 \\
\hline$C ?$ & 20 & t & 25 & & 2x Cross-Frames & 0.485 & 0.510 & 0.470 & 0.494 & 1.128 & 1.146 & & & 0.818 & 0.824 \\
\hline G2 & 200 & 4 & 25 & 69 & No Barrier & 0.514 & 0.544 & 0.528 & 0.553 & 1.128 & 1.146 & & & 0.818 & 0.824 \\
\hline & & & & & No Cross-Frames & 0.520 & 0.566 & 0.497 & 0.538 & 1.128 & 1.146 & & & 0.818 & 0.824 \\
\hline & & & & & CONTROL & 0.413 & 0.453 & 0.401 & 0.438 & 0.861 & 0.946 & & & 0.652 & 0.669 \\
\hline 50 & 200 & 5 & 30 & 4 & 2x Cross-Frames & 0.402 & 0.435 & 0.393 & 0.423 & 0.861 & 0.946 & & & 0.652 & 0.669 \\
\hline G2 & 200 & 5 & 20 & 46 & No Barrier & 0.426 & 0.464 & 0.437 & 0.471 & 0.861 & 0.946 & & & 0.652 & 0.669 \\
\hline & & & & & No Cross-Frames & 0.440 & 0.497 & 0.424 & 0.476 & 0.861 & 0.946 & & & 0.652 & 0.669 \\
\hline & & & & & CONTROL & 0.453 & 0.489 & 0.443 & 0.476 & 1.128 & 1.146 & & & 0.706 & 0.709 \\
\hline $5 ?$ & 200 & 5 & 30 & 69 & 2x Cross-Frames & 0.434 & 0.463 & 0.429 & 0.454 & 1.128 & 1.146 & & & 0.706 & 0.709 \\
\hline G2 & 200 & 5 & 20 & 69 & No Barrier & 0.469 & 0.505 & 0.486 & 0.516 & 1.128 & 1.146 & & & 0.706 & 0.709 \\
\hline & & & & & No Cross-Frames & 0.495 & 0.550 & 0.477 & 0.526 & 1.128 & 1.146 & & & 0.706 & 0.709 \\
\hline & & & & & CONTROL & 0.414 & 0.454 & 0.402 & 0.440 & 0.861 & 0.946 & & & 0.652 & 0.669 \\
\hline$G 2$ & 200 & & 25 & & 2x Cross-Frames & 0.403 & 0.436 & 0.394 & 0.425 & 0.861 & 0.946 & & & 0.652 & 0.669 \\
\hline G2 & 200 & 5 & 25 & 46 & No Barrier & 0.427 & 0.466 & 0.438 & 0.473 & 0.861 & 0.946 & & & 0.652 & 0.669 \\
\hline & & & & & No Cross-Frames & 0.440 & 0.497 & 0.424 & 0.476 & 0.861 & 0.946 & & & 0.652 & 0.669 \\
\hline & & & & & CONTROL & 0.454 & 0.492 & 0.445 & 0.479 & 1.128 & 1.146 & & & 0.706 & 0.709 \\
\hline $\mathrm{G}^{2}$ & 200 & 5 & 25 & 69 & 2x Cross-Frames & 0.435 & 0.465 & 0.430 & 0.457 & 1.128 & 1.146 & & & 0.706 & 0.709 \\
\hline G2 & 200 & 5 & 25 & 69 & No Barrier & 0.471 & 0.508 & 0.488 & 0.520 & 1.128 & 1.146 & & & 0.706 & 0.709 \\
\hline & & & & & No Cross-Frames & 0.495 & 0.550 & 0.477 & 0.526 & 1.128 & 1.146 & & & 0.706 & 0.709 \\
\hline
\end{tabular}




\begin{tabular}{|c|c|c|c|c|c|c|c|c|c|c|c|c|c|c|c|}
\hline \multicolumn{16}{|c|}{$\begin{array}{l}\text { Comparis on of the Effect of Girder Spacing (S) } \\
\text { (bending moment, two lanes loaded) }\end{array}$} \\
\hline \multirow{2}{*}{\multicolumn{6}{|c|}{ Constant Parameters }} & \multicolumn{10}{|c|}{ Dis tribution Factors (organized by me thod and varied parame ters) } \\
\hline & & & & & & \multicolumn{2}{|c|}{ Stallings / Yoo } & \multicolumn{2}{|c|}{ Tarhini / Frede rick } & \multicolumn{2}{|c|}{ Lever Rule } & \multicolumn{2}{|c|}{ AASHTO Mod. } & Special & nalys is \\
\hline Girder & $L(f t)$ & $\mathbf{N}_{\mathrm{b}}$ & $\mathbf{L}_{\mathrm{b}}$ (ft) & OH (in) & Iteration & $8.625^{\prime}$ & $11.5^{\prime}$ & $8.625^{\prime}$ & $11.5^{\prime}$ & $8.625^{\prime}$ & $11.5^{\prime}$ & $8.625^{\prime}$ & 11.5' & $8.625^{\prime}$ & 11.5' \\
\hline & & & & & CONTROL & 0.663 & 0.769 & 0.629 & 0.729 & & & 0.807 & 0.995 & 0.813 & 0.960 \\
\hline & 100 & & 30 & & 2x Cross-Frames & 0.674 & 0.774 & 0.639 & 0.733 & & & 0.807 & 0.995 & 0.813 & 0.960 \\
\hline G2 & 100 & 4 & 20 & 46 & No Barrier & 0.692 & 0.801 & 0.692 & 0.793 & & & 0.807 & 0.995 & 0.813 & 0.960 \\
\hline & & & & & No Cross-Frames & 0.675 & 0.796 & 0.641 & 0.755 & & & 0.807 & 0.995 & 0.813 & 0.960 \\
\hline & & & & & CONTROL & 0.783 & 0.888 & 0.746 & 0.844 & & & 0.968 & 1.194 & 0.946 & 1.060 \\
\hline & & & 30 & 60 & 2x Cross-Frames & 0.780 & 0.876 & 0.743 & 0.833 & & & 0.968 & 1.194 & 0.946 & 1.060 \\
\hline G2 & 100 & 4 & 20 & 69 & No Barrier & 0.821 & 0.928 & 0.825 & 0.923 & & & 0.968 & 1.194 & 0.946 & 1.060 \\
\hline & & & & & No Cross-Frames & 0.818 & 0.937 & 0.781 & 0.891 & & & 0.968 & 1.194 & 0.946 & 1.060 \\
\hline & & & & & CONTROL & 0.662 & 0.765 & 0.634 & 0.734 & & & 0.807 & 0.995 & 0.813 & 0.960 \\
\hline $\mathrm{G}^{2}$ & 100 & 4 & 25 & & 2x Cross-Frames & 0.681 & 0.776 & 0.646 & 0.738 & & & 0.807 & 0.995 & 0.813 & 0.960 \\
\hline G2 & 100 & 4 & 25 & 46 & No Barrier & 0.689 & 0.796 & 0.696 & 0.798 & & & 0.807 & 0.995 & 0.813 & 0.960 \\
\hline & & & & & No Cross-Frames & 0.666 & 0.787 & 0.645 & 0.761 & & & 0.807 & 0.995 & 0.813 & 0.960 \\
\hline & & & & & CONTROL & 0.778 & 0.881 & 0.750 & 0.849 & & & 0.968 & 1.194 & 0.946 & 1.060 \\
\hline$G 2$ & 100 & 4 & 25 & 69 & 2x Cross-Frames & 0.778 & 0.873 & 0.750 & 0.839 & & & 0.968 & 1.194 & 0.946 & 1.060 \\
\hline $\mathrm{G} 2$ & 100 & 4 & 25 & 69 & No Barrier & 0.814 & 0.919 & 0.828 & 0.928 & & & 0.968 & 1.194 & 0.946 & 1.060 \\
\hline & & & & & No Cross-Frames & 0.808 & 0.926 & 0.784 & 0.896 & & & 0.968 & 1.194 & 0.946 & 1.060 \\
\hline & & & & & CONTROL & 0.639 & 0.751 & 0.612 & 0.715 & & & 0.807 & 0.995 & 0.809 & 0.907 \\
\hline & & & & & 2x Cross-Frames & 0.643 & 0.744 & 0.616 & 0.708 & & & 0.807 & 0.995 & 0.809 & 0.907 \\
\hline G2 & 100 & 5 & 20 & 46 & No Barrier & 0.671 & 0.783 & 0.672 & 0.774 & & & 0.807 & 0.995 & 0.809 & 0.907 \\
\hline & & & & & No Cross-Frames & 0.666 & 0.787 & 0.639 & 0.750 & & & 0.807 & 0.995 & 0.809 & 0.907 \\
\hline & & & & & CONTROL & 0.752 & 0.868 & 0.723 & 0.829 & & & 0.968 & 1.194 & 0.898 & 0.973 \\
\hline 80 & 100 & 5 & 20 & 69 & 2x Cross-Frames & 0.742 & 0.846 & 0.713 & 0.808 & & & 0.968 & 1.194 & 0.898 & 0.973 \\
\hline G2 & 100 & 5 & 20 & 69 & No Barrier & 0.795 & 0.908 & 0.800 & 0.904 & & & 0.968 & 1.194 & 0.898 & 0.973 \\
\hline & & & & & No Cross-Frames & 0.799 & 0.924 & 0.769 & 0.882 & & & 0.968 & 1.194 & 0.898 & 0.973 \\
\hline & & & & & CONTROL & 0.634 & 0.743 & 0.616 & 0.720 & & & 0.807 & 0.995 & 0.809 & 0.907 \\
\hline 40 & 100 & 5 & 25 & 46 & 2x Cross-Frames & 0.644 & 0.740 & 0.621 & 0.715 & & & 0.807 & 0.995 & 0.809 & 0.907 \\
\hline G2 & 100 & 5 & 25 & 46 & No Barrier & 0.665 & 0.775 & 0.675 & 0.780 & & & 0.807 & 0.995 & 0.809 & 0.907 \\
\hline & & & & & No Cross-Frames & 0.657 & 0.778 & 0.643 & 0.756 & & & 0.807 & 0.995 & 0.809 & 0.907 \\
\hline & & & & & CONTROL & 0.743 & 0.858 & 0.727 & 0.835 & & & 0.968 & 1.194 & 0.898 & 0.973 \\
\hline$e^{2}$ & 100 & 5 & 25 & 69 & 2x Cross-Frames & 0.735 & 0.837 & 0.718 & 0.815 & & & 0.968 & 1.194 & 0.898 & 0.973 \\
\hline & & & & & No Barrier & 0.784 & 0.897 & 0.802 & 0.909 & & & 0.968 & 1.194 & 0.898 & 0.973 \\
\hline & & & & & No Cross-Frames & 0.789 & 0.913 & 0.772 & 0.887 & & & 0.968 & 1.194 & 0.898 & 0.973 \\
\hline & & & & & CONTROL & 0.675 & 0.759 & 0.646 & 0.725 & & & 0.670 & 0.823 & 0.813 & 0.960 \\
\hline G2 & 200 & 4 & 20 & 46 & 2x Cross-Frames & 0.683 & 0.766 & 0.652 & 0.730 & & & 0.670 & 0.823 & 0.813 & 0.960 \\
\hline & & & & 46 & No Barrier & 0.691 & 0.778 & 0.701 & 0.781 & & & 0.670 & 0.823 & 0.813 & 0.960 \\
\hline & & & & & No Cross-Frames & 0.666 & 0.758 & 0.641 & 0.727 & & & 0.670 & 0.823 & 0.813 & 0.960 \\
\hline & & & & & CONTROL & 0.756 & 0.834 & 0.729 & 0.802 & & & 0.804 & 0.988 & 0.946 & 1.060 \\
\hline$G_{2}$ & 200 & 4 & 20 & 69 & 2x Cross-Frames & 0.758 & 0.832 & 0.730 & 0.800 & & & 0.804 & 0.988 & 0.946 & 1.060 \\
\hline & & & & 69 & No Barrier & 0.778 & 0.857 & 0.794 & 0.866 & & & 0.804 & 0.988 & 0.946 & 1.060 \\
\hline & & & & & No Cross-Frames & 0.760 & 0.852 & 0.734 & 0.820 & & & 0.804 & 0.988 & 0.946 & 1.060 \\
\hline & & & & & CONTROL & 0.674 & 0.758 & 0.645 & 0.723 & & & 0.670 & 0.823 & 0.813 & 0.960 \\
\hline & & & & & 2x Cross-Frames & 0.683 & 0.765 & 0.651 & 0.729 & & & 0.670 & 0.823 & 0.813 & 0.960 \\
\hline G2 & 200 & 4 & 25 & 46 & No Barrier & 0.690 & 0.777 & 0.700 & 0.780 & & & 0.670 & 0.823 & 0.813 & 0.960 \\
\hline & & & & & No Cross-Frames & 0.666 & 0.758 & 0.641 & 0.727 & & & 0.670 & 0.823 & 0.813 & 0.960 \\
\hline & & & & & CONTROL & 0.756 & 0.833 & 0.729 & 0.802 & & & 0.804 & 0.988 & 0.946 & 1.060 \\
\hline$C ?$ & 20 & t & 25 & & 2x Cross-Frames & 0.758 & 0.832 & 0.730 & 0.800 & & & 0.804 & 0.988 & 0.946 & 1.060 \\
\hline G2 & 200 & 4 & 25 & 69 & No Barrier & 0.778 & 0.857 & 0.794 & 0.866 & & & 0.804 & 0.988 & 0.946 & 1.060 \\
\hline & & & & & No Cross-Frames & 0.760 & 0.852 & 0.735 & 0.820 & & & 0.804 & 0.988 & 0.946 & 1.060 \\
\hline & & & & & CONTROL & 0.628 & 0.705 & 0.608 & 0.681 & & & 0.670 & 0.823 & 0.809 & 0.907 \\
\hline$G 2$ & 200 & 5 & 20 & 46 & 2x Cross-Frames & 0.634 & 0.704 & 0.612 & 0.680 & & & 0.670 & 0.823 & 0.809 & 0.907 \\
\hline G2 & 200 & 5 & 20 & 46 & No Barrier & 0.647 & 0.725 & 0.657 & 0.730 & & & 0.670 & 0.823 & 0.809 & 0.907 \\
\hline & & & & & No Cross-Frames & 0.629 & 0.727 & 0.610 & 0.702 & & & 0.670 & 0.823 & 0.809 & 0.907 \\
\hline & & & & & CONTROL & 0.698 & 0.775 & 0.682 & 0.754 & & & 0.804 & 0.988 & 0.898 & 0.973 \\
\hline $5 ?$ & 200 & 5 & 30 & 69 & 2x Cross-Frames & 0.695 & 0.761 & 0.679 & 0.743 & & & 0.804 & 0.988 & 0.898 & 0.973 \\
\hline G2 & 200 & 5 & 20 & 69 & No Barrier & 0.722 & 0.798 & 0.740 & 0.810 & & & 0.804 & 0.988 & 0.898 & 0.973 \\
\hline & & & & & No Cross-Frames & 0.718 & 0.821 & 0.700 & 0.796 & & & 0.804 & 0.988 & 0.898 & 0.973 \\
\hline & & & & & CONTROL & 0.627 & 0.705 & 0.607 & 0.681 & & & 0.670 & 0.823 & 0.809 & 0.907 \\
\hline$G 2$ & 200 & & 25 & & 2x Cross-Frames & 0.634 & 0.704 & 0.612 & 0.679 & & & 0.670 & 0.823 & 0.809 & 0.907 \\
\hline G2 & 200 & 5 & 25 & 46 & No Barrier & 0.646 & 0.725 & 0.656 & 0.730 & & & 0.670 & 0.823 & 0.809 & 0.907 \\
\hline & & & & & No Cross-Frames & 0.629 & 0.727 & 0.611 & 0.702 & & & 0.670 & 0.823 & 0.809 & 0.907 \\
\hline & & & & & CONTROL & 0.698 & 0.776 & 0.682 & 0.756 & & & 0.804 & 0.988 & 0.898 & 0.973 \\
\hline $\mathrm{G}^{2}$ & 200 & 5 & 25 & 69 & 2x Cross-Frames & 0.695 & 0.762 & 0.679 & 0.744 & & & 0.804 & 0.988 & 0.898 & 0.973 \\
\hline G2 & 200 & 5 & 25 & 69 & No Barrier & 0.722 & 0.800 & 0.740 & 0.812 & & & 0.804 & 0.988 & 0.898 & 0.973 \\
\hline & & & & & No Cross-Frames & 0.718 & 0.821 & 0.700 & 0.796 & & & 0.804 & 0.988 & 0.898 & 0.973 \\
\hline
\end{tabular}




\begin{tabular}{|c|c|c|c|c|c|c|c|c|c|c|c|c|c|c|c|}
\hline \multicolumn{16}{|c|}{$\begin{array}{l}\text { Comparis on of the Effect of Girder Spacing (S) } \\
\text { (bending moment, three lanes loaded) }\end{array}$} \\
\hline \multirow{2}{*}{\multicolumn{6}{|c|}{ Constant Parameters }} & \multicolumn{10}{|c|}{ Dis tribution Factors (organized by method and varied parameters) } \\
\hline & & & & & & \multicolumn{2}{|c|}{ Stallings / Yoo } & \multicolumn{2}{|c|}{ Tarhini / Frederick } & \multicolumn{2}{|c|}{ Lever Rule } & \multicolumn{2}{|c|}{ AASHTO Mod. } & \multicolumn{2}{|c|}{ Special Analys is } \\
\hline Girder & L (ft) & $N_{b}$ & $\mathbf{L}_{\mathrm{b}}(\mathrm{ft})$ & OH (in) & Ite ration & $8.625 '$ & $11.5^{\prime}$ & 8.625 ' & \begin{tabular}{l|l}
11.5 \\
\end{tabular} & 8.625 ' & $11.5^{\prime}$ & $8.625^{\prime}$ & 11.5' & $8.625^{\prime}$ & 11.5' \\
\hline \multirow{4}{*}{ G2 } & \multirow{4}{*}{100} & \multirow{4}{*}{5} & \multirow{4}{*}{20} & \multirow{4}{*}{46} & CONTROL & 0.702 & 0.831 & 0.681 & 0.804 & & & 0.807 & 0.995 & 0.676 & 0.890 \\
\hline & & & & & 2x Cross-Frames & 0.717 & 0.840 & 0.694 & 0.812 & & & 0.807 & 0.995 & 0.676 & 0.890 \\
\hline & & & & & No Barrier & 0.734 & 0.870 & 0.741 & 0.869 & & & 0.807 & 0.995 & 0.676 & 0.890 \\
\hline & & & & & No Cross-Frames & 0.707 & 0.856 & 0.686 & 0.829 & & & 0.807 & 0.995 & 0.676 & 0.890 \\
\hline \multirow{4}{*}{ G2 } & \multirow{4}{*}{100} & \multirow{4}{*}{5} & \multirow{4}{*}{20} & \multirow{4}{*}{69} & CONTROL & 0.823 & 0.958 & 0.804 & 0.932 & & & 0.968 & 1.194 & 0.790 & 0.975 \\
\hline & & & & & 2x Cross-Frames & 0.827 & 0.954 & 0.807 & 0.928 & & & 0.968 & 1.194 & 0.790 & 0.975 \\
\hline & & & & & No Barrier & 0.870 & 1.009 & 0.884 & 1.014 & & & 0.968 & 1.194 & 0.790 & 0.975 \\
\hline & & & & & No Cross-Frames & 0.849 & 1.001 & 0.830 & 0.975 & & & 0.968 & 1.194 & 0.790 & 0.975 \\
\hline \multirow{4}{*}{ G2 } & \multirow{4}{*}{100} & \multirow{4}{*}{5} & \multirow{4}{*}{25} & \multirow{4}{*}{46} & CONTROL & 0.697 & 0.823 & 0.684 & 0.808 & & & 0.807 & 0.995 & 0.676 & 0.890 \\
\hline & & & & & 2x Cross-Frames & 0.718 & 0.838 & 0.698 & 0.815 & & & 0.807 & 0.995 & 0.676 & 0.890 \\
\hline & & & & & No Barrier & 0.727 & 0.862 & 0.744 & 0.873 & & & 0.807 & 0.995 & 0.676 & 0.890 \\
\hline & & & & & No Cross-Frames & 0.697 & 0.844 & 0.691 & 0.835 & & & 0.807 & 0.995 & 0.676 & 0.890 \\
\hline & & & & & CONTROL & 0.815 & 0.947 & 0.807 & 0.937 & & & 0.968 & 1.194 & 0.790 & 0.975 \\
\hline (C) & 100 & 5 & 25 & 69 & 2x Cross-Frames & 0.824 & 0.948 & 0.810 & 0.932 & & & 0.968 & 1.194 & 0.790 & 0.975 \\
\hline G2 & 100 & 3 & 23 & 03 & No Barrier & 0.859 & 0.997 & 0.886 & 1.018 & & & 0.968 & 1.194 & 0.790 & 0.975 \\
\hline & & & & & No Cross-Frames & 0.837 & 0.988 & 0.834 & 0.981 & & & 0.968 & 1.194 & 0.790 & 0.975 \\
\hline & & & & & CONTROL & 0.732 & 0.844 & 0.707 & 0.814 & & & 0.670 & 0.823 & 0.676 & 0.890 \\
\hline (2) & 200 & 5 & 20 & 46 & 2x Cross-Frames & 0.750 & 0.865 & 0.721 & 0.832 & & & 0.670 & 0.823 & 0.676 & 0.890 \\
\hline $\mathrm{G} 2$ & 200 & 5 & 20 & 46 & No Barrier & 0.749 & 0.868 & 0.759 & 0.870 & & & 0.670 & 0.823 & 0.676 & 0.890 \\
\hline & & & & & No Cross-Frames & 0.709 & 0.826 & 0.690 & 0.802 & & & 0.670 & 0.823 & 0.676 & 0.890 \\
\hline & & & & & CONTROL & 0.820 & 0.930 & 0.799 & 0.904 & & & 0.804 & 0.988 & 0.790 & 0.975 \\
\hline G2 & 200 & 5 & 20 & 69 & 2x Cross-Frames & 0.831 & 0.940 & 0.808 & 0.912 & & & 0.804 & 0.988 & 0.790 & 0.975 \\
\hline & & 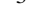 & & & No Barrier & 0.845 & 0.958 & 0.862 & 0.969 & & & 0.804 & 0.988 & 0.790 & 0.975 \\
\hline & & & & & No Cross-Frames & 0.812 & 0.935 & 0.796 & 0.912 & & & 0.804 & 0.988 & 0.790 & 0.975 \\
\hline & & & & & CONTROL & 0.730 & 0.840 & 0.705 & 0.810 & & & 0.670 & 0.823 & 0.676 & 0.890 \\
\hline (C) & 200 & & 25 & & 2x Cross-Frames & 0.748 & 0.862 & 0.719 & 0.828 & & & 0.670 & 0.823 & 0.676 & 0.890 \\
\hline $\mathrm{G} 2$ & 200 & 5 & 25 & 46 & No Barrier & 0.748 & 0.864 & 0.757 & 0.867 & & & 0.670 & 0.823 & 0.676 & 0.890 \\
\hline & & & & & No Cross-Frames & 0.709 & 0.826 & 0.690 & 0.802 & & & 0.670 & 0.823 & 0.676 & 0.890 \\
\hline & & & & & CONTROL & 0.818 & 0.927 & 0.798 & 0.902 & & & 0.804 & 0.988 & 0.790 & 0.975 \\
\hline G2 & 200 & 5 & 25 & 69 & 2x Cross-Frames & 0.830 & 0.938 & 0.806 & 0.910 & & & 0.804 & 0.988 & 0.790 & 0.975 \\
\hline $\mathrm{G} 2$ & 200 & 5 & 25 & 69 & No Barrier & 0.843 & 0.957 & 0.860 & 0.967 & & & 0.804 & 0.988 & 0.790 & 0.975 \\
\hline & & & & & No Cross-Frames & 0.812 & 0.935 & 0.796 & 0.913 & & & 0.804 & 0.988 & 0.790 & 0.975 \\
\hline
\end{tabular}




\begin{tabular}{|c|c|c|c|c|c|c|c|c|c|c|c|c|c|c|c|}
\hline \multicolumn{16}{|c|}{$\begin{array}{l}\text { Comparis on of the Effect of Span Length (L) } \\
\text { (bending moment, one lane loaded) }\end{array}$} \\
\hline \multirow{2}{*}{\multicolumn{6}{|c|}{ Constant Parameters }} & \multicolumn{10}{|c|}{ Dis tribution Factors (organized by me thod and varied parame ters) } \\
\hline & & & & & & \multicolumn{2}{|c|}{ Stallings / Yoo } & \multicolumn{2}{|c|}{ Tarhini / Fre de rick } & \multicolumn{2}{|c|}{ Lever Rule } & \multicolumn{2}{|c|}{ AASHTO Mod. } & Special & nalysis \\
\hline Girder & $\mathbf{S}(\mathbf{f t})$ & $\mathbf{N}_{\mathrm{b}}$ & $\mathbf{L}_{\mathrm{b}}(\mathrm{ft})$ & OH (in) & Iteration & $100^{\prime}$ & $200^{\prime}$ & $100^{\prime}$ & $200^{\prime}$ & $100^{\prime}$ & $200^{\prime}$ & $100^{\prime}$ & $200^{\prime}$ & $100^{\prime}$ & $200^{\prime}$ \\
\hline & & & & & "CONTROL & 0.502 & 0.451 & $\overline{0.472}$ & 0.432 & 0.861 & 0.861 & & & 0.738 & 0.738 \\
\hline (C) & 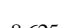 & 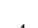 & ר & 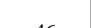 & 2x Cross-Frames & 0.489 & 0.447 & 0.459 & 0.429 & 0.861 & 0.861 & & & 0.738 & 0.738 \\
\hline G2 & 8.625 & 4 & 20 & 46 & No Barrier & 0.521 & 0.466 & 0.521 & 0.475 & 0.861 & 0.861 & & & 0.738 & 0.738 \\
\hline & & & & & No Cross-Frames & 0.540 & 0.466 & 0.507 & 0.445 & 0.861 & 0.861 & & & 0.738 & 0.738 \\
\hline & & & & & CONTROL & 0.581 & 0.495 & 0.544 & 0.477 & 1.128 & 1.128 & & & 0.818 & 0.818 \\
\hline ? & 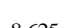 & 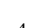 & ר & $f 0$ & 2x Cross-Frames & 0.555 & 0.485 & 0.521 & 0.470 & 1.128 & 1.128 & & & 0.818 & 0.818 \\
\hline $\mathrm{G} 2$ & 8.625 & 4 & 20 & 69 & No Barrier & 0.606 & 0.514 & 0.608 & 0.528 & 1.128 & 1.128 & & & 0.818 & 0.818 \\
\hline & & & & & No Cross-Frames & 0.637 & 0.520 & 0.595 & 0.497 & 1.128 & 1.128 & & & 0.818 & 0.818 \\
\hline & & & & & CONTROL & 0.495 & 0.451 & 0.474 & 0.432 & 0.861 & 0.861 & & & 0.738 & 0.738 \\
\hline$C_{0}$ & 8605 & 4 & 25 & 46 & 2x Cross-Frames & 0.479 & 0.446 & 0.462 & 0.429 & 0.861 & 0.861 & & & 0.738 & 0.738 \\
\hline$G 2$ & 8.625 & 4 & 25 & 40 & No Barrier & 0.512 & 0.465 & 0.523 & 0.474 & 0.861 & 0.861 & & & 0.738 & 0.738 \\
\hline & & & & & No Cross-Frames & 0.535 & 0.464 & 0.509 & 0.443 & 0.861 & 0.861 & & & 0.738 & 0.738 \\
\hline & & & & & CONTROL & 0.568 & 0.496 & 0.545 & 0.478 & 1.128 & 1.128 & & & 0.818 & 0.818 \\
\hline G2 & 8625 & 4 & 25 & 69 & 2x Cross-Frames & 0.534 & 0.485 & 0.521 & 0.470 & 1.128 & 1.128 & & & 0.818 & 0.818 \\
\hline$U_{2}$ & 0.020 & 4 & 25 & 03 & No Barrier & 0.590 & 0.514 & 0.609 & 0.528 & 1.128 & 1.128 & & & 0.818 & 0.818 \\
\hline & & & & & No Cross-Frames & 0.632 & 0.520 & 0.596 & 0.497 & 1.128 & 1.128 & & & 0.818 & 0.818 \\
\hline & & & & & CONTROL & 0.488 & 0.413 & 0.461 & 0.401 & 0.861 & 0.861 & & & 0.652 & 0.652 \\
\hline$G 2$ & 8625 & 5 & 20 & 46 & 2x Cross-Frames & 0.467 & 0.402 & 0.442 & 0.393 & 0.861 & 0.861 & & & 0.652 & 0.652 \\
\hline U2 & 0.020 & & 20 & 40 & No Barrier & 0.506 & 0.426 & 0.506 & 0.437 & 0.861 & 0.861 & & & 0.652 & 0.652 \\
\hline & & & & & No Cross-Frames & 0.532 & 0.440 & 0.502 & 0.424 & 0.861 & 0.861 & & & 0.652 & 0.652 \\
\hline & & & & & CONTROL & 0.567 & 0.453 & 0.533 & 0.443 & 1.128 & 1.128 & & & 0.706 & 0.706 \\
\hline$C_{2}$ & 8625 & 5 & 20 & 69 & 2x Cross-Frames & 0.533 & 0.434 & 0.503 & 0.429 & 1.128 & 1.128 & & & 0.706 & 0.706 \\
\hline & 0.020 & & 20 & J & No Barrier & 0.591 & 0.469 & 0.593 & 0.486 & 1.128 & 1.128 & & & 0.706 & 0.706 \\
\hline & & & & & No Cross-Frames & 0.627 & 0.495 & 0.589 & 0.477 & 1.128 & 1.128 & & & 0.706 & 0.706 \\
\hline & & & & & CONTROL & 0.479 & 0.414 & 0.464 & 0.402 & 0.861 & 0.861 & & & 0.652 & 0.652 \\
\hline$G 2$ & 8625 & 5 & 25 & 46 & 2x Cross-Frames & 0.454 & 0.403 & 0.445 & 0.394 & 0.861 & 0.861 & & & 0.652 & 0.652 \\
\hline U2 & 0.020 & J & 25 & 40 & No Barrier & 0.496 & 0.427 & 0.508 & 0.438 & 0.861 & 0.861 & & & 0.652 & 0.652 \\
\hline & & & & & No Cross-Frames & 0.527 & 0.440 & 0.504 & 0.424 & 0.861 & 0.861 & & & 0.652 & 0.652 \\
\hline & & & & & CONTROL & 0.552 & 0.454 & 0.535 & 0.445 & 1.128 & 1.128 & & & 0.706 & 0.706 \\
\hline$G_{2}$ & 8625 & 5 & 25 & 69 & 2x Cross-Frames & 0.508 & 0.435 & 0.504 & 0.430 & 1.128 & 1.128 & & & 0.706 & 0.706 \\
\hline UL & 0.020 & S & 20 & 03 & No Barrier & 0.574 & 0.471 & 0.594 & 0.488 & 1.128 & 1.128 & & & 0.706 & 0.706 \\
\hline & & & & & No Cross-Frames & 0.622 & 0.495 & 0.590 & 0.477 & 1.128 & 1.128 & & & 0.706 & 0.706 \\
\hline & & & & & CONTROL & 0.563 & 0.486 & 0.527 & 0.465 & 0.946 & 0.946 & & & 0.764 & 0.764 \\
\hline G2 & 11.5 & 4 & 20 & 46 & 2x Cross-Frames & 0.540 & 0.477 & 0.506 & 0.458 & 0.946 & 0.946 & & & 0.764 & 0.764 \\
\hline & & & & & No Barrier & 0.580 & 0.499 & 0.574 & 0.504 & 0.946 & 0.946 & & & 0.764 & 0.764 \\
\hline & & & & & No Cross-Frames & 0.611 & 0.513 & 0.572 & 0.488 & 0.946 & 0.946 & & & 0.764 & 0.764 \\
\hline & & & & & CONTROL & 0.635 & 0.525 & 0.593 & 0.505 & 1.146 & 1.146 & & & 0.824 & 0.824 \\
\hline$G^{2}$ & 115 & 4 & 20 & 69 & $2 \mathrm{x}$ Cross-Frames & 0.600 & 0.510 & 0.561 & 0.493 & 1.146 & 1.146 & & & 0.824 & 0.824 \\
\hline & & & & & No Barrier & 0.657 & 0.542 & 0.654 & 0.552 & 1.146 & 1.146 & & & 0.824 & 0.824 \\
\hline & & & & & No Cross-Frames & 0.699 & 0.566 & 0.651 & 0.538 & 1.146 & 1.146 & & & 0.824 & 0.824 \\
\hline & & & & & CONTROL & 0.556 & 0.487 & 0.531 & 0.466 & 0.946 & 0.946 & & & 0.764 & 0.764 \\
\hline G2 & 11.5 & 4 & 25 & 46 & 2x Cross-Frames & 0.530 & 0.477 & 0.510 & 0.459 & 0.946 & 0.946 & & & 0.764 & 0.764 \\
\hline & & & & & No Barrier & 0.572 & 0.500 & 0.578 & 0.505 & 0.946 & 0.946 & & & 0.764 & 0.764 \\
\hline & & & & & No Cross-Frames & 0.606 & 0.513 & 0.575 & 0.488 & 0.946 & 0.946 & & & 0.764 & 0.764 \\
\hline & & & & & CONTROL & 0.625 & 0.526 & 0.596 & 0.506 & 1.146 & 1.146 & & & 0.824 & 0.824 \\
\hline G2 & 11.5 & 4 & 25 & 69 & 2x Cross-Frames & 0.583 & 0.510 & 0.564 & 0.494 & 1.146 & 1.146 & & & 0.824 & 0.824 \\
\hline & & & & & No Barrier & 0.645 & 0.544 & 0.657 & 0.553 & 1.146 & 1.146 & & & 0.824 & 0.824 \\
\hline & & & & & No Cross-Frames & 0.695 & 0.566 & 0.653 & 0.538 & 1.146 & 1.146 & & & 0.824 & 0.824 \\
\hline & & & & & CONTROL & 0.553 & 0.453 & 0.519 & 0.438 & 0.946 & 0.946 & & & 0.669 & 0.669 \\
\hline $\mathrm{G}_{2}$ & 115 & 5 & 20 & 46 & 2x Cross-Frames & 0.525 & 0.435 & 0.494 & 0.423 & 0.946 & 0.946 & & & 0.669 & 0.669 \\
\hline & & & & & No Barrier & 0.568 & 0.464 & 0.562 & 0.471 & 0.946 & 0.946 & & & 0.669 & 0.669 \\
\hline & & & & & No Cross-Frames & 0.600 & 0.497 & 0.563 & 0.476 & 0.946 & 0.946 & & & 0.669 & 0.669 \\
\hline & & & & & CONTROL & 0.626 & 0.489 & 0.585 & 0.476 & 1.146 & 1.146 & & & 0.709 & 0.709 \\
\hline G2 & 11.5 & 5 & 20 & 69 & 2x Cross-Frames & 0.586 & 0.463 & 0.549 & 0.454 & 1.146 & 1.146 & & & 0.709 & 0.709 \\
\hline & & & & & No Barrier & 0.646 & 0.505 & 0.642 & 0.516 & 1.146 & 1.146 & & & 0.709 & 0.709 \\
\hline & & & & & No Cross-Frames & 0.687 & 0.550 & 0.640 & 0.526 & 1.146 & 1.146 & & & 0.709 & 0.709 \\
\hline & & & & & CONTROL & 0.545 & 0.454 & 0.523 & 0.440 & 0.946 & 0.946 & & & 0.669 & 0.669 \\
\hline $\mathrm{CO}^{2}$ & 115 & 5 & 25 & $\Delta 6$ & 2x Cross-Frames & 0.513 & 0.436 & 0.498 & 0.425 & 0.946 & 0.946 & & & 0.669 & 0.669 \\
\hline G2 & 11.0 & 3 & 25 & 40 & No Barrier & 0.559 & 0.466 & 0.566 & 0.473 & 0.946 & 0.946 & & & 0.669 & 0.669 \\
\hline & & & & & No Cross-Frames & 0.595 & 0.497 & 0.566 & 0.476 & 0.946 & 0.946 & & & 0.669 & 0.669 \\
\hline & & & & & CONTROL & 0.614 & 0.492 & 0.588 & 0.479 & 1.146 & 1.146 & & & 0.709 & 0.709 \\
\hline G2 & 11.5 & 5 & 25 & 69 & 2x Cross-Frames & 0.566 & 0.465 & 0.552 & 0.457 & 1.146 & 1.146 & & & 0.709 & 0.709 \\
\hline & & & & & No Barrier & 0.633 & 0.508 & 0.645 & 0.520 & 1.146 & 1.146 & & & 0.709 & 0.709 \\
\hline & & & & & No Cross-Frames & 0.682 & 0.550 & 0.643 & 0.526 & 1.146 & 1.146 & & & 0.709 & 0.709 \\
\hline
\end{tabular}




\begin{tabular}{|c|c|c|c|c|c|c|c|c|c|c|c|c|c|c|c|}
\hline \multicolumn{16}{|c|}{$\begin{array}{l}\text { Comparis on of the Effect of Span Length (L) } \\
\text { (bending moment, two lanes loaded) }\end{array}$} \\
\hline \multirow{2}{*}{\multicolumn{6}{|c|}{ Constant Parameters }} & \multicolumn{10}{|c|}{ Distribution Factors (organized by method and varied parame ters) } \\
\hline & & & & & & \multicolumn{2}{|c|}{ Stallings / Yoo } & \multicolumn{2}{|c|}{ Tarhini / Frederick } & \multicolumn{2}{|c|}{ Lever Rule } & \multicolumn{2}{|c|}{ AASHTO Mod. } & Specia & nalys is \\
\hline Girder & S (ft) & $\mathbf{N}_{\mathbf{b}}$ & $\mathbf{L}_{\mathrm{b}}(\mathrm{ft})$ & OH (in) & Iteration & $100^{\prime}$ & $200^{\prime}$ & $100^{\prime}$ & $200^{\prime}$ & $100^{\prime}$ & $200^{\prime}$ & $100^{\prime}$ & 200' & $100^{\prime}$ & $200^{\prime}$ \\
\hline & & & & & CONTROL & 0.663 & 0.675 & 0.629 & 0.646 & & & 0.807 & 0.670 & 0.813 & 0.813 \\
\hline G2 & 8.625 & 4 & 20 & 46 & 2x Cross-Frames & 0.674 & 0.683 & 0.639 & 0.652 & & & 0.807 & 0.670 & 0.813 & 0.813 \\
\hline $\mathrm{G} 2$ & 0.020 & 4 & 20 & 40 & No Barrier & 0.692 & 0.691 & 0.692 & 0.701 & & & 0.807 & 0.670 & 0.813 & 0.813 \\
\hline & & & & & No Cross-Frames & 0.675 & 0.666 & 0.641 & 0.641 & & & 0.807 & 0.670 & 0.813 & 0.813 \\
\hline & & & & & CONTROL & 0.783 & 0.756 & 0.746 & 0.729 & & & 0.968 & 0.804 & 0.946 & 0.946 \\
\hline G2 & 8.625 & 4 & 20 & 69 & 2x Cross-Frames & 0.780 & 0.758 & 0.743 & 0.730 & & & 0.968 & 0.804 & 0.946 & 0.946 \\
\hline $\mathrm{G} 2$ & 8.625 & 4 & 20 & 69 & No Barrier & 0.821 & 0.778 & 0.825 & 0.794 & & & 0.968 & 0.804 & 0.946 & 0.946 \\
\hline & & & & & No Cross-Frames & 0.818 & 0.760 & 0.781 & 0.734 & & & 0.968 & 0.804 & 0.946 & 0.946 \\
\hline & & & & & CONTROL & 0.662 & 0.674 & 0.634 & 0.645 & & & 0.807 & 0.670 & 0.813 & 0.813 \\
\hline G2 & 8.625 & 4 & 25 & 46 & 2x Cross-Frames & 0.681 & 0.683 & 0.646 & 0.651 & & & 0.807 & 0.670 & 0.813 & 0.813 \\
\hline G2 & 8.025 & 4 & 25 & 40 & No Barrier & 0.689 & 0.690 & 0.696 & 0.700 & & & 0.807 & 0.670 & 0.813 & 0.813 \\
\hline & & & & & No Cross-Frames & 0.666 & 0.666 & 0.645 & 0.641 & & & 0.807 & 0.670 & 0.813 & 0.813 \\
\hline & & & & & CONTROL & 0.778 & 0.756 & 0.750 & 0.729 & & & 0.968 & 0.804 & 0.946 & 0.946 \\
\hline G2 & 8.625 & 4 & 25 & 69 & 2x Cross-Frames & 0.778 & 0.758 & 0.750 & 0.730 & & & 0.968 & 0.804 & 0.946 & 0.946 \\
\hline 32 & 0.025 & 4 & 20 & 03 & No Barrier & 0.814 & 0.778 & 0.828 & 0.794 & & & 0.968 & 0.804 & 0.946 & 0.946 \\
\hline & & & & & No Cross-Frames & 0.808 & 0.760 & 0.784 & 0.735 & & & 0.968 & 0.804 & 0.946 & 0.946 \\
\hline & & & & & CONTROL & 0.639 & 0.628 & 0.612 & 0.608 & & & 0.807 & 0.670 & 0.809 & 0.809 \\
\hline $\mathrm{G}^{2}$ & 865 & 5 & 20 & 46 & 2x Cross-Frames & 0.643 & 0.634 & 0.616 & 0.612 & & & 0.807 & 0.670 & 0.809 & 0.809 \\
\hline 32 & 0.025 & J & 20 & 40 & No Barrier & 0.671 & 0.647 & 0.672 & 0.657 & & & 0.807 & 0.670 & 0.809 & 0.809 \\
\hline & & & & & No Cross-Frames & 0.666 & 0.629 & 0.639 & 0.610 & & & 0.807 & 0.670 & 0.809 & 0.809 \\
\hline & & & & & CONTROL & 0.752 & 0.698 & 0.723 & 0.682 & & & 0.968 & 0.804 & 0.898 & 0.898 \\
\hline G2 & & 5 & 20 & 69 & 2x Cross-Frames & 0.742 & 0.695 & 0.713 & 0.679 & & & 0.968 & 0.804 & 0.898 & 0.898 \\
\hline G2 & 8.625 & 5 & 20 & 69 & No Barrier & 0.795 & 0.722 & 0.800 & 0.740 & & & 0.968 & 0.804 & 0.898 & 0.898 \\
\hline & & & & & No Cross-Frames & 0.799 & 0.718 & 0.769 & 0.700 & & & 0.968 & 0.804 & 0.898 & 0.898 \\
\hline & & & & & CONTROL & 0.634 & 0.627 & 0.616 & 0.607 & & & 0.807 & 0.670 & 0.809 & 0.809 \\
\hline$C_{0}$ & 8655 & 5 & 25 & 46 & 2x Cross-Frames & 0.644 & 0.634 & 0.621 & 0.612 & & & 0.807 & 0.670 & 0.809 & 0.809 \\
\hline G2 & 8.025 & 5 & 25 & 40 & No Barrier & 0.665 & 0.646 & 0.675 & 0.656 & & & 0.807 & 0.670 & 0.809 & 0.809 \\
\hline & & & & & No Cross-Frames & 0.657 & 0.629 & 0.643 & 0.611 & & & 0.807 & 0.670 & 0.809 & 0.809 \\
\hline & & & & & CONTROL & 0.743 & 0.698 & 0.727 & 0.682 & & & 0.968 & 0.804 & 0.898 & 0.898 \\
\hline $\mathrm{CP}^{2}$ & 8625 & 5 & 25 & 69 & 2x Cross-Frames & 0.735 & 0.695 & 0.718 & 0.679 & & & 0.968 & 0.804 & 0.898 & 0.898 \\
\hline $\mathrm{G} 2$ & 0.020 & 5 & 20 & 09 & No Barrier & 0.784 & 0.722 & 0.802 & 0.740 & & & 0.968 & 0.804 & 0.898 & 0.898 \\
\hline & & & & & No Cross-Frames & 0.789 & 0.718 & 0.772 & 0.700 & & & 0.968 & 0.804 & 0.898 & 0.898 \\
\hline & & & & & CONTROL & 0.769 & 0.759 & 0.729 & 0.725 & & & 0.995 & 0.823 & 0.960 & 0.960 \\
\hline $\mathrm{G}_{2}$ & 115 & 4 & 20 & 46 & 2x Cross-Frames & 0.774 & 0.766 & 0.733 & 0.730 & & & 0.995 & 0.823 & 0.960 & 0.960 \\
\hline $\mathrm{G} 2$ & 11.5 & 4 & 20 & 46 & No Barrier & 0.801 & 0.778 & 0.793 & 0.781 & & & 0.995 & 0.823 & 0.960 & 0.960 \\
\hline & & & & & No Cross-Frames & 0.796 & 0.758 & 0.755 & 0.727 & & & 0.995 & 0.823 & 0.960 & 0.960 \\
\hline & & & & & CONTROL & 0.888 & 0.834 & 0.844 & 0.802 & & & 1.194 & 0.988 & 1.060 & 1.060 \\
\hline $\mathrm{G}_{2}$ & 115 & 4 & 20 & 69 & 2x Cross-Frames & 0.876 & 0.832 & 0.833 & 0.800 & & & 1.194 & 0.988 & 1.060 & 1.060 \\
\hline $\mathrm{G} 2$ & 11.5 & 4 & 20 & 69 & No Barrier & 0.928 & 0.857 & 0.923 & 0.866 & & & 1.194 & 0.988 & 1.060 & 1.060 \\
\hline & & & & & No Cross-Frames & 0.937 & 0.852 & 0.891 & 0.820 & & & 1.194 & 0.988 & 1.060 & 1.060 \\
\hline & & & & & CONTROL & 0.765 & 0.758 & 0.734 & 0.723 & & & 0.995 & 0.823 & 0.960 & 0.960 \\
\hline G2 & 11.5 & 4 & 25 & 46 & 2x Cross-Frames & 0.776 & 0.765 & 0.738 & 0.729 & & & 0.995 & 0.823 & 0.960 & 0.960 \\
\hline & & & & 40 & No Barrier & 0.796 & 0.777 & 0.798 & 0.780 & & & 0.995 & 0.823 & 0.960 & 0.960 \\
\hline & & & & & No Cross-Frames & 0.787 & 0.758 & 0.761 & 0.727 & & & 0.995 & 0.823 & 0.960 & 0.960 \\
\hline & & & & & CONTROL & 0.881 & 0.833 & 0.849 & 0.802 & & & 1.194 & 0.988 & 1.060 & 1.060 \\
\hline G2 & 11.5 & 4 & 25 & 69 & 2x Cross-Frames & 0.873 & 0.832 & 0.839 & 0.800 & & & 1.194 & 0.988 & 1.060 & 1.060 \\
\hline G2 & 11.5 & 4 & 25 & 69 & No Barrier & 0.919 & 0.857 & 0.928 & 0.866 & & & 1.194 & 0.988 & 1.060 & 1.060 \\
\hline & & & & & No Cross-Frames & 0.926 & 0.852 & 0.896 & 0.820 & & & 1.194 & 0.988 & 1.060 & 1.060 \\
\hline & & & & & CONTROL & 0.751 & 0.705 & 0.715 & 0.681 & & & 0.995 & 0.823 & 0.907 & 0.907 \\
\hline G2 & 11.5 & 5 & 20 & 46 & 2x Cross-Frames & 0.744 & 0.704 & 0.708 & 0.680 & & & 0.995 & 0.823 & 0.907 & 0.907 \\
\hline $\mathrm{G} 2$ & 11.5 & 5 & 20 & 40 & No Barrier & 0.783 & 0.725 & 0.774 & 0.730 & & & 0.995 & 0.823 & 0.907 & 0.907 \\
\hline & & & & & No Cross-Frames & 0.787 & 0.727 & 0.750 & 0.702 & & & 0.995 & 0.823 & 0.907 & 0.907 \\
\hline & & & & & CONTROL & 0.868 & 0.775 & 0.829 & 0.754 & & & 1.194 & 0.988 & 0.973 & 0.973 \\
\hline G2 & 11.5 & 5 & 20 & 69 & 2x Cross-Frames & 0.846 & 0.761 & 0.808 & 0.743 & & & 1.194 & 0.988 & 0.973 & 0.973 \\
\hline $\mathrm{G} 2$ & 11.5 & 5 & 20 & 69 & No Barrier & 0.908 & 0.798 & 0.904 & 0.810 & & & 1.194 & 0.988 & 0.973 & 0.973 \\
\hline & & & & & No Cross-Frames & 0.924 & 0.821 & 0.882 & 0.796 & & & 1.194 & 0.988 & 0.973 & 0.973 \\
\hline & & & & & CONTROL & 0.743 & 0.705 & 0.720 & 0.681 & & & 0.995 & 0.823 & 0.907 & 0.907 \\
\hline G2 & 11.5 & 5 & 25 & 46 & 2x Cross-Frames & 0.740 & 0.704 & 0.715 & 0.679 & & & 0.995 & 0.823 & 0.907 & 0.907 \\
\hline G2 & 11.5 & 5 & 20 & 40 & No Barrier & 0.775 & 0.725 & 0.780 & 0.730 & & & 0.995 & 0.823 & 0.907 & 0.907 \\
\hline & & & & & No Cross-Frames & 0.778 & 0.727 & 0.756 & 0.702 & & & 0.995 & 0.823 & 0.907 & 0.907 \\
\hline & & & & & CONTROL & 0.858 & 0.776 & 0.835 & 0.756 & & & 1.194 & 0.988 & 0.973 & 0.973 \\
\hline G2 & 11.5 & 5 & 25 & 69 & 2x Cross-Frames & 0.837 & 0.762 & 0.815 & 0.744 & & & 1.194 & 0.988 & 0.973 & 0.973 \\
\hline 02 & & $\mathrm{~J}$ & & & No Barrier & 0.897 & 0.800 & 0.909 & 0.812 & & & 1.194 & 0.988 & 0.973 & 0.973 \\
\hline & & & & & No Cross-Frames & 0.913 & 0.821 & 0.887 & 0.796 & & & 1.194 & 0.988 & 0.973 & 0.973 \\
\hline
\end{tabular}




\begin{tabular}{|c|c|c|c|c|c|c|c|c|c|c|c|c|c|c|c|}
\hline \multicolumn{16}{|c|}{$\begin{array}{l}\text { Comparis on of the Effect of Span Le ngth (L) } \\
\text { (bending moment, three lanes loaded) }\end{array}$} \\
\hline \multirow{2}{*}{\multicolumn{6}{|c|}{ Constant Parameters }} & \multicolumn{10}{|c|}{ Dis tribution Factors (organized by method and varied parame ters) } \\
\hline & & & & & & \multicolumn{2}{|c|}{ Stallings / Yoo } & \multicolumn{2}{|c|}{ Tarhini / Frederick } & \multicolumn{2}{|c|}{ Lever Rule } & \multicolumn{2}{|c|}{ AASHTO Mod. } & \multicolumn{2}{|c|}{ Special Analys is } \\
\hline Girder & S (ft) & $\mathbf{N}_{\mathrm{b}}$ & $\mathbf{L}_{\mathbf{b}}(\mathbf{f t})$ & OH (in) & Iteration & $100^{\prime}$ & $200^{\prime}$ & $100^{\prime}$ & $200^{\prime}$ & $100^{\prime}$ & $200^{\prime}$ & $100^{\prime}$ & $200^{\prime}$ & $100^{\prime}$ & $200^{\prime}$ \\
\hline \multirow{4}{*}{ G2 } & \multirow{4}{*}{8.625} & \multirow{4}{*}{5} & \multirow{4}{*}{20} & \multirow{4}{*}{46} & CONTROL & 0.702 & 0.732 & 0.681 & 0.707 & & & 0.807 & 0.670 & $\overline{0.676}$ & 0.676 \\
\hline & & & & & 2x Cross-Frames & 0.717 & 0.750 & 0.694 & 0.721 & & & 0.807 & 0.670 & 0.676 & 0.676 \\
\hline & & & & & No Barrier & 0.734 & 0.749 & 0.741 & 0.759 & & & 0.807 & 0.670 & 0.676 & 0.676 \\
\hline & & & & & No Cross-Frames & 0.707 & 0.709 & 0.686 & 0.690 & & & 0.807 & 0.670 & 0.676 & 0.676 \\
\hline \multirow{4}{*}{ G2 } & \multirow{4}{*}{8.625} & & & & CONTROL & 0.823 & 0.820 & 0.804 & 0.799 & & & 0.968 & 0.804 & 0.790 & 0.790 \\
\hline & & 5 & 20 & 69 & 2x Cross-Frames & 0.827 & 0.831 & 0.807 & 0.808 & & & 0.968 & 0.804 & 0.790 & 0.790 \\
\hline & & & & & No Barrier & 0.870 & 0.845 & 0.884 & 0.862 & & & 0.968 & 0.804 & 0.790 & 0.790 \\
\hline & & & & & No Cross-Frames & 0.849 & 0.812 & 0.830 & 0.796 & & & 0.968 & 0.804 & 0.790 & 0.790 \\
\hline & & & & & CONTROL & 0.697 & 0.730 & 0.684 & 0.705 & & & 0.807 & 0.670 & 0.676 & 0.676 \\
\hline G2 & 8.625 & 5 & 25 & 46 & 2x Cross-Frames & 0.718 & 0.748 & 0.698 & 0.719 & & & 0.807 & 0.670 & 0.676 & 0.676 \\
\hline & & & & & No Barrier & 0.727 & 0.748 & 0.744 & 0.757 & & & 0.807 & 0.670 & 0.676 & 0.676 \\
\hline & & & & & No Cross-Frames & 0.697 & 0.709 & 0.691 & 0.690 & & & 0.807 & 0.670 & 0.676 & 0.676 \\
\hline & & & & & CONTROL & 0.815 & 0.818 & 0.807 & 0.798 & & & 0.968 & 0.804 & 0.790 & 0.790 \\
\hline $\mathrm{G}^{2}$ & 8625 & 5 & 25 & 69 & 2x Cross-Frames & 0.824 & 0.830 & 0.810 & 0.806 & & & 0.968 & 0.804 & 0.790 & 0.790 \\
\hline & & J & & 69 & No Barrier & 0.859 & 0.843 & 0.886 & 0.860 & & & 0.968 & 0.804 & 0.790 & 0.790 \\
\hline & & & & & No Cross-Frames & 0.837 & 0.812 & 0.834 & 0.796 & & & 0.968 & 0.804 & 0.790 & 0.790 \\
\hline & & & & & CONTROL & 0.853 & 0.898 & 0.818 & 0.857 & & & 0.995 & 0.823 & 0.825 & 0.825 \\
\hline G2 & 11.5 & 4 & 20 & 46 & 2x Cross-Frames & 0.874 & 0.917 & 0.838 & 0.872 & & & 0.995 & 0.823 & 0.825 & 0.825 \\
\hline & & & & & No Barrier & 0.883 & 0.915 & 0.883 & 0.917 & & & 0.995 & 0.823 & 0.825 & 0.825 \\
\hline & & & & & No Cross-Frames & 0.849 & 0.868 & 0.815 & 0.834 & & & 0.995 & 0.823 & 0.825 & 0.825 \\
\hline & & & & & CONTROL & 0.983 & 0.993 & 0.949 & 0.955 & & & 1.194 & 0.988 & 0.952 & 0.952 \\
\hline G2 & 115 & 4 & 20 & 69 & 2x Cross-Frames & 0.992 & 1.007 & 0.957 & 0.966 & & & 1.194 & 0.988 & 0.952 & 0.952 \\
\hline G2 & 11.5 & 4 & 20 & 69 & No Barrier & 1.028 & 1.018 & 1.033 & 1.026 & & & 1.194 & 0.988 & 0.952 & 0.952 \\
\hline & & & & & No Cross-Frames & 1.001 & 0.979 & 0.968 & 0.947 & & & 1.194 & 0.988 & 0.952 & 0.952 \\
\hline & & & & & CONTROL & 0.847 & 0.596 & 0.822 & 0.854 & & & 0.995 & 0.823 & 0.825 & 0.825 \\
\hline G2 & 115 & 4 & 25 & 46 & 2x Cross-Frames & 0.874 & 0.610 & 0.842 & 0.870 & & & 0.995 & 0.823 & 0.825 & 0.825 \\
\hline G2 & 11.5 & 4 & 25 & 46 & No Barrier & 0.876 & 0.609 & 0.887 & 0.914 & & & 0.995 & 0.823 & 0.825 & 0.825 \\
\hline & & & & & No Cross-Frames & 0.839 & 0.579 & 0.821 & 0.834 & & & 0.995 & 0.823 & 0.825 & 0.825 \\
\hline & & & & & CONTROL & 0.975 & 0.991 & 0.954 & 0.953 & & & 1.194 & 0.988 & 0.952 & 0.952 \\
\hline G2 & 11.5 & 4 & 25 & 69 & 2x Cross-Frames & 0.990 & 1.006 & 0.962 & 0.964 & & & 1.194 & 0.988 & 0.952 & 0.952 \\
\hline & & & & 69 & No Barrier & 1.018 & 1.016 & 1.036 & 1.024 & & & 1.194 & 0.988 & 0.952 & 0.952 \\
\hline & & & & & No Cross-Frames & 0.988 & 0.979 & 0.974 & 0.947 & & & 1.194 & 0.988 & 0.952 & 0.952 \\
\hline & & & & & CONTROL & 0.831 & 0.844 & 0.804 & 0.814 & & & 0.995 & 0.823 & 0.890 & 0.890 \\
\hline G2 & 11.5 & 5 & 20 & 46 & 2x Cross-Frames & 0.840 & 0.865 & 0.812 & 0.832 & & & 0.995 & 0.823 & 0.890 & 0.890 \\
\hline & & & & & No Barrier & 0.870 & 0.868 & 0.869 & 0.870 & & & 0.995 & 0.823 & 0.890 & 0.890 \\
\hline & & & & & No Cross-Frames & 0.856 & 0.826 & 0.829 & 0.802 & & & 0.995 & 0.823 & 0.890 & 0.890 \\
\hline & & & & & CONTROL & 0.958 & 0.930 & 0.932 & 0.904 & & & 1.194 & 0.988 & 0.975 & 0.975 \\
\hline$G_{2}$ & 11.5 & 5 & 20 & 69 & 2x Cross-Frames & 0.954 & 0.940 & 0.928 & 0.912 & & & 1.194 & 0.988 & 0.975 & 0.975 \\
\hline & 11.5 & 5 & 20 & 69 & No Barrier & 1.009 & 0.958 & 1.014 & 0.969 & & & 1.194 & 0.988 & 0.975 & 0.975 \\
\hline & & & & & No Cross-Frames & 1.001 & 0.935 & 0.975 & 0.912 & & & 1.194 & 0.988 & 0.975 & 0.975 \\
\hline & & & & & CONTROL & 0.823 & 0.840 & 0.808 & 0.810 & & & 0.995 & 0.823 & 0.890 & 0.890 \\
\hline G2 & 11.5 & 5 & 25 & 46 & 2x Cross-Frames & 0.838 & 0.862 & 0.815 & 0.828 & & & 0.995 & 0.823 & 0.890 & 0.890 \\
\hline $\mathrm{G} 2$ & 11.5 & 5 & 25 & 46 & No Barrier & 0.862 & 0.864 & 0.873 & 0.867 & & & 0.995 & 0.823 & 0.890 & 0.890 \\
\hline & & & & & No Cross-Frames & 0.844 & 0.826 & 0.835 & 0.802 & & & 0.995 & 0.823 & 0.890 & 0.890 \\
\hline & & & & & CONTROL & 0.947 & 0.927 & 0.937 & 0.902 & & & 1.194 & 0.988 & 0.975 & 0.975 \\
\hline G2 & 11.5 & 5 & 25 & 69 & 2x Cross-Frames & 0.948 & 0.938 & 0.932 & 0.910 & & & 1.194 & 0.988 & 0.975 & 0.975 \\
\hline & & & & 69 & No Barrier & 0.997 & 0.957 & 1.018 & 0.967 & & & 1.194 & 0.988 & 0.975 & 0.975 \\
\hline & & & & & No Cross-Frames & 0.988 & 0.935 & 0.981 & 0.913 & & & 1.194 & 0.988 & 0.975 & 0.975 \\
\hline
\end{tabular}

\begin{tabular}{|c|c|c|c|c|c|c|c|c|c|c|c|c|c|c|c|}
\hline \multicolumn{16}{|c|}{$\begin{array}{l}\text { Comparis on of the Effect of Span Length (L) } \\
\text { (bending moment, four lanes loaded) }\end{array}$} \\
\hline \multirow{2}{*}{\multicolumn{6}{|c|}{ Constant Parameters }} & \multicolumn{10}{|c|}{$\begin{array}{l}\text { Distribution Factors (organized by method and varied parameters) } \\
\end{array}$} \\
\hline & & & & & & \multicolumn{2}{|c|}{ Stallings / Yoo } & \multicolumn{2}{|c|}{ Tarhini / Frederick } & \multicolumn{2}{|c|}{ Lever Rule } & \multicolumn{2}{|c|}{ AASHTO Mod. } & \multicolumn{2}{|c|}{ Special Analys is } \\
\hline Girder & $\mathrm{S}(\mathrm{ft})$ & $\mathbf{N}_{\mathrm{b}}$ & $\mathbf{L}_{\mathrm{b}}(\mathrm{ft})$ & OH (in) & Ite ration & $100^{\prime}$ & $200^{\prime}$ & $100^{\prime}$ & $200^{\prime}$ & $100^{\prime}$ & $200^{\prime}$ & $100^{\prime}$ & $200^{\prime}$ & $100^{\prime}$ & $200^{\prime}$ \\
\hline \multirow{4}{*}{ G2 } & \multirow{4}{*}{11.5} & \multirow{4}{*}{5} & \multirow{4}{*}{20} & \multirow{4}{*}{46} & CONTROL & 0.879 & 0.921 & 0.852 & 0.888 & & & 0.995 & 0.823 & 0.636 & 0.636 \\
\hline & & & & & 2x Cross-Frames & 0.896 & 0.955 & 0.867 & 0.916 & & & 0.995 & 0.823 & 0.636 & 0.636 \\
\hline & & & & & No Barrier & 0.914 & 0.943 & 0.914 & 0.944 & & & 0.995 & 0.823 & 0.636 & 0.636 \\
\hline & & & & & No Cross-Frames & 0.881 & 0.877 & 0.854 & 0.852 & & & 0.995 & 0.823 & 0.636 & 0.636 \\
\hline \multirow{4}{*}{ G2 } & \multirow{4}{*}{11.5} & \multirow{4}{*}{5} & \multirow{4}{*}{20} & \multirow{4}{*}{69} & CONTROL & 1.012 & 1.016 & 0.989 & 0.988 & & & 1.194 & 0.988 & 0.723 & 0.723 \\
\hline & & & & & 2x Cross-Frames & 1.016 & 1.041 & 0.992 & 1.008 & & & 1.194 & 0.988 & 0.723 & 0.723 \\
\hline & & & & & No Barrier & 1.063 & 1.044 & 1.070 & 1.054 & & & 1.194 & 0.988 & 0.723 & 0.723 \\
\hline & & & & & No Cross-Frames & 1.035 & 0.991 & 1.012 & 0.970 & & & 1.194 & 0.988 & 0.723 & 0.723 \\
\hline \multirow{4}{*}{ G2 } & \multirow{4}{*}{11.5} & \multirow{4}{*}{5} & \multirow{4}{*}{25} & \multirow{4}{*}{46} & CONTROL & 0.870 & 0.915 & 0.857 & 0.882 & & & 0.995 & 0.823 & 0.636 & 0.636 \\
\hline & & & & & 2x Cross-Frames & 0.893 & 0.950 & 0.871 & 0.911 & & & 0.995 & 0.823 & 0.636 & 0.636 \\
\hline & & & & & No Barrier & 0.905 & 0.938 & 0.919 & 0.939 & & & 0.995 & 0.823 & 0.636 & 0.636 \\
\hline & & & & & No Cross-Frames & 0.869 & 0.877 & 0.861 & 0.853 & & & 0.995 & 0.823 & 0.636 & 0.636 \\
\hline \multirow{4}{*}{ G2 } & \multirow{4}{*}{11.5} & \multirow{4}{*}{5} & \multirow{4}{*}{25} & \multirow{4}{*}{69} & CONTROL & 1.001 & 1.011 & 0.994 & 0.983 & & & 1.194 & 0.988 & 0.723 & 0.723 \\
\hline & & & & & 2x Cross-Frames & 1.011 & 1.037 & 0.996 & 1.004 & & & 1.194 & 0.988 & 0.723 & 0.723 \\
\hline & & & & & No Barrier & 1.050 & 1.041 & 1.074 & 1.050 & & & 1.194 & 0.988 & 0.723 & 0.723 \\
\hline & & & & & No Cross-Frames & 1.020 & 0.991 & 1.019 & 0.970 & & & 1.194 & 0.988 & 0.723 & 0.723 \\
\hline
\end{tabular}




\begin{tabular}{|c|c|c|c|c|c|c|c|c|c|c|c|c|c|c|c|}
\hline \multicolumn{16}{|c|}{$\begin{array}{l}\text { Comparis on of the Effect of the Number of Girders }\left(\mathbf{N}_{\mathbf{b}}\right) \\
\text { (bending moment, one lane loaded) }\end{array}$} \\
\hline \multirow{2}{*}{\multicolumn{6}{|c|}{ Constant Parameters }} & \multicolumn{10}{|c|}{ Distribution Factors (organize d by method and varied parame ters) } \\
\hline & & & & & & \multicolumn{2}{|c|}{ Stallings / Yoo } & \multicolumn{2}{|c|}{ Tarhini / Frederick } & \multicolumn{2}{|c|}{ Lever Rule } & \multicolumn{2}{|c|}{ AASHTO Mod. } & Special & nalysis \\
\hline Girder & L (ft) & S (ft) & $\mathbf{L}_{\mathrm{b}}(\mathbf{f t})$ & OH (in) & Iteration & 4 & 5 & 4 & 5 & 4 & 5 & 4 & 5 & 4 & 5 \\
\hline & & & & & CONTROL & 0.502 & 0.488 & 0.472 & 0.461 & $\overline{0.861}$ & 0.861 & & & 0.738 & 0.652 \\
\hline G2 & 100 & 8625 & 20 & 46 & 2x Cross-Frames & 0.489 & 0.467 & 0.459 & 0.442 & 0.861 & 0.861 & & & 0.738 & 0.652 \\
\hline $\mathrm{G} 2$ & 100 & 8.625 & 20 & 40 & No Barrier & 0.521 & 0.506 & 0.521 & 0.506 & 0.861 & 0.861 & & & 0.738 & 0.652 \\
\hline & & & & & No Cross-Frames & 0.540 & 0.532 & 0.507 & 0.502 & 0.861 & 0.861 & & & 0.738 & 0.652 \\
\hline & & & & & CONTROL & 0.581 & 0.567 & 0.544 & 0.533 & 1.128 & 1.128 & & & 0.818 & 0.706 \\
\hline G2 & 100 & 8625 & 20 & 69 & 2x Cross-Frames & 0.555 & 0.533 & 0.521 & 0.503 & 1.128 & 1.128 & & & 0.818 & 0.706 \\
\hline $\mathrm{G} 2$ & 100 & 8.025 & 20 & 69 & No Barrier & 0.606 & 0.591 & 0.608 & 0.593 & 1.128 & 1.128 & & & 0.818 & 0.706 \\
\hline & & & & & No Cross-Frames & 0.637 & 0.627 & 0.595 & 0.589 & 1.128 & 1.128 & & & 0.818 & 0.706 \\
\hline & & & & & CONTROL & 0.495 & 0.479 & 0.474 & 0.464 & 0.861 & 0.861 & & & 0.738 & 0.652 \\
\hline G2 & 100 & 8625 & 25 & 46 & 2x Cross-Frames & 0.479 & 0.454 & 0.462 & 0.445 & 0.861 & 0.861 & & & 0.738 & 0.652 \\
\hline 32 & 100 & 0.025 & 25 & 40 & No Barrier & 0.512 & 0.496 & 0.523 & 0.508 & 0.861 & 0.861 & & & 0.738 & 0.652 \\
\hline & & & & & No Cross-Frames & 0.535 & 0.527 & 0.509 & 0.504 & 0.861 & 0.861 & & & 0.738 & 0.652 \\
\hline & & & & & CONTROL & 0.568 & 0.552 & 0.545 & 0.535 & 1.128 & 1.128 & & & 0.818 & 0.706 \\
\hline G2 & 100 & 8625 & 25 & 69 & 2x Cross-Frames & 0.534 & 0.508 & 0.521 & 0.504 & 1.128 & 1.128 & & & 0.818 & 0.706 \\
\hline 02 & 100 & 0.025 & 20 & 80 & No Barrier & 0.590 & 0.574 & 0.609 & 0.594 & 1.128 & 1.128 & & & 0.818 & 0.706 \\
\hline & & & & & No Cross-Frames & 0.632 & 0.622 & 0.596 & 0.590 & 1.128 & 1.128 & & & 0.818 & 0.706 \\
\hline & & & & & CONTROL & 0.563 & 0.553 & 0.527 & 0.519 & 0.946 & 0.946 & & & 0.764 & 0.669 \\
\hline G2 & 100 & 115 & 20 & 46 & 2x Cross-Frames & 0.540 & 0.525 & 0.506 & 0.494 & 0.946 & 0.946 & & & 0.764 & 0.669 \\
\hline 02 & 00 & 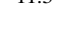 & 20 & 40 & No Barrier & 0.580 & 0.568 & 0.574 & 0.562 & 0.946 & 0.946 & & & 0.764 & 0.669 \\
\hline & & & & & No Cross-Frames & 0.611 & 0.600 & 0.572 & 0.563 & 0.946 & 0.946 & & & 0.764 & 0.669 \\
\hline & & & & & CONTROL & 0.635 & 0.626 & 0.593 & 0.585 & 1.146 & 1.146 & & & 0.824 & 0.709 \\
\hline G2 & 100 & 115 & 20 & 69 & 2x Cross-Frames & 0.600 & 0.586 & 0.561 & 0.549 & 1.146 & 1.146 & & & 0.824 & 0.709 \\
\hline $\mathrm{G}$ & 100 & 11.5 & 20 & 09 & No Barrier & 0.657 & 0.646 & 0.654 & 0.642 & 1.146 & 1.146 & & & 0.824 & 0.709 \\
\hline & & & & & No Cross-Frames & 0.699 & 0.687 & 0.651 & 0.640 & 1.146 & 1.146 & & & 0.824 & 0.709 \\
\hline & & & & & CONTROL & 0.556 & 0.545 & 0.531 & 0.523 & 0.946 & 0.946 & & & 0.764 & 0.669 \\
\hline G2 & 100 & 115 & 25 & 46 & 2x Cross-Frames & 0.530 & 0.513 & 0.510 & 0.498 & 0.946 & 0.946 & & & 0.764 & 0.669 \\
\hline $\mathrm{G} 2$ & 100 & 11.5 & 25 & 40 & No Barrier & 0.572 & 0.559 & 0.578 & 0.566 & 0.946 & 0.946 & & & 0.764 & 0.669 \\
\hline & & & & & No Cross-Frames & 0.606 & 0.595 & 0.575 & 0.566 & 0.946 & 0.946 & & & 0.764 & 0.669 \\
\hline & & & & & CONTROL & 0.625 & 0.614 & 0.596 & 0.588 & 1.146 & 1.146 & & & 0.824 & 0.709 \\
\hline G? & 100 & 115 & 25 & 69 & 2x Cross-Frames & 0.583 & 0.566 & 0.564 & 0.552 & 1.146 & 1.146 & & & 0.824 & 0.709 \\
\hline GL & 100 & 11.5 & 25 & 03 & No Barrier & 0.645 & 0.633 & 0.657 & 0.645 & 1.146 & 1.146 & & & 0.824 & 0.709 \\
\hline & & & & & No Cross-Frames & 0.695 & 0.682 & 0.653 & 0.643 & 1.146 & 1.146 & & & 0.824 & 0.709 \\
\hline & & & & & CONTROL & 0.451 & 0.413 & 0.432 & 0.401 & 0.861 & 0.861 & & & 0.738 & 0.652 \\
\hline G2 & 200 & 8625 & 20 & 46 & 2x Cross-Frames & 0.447 & 0.402 & 0.429 & 0.393 & 0.861 & 0.861 & & & 0.738 & 0.652 \\
\hline 32 & 200 & 0.025 & 20 & 40 & No Barrier & 0.466 & 0.426 & 0.475 & 0.437 & 0.861 & 0.861 & & & 0.738 & 0.652 \\
\hline & & & & & No Cross-Frames & 0.466 & 0.440 & 0.445 & 0.424 & 0.861 & 0.861 & & & 0.738 & 0.652 \\
\hline & & & & & CONTROL & 0.495 & 0.453 & 0.477 & 0.443 & 1.128 & 1.128 & & & 0.818 & 0.706 \\
\hline G2 & 200 & 8625 & 20 & 69 & 2x Cross-Frames & 0.485 & 0.434 & 0.470 & 0.429 & 1.128 & 1.128 & & & 0.818 & 0.706 \\
\hline $\mathrm{G} 2$ & 200 & 8.625 & 20 & 69 & No Barrier & 0.514 & 0.469 & 0.528 & 0.486 & 1.128 & 1.128 & & & 0.818 & 0.706 \\
\hline & & & & & No Cross-Frames & 0.520 & 0.495 & 0.497 & 0.477 & 1.128 & 1.128 & & & 0.818 & 0.706 \\
\hline & & & & & CONTROL & 0.451 & 0.414 & 0.432 & 0.402 & 0.861 & 0.861 & & & 0.738 & 0.652 \\
\hline G2 & 200 & 8.625 & 25 & 46 & 2x Cross-Frames & 0.446 & 0.403 & 0.429 & 0.394 & 0.861 & 0.861 & & & 0.738 & 0.652 \\
\hline & & & & & No Barrier & 0.465 & 0.427 & 0.474 & 0.438 & 0.861 & 0.861 & & & 0.738 & 0.652 \\
\hline & & & & & No Cross-Frames & 0.464 & 0.440 & 0.443 & 0.424 & 0.861 & 0.861 & & & 0.738 & 0.652 \\
\hline & & & & & CONTROL & 0.496 & 0.454 & 0.478 & 0.445 & 1.128 & 1.128 & & & 0.818 & 0.706 \\
\hline G2 & 200 & 8.625 & 25 & 69 & 2x Cross-Frames & 0.485 & 0.435 & 0.470 & 0.430 & 1.128 & 1.128 & & & 0.818 & 0.706 \\
\hline & & & & & No Barrier & 0.514 & 0.471 & 0.528 & 0.488 & 1.128 & 1.128 & & & 0.818 & 0.706 \\
\hline & & & & & No Cross-Frames & 0.520 & 0.495 & 0.497 & 0.477 & 1.128 & 1.128 & & & 0.818 & 0.706 \\
\hline & & & & & CONTROL & 0.486 & 0.453 & 0.465 & 0.438 & 0.946 & 0.946 & & & 0.764 & 0.669 \\
\hline G2 & 200 & 11.5 & 20 & 46 & 2x Cross-Frames & 0.477 & 0.435 & 0.458 & 0.423 & 0.946 & 0.946 & & & 0.764 & 0.669 \\
\hline & & & & & No Barrier & 0.499 & 0.464 & 0.504 & 0.471 & 0.946 & 0.946 & & & 0.764 & 0.669 \\
\hline & & & & & No Cross-Frames & 0.513 & 0.497 & 0.488 & 0.476 & 0.946 & 0.946 & & & 0.764 & 0.669 \\
\hline & & & & & CONTROL & 0.525 & 0.489 & 0.505 & 0.476 & 1.146 & 1.146 & & & 0.824 & 0.709 \\
\hline G2 & 200 & 11.5 & 20 & 69 & 2x Cross-Frames & 0.510 & 0.463 & 0.493 & 0.454 & 1.146 & 1.146 & & & 0.824 & 0.709 \\
\hline $\mathrm{G} 2$ & & & & & No Barrier & 0.542 & 0.505 & 0.552 & 0.516 & 1.146 & 1.146 & & & 0.824 & 0.709 \\
\hline & & & & & No Cross-Frames & 0.566 & 0.550 & 0.538 & 0.526 & 1.146 & 1.146 & & & 0.824 & 0.709 \\
\hline & & & & & CONTROL & 0.487 & 0.454 & 0.466 & 0.440 & 0.946 & 0.946 & & & 0.764 & 0.669 \\
\hline G2 & 200 & 11.5 & 25 & 46 & 2x Cross-Frames & 0.477 & 0.436 & 0.459 & 0.425 & 0.946 & 0.946 & & & 0.764 & 0.669 \\
\hline $\mathrm{G} 2$ & 200 & 11.5 & 25 & 46 & No Barrier & 0.500 & 0.466 & 0.505 & 0.473 & 0.946 & 0.946 & & & 0.764 & 0.669 \\
\hline & & & & & No Cross-Frames & 0.513 & 0.497 & 0.488 & 0.476 & 0.946 & 0.946 & & & 0.764 & 0.669 \\
\hline & & & & & CONTROL & 0.526 & 0.492 & 0.506 & 0.479 & 1.146 & 1.146 & & & 0.824 & 0.709 \\
\hline G2 & 200 & 11.5 & 25 & 69 & 2x Cross-Frames & 0.510 & 0.465 & 0.494 & 0.457 & 1.146 & 1.146 & & & 0.824 & 0.709 \\
\hline $\mathrm{G}$ & 200 & 11.5 & 20 & 09 & No Barrier & 0.544 & 0.508 & 0.553 & 0.520 & 1.146 & 1.146 & & & 0.824 & 0.709 \\
\hline & & & & & No Cross-Frames & 0.566 & 0.550 & 0.538 & 0.526 & 1.146 & 1.146 & & & 0.824 & 0.709 \\
\hline
\end{tabular}




\begin{tabular}{|c|c|c|c|c|c|c|c|c|c|c|c|c|c|c|c|}
\hline \multicolumn{16}{|c|}{$\begin{array}{l}\text { Comparis on of the Effect of the Number of Girders }\left(\mathbf{N}_{\mathbf{b}}\right) \\
\text { (bending moment, one lane loaded) }\end{array}$} \\
\hline \multirow{2}{*}{\multicolumn{6}{|c|}{ Constant Parameters }} & \multicolumn{10}{|c|}{ Distribution Factors (organize d by method and varied parame ters) } \\
\hline & & & & & & \multicolumn{2}{|c|}{ Stallings / Yoo } & \multicolumn{2}{|c|}{ Tarhini / Frederick } & \multicolumn{2}{|c|}{ Lever Rule } & \multicolumn{2}{|c|}{ AASHTO Mod. } & Special & nalysis \\
\hline Girder & L (ft) & S (ft) & $\mathbf{L}_{\mathrm{b}}(\mathbf{f t})$ & OH (in) & Iteration & 4 & 5 & 4 & 5 & 4 & 5 & 4 & 5 & 4 & 5 \\
\hline & & & & & CONTROL & 0.502 & 0.488 & 0.472 & 0.461 & $\overline{0.861}$ & 0.861 & & & 0.738 & 0.652 \\
\hline G2 & 100 & 8625 & 20 & 46 & 2x Cross-Frames & 0.489 & 0.467 & 0.459 & 0.442 & 0.861 & 0.861 & & & 0.738 & 0.652 \\
\hline $\mathrm{G} 2$ & 100 & 8.625 & 20 & 40 & No Barrier & 0.521 & 0.506 & 0.521 & 0.506 & 0.861 & 0.861 & & & 0.738 & 0.652 \\
\hline & & & & & No Cross-Frames & 0.540 & 0.532 & 0.507 & 0.502 & 0.861 & 0.861 & & & 0.738 & 0.652 \\
\hline & & & & & CONTROL & 0.581 & 0.567 & 0.544 & 0.533 & 1.128 & 1.128 & & & 0.818 & 0.706 \\
\hline G2 & 100 & 8625 & 20 & 69 & 2x Cross-Frames & 0.555 & 0.533 & 0.521 & 0.503 & 1.128 & 1.128 & & & 0.818 & 0.706 \\
\hline $\mathrm{G} 2$ & 100 & 8.025 & 20 & 69 & No Barrier & 0.606 & 0.591 & 0.608 & 0.593 & 1.128 & 1.128 & & & 0.818 & 0.706 \\
\hline & & & & & No Cross-Frames & 0.637 & 0.627 & 0.595 & 0.589 & 1.128 & 1.128 & & & 0.818 & 0.706 \\
\hline & & & & & CONTROL & 0.495 & 0.479 & 0.474 & 0.464 & 0.861 & 0.861 & & & 0.738 & 0.652 \\
\hline G2 & 100 & 8625 & 25 & 46 & 2x Cross-Frames & 0.479 & 0.454 & 0.462 & 0.445 & 0.861 & 0.861 & & & 0.738 & 0.652 \\
\hline 32 & 100 & 0.025 & 25 & 40 & No Barrier & 0.512 & 0.496 & 0.523 & 0.508 & 0.861 & 0.861 & & & 0.738 & 0.652 \\
\hline & & & & & No Cross-Frames & 0.535 & 0.527 & 0.509 & 0.504 & 0.861 & 0.861 & & & 0.738 & 0.652 \\
\hline & & & & & CONTROL & 0.568 & 0.552 & 0.545 & 0.535 & 1.128 & 1.128 & & & 0.818 & 0.706 \\
\hline G2 & 100 & 8625 & 25 & 69 & 2x Cross-Frames & 0.534 & 0.508 & 0.521 & 0.504 & 1.128 & 1.128 & & & 0.818 & 0.706 \\
\hline 02 & 100 & 0.025 & 20 & 80 & No Barrier & 0.590 & 0.574 & 0.609 & 0.594 & 1.128 & 1.128 & & & 0.818 & 0.706 \\
\hline & & & & & No Cross-Frames & 0.632 & 0.622 & 0.596 & 0.590 & 1.128 & 1.128 & & & 0.818 & 0.706 \\
\hline & & & & & CONTROL & 0.563 & 0.553 & 0.527 & 0.519 & 0.946 & 0.946 & & & 0.764 & 0.669 \\
\hline G2 & 100 & 115 & 20 & 46 & 2x Cross-Frames & 0.540 & 0.525 & 0.506 & 0.494 & 0.946 & 0.946 & & & 0.764 & 0.669 \\
\hline 02 & 00 & 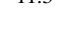 & 20 & 40 & No Barrier & 0.580 & 0.568 & 0.574 & 0.562 & 0.946 & 0.946 & & & 0.764 & 0.669 \\
\hline & & & & & No Cross-Frames & 0.611 & 0.600 & 0.572 & 0.563 & 0.946 & 0.946 & & & 0.764 & 0.669 \\
\hline & & & & & CONTROL & 0.635 & 0.626 & 0.593 & 0.585 & 1.146 & 1.146 & & & 0.824 & 0.709 \\
\hline G2 & 100 & 115 & 20 & 69 & 2x Cross-Frames & 0.600 & 0.586 & 0.561 & 0.549 & 1.146 & 1.146 & & & 0.824 & 0.709 \\
\hline $\mathrm{G}$ & 100 & 11.5 & 20 & 09 & No Barrier & 0.657 & 0.646 & 0.654 & 0.642 & 1.146 & 1.146 & & & 0.824 & 0.709 \\
\hline & & & & & No Cross-Frames & 0.699 & 0.687 & 0.651 & 0.640 & 1.146 & 1.146 & & & 0.824 & 0.709 \\
\hline & & & & & CONTROL & 0.556 & 0.545 & 0.531 & 0.523 & 0.946 & 0.946 & & & 0.764 & 0.669 \\
\hline G2 & 100 & 115 & 25 & 46 & 2x Cross-Frames & 0.530 & 0.513 & 0.510 & 0.498 & 0.946 & 0.946 & & & 0.764 & 0.669 \\
\hline $\mathrm{G} 2$ & 100 & 11.5 & 25 & 40 & No Barrier & 0.572 & 0.559 & 0.578 & 0.566 & 0.946 & 0.946 & & & 0.764 & 0.669 \\
\hline & & & & & No Cross-Frames & 0.606 & 0.595 & 0.575 & 0.566 & 0.946 & 0.946 & & & 0.764 & 0.669 \\
\hline & & & & & CONTROL & 0.625 & 0.614 & 0.596 & 0.588 & 1.146 & 1.146 & & & 0.824 & 0.709 \\
\hline G? & 100 & 115 & 25 & 69 & 2x Cross-Frames & 0.583 & 0.566 & 0.564 & 0.552 & 1.146 & 1.146 & & & 0.824 & 0.709 \\
\hline GL & 100 & 11.5 & 25 & 03 & No Barrier & 0.645 & 0.633 & 0.657 & 0.645 & 1.146 & 1.146 & & & 0.824 & 0.709 \\
\hline & & & & & No Cross-Frames & 0.695 & 0.682 & 0.653 & 0.643 & 1.146 & 1.146 & & & 0.824 & 0.709 \\
\hline & & & & & CONTROL & 0.451 & 0.413 & 0.432 & 0.401 & 0.861 & 0.861 & & & 0.738 & 0.652 \\
\hline G2 & 200 & 8625 & 20 & 46 & 2x Cross-Frames & 0.447 & 0.402 & 0.429 & 0.393 & 0.861 & 0.861 & & & 0.738 & 0.652 \\
\hline 32 & 200 & 0.025 & 20 & 40 & No Barrier & 0.466 & 0.426 & 0.475 & 0.437 & 0.861 & 0.861 & & & 0.738 & 0.652 \\
\hline & & & & & No Cross-Frames & 0.466 & 0.440 & 0.445 & 0.424 & 0.861 & 0.861 & & & 0.738 & 0.652 \\
\hline & & & & & CONTROL & 0.495 & 0.453 & 0.477 & 0.443 & 1.128 & 1.128 & & & 0.818 & 0.706 \\
\hline G2 & 200 & 8625 & 20 & 69 & 2x Cross-Frames & 0.485 & 0.434 & 0.470 & 0.429 & 1.128 & 1.128 & & & 0.818 & 0.706 \\
\hline $\mathrm{G} 2$ & 200 & 8.625 & 20 & 69 & No Barrier & 0.514 & 0.469 & 0.528 & 0.486 & 1.128 & 1.128 & & & 0.818 & 0.706 \\
\hline & & & & & No Cross-Frames & 0.520 & 0.495 & 0.497 & 0.477 & 1.128 & 1.128 & & & 0.818 & 0.706 \\
\hline & & & & & CONTROL & 0.451 & 0.414 & 0.432 & 0.402 & 0.861 & 0.861 & & & 0.738 & 0.652 \\
\hline G2 & 200 & 8.625 & 25 & 46 & 2x Cross-Frames & 0.446 & 0.403 & 0.429 & 0.394 & 0.861 & 0.861 & & & 0.738 & 0.652 \\
\hline & & & & & No Barrier & 0.465 & 0.427 & 0.474 & 0.438 & 0.861 & 0.861 & & & 0.738 & 0.652 \\
\hline & & & & & No Cross-Frames & 0.464 & 0.440 & 0.443 & 0.424 & 0.861 & 0.861 & & & 0.738 & 0.652 \\
\hline & & & & & CONTROL & 0.496 & 0.454 & 0.478 & 0.445 & 1.128 & 1.128 & & & 0.818 & 0.706 \\
\hline G2 & 200 & 8.625 & 25 & 69 & 2x Cross-Frames & 0.485 & 0.435 & 0.470 & 0.430 & 1.128 & 1.128 & & & 0.818 & 0.706 \\
\hline & & & & & No Barrier & 0.514 & 0.471 & 0.528 & 0.488 & 1.128 & 1.128 & & & 0.818 & 0.706 \\
\hline & & & & & No Cross-Frames & 0.520 & 0.495 & 0.497 & 0.477 & 1.128 & 1.128 & & & 0.818 & 0.706 \\
\hline & & & & & CONTROL & 0.486 & 0.453 & 0.465 & 0.438 & 0.946 & 0.946 & & & 0.764 & 0.669 \\
\hline G2 & 200 & 11.5 & 20 & 46 & 2x Cross-Frames & 0.477 & 0.435 & 0.458 & 0.423 & 0.946 & 0.946 & & & 0.764 & 0.669 \\
\hline & & & & & No Barrier & 0.499 & 0.464 & 0.504 & 0.471 & 0.946 & 0.946 & & & 0.764 & 0.669 \\
\hline & & & & & No Cross-Frames & 0.513 & 0.497 & 0.488 & 0.476 & 0.946 & 0.946 & & & 0.764 & 0.669 \\
\hline & & & & & CONTROL & 0.525 & 0.489 & 0.505 & 0.476 & 1.146 & 1.146 & & & 0.824 & 0.709 \\
\hline G2 & 200 & 11.5 & 20 & 69 & 2x Cross-Frames & 0.510 & 0.463 & 0.493 & 0.454 & 1.146 & 1.146 & & & 0.824 & 0.709 \\
\hline $\mathrm{G} 2$ & & & & & No Barrier & 0.542 & 0.505 & 0.552 & 0.516 & 1.146 & 1.146 & & & 0.824 & 0.709 \\
\hline & & & & & No Cross-Frames & 0.566 & 0.550 & 0.538 & 0.526 & 1.146 & 1.146 & & & 0.824 & 0.709 \\
\hline & & & & & CONTROL & 0.487 & 0.454 & 0.466 & 0.440 & 0.946 & 0.946 & & & 0.764 & 0.669 \\
\hline G2 & 200 & 11.5 & 25 & 46 & 2x Cross-Frames & 0.477 & 0.436 & 0.459 & 0.425 & 0.946 & 0.946 & & & 0.764 & 0.669 \\
\hline $\mathrm{G} 2$ & 200 & 11.5 & 25 & 46 & No Barrier & 0.500 & 0.466 & 0.505 & 0.473 & 0.946 & 0.946 & & & 0.764 & 0.669 \\
\hline & & & & & No Cross-Frames & 0.513 & 0.497 & 0.488 & 0.476 & 0.946 & 0.946 & & & 0.764 & 0.669 \\
\hline & & & & & CONTROL & 0.526 & 0.492 & 0.506 & 0.479 & 1.146 & 1.146 & & & 0.824 & 0.709 \\
\hline G2 & 200 & 11.5 & 25 & 69 & 2x Cross-Frames & 0.510 & 0.465 & 0.494 & 0.457 & 1.146 & 1.146 & & & 0.824 & 0.709 \\
\hline $\mathrm{G}$ & 200 & 11.5 & 20 & 09 & No Barrier & 0.544 & 0.508 & 0.553 & 0.520 & 1.146 & 1.146 & & & 0.824 & 0.709 \\
\hline & & & & & No Cross-Frames & 0.566 & 0.550 & 0.538 & 0.526 & 1.146 & 1.146 & & & 0.824 & 0.709 \\
\hline
\end{tabular}




\begin{tabular}{|c|c|c|c|c|c|c|c|c|c|c|c|c|c|c|c|}
\hline \multicolumn{16}{|c|}{$\begin{array}{l}\text { Comparis on of the Effect of the Number of Girders }\left(\mathbf{N}_{\mathbf{b}}\right) \\
\text { (bending moment, two lanes loaded) }\end{array}$} \\
\hline \multirow{2}{*}{\multicolumn{6}{|c|}{ Constant Parameters }} & \multicolumn{10}{|c|}{ Dis tribution Factors (organized by me thod and varied parame ters) } \\
\hline & & & & & & \multicolumn{2}{|c|}{ Stallings / Yoo } & \multicolumn{2}{|c|}{ Tarhini / Frederick } & \multicolumn{2}{|c|}{ Lever Rule } & \multicolumn{2}{|c|}{ AASHTO Mod. } & Special & nalys is \\
\hline Girder & $L(f t)$ & S (ft) & $\mathbf{L}_{\mathrm{b}}(\mathrm{ft})$ & OH (in) & Iteration & 4 & 5 & 4 & 5 & 4 & 5 & 4 & 5 & 4 & 5 \\
\hline & & & & & CONTROL & 0.663 & 0.639 & 0.629 & 0.612 & & & 0.807 & 0.807 & 0.813 & $\overline{0.809}$ \\
\hline PO & 100 & 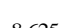 & P & (1) & 2x Cross-Frames & 0.674 & 0.643 & 0.639 & 0.616 & & & 0.807 & 0.807 & 0.813 & 0.809 \\
\hline G2 & 100 & 8.625 & 20 & 46 & No Barrier & 0.692 & 0.671 & 0.692 & 0.672 & & & 0.807 & 0.807 & 0.813 & 0.809 \\
\hline & & & & & No Cross-Frames & 0.675 & 0.666 & 0.641 & 0.639 & & & 0.807 & 0.807 & 0.813 & 0.809 \\
\hline & & & & & CONTROL & 0.783 & 0.752 & 0.746 & 0.723 & & & 0.968 & 0.968 & 0.946 & 0.898 \\
\hline$C_{2}$ & 100 & 8625 & 20 & 60 & 2x Cross-Frames & 0.780 & 0.742 & 0.743 & 0.713 & & & 0.968 & 0.968 & 0.946 & 0.898 \\
\hline G2 & 100 & 8.625 & 20 & 69 & No Barrier & 0.821 & 0.795 & 0.825 & 0.800 & & & 0.968 & 0.968 & 0.946 & 0.898 \\
\hline & & & & & No Cross-Frames & 0.818 & 0.799 & 0.781 & 0.769 & & & 0.968 & 0.968 & 0.946 & 0.898 \\
\hline & & & & & CONTROL & 0.662 & 0.634 & 0.634 & 0.616 & & & 0.807 & 0.807 & 0.813 & 0.809 \\
\hline ? & 100 & 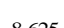 & 5 & AC & 2x Cross-Frames & 0.681 & 0.644 & 0.646 & 0.621 & & & 0.807 & 0.807 & 0.813 & 0.809 \\
\hline $\mathrm{G} 2$ & 100 & 8.625 & 25 & 46 & No Barrier & 0.689 & 0.665 & 0.696 & 0.675 & & & 0.807 & 0.807 & 0.813 & 0.809 \\
\hline & & & & & No Cross-Frames & 0.666 & 0.657 & 0.645 & 0.643 & & & 0.807 & 0.807 & 0.813 & 0.809 \\
\hline & & & & & CONTROL & 0.778 & 0.743 & 0.750 & 0.727 & & & 0.968 & 0.968 & 0.946 & 0.898 \\
\hline G2 & 100 & 8625 & 25 & 69 & 2x Cross-Frames & 0.778 & 0.735 & 0.750 & 0.718 & & & 0.968 & 0.968 & 0.946 & 0.898 \\
\hline $\mathrm{G} 2$ & 100 & 8.025 & 25 & 69 & No Barrier & 0.814 & 0.784 & 0.828 & 0.802 & & & 0.968 & 0.968 & 0.946 & 0.898 \\
\hline & & & & & No Cross-Frames & 0.808 & 0.789 & 0.784 & 0.772 & & & 0.968 & 0.968 & 0.946 & 0.898 \\
\hline & & & & & CONTROL & 0.769 & 0.751 & 0.729 & 0.715 & & & 0.995 & 0.995 & 0.960 & 0.907 \\
\hline G2 & 100 & 115 & 20 & 46 & 2x Cross-Frames & 0.774 & 0.744 & 0.733 & 0.708 & & & 0.995 & 0.995 & 0.960 & 0.907 \\
\hline G2 & 100 & 11.5 & 20 & 46 & No Barrier & 0.801 & 0.783 & 0.793 & 0.774 & & & 0.995 & 0.995 & 0.960 & 0.907 \\
\hline & & & & & No Cross-Frames & 0.796 & 0.787 & 0.755 & 0.750 & & & 0.995 & 0.995 & 0.960 & 0.907 \\
\hline & & & & & CONTROL & 0.888 & 0.868 & 0.844 & 0.829 & & & 1.194 & 1.194 & 1.060 & 0.973 \\
\hline$C_{2}$ & 100 & 115 & 20 & 69 & 2x Cross-Frames & 0.876 & 0.846 & 0.833 & 0.808 & & & 1.194 & 1.194 & 1.060 & 0.973 \\
\hline G2 & 100 & 11.5 & 20 & 69 & No Barrier & 0.928 & 0.908 & 0.923 & 0.904 & & & 1.194 & 1.194 & 1.060 & 0.973 \\
\hline & & & & & No Cross-Frames & 0.937 & 0.924 & 0.891 & 0.882 & & & 1.194 & 1.194 & 1.060 & 0.973 \\
\hline & & & & & CONTROL & 0.765 & 0.743 & 0.734 & 0.720 & & & 0.995 & 0.995 & 0.960 & 0.907 \\
\hline G2 & 100 & 115 & 25 & 46 & 2x Cross-Frames & 0.776 & 0.740 & 0.738 & 0.715 & & & 0.995 & 0.995 & 0.960 & 0.907 \\
\hline G2 & 100 & 11.5 & 25 & 46 & No Barrier & 0.796 & 0.775 & 0.798 & 0.780 & & & 0.995 & 0.995 & 0.960 & 0.907 \\
\hline & & & & & No Cross-Frames & 0.787 & 0.778 & 0.761 & 0.756 & & & 0.995 & 0.995 & 0.960 & 0.907 \\
\hline & & & & & CONTROL & 0.881 & 0.858 & 0.849 & 0.835 & & & 1.194 & 1.194 & 1.060 & 0.973 \\
\hline$G_{2}$ & 100 & 11.5 & 25 & 69 & 2x Cross-Frames & 0.873 & 0.837 & 0.839 & 0.815 & & & 1.194 & 1.194 & 1.060 & 0.973 \\
\hline G2 & 100 & 11.5 & 25 & 69 & No Barrier & 0.919 & 0.897 & 0.928 & 0.909 & & & 1.194 & 1.194 & 1.060 & 0.973 \\
\hline & & & & & No Cross-Frames & 0.926 & 0.913 & 0.896 & 0.887 & & & 1.194 & 1.194 & 1.060 & 0.973 \\
\hline & & & & & CONTROL & 0.675 & 0.628 & 0.646 & 0.608 & & & 0.670 & 0.670 & 0.813 & 0.809 \\
\hline G2 & 200 & 8.625 & 20 & 46 & 2x Cross-Frames & 0.683 & 0.634 & 0.652 & 0.612 & & & 0.670 & 0.670 & 0.813 & 0.809 \\
\hline & & & & & No Barrier & 0.691 & 0.647 & 0.701 & 0.657 & & & 0.670 & 0.670 & 0.813 & 0.809 \\
\hline & & & & & No Cross-Frames & 0.666 & 0.629 & 0.641 & 0.610 & & & 0.670 & 0.670 & 0.813 & 0.809 \\
\hline & & & & & CONTROL & 0.756 & 0.698 & 0.729 & 0.682 & & & 0.804 & 0.804 & 0.946 & 0.898 \\
\hline G2 & 200 & 8.625 & 20 & 69 & 2x Cross-Frames & 0.758 & 0.695 & 0.730 & 0.679 & & & 0.804 & 0.804 & 0.946 & 0.898 \\
\hline & & & & & No Barrier & 0.778 & 0.722 & 0.794 & 0.740 & & & 0.804 & 0.804 & 0.946 & 0.898 \\
\hline & & & & & No Cross-Frames & 0.760 & 0.718 & 0.734 & 0.700 & & & 0.804 & 0.804 & 0.946 & 0.898 \\
\hline & & & & & CONTROL & 0.674 & 0.627 & 0.645 & 0.607 & & & 0.670 & 0.670 & 0.813 & 0.809 \\
\hline G2 & 200 & 8.625 & 25 & 46 & 2x Cross-Frames & 0.683 & 0.634 & 0.651 & 0.612 & & & 0.670 & 0.670 & 0.813 & 0.809 \\
\hline & & & & & No Barrier & 0.690 & 0.646 & 0.700 & 0.656 & & & 0.670 & 0.670 & 0.813 & 0.809 \\
\hline & & & & & No Cross-Frames & 0.666 & 0.629 & 0.641 & 0.611 & & & 0.670 & 0.670 & 0.813 & 0.809 \\
\hline & & & & & CONTROL & 0.756 & 0.698 & 0.729 & 0.682 & & & 0.804 & 0.804 & 0.946 & 0.898 \\
\hline $\mathrm{G}^{2}$ & 200 & 8625 & 25 & 69 & 2x Cross-Frames & 0.758 & 0.695 & 0.730 & 0.679 & & & 0.804 & 0.804 & 0.946 & 0.898 \\
\hline & 200 & 0.025 & 25 & 69 & No Barrier & 0.778 & 0.722 & 0.794 & 0.740 & & & 0.804 & 0.804 & 0.946 & 0.898 \\
\hline & & & & & No Cross-Frames & 0.760 & 0.718 & 0.735 & 0.700 & & & 0.804 & 0.804 & 0.946 & 0.898 \\
\hline & & & & & CONTROL & 0.759 & 0.705 & 0.725 & 0.681 & & & 0.823 & 0.823 & 0.960 & 0.907 \\
\hline $\mathrm{G}_{2}$ & 200 & 11.5 & 20 & 46 & 2x Cross-Frames & 0.766 & 0.704 & 0.730 & 0.680 & & & 0.823 & 0.823 & 0.960 & 0.907 \\
\hline G2 & 200 & 11.5 & 20 & 46 & No Barrier & 0.778 & 0.725 & 0.781 & 0.730 & & & 0.823 & 0.823 & 0.960 & 0.907 \\
\hline & & & & & No Cross-Frames & 0.758 & 0.727 & 0.727 & 0.702 & & & 0.823 & 0.823 & 0.960 & 0.907 \\
\hline & & & & & CONTROL & 0.834 & 0.775 & 0.802 & 0.754 & & & 0.988 & 0.988 & 1.060 & 0.973 \\
\hline$C_{2}$ & 200 & 115 & 20 & 60 & 2x Cross-Frames & 0.832 & 0.761 & 0.800 & 0.743 & & & 0.988 & 0.988 & 1.060 & 0.973 \\
\hline $\mathrm{G} 2$ & 200 & 11.5 & 20 & 69 & No Barrier & 0.857 & 0.798 & 0.866 & 0.810 & & & 0.988 & 0.988 & 1.060 & 0.973 \\
\hline & & & & & No Cross-Frames & 0.852 & 0.821 & 0.820 & 0.796 & & & 0.988 & 0.988 & 1.060 & 0.973 \\
\hline & & & & & CONTROL & 0.758 & 0.705 & 0.723 & 0.681 & & & 0.823 & 0.823 & 0.960 & 0.907 \\
\hline$C_{2}$ & 200 & 115 & 25 & 46 & 2x Cross-Frames & 0.765 & 0.704 & 0.729 & 0.679 & & & 0.823 & 0.823 & 0.960 & 0.907 \\
\hline$G 2$ & 200 & 11.5 & 25 & 46 & No Barrier & 0.777 & 0.725 & 0.780 & 0.730 & & & 0.823 & 0.823 & 0.960 & 0.907 \\
\hline & & & & & No Cross-Frames & 0.758 & 0.727 & 0.727 & 0.702 & & & 0.823 & 0.823 & 0.960 & 0.907 \\
\hline & & & & & CONTROL & 0.833 & 0.776 & 0.802 & 0.756 & & & 0.988 & 0.988 & 1.060 & 0.973 \\
\hline$G_{2}$ & 200 & 115 & 25 & 69 & 2x Cross-Frames & 0.832 & 0.762 & 0.800 & 0.744 & & & 0.988 & 0.988 & 1.060 & 0.973 \\
\hline $\mathrm{G} 2$ & 200 & 11.5 & 25 & 69 & No Barrier & 0.857 & 0.800 & 0.866 & 0.812 & & & 0.988 & 0.988 & 1.060 & 0.973 \\
\hline & & & & & No Cross-Frames & 0.852 & 0.821 & 0.820 & 0.796 & & & 0.988 & 0.988 & 1.060 & 0.973 \\
\hline
\end{tabular}




\begin{tabular}{|c|c|c|c|c|c|c|c|c|c|c|c|c|c|c|c|}
\hline \multicolumn{16}{|c|}{$\begin{array}{l}\text { Comparis on of the Effect of the Number of Girders }\left(\mathbf{N}_{\mathbf{b}}\right) \\
\text { (bending moment, three lanes loaded) }\end{array}$} \\
\hline \multirow{2}{*}{\multicolumn{6}{|c|}{ Constant Parameters }} & \multicolumn{10}{|c|}{ Dis tribution Factors (organized by method and varied parameters) } \\
\hline & & & & & & \multicolumn{2}{|c|}{ Stallings / Yoo } & \multicolumn{2}{|c|}{ Tarhini / Frederick } & \multicolumn{2}{|c|}{ Lever Rule } & \multicolumn{2}{|c|}{ AASHTO Mod. } & \multicolumn{2}{|c|}{ Special Analys is } \\
\hline Girder & L (ft) & $\mathbf{S}$ (ft) & $\mathbf{L}_{\mathrm{b}}(\mathrm{ft})$ & OH (in) & Iteration & 4 & 5 & 4 & 5 & 4 & 5 & 4 & 5 & 4 & 5 \\
\hline \multirow{4}{*}{ G2 } & \multirow{4}{*}{100} & \multirow{4}{*}{11.5} & \multirow{4}{*}{20} & \multirow{4}{*}{46} & CONTROL & 0.853 & 0.831 & $\overline{0.818}$ & 0.804 & & & 0.995 & 0.995 & 0.825 & 0.890 \\
\hline & & & & & 2x Cross-Frames & 0.874 & 0.840 & 0.838 & 0.812 & & & 0.995 & 0.995 & 0.825 & 0.890 \\
\hline & & & & & No Barrier & 0.883 & 0.870 & 0.883 & 0.869 & & & 0.995 & 0.995 & 0.825 & 0.890 \\
\hline & & & & & No Cross-Frames & 0.849 & 0.856 & 0.815 & 0.829 & & & 0.995 & 0.995 & 0.825 & 0.890 \\
\hline \multirow{4}{*}{ G2 } & \multirow{4}{*}{100} & \multirow{4}{*}{11.5} & \multirow{4}{*}{20} & \multirow{4}{*}{69} & CONTROL & 0.983 & 0.958 & 0.949 & 0.932 & & & 1.194 & 1.194 & 0.952 & 0.975 \\
\hline & & & & & 2x Cross-Frames & 0.992 & 0.954 & 0.957 & 0.928 & & & 1.194 & 1.194 & 0.952 & 0.975 \\
\hline & & & & & No Barrier & 1.028 & 1.009 & 1.033 & 1.014 & & & 1.194 & 1.194 & 0.952 & 0.975 \\
\hline & & & & & No Cross-Frames & 1.001 & 1.001 & 0.968 & 0.975 & & & 1.194 & 1.194 & 0.952 & 0.975 \\
\hline \multirow{4}{*}{ G2 } & \multirow{4}{*}{100} & \multirow{4}{*}{11.5} & \multirow{4}{*}{25} & \multirow{4}{*}{46} & CONTROL & 0.847 & 0.823 & 0.822 & 0.808 & & & 0.995 & 0.995 & 0.825 & 0.890 \\
\hline & & & & & 2x Cross-Frames & 0.874 & 0.838 & 0.842 & 0.815 & & & 0.995 & 0.995 & 0.825 & 0.890 \\
\hline & & & & & No Barrier & 0.876 & 0.862 & 0.887 & 0.873 & & & 0.995 & 0.995 & 0.825 & 0.890 \\
\hline & & & & & No Cross-Frames & 0.839 & 0.844 & 0.821 & 0.835 & & & 0.995 & 0.995 & 0.825 & 0.890 \\
\hline & & & & & CONTROL & 0.975 & 0.947 & 0.954 & 0.937 & & & 1.194 & 1.194 & 0.952 & 0.975 \\
\hline (C) & 100 & 115 & 25 & 69 & 2x Cross-Frames & 0.990 & 0.948 & 0.962 & 0.932 & & & 1.194 & 1.194 & 0.952 & 0.975 \\
\hline G2 & 100 & 11.5 & 20 & 03 & No Barrier & 1.018 & 0.997 & 1.036 & 1.018 & & & 1.194 & 1.194 & 0.952 & 0.975 \\
\hline & & & & & No Cross-Frames & 0.988 & 0.988 & 0.974 & 0.981 & & & 1.194 & 1.194 & 0.952 & 0.975 \\
\hline & & & & & CONTROL & 0.898 & 0.844 & 0.857 & 0.814 & & & 0.823 & 0.823 & 0.825 & 0.890 \\
\hline (C) & 200 & 115 & 20 & 46 & 2x Cross-Frames & 0.917 & 0.865 & 0.872 & 0.832 & & & 0.823 & 0.823 & 0.825 & 0.890 \\
\hline $\mathrm{G} 2$ & 200 & 11.5 & 20 & 46 & No Barrier & 0.915 & 0.868 & 0.917 & 0.870 & & & 0.823 & 0.823 & 0.825 & 0.890 \\
\hline & & & & & No Cross-Frames & 0.868 & 0.826 & 0.834 & 0.802 & & & 0.823 & 0.823 & 0.825 & 0.890 \\
\hline & & & & & CONTROL & 0.993 & 0.930 & 0.955 & 0.904 & & & 0.988 & 0.988 & 0.952 & 0.975 \\
\hline G2 & 200 & 11.5 & 20 & 69 & 2x Cross-Frames & 1.007 & 0.940 & 0.966 & 0.912 & & & 0.988 & 0.988 & 0.952 & 0.975 \\
\hline 2 & & 11.6 & & & No Barrier & 1.018 & 0.958 & 1.026 & 0.969 & & & 0.988 & 0.988 & 0.952 & 0.975 \\
\hline & & & & & No Cross-Frames & 0.979 & 0.935 & 0.947 & 0.912 & & & 0.988 & 0.988 & 0.952 & 0.975 \\
\hline & & & & & CONTROL & 0.596 & 0.840 & 0.854 & 0.810 & & & 0.823 & 0.823 & 0.825 & 0.890 \\
\hline$C_{2}$ & 200 & 115 & 25 & & 2x Cross-Frames & 0.610 & 0.862 & 0.870 & 0.828 & & & 0.823 & 0.823 & 0.825 & 0.890 \\
\hline $\mathrm{G} 2$ & 200 & 11.5 & 25 & 46 & No Barrier & 0.609 & 0.864 & 0.914 & 0.867 & & & 0.823 & 0.823 & 0.825 & 0.890 \\
\hline & & & & & No Cross-Frames & 0.579 & 0.826 & 0.834 & 0.802 & & & 0.823 & 0.823 & 0.825 & 0.890 \\
\hline & & & & & CONTROL & 0.991 & 0.927 & 0.953 & 0.902 & & & 0.988 & 0.988 & 0.952 & 0.975 \\
\hline G2 & 200 & 115 & 25 & 69 & 2x Cross-Frames & 1.006 & 0.938 & 0.964 & 0.910 & & & 0.988 & 0.988 & 0.952 & 0.975 \\
\hline $\mathrm{G} 2$ & 200 & 11.5 & 25 & 69 & No Barrier & 1.016 & 0.957 & 1.024 & 0.967 & & & 0.988 & 0.988 & 0.952 & 0.975 \\
\hline & & & & & No Cross-Frames & 0.979 & 0.935 & 0.947 & 0.913 & & & 0.988 & 0.988 & 0.952 & 0.975 \\
\hline
\end{tabular}




\begin{tabular}{|c|c|c|c|c|c|c|c|c|c|c|c|c|c|c|c|}
\hline \multicolumn{16}{|c|}{$\begin{array}{l}\text { Comparis on of the Effect of Unbrace d Length }\left(\mathbf{L}_{\mathbf{b}}\right) \\
\text { (bending moment, one lane loaded) }\end{array}$} \\
\hline \multirow{2}{*}{\multicolumn{6}{|c|}{ Constant Parameters }} & \multicolumn{10}{|c|}{ Distribution Factors (organized by me thod and varied parameters) } \\
\hline & & & & & & \multicolumn{2}{|c|}{ Stallings / Yoo } & \multicolumn{2}{|c|}{ Tarhini / Frederick } & \multicolumn{2}{|c|}{ Lever Rule } & \multicolumn{2}{|c|}{ AASHTO Mod. } & Specia & nalys is \\
\hline Girder & $L(f t)$ & S (ft) & $\mathbf{N}_{\mathrm{b}}$ & OH (in) & Iteration & $20^{\prime}$ & $25^{\prime}$ & $20^{\prime}$ & $25^{\prime}$ & $20^{\prime}$ & $25^{\prime}$ & $20^{\prime}$ & $25^{\prime}$ & $20^{\prime}$ & $25^{\prime}$ \\
\hline & & & & & CONTROL & 0.502 & 0.495 & 0.472 & 0.474 & 0.861 & 0.861 & & & 0.738 & 0.738 \\
\hline OP & 100 & ברכת & 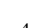 & 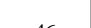 & 2x Cross-Frames & 0.489 & 0.479 & 0.459 & 0.462 & 0.861 & 0.861 & & & 0.738 & 0.738 \\
\hline G2 & 100 & 8.625 & 4 & 46 & No Barrier & 0.521 & 0.512 & 0.521 & 0.523 & 0.861 & 0.861 & & & 0.738 & 0.738 \\
\hline & & & & & No Cross-Frames & 0.540 & 0.535 & 0.507 & 0.509 & 0.861 & 0.861 & & & 0.738 & 0.738 \\
\hline & & & & & CONTROL & 0.581 & 0.568 & 0.544 & 0.545 & 1.128 & 1.128 & & & 0.818 & 0.818 \\
\hline$C_{2}$ & 100 & 8625 & 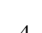 & 60 & 2x Cross-Frames & 0.555 & 0.534 & 0.521 & 0.521 & 1.128 & 1.128 & & & 0.818 & 0.818 \\
\hline G2 & 100 & 8.625 & 4 & 69 & No Barrier & 0.606 & 0.590 & 0.608 & 0.609 & 1.128 & 1.128 & & & 0.818 & 0.818 \\
\hline & & & & & No Cross-Frames & 0.637 & 0.632 & 0.595 & 0.596 & 1.128 & 1.128 & & & 0.818 & 0.818 \\
\hline & & & & & CONTROL & 0.488 & 0.479 & 0.461 & 0.464 & 0.861 & 0.861 & & & 0.652 & 0.652 \\
\hline$C_{2}$ & 100 & 8602 & 5 & & 2x Cross-Frames & 0.467 & 0.454 & 0.442 & 0.445 & 0.861 & 0.861 & & & 0.652 & 0.652 \\
\hline $\mathrm{G} 2$ & 100 & 8.625 & 5 & 46 & No Barrier & 0.506 & 0.496 & 0.506 & 0.508 & 0.861 & 0.861 & & & 0.652 & 0.652 \\
\hline & & & & & No Cross-Frames & 0.532 & 0.527 & 0.502 & 0.504 & 0.861 & 0.861 & & & 0.652 & 0.652 \\
\hline & & & & & CONTROL & 0.567 & 0.552 & 0.533 & 0.535 & 1.128 & 1.128 & & & 0.706 & 0.706 \\
\hline $\mathrm{G}^{2}$ & 100 & 8625 & 5 & 69 & 2x Cross-Frames & 0.533 & 0.508 & 0.503 & 0.504 & 1.128 & 1.128 & & & 0.706 & 0.706 \\
\hline $\mathrm{G} 2$ & 100 & 8.025 & 5 & 69 & No Barrier & 0.591 & 0.574 & 0.593 & 0.594 & 1.128 & 1.128 & & & 0.706 & 0.706 \\
\hline & & & & & No Cross-Frames & 0.627 & 0.622 & 0.589 & 0.590 & 1.128 & 1.128 & & & 0.706 & 0.706 \\
\hline & & & & & CONTROL & 0.563 & 0.556 & 0.527 & 0.531 & 0.946 & 0.946 & & & 0.764 & 0.764 \\
\hline$G ?$ & 100 & 115 & 4 & 46 & 2x Cross-Frames & 0.540 & 0.530 & 0.506 & 0.510 & 0.946 & 0.946 & & & 0.764 & 0.764 \\
\hline $\mathrm{G}_{2}$ & 100 & 11.5 & 4 & 46 & No Barrier & 0.580 & 0.572 & 0.574 & 0.578 & 0.946 & 0.946 & & & 0.764 & 0.764 \\
\hline & & & & & No Cross-Frames & 0.611 & 0.606 & 0.572 & 0.575 & 0.946 & 0.946 & & & 0.764 & 0.764 \\
\hline & & & & & CONTROL & 0.635 & 0.625 & 0.593 & 0.596 & 1.146 & 1.146 & & & 0.824 & 0.824 \\
\hline$C ?$ & 100 & 115 & 4 & 69 & 2x Cross-Frames & 0.600 & 0.583 & 0.561 & 0.564 & 1.146 & 1.146 & & & 0.824 & 0.824 \\
\hline G2 & 100 & 11.5 & 4 & 69 & No Barrier & 0.657 & 0.645 & 0.654 & 0.657 & 1.146 & 1.146 & & & 0.824 & 0.824 \\
\hline & & & & & No Cross-Frames & 0.699 & 0.695 & 0.651 & 0.653 & 1.146 & 1.146 & & & 0.824 & 0.824 \\
\hline & & & & & CONTROL & 0.553 & 0.545 & 0.519 & 0.523 & 0.946 & 0.946 & & & 0.669 & 0.669 \\
\hline 40 & 100 & 115 & 5 & 46 & 2x Cross-Frames & 0.525 & 0.513 & 0.494 & 0.498 & 0.946 & 0.946 & & & 0.669 & 0.669 \\
\hline G2 & 100 & 11.5 & 5 & 46 & No Barrier & 0.568 & 0.559 & 0.562 & 0.566 & 0.946 & 0.946 & & & 0.669 & 0.669 \\
\hline & & & & & No Cross-Frames & 0.600 & 0.595 & 0.563 & 0.566 & 0.946 & 0.946 & & & 0.669 & 0.669 \\
\hline & & & & & CONTROL & 0.626 & 0.614 & 0.585 & 0.588 & 1.146 & 1.146 & & & 0.709 & 0.709 \\
\hline 40 & 100 & 115 & 5 & 69 & 2x Cross-Frames & 0.586 & 0.566 & 0.549 & 0.552 & 1.146 & 1.146 & & & 0.709 & 0.709 \\
\hline G2 & 100 & & 5 & & No Barrier & 0.646 & 0.633 & 0.642 & 0.645 & 1.146 & 1.146 & & & 0.709 & 0.709 \\
\hline & & & & & No Cross-Frames & 0.687 & 0.682 & 0.640 & 0.643 & 1.146 & 1.146 & & & 0.709 & 0.709 \\
\hline & & & & & CONTROL & 0.451 & 0.451 & 0.432 & 0.432 & 0.861 & 0.861 & & & 0.738 & 0.738 \\
\hline G2 & 200 & 8625 & 4 & 46 & 2x Cross-Frames & 0.447 & 0.446 & 0.429 & 0.429 & 0.861 & 0.861 & & & 0.738 & 0.738 \\
\hline & & & & & No Barrier & 0.466 & 0.465 & 0.475 & 0.474 & 0.861 & 0.861 & & & 0.738 & 0.738 \\
\hline & & & & & No Cross-Frames & 0.466 & 0.464 & 0.445 & 0.443 & 0.861 & 0.861 & & & 0.738 & 0.738 \\
\hline & & & & & CONTROL & 0.495 & 0.496 & 0.477 & 0.478 & 1.128 & 1.128 & & & 0.818 & 0.818 \\
\hline G2 & 200 & 8.625 & 4 & 69 & 2x Cross-Frames & 0.485 & 0.485 & 0.470 & 0.470 & 1.128 & 1.128 & & & 0.818 & 0.818 \\
\hline & & & & & No Barrier & 0.514 & 0.514 & 0.528 & 0.528 & 1.128 & 1.128 & & & 0.818 & 0.818 \\
\hline & & & & & No Cross-Frames & 0.520 & 0.520 & 0.497 & 0.497 & 1.128 & 1.128 & & & 0.818 & 0.818 \\
\hline & & & & & CONTROL & 0.413 & 0.414 & 0.401 & 0.402 & 0.861 & 0.861 & & & 0.652 & 0.652 \\
\hline G2 & 200 & 8625 & 5 & 46 & 2x Cross-Frames & 0.402 & 0.403 & 0.393 & 0.394 & 0.861 & 0.861 & & & 0.652 & 0.652 \\
\hline & & 8.625 & 5 & 46 & No Barrier & 0.426 & 0.427 & 0.437 & 0.438 & 0.861 & 0.861 & & & 0.652 & 0.652 \\
\hline & & & & & No Cross-Frames & 0.440 & 0.440 & 0.424 & 0.424 & 0.861 & 0.861 & & & 0.652 & 0.652 \\
\hline & & & & & CONTROL & 0.453 & 0.454 & 0.443 & 0.445 & 1.128 & 1.128 & & & 0.706 & 0.706 \\
\hline $\mathrm{G} 2$ & 200 & 8.625 & 5 & 69 & 2x Cross-Frames & 0.434 & 0.435 & 0.429 & 0.430 & 1.128 & 1.128 & & & 0.706 & 0.706 \\
\hline G2 & 200 & 8.625 & 5 & 69 & No Barrier & 0.469 & 0.471 & 0.486 & 0.488 & 1.128 & 1.128 & & & 0.706 & 0.706 \\
\hline & & & & & No Cross-Frames & 0.495 & 0.495 & 0.477 & 0.477 & 1.128 & 1.128 & & & 0.706 & 0.706 \\
\hline & & & & & CONTROL & 0.486 & 0.487 & 0.465 & 0.466 & 0.946 & 0.946 & & & 0.764 & 0.764 \\
\hline$C_{2}$ & 200 & 115 & 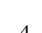 & 4 & 2x Cross-Frames & 0.477 & 0.477 & 0.458 & 0.459 & 0.946 & 0.946 & & & 0.764 & 0.764 \\
\hline G2 & 200 & 11.5 & 4 & 46 & No Barrier & 0.499 & 0.500 & 0.504 & 0.505 & 0.946 & 0.946 & & & 0.764 & 0.764 \\
\hline & & & & & No Cross-Frames & 0.513 & 0.513 & 0.488 & 0.488 & 0.946 & 0.946 & & & 0.764 & 0.764 \\
\hline & & & & & CONTROL & 0.525 & 0.526 & 0.505 & 0.506 & 1.146 & 1.146 & & & 0.824 & 0.824 \\
\hline $5 ?$ & 200 & 115 & 4 & 69 & 2x Cross-Frames & 0.510 & 0.510 & 0.493 & 0.494 & 1.146 & 1.146 & & & 0.824 & 0.824 \\
\hline G2 & 200 & 11.5 & 4 & 69 & No Barrier & 0.542 & 0.544 & 0.552 & 0.553 & 1.146 & 1.146 & & & 0.824 & 0.824 \\
\hline & & & & & No Cross-Frames & 0.566 & 0.566 & 0.538 & 0.538 & 1.146 & 1.146 & & & 0.824 & 0.824 \\
\hline & & & & & CONTROL & 0.453 & 0.454 & 0.438 & 0.440 & 0.946 & 0.946 & & & 0.669 & 0.669 \\
\hline$C_{2}$ & 200 & & & & 2x Cross-Frames & 0.435 & 0.436 & 0.423 & 0.425 & 0.946 & 0.946 & & & 0.669 & 0.669 \\
\hline G2 & 200 & 11.5 & 5 & 46 & No Barrier & 0.464 & 0.466 & 0.471 & 0.473 & 0.946 & 0.946 & & & 0.669 & 0.669 \\
\hline & & & & & No Cross-Frames & 0.497 & 0.497 & 0.476 & 0.476 & 0.946 & 0.946 & & & 0.669 & 0.669 \\
\hline & & & & & CONTROL & 0.489 & 0.492 & 0.476 & 0.479 & 1.146 & 1.146 & & & 0.709 & 0.709 \\
\hline$g_{2}$ & 200 & 115 & 5 & 69 & 2x Cross-Frames & 0.463 & 0.465 & 0.454 & 0.457 & 1.146 & 1.146 & & & 0.709 & 0.709 \\
\hline $\mathrm{G} 2$ & 200 & 11.5 & 5 & 69 & No Barrier & 0.505 & 0.508 & 0.516 & 0.520 & 1.146 & 1.146 & & & 0.709 & 0.709 \\
\hline & & & & & No Cross-Frames & 0.550 & 0.550 & 0.526 & 0.526 & 1.146 & 1.146 & & & 0.709 & 0.709 \\
\hline
\end{tabular}




\begin{tabular}{|c|c|c|c|c|c|c|c|c|c|c|c|c|c|c|c|}
\hline \multicolumn{16}{|c|}{$\begin{array}{l}\text { Comparis on of the Effect of Unbrace d Length }\left(\mathbf{L}_{\mathbf{b}}\right) \\
\text { (bending moment, two lanes loaded) }\end{array}$} \\
\hline \multirow{2}{*}{\multicolumn{6}{|c|}{ Constant Parameters }} & \multicolumn{10}{|c|}{ Dis tribution Factors (organized by me thod and varied parame ters) } \\
\hline & & & & & & \multicolumn{2}{|c|}{ Stallings / Yoo } & \multicolumn{2}{|c|}{ Tarhini / Frederick } & \multicolumn{2}{|c|}{ Lever Rule } & \multicolumn{2}{|c|}{ AASHTO Mod. } & Specia & nalys is \\
\hline Girder & $L(f t)$ & S (ft) & $\mathbf{N}_{\mathrm{b}}$ & OH (in) & Iteration & $20^{\prime}$ & $25^{\prime}$ & $20^{\prime}$ & $25^{\prime}$ & $20^{\prime}$ & $25^{\prime}$ & $20^{\prime}$ & $25^{\prime}$ & $20^{\prime}$ & $25^{\prime}$ \\
\hline & & & & & CONTROL & 0.663 & 0.662 & 0.629 & 0.634 & & & 0.807 & 0.807 & 0.813 & 0.813 \\
\hline & & ברכת & & & 2x Cross-Frames & 0.674 & 0.681 & 0.639 & 0.646 & & & 0.807 & 0.807 & 0.813 & 0.813 \\
\hline G2 & 100 & 8.625 & 4 & 46 & No Barrier & 0.692 & 0.689 & 0.692 & 0.696 & & & 0.807 & 0.807 & 0.813 & 0.813 \\
\hline & & & & & No Cross-Frames & 0.675 & 0.666 & 0.641 & 0.645 & & & 0.807 & 0.807 & 0.813 & 0.813 \\
\hline & & & & & CONTROL & 0.783 & 0.778 & 0.746 & 0.750 & & & 0.968 & 0.968 & 0.946 & 0.946 \\
\hline & & 8625 & 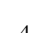 & 60 & 2x Cross-Frames & 0.780 & 0.778 & 0.743 & 0.750 & & & 0.968 & 0.968 & 0.946 & 0.946 \\
\hline G2 & 100 & 8.625 & 4 & 69 & No Barrier & 0.821 & 0.814 & 0.825 & 0.828 & & & 0.968 & 0.968 & 0.946 & 0.946 \\
\hline & & & & & No Cross-Frames & 0.818 & 0.808 & 0.781 & 0.784 & & & 0.968 & 0.968 & 0.946 & 0.946 \\
\hline & & & & & CONTROL & 0.639 & 0.634 & 0.612 & 0.616 & & & 0.807 & 0.807 & 0.809 & 0.809 \\
\hline $\mathrm{G}^{2}$ & 100 & 8625 & 5 & & 2x Cross-Frames & 0.643 & 0.644 & 0.616 & 0.621 & & & 0.807 & 0.807 & 0.809 & 0.809 \\
\hline G2 & 100 & 8.625 & 5 & 46 & No Barrier & 0.671 & 0.665 & 0.672 & 0.675 & & & 0.807 & 0.807 & 0.809 & 0.809 \\
\hline & & & & & No Cross-Frames & 0.666 & 0.657 & 0.639 & 0.643 & & & 0.807 & 0.807 & 0.809 & 0.809 \\
\hline & & & & & CONTROL & 0.752 & 0.743 & 0.723 & 0.727 & & & 0.968 & 0.968 & 0.898 & 0.898 \\
\hline G2 & 100 & 8625 & 5 & 69 & 2x Cross-Frames & 0.742 & 0.735 & 0.713 & 0.718 & & & 0.968 & 0.968 & 0.898 & 0.898 \\
\hline $\mathrm{G} 2$ & 100 & 8.025 & 5 & 69 & No Barrier & 0.795 & 0.784 & 0.800 & 0.802 & & & 0.968 & 0.968 & 0.898 & 0.898 \\
\hline & & & & & No Cross-Frames & 0.799 & 0.789 & 0.769 & 0.772 & & & 0.968 & 0.968 & 0.898 & 0.898 \\
\hline & & & & & CONTROL & 0.769 & 0.765 & 0.729 & 0.734 & & & 0.995 & 0.995 & 0.960 & 0.960 \\
\hline & & & & & 2x Cross-Frames & 0.774 & 0.776 & 0.733 & 0.738 & & & 0.995 & 0.995 & 0.960 & 0.960 \\
\hline G2 & 100 & 11.5 & 4 & 46 & No Barrier & 0.801 & 0.796 & 0.793 & 0.798 & & & 0.995 & 0.995 & 0.960 & 0.960 \\
\hline & & & & & No Cross-Frames & 0.796 & 0.787 & 0.755 & 0.761 & & & 0.995 & 0.995 & 0.960 & 0.960 \\
\hline & & & & & CONTROL & 0.888 & 0.881 & 0.844 & 0.849 & & & 1.194 & 1.194 & 1.060 & 1.060 \\
\hline$C ?$ & 100 & 115 & 4 & 69 & 2x Cross-Frames & 0.876 & 0.873 & 0.833 & 0.839 & & & 1.194 & 1.194 & 1.060 & 1.060 \\
\hline G2 & 100 & 11.5 & 4 & 69 & No Barrier & 0.928 & 0.919 & 0.923 & 0.928 & & & 1.194 & 1.194 & 1.060 & 1.060 \\
\hline & & & & & No Cross-Frames & 0.937 & 0.926 & 0.891 & 0.896 & & & 1.194 & 1.194 & 1.060 & 1.060 \\
\hline & & & & & CONTROL & 0.751 & 0.743 & 0.715 & 0.720 & & & 0.995 & 0.995 & 0.907 & 0.907 \\
\hline 40 & 100 & 115 & 5 & 46 & 2x Cross-Frames & 0.744 & 0.740 & 0.708 & 0.715 & & & 0.995 & 0.995 & 0.907 & 0.907 \\
\hline G2 & 100 & 11.5 & 5 & 46 & No Barrier & 0.783 & 0.775 & 0.774 & 0.780 & & & 0.995 & 0.995 & 0.907 & 0.907 \\
\hline & & & & & No Cross-Frames & 0.787 & 0.778 & 0.750 & 0.756 & & & 0.995 & 0.995 & 0.907 & 0.907 \\
\hline & & & & & CONTROL & 0.868 & 0.858 & 0.829 & 0.835 & & & 1.194 & 1.194 & 0.973 & 0.973 \\
\hline 40 & 100 & 115 & 5 & 69 & 2x Cross-Frames & 0.846 & 0.837 & 0.808 & 0.815 & & & 1.194 & 1.194 & 0.973 & 0.973 \\
\hline & & & & & No Barrier & 0.908 & 0.897 & 0.904 & 0.909 & & & 1.194 & 1.194 & 0.973 & 0.973 \\
\hline & & & & & No Cross-Frames & 0.924 & 0.913 & 0.882 & 0.887 & & & 1.194 & 1.194 & 0.973 & 0.973 \\
\hline & & & & & CONTROL & 0.675 & 0.674 & 0.646 & 0.645 & & & 0.670 & 0.670 & 0.813 & 0.813 \\
\hline G2 & 200 & 8.625 & 4 & 46 & 2x Cross-Frames & 0.683 & 0.683 & 0.652 & 0.651 & & & 0.670 & 0.670 & 0.813 & 0.813 \\
\hline$G 2$ & 200 & 8.625 & 4 & 46 & No Barrier & 0.691 & 0.690 & 0.701 & 0.700 & & & 0.670 & 0.670 & 0.813 & 0.813 \\
\hline & & & & & No Cross-Frames & 0.666 & 0.666 & 0.641 & 0.641 & & & 0.670 & 0.670 & 0.813 & 0.813 \\
\hline & & & & & CONTROL & 0.756 & 0.756 & 0.729 & 0.729 & & & 0.804 & 0.804 & 0.946 & 0.946 \\
\hline$G_{2}$ & 200 & 8.625 & 4 & 69 & 2x Cross-Frames & 0.758 & 0.758 & 0.730 & 0.730 & & & 0.804 & 0.804 & 0.946 & 0.946 \\
\hline & & & & & No Barrier & 0.778 & 0.778 & 0.794 & 0.794 & & & 0.804 & 0.804 & 0.946 & 0.946 \\
\hline & & & & & No Cross-Frames & 0.760 & 0.760 & 0.734 & 0.735 & & & 0.804 & 0.804 & 0.946 & 0.946 \\
\hline & & & & & CONTROL & 0.628 & 0.627 & 0.608 & 0.607 & & & 0.670 & 0.670 & 0.809 & 0.809 \\
\hline & & & & & 2x Cross-Frames & 0.634 & 0.634 & 0.612 & 0.612 & & & 0.670 & 0.670 & 0.809 & 0.809 \\
\hline G2 & 200 & 8.625 & 5 & 46 & No Barrier & 0.647 & 0.646 & 0.657 & 0.656 & & & 0.670 & 0.670 & 0.809 & 0.809 \\
\hline & & & & & No Cross-Frames & 0.629 & 0.629 & 0.610 & 0.611 & & & 0.670 & 0.670 & 0.809 & 0.809 \\
\hline & & & & & CONTROL & 0.698 & 0.698 & 0.682 & 0.682 & & & 0.804 & 0.804 & 0.898 & 0.898 \\
\hline$C ?$ & 200 & 8075 & 5 & & 2x Cross-Frames & 0.695 & 0.695 & 0.679 & 0.679 & & & 0.804 & 0.804 & 0.898 & 0.898 \\
\hline G2 & 200 & 8.625 & 5 & 69 & No Barrier & 0.722 & 0.722 & 0.740 & 0.740 & & & 0.804 & 0.804 & 0.898 & 0.898 \\
\hline & & & & & No Cross-Frames & 0.718 & 0.718 & 0.700 & 0.700 & & & 0.804 & 0.804 & 0.898 & 0.898 \\
\hline & & & & & CONTROL & 0.759 & 0.758 & 0.725 & 0.723 & & & 0.823 & 0.823 & 0.960 & 0.960 \\
\hline$G 2$ & 200 & 115 & 4 & 46 & 2x Cross-Frames & 0.766 & 0.765 & 0.730 & 0.729 & & & 0.823 & 0.823 & 0.960 & 0.960 \\
\hline G2 & 200 & 11.5 & 4 & 46 & No Barrier & 0.778 & 0.777 & 0.781 & 0.780 & & & 0.823 & 0.823 & 0.960 & 0.960 \\
\hline & & & & & No Cross-Frames & 0.758 & 0.758 & 0.727 & 0.727 & & & 0.823 & 0.823 & 0.960 & 0.960 \\
\hline & & & & & CONTROL & 0.834 & 0.833 & 0.802 & 0.802 & & & 0.988 & 0.988 & 1.060 & 1.060 \\
\hline$g^{2}$ & 200 & 115 & 4 & 69 & 2x Cross-Frames & 0.832 & 0.832 & 0.800 & 0.800 & & & 0.988 & 0.988 & 1.060 & 1.060 \\
\hline G2 & 200 & 11.5 & 4 & 69 & No Barrier & 0.857 & 0.857 & 0.866 & 0.866 & & & 0.988 & 0.988 & 1.060 & 1.060 \\
\hline & & & & & No Cross-Frames & 0.852 & 0.852 & 0.820 & 0.820 & & & 0.988 & 0.988 & 1.060 & 1.060 \\
\hline & & & & & CONTROL & 0.705 & 0.705 & 0.681 & 0.681 & & & 0.823 & 0.823 & 0.907 & 0.907 \\
\hline$G 2$ & 200 & & & & 2x Cross-Frames & 0.704 & 0.704 & 0.680 & 0.679 & & & 0.823 & 0.823 & 0.907 & 0.907 \\
\hline G2 & 200 & 11.5 & 5 & 46 & No Barrier & 0.725 & 0.725 & 0.730 & 0.730 & & & 0.823 & 0.823 & 0.907 & 0.907 \\
\hline & & & & & No Cross-Frames & 0.727 & 0.727 & 0.702 & 0.702 & & & 0.823 & 0.823 & 0.907 & 0.907 \\
\hline & & & & & CONTROL & 0.775 & 0.776 & 0.754 & 0.756 & & & 0.988 & 0.988 & 0.973 & 0.973 \\
\hline $\mathrm{G}^{2}$ & 200 & 11.5 & 5 & 69 & 2x Cross-Frames & 0.761 & 0.762 & 0.743 & 0.744 & & & 0.988 & 0.988 & 0.973 & 0.973 \\
\hline G2 & 200 & 11.5 & 5 & 69 & No Barrier & 0.798 & 0.800 & 0.810 & 0.812 & & & 0.988 & 0.988 & 0.973 & 0.973 \\
\hline & & & & & No Cross-Frames & 0.821 & 0.821 & 0.796 & 0.796 & & & 0.988 & 0.988 & 0.973 & 0.973 \\
\hline
\end{tabular}




\begin{tabular}{|c|c|c|c|c|c|c|c|c|c|c|c|c|c|c|c|}
\hline \multicolumn{16}{|c|}{$\begin{array}{l}\text { Comparison of the Effect of U nbrace d Le ngth }\left(\mathbf{L}_{\mathbf{b}}\right) \\
\text { (bending moment, three lanes loaded) }\end{array}$} \\
\hline \multirow{2}{*}{\multicolumn{6}{|c|}{ Constant Parameters }} & \multirow{2}{*}{\multicolumn{10}{|c|}{ 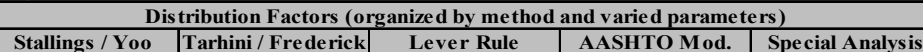 }} \\
\hline & & & & & & \multicolumn{2}{|c|}{ Stallings / Yoo } & & & \multicolumn{2}{|c|}{ Lever Rule } & \multicolumn{2}{|c|}{ AASHTO Mod. } & \multicolumn{2}{|c|}{ Special Analys is } \\
\hline Girder & S (ft) & L (ft) & $\mathbf{N}_{\mathrm{b}}$ & OH (in) & Iteration & $20^{\prime}$ & $25^{\prime}$ & $20^{\prime}$ & $25^{\prime}$ & $20^{\prime}$ & $25^{\prime}$ & $20^{\prime}$ & $25^{\prime}$ & $20^{\prime}$ & $25^{\prime}$ \\
\hline \multirow{4}{*}{ G2 } & \multirow{4}{*}{100} & \multirow{4}{*}{8.625} & \multirow{4}{*}{5} & \multirow{4}{*}{46} & CONTROL & 0.702 & 0.697 & 0.681 & 0.684 & & & 0.807 & 0.807 & 0.676 & 0.676 \\
\hline & & & & & 2x Cross-Frames & 0.717 & 0.718 & 0.694 & 0.698 & & & 0.807 & 0.807 & 0.676 & 0.676 \\
\hline & & & & & No Barrier & 0.734 & 0.727 & 0.741 & 0.744 & & & 0.807 & 0.807 & 0.676 & 0.676 \\
\hline & & & & & No Cross-Frames & 0.707 & 0.697 & 0.686 & 0.691 & & & 0.807 & 0.807 & 0.676 & 0.676 \\
\hline \multirow{4}{*}{ G2 } & \multirow{4}{*}{100} & \multirow{4}{*}{8.625} & & & CONTROL & 0.823 & 0.815 & 0.804 & 0.807 & & & 0.968 & 0.968 & 0.790 & 0.790 \\
\hline & & & 5 & 69 & 2x Cross-Frames & 0.827 & 0.824 & 0.807 & 0.810 & & & 0.968 & 0.968 & 0.790 & 0.790 \\
\hline & & & & & No Barrier & 0.870 & 0.859 & 0.884 & 0.886 & & & 0.968 & 0.968 & 0.790 & 0.790 \\
\hline & & & & & No Cross-Frames & 0.849 & 0.837 & 0.830 & 0.834 & & & 0.968 & 0.968 & 0.790 & 0.790 \\
\hline & & & & & CONTROL & 0.853 & 0.847 & 0.818 & 0.822 & & & 0.995 & 0.995 & 0.825 & 0.825 \\
\hline G2 & 100 & 11.5 & 4 & 46 & 2x Cross-Frames & 0.874 & 0.874 & 0.838 & 0.842 & & & 0.995 & 0.995 & 0.825 & 0.825 \\
\hline & & & & & No Barrier & 0.883 & 0.876 & 0.883 & 0.887 & & & 0.995 & 0.995 & 0.825 & 0.825 \\
\hline & & & & & No Cross-Frames & 0.849 & 0.839 & 0.815 & 0.821 & & & 0.995 & 0.995 & 0.825 & 0.825 \\
\hline & & & & & CONTROL & 0.983 & 0.975 & 0.949 & 0.954 & & & 1.194 & 1.194 & 0.952 & 0.952 \\
\hline G2 & 100 & 11.5 & 4 & 69 & 2x Cross-Frames & 0.992 & 0.990 & 0.957 & 0.962 & & & 1.194 & 1.194 & 0.952 & 0.952 \\
\hline & & & 4 & 69 & No Barrier & 1.028 & 1.018 & 1.033 & 1.036 & & & 1.194 & 1.194 & 0.952 & 0.952 \\
\hline & & & & & No Cross-Frames & 1.001 & 0.988 & 0.968 & 0.974 & & & 1.194 & 1.194 & 0.952 & 0.952 \\
\hline & & & & & CONTROL & 0.831 & 0.823 & 0.804 & 0.808 & & & 0.995 & 0.995 & 0.890 & 0.890 \\
\hline G2 & 100 & 11.5 & 5 & 46 & 2x Cross-Frames & 0.840 & 0.838 & 0.812 & 0.815 & & & 0.995 & 0.995 & 0.890 & 0.890 \\
\hline $\mathrm{G} 2$ & 100 & 11.5 & 5 & 40 & No Barrier & 0.870 & 0.862 & 0.869 & 0.873 & & & 0.995 & 0.995 & 0.890 & 0.890 \\
\hline & & & & & No Cross-Frames & 0.856 & 0.844 & 0.829 & 0.835 & & & 0.995 & 0.995 & 0.890 & 0.890 \\
\hline & & & & & CONTROL & 0.958 & 0.947 & 0.932 & 0.937 & & & 1.194 & 1.194 & 0.975 & 0.975 \\
\hline$G_{2}$ & 100 & 115 & 5 & 69 & 2x Cross-Frames & 0.954 & 0.948 & 0.928 & 0.932 & & & 1.194 & 1.194 & 0.975 & 0.975 \\
\hline & & 11.5 & 5 & 69 & No Barrier & 1.009 & 0.997 & 1.014 & 1.018 & & & 1.194 & 1.194 & 0.975 & 0.975 \\
\hline & & & & & No Cross-Frames & 1.001 & 0.988 & 0.975 & 0.981 & & & 1.194 & 1.194 & 0.975 & 0.975 \\
\hline & & & & & CONTROL & 0.732 & 0.730 & 0.707 & 0.705 & & & 0.670 & 0.670 & 0.676 & 0.676 \\
\hline G2 & 200 & 8625 & 5 & 46 & 2x Cross-Frames & 0.750 & 0.748 & 0.721 & 0.719 & & & 0.670 & 0.670 & 0.676 & 0.676 \\
\hline G2 & 200 & 8.625 & 5 & 46 & No Barrier & 0.749 & 0.748 & 0.759 & 0.757 & & & 0.670 & 0.670 & 0.676 & 0.676 \\
\hline & & & & & No Cross-Frames & 0.709 & 0.709 & 0.690 & 0.690 & & & 0.670 & 0.670 & 0.676 & 0.676 \\
\hline & & & & & CONTROL & 0.820 & 0.818 & 0.799 & 0.798 & & & 0.804 & 0.804 & 0.790 & 0.790 \\
\hline G2 & 200 & 8.625 & 5 & 69 & 2x Cross-Frames & 0.831 & 0.830 & 0.808 & 0.806 & & & 0.804 & 0.804 & 0.790 & 0.790 \\
\hline & & & & 69 & No Barrier & 0.845 & 0.843 & 0.862 & 0.860 & & & 0.804 & 0.804 & 0.790 & 0.790 \\
\hline & & & & & No Cross-Frames & 0.812 & 0.812 & 0.796 & 0.796 & & & 0.804 & 0.804 & 0.790 & 0.790 \\
\hline & & & & & CONTROL & 0.898 & 0.596 & 0.857 & 0.854 & & & 0.823 & 0.823 & 0.825 & 0.825 \\
\hline$G_{2}$ & 200 & 11.5 & 4 & 46 & 2x Cross-Frames & 0.917 & 0.610 & 0.872 & 0.870 & & & 0.823 & 0.823 & 0.825 & 0.825 \\
\hline & & & & & No Barrier & 0.915 & 0.609 & 0.917 & 0.914 & & & 0.823 & 0.823 & 0.825 & 0.825 \\
\hline & & & & & No Cross-Frames & 0.868 & 0.579 & 0.834 & 0.834 & & & 0.823 & 0.823 & 0.825 & 0.825 \\
\hline & & & & & CONTROL & 0.993 & 0.991 & 0.955 & 0.953 & & & 0.988 & 0.988 & 0.952 & 0.952 \\
\hline$G^{2}$ & 200 & 11.5 & 4 & 69 & 2x Cross-Frames & 1.007 & 1.006 & 0.966 & 0.964 & & & 0.988 & 0.988 & 0.952 & 0.952 \\
\hline & & & & & No Barrier & 1.018 & 1.016 & 1.026 & 1.024 & & & 0.988 & 0.988 & 0.952 & 0.952 \\
\hline & & & & & No Cross-Frames & 0.979 & 0.979 & 0.947 & 0.947 & & & 0.988 & 0.988 & 0.952 & 0.952 \\
\hline & & & & & CONTROL & 0.844 & 0.840 & 0.814 & 0.810 & & & 0.823 & 0.823 & 0.890 & 0.890 \\
\hline G2 & 200 & 11.5 & 5 & 46 & 2x Cross-Frames & 0.865 & 0.862 & 0.832 & 0.828 & & & 0.823 & 0.823 & 0.890 & 0.890 \\
\hline & & & & 46 & No Barrier & 0.868 & 0.864 & 0.870 & 0.867 & & & 0.823 & 0.823 & 0.890 & 0.890 \\
\hline & & & & & No Cross-Frames & 0.826 & 0.826 & 0.802 & 0.802 & & & 0.823 & 0.823 & 0.890 & 0.890 \\
\hline & & & & & CONTROL & 0.930 & 0.927 & 0.904 & 0.902 & & & 0.988 & 0.988 & 0.975 & 0.975 \\
\hline G2 & 200 & 11.5 & 5 & 69 & 2x Cross-Frames & 0.940 & 0.938 & 0.912 & 0.910 & & & 0.988 & 0.988 & 0.975 & 0.975 \\
\hline & & & & & No Barrier & 0.958 & 0.957 & 0.969 & 0.967 & & & 0.988 & 0.988 & 0.975 & 0.975 \\
\hline & & & & & No Cross-Frames & 0.935 & 0.935 & 0.912 & 0.913 & & & 0.988 & 0.988 & 0.975 & 0.975 \\
\hline
\end{tabular}

\begin{tabular}{|c|c|c|c|c|c|c|c|c|c|c|c|c|c|c|c|}
\hline \multicolumn{16}{|c|}{$\begin{array}{l}\text { Comparis on of the Effect of U nbrace d Length }\left(\mathbf{L}_{\mathbf{b}}\right) \\
\text { (bending moment, four lanes loaded) }\end{array}$} \\
\hline \multirow{2}{*}{\multicolumn{6}{|c|}{ Constant Parameters }} & \multicolumn{10}{|c|}{ Dis tribution Factors (organized by method and varied parame te rs) } \\
\hline & & & & & & \multicolumn{2}{|c|}{ Stallings / Yoo } & \multicolumn{2}{|c|}{ Tarhini / Frederick } & \multicolumn{2}{|c|}{ Lever Rule } & \multicolumn{2}{|c|}{ AASHTO Mod. } & \multicolumn{2}{|c|}{ Special Analys is } \\
\hline Girder & S (ft) & $\mathbf{L}$ (ft) & $\mathbf{N}_{\mathrm{b}}$ & $\mathrm{OH}$ (in) & Iteration & $20^{\prime}$ & $25^{\prime}$ & $20^{\prime}$ & $25^{\prime}$ & $20^{\prime}$ & 25' & $20^{\prime}$ & $25^{\prime}$ & $20^{\prime}$ & $25^{\prime}$ \\
\hline \multirow{4}{*}{ G2 } & \multirow{4}{*}{100} & \multirow{4}{*}{11.5} & \multirow{4}{*}{5} & \multirow{4}{*}{46} & CONTROL & 0.879 & 0.870 & 0.852 & 0.857 & & & 0.995 & 0.995 & 0.636 & 0.636 \\
\hline & & & & & 2x Cross-Frames & 0.896 & 0.893 & 0.867 & 0.871 & & & 0.995 & 0.995 & 0.636 & 0.636 \\
\hline & & & & & No Barrier & 0.914 & 0.905 & 0.914 & 0.919 & & & 0.995 & 0.995 & 0.636 & 0.636 \\
\hline & & & & & No Cross-Frames & 0.881 & 0.869 & 0.854 & 0.861 & & & 0.995 & 0.995 & 0.636 & 0.636 \\
\hline \multirow{4}{*}{ G2 } & \multirow{4}{*}{100} & \multirow{4}{*}{11.5} & \multirow{4}{*}{5} & \multirow{4}{*}{69} & CONTROL & 1.012 & 1.001 & 0.989 & 0.994 & & & 1.194 & 1.194 & 0.723 & 0.723 \\
\hline & & & & & 2x Cross-Frames & 1.016 & 1.011 & 0.992 & 0.996 & & & 1.194 & 1.194 & 0.723 & 0.723 \\
\hline & & & & & No Barrier & 1.063 & 1.050 & 1.070 & 1.074 & & & 1.194 & 1.194 & 0.723 & 0.723 \\
\hline & & & & & No Cross-Frames & 1.035 & 1.020 & 1.012 & 1.019 & & & 1.194 & 1.194 & 0.723 & 0.723 \\
\hline \multirow{4}{*}{ G2 } & \multirow{4}{*}{200} & \multirow{4}{*}{11.5} & \multirow{4}{*}{5} & \multirow{4}{*}{46} & CONTROL & 0.921 & 0.915 & 0.888 & 0.882 & & & 0.823 & 0.823 & 0.636 & 0.636 \\
\hline & & & & & 2x Cross-Frames & 0.955 & 0.950 & 0.916 & 0.911 & & & 0.823 & 0.823 & 0.636 & 0.636 \\
\hline & & & & & No Barrier & 0.943 & 0.938 & 0.944 & 0.939 & & & 0.823 & 0.823 & 0.636 & 0.636 \\
\hline & & & & & No Cross-Frames & 0.877 & 0.877 & 0.852 & 0.853 & & & 0.823 & 0.823 & 0.636 & 0.636 \\
\hline \multirow{4}{*}{ G2 } & \multirow{4}{*}{200} & \multirow{4}{*}{11.5} & \multirow{4}{*}{5} & \multirow{4}{*}{69} & CONTROL & 1.016 & 1.011 & 0.988 & 0.983 & & & 0.988 & 0.988 & 0.723 & 0.723 \\
\hline & & & & & 2x Cross-Frames & 1.041 & 1.037 & 1.008 & 1.004 & & & 0.988 & 0.988 & 0.723 & 0.723 \\
\hline & & & & & No Barrier & 1.044 & 1.041 & 1.054 & 1.050 & & & 0.988 & 0.988 & 0.723 & 0.723 \\
\hline & & & & & No Cross-Frames & 0.991 & 0.991 & 0.970 & 0.970 & & & 0.988 & 0.988 & 0.723 & 0.723 \\
\hline
\end{tabular}




\begin{tabular}{|c|c|c|c|c|c|c|c|c|c|c|c|c|c|c|c|}
\hline \multicolumn{16}{|c|}{$\begin{array}{l}\text { Comparis on of the Effect of Overhang Width (OH) } \\
\text { (bending moment, one lane loaded) }\end{array}$} \\
\hline \multirow{2}{*}{\multicolumn{6}{|c|}{ Constant Parameters }} & \multicolumn{10}{|c|}{ Distribution Factors (organize d by method and varied parame ters) } \\
\hline & & & & & & \multicolumn{2}{|c|}{ Stallings/Yoo } & \multicolumn{2}{|c|}{ Tarhini/Frederick } & \multicolumn{2}{|c|}{ Lever Rule } & \multicolumn{2}{|c|}{ AASHTO Mod. } & Special & nalys is \\
\hline Girder & L (ft) & S (ft) & $\mathbf{N}_{\mathrm{b}}$ & $\mathbf{L}_{\mathrm{b}}(\mathrm{ft})$ & Iteration & 46" & 69" & 46" & 69" & 46" & 69" & $46 "$ & 69" & 46" & 69" \\
\hline & & & & & CONTROL & 0.502 & 0.581 & 0.472 & $\overline{0.544}$ & 0.861 & 1.128 & & & $\begin{array}{c}0.738 \\
\end{array}$ & 0.818 \\
\hline G2 & 100 & 8625 & 4 & 20 & 2x Cross-Frames & 0.489 & 0.555 & 0.459 & 0.521 & 0.861 & 1.128 & & & 0.738 & 0.818 \\
\hline $\mathrm{G} 2$ & 100 & 8.625 & 4 & 20 & No Barrier & 0.521 & 0.606 & 0.521 & 0.608 & 0.861 & 1.128 & & & 0.738 & 0.818 \\
\hline & & & & & No Cross-Frames & 0.540 & 0.637 & 0.507 & 0.595 & 0.861 & 1.128 & & & 0.738 & 0.818 \\
\hline & & & & & CONTROL & 0.495 & 0.568 & 0.474 & 0.545 & 0.861 & 1.128 & & & 0.738 & 0.818 \\
\hline G2 & 100 & 8625 & 4 & 25 & 2x Cross-Frames & 0.479 & 0.534 & 0.462 & 0.521 & 0.861 & 1.128 & & & 0.738 & 0.818 \\
\hline $\mathrm{G} 2$ & 100 & 8.025 & 4 & 20 & No Barrier & 0.512 & 0.590 & 0.523 & 0.609 & 0.861 & 1.128 & & & 0.738 & 0.818 \\
\hline & & & & & No Cross-Frames & 0.535 & 0.632 & 0.509 & 0.596 & 0.861 & 1.128 & & & 0.738 & 0.818 \\
\hline & & & & & CONTROL & 0.488 & 0.567 & 0.461 & 0.533 & 0.861 & 1.128 & & & 0.652 & 0.706 \\
\hline & & & & & 2x Cross-Frames & 0.467 & 0.533 & 0.442 & 0.503 & 0.861 & 1.128 & & & 0.652 & 0.706 \\
\hline $\mathrm{G} 2$ & 100 & 8.625 & 5 & 20 & No Barrier & 0.506 & 0.591 & 0.506 & 0.593 & 0.861 & 1.128 & & & 0.652 & 0.706 \\
\hline & & & & & No Cross-Frames & 0.532 & 0.627 & 0.502 & 0.589 & 0.861 & 1.128 & & & 0.652 & 0.706 \\
\hline & & & & & CONTROL & 0.479 & 0.552 & 0.464 & 0.535 & 0.861 & 1.128 & & & 0.652 & 0.706 \\
\hline G2 & 100 & 8625 & 5 & 25 & 2x Cross-Frames & 0.454 & 0.508 & 0.445 & 0.504 & 0.861 & 1.128 & & & 0.652 & 0.706 \\
\hline 02 & 100 & 0.025 & 5 & 20 & No Barrier & 0.496 & 0.574 & 0.508 & 0.594 & 0.861 & 1.128 & & & 0.652 & 0.706 \\
\hline & & & & & No Cross-Frames & 0.527 & 0.622 & 0.504 & 0.590 & 0.861 & 1.128 & & & 0.652 & 0.706 \\
\hline & & & & & CONTROL & 0.563 & 0.635 & 0.527 & 0.593 & 0.946 & 1.146 & & & 0.764 & 0.824 \\
\hline G2 & 100 & 115 & 4 & 20 & 2x Cross-Frames & 0.540 & 0.600 & 0.506 & 0.561 & 0.946 & 1.146 & & & 0.764 & 0.824 \\
\hline 02 & 00 & 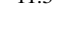 & 4 & 20 & No Barrier & 0.580 & 0.657 & 0.574 & 0.654 & 0.946 & 1.146 & & & 0.764 & 0.824 \\
\hline & & & & & No Cross-Frames & 0.611 & 0.699 & 0.572 & 0.651 & 0.946 & 1.146 & & & 0.764 & 0.824 \\
\hline & & & & & CONTROL & 0.556 & 0.625 & 0.531 & 0.596 & 0.946 & 1.146 & & & 0.764 & 0.824 \\
\hline G2 & 100 & 115 & 4 & 25 & 2x Cross-Frames & 0.530 & 0.583 & 0.510 & 0.564 & 0.946 & 1.146 & & & 0.764 & 0.824 \\
\hline $\mathrm{G}$ & 100 & 11.5 & 4 & 20 & No Barrier & 0.572 & 0.645 & 0.578 & 0.657 & 0.946 & 1.146 & & & 0.764 & 0.824 \\
\hline & & & & & No Cross-Frames & 0.606 & 0.695 & 0.575 & 0.653 & 0.946 & 1.146 & & & 0.764 & 0.824 \\
\hline & & & & & CONTROL & 0.553 & 0.626 & 0.519 & 0.585 & 0.946 & 1.146 & & & 0.669 & 0.709 \\
\hline G2 & 100 & 115 & 5 & 20 & 2x Cross-Frames & 0.525 & 0.586 & 0.494 & 0.549 & 0.946 & 1.146 & & & 0.669 & 0.709 \\
\hline $\mathrm{G} 2$ & 100 & 11.5 & 5 & 20 & No Barrier & 0.568 & 0.646 & 0.562 & 0.642 & 0.946 & 1.146 & & & 0.669 & 0.709 \\
\hline & & & & & No Cross-Frames & 0.600 & 0.687 & 0.563 & 0.640 & 0.946 & 1.146 & & & 0.669 & 0.709 \\
\hline & & & & & CONTROL & 0.545 & 0.614 & 0.523 & 0.588 & 0.946 & 1.146 & & & 0.669 & 0.709 \\
\hline G? & 100 & 115 & 5 & 25 & 2x Cross-Frames & 0.513 & 0.566 & 0.498 & 0.552 & 0.946 & 1.146 & & & 0.669 & 0.709 \\
\hline GL & 100 & 11.5 & 3 & 25 & No Barrier & 0.559 & 0.633 & 0.566 & 0.645 & 0.946 & 1.146 & & & 0.669 & 0.709 \\
\hline & & & & & No Cross-Frames & 0.595 & 0.682 & 0.566 & 0.643 & 0.946 & 1.146 & & & 0.669 & 0.709 \\
\hline & & & & & CONTROL & 0.451 & 0.495 & 0.432 & 0.477 & 0.861 & 1.128 & & & 0.738 & 0.818 \\
\hline G2 & 200 & 8625 & 4 & 20 & 2x Cross-Frames & 0.447 & 0.485 & 0.429 & 0.470 & 0.861 & 1.128 & & & 0.738 & 0.818 \\
\hline $\mathrm{G} 2$ & 200 & 8.625 & 4 & 20 & No Barrier & 0.466 & 0.514 & 0.475 & 0.528 & 0.861 & 1.128 & & & 0.738 & 0.818 \\
\hline & & & & & No Cross-Frames & 0.466 & 0.520 & 0.445 & 0.497 & 0.861 & 1.128 & & & 0.738 & 0.818 \\
\hline & & & & & CONTROL & 0.451 & 0.496 & 0.432 & 0.478 & 0.861 & 1.128 & & & 0.738 & 0.818 \\
\hline G2 & 200 & 8625 & 4 & 25 & 2x Cross-Frames & 0.446 & 0.485 & 0.429 & 0.470 & 0.861 & 1.128 & & & 0.738 & 0.818 \\
\hline $\mathrm{G} 2$ & 200 & 8.625 & 4 & 25 & No Barrier & 0.465 & 0.514 & 0.474 & 0.528 & 0.861 & 1.128 & & & 0.738 & 0.818 \\
\hline & & & & & No Cross-Frames & 0.464 & 0.520 & 0.443 & 0.497 & 0.861 & 1.128 & & & 0.738 & 0.818 \\
\hline & & & & & CONTROL & 0.413 & 0.453 & 0.401 & 0.443 & 0.861 & 1.128 & & & 0.652 & 0.706 \\
\hline G2 & 200 & 8.625 & 5 & 20 & 2x Cross-Frames & 0.402 & 0.434 & 0.393 & 0.429 & 0.861 & 1.128 & & & 0.652 & 0.706 \\
\hline & & & & & No Barrier & 0.426 & 0.469 & 0.437 & 0.486 & 0.861 & 1.128 & & & 0.652 & 0.706 \\
\hline & & & & & No Cross-Frames & 0.440 & 0.495 & 0.424 & 0.477 & 0.861 & 1.128 & & & 0.652 & 0.706 \\
\hline & & & & & CONTROL & 0.414 & 0.454 & 0.402 & 0.445 & 0.861 & 1.128 & & & 0.652 & 0.706 \\
\hline G2 & 200 & 8.625 & 5 & 25 & 2x Cross-Frames & 0.403 & 0.435 & 0.394 & 0.430 & 0.861 & 1.128 & & & 0.652 & 0.706 \\
\hline & & & & & No Barrier & 0.427 & 0.471 & 0.438 & 0.488 & 0.861 & 1.128 & & & 0.652 & 0.706 \\
\hline & & & & & No Cross-Frames & 0.440 & 0.495 & 0.424 & 0.477 & 0.861 & 1.128 & & & 0.652 & 0.706 \\
\hline & & & & & CONTROL & 0.486 & 0.525 & 0.465 & 0.505 & 0.946 & 1.146 & & & 0.764 & 0.824 \\
\hline G2 & 200 & 11.5 & 4 & 20 & 2x Cross-Frames & 0.477 & 0.510 & 0.458 & 0.493 & 0.946 & 1.146 & & & 0.764 & 0.824 \\
\hline & & & & & No Barrier & 0.499 & 0.542 & 0.504 & 0.552 & 0.946 & 1.146 & & & 0.764 & 0.824 \\
\hline & & & & & No Cross-Frames & 0.513 & 0.566 & 0.488 & 0.538 & 0.946 & 1.146 & & & 0.764 & 0.824 \\
\hline & & & & & CONTROL & 0.487 & 0.526 & 0.466 & 0.506 & 0.946 & 1.146 & & & 0.764 & 0.824 \\
\hline G2 & 200 & 11.5 & 4 & 25 & 2x Cross-Frames & 0.477 & 0.510 & 0.459 & 0.494 & 0.946 & 1.146 & & & 0.764 & 0.824 \\
\hline $\mathrm{G} 2$ & & & 4 & & No Barrier & 0.500 & 0.544 & 0.505 & 0.553 & 0.946 & 1.146 & & & 0.764 & 0.824 \\
\hline & & & & & No Cross-Frames & 0.513 & 0.566 & 0.488 & 0.538 & 0.946 & 1.146 & & & 0.764 & 0.824 \\
\hline & & & & & CONTROL & 0.453 & 0.489 & 0.438 & 0.476 & 0.946 & 1.146 & & & 0.669 & 0.709 \\
\hline G2 & 200 & 11.5 & 5 & 20 & 2x Cross-Frames & 0.435 & 0.463 & 0.423 & 0.454 & 0.946 & 1.146 & & & 0.669 & 0.709 \\
\hline $\mathrm{G} 2$ & 200 & 11.5 & 5 & 20 & No Barrier & 0.464 & 0.505 & 0.471 & 0.516 & 0.946 & 1.146 & & & 0.669 & 0.709 \\
\hline & & & & & No Cross-Frames & 0.497 & 0.550 & 0.476 & 0.526 & 0.946 & 1.146 & & & 0.669 & 0.709 \\
\hline & & & & & CONTROL & 0.454 & 0.492 & 0.440 & 0.479 & 0.946 & 1.146 & & & 0.669 & 0.709 \\
\hline G2 & 200 & 11.5 & 5 & 25 & 2x Cross-Frames & 0.436 & 0.465 & 0.425 & 0.457 & 0.946 & 1.146 & & & 0.669 & 0.709 \\
\hline $\mathrm{G}$ & 200 & 11.5 & 3 & 20 & No Barrier & 0.466 & 0.508 & 0.473 & 0.520 & 0.946 & 1.146 & & & 0.669 & 0.709 \\
\hline & & & & & No Cross-Frames & 0.497 & 0.550 & 0.476 & 0.526 & 0.946 & 1.146 & & & 0.669 & 0.709 \\
\hline
\end{tabular}




\begin{tabular}{|c|c|c|c|c|c|c|c|c|c|c|c|c|c|c|c|}
\hline \multicolumn{16}{|c|}{$\begin{array}{l}\text { Comparis on of the Effect of Overhang Width }(\mathbf{O H}) \\
\text { (bending moment, two lanes loaded) }\end{array}$} \\
\hline \multirow{2}{*}{\multicolumn{6}{|c|}{ Constant Parameters }} & \multicolumn{10}{|c|}{ Dis tribution Factors (organize d by method and varied parame ters) } \\
\hline & & & & & & \multicolumn{2}{|c|}{ Stallings/Yoo } & \multicolumn{2}{|c|}{ Tarhini/Frederick } & \multicolumn{2}{|c|}{ Lever Rule } & \multicolumn{2}{|c|}{ AASHTO Mod. } & Specia & nalys is \\
\hline Girder & L (ft) & S (ft) & $\mathbf{N}_{\mathrm{b}}$ & $\mathbf{L}_{\mathrm{b}}$ (ft) & Iteration & $46 "$ & 69" & $46 "$ & 69" & 46" & 69" & $46 "$ & $69 "$ & 46" & $69 "$ \\
\hline & & & & & CONTROL & 0.663 & 0.783 & 0.629 & 0.746 & & & 0.807 & 0.968 & 0.813 & 0.946 \\
\hline & 100 & 8602 & 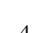 & 30 & 2x Cross-Frames & 0.674 & 0.780 & 0.639 & 0.743 & & & 0.807 & 0.968 & 0.813 & 0.946 \\
\hline G2 & 100 & 8.625 & 4 & 20 & No Barrier & 0.692 & 0.821 & 0.692 & 0.825 & & & 0.807 & 0.968 & 0.813 & 0.946 \\
\hline & & & & & No Cross-Frames & 0.675 & 0.818 & 0.641 & 0.781 & & & 0.807 & 0.968 & 0.813 & 0.946 \\
\hline & & & & & CONTROL & 0.662 & 0.778 & 0.634 & 0.750 & & & 0.807 & 0.968 & 0.813 & 0.946 \\
\hline & & 8625 & 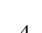 & 25 & 2x Cross-Frames & 0.681 & 0.778 & 0.646 & 0.750 & & & 0.807 & 0.968 & 0.813 & 0.946 \\
\hline G2 & 100 & 8.625 & 4 & 25 & No Barrier & 0.689 & 0.814 & 0.696 & 0.828 & & & 0.807 & 0.968 & 0.813 & 0.946 \\
\hline & & & & & No Cross-Frames & 0.666 & 0.808 & 0.645 & 0.784 & & & 0.807 & 0.968 & 0.813 & 0.946 \\
\hline & & & & & CONTROL & 0.639 & 0.752 & 0.612 & 0.723 & & & 0.807 & 0.968 & 0.809 & 0.898 \\
\hline$g^{2}$ & & & & & 2x Cross-Frames & 0.643 & 0.742 & 0.616 & 0.713 & & & 0.807 & 0.968 & 0.809 & 0.898 \\
\hline G2 & 100 & 8.625 & 5 & 20 & No Barrier & 0.671 & 0.795 & 0.672 & 0.800 & & & 0.807 & 0.968 & 0.809 & 0.898 \\
\hline & & & & & No Cross-Frames & 0.666 & 0.799 & 0.639 & 0.769 & & & 0.807 & 0.968 & 0.809 & 0.898 \\
\hline & & & & & CONTROL & 0.634 & 0.743 & 0.616 & 0.727 & & & 0.807 & 0.968 & 0.809 & 0.898 \\
\hline$G 2$ & & & & & 2x Cross-Frames & 0.644 & 0.735 & 0.621 & 0.718 & & & 0.807 & 0.968 & 0.809 & 0.898 \\
\hline G2 & 100 & 8.625 & 5 & 25 & No Barrier & 0.665 & 0.784 & 0.675 & 0.802 & & & 0.807 & 0.968 & 0.809 & 0.898 \\
\hline & & & & & No Cross-Frames & 0.657 & 0.789 & 0.643 & 0.772 & & & 0.807 & 0.968 & 0.809 & 0.898 \\
\hline & & & & & CONTROL & 0.769 & 0.888 & 0.729 & 0.844 & & & 0.995 & 1.194 & 0.960 & 1.060 \\
\hline & & & & & 2x Cross-Frames & 0.774 & 0.876 & 0.733 & 0.833 & & & 0.995 & 1.194 & 0.960 & 1.060 \\
\hline G2 & 100 & 11.5 & 4 & 20 & No Barrier & 0.801 & 0.928 & 0.793 & 0.923 & & & 0.995 & 1.194 & 0.960 & 1.060 \\
\hline & & & & & No Cross-Frames & 0.796 & 0.937 & 0.755 & 0.891 & & & 0.995 & 1.194 & 0.960 & 1.060 \\
\hline & & & & & CONTROL & 0.765 & 0.881 & 0.734 & 0.849 & & & 0.995 & 1.194 & 0.960 & 1.060 \\
\hline 80 & 100 & 115 & 4 & 25 & 2x Cross-Frames & 0.776 & 0.873 & 0.738 & 0.839 & & & 0.995 & 1.194 & 0.960 & 1.060 \\
\hline G2 & 100 & 11.5 & 4 & 25 & No Barrier & 0.796 & 0.919 & 0.798 & 0.928 & & & 0.995 & 1.194 & 0.960 & 1.060 \\
\hline & & & & & No Cross-Frames & 0.787 & 0.926 & 0.761 & 0.896 & & & 0.995 & 1.194 & 0.960 & 1.060 \\
\hline & & & & & CONTROL & 0.751 & 0.868 & 0.715 & 0.829 & & & 0.995 & 1.194 & 0.907 & 0.973 \\
\hline 40 & 100 & 115 & 5 & 30 & 2x Cross-Frames & 0.744 & 0.846 & 0.708 & 0.808 & & & 0.995 & 1.194 & 0.907 & 0.973 \\
\hline G2 & 100 & 11.5 & 5 & 20 & No Barrier & 0.783 & 0.908 & 0.774 & 0.904 & & & 0.995 & 1.194 & 0.907 & 0.973 \\
\hline & & & & & No Cross-Frames & 0.787 & 0.924 & 0.750 & 0.882 & & & 0.995 & 1.194 & 0.907 & 0.973 \\
\hline & & & & & CONTROL & 0.743 & 0.858 & 0.720 & 0.835 & & & 0.995 & 1.194 & 0.907 & 0.973 \\
\hline G2 & 100 & 11.5 & 5 & 25 & 2x Cross-Frames & 0.740 & 0.837 & 0.715 & 0.815 & & & 0.995 & 1.194 & 0.907 & 0.973 \\
\hline G2 & 100 & 11.5 & 5 & 25 & No Barrier & 0.775 & 0.897 & 0.780 & 0.909 & & & 0.995 & 1.194 & 0.907 & 0.973 \\
\hline & & & & & No Cross-Frames & 0.778 & 0.913 & 0.756 & 0.887 & & & 0.995 & 1.194 & 0.907 & 0.973 \\
\hline & & & & & CONTROL & 0.675 & 0.756 & 0.646 & 0.729 & & & 0.670 & 0.804 & 0.813 & 0.946 \\
\hline$G^{2}$ & 200 & 8625 & 4 & 20 & 2x Cross-Frames & 0.683 & 0.758 & 0.652 & 0.730 & & & 0.670 & 0.804 & 0.813 & 0.946 \\
\hline & & & & & No Barrier & 0.691 & 0.778 & 0.701 & 0.794 & & & 0.670 & 0.804 & 0.813 & 0.946 \\
\hline & & & & & No Cross-Frames & 0.666 & 0.760 & 0.641 & 0.734 & & & 0.670 & 0.804 & 0.813 & 0.946 \\
\hline & & & & & CONTROL & 0.674 & 0.756 & 0.645 & 0.729 & & & 0.670 & 0.804 & 0.813 & 0.946 \\
\hline$G_{2}$ & 200 & 8.625 & 4 & 25 & 2x Cross-Frames & 0.683 & 0.758 & 0.651 & 0.730 & & & 0.670 & 0.804 & 0.813 & 0.946 \\
\hline & & & & & No Barrier & 0.690 & 0.778 & 0.700 & 0.794 & & & 0.670 & 0.804 & 0.813 & 0.946 \\
\hline & & & & & No Cross-Frames & 0.666 & 0.760 & 0.641 & 0.735 & & & 0.670 & 0.804 & 0.813 & 0.946 \\
\hline & & & & & CONTROL & 0.628 & 0.698 & 0.608 & 0.682 & & & 0.670 & 0.804 & 0.809 & 0.898 \\
\hline $\mathrm{G}^{2}$ & & & & & 2x Cross-Frames & 0.634 & 0.695 & 0.612 & 0.679 & & & 0.670 & 0.804 & 0.809 & 0.898 \\
\hline G2 & 200 & 8.625 & 5 & 20 & No Barrier & 0.647 & 0.722 & 0.657 & 0.740 & & & 0.670 & 0.804 & 0.809 & 0.898 \\
\hline & & & & & No Cross-Frames & 0.629 & 0.718 & 0.610 & 0.700 & & & 0.670 & 0.804 & 0.809 & 0.898 \\
\hline & & & & & CONTROL & 0.627 & 0.698 & 0.607 & 0.682 & & & 0.670 & 0.804 & 0.809 & 0.898 \\
\hline & & & & & 2x Cross-Frames & 0.634 & 0.695 & 0.612 & 0.679 & & & 0.670 & 0.804 & 0.809 & 0.898 \\
\hline G2 & 200 & 8.625 & 5 & 25 & No Barrier & 0.646 & 0.722 & 0.656 & 0.740 & & & 0.670 & 0.804 & 0.809 & 0.898 \\
\hline & & & & & No Cross-Frames & 0.629 & 0.718 & 0.611 & 0.700 & & & 0.670 & 0.804 & 0.809 & 0.898 \\
\hline & & & & & CONTROL & 0.759 & 0.834 & 0.725 & 0.802 & & & 0.823 & 0.988 & 0.960 & 1.060 \\
\hline$g ?$ & 200 & 115 & 4 & 30 & 2x Cross-Frames & 0.766 & 0.832 & 0.730 & 0.800 & & & 0.823 & 0.988 & 0.960 & 1.060 \\
\hline G2 & 200 & 11.5 & 4 & 20 & No Barrier & 0.778 & 0.857 & 0.781 & 0.866 & & & 0.823 & 0.988 & 0.960 & 1.060 \\
\hline & & & & & No Cross-Frames & 0.758 & 0.852 & 0.727 & 0.820 & & & 0.823 & 0.988 & 0.960 & 1.060 \\
\hline & & & & & CONTROL & 0.758 & 0.833 & 0.723 & 0.802 & & & 0.823 & 0.988 & 0.960 & 1.060 \\
\hline $0 ?$ & 200 & 115 & 4 & 25 & 2x Cross-Frames & 0.765 & 0.832 & 0.729 & 0.800 & & & 0.823 & 0.988 & 0.960 & 1.060 \\
\hline G2 & 200 & 11.5 & 4 & 25 & No Barrier & 0.777 & 0.857 & 0.780 & 0.866 & & & 0.823 & 0.988 & 0.960 & 1.060 \\
\hline & & & & & No Cross-Frames & 0.758 & 0.852 & 0.727 & 0.820 & & & 0.823 & 0.988 & 0.960 & 1.060 \\
\hline & & & & & CONTROL & 0.705 & 0.775 & 0.681 & 0.754 & & & 0.823 & 0.988 & 0.907 & 0.973 \\
\hline $5 ?$ & 200 & 115 & 5 & 30 & 2x Cross-Frames & 0.704 & 0.761 & 0.680 & 0.743 & & & 0.823 & 0.988 & 0.907 & 0.973 \\
\hline G2 & 200 & 11.5 & 5 & 20 & No Barrier & 0.725 & 0.798 & 0.730 & 0.810 & & & 0.823 & 0.988 & 0.907 & 0.973 \\
\hline & & & & & No Cross-Frames & 0.727 & 0.821 & 0.702 & 0.796 & & & 0.823 & 0.988 & 0.907 & 0.973 \\
\hline & & & & & CONTROL & 0.705 & 0.776 & 0.681 & 0.756 & & & 0.823 & 0.988 & 0.907 & 0.973 \\
\hline $\mathrm{G}_{2}$ & 200 & 11.5 & 5 & 25 & 2x Cross-Frames & 0.704 & 0.762 & 0.679 & 0.744 & & & 0.823 & 0.988 & 0.907 & 0.973 \\
\hline G2 & 200 & 11.5 & 5 & 25 & No Barrier & 0.725 & 0.800 & 0.730 & 0.812 & & & 0.823 & 0.988 & 0.907 & 0.973 \\
\hline & & & & & No Cross-Frames & 0.727 & 0.821 & 0.702 & 0.796 & & & 0.823 & 0.988 & 0.907 & 0.973 \\
\hline
\end{tabular}




\begin{tabular}{|c|c|c|c|c|c|c|c|c|c|c|c|c|c|c|c|}
\hline \multicolumn{16}{|c|}{$\begin{array}{l}\text { Comparis on of the Effect of Overhang Width }(\mathbf{O H}) \\
\text { (bending moment, three lanes loaded) }\end{array}$} \\
\hline \multirow{2}{*}{\multicolumn{6}{|c|}{ Cons tant Parameters }} & \multicolumn{10}{|c|}{ Dis tribution Factors (organized by me thod and varied parame ters) } \\
\hline & & & & & & \multicolumn{2}{|c|}{ Stallings/Yoo } & \multicolumn{2}{|c|}{ Tarhini/Frederick } & \multicolumn{2}{|c|}{ Lever Rule } & \multicolumn{2}{|c|}{ AASHTO Mod. } & \multicolumn{2}{|c|}{ Special Analys is } \\
\hline Girder & $\mathbf{L}(\mathrm{ft})$ & S (ft) & $\mathbf{N}_{\mathrm{b}}$ & $\mathbf{L}_{\mathrm{b}}(\mathrm{ft})$ & Iteration & $46 "$ & $69 "$ & $46 "$ & 69" & $46 "$ & 69" & $46 "$ & $69 "$ & $46 "$ & 69" \\
\hline \multirow{4}{*}{ G2 } & \multirow{4}{*}{100} & \multirow{4}{*}{8.625} & \multirow{4}{*}{5} & \multirow{4}{*}{20} & "CONTROL & 0.702 & 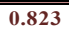 & 0.681 & 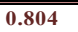 & & & 0.807 & ב0.968 & 0.676 & 0.790 \\
\hline & & & & & 2x Cross-Frames & 0.717 & 0.827 & 0.694 & 0.807 & & & 0.807 & 0.968 & 0.676 & 0.790 \\
\hline & & & & & No Barrier & 0.734 & 0.870 & 0.741 & 0.884 & & & 0.807 & 0.968 & 0.676 & 0.790 \\
\hline & & & & & No Cross-Frames & 0.707 & 0.849 & 0.686 & 0.830 & & & 0.807 & 0.968 & 0.676 & 0.790 \\
\hline \multirow{4}{*}{ G2 } & \multirow{4}{*}{100} & & & & CONTROL & 0.697 & 0.815 & 0.684 & 0.807 & & & 0.807 & 0.968 & 0.676 & 0.790 \\
\hline & & 8625 & 5 & 25 & 2x Cross-Frames & 0.718 & 0.824 & 0.698 & 0.810 & & & 0.807 & 0.968 & 0.676 & 0.790 \\
\hline & & 8.625 & 5 & 25 & No Barrier & 0.727 & 0.859 & 0.744 & 0.886 & & & 0.807 & 0.968 & 0.676 & 0.790 \\
\hline & & & & & No Cross-Frames & 0.697 & 0.837 & 0.691 & 0.834 & & & 0.807 & 0.968 & 0.676 & 0.790 \\
\hline & & & & & CONTROL & 0.853 & 0.983 & 0.818 & 0.949 & & & 0.995 & 1.194 & 0.825 & 0.952 \\
\hline G? & 100 & 115 & 4 & 20 & 2x Cross-Frames & 0.874 & 0.992 & 0.838 & 0.957 & & & 0.995 & 1.194 & 0.825 & 0.952 \\
\hline $\mathrm{G} 2$ & 100 & 11.5 & 4 & 20 & No Barrier & 0.883 & 1.028 & 0.883 & 1.033 & & & 0.995 & 1.194 & 0.825 & 0.952 \\
\hline & & & & & No Cross-Frames & 0.849 & 1.001 & 0.815 & 0.968 & & & 0.995 & 1.194 & 0.825 & 0.952 \\
\hline & & & & & CONTROL & 0.847 & 0.975 & 0.822 & 0.954 & & & 0.995 & 1.194 & 0.825 & 0.952 \\
\hline G2 & 100 & 11.5 & 4 & 25 & 2x Cross-Frames & 0.874 & 0.990 & 0.842 & 0.962 & & & 0.995 & 1.194 & 0.825 & 0.952 \\
\hline & & & & 25 & No Barrier & 0.876 & 1.018 & 0.887 & 1.036 & & & 0.995 & 1.194 & 0.825 & 0.952 \\
\hline & & & & & No Cross-Frames & 0.839 & 0.988 & 0.821 & 0.974 & & & 0.995 & 1.194 & 0.825 & 0.952 \\
\hline & & & & & CONTROL & 0.831 & 0.958 & 0.804 & 0.932 & & & 0.995 & 1.194 & 0.890 & 0.975 \\
\hline G2 & 100 & 11.5 & 5 & 20 & 2x Cross-Frames & 0.840 & 0.954 & 0.812 & 0.928 & & & 0.995 & 1.194 & 0.890 & 0.975 \\
\hline & & & 5 & 20 & No Barrier & 0.870 & 1.009 & 0.869 & 1.014 & & & 0.995 & 1.194 & 0.890 & 0.975 \\
\hline & & & & & No Cross-Frames & 0.856 & 1.001 & 0.829 & 0.975 & & & 0.995 & 1.194 & 0.890 & 0.975 \\
\hline & & & & & CONTROL & 0.823 & 0.947 & 0.808 & 0.937 & & & 0.995 & 1.194 & 0.890 & 0.975 \\
\hline G2 & 100 & 11.5 & 5 & 25 & 2x Cross-Frames & 0.838 & 0.948 & 0.815 & 0.932 & & & 0.995 & 1.194 & 0.890 & 0.975 \\
\hline G2 & 100 & 11.5 & 5 & 25 & No Barrier & 0.862 & 0.997 & 0.873 & 1.018 & & & 0.995 & 1.194 & 0.890 & 0.975 \\
\hline & & & & & No Cross-Frames & 0.844 & 0.988 & 0.835 & 0.981 & & & 0.995 & 1.194 & 0.890 & 0.975 \\
\hline & & & & & CONTROL & 0.732 & 0.820 & 0.707 & 0.799 & & & 0.670 & 0.804 & 0.676 & 0.790 \\
\hline & & & & & 2x Cross-Frames & 0.750 & 0.831 & 0.721 & 0.808 & & & 0.670 & 0.804 & 0.676 & 0.790 \\
\hline G2 & 200 & 8.625 & 5 & 20 & No Barrier & 0.749 & 0.845 & 0.759 & 0.862 & & & 0.670 & 0.804 & 0.676 & 0.790 \\
\hline & & & & & No Cross-Frames & 0.709 & 0.812 & 0.690 & 0.796 & & & 0.670 & 0.804 & 0.676 & 0.790 \\
\hline & & & & & CONTROL & 0.730 & 0.818 & 0.705 & 0.798 & & & 0.670 & 0.804 & 0.676 & 0.790 \\
\hline & & & & & 2x Cross-Frames & 0.748 & 0.830 & 0.719 & 0.806 & & & 0.670 & 0.804 & 0.676 & 0.790 \\
\hline G2 & 200 & 8.625 & 5 & 25 & No Barrier & 0.748 & 0.843 & 0.757 & 0.860 & & & 0.670 & 0.804 & 0.676 & 0.790 \\
\hline & & & & & No Cross-Frames & 0.709 & 0.812 & 0.690 & 0.796 & & & 0.670 & 0.804 & 0.676 & 0.790 \\
\hline & & & & & CONTROL & 0.898 & 0.993 & 0.857 & 0.955 & & & 0.823 & 0.988 & 0.825 & 0.952 \\
\hline G? & 200 & 115 & 4 & 20 & 2x Cross-Frames & 0.917 & 1.007 & 0.872 & 0.966 & & & 0.823 & 0.988 & 0.825 & 0.952 \\
\hline $\mathrm{G} 2$ & 200 & 11.5 & 4 & 20 & No Barrier & 0.915 & 1.018 & 0.917 & 1.026 & & & 0.823 & 0.988 & 0.825 & 0.952 \\
\hline & & & & & No Cross-Frames & 0.868 & 0.979 & 0.834 & 0.947 & & & 0.823 & 0.988 & 0.825 & 0.952 \\
\hline & & & & & CONTROL & 0.596 & 0.991 & 0.854 & 0.953 & & & 0.823 & 0.988 & 0.825 & 0.952 \\
\hline & 200 & & & & 2x Cross-Frames & 0.610 & 1.006 & 0.870 & 0.964 & & & 0.823 & 0.988 & 0.825 & 0.952 \\
\hline G2 & 200 & 11.5 & 4 & 25 & No Barrier & 0.609 & 1.016 & 0.914 & 1.024 & & & 0.823 & 0.988 & 0.825 & 0.952 \\
\hline & & & & & No Cross-Frames & 0.579 & 0.979 & 0.834 & 0.947 & & & 0.823 & 0.988 & 0.825 & 0.952 \\
\hline & & & & & CONTROL & 0.844 & 0.930 & 0.814 & 0.904 & & & 0.823 & 0.988 & 0.890 & 0.975 \\
\hline G2 & 200 & 11.5 & 5 & 20 & 2x Cross-Frames & 0.865 & 0.940 & 0.832 & 0.912 & & & 0.823 & 0.988 & 0.890 & 0.975 \\
\hline G2 & 200 & 11.5 & 5 & 20 & No Barrier & 0.868 & 0.958 & 0.870 & 0.969 & & & 0.823 & 0.988 & 0.890 & 0.975 \\
\hline & & & & & No Cross-Frames & 0.826 & 0.935 & 0.802 & 0.912 & & & 0.823 & 0.988 & 0.890 & 0.975 \\
\hline & & & & & CONTROL & 0.840 & 0.927 & 0.810 & 0.902 & & & 0.823 & 0.988 & 0.890 & 0.975 \\
\hline G2 & 200 & 11.5 & 5 & 25 & 2x Cross-Frames & 0.862 & 0.938 & 0.828 & 0.910 & & & 0.823 & 0.988 & 0.890 & 0.975 \\
\hline G2 & 200 & 11.5 & 5 & 25 & No Barrier & 0.864 & 0.957 & 0.867 & 0.967 & & & 0.823 & 0.988 & 0.890 & 0.975 \\
\hline & & & & & No Cross-Frames & 0.826 & 0.935 & 0.802 & 0.913 & & & 0.823 & 0.988 & 0.890 & 0.975 \\
\hline
\end{tabular}

\begin{tabular}{|c|c|c|c|c|c|c|c|c|c|c|c|c|c|c|c|}
\hline \multicolumn{16}{|c|}{$\begin{array}{l}\text { Comparis on of the Effect of Overhang Width (OH) } \\
\text { (bending moment, four lanes loaded) }\end{array}$} \\
\hline \multirow{2}{*}{\multicolumn{6}{|c|}{ Cons tant Parameters }} & \multicolumn{10}{|c|}{ Distribution Factors (organized by method and varied parameters) } \\
\hline & & & & & & \multicolumn{2}{|c|}{ Stallings/Yoo } & \multicolumn{2}{|c|}{ Tarhini/Frederick } & \multicolumn{2}{|c|}{ Lever Rule } & \multicolumn{2}{|c|}{ AASHTO Mod. } & \multicolumn{2}{|c|}{ Special Analys is } \\
\hline Girder & L (ft) & $S$ (ft) & $\mathbf{N}_{\mathrm{b}}$ & $\mathbf{L}_{b}(\mathrm{ft})$ & Ite ration & $46 "$ & 69" & $46^{\prime \prime}$ & $69 "$ & $46^{\prime \prime}$ & 69" & $46^{\prime \prime}$ & $69 "$ & $46 "$ & 69" \\
\hline \multirow{4}{*}{ G2 } & \multirow{4}{*}{100} & \multirow{4}{*}{11.5} & \multirow{4}{*}{5} & \multirow{4}{*}{20} & CONTROL & 0.879 & 1.012 & 0.852 & 0.989 & & & 0.995 & 1.194 & 0.636 & 0.723 \\
\hline & & & & & 2x Cross-Frames & 0.896 & 1.016 & 0.867 & 0.992 & & & 0.995 & 1.194 & 0.636 & 0.723 \\
\hline & & & & & No Barrier & 0.914 & 1.063 & 0.914 & 1.070 & & & 0.995 & 1.194 & 0.636 & 0.723 \\
\hline & & & & & No Cross-Frames & 0.881 & 1.035 & 0.854 & 1.012 & & & 0.995 & 1.194 & 0.636 & 0.723 \\
\hline \multirow{4}{*}{ G2 } & \multirow{4}{*}{100} & \multirow{4}{*}{11.5} & \multirow{4}{*}{5} & \multirow{4}{*}{25} & CONTROL & 0.870 & 1.001 & 0.857 & 0.994 & & & 0.995 & 1.194 & 0.636 & 0.723 \\
\hline & & & & & 2x Cross-Frames & 0.893 & 1.011 & 0.871 & 0.996 & & & 0.995 & 1.194 & 0.636 & 0.723 \\
\hline & & & & & No Barrier & 0.905 & 1.050 & 0.919 & 1.074 & & & 0.995 & 1.194 & 0.636 & 0.723 \\
\hline & & & & & No Cross-Frames & 0.869 & 1.020 & 0.861 & 1.019 & & & 0.995 & 1.194 & 0.636 & 0.723 \\
\hline \multirow{4}{*}{ G2 } & \multirow{4}{*}{200} & \multirow{4}{*}{11.5} & \multirow{4}{*}{5} & \multirow{4}{*}{20} & CONTROL & 0.921 & 1.016 & 0.888 & 0.988 & & & 0.823 & 0.988 & 0.636 & 0.723 \\
\hline & & & & & 2x Cross-Frames & 0.955 & 1.041 & 0.916 & 1.008 & & & 0.823 & 0.988 & 0.636 & 0.723 \\
\hline & & & & & No Barrier & 0.943 & 1.044 & 0.944 & 1.054 & & & 0.823 & 0.988 & 0.636 & 0.723 \\
\hline & & & & & No Cross-Frames & 0.877 & 0.991 & 0.852 & 0.970 & & & 0.823 & 0.988 & 0.636 & 0.723 \\
\hline \multirow{4}{*}{ G2 } & \multirow{4}{*}{200} & \multirow{4}{*}{11.5} & \multirow{4}{*}{5} & \multirow{4}{*}{25} & CONTROL & 0.915 & 1.011 & 0.882 & 0.983 & & & 0.823 & 0.988 & 0.636 & 0.723 \\
\hline & & & & & 2x Cross-Frames & 0.950 & 1.037 & 0.911 & 1.004 & & & 0.823 & 0.988 & 0.636 & 0.723 \\
\hline & & & & & No Barrier & 0.938 & 1.041 & 0.939 & 1.050 & & & 0.823 & 0.988 & 0.636 & 0.723 \\
\hline & & & & & No Cross-Frames & 0.877 & 0.991 & 0.853 & 0.970 & & & 0.823 & 0.988 & 0.636 & 0.723 \\
\hline
\end{tabular}




\begin{tabular}{|c|c|c|c|c|c|c|c|c|c|c|c|c|c|c|c|}
\hline \multicolumn{12}{|c|}{$\begin{array}{c}\text { Comparis on of the Effect of } \mathbf{B} \text { arrier Presence / B arrier Stiffiness } \\
\text { (bending moment, one lane loaded) }\end{array}$} & \multicolumn{4}{|c|}{$\frac{100 \% \text { Represents Full Scale B arrier }}{0 \% \text { Represents No Barrier }}$} \\
\hline \multirow{2}{*}{\multicolumn{6}{|c|}{ Constant Parameters }} & \multicolumn{10}{|c|}{ Distribution Factors (organized by method and varied parameters) } \\
\hline & & & & & & \multicolumn{2}{|c|}{ Stallings/Yoo } & \multicolumn{2}{|c|}{ Tarhini/Fre de rick } & \multicolumn{2}{|c|}{ Lever Rule } & \multicolumn{2}{|c|}{ AASHTO Mod. } & \multicolumn{2}{|c|}{ Spe cial Analys is } \\
\hline Girder & $\mathbf{L}$ (ft) & S (ft) & $\mathbf{N}_{\mathbf{b}}$ & $\mathbf{L}_{\mathrm{b}}(\mathbf{f t})$ & OH (in) & $100 \%$ & $\mathbf{0} \%$ & $100 \%$ & $\mathbf{0 \%}$ & $100 \%$ & $\mathbf{0} \%$ & $100 \%$ & 0\% & $100 \%$ & $0 \%$ \\
\hline G2 & 10100 & 8.625 & 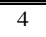 & 20 & 46 & 0.502 & 0.521 & 0.472 & 0.521 & $\begin{array}{c}0.861 \\
\end{array}$ & $\overline{0.861}$ & & & $\begin{array}{c}0.738 \\
\end{array}$ & $\begin{array}{c}0.738 \\
\end{array}$ \\
\hline G2 & 100 & 8.625 & 4 & 20 & 69 & 0.581 & 0.606 & 0.544 & 0.608 & 1.128 & 1.128 & & & 0.818 & 0.818 \\
\hline G2 & 100 & 8.625 & 4 & 25 & 46 & 0.495 & 0.512 & 0.474 & 0.523 & 0.861 & 0.861 & & & 0.738 & 0.738 \\
\hline G2 & 100 & 8.625 & 4 & 25 & 69 & 0.568 & 0.590 & 0.545 & 0.609 & 1.128 & 1.128 & & & 0.818 & 0.818 \\
\hline G2 & 100 & 8.625 & 5 & 20 & 46 & 0.488 & 0.506 & 0.461 & 0.506 & 0.861 & 0.861 & & & 0.652 & 0.652 \\
\hline G2 & 100 & 8.625 & 5 & 20 & 69 & 0.567 & 0.591 & 0.533 & 0.593 & 1.128 & 1.128 & & & 0.706 & 0.706 \\
\hline G2 & 100 & 8.625 & 5 & 25 & 46 & 0.479 & 0.496 & 0.464 & 0.508 & 0.861 & 0.861 & & & 0.652 & 0.652 \\
\hline G2 & 100 & 8.625 & 5 & 25 & 69 & 0.552 & 0.574 & 0.535 & 0.594 & 1.128 & 1.128 & & & 0.706 & 0.706 \\
\hline G2 & 100 & 11.5 & 4 & 20 & 46 & 0.563 & 0.580 & 0.527 & 0.574 & 0.946 & 0.946 & & & 0.764 & 0.764 \\
\hline G2 & 100 & 11.5 & 4 & 20 & 69 & 0.635 & 0.657 & 0.593 & 0.654 & 1.146 & 1.146 & & & 0.824 & 0.824 \\
\hline G2 & 100 & 11.5 & 4 & 25 & 46 & 0.556 & 0.572 & 0.531 & 0.578 & 0.946 & 0.946 & & & 0.764 & 0.764 \\
\hline G2 & 100 & 11.5 & 4 & 25 & 69 & 0.625 & 0.645 & 0.596 & 0.657 & 1.146 & 1.146 & & & 0.824 & 0.824 \\
\hline G2 & 100 & 11.5 & 5 & 20 & 46 & 0.553 & 0.568 & 0.519 & 0.562 & 0.946 & 0.946 & & & 0.669 & 0.669 \\
\hline G2 & 100 & 11.5 & 5 & 20 & 69 & 0.626 & 0.646 & 0.585 & 0.642 & 1.146 & 1.146 & & & 0.709 & 0.709 \\
\hline G2 & 100 & 11.5 & 5 & 25 & 46 & 0.545 & 0.559 & 0.523 & 0.566 & 0.946 & 0.946 & & & 0.669 & 0.669 \\
\hline G2 & 100 & 11.5 & 5 & 25 & 69 & 0.614 & 0.633 & 0.588 & 0.645 & 1.146 & 1.146 & & & 0.709 & 0.709 \\
\hline G2 & 200 & 8.625 & 4 & 20 & 46 & 0.451 & 0.466 & 0.432 & 0.475 & 0.861 & 0.861 & & & 0.738 & 0.738 \\
\hline G2 & 200 & 8.625 & 4 & 20 & 69 & 0.495 & 0.514 & 0.477 & 0.528 & 1.128 & 1.128 & & & 0.818 & 0.818 \\
\hline G2 & 200 & 8.625 & 4 & 25 & 46 & 0.451 & 0.465 & 0.432 & 0.474 & 0.861 & 0.861 & & & 0.738 & 0.738 \\
\hline G2 & 200 & 8.625 & 4 & 25 & 69 & 0.496 & 0.514 & 0.478 & 0.528 & 1.128 & 1.128 & & & 0.818 & 0.818 \\
\hline G2 & 200 & 8.625 & 5 & 20 & 46 & 0.413 & 0.426 & 0.401 & 0.437 & 0.861 & 0.861 & & & 0.652 & 0.652 \\
\hline G2 & 200 & 8.625 & 5 & 20 & 69 & 0.453 & 0.469 & 0.443 & 0.486 & 1.128 & 1.128 & & & 0.706 & 0.706 \\
\hline G2 & 200 & 8.625 & 5 & 25 & 46 & 0.414 & 0.427 & 0.402 & 0.438 & 0.861 & 0.861 & & & 0.652 & 0.652 \\
\hline G2 & 200 & 8.625 & 5 & 25 & 69 & 0.454 & 0.471 & 0.445 & 0.488 & 1.128 & 1.128 & & & 0.706 & 0.706 \\
\hline $\mathrm{G} 2$ & 200 & 11.5 & 4 & 20 & 46 & 0.486 & 0.499 & 0.465 & 0.504 & 0.946 & 0.946 & & & 0.764 & 0.764 \\
\hline G2 & 200 & 11.5 & 4 & 20 & 69 & 0.525 & 0.542 & 0.505 & 0.552 & 1.146 & 1.146 & & & 0.824 & 0.824 \\
\hline G2 & 200 & 11.5 & 4 & 25 & 46 & 0.487 & 0.500 & 0.466 & 0.505 & 0.946 & 0.946 & & & 0.764 & 0.764 \\
\hline G2 & 200 & 11.5 & 4 & 25 & 69 & 0.526 & 0.544 & 0.506 & 0.553 & 1.146 & 1.146 & & & 0.824 & 0.824 \\
\hline G2 & 200 & 11.5 & 5 & 20 & 46 & 0.453 & 0.464 & 0.438 & 0.471 & 0.946 & 0.946 & & & 0.669 & 0.669 \\
\hline G2 & 200 & 11.5 & 5 & 20 & 69 & 0.489 & 0.505 & 0.476 & 0.516 & 1.146 & 1.146 & & & 0.709 & 0.709 \\
\hline G2 & 200 & 11.5 & 5 & 25 & 46 & 0.454 & 0.466 & 0.440 & 0.473 & 0.946 & 0.946 & & & 0.669 & 0.669 \\
\hline G2 & 200 & 11.5 & 5 & 25 & 69 & 0.492 & 0.508 & 0.479 & 0.520 & 1.146 & 1.146 & & & 0.709 & 0.709 \\
\hline
\end{tabular}

\begin{tabular}{|c|c|c|c|c|c|c|c|c|c|c|c|c|c|c|c|}
\hline \multicolumn{12}{|c|}{$\begin{array}{c}\text { Comparis on of the Effect of } \mathbf{B} \text { arrier Pres ence / B arrier Stiffiness } \\
\text { (bending moment, two lanes loaded) }\end{array}$} & \multicolumn{4}{|c|}{$\begin{array}{c}100 \% \text { Represents Full Scale Barrier } \\
\text { 0\% Represents No Barrier }\end{array}$} \\
\hline \multirow{2}{*}{\multicolumn{6}{|c|}{ Constant Parameters }} & \multicolumn{10}{|c|}{ Distribution Factors (organized by method and varied parameters) } \\
\hline & & & & & & \multicolumn{2}{|c|}{ Stallings/Yoo } & \multicolumn{2}{|c|}{ Tarhini/Fre de rick } & \multicolumn{2}{|c|}{ Lever Rule } & \multicolumn{2}{|c|}{ AASHTO Mod. } & \multicolumn{2}{|c|}{ Special Analys is } \\
\hline Girder & L (ft) & S (ft) & $\mathbf{N}_{\mathbf{b}}$ & $\mathbf{L}_{\mathbf{b}}(\mathbf{f t})$ & OH (in) & $100 \%$ & $\mathbf{0 \%}$ & $100 \%$ & $\mathbf{0} \%$ & $100 \%$ & $\mathbf{0 \%}$ & $100 \%$ & $\mathbf{0 \%}$ & $100 \%$ & 0\% \\
\hline G2 & 100 & 8.625 & 4 & 20 & 46 & 0.663 & 0.692 & 0.629 & 0.692 & & & 0.807 & $\overline{0.807}$ & 0.813 & 0.813 \\
\hline G2 & 100 & 8.625 & 4 & 20 & 69 & 0.783 & 0.821 & 0.746 & 0.825 & & & 0.968 & 0.968 & 0.946 & 0.946 \\
\hline G2 & 100 & 8.625 & 4 & 25 & 46 & 0.662 & 0.689 & 0.634 & 0.696 & & & 0.807 & 0.807 & 0.813 & 0.813 \\
\hline G2 & 100 & 8.625 & 4 & 25 & 69 & 0.778 & 0.814 & 0.750 & 0.828 & & & 0.968 & 0.968 & 0.946 & 0.946 \\
\hline G2 & 100 & 8.625 & 5 & 20 & 46 & 0.639 & 0.671 & 0.612 & 0.672 & & & 0.807 & 0.807 & 0.809 & 0.809 \\
\hline G2 & 100 & 8.625 & 5 & 20 & 69 & 0.752 & 0.795 & 0.723 & 0.800 & & & 0.968 & 0.968 & 0.898 & 0.898 \\
\hline G2 & 100 & 8.625 & 5 & 25 & 46 & 0.634 & 0.665 & 0.616 & 0.675 & & & 0.807 & 0.807 & 0.809 & 0.809 \\
\hline G2 & 100 & 8.625 & 5 & 25 & 69 & 0.743 & 0.784 & 0.727 & 0.802 & & & 0.968 & 0.968 & 0.898 & 0.898 \\
\hline G2 & 100 & 11.5 & 4 & 20 & 46 & 0.769 & 0.801 & 0.729 & 0.793 & & & 0.995 & 0.995 & 0.960 & 0.960 \\
\hline G2 & 100 & 11.5 & 4 & 20 & 69 & 0.888 & 0.928 & 0.844 & 0.923 & & & 1.194 & 1.194 & 1.060 & 1.060 \\
\hline G2 & 100 & 11.5 & 4 & 25 & 46 & 0.765 & 0.796 & 0.734 & 0.798 & & & 0.995 & 0.995 & 0.960 & 0.960 \\
\hline G2 & 100 & 11.5 & 4 & 25 & 69 & 0.881 & 0.919 & 0.849 & 0.928 & & & 1.194 & 1.194 & 1.060 & 1.060 \\
\hline G2 & 100 & 11.5 & 5 & 20 & 46 & 0.751 & 0.783 & 0.715 & 0.774 & & & 0.995 & 0.995 & 0.907 & 0.907 \\
\hline G2 & 100 & 11.5 & 5 & 20 & 69 & 0.868 & 0.908 & 0.829 & 0.904 & & & 1.194 & 1.194 & 0.973 & 0.973 \\
\hline G2 & 100 & 11.5 & 5 & 25 & 46 & 0.743 & 0.775 & 0.720 & 0.780 & & & 0.995 & 0.995 & 0.907 & 0.907 \\
\hline G2 & 100 & 11.5 & 5 & 25 & 69 & 0.858 & 0.897 & 0.835 & 0.909 & & & 1.194 & 1.194 & 0.973 & 0.973 \\
\hline G2 & 200 & 8.625 & 4 & 20 & 46 & 0.675 & 0.691 & 0.646 & 0.701 & & & 0.670 & 0.670 & 0.813 & 0.813 \\
\hline G2 & 200 & 8.625 & 4 & 20 & 69 & 0.756 & 0.778 & 0.729 & 0.794 & & & 0.804 & 0.804 & 0.946 & 0.946 \\
\hline G2 & 200 & 8.625 & 4 & 25 & 46 & 0.674 & 0.690 & 0.645 & 0.700 & & & 0.670 & 0.670 & 0.813 & 0.813 \\
\hline G2 & 200 & 8.625 & 4 & 25 & 69 & 0.756 & 0.778 & 0.729 & 0.794 & & & 0.804 & 0.804 & 0.946 & 0.946 \\
\hline G2 & 200 & 8.625 & 5 & 20 & 46 & 0.628 & 0.647 & 0.608 & 0.657 & & & 0.670 & 0.670 & 0.809 & 0.809 \\
\hline G2 & 200 & 8.625 & 5 & 20 & 69 & 0.698 & 0.722 & 0.682 & 0.740 & & & 0.804 & 0.804 & 0.898 & 0.898 \\
\hline G2 & 200 & 8.625 & 5 & 25 & 46 & 0.627 & 0.646 & 0.607 & 0.656 & & & 0.670 & 0.670 & 0.809 & 0.809 \\
\hline G2 & 200 & 8.625 & 5 & 25 & 69 & 0.698 & 0.722 & 0.682 & 0.740 & & & 0.804 & 0.804 & 0.898 & 0.898 \\
\hline G2 & 200 & 11.5 & 4 & 20 & 46 & 0.759 & 0.778 & 0.725 & 0.781 & & & 0.823 & 0.823 & 0.960 & 0.960 \\
\hline G2 & 200 & 11.5 & 4 & 20 & 69 & 0.834 & 0.857 & 0.802 & 0.866 & & & 0.988 & 0.988 & 1.060 & 1.060 \\
\hline G2 & 200 & 11.5 & 4 & 25 & 46 & 0.758 & 0.777 & 0.723 & 0.780 & & & 0.823 & 0.823 & 0.960 & 0.960 \\
\hline G2 & 200 & 11.5 & 4 & 25 & 69 & 0.833 & 0.857 & 0.802 & 0.866 & & & 0.988 & 0.988 & 1.060 & 1.060 \\
\hline G2 & 200 & 11.5 & 5 & 20 & 46 & 0.705 & 0.725 & 0.681 & 0.730 & & & 0.823 & 0.823 & 0.907 & 0.907 \\
\hline G2 & 200 & 11.5 & 5 & 20 & 69 & 0.775 & 0.798 & 0.754 & 0.810 & & & 0.988 & 0.988 & 0.973 & 0.973 \\
\hline G2 & 200 & 11.5 & 5 & 25 & 46 & 0.705 & 0.725 & 0.681 & 0.730 & & & 0.823 & 0.823 & 0.907 & 0.907 \\
\hline G2 & 200 & 11.5 & 5 & 25 & 69 & 0.776 & 0.800 & 0.756 & 0.812 & & & 0.988 & 0.988 & 0.973 & 0.973 \\
\hline
\end{tabular}




\begin{tabular}{|c|c|c|c|c|c|c|c|c|c|c|c|c|c|c|c|}
\hline \multicolumn{12}{|c|}{$\begin{array}{c}\text { Comparis on of the Effect of B arrier Presence / B arrier Stiffiness } \\
\text { (bending moment, three lanes loaded) }\end{array}$} & \multicolumn{4}{|c|}{$\begin{array}{c}\text { 100\% Represents Full Scale Barrier } \\
\text { 0\% Represents No Barrier }\end{array}$} \\
\hline \multirow{2}{*}{\multicolumn{6}{|c|}{ Constant Parameters }} & \multicolumn{10}{|c|}{ Dis tribution Factors (organized by method and varied parameters) } \\
\hline & & & & & & \multicolumn{2}{|c|}{ Stallings/Yoo } & \multicolumn{2}{|c|}{ Tarhini/Fre derick } & \multicolumn{2}{|c|}{ Lever Rule } & \multicolumn{2}{|c|}{ AASHTO Mod. } & \multicolumn{2}{|c|}{ Spe cial Analys is } \\
\hline Girder & L (ft) & S (ft) & $\mathbf{N}_{\mathrm{b}}$ & $\mathbf{L}_{\mathrm{b}}$ (ft) & OH (in) & $100 \%$ & $\mathbf{0 \%}$ & $100 \%$ & $\mathbf{0 \%}$ & $100 \%$ & $\mathbf{0 \%}$ & $100 \%$ & $\mathbf{0 \%}$ & $100 \%$ & $0 \%$ \\
\hline G2 & 100 & 8.625 & 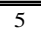 & 20 & 46 & 0.702 & 0.734 & 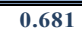 & 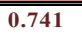 & & & 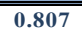 & 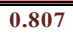 & $\overline{0.676}$ & 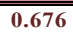 \\
\hline G2 & 100 & 8.625 & 5 & 20 & 69 & 0.823 & 0.870 & 0.804 & 0.884 & & & 0.968 & 0.968 & 0.790 & 0.790 \\
\hline G2 & 100 & 8.625 & 5 & 25 & 46 & 0.697 & 0.727 & 0.684 & 0.744 & & & 0.807 & 0.807 & 0.676 & 0.676 \\
\hline G2 & 100 & 8.625 & 5 & 25 & 69 & 0.815 & 0.859 & 0.807 & 0.886 & & & 0.968 & 0.968 & 0.790 & 0.790 \\
\hline G2 & 100 & 11.5 & 4 & 20 & 46 & 0.853 & 0.883 & 0.818 & 0.883 & & & 0.995 & 0.995 & 0.825 & 0.825 \\
\hline G2 & 100 & 11.5 & 4 & 20 & 69 & 0.983 & 1.028 & 0.949 & 1.033 & & & 1.194 & 1.194 & 0.952 & 0.952 \\
\hline G2 & 100 & 11.5 & 4 & 25 & 46 & 0.847 & 0.876 & 0.822 & 0.887 & & & 0.995 & 0.995 & 0.825 & 0.825 \\
\hline G2 & 100 & 11.5 & 4 & 25 & 69 & 0.975 & 1.018 & 0.954 & 1.036 & & & 1.194 & 1.194 & 0.952 & 0.952 \\
\hline G2 & 100 & 11.5 & 5 & 20 & 46 & 0.831 & 0.870 & 0.804 & 0.869 & & & 0.995 & 0.995 & 0.890 & 0.890 \\
\hline G2 & 100 & 11.5 & 5 & 20 & 69 & 0.958 & 1.009 & 0.932 & 1.014 & & & 1.194 & 1.194 & 0.975 & 0.975 \\
\hline G2 & 100 & 11.5 & 5 & 25 & 46 & 0.823 & 0.862 & 0.808 & 0.873 & & & 0.995 & 0.995 & 0.890 & 0.890 \\
\hline G2 & 100 & 11.5 & 5 & 25 & 69 & 0.947 & 0.997 & 0.937 & 1.018 & & & 1.194 & 1.194 & 0.975 & 0.975 \\
\hline G2 & 200 & 8.625 & 5 & 20 & 46 & 0.732 & 0.749 & 0.707 & 0.759 & & & 0.670 & 0.670 & 0.676 & 0.676 \\
\hline G2 & 200 & 8.625 & 5 & 20 & 69 & 0.820 & 0.845 & 0.799 & 0.862 & & & 0.804 & 0.804 & 0.790 & 0.790 \\
\hline G2 & 200 & 8.625 & 5 & 25 & 46 & 0.730 & 0.748 & 0.705 & 0.757 & & & 0.670 & 0.670 & 0.676 & 0.676 \\
\hline G2 & 200 & 8.625 & 5 & 25 & 69 & 0.818 & 0.843 & 0.798 & 0.860 & & & 0.804 & 0.804 & 0.790 & 0.790 \\
\hline G2 & 200 & 11.5 & 4 & 20 & 46 & 0.898 & 0.915 & 0.857 & 0.917 & & & 0.823 & 0.823 & 0.825 & 0.825 \\
\hline G2 & 200 & 11.5 & 4 & 20 & 69 & 0.993 & 1.018 & 0.955 & 1.026 & & & 0.988 & 0.988 & 0.952 & 0.952 \\
\hline G2 & 200 & 11.5 & 4 & 25 & 46 & 0.596 & 0.609 & 0.854 & 0.914 & & & 0.823 & 0.823 & 0.825 & 0.825 \\
\hline G2 & 200 & 11.5 & 4 & 25 & 69 & 0.991 & 1.016 & 0.953 & 1.024 & & & 0.988 & 0.988 & 0.952 & 0.952 \\
\hline G2 & 200 & 11.5 & 5 & 20 & 46 & 0.844 & 0.868 & 0.814 & 0.870 & & & 0.823 & 0.823 & 0.890 & 0.890 \\
\hline G2 & 200 & 11.5 & 5 & 20 & 69 & 0.930 & 0.958 & 0.904 & 0.969 & & & 0.988 & 0.988 & 0.975 & 0.975 \\
\hline G2 & 200 & 11.5 & 5 & 25 & 46 & 0.840 & 0.864 & 0.810 & 0.867 & & & 0.823 & 0.823 & 0.890 & 0.890 \\
\hline G2 & 200 & 11.5 & 5 & 25 & 69 & 0.927 & 0.957 & 0.902 & 0.967 & & & 0.988 & 0.988 & 0.975 & 0.975 \\
\hline
\end{tabular}

\begin{tabular}{|c|c|c|c|c|c|c|c|c|c|c|c|c|c|c|c|}
\hline \multicolumn{12}{|c|}{$\begin{array}{l}\text { Comparis on of the Effect of B arrier Presence / B arrier Stiffiness } \\
\text { (bending moment, four lanes loaded) }\end{array}$} & \multicolumn{4}{|c|}{$\begin{array}{c}100 \% \text { Represents Full Scale Barrier } \\
0 \% \text { Represents No Barrier }\end{array}$} \\
\hline \multirow{2}{*}{\multicolumn{6}{|c|}{ Constant Parame ters }} & \multicolumn{10}{|c|}{ Dis tribution Factors (organized by me thod and varied parame ters) } \\
\hline & & & & & & \multicolumn{2}{|c|}{ Stallings/Yoo } & \multicolumn{2}{|c|}{ Tarhini/Frederick } & \multicolumn{2}{|c|}{ Lever Rule } & \multicolumn{2}{|c|}{ AASHTO Mod. } & \multicolumn{2}{|c|}{ Special Analys is } \\
\hline Girder & $L$ (ft) & $\mathrm{S}$ (ft) & $\mathbf{N}_{\mathbf{b}}$ & $\mathbf{L}_{\mathrm{b}}$ (ft) & OH (in) & $100 \%$ & $0 \%$ & $100 \%$ & $0 \%$ & $100 \%$ & $\mathbf{0 \%}$ & $100 \%$ & $0 \%$ & $100 \%$ & $0 \%$ \\
\hline G2 & 100 & 11.5 & 5 & 20 & 46 & 0.879 & 0.914 & 0.852 & 0.914 & & & 0.995 & 0.995 & 0.636 & 0.636 \\
\hline G2 & 100 & 11.5 & 5 & 20 & 69 & 1.012 & 1.063 & 0.989 & 1.070 & & & 1.194 & 1.194 & 0.723 & 0.723 \\
\hline G2 & 100 & 11.5 & 5 & 25 & 46 & 0.870 & 0.905 & 0.857 & 0.919 & & & 0.995 & 0.995 & 0.636 & 0.636 \\
\hline G2 & 100 & 11.5 & 5 & 25 & 69 & 1.001 & 1.050 & 0.994 & 1.074 & & & 1.194 & 1.194 & 0.723 & 0.723 \\
\hline G2 & 200 & 11.5 & 5 & 20 & 46 & 0.921 & 0.943 & 0.888 & 0.944 & & & 0.823 & 0.823 & 0.636 & 0.636 \\
\hline G2 & 200 & 11.5 & 5 & 20 & 69 & 1.016 & 1.044 & 0.988 & 1.054 & & & 0.988 & 0.988 & 0.723 & 0.723 \\
\hline G2 & 200 & 11.5 & 5 & 25 & 46 & 0.915 & 0.938 & 0.882 & 0.939 & & & 0.823 & 0.823 & 0.636 & 0.636 \\
\hline G2 & 200 & 11.5 & 5 & 25 & 69 & 1.011 & 1.041 & 0.983 & 1.050 & & & 0.988 & 0.988 & 0.723 & 0.723 \\
\hline
\end{tabular}




\begin{tabular}{|c|c|c|c|c|c|c|c|c|c|c|c|c|c|c|c|c|c|c|c|c|}
\hline \multirow{2}{*}{\multicolumn{6}{|c|}{ Constant Parameters }} & \multicolumn{15}{|c|}{ Distribution Factors (organized by me thod and varied parame ters) } \\
\hline & & & & & & \multicolumn{3}{|c|}{ Stallings/Yoo } & \multicolumn{3}{|c|}{ Tarhini/Fre de rick } & \multicolumn{3}{|c|}{ Lever Rule } & \multicolumn{3}{|c|}{ AASHTO Modified } & \multicolumn{3}{|c|}{ Special Analysis } \\
\hline Girder & $\mathbf{L}(\mathrm{ft})$ & $\mathbf{S}(\mathrm{ft})$ & $\mathbf{N}_{\mathrm{b}}$ & $\mathbf{L}_{\mathrm{b}}(\mathrm{ft})$ & OH (in) & $200 \%$ & $100 \%$ & $\mathbf{0 \%}$ & $200 \%$ & $100 \%$ & $\mathbf{0 \%}$ & $200 \%$ & $100 \%$ & $\mathbf{0 \%}$ & $200 \%$ & $100 \%$ & $\mathbf{0 \%}$ & $200 \%$ & $100 \%$ & $0 \%$ \\
\hline G2 & 100 & 8.625 & 4 & 20 & 46 & 0.489 & 0.502 & 0.540 & 0.459 & 0.472 & 0.507 & 0.861 & 0.861 & 0.861 & & & & 0.738 & 0.738 & 0.738 \\
\hline G2 & 100 & 8.625 & 4 & 20 & 69 & 0.555 & 0.581 & 0.637 & 0.521 & 0.544 & 0.595 & 1.128 & 1.128 & 1.128 & & & & 0.818 & 0.818 & 0.818 \\
\hline G2 & 100 & 8.625 & 4 & 25 & 46 & 0.479 & 0.495 & 0.535 & 0.462 & 0.474 & 0.509 & 0.861 & 0.861 & 0.861 & & & & 0.738 & 0.738 & 0.738 \\
\hline G2 & 100 & 8.625 & 4 & 25 & 69 & 0.534 & 0.568 & 0.632 & 0.521 & 0.545 & 0.596 & 1.128 & 1.128 & 1.128 & & & & 0.818 & 0.818 & 0.818 \\
\hline G2 & 100 & 8.625 & 5 & 20 & 46 & 0.467 & 0.488 & 0.532 & 0.442 & 0.461 & 0.502 & 0.861 & 0.861 & 0.861 & & & & 0.652 & 0.652 & 0.652 \\
\hline G2 & 100 & 8.625 & 5 & 20 & 69 & 0.533 & 0.567 & 0.627 & 0.503 & 0.533 & 0.589 & 1.128 & 1.128 & 1.128 & & & & 0.706 & 0.706 & 0.706 \\
\hline G2 & 100 & 8.625 & 5 & 25 & 46 & 0.454 & 0.479 & 0.527 & 0.445 & 0.464 & 0.504 & 0.861 & 0.861 & 0.861 & & & & 0.652 & 0.652 & 0.652 \\
\hline G2 & 100 & 8.625 & 5 & 25 & 69 & 0.508 & 0.552 & 0.622 & 0.504 & 0.535 & 0.590 & 1.128 & 1.128 & 1.128 & & & & 0.706 & 0.706 & 0.706 \\
\hline G2 & 100 & 11.5 & 4 & 20 & 46 & 0.540 & 0.563 & 0.611 & 0.506 & 0.527 & 0.572 & 0.946 & 0.946 & 0.946 & & & & 0.764 & 0.764 & 0.764 \\
\hline G2 & 100 & 11.5 & 4 & 20 & 69 & 0.600 & 0.635 & 0.699 & 0.561 & 0.593 & 0.651 & 1.146 & 1.146 & 1.146 & & & & 0.824 & 0.824 & 0.824 \\
\hline G2 & 100 & 11.5 & 4 & 25 & 46 & 0.530 & 0.556 & 0.606 & 0.510 & 0.531 & 0.575 & 0.946 & 0.946 & 0.946 & & & & 0.764 & 0.764 & 0.764 \\
\hline G2 & 100 & 11.5 & 4 & 25 & 69 & 0.583 & 0.625 & 0.695 & 0.564 & 0.596 & 0.653 & 1.146 & 1.146 & 1.146 & & & & 0.824 & 0.824 & 0.824 \\
\hline G2 & 100 & 11.5 & 5 & 20 & 46 & 0.525 & 0.553 & 0.600 & 0.494 & 0.519 & 0.563 & 0.946 & 0.946 & 0.946 & & & & 0.669 & 0.669 & 0.669 \\
\hline G2 & 100 & 11.5 & 5 & 20 & 69 & 0.586 & 0.626 & 0.687 & 0.549 & 0.585 & 0.640 & 1.146 & 1.146 & 1.146 & & & & 0.709 & 0.709 & 0.709 \\
\hline G2 & 100 & 11.5 & 5 & 25 & 46 & 0.513 & 0.545 & 0.595 & 0.498 & 0.523 & 0.566 & 0.946 & 0.946 & 0.946 & & & & 0.669 & 0.669 & 0.669 \\
\hline G2 & 100 & 11.5 & 5 & 25 & 69 & 0.566 & 0.614 & 0.682 & 0.552 & 0.588 & 0.643 & 1.146 & 1.146 & 1.146 & & & & 0.709 & 0.709 & 0.709 \\
\hline G2 & 200 & 8.625 & 4 & 20 & 46 & 0.447 & 0.451 & 0.466 & 0.429 & 0.432 & 0.445 & 0.861 & 0.861 & 0.861 & & & & 0.738 & 0.738 & 0.738 \\
\hline G2 & 200 & 8.625 & 4 & 20 & 69 & 0.485 & 0.495 & 0.520 & 0.470 & 0.477 & 0.497 & 1.128 & 1.128 & 1.128 & & & & 0.818 & 0.818 & 0.818 \\
\hline G2 & 200 & 8.625 & 4 & 25 & 46 & 0.446 & 0.451 & 0.464 & 0.429 & 0.432 & 0.443 & 0.861 & 0.861 & 0.861 & & & & 0.738 & 0.738 & 0.738 \\
\hline G2 & 200 & 8.625 & 4 & 25 & 69 & 0.485 & 0.496 & 0.520 & 0.470 & 0.478 & 0.497 & 1.128 & 1.128 & 1.128 & & & & 0.818 & 0.818 & 0.818 \\
\hline G2 & 200 & 8.625 & 5 & 20 & 46 & 0.402 & 0.413 & 0.440 & 0.393 & 0.401 & 0.424 & 0.861 & 0.861 & 0.861 & & & & 0.652 & 0.652 & 0.652 \\
\hline G2 & 200 & 8.625 & 5 & 20 & 69 & 0.434 & 0.453 & 0.495 & 0.429 & 0.443 & 0.477 & 1.128 & 1.128 & 1.128 & & & & 0.706 & 0.706 & 0.706 \\
\hline G2 & 200 & 8.625 & 5 & 25 & 46 & 0.403 & 0.414 & 0.440 & 0.394 & 0.402 & 0.424 & 0.861 & 0.861 & 0.861 & & & & 0.652 & 0.652 & 0.652 \\
\hline G2 & 200 & 8.625 & 5 & 25 & 69 & 0.435 & 0.454 & 0.495 & 0.430 & 0.445 & 0.477 & 1.128 & 1.128 & 1.128 & & & & 0.706 & 0.706 & 0.706 \\
\hline G2 & 200 & 11.5 & 4 & 20 & 46 & 0.477 & 0.486 & 0.513 & 0.458 & 0.465 & 0.488 & 0.946 & 0.946 & 0.946 & & & & 0.764 & 0.764 & 0.764 \\
\hline G2 & 200 & 11.5 & 4 & 20 & 69 & 0.510 & 0.525 & 0.566 & 0.493 & 0.505 & 0.538 & 1.146 & 1.146 & 1.146 & & & & 0.824 & 0.824 & 0.824 \\
\hline G2 & 200 & 11.5 & 4 & 25 & 46 & 0.477 & 0.487 & 0.513 & 0.459 & 0.466 & 0.488 & 0.946 & 0.946 & 0.946 & & & & 0.764 & 0.764 & 0.764 \\
\hline G2 & 200 & 11.5 & 4 & 25 & 69 & 0.510 & 0.526 & 0.566 & 0.494 & 0.506 & 0.538 & 1.146 & 1.146 & 1.146 & & & & 0.824 & 0.824 & 0.824 \\
\hline G2 & 200 & 11.5 & 5 & 20 & 46 & 0.435 & 0.453 & 0.497 & 0.423 & 0.438 & 0.476 & 0.946 & 0.946 & 0.946 & & & & 0.669 & 0.669 & 0.669 \\
\hline G2 & 200 & 11.5 & 5 & 20 & 69 & 0.463 & 0.489 & 0.550 & 0.454 & 0.476 & 0.526 & 1.146 & 1.146 & 1.146 & & & & 0.709 & 0.709 & 0.709 \\
\hline G2 & 200 & 11.5 & 5 & 25 & 46 & 0.436 & 0.454 & 0.497 & 0.425 & 0.440 & 0.476 & 0.946 & 0.946 & 0.946 & & & & 0.669 & 0.669 & 0.669 \\
\hline G2 & 200 & 11.5 & 5 & 25 & 69 & 0.465 & 0.492 & 0.550 & 0.457 & 0.479 & 0.526 & 1.146 & 1.146 & 1.146 & & & & 0.709 & 0.709 & 0.709 \\
\hline
\end{tabular}




\begin{tabular}{|c|c|c|c|c|c|c|c|c|c|c|c|c|c|c|c|c|c|c|c|c|}
\hline \multirow{2}{*}{\multicolumn{6}{|c|}{ Constant Parameters }} & \multicolumn{15}{|c|}{ nets) } \\
\hline & & & & & & \multicolumn{3}{|c|}{ Stallings/Yoo } & \multicolumn{3}{|c|}{ Tarhini/Fre de rick } & \multicolumn{3}{|c|}{ Lever Rule } & \multicolumn{3}{|c|}{ AASHTO Modified } & \multicolumn{3}{|c|}{ Special Analys is } \\
\hline Girder & L (ft) & $S$ (ft) & $\mathbf{N}_{\mathrm{b}}$ & $L_{b}(\mathrm{ft})$ & OH (in) & $200 \%$ & $100 \%$ & 0\% & $200 \%$ & $100 \%$ & $0 \%$ & $200 \%$ & $100 \%$ & $0 \%$ & $200 \%$ & $100 \%$ & $0 \%$ & $200 \%$ & $100 \%$ & $0 \%$ \\
\hline $\begin{array}{c}\mathrm{G} 2 \\
\end{array}$ & 100 & 8.625 & 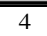 & 20 & 40 & 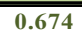 & 0.663 & 0.675 & 0.639 & 0.629 & $\overline{0.641}$ & & & & 0.807 & 0.807 & 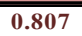 & 0.813 & 0.813 & 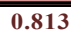 \\
\hline G2 & 100 & 8.625 & 4 & 20 & 69 & 0.780 & 0.783 & 0.818 & 0.743 & 0.746 & 0.781 & & & & 0.968 & 0.968 & 0.968 & 0.946 & 0.946 & 0.946 \\
\hline G2 & 100 & 8.625 & 4 & 25 & 46 & 0.681 & 0.662 & 0.666 & 0.646 & 0.634 & 0.645 & & & & 0.807 & 0.807 & 0.807 & 0.813 & 0.813 & 0.813 \\
\hline G2 & 100 & 8.625 & 4 & 25 & 69 & 0.778 & 0.778 & 0.808 & 0.750 & 0.750 & 0.784 & & & & 0.968 & 0.968 & 0.968 & 0.946 & 0.946 & 0.946 \\
\hline G2 & 100 & 8.625 & 5 & 20 & 46 & 0.643 & 0.639 & 0.666 & 0.616 & 0.612 & 0.639 & & & & 0.807 & 0.807 & 0.807 & 0.809 & 0.809 & 0.809 \\
\hline G2 & 100 & 8.625 & 5 & 20 & 69 & 0.742 & 0.752 & 0.799 & 0.713 & 0.723 & 0.769 & & & & 0.968 & 0.968 & 0.968 & 0.898 & 0.898 & 0.898 \\
\hline G2 & 100 & 8.625 & 5 & 25 & 46 & 0.644 & 0.634 & 0.657 & 0.621 & 0.616 & 0.643 & & & & 0.807 & 0.807 & 0.807 & 0.809 & 0.809 & 0.809 \\
\hline G2 & 100 & 8.625 & 5 & 25 & 69 & 0.735 & 0.743 & 0.789 & 0.718 & 0.727 & 0.772 & & & & 0.968 & 0.968 & 0.968 & 0.898 & 0.898 & 0.898 \\
\hline G2 & 100 & 11.5 & 4 & 20 & 46 & 0.774 & 0.769 & 0.796 & 0.733 & 0.729 & 0.755 & & & & 0.995 & 0.995 & 0.995 & 0.960 & 0.960 & 0.960 \\
\hline G2 & 100 & 11.5 & 4 & 20 & 69 & 0.876 & 0.888 & 0.937 & 0.833 & 0.844 & 0.891 & & & & 1.194 & 1.194 & 1.194 & 1.060 & 1.060 & 1.060 \\
\hline G2 & 100 & 11.5 & 4 & 25 & 46 & 0.776 & 0.765 & 0.787 & 0.738 & 0.734 & 0.761 & & & & 0.995 & 0.995 & 0.995 & 0.960 & 0.960 & 0.960 \\
\hline G2 & 100 & 11.5 & 4 & 25 & 69 & 0.873 & 0.881 & 0.926 & 0.839 & 0.849 & 0.896 & & & & 1.194 & 1.194 & 1.194 & 1.060 & 1.060 & 1.060 \\
\hline G2 & 100 & 11.5 & 5 & 20 & 46 & 0.744 & 0.751 & 0.787 & 0.708 & 0.715 & 0.750 & & & & 0.995 & 0.995 & 0.995 & 0.907 & 0.907 & 0.907 \\
\hline G2 & 100 & 11.5 & 5 & 20 & 69 & 0.846 & 0.868 & 0.924 & 0.808 & 0.829 & 0.882 & & & & 1.194 & 1.194 & 1.194 & 0.973 & 0.973 & 0.973 \\
\hline G2 & 100 & 11.5 & 5 & 25 & 46 & 0.740 & 0.743 & 0.778 & 0.715 & 0.720 & 0.756 & & & & 0.995 & 0.995 & 0.995 & 0.907 & 0.907 & 0.907 \\
\hline G2 & 100 & 11.5 & 5 & 25 & 69 & 0.837 & 0.858 & 0.913 & 0.815 & 0.835 & 0.887 & & & & 1.194 & 1.194 & 1.194 & 0.973 & 0.973 & 0.973 \\
\hline G2 & 200 & 8.625 & 4 & 20 & 46 & 0.683 & 0.675 & 0.666 & 0.652 & 0.646 & 0.641 & & & & 0.670 & 0.670 & 0.670 & 0.813 & 0.813 & 0.813 \\
\hline G2 & 200 & 8.625 & 4 & 20 & 69 & 0.758 & 0.756 & 0.760 & 0.730 & 0.729 & 0.734 & & & & 0.804 & 0.804 & 0.804 & 0.946 & 0.946 & 0.946 \\
\hline G2 & 200 & 8.625 & 4 & 25 & 46 & 0.683 & 0.674 & 0.666 & 0.651 & 0.645 & 0.641 & & & & 0.670 & 0.670 & 0.670 & 0.813 & 0.813 & 0.813 \\
\hline G2 & 200 & 8.625 & 4 & 25 & 69 & 0.758 & 0.756 & 0.760 & 0.730 & 0.729 & 0.735 & & & & 0.804 & 0.804 & 0.804 & 0.946 & 0.946 & 0.946 \\
\hline G2 & 200 & 8.625 & 5 & 20 & 46 & 0.634 & 0.628 & 0.629 & 0.612 & 0.608 & 0.610 & & & & 0.670 & 0.670 & 0.670 & 0.809 & 0.809 & 0.809 \\
\hline G2 & 200 & 8.625 & 5 & 20 & 69 & 0.695 & 0.698 & 0.718 & 0.679 & 0.682 & 0.700 & & & & 0.804 & 0.804 & 0.804 & 0.898 & 0.898 & 0.898 \\
\hline G2 & 200 & 8.625 & 5 & 25 & 46 & 0.634 & 0.627 & 0.629 & 0.612 & 0.607 & 0.611 & & & & 0.670 & 0.670 & 0.670 & 0.809 & 0.809 & 0.809 \\
\hline G2 & 200 & 8.625 & 5 & 25 & 69 & 0.695 & 0.698 & 0.718 & 0.679 & 0.682 & 0.700 & & & & 0.804 & 0.804 & 0.804 & 0.898 & 0.898 & 0.898 \\
\hline G2 & 200 & 11.5 & 4 & 20 & 46 & 0.766 & 0.759 & 0.758 & 0.730 & 0.725 & 0.727 & & & & 0.823 & 0.823 & 0.823 & 0.960 & 0.960 & 0.960 \\
\hline G2 & 200 & 11.5 & 4 & 20 & 69 & 0.832 & 0.834 & 0.852 & 0.800 & 0.802 & 0.820 & & & & 0.988 & 0.988 & 0.988 & 1.060 & 1.060 & 1.060 \\
\hline G2 & 200 & 11.5 & 4 & 25 & 46 & 0.765 & 0.758 & 0.758 & 0.729 & 0.723 & 0.727 & & & & 0.823 & 0.823 & 0.823 & 0.960 & 0.960 & 0.960 \\
\hline G2 & 200 & 11.5 & 4 & 25 & 69 & 0.832 & 0.833 & 0.852 & 0.800 & 0.802 & 0.820 & & & & 0.988 & 0.988 & 0.988 & 1.060 & 1.060 & 1.060 \\
\hline G2 & 200 & 11.5 & 5 & 20 & 46 & 0.704 & 0.705 & 0.727 & 0.680 & 0.681 & 0.702 & & & & 0.823 & 0.823 & 0.823 & 0.907 & 0.907 & 0.907 \\
\hline G2 & 200 & 11.5 & 5 & 20 & 69 & 0.761 & 0.775 & 0.821 & 0.743 & 0.754 & 0.796 & & & & 0.988 & 0.988 & 0.988 & 0.973 & 0.973 & 0.973 \\
\hline G2 & 200 & 11.5 & 5 & 25 & 46 & 0.704 & 0.705 & 0.727 & 0.679 & 0.681 & 0.702 & & & & 0.823 & 0.823 & 0.823 & 0.907 & 0.907 & 0.907 \\
\hline $\mathrm{G} 2$ & 200 & 11.5 & 5 & 25 & 69 & 0.762 & 0.776 & 0.821 & 0.744 & 0.756 & 0.796 & & & & 0.988 & 0.988 & 0.988 & 0.973 & 0.973 & 0.973 \\
\hline
\end{tabular}




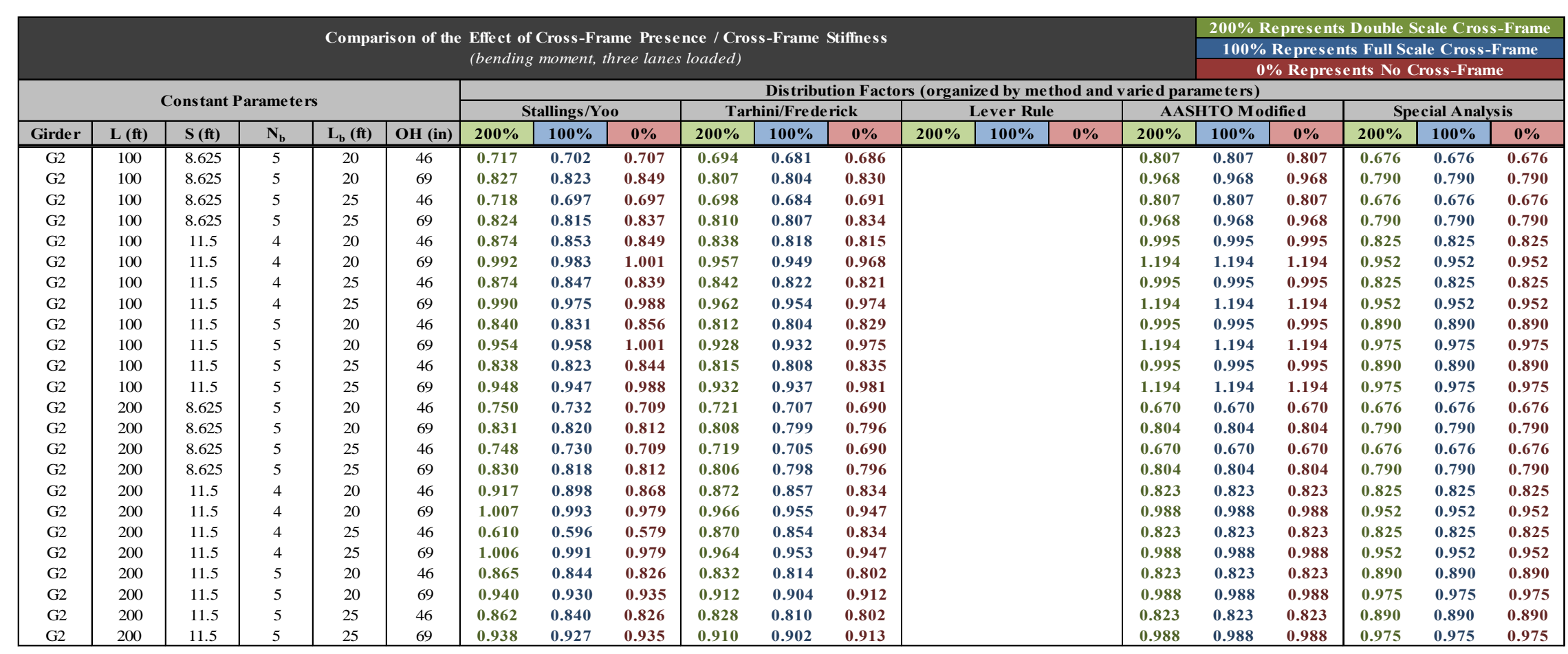

\begin{tabular}{|c|c|c|c|c|c|c|c|c|c|c|c|c|c|c|c|c|c|c|c|c|}
\hline \multicolumn{16}{|c|}{$\begin{array}{l}\text { Comparison of the Effect of Cross-Frame Presence / Cross-Frame Stiffiness } \\
\text { (bending moment, four lanes loaded) }\end{array}$} & \multicolumn{5}{|c|}{$\begin{array}{c}200 \% \text { Represents Double Scale Cross-Frame } \\
\text { 100\% Represents Full Scale Cross-Frame } \\
\text { 0\% Represents No Cross-Frame }\end{array}$} \\
\hline \multirow{2}{*}{\multicolumn{6}{|c|}{ Constant Parameters }} & \multirow{2}{*}{\multicolumn{15}{|c|}{ 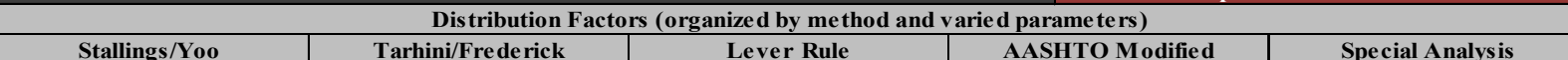 }} \\
\hline & & & & & & \multicolumn{3}{|c|}{ Stallings/Yoo } & \multicolumn{2}{|c|}{ Tarhini/Frederick } & & \multicolumn{3}{|c|}{ Lever Rule } & \multicolumn{3}{|c|}{ AASHTO Modified } & \multicolumn{3}{|c|}{ Spe cial Analys is } \\
\hline Girder & L (ft) & $S(f t)$ & $\mathbf{N}_{\mathrm{b}}$ & $\mathbf{L}_{\mathrm{b}}$ (ft) & OH (in) & $200 \%$ & $100 \%$ & $0 \%$ & $200 \%$ & $100 \%$ & $0 \%$ & $200 \%$ & $100 \%$ & $0 \%$ & $200 \%$ & $100 \%$ & $0 \%$ & $200 \%$ & $100 \%$ & $0 \%$ \\
\hline G2 & 100 & 111.5 & 5 & 20 & 46 & 0.896 & 0.879 & 0.881 & 0.867 & 0.852 & 0.854 & & & & 0.995 & 0.995 & 0.995 & 0.636 & 0.636 & 0.636 \\
\hline G2 & 100 & 11.5 & 5 & 20 & 69 & 1.016 & 1.012 & 1.035 & 0.992 & 0.989 & 1.012 & & & & 1.194 & 1.194 & 1.194 & 0.723 & 0.723 & 0.723 \\
\hline G2 & 100 & 11.5 & 5 & 25 & 46 & 0.893 & 0.870 & 0.869 & 0.871 & 0.857 & 0.861 & & & & 0.995 & 0.995 & 0.995 & 0.636 & 0.636 & 0.636 \\
\hline G2 & 100 & 11.5 & 5 & 25 & 69 & 1.011 & 1.001 & 1.020 & 0.996 & 0.994 & 1.019 & & & & 1.194 & 1.194 & 1.194 & 0.723 & 0.723 & 0.723 \\
\hline G2 & 200 & 11.5 & 5 & 20 & 46 & 0.955 & 0.921 & 0.877 & 0.916 & 0.888 & 0.852 & & & & 0.823 & 0.823 & 0.823 & 0.636 & 0.636 & 0.636 \\
\hline G2 & 200 & 11.5 & 5 & 20 & 69 & 1.041 & 1.016 & 0.991 & 1.008 & 0.988 & 0.970 & & & & 0.988 & 0.988 & 0.988 & 0.723 & 0.723 & 0.723 \\
\hline G2 & 200 & 11.5 & 5 & 25 & 46 & 0.950 & 0.915 & 0.877 & 0.911 & 0.882 & 0.853 & & & & 0.823 & 0.823 & 0.823 & 0.636 & 0.636 & 0.636 \\
\hline $\mathrm{G} 2$ & 200 & 11.5 & 5 & 25 & 69 & 1.037 & 1.011 & 0.991 & 1.004 & 0.983 & 0.970 & & & & 0.988 & 0.988 & 0.988 & 0.723 & 0.723 & 0.723 \\
\hline
\end{tabular}




\section{APPENDix C: PARAMETRIC VARIATION \#2 ReSUltS}

The following appendix lists in tabular form the distribution factors calculated from the finite element models of Parametric Variation \#2 discussed in Section 6.3. For the reader's convenience, this data has been organized such that each table is focused on the influence of a single parameter on exterior girder live load distribution. These tables are then further discretized based on the number of lanes loaded.

These tables follow the same format as the ones listed in Appendices A \& B. In these tables, the following nomenclature is used.

- $\quad \mathrm{S}=$ girder spacing (feet)

- $\quad \mathrm{L}=$ span length (feet)

- $\mathrm{N}_{\mathrm{b}}=$ number of beams

- $\mathrm{OH}=$ overhang width (inches)

Also, references are made to the different types of girders used in the sensitivity matrix. For these tables, the nomenclature is as follows:

- “G1” represents the girder that was designed and implemented for the bridges with a 100foot span length.

- “G2” represents the girder that was designed and implemented for the bridges with a 150foot span length.

- “G3” represents the girder that was designed and implemented for the bridges with a 200foot span length.

- “G4” represents the girder that was designed and implemented for the bridges with a 250foot span length.

One further note about these tables is that while some distribution factors fall outside the ranges ( $L \geq 240$ feet) specified in the current edition of the AASHTO LRFD Specifications, they have still been calculated for comparison purposes, and have been denoted with a “*”. 


\begin{tabular}{|c|c|c|c|c|c|c|c|c|c|c|c|c|c|c|c|c|c|c|c|c|}
\hline \multicolumn{11}{|c|}{$\begin{array}{l}\text { Comparis on of the Effect of Girder Spacing (S) } \\
\text { (bending moment, one lane loaded) }\end{array}$} & \multicolumn{3}{|c|}{$\begin{array}{c}25 \% \mathrm{OH}=21.5625 " \\
33 \% \mathrm{OH}=28.75^{\prime \prime} \\
\end{array}$} & \multicolumn{2}{|c|}{$\begin{array}{c}25 \% \mathrm{OH}=25.875^{\prime \prime} \\
33 \% \mathrm{OH}=34.5^{\prime \prime}\end{array}$} & \multicolumn{2}{|c|}{$\begin{array}{c}25 \% \mathrm{OH}=30.1875^{\prime \prime} \\
33 \% \mathrm{OH}=40.25^{\prime \prime}\end{array}$} & \multicolumn{3}{|c|}{$\begin{aligned} 25 \% \mathrm{OH} & =34.5^{\prime \prime} \\
33 \% \mathrm{OH} & =46^{\prime \prime}\end{aligned}$} \\
\hline \multicolumn{3}{|c|}{ Constant Parameters } & \multirow{2}{*}{\multicolumn{18}{|c|}{\begin{tabular}{|l|c|c|}
\multicolumn{2}{|c|}{ Exterior Girder Distribution Factors (organized by method and varied parameters) } \\
Tarhini/Frederick & Lever Rule & AASHTO Modified
\end{tabular}}} \\
\hline & & OH (in) & & & & & & & & & & & & & & & & & & \\
\hline L (ft) & $\mathbf{N}_{\mathrm{b}}$ & $\%$ & 7.1875' & $8.625^{\prime}$ & 10.0625 & $11.5^{\prime}$ & $\begin{array}{l}7.1875^{\prime} \\
\end{array}$ & $8.625^{\prime}$ & 10.0625 & $11.5^{\prime}$ & \begin{tabular}{|l|l|}
$7.1875^{\prime}$ \\
\end{tabular} & $8.625^{\prime}$ & 10.0625 & $11.5^{\prime}$ & \begin{tabular}{|l|l|}
$7.1875^{\prime}$ & $8.625^{\prime}$ \\
\end{tabular} & \begin{tabular}{|l|l|}
$10.0625^{\prime}$ & $11.5^{\prime}$ \\
\end{tabular} & $7.1875^{\prime}$ & $8.625^{\prime}$ & 10.0625 & $11.5^{\prime}$ \\
\hline 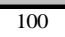 & $\overline{44}$ & $20 \%$ & 0.367 & 0.398 & 0.435 & 0.468 & 0.292 & 0.322 & 0.354 & 0.383 & 0.393 & 0.568 & 0.692 & 0.786 & & & $\begin{array}{l}0.598 \\
\end{array}$ & 0.650 & 0.688 & 0.716 \\
\hline 100 & 4 & $25 \%$ & 0.378 & 0.412 & 0.450 & 0.485 & 0.302 & 0.335 & 0.368 & 0.398 & 0.453 & 0.628 & 0.752 & 0.846 & & & 0.616 & 0.668 & 0.706 & 0.734 \\
\hline 100 & 4 & $33 \%$ & 0.396 & 0.436 & 0.474 & 0.512 & 0.319 & 0.356 & 0.390 & 0.422 & 0.553 & 0.728 & 0.852 & 0.946 & & & 0.646 & 0.698 & 0.736 & 0.764 \\
\hline 100 & 5 & $20 \%$ & 0.341 & 0.375 & 0.414 & 0.451 & 0.277 & 0.310 & 0.343 & 0.374 & 0.393 & 0.568 & 0.692 & 0.786 & & & 0.559 & 0.594 & 0.618 & 0.637 \\
\hline 100 & 5 & $25 \%$ & 0.351 & 0.390 & 0.429 & 0.468 & 0.287 & 0.323 & 0.356 & 0.389 & 0.453 & 0.628 & 0.752 & 0.846 & & & 0.571 & 0.606 & 0.630 & 0.649 \\
\hline 100 & 5 & $33 \%$ & 0.368 & 0.414 & 0.454 & 0.496 & 0.303 & 0.344 & 0.378 & 0.413 & 0.553 & 0.728 & 0.852 & 0.946 & & & 0.591 & 0.626 & 0.650 & 0.669 \\
\hline 150 & 4 & $20 \%$ & 0.362 & 0.394 & 0.422 & 0.449 & 0.323 & 0.356 & 0.386 & 0.414 & 0.393 & 0.568 & 0.692 & 0.786 & & & 0.598 & 0.650 & 0.688 & 0.716 \\
\hline 150 & 4 & $25 \%$ & 0.372 & 0.404 & 0.435 & 0.463 & 0.334 & 0.368 & 0.399 & 0.428 & 0.453 & 0.628 & 0.752 & 0.846 & & & 0.616 & 0.668 & 0.706 & 0.734 \\
\hline 150 & 4 & $33 \%$ & 0.387 & 0.422 & 0.454 & 0.485 & 0.351 & 0.388 & 0.421 & 0.451 & 0.553 & 0.728 & 0.852 & 0.946 & & & 0.646 & 0.698 & 0.736 & 0.764 \\
\hline 150 & 5 & $20 \%$ & 0.333 & 0.363 & 0.393 & 0.423 & 0.303 & 0.335 & 0.365 & 0.395 & 0.393 & 0.568 & 0.692 & 0.786 & & & 0.559 & 0.594 & 0.618 & 0.637 \\
\hline 150 & 5 & $25 \%$ & 0.341 & 0.373 & 0.405 & 0.436 & 0.312 & 0.346 & 0.378 & 0.409 & 0.453 & 0.628 & 0.752 & 0.846 & & & 0.571 & 0.606 & 0.630 & 0.649 \\
\hline 150 & 5 & $33 \%$ & 0.355 & 0.390 & 0.424 & 0.458 & 0.328 & 0.364 & 0.399 & 0.431 & 0.553 & 0.728 & 0.852 & 0.946 & & & 0.591 & 0.626 & 0.650 & 0.669 \\
\hline 200 & 4 & $20 \%$ & 0.368 & 0.399 & 0.427 & 0.451 & 0.341 & 0.375 & $\begin{array}{l}0.404 \\
\end{array}$ & 0.431 & 0.393 & 0.568 & 0.692 & 0.786 & & & 0.598 & 0.650 & 0.688 & 0.716 \\
\hline 200 & 4 & $25 \%$ & 0.377 & 0.410 & 0.438 & 0.464 & 0.352 & 0.387 & 0.418 & 0.445 & 0.453 & 0.628 & 0.752 & 0.846 & & & 0.616 & 0.668 & 0.706 & 0.734 \\
\hline 200 & 4 & $33 \%$ & 0.392 & 0.427 & 0.457 & 0.485 & 0.369 & 0.407 & 0.439 & 0.468 & 0.553 & 0.728 & 0.852 & 0.946 & & & 0.646 & 0.698 & 0.736 & 0.764 \\
\hline 200 & 5 & $20 \%$ & 0.338 & 0.366 & 0.393 & 0.419 & 0.318 & 0.349 & 0.377 & 0.405 & 0.393 & 0.568 & 0.692 & 0.786 & & & 0.559 & 0.594 & 0.618 & 0.637 \\
\hline 200 & 5 & $25 \%$ & 0.346 & 0.376 & 0.404 & 0.431 & 0.327 & 0.360 & 0.390 & 0.418 & 0.453 & 0.628 & 0.752 & 0.846 & & & 0.571 & 0.606 & 0.630 & 0.649 \\
\hline 200 & 5 & $33 \%$ & 0.359 & 0.391 & 0.422 & 0.451 & 0.343 & 0.378 & 0.410 & 0.440 & 0.553 & 0.728 & 0.852 & 0.946 & & & 0.591 & 0.626 & 0.650 & 0.669 \\
\hline 250 & 4 & $20 \%$ & 0.371 & 0.404 & 0.431 & 0.455 & 0.347 & 0.382 & 0.411 & 0.437 & 0.393 & 0.568 & 0.692 & 0.786 & & & 0.598 & 0.650 & 0.688 & 0.716 \\
\hline 250 & 4 & $25 \%$ & 0.380 & 0.414 & 0.443 & 0.468 & 0.358 & 0.394 & 0.425 & 0.452 & 0.453 & 0.628 & 0.752 & 0.846 & & & 0.616 & 0.668 & 0.706 & 0.734 \\
\hline 250 & 4 & $33 \%$ & 0.396 & 0.432 & 0.462 & 0.488 & 0.377 & 0.415 & 0.447 & 0.476 & 0.553 & 0.728 & 0.852 & 0.946 & & & 0.646 & 0.698 & 0.736 & 0.764 \\
\hline 250 & 5 & $20 \%$ & 0.341 & 0.370 & 0.396 & 0.420 & & 0.354 & 0.382 & 0.408 & 0.393 & 0.568 & 0.692 & 0.786 & & & 0.559 & 0.594 & 0.618 & 0.637 \\
\hline 250 & 5 & $25 \%$ & 0.349 & 0.379 & 0.407 & 0.432 & 0.333 & 0.365 & 0.395 & 0.422 & 0.453 & 0.628 & 0.752 & 0.846 & & & 0.571 & 0.606 & 0.630 & 0.649 \\
\hline 250 & 5 & $33 \%$ & 0.362 & 0.395 & 0.424 & 0.451 & 0.350 & 0.384 & 0.416 & 0.444 & 0.553 & 0.728 & 0.852 & 0.946 & & & 0.591 & 0.626 & 0.650 & 0.669 \\
\hline
\end{tabular}




\begin{tabular}{|c|c|c|c|c|c|c|c|c|c|c|c|c|c|c|c|c|c|c|c|c|}
\hline \multicolumn{11}{|c|}{$\begin{array}{l}\text { Comparison of the Effect of Girder Spacing (S) } \\
\text { (bending moment, two lanes loaded) }\end{array}$} & \begin{tabular}{|c|} 
For $\mathbf{S}=\mathbf{7 . 1 8 7 5}$ \\
$20 \% \mathrm{OH}=17.25^{\prime \prime}$ \\
$25 \% \mathrm{OH}=21.5625^{\prime \prime}$ \\
$33 \% \mathrm{OH}=28.75^{\prime \prime}$ \\
\end{tabular} & \multicolumn{3}{|c|}{$\begin{array}{c}20 \% \text { OH }=20.7^{\prime \prime} \\
25 \% \text { OH }=25.875 " \\
33 \% \text { OH }=34.5^{\prime \prime}\end{array}$} & \multicolumn{3}{|c|}{$\begin{array}{c}20 \% \mathrm{OH}=24.15 " \\
25 \% \mathrm{OH}=30.1875 " \\
33 \% \mathrm{OH}=40.25 "\end{array}$} & \multicolumn{3}{|c|}{$\begin{array}{c}20 \% \mathrm{OH}=27.6^{\prime \prime} \\
25 \% \mathrm{OH}=34.5^{\prime \prime} \\
33 \% \mathrm{OH}=46^{\prime \prime}\end{array}$} \\
\hline \multicolumn{3}{|c|}{ Constant Parameters } & \multicolumn{18}{|c|}{ Exterior Girder Distribution Factors (organized by method and varied parame ters) } \\
\hline \multirow{2}{*}{$\mathbf{L}$ (ft) } & \multirow{2}{*}{$\mathbf{N}_{\mathrm{b}}$} & \multirow{2}{*}{\begin{tabular}{|c|} 
OH (in) \\
$\%$ \\
\end{tabular}} & \multicolumn{4}{|c|}{ Stallings/Yoo } & \multicolumn{4}{|c|}{ Tarhini/Fre derick } & \multicolumn{2}{|c|}{ Lever Rule } & \multicolumn{4}{|c|}{ AASHTO Modified } & \multicolumn{4}{|c|}{ Special Analysis } \\
\hline & & & $7.1875^{\prime}$ & $8.625^{\prime}$ & 10.0625 & $11.5^{\prime}$ & $7.1875^{\prime}$ & $8.625^{\prime}$ & 10.0625 & $11.5^{\prime}$ & \begin{tabular}{l|l|l|l|}
$7.1875^{\prime}$ & $8.625^{\prime}$ & $10.0625^{\prime}$ \\
\end{tabular} & $11.5^{\prime}$ & $7.1875^{\prime}$ & $8.625^{\prime}$ & 10.0625 & $11.5^{\prime}$ & $7.1875^{\prime}$ & $8.625^{\prime}$ & $|10.0625|$ & $11.5^{\prime}$ \\
\hline 100 & 24 & $20 \%$ & 0.500 & 0.541 & 0.620 & 0.673 & 0.397 & 0.443 & 0.508 & 0.557 & & & 0.457 & 0.540 & 0.626 & 0.715 & 0.500 & \begin{tabular}{c|c|}
0.666 \\
\end{tabular} & 0.788 & 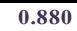 \\
\hline 100 & 4 & $25 \%$ & 0.517 & 0.562 & 0.644 & 0.701 & 0.413 & 0.463 & 0.531 & 0.583 & & & 0.479 & 0.571 & 0.666 & 0.766 & 0.526 & 0.696 & 0.818 & 0.910 \\
\hline 100 & 4 & $33 \%$ & 0.545 & 0.597 & 0.684 & 0.748 & 0.440 & 0.496 & 0.568 & 0.626 & & & 0.518 & 0.623 & 0.734 & 0.851 & 0.576 & 0.746 & 0.868 & 0.960 \\
\hline 100 & 5 & $20 \%$ & 0.471 & 0.502 & 0.580 & 0.638 & 0.385 & 0.421 & 0.487 & 0.539 & & & 0.457 & 0.540 & 0.626 & 0.715 & 0.597 & 0.711 & 0.792 & 0.853 \\
\hline 100 & 5 & $25 \%$ & 0.486 & 0.522 & 0.604 & 0.666 & 0.400 & 0.441 & 0.510 & 0.565 & & & 0.479 & 0.571 & 0.666 & 0.766 & 0.617 & 0.731 & 0.812 & 0.873 \\
\hline 100 & 5 & $33 \%$ & 0.511 & 0.557 & 0.644 & 0.713 & 0.425 & 0.473 & 0.546 & 0.607 & & & 0.518 & 0.623 & 0.734 & 0.851 & 0.650 & 0.764 & 0.846 & 0.907 \\
\hline 150 & 4 & $20 \%$ & 0.509 & 0.578 & 0.634 & 0.683 & 0.454 & 0.523 & 0.579 & 0.630 & & & 0.440 & 0.519 & 0.602 & 0.687 & 0.500 & 0.666 & 0.788 & 0.880 \\
\hline 150 & 4 & $25 \%$ & 0.525 & 0.596 & 0.654 & 0.707 & 0.471 & 0.542 & 0.601 & 0.655 & & & 0.462 & 0.549 & 0.641 & 0.736 & 0.526 & 0.696 & 0.818 & 0.910 \\
\hline 150 & 4 & $33 \%$ & 0.551 & 0.626 & 0.688 & 0.746 & 0.499 & 0.574 & 0.638 & 0.696 & & & 0.498 & 0.599 & 0.706 & 0.818 & 0.576 & 0.746 & 0.868 & 0.960 \\
\hline 150 & 5 & $20 \%$ & 0.485 & 0.539 & 0.588 & 0.637 & 0.440 & 0.496 & 0.547 & 0.597 & & & 0.440 & 0.519 & 0.602 & 0.687 & 0.597 & 0.711 & 0.792 & 0.853 \\
\hline 150 & 5 & $25 \%$ & 0.498 & 0.554 & 0.607 & 0.660 & 0.455 & 0.513 & 0.568 & 0.621 & & & 0.462 & 0.549 & 0.641 & 0.736 & 0.617 & 0.731 & 0.812 & 0.873 \\
\hline 150 & 5 & $33 \%$ & 0.519 & 0.581 & 0.639 & 0.698 & 0.479 & 0.543 & 0.602 & 0.661 & & & 0.498 & 0.599 & 0.706 & 0.818 & 0.650 & 0.764 & 0.846 & 0.907 \\
\hline 200 & 4 & $20 \%$ & 0.513 & 0.588 & 0.648 & 0.699 & 0.476 & 0.550 & 0.611 & 0.664 & & & 0.442 & 0.522 & 0.605 & 0.691 & 0.500 & 0.666 & 0.788 & 0.880 \\
\hline 200 & 4 & $25 \%$ & 0.530 & 0.606 & 0.668 & 0.721 & 0.494 & 0.570 & 0.634 & 0.689 & & & 0.464 & 0.553 & 0.645 & 0.741 & 0.526 & 0.696 & 0.818 & 0.910 \\
\hline 200 & 4 & $33 \%$ & 0.557 & 0.636 & 0.701 & 0.758 & 0.523 & 0.604 & 0.671 & 0.730 & & & 0.501 & 0.603 & 0.710 & 0.823 & 0.576 & 0.746 & 0.868 & 0.960 \\
\hline 200 & 5 & $20 \%$ & 0.495 & 0.553 & 0.602 & 0.649 & 0.464 & 0.523 & 0.575 & 0.624 & & & 0.442 & 0.522 & 0.605 & 0.691 & 0.597 & 0.711 & 0.792 & 0.853 \\
\hline 200 & 5 & $25 \%$ & 0.508 & 0.568 & 0.620 & 0.670 & 0.479 & 0.541 & 0.596 & 0.648 & & & 0.464 & 0.553 & 0.645 & 0.741 & 0.617 & 0.731 & 0.812 & 0.873 \\
\hline 200 & 5 & $33 \%$ & 0.529 & 0.593 & 0.650 & 0.704 & 0.504 & 0.570 & 0.630 & 0.686 & & & 0.501 & 0.603 & 0.710 & 0.823 & 0.650 & 0.764 & 0.846 & 0.907 \\
\hline 250 & 4 & $20 \%$ & 0.514 & 0.592 & 0.654 & 0.707 & 0.480 & 0.558 & 0.620 & 0.675 & & & $0.444^{*}$ & $0.525^{*}$ & $0.608^{*}$ & 0.694 * & 0.500 & 0.666 & 0.788 & 0.880 \\
\hline 250 & 4 & $25 \%$ & 0.531 & 0.610 & 0.674 & 0.729 & 0.499 & 0.578 & 0.643 & 0.700 & & & $0.466^{*}$ & $0.555^{*}$ & $0.647^{*}$ & $0.744^{*}$ & 0.526 & 0.696 & 0.818 & 0.910 \\
\hline 250 & 4 & $33 \%$ & 0.558 & 0.641 & 0.708 & 0.766 & 0.529 & 0.612 & 0.681 & 0.742 & & & 0.503 * & $0.605^{*}$ & $0.713^{*}$ & $0.827^{*}$ & 0.576 & 0.746 & 0.868 & 0.960 \\
\hline 250 & 5 & $20 \%$ & 0.498 & 0.558 & 0.609 & 0.655 & 0.469 & 0.530 & 0.583 & 0.631 & & & $0.444^{*}$ & $0.525^{*}$ & $0.608^{*}$ & 0.694 * & 0.597 & 0.711 & 0.792 & 0.853 \\
\hline 250 & 5 & $25 \%$ & 0.511 & 0.573 & 0.626 & 0.675 & 0.484 & 0.548 & 0.603 & 0.655 & & & $0.466^{*}$ & $0.555^{*}$ & 0.647 * & $0.744 *$ & 0.617 & 0.731 & 0.812 & 0.873 \\
\hline 250 & 5 & $33 \%$ & 0.533 & 0.599 & 0.656 & 0.709 & 0.510 & 0.578 & 0.638 & 0.694 & & & $0.503^{*}$ & $0.605^{*}$ & $0.713^{*}$ & $0.827^{*}$ & 0.650 & 0.764 & 0.846 & 0.907 \\
\hline
\end{tabular}




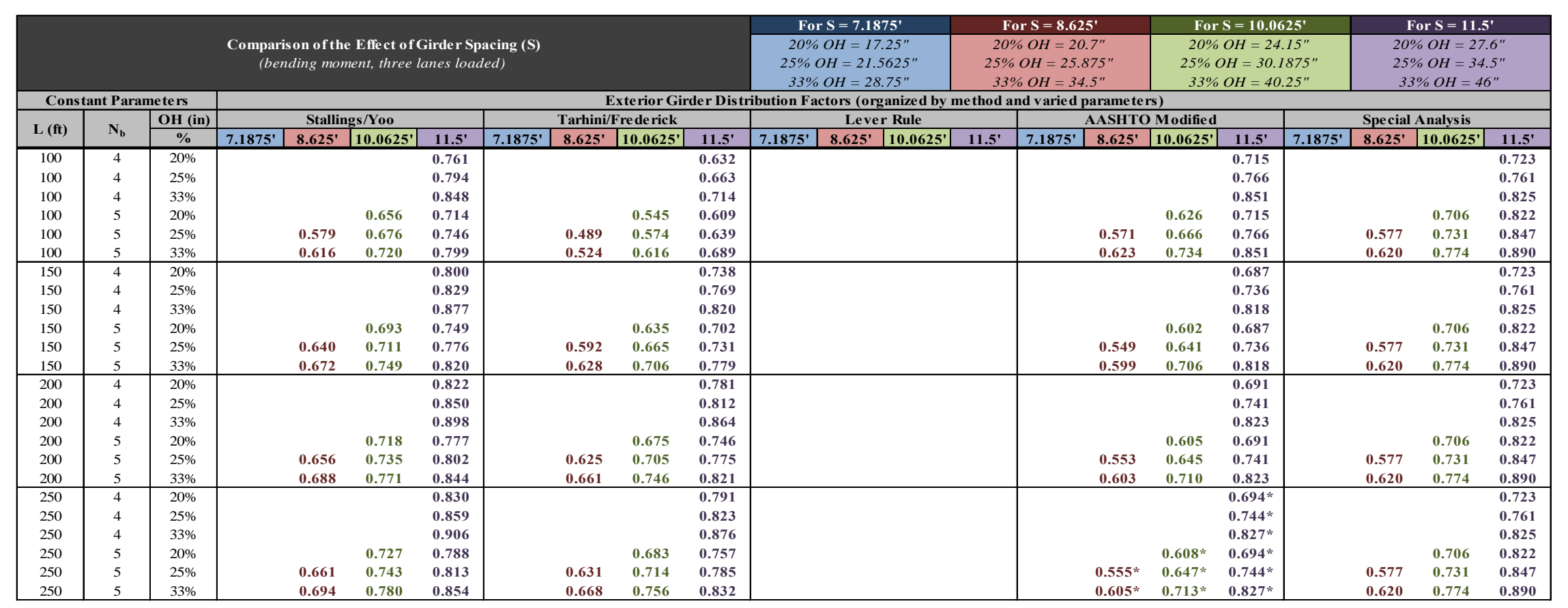




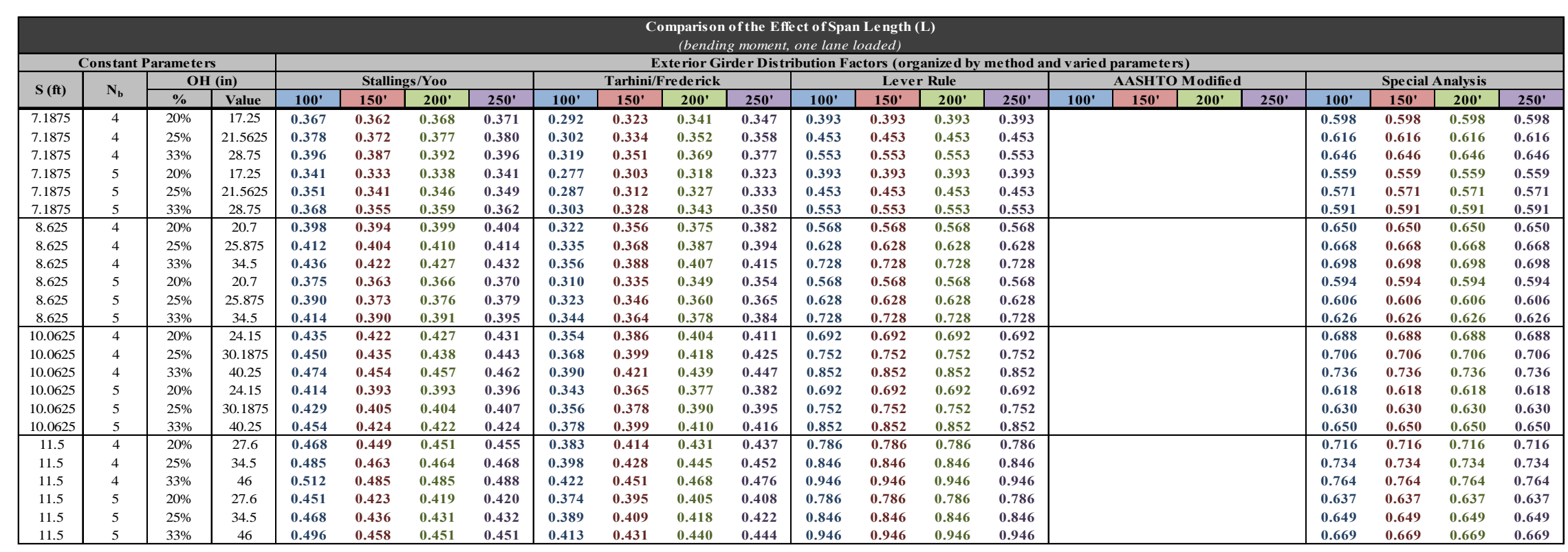

\begin{tabular}{|c|c|c|c|c|c|c|c|c|c|c|c|c|c|c|c|c|c|c|c|c|c|c|}
\hline & & & & & & & & & & $\begin{array}{l}\text { arise } \\
\text { bend }\end{array}$ & $\begin{array}{l}\text { the E, } \\
\text { noment }\end{array}$ & of $\mathrm{S}$ & eng & & & & & & & & & \\
\hline & nstar & iramet & & & & & & & & terior $\mathbf{G}$ & der Dist & oution & tors (o & inized by me thod & d variec & arametc & & & & & & \\
\hline & V. & & (in) & & Stalli & s/Yoo & & & Tarhini/ & ederick & & & Lev & Rule & & AASHT & Modifie & & & Specia & Analysis & \\
\hline$S$ (ft) & $N_{b}$ & $\%$ & Value & $100^{\prime}$ & $150^{\circ}$ & $200^{\prime}$ & $250^{\prime}$ & $100^{\prime}$ & $150^{\prime}$ & $200^{\prime}$ & $250^{\prime}$ & $100^{\prime}$ & $150^{\prime}$ & $200^{\prime}$ & $100^{\prime}$ & $150^{\prime}$ & $200^{\circ}$ & $250^{\prime}$ & $100^{\prime}$ & $150^{\prime}$ & $200^{\prime}$ & $250^{\prime}$ \\
\hline 7.1875 & 4 & $20 \%$ & 17.25 & 0.500 & 0.509 & 0.513 & 0.514 & 0.397 & 0.454 & 0.476 & 0.480 & & & & 0.457 & 0.440 & 0.442 & $0.444^{*}$ & 0.500 & 0.500 & 0.500 & 0.500 \\
\hline 7.1875 & 4 & $25 \%$ & 21.5625 & 0.517 & 0.525 & 0.530 & 0.531 & 0.413 & 0.471 & 0.494 & 0.499 & & & & 0.479 & 0.462 & 0.464 & $0.466^{*}$ & 0.526 & 0.526 & 0.526 & 0.526 \\
\hline 7.1875 & 4 & $33 \%$ & 28.75 & 0.545 & 0.551 & 0.557 & 0.558 & 0.440 & 0.499 & 0.523 & 0.529 & & & & 0.518 & 0.498 & 0.501 & $0.503^{*}$ & 0.576 & 0.576 & 0.576 & 0.576 \\
\hline 7.1875 & 5 & $20 \%$ & 17.25 & 0.471 & 0.485 & 0.495 & 0.498 & 0.385 & 0.440 & 0.464 & 0.469 & & & & 0.457 & 0.440 & 0.442 & $0.444^{*}$ & 0.597 & 0.597 & 0.597 & 0.597 \\
\hline 7.1875 & 5 & $25 \%$ & 21.5625 & 0.486 & 0.498 & 0.508 & 0.511 & 0.400 & 0.455 & 0.479 & 0.484 & & & & 0.479 & 0.462 & 0.464 & $0.466^{*}$ & 0.617 & 0.617 & 0.617 & 0.617 \\
\hline 7.1875 & 5 & $33 \%$ & 28.75 & 0.511 & 0.519 & 0.529 & 0.533 & 0.425 & 0.479 & 0.504 & 0.510 & & & & 0.518 & 0.498 & 0.501 & $0.503 *$ & 0.650 & 0.650 & 0.650 & 0.650 \\
\hline 8.625 & 4 & $20 \%$ & 20.7 & 0.541 & 0.578 & 0.588 & 0.592 & 0.443 & 0.523 & 0.550 & 0.558 & & & & 0.540 & 0.519 & 0.522 & $0.525^{*}$ & 0.666 & 0.666 & 0.666 & 0.666 \\
\hline 8.625 & 4 & $25 \%$ & 25.875 & 0.562 & 0.596 & 0.606 & 0.610 & 0.463 & 0.542 & 0.570 & 0.578 & & & & 0.571 & 0.549 & 0.553 & $0.555^{*}$ & 0.696 & 0.696 & 0.696 & 0.696 \\
\hline 8.625 & 4 & $33 \%$ & 34.5 & 0.597 & 0.626 & 0.636 & 0.641 & 0.496 & 0.574 & 0.604 & 0.612 & & & & 0.623 & 0.599 & 0.603 & $0.605^{*}$ & 0.746 & 0.746 & 0.746 & 0.746 \\
\hline 8.625 & 5 & $20 \%$ & 20.7 & 0.502 & 0.539 & 0.553 & 0.558 & 0.421 & 0.496 & 0.523 & 0.530 & & & & 0.540 & 0.519 & 0.522 & $0.525^{*}$ & 0.711 & 0.711 & 0.711 & 0.711 \\
\hline 8.625 & 5 & $25 \%$ & 25.875 & 0.522 & 0.554 & 0.568 & 0.573 & 0.441 & 0.513 & 0.541 & 0.548 & & & & 0.571 & 0.549 & 0.553 & $0.555^{*}$ & 0.731 & 0.731 & 0.731 & 0.731 \\
\hline 8.625 & 5 & $33 \%$ & 34.5 & 0.557 & 0.581 & 0.593 & 0.599 & 0.473 & 0.543 & 0.570 & 0.578 & & & & 0.623 & 0.599 & 0.603 & $0.605^{*}$ & 0.764 & 0.764 & 0.764 & 0.764 \\
\hline 10.0625 & 4 & $20 \%$ & 24.15 & 0.620 & 0.634 & 0.648 & 0.654 & 0.508 & 0.579 & 0.611 & 0.620 & & & & 0.626 & 0.602 & 0.605 & $0.608^{*}$ & 0.788 & 0.788 & 0.788 & 0.788 \\
\hline 10.0625 & 4 & $25 \%$ & 30.1875 & 0.644 & 0.654 & 0.668 & 0.674 & 0.531 & 0.601 & 0.634 & 0.643 & & & & 0.666 & 0.641 & 0.645 & 0.647 * & 0.818 & 0.818 & 0.818 & 0.818 \\
\hline 10.0625 & 4 & $33 \%$ & 40.25 & 0.684 & 0.688 & 0.701 & 0.708 & 0.568 & 0.638 & 0.671 & 0.681 & & & & 0.734 & 0.706 & 0.710 & 0.713* & 0.868 & 0.868 & 0.868 & 0.868 \\
\hline 10.0625 & 5 & $20 \%$ & 24.15 & 0.580 & 0.588 & 0.602 & 0.609 & 0.487 & 0.547 & 0.575 & 0.583 & & & & 0.626 & 0.602 & 0.605 & $0.608 *$ & 0.792 & 0.792 & 0.792 & 0.792 \\
\hline 10.0625 & 5 & $25 \%$ & 30.1875 & 0.604 & 0.607 & 0.620 & 0.626 & 0.510 & 0.568 & 0.596 & 0.603 & & & & 0.666 & 0.641 & 0.645 & $0.647^{*}$ & 0.812 & 0.812 & 0.812 & 0.812 \\
\hline 10.0625 & 5 & $33 \%$ & 40.25 & 0.644 & 0.639 & 0.650 & 0.656 & 0.546 & 0.602 & 0.630 & 0.638 & & & & 0.734 & 0.706 & 0.710 & $0.713^{*}$ & 0.846 & 0.846 & 0.846 & 0.846 \\
\hline 11.5 & 4 & $20 \%$ & 27.6 & 0.673 & 0.683 & 0.699 & 0.707 & 0.557 & 0.630 & 0.664 & 0.675 & & & & 0.715 & 0.687 & 0.691 & $0.694^{*}$ & 0.880 & 0.880 & 0.880 & 0.880 \\
\hline 11.5 & 4 & $25 \%$ & 34.5 & 0.701 & 0.707 & 0.721 & 0.729 & 0.583 & 0.655 & 0.689 & 0.700 & & & & 0.766 & 0.736 & 0.741 & $0.744^{*}$ & 0.910 & 0.910 & 0.910 & 0.910 \\
\hline 11.5 & 4 & $33 \%$ & 46 & 0.748 & 0.746 & 0.758 & 0.766 & 0.626 & 0.696 & 0.730 & 0.742 & & & & 0.851 & 0.818 & 0.823 & $0.827^{*}$ & 0.960 & 0.960 & 0.960 & 0.960 \\
\hline 11.5 & 5 & $20 \%$ & 27.6 & 0.638 & 0.637 & 0.649 & 0.655 & 0.539 & 0.597 & 0.624 & 0.631 & & & & 0.715 & 0.687 & 0.691 & & 0.853 & 0.853 & 0.853 & 0.853 \\
\hline 11.5 & 5 & $25 \%$ & 34.5 & 0.666 & 0.660 & 0.670 & 0.675 & 0.565 & 0.621 & 0.648 & 0.655 & & & & 0.766 & 0.736 & 0.741 & $0.744^{*}$ & 0.873 & 0.873 & 0.873 & 0.873 \\
\hline 11.5 & 5 & $33 \%$ & 46 & 0.713 & 0.698 & 0.704 & 0.709 & 0.607 & 0.661 & 0.686 & 0.694 & & & & 0.851 & 0.818 & 0.823 & $0.827 *$ & 0.907 & 0.907 & 0.907 & 0.907 \\
\hline
\end{tabular}




\begin{tabular}{|c|c|c|c|c|c|c|c|c|c|c|c|c|c|c|c|c|c|c|c|c|c|c|c|}
\hline \multicolumn{24}{|c|}{$\begin{array}{l}\text { Comparison of the Effect of Span Length (L) } \\
\text { (bending moment, three lanes loaded) }\end{array}$} \\
\hline \multicolumn{4}{|c|}{ Constant Parameters } & \multicolumn{20}{|c|}{ Exte rior Girder Distribution Factors (organized by method and varied parame ters) } \\
\hline \multirow{2}{*}{$\mathbf{S}$ (ft) } & \multirow{2}{*}{$\mathbf{N}_{\mathrm{b}}$} & \multicolumn{2}{|c|}{ OH (in) } & \multicolumn{4}{|c|}{ Stallings/Yoo } & \multicolumn{4}{|c|}{ Tarhini/Frederick } & \multicolumn{4}{|c|}{ Lever Rule } & \multicolumn{4}{|c|}{ AASHTO Modified } & \multicolumn{4}{|c|}{ Special Analysis } \\
\hline & & $\%$ & Value & $100^{\prime}$ & $150^{\prime}$ & $200^{\prime}$ & $250^{\prime}$ & $100^{\prime}$ & $150^{\prime}$ & $200^{\prime}$ & $250^{\prime}$ & $100^{\prime}$ & $150^{\prime}$ & $200^{\prime}$ & $250^{\prime}$ & $100^{\prime}$ & $150^{\prime}$ & $200^{\circ}$ & $250^{\circ}$ & $100^{\prime}$ & $150^{\prime}$ & $200^{\circ}$ & $250^{\circ}$ \\
\hline 7.1875 & 4 & $20 \%$ & 217.25 & & & & & & & & & & & & & & & & & & & & \\
\hline 7.1875 & 4 & $25 \%$ & 21.5625 & & & & & & & & & & & & & & & & & & & & \\
\hline 7.1875 & 4 & $33 \%$ & 28.75 & & & & & & & & & & & & & & & & & & & & \\
\hline 7.1875 & 5 & $20 \%$ & 17.25 & & & & & & & & & & & & & & & & & & & & \\
\hline 7.1875 & 5 & $25 \%$ & 21.5625 & & & & & & & & & & & & & & & & & & & & \\
\hline 7.1875 & 5 & $33 \%$ & 28.75 & & & & & & & & & & & & & & & & & & & & \\
\hline 8.625 & 4 & $20 \%$ & 20.7 & & & & & & & & & & & & & & & & & & & & \\
\hline 8.625 & 4 & $25 \%$ & 25.875 & & & & & & & & & & & & & & & & & & & & \\
\hline 8.625 & 4 & $33 \%$ & 34.5 & & & & & & & & & & & & & & & & & & & & \\
\hline 8.625 & 5 & $20 \%$ & 20.7 & & & & & & & & & & & & & & & & & & & & \\
\hline 8.625 & 5 & $25 \%$ & 25.875 & 0.579 & 0.640 & 0.656 & 0.661 & 0.489 & 0.592 & 0.625 & 0.631 & & & & & 0.571 & 0.549 & 0.553 & $0.555^{*}$ & 0.577 & 0.577 & 0.577 & 0.577 \\
\hline 8.625 & 5 & $33 \%$ & 34.5 & 0.616 & 0.672 & 0.688 & 0.694 & 0.524 & 0.628 & 0.661 & 0.668 & & & & & 0.623 & 0.599 & 0.603 & $0.605^{*}$ & 0.620 & 0.620 & 0.620 & 0.620 \\
\hline 10.0625 & 4 & $20 \%$ & 24.15 & & & & & & & & & & & & & & & & & & & & \\
\hline 10.0625 & 4 & $25 \%$ & 30.1875 & & & & & & & & & & & & & & & & & & & & \\
\hline 10.0625 & 4 & $33 \%$ & 40.25 & & & & & & & & & & & & & & & & & & & & \\
\hline 10.0625 & 5 & $20 \%$ & 24.15 & 0.656 & 0.693 & 0.718 & 0.727 & 0.545 & 0.635 & 0.675 & 0.683 & & & & & 0.626 & 0.602 & 0.605 & $0.608^{*}$ & 0.706 & 0.706 & 0.706 & 0.706 \\
\hline 10.0625 & 5 & $25 \%$ & 30.1875 & 0.676 & 0.711 & 0.735 & 0.743 & 0.574 & 0.665 & 0.705 & 0.714 & & & & & 0.666 & 0.641 & 0.645 & $0.647^{*}$ & 0.731 & 0.731 & 0.731 & 0.731 \\
\hline 10.0625 & 5 & $33 \%$ & 40.25 & 0.720 & 0.749 & 0.771 & 0.780 & 0.616 & 0.706 & 0.746 & 0.756 & & & & & 0.734 & 0.706 & 0.710 & $0.713^{*}$ & 0.774 & 0.774 & 0.774 & 0.774 \\
\hline 11.5 & 4 & $20 \%$ & 27.6 & 0.761 & 0.800 & 0.822 & 0.830 & 0.632 & 0.738 & 0.781 & 0.791 & & & & & 0.715 & 0.687 & 0.691 & $0.694 *$ & 0.723 & 0.723 & 0.723 & 0.723 \\
\hline 11.5 & 4 & $25 \%$ & 34.5 & 0.794 & 0.829 & 0.850 & 0.859 & 0.663 & 0.769 & 0.812 & 0.823 & & & & & 0.766 & 0.736 & 0.741 & $0.744^{*}$ & 0.761 & 0.761 & 0.761 & 0.761 \\
\hline 11.5 & 4 & $33 \%$ & 46 & 0.848 & 0.877 & 0.898 & 0.906 & 0.714 & 0.820 & 0.864 & 0.876 & & & & & 0.851 & 0.818 & 0.823 & $0.827^{*}$ & 0.825 & 0.825 & 0.825 & 0.825 \\
\hline 11.5 & 5 & $20 \%$ & 27.6 & 0.714 & 0.749 & 0.777 & 0.788 & 0.609 & 0.702 & 0.746 & 0.757 & & & & & 0.715 & 0.687 & 0.691 & 0.694* & 0.822 & 0.822 & 0.822 & 0.822 \\
\hline 11.5 & 5 & $25 \%$ & 34.5 & 0.746 & 0.776 & 0.802 & 0.813 & 0.639 & 0.731 & 0.775 & 0.785 & & & & & 0.766 & 0.736 & 0.741 & $0.744^{*}$ & 0.847 & 0.847 & 0.847 & 0.847 \\
\hline 11.5 & 5 & $33 \%$ & 46 & 0.799 & 0.820 & 0.844 & 0.854 & 0.689 & 0.779 & 0.821 & 0.832 & & & & & 0.851 & 0.818 & 0.823 & $0.827^{*}$ & 0.890 & 0.890 & 0.890 & 0.890 \\
\hline
\end{tabular}

\begin{tabular}{|c|c|c|c|c|c|c|c|c|c|c|c|c|c|c|c|c|c|c|c|c|c|c|}
\hline \multicolumn{23}{|c|}{$\begin{array}{l}\text { Comparison of the Effie ct of Span Length (L) } \\
\text { (bending moment, four lanes loaded) }\end{array}$} \\
\hline \multicolumn{4}{|c|}{ Constant Parameters } & \multicolumn{19}{|c|}{ Exte rior Girder D is tribution Factors (organized by me thod and varied parame te rs) } \\
\hline \multirow{2}{*}{$\mathrm{S}$ (ft) } & \multirow{2}{*}{$\mathbf{N}_{\mathrm{b}}$} & \multicolumn{2}{|c|}{ OH (in) } & \multicolumn{4}{|c|}{ Stallings/Yoo } & \multicolumn{4}{|c|}{ Tarhini/Frede rick } & \multicolumn{3}{|c|}{ Lever Rule } & \multicolumn{4}{|c|}{\begin{tabular}{|c|c|c|} 
AASHTO Modified \\
\end{tabular}} & \multicolumn{4}{|c|}{ Special Analysis } \\
\hline & & $\%$ & Value & $100^{\prime}$ & $150^{\circ}$ & $200^{\prime}$ & $250^{\prime}$ & $100^{\prime}$ & $150^{\prime}$ & $200^{\prime}$ & $250^{\prime}$ & $100^{\prime}$ & $150^{\prime}$ & \begin{tabular}{|l|l}
$200^{\prime}$ & 1 \\
\end{tabular} & $100^{\prime}$ & $150^{\prime}$ & $\mathbf{2 0 0 ^ { \circ }}$ & $250^{\prime}$ & $100^{\prime}$ & $150^{\prime}$ & $200^{\prime}$ & $250^{\prime}$ \\
\hline 7.1875 & 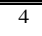 & $20 \%$ & 17.25 & & & & & & & & & & & & & & & & & & & \\
\hline 7.1875 & 4 & $25 \%$ & 21.5625 & & & & & & & & & & & & & & & & & & & \\
\hline 7.1875 & 4 & $33 \%$ & 28.75 & & & & & & & & & & & & & & & & & & & \\
\hline 7.1875 & 5 & $20 \%$ & 17.25 & & & & & & & & & & & & & & & & & & & \\
\hline 7.1875 & 5 & $25 \%$ & 21.5625 & & & & & & & & & & & & & & & & & & & \\
\hline 7.1875 & 5 & $33 \%$ & 28.75 & & & & & & & & & & & & & & & & & & & \\
\hline 8.625 & 4 & $20 \%$ & 20.7 & & & & & & & & & & & & & & & & & & & \\
\hline 8.625 & 4 & $25 \%$ & 25.875 & & & & & & & & & & & & & & & & & & & \\
\hline 8.625 & 4 & $33 \%$ & 34.5 & & & & & & & & & & & & & & & & & & & \\
\hline 8.625 & 5 & $20 \%$ & 20.7 & & & & & & & & & & & & & & & & & & & \\
\hline 8.625 & 5 & $25 \%$ & 25.875 & & & & & & & & & & & & & & & & & & & \\
\hline 8.625 & 5 & $33 \%$ & 34.5 & & & & & & & & & & & & & & & & & & & \\
\hline 10.0625 & 4 & $20 \%$ & 24.15 & & & & & & & & & & & & & & & & & & & \\
\hline 10.0625 & 4 & $25 \%$ & 30.1875 & & & & & & & & & & & & & & & & & & & \\
\hline 10.0625 & 4 & $33 \%$ & 40.25 & & & & & & & & & & & & & & & & & & & \\
\hline 10.0625 & 5 & $20 \%$ & 24.15 & & & & & & & & & & & & & & & & & & & \\
\hline 10.0625 & 5 & $25 \%$ & 30.1875 & & & & & & & & & & & & & & & & & & & \\
\hline 10.0625 & 5 & $33 \%$ & 40.25 & & & & & & & & & & & & & & & & & & & \\
\hline $\begin{array}{l}11.5 \\
\end{array}$ & 4 & $20 \%$ & 27.6 & & & & & & & & & & & & & & & & & & & \\
\hline 11.5 & 4 & $25 \%$ & 34.5 & & & & & & & & & & & & & & & & & & & \\
\hline 11.5 & 4 & $33 \%$ & 46 & & & & & & & & & & & & & & & & & & & \\
\hline 11.5 & 5 & $20 \%$ & 27.6 & 0.754 & 0.811 & 0.844 & 0.856 & 0.644 & 0.761 & 0.811 & 0.822 & & & & 0.715 & 0.687 & 0.691 & $0.694^{*}$ & 0.567 & 0.567 & 0.567 & 0.567 \\
\hline 11.5 & 5 & $25 \%$ & 34.5 & 0.787 & 0.840 & 0.872 & 0.884 & 0.676 & 0.792 & 0.842 & 0.854 & & & & 0.766 & 0.736 & 0.741 & $0.744^{*}$ & 0.593 & 0.593 & 0.593 & 0.593 \\
\hline 11.5 & 5 & $33 \%$ & 46 & 0.843 & 0.889 & 0.920 & 0.932 & 0.729 & 0.845 & 0.895 & 0.907 & & & & 0.851 & 0.818 & 0.823 & $0.827^{*}$ & 0.636 & 0.636 & 0.636 & 0.636 \\
\hline
\end{tabular}




\begin{tabular}{|c|c|c|c|c|c|c|c|c|c|c|c|c|c|}
\hline \multicolumn{14}{|c|}{$\begin{array}{l}\text { Comparis on of the Effect of the Number of Girders }\left(\mathbf{N}_{\mathbf{b}}\right) \\
\text { (bending moment, one lane loaded) }\end{array}$} \\
\hline \multicolumn{4}{|c|}{ Constant Parameters } & \multicolumn{10}{|c|}{ Exte rior Girder Dis tribution Factors (organized by me thod and $v$ aried parame ters) } \\
\hline \multirow{2}{*}{ L (ft) } & \multirow{2}{*}{$S$ (ft) } & \multicolumn{2}{|c|}{ OH (in) } & \multicolumn{2}{|c|}{ Stallings/Yoo } & \multicolumn{2}{|c|}{ Tarhini/Frederick } & \multicolumn{2}{|c|}{ Lever Rule } & \multicolumn{2}{|c|}{ AASHTO Mod. } & \multicolumn{2}{|c|}{ Special Analys is } \\
\hline & & $\%$ & Value & 4 & 5 & 4 & 5 & 4 & 5 & 4 & 5 & 4 & 5 \\
\hline 100 & 7.1875 & $20 \%$ & 17.25 & 0.367 & 0.341 & 0.292 & 0.277 & 0.393 & 0.393 & & & 0.598 & 0.559 \\
\hline 100 & 7.1875 & $25 \%$ & 21.5625 & 0.378 & 0.351 & 0.302 & 0.287 & 0.453 & 0.453 & & & 0.616 & 0.571 \\
\hline 100 & 7.1875 & $33 \%$ & 28.75 & 0.396 & 0.368 & 0.319 & 0.303 & 0.553 & 0.553 & & & 0.646 & 0.591 \\
\hline 100 & 8.625 & $20 \%$ & 20.7 & 0.398 & 0.375 & 0.322 & 0.310 & 0.568 & 0.568 & & & 0.650 & 0.594 \\
\hline 100 & 8.625 & $25 \%$ & 25.875 & 0.412 & 0.390 & 0.335 & 0.323 & 0.628 & 0.628 & & & 0.668 & 0.606 \\
\hline 100 & 8.625 & $33 \%$ & 34.5 & 0.436 & 0.414 & 0.356 & 0.344 & 0.728 & 0.728 & & & 0.698 & 0.626 \\
\hline 100 & 10.0625 & $20 \%$ & 24.15 & 0.435 & 0.414 & 0.354 & 0.343 & 0.692 & 0.692 & & & 0.688 & 0.618 \\
\hline 100 & 10.0625 & $25 \%$ & 30.1875 & 0.450 & 0.429 & 0.368 & 0.356 & 0.752 & 0.752 & & & 0.706 & 0.630 \\
\hline 100 & 10.0625 & $33 \%$ & 40.25 & 0.474 & 0.454 & 0.390 & 0.378 & 0.852 & 0.852 & & & 0.736 & 0.650 \\
\hline 100 & 11.5 & $20 \%$ & 27.6 & 0.468 & 0.451 & 0.383 & 0.374 & 0.786 & 0.786 & & & 0.716 & 0.637 \\
\hline 100 & 11.5 & $25 \%$ & 34.5 & 0.485 & 0.468 & 0.398 & 0.389 & 0.846 & 0.846 & & & 0.734 & 0.649 \\
\hline 100 & 11.5 & $33 \%$ & 46 & 0.512 & 0.496 & 0.422 & 0.413 & 0.946 & 0.946 & & & 0.764 & 0.669 \\
\hline 150 & 7.1875 & $20 \%$ & 17.25 & 0.362 & 0.333 & 0.323 & 0.303 & 0.393 & 0.393 & & & 0.598 & 0.559 \\
\hline 150 & 7.1875 & $25 \%$ & 21.5625 & 0.372 & 0.341 & 0.334 & 0.312 & 0.453 & 0.453 & & & 0.616 & 0.571 \\
\hline 150 & 7.1875 & $33 \%$ & 28.75 & 0.387 & 0.355 & 0.351 & 0.328 & 0.553 & 0.553 & & & 0.646 & 0.591 \\
\hline 150 & 8.625 & $20 \%$ & 20.7 & 0.394 & 0.363 & 0.356 & 0.335 & 0.568 & 0.568 & & & 0.650 & 0.594 \\
\hline 150 & 8.625 & $25 \%$ & 25.875 & 0.404 & 0.373 & 0.368 & 0.346 & 0.628 & 0.628 & & & 0.668 & 0.606 \\
\hline 150 & 8.625 & $33 \%$ & 34.5 & 0.422 & 0.390 & 0.388 & 0.364 & 0.728 & 0.728 & & & 0.698 & 0.626 \\
\hline 150 & 10.0625 & $20 \%$ & 24.15 & 0.422 & 0.393 & 0.386 & 0.365 & 0.692 & 0.692 & & & 0.688 & 0.618 \\
\hline 150 & 10.0625 & $25 \%$ & 30.1875 & 0.435 & 0.405 & 0.399 & 0.378 & 0.752 & 0.752 & & & 0.706 & 0.630 \\
\hline 150 & 10.0625 & $33 \%$ & 40.25 & 0.454 & 0.424 & 0.421 & 0.399 & 0.852 & 0.852 & & & 0.736 & 0.650 \\
\hline 150 & 11.5 & $20 \%$ & 27.6 & 0.449 & 0.423 & 0.414 & 0.395 & 0.786 & 0.786 & & & 0.716 & 0.637 \\
\hline 150 & 11.5 & $25 \%$ & 34.5 & 0.463 & 0.436 & 0.428 & 0.409 & 0.846 & 0.846 & & & 0.734 & 0.649 \\
\hline 150 & 11.5 & $33 \%$ & 46 & 0.485 & 0.458 & 0.451 & 0.431 & 0.946 & 0.946 & & & 0.764 & 0.669 \\
\hline 200 & 7.1875 & $20 \%$ & 17.25 & 0.368 & 0.338 & 0.341 & 0.318 & 0.393 & 0.393 & & & 0.598 & 0.559 \\
\hline 200 & 7.1875 & $25 \%$ & 21.5625 & 0.377 & 0.346 & 0.352 & 0.327 & 0.453 & 0.453 & & & 0.616 & 0.571 \\
\hline 200 & 7.1875 & $33 \%$ & 28.75 & 0.392 & 0.359 & 0.369 & 0.343 & 0.553 & 0.553 & & & 0.646 & 0.591 \\
\hline 200 & 8.625 & $20 \%$ & 20.7 & 0.399 & 0.366 & 0.375 & 0.349 & 0.568 & 0.568 & & & 0.650 & 0.594 \\
\hline 200 & 8.625 & $25 \%$ & 25.875 & 0.410 & 0.376 & 0.387 & 0.360 & 0.628 & 0.628 & & & 0.668 & 0.606 \\
\hline 200 & 8.625 & $33 \%$ & 34.5 & 0.427 & 0.391 & 0.407 & 0.378 & 0.728 & 0.728 & & & 0.698 & 0.626 \\
\hline 200 & 10.0625 & $20 \%$ & 24.15 & 0.427 & 0.393 & 0.404 & 0.377 & 0.692 & 0.692 & & & 0.688 & 0.618 \\
\hline 200 & 10.0625 & $25 \%$ & 30.1875 & 0.438 & 0.404 & 0.418 & 0.390 & 0.752 & 0.752 & & & 0.706 & 0.630 \\
\hline 200 & 10.0625 & $33 \%$ & 40.25 & 0.457 & 0.422 & 0.439 & 0.410 & 0.852 & 0.852 & & & 0.736 & 0.650 \\
\hline 200 & 11.5 & $20 \%$ & 27.6 & 0.451 & 0.419 & 0.431 & 0.405 & 0.786 & 0.786 & & & 0.716 & 0.637 \\
\hline 200 & 11.5 & $25 \%$ & 34.5 & 0.464 & 0.431 & 0.445 & 0.418 & 0.846 & 0.846 & & & 0.734 & 0.649 \\
\hline 200 & 11.5 & $33 \%$ & 46 & 0.485 & 0.451 & 0.468 & 0.440 & 0.946 & 0.946 & & & 0.764 & 0.669 \\
\hline 250 & 7.1875 & $20 \%$ & 17.25 & 0.371 & 0.341 & 0.347 & 0.323 & 0.393 & 0.393 & & & 0.598 & 0.559 \\
\hline 250 & 7.1875 & $25 \%$ & 21.5625 & 0.380 & 0.349 & 0.358 & 0.333 & 0.453 & 0.453 & & & 0.616 & 0.571 \\
\hline 250 & 7.1875 & $33 \%$ & 28.75 & 0.396 & 0.362 & 0.377 & 0.350 & 0.553 & 0.553 & & & 0.646 & 0.591 \\
\hline 250 & 8.625 & $20 \%$ & 20.7 & 0.404 & 0.370 & 0.382 & 0.354 & 0.568 & 0.568 & & & 0.650 & 0.594 \\
\hline 250 & 8.625 & $25 \%$ & 25.875 & 0.414 & 0.379 & 0.394 & 0.365 & 0.628 & 0.628 & & & 0.668 & 0.606 \\
\hline 250 & 8.625 & $33 \%$ & 34.5 & 0.432 & 0.395 & 0.415 & 0.384 & 0.728 & 0.728 & & & 0.698 & 0.626 \\
\hline 250 & 10.0625 & $20 \%$ & 24.15 & 0.431 & 0.396 & 0.411 & 0.382 & 0.692 & 0.692 & & & 0.688 & 0.618 \\
\hline 250 & 10.0625 & $25 \%$ & 30.1875 & 0.443 & 0.407 & 0.425 & 0.395 & 0.752 & 0.752 & & & 0.706 & 0.630 \\
\hline 250 & 10.0625 & $33 \%$ & 40.25 & 0.462 & 0.424 & 0.447 & 0.416 & 0.852 & 0.852 & & & 0.736 & 0.650 \\
\hline 250 & 11.5 & $20 \%$ & 27.6 & 0.455 & 0.420 & 0.437 & 0.408 & 0.786 & 0.786 & & & 0.716 & 0.637 \\
\hline 250 & 11.5 & $25 \%$ & 34.5 & 0.468 & 0.432 & 0.452 & 0.422 & 0.846 & 0.846 & & & 0.734 & 0.649 \\
\hline 250 & 11.5 & $33 \%$ & 46 & 0.488 & 0.451 & 0.476 & 0.444 & 0.946 & 0.946 & & & 0.764 & 0.669 \\
\hline
\end{tabular}




\begin{tabular}{|c|c|c|c|c|c|c|c|c|c|c|c|c|c|}
\hline \multicolumn{14}{|c|}{$\begin{array}{l}\text { Comparis on of the Effect of the Number of Girders }\left(\mathbf{N}_{\mathbf{b}}\right) \\
\text { (bending moment, two lanes loaded) }\end{array}$} \\
\hline \multicolumn{4}{|c|}{ Constant Parame ters } & \multicolumn{10}{|c|}{ Exte rior Girder Dis tribution Factors (organized by me thod and varied parame ters) } \\
\hline \multirow{2}{*}{$\mathbf{L}(\mathbf{f t})$} & \multirow{2}{*}{$\mathbf{S}(\mathbf{f t})$} & \multicolumn{2}{|c|}{ OH (in) } & \multicolumn{2}{|c|}{ Stallings/Yoo } & \multicolumn{2}{|c|}{ Tarhini/Frederick } & \multicolumn{2}{|c|}{ Lever Rule } & \multicolumn{2}{|c|}{ AASHTO Mod. } & \multicolumn{2}{|c|}{ Special Analysis } \\
\hline & & $\%$ & Value & 4 & 5 & 4 & 5 & 4 & 5 & 4 & 5 & 4 & 5 \\
\hline 100 & 7.1875 & $20 \%$ & 17.25 & 0.500 & 0.471 & 0.397 & 0.385 & & & 0.457 & 0.457 & 0.500 & 0.597 \\
\hline 100 & 7.1875 & $25 \%$ & 21.5625 & 0.517 & 0.486 & 0.413 & 0.400 & & & 0.479 & 0.479 & 0.526 & 0.617 \\
\hline 100 & 7.1875 & $33 \%$ & 28.75 & 0.545 & 0.511 & 0.440 & 0.425 & & & 0.518 & 0.518 & 0.576 & 0.650 \\
\hline 100 & 8.625 & $20 \%$ & 20.7 & 0.541 & 0.502 & 0.443 & 0.421 & & & 0.540 & 0.540 & 0.666 & 0.711 \\
\hline 100 & 8.625 & $25 \%$ & 25.875 & 0.562 & 0.522 & 0.463 & 0.441 & & & 0.571 & 0.571 & 0.696 & 0.731 \\
\hline 100 & 8.625 & $33 \%$ & 34.5 & 0.597 & 0.557 & 0.496 & 0.473 & & & 0.623 & 0.623 & 0.746 & 0.764 \\
\hline 100 & 10.0625 & $20 \%$ & 24.15 & 0.620 & 0.580 & 0.508 & 0.487 & & & 0.626 & 0.626 & 0.788 & 0.792 \\
\hline 100 & 10.0625 & $25 \%$ & 30.1875 & 0.644 & 0.604 & 0.531 & 0.510 & & & 0.666 & 0.666 & 0.818 & 0.812 \\
\hline 100 & 10.0625 & $33 \%$ & 40.25 & 0.684 & 0.644 & 0.568 & 0.546 & & & 0.734 & 0.734 & 0.868 & 0.846 \\
\hline 100 & 11.5 & $20 \%$ & 27.6 & 0.673 & 0.638 & 0.557 & 0.539 & & & 0.715 & 0.715 & 0.880 & 0.853 \\
\hline 100 & 11.5 & $25 \%$ & 34.5 & 0.701 & 0.666 & 0.583 & 0.565 & & & 0.766 & 0.766 & 0.910 & 0.873 \\
\hline 100 & 11.5 & $33 \%$ & 46 & 0.748 & 0.713 & 0.626 & 0.607 & & & 0.851 & 0.851 & 0.960 & 0.907 \\
\hline 150 & 7.1875 & $20 \%$ & 17.25 & 0.509 & 0.485 & 0.454 & 0.440 & & & 0.440 & 0.440 & 0.500 & 0.597 \\
\hline 150 & 7.1875 & $25 \%$ & 21.5625 & 0.525 & 0.498 & 0.471 & 0.455 & & & 0.462 & 0.462 & 0.526 & 0.617 \\
\hline 150 & 7.1875 & $33 \%$ & 28.75 & 0.551 & 0.519 & 0.499 & 0.479 & & & 0.498 & 0.498 & 0.576 & 0.650 \\
\hline 150 & 8.625 & $20 \%$ & 20.7 & 0.578 & 0.539 & 0.523 & 0.496 & & & 0.519 & 0.519 & 0.666 & 0.711 \\
\hline 150 & 8.625 & $25 \%$ & 25.875 & 0.596 & 0.554 & 0.542 & 0.513 & & & 0.549 & 0.549 & 0.696 & 0.731 \\
\hline 150 & 8.625 & $33 \%$ & 34.5 & 0.626 & 0.581 & 0.574 & 0.543 & & & 0.599 & 0.599 & 0.746 & 0.764 \\
\hline 150 & 10.0625 & $20 \%$ & 24.15 & 0.634 & 0.588 & 0.579 & 0.547 & & & 0.602 & 0.602 & 0.788 & 0.792 \\
\hline 150 & 10.0625 & $25 \%$ & 30.1875 & 0.654 & 0.607 & 0.601 & 0.568 & & & 0.641 & 0.641 & 0.818 & 0.812 \\
\hline 150 & 10.0625 & $33 \%$ & 40.25 & 0.688 & 0.639 & 0.638 & 0.602 & & & 0.706 & 0.706 & 0.868 & 0.846 \\
\hline 150 & 11.5 & $20 \%$ & 27.6 & 0.683 & 0.637 & 0.630 & 0.597 & & & 0.687 & 0.687 & 0.880 & 0.853 \\
\hline 150 & 11.5 & $25 \%$ & 34.5 & 0.707 & 0.660 & 0.655 & 0.621 & & & 0.736 & 0.736 & 0.910 & 0.873 \\
\hline 150 & 11.5 & $33 \%$ & 46 & 0.746 & 0.698 & 0.696 & 0.661 & & & 0.818 & 0.818 & 0.960 & 0.907 \\
\hline 200 & 7.1875 & $20 \%$ & 17.25 & 0.513 & 0.495 & 0.476 & 0.464 & & & 0.442 & 0.442 & 0.500 & 0.597 \\
\hline 200 & 7.1875 & $25 \%$ & 21.5625 & 0.530 & 0.508 & 0.494 & 0.479 & & & 0.464 & 0.464 & 0.526 & 0.617 \\
\hline 200 & 7.1875 & $33 \%$ & 28.75 & 0.557 & 0.529 & 0.523 & 0.504 & & & 0.501 & 0.501 & 0.576 & 0.650 \\
\hline 200 & 8.625 & $20 \%$ & 20.7 & 0.588 & 0.553 & 0.550 & 0.523 & & & 0.522 & 0.522 & 0.666 & 0.711 \\
\hline 200 & 8.625 & $25 \%$ & 25.875 & 0.606 & 0.568 & 0.570 & 0.541 & & & 0.553 & 0.553 & 0.696 & 0.731 \\
\hline 200 & 8.625 & $33 \%$ & 34.5 & 0.636 & 0.593 & 0.604 & 0.570 & & & 0.603 & 0.603 & 0.746 & 0.764 \\
\hline 200 & 10.0625 & $20 \%$ & 24.15 & 0.648 & 0.602 & 0.611 & 0.575 & & & 0.605 & 0.605 & 0.788 & 0.792 \\
\hline 200 & 10.0625 & $25 \%$ & 30.1875 & 0.668 & 0.620 & 0.634 & 0.596 & & & 0.645 & 0.645 & 0.818 & 0.812 \\
\hline 200 & 10.0625 & $33 \%$ & 40.25 & 0.701 & 0.650 & 0.671 & 0.630 & & & 0.710 & 0.710 & 0.868 & 0.846 \\
\hline 200 & 11.5 & $20 \%$ & 27.6 & 0.699 & 0.649 & 0.664 & 0.624 & & & 0.691 & 0.691 & 0.880 & 0.853 \\
\hline 200 & 11.5 & $25 \%$ & 34.5 & 0.721 & 0.670 & 0.689 & 0.648 & & & 0.741 & 0.741 & 0.910 & 0.873 \\
\hline 200 & 11.5 & $33 \%$ & 46 & 0.758 & 0.704 & 0.730 & 0.686 & & & 0.823 & 0.823 & 0.960 & 0.907 \\
\hline 250 & 7.1875 & $20 \%$ & 17.25 & 0.514 & 0.498 & 0.480 & 0.469 & & & $0.444 \%$ & $0.444 \%$ & 0.500 & 0.597 \\
\hline 250 & 7.1875 & $25 \%$ & 21.5625 & 0.531 & 0.511 & 0.499 & 0.484 & & & $0.466^{*}$ & $0.466 *$ & 0.526 & 0.617 \\
\hline 250 & 7.1875 & $33 \%$ & 28.75 & 0.558 & 0.533 & 0.529 & 0.510 & & & $0.503 *$ & $0.503 *$ & 0.576 & 0.650 \\
\hline 250 & 8.625 & $20 \%$ & 20.7 & 0.592 & 0.558 & 0.558 & 0.530 & & & $0.525 *$ & $0.525 *$ & 0.666 & 0.711 \\
\hline 250 & 8.625 & $25 \%$ & 25.875 & 0.610 & 0.573 & 0.578 & 0.548 & & & $0.555^{*}$ & $0.555 \%$ & 0.696 & 0.731 \\
\hline 250 & 8.625 & $33 \%$ & 34.5 & 0.641 & 0.599 & 0.612 & 0.578 & & & $0.605 \%$ & $0.605 \%$ & 0.746 & 0.764 \\
\hline 250 & 10.0625 & $20 \%$ & 24.15 & 0.654 & 0.609 & 0.620 & 0.583 & & & $0.608 *$ & $0.608 \%$ & 0.788 & 0.792 \\
\hline 250 & 10.0625 & $25 \%$ & 30.1875 & 0.674 & 0.626 & 0.643 & 0.603 & & & $0.647 *$ & 0.647 * & 0.818 & 0.812 \\
\hline 250 & 10.0625 & $33 \%$ & 40.25 & 0.708 & 0.656 & 0.681 & 0.638 & & & $0.713 *$ & $0.713 *$ & 0.868 & 0.846 \\
\hline 250 & 11.5 & $20 \%$ & 27.6 & 0.707 & 0.655 & 0.675 & 0.631 & & & $0.694 \%$ & $0.694 \%$ & 0.880 & 0.853 \\
\hline 250 & 11.5 & $25 \%$ & 34.5 & 0.729 & 0.675 & 0.700 & 0.655 & & & $0.744 *$ & $0.744 \%$ & 0.910 & 0.873 \\
\hline 250 & 11.5 & $33 \%$ & 46 & 0.766 & 0.709 & 0.742 & 0.694 & & & $0.827 *$ & $0.827 *$ & 0.960 & 0.907 \\
\hline
\end{tabular}




\begin{tabular}{|c|c|c|c|c|c|c|c|c|c|c|c|c|c|}
\hline \multicolumn{14}{|c|}{$\begin{array}{l}\text { Comparis on of the Effect of the Number of Girders }\left(\mathbf{N}_{\mathbf{b}}\right) \\
\text { (bending moment, three lanes loaded) }\end{array}$} \\
\hline \multicolumn{4}{|c|}{ Cons tant Parame ters } & \multicolumn{10}{|c|}{ Exte rior Girder Dis tribution Factors (organized by me thod and varied parame te rs) } \\
\hline \multirow{2}{*}{$\mathbf{L}(\mathbf{f t})$} & \multirow{2}{*}{$\mathbf{S}$ (ft) } & \multicolumn{2}{|c|}{ OH (in) } & \multicolumn{2}{|c|}{ Stallings/Yoo } & \multicolumn{2}{|c|}{ Tarhini/Frederick } & \multicolumn{2}{|c|}{ Lever Rule } & \multicolumn{2}{|c|}{ AASHTO Mod. } & \multicolumn{2}{|c|}{ Special Analysis } \\
\hline & & $\%$ & Value & 4 & 5 & 4 & 5 & 4 & 5 & 4 & 5 & 4 & 5 \\
\hline 100 & 7.1875 & $20 \%$ & 17.25 & & & & & & & & & & \\
\hline 100 & 7.1875 & $25 \%$ & 21.5625 & & & & & & & & & & \\
\hline 100 & 7.1875 & $33 \%$ & 28.75 & & & & & & & & & & \\
\hline 100 & 8.625 & $20 \%$ & 20.7 & & & & & & & & & & \\
\hline 100 & 8.625 & $25 \%$ & 25.875 & & 0.579 & & 0.489 & & & & 0.571 & & 0.577 \\
\hline 100 & 8.625 & $33 \%$ & 34.5 & & 0.616 & & 0.524 & & & & 0.623 & & 0.620 \\
\hline 100 & 10.0625 & $20 \%$ & 24.15 & & 0.656 & & 0.545 & & & & 0.626 & & 0.706 \\
\hline 100 & 10.0625 & $25 \%$ & 30.1875 & & 0.676 & & 0.574 & & & & 0.666 & & 0.731 \\
\hline 100 & 10.0625 & $33 \%$ & 40.25 & & 0.720 & & 0.616 & & & & 0.734 & & 0.774 \\
\hline 100 & 11.5 & $20 \%$ & 27.6 & 0.761 & 0.714 & 0.632 & 0.609 & & & 0.715 & 0.715 & 0.723 & 0.822 \\
\hline 100 & 11.5 & $25 \%$ & 34.5 & 0.794 & 0.746 & 0.663 & 0.639 & & & 0.766 & 0.766 & 0.761 & 0.847 \\
\hline 100 & 11.5 & $33 \%$ & 46 & 0.848 & 0.799 & 0.714 & 0.689 & & & 0.851 & 0.851 & 0.825 & 0.890 \\
\hline 150 & 7.1875 & $20 \%$ & 17.25 & & & & & & & & & & \\
\hline 150 & 7.1875 & $25 \%$ & 21.5625 & & & & & & & & & & \\
\hline 150 & 7.1875 & $33 \%$ & 28.75 & & & & & & & & & & \\
\hline 150 & 8.625 & $20 \%$ & 20.7 & & & & & & & & & & \\
\hline 150 & 8.625 & $25 \%$ & 25.875 & & 0.640 & & 0.592 & & & & 0.549 & & 0.577 \\
\hline 150 & 8.625 & $33 \%$ & 34.5 & & 0.672 & & 0.628 & & & & 0.599 & & 0.620 \\
\hline 150 & 10.0625 & $20 \%$ & 24.15 & & 0.693 & & 0.635 & & & & 0.602 & & 0.706 \\
\hline 150 & 10.0625 & $25 \%$ & 30.1875 & & 0.711 & & 0.665 & & & & 0.641 & & 0.731 \\
\hline 150 & 10.0625 & $33 \%$ & 40.25 & & 0.749 & & 0.706 & & & & 0.706 & & 0.774 \\
\hline 150 & 11.5 & $20 \%$ & 27.6 & 0.800 & 0.749 & 0.738 & 0.702 & & & 0.687 & 0.687 & 0.723 & 0.822 \\
\hline 150 & 11.5 & $25 \%$ & 34.5 & 0.829 & 0.776 & 0.769 & 0.731 & & & 0.736 & 0.736 & 0.761 & 0.847 \\
\hline 150 & 11.5 & $33 \%$ & 46 & 0.877 & 0.820 & 0.820 & 0.779 & & & 0.818 & 0.818 & 0.825 & 0.890 \\
\hline 200 & 7.1875 & $20 \%$ & 17.25 & & & & & & & & & & \\
\hline 200 & 7.1875 & $25 \%$ & 21.5625 & & & & & & & & & & \\
\hline 200 & 7.1875 & $33 \%$ & 28.75 & & & & & & & & & & \\
\hline 200 & 8.625 & $20 \%$ & 20.7 & & & & & & & & & & \\
\hline 200 & 8.625 & $25 \%$ & 25.875 & & 0.656 & & 0.625 & & & & 0.553 & & 0.577 \\
\hline 200 & 8.625 & $33 \%$ & 34.5 & & 0.688 & & 0.661 & & & & 0.603 & & 0.620 \\
\hline 200 & 10.0625 & $20 \%$ & 24.15 & & 0.718 & & 0.675 & & & & 0.605 & & 0.706 \\
\hline 200 & 10.0625 & $25 \%$ & 30.1875 & & 0.735 & & 0.705 & & & & 0.645 & & 0.731 \\
\hline 200 & 10.0625 & $33 \%$ & 40.25 & & 0.771 & & 0.746 & & & & 0.710 & & 0.774 \\
\hline 200 & 11.5 & $20 \%$ & 27.6 & 0.822 & 0.777 & 0.781 & 0.746 & & & 0.691 & 0.691 & 0.723 & 0.822 \\
\hline 200 & 11.5 & $25 \%$ & 34.5 & 0.850 & 0.802 & 0.812 & 0.775 & & & 0.741 & 0.741 & 0.761 & 0.847 \\
\hline 200 & 11.5 & $33 \%$ & 46 & 0.898 & 0.844 & 0.864 & 0.821 & & & 0.823 & 0.823 & 0.825 & 0.890 \\
\hline 250 & 7.1875 & $20 \%$ & 17.25 & & & & & & & & & & \\
\hline 250 & 7.1875 & $25 \%$ & 21.5625 & & & & & & & & & & \\
\hline 250 & 7.1875 & $33 \%$ & 28.75 & & & & & & & & & & \\
\hline 250 & 8.625 & $20 \%$ & 20.7 & & & & & & & & & & \\
\hline 250 & 8.625 & $25 \%$ & 25.875 & & 0.661 & & 0.631 & & & & $0.555^{*}$ & & 0.577 \\
\hline 250 & 8.625 & $33 \%$ & 34.5 & & 0.694 & & 0.668 & & & & $0.605 *$ & & 0.620 \\
\hline 250 & 10.0625 & $20 \%$ & 24.15 & & 0.727 & & 0.683 & & & & $0.608 *$ & & 0.706 \\
\hline 250 & 10.0625 & $25 \%$ & 30.1875 & & 0.743 & & 0.714 & & & & $0.647 *$ & & 0.731 \\
\hline 250 & 10.0625 & $33 \%$ & 40.25 & & 0.780 & & 0.756 & & & & $0.713 *$ & & 0.774 \\
\hline 250 & 11.5 & $20 \%$ & 27.6 & 0.830 & 0.788 & 0.791 & 0.757 & & & $0.694 \%$ & $0.694 \%$ & 0.723 & 0.822 \\
\hline 250 & 11.5 & $25 \%$ & 34.5 & 0.859 & 0.813 & 0.823 & 0.785 & & & $0.744 *$ & $0.744 *$ & 0.761 & 0.847 \\
\hline 250 & 11.5 & $33 \%$ & 46 & 0.906 & 0.854 & 0.876 & 0.832 & & & $0.827 *$ & $0.827 *$ & 0.825 & 0.890 \\
\hline
\end{tabular}




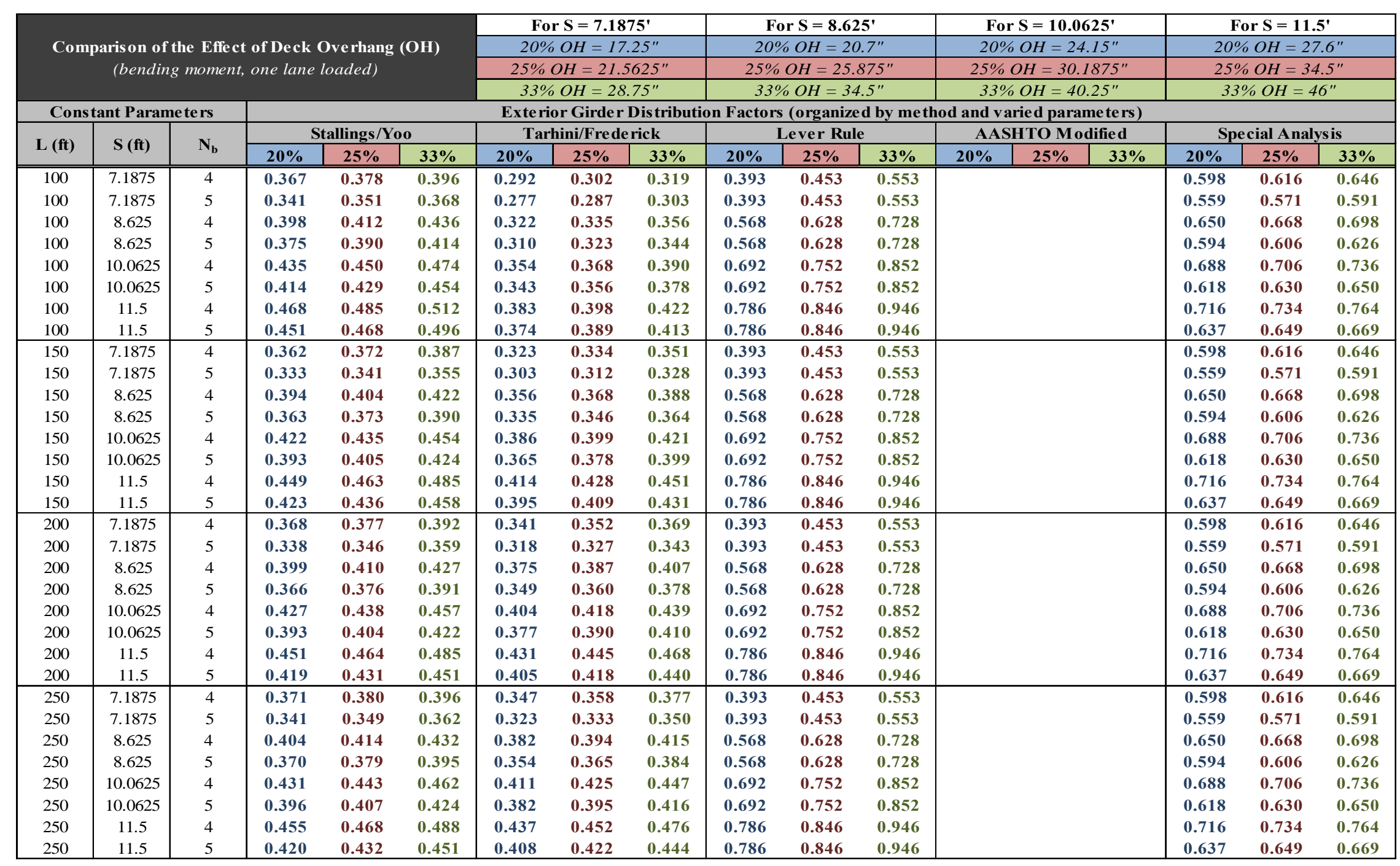




\begin{tabular}{|c|c|c|c|c|c|c|c|c|c|c|c|c|c|c|c|c|c|}
\hline \multirow{4}{*}{\multicolumn{6}{|c|}{$\begin{array}{l}\text { Comparison of the Effect of Deck Overhang (OH) } \\
\text { (bending moment, two lanes loaded) }\end{array}$}} & \multirow{2}{*}{\multicolumn{3}{|c|}{$\begin{array}{c}\text { For } \mathbf{S}=\mathbf{7 . 1 8 7 5}^{\prime} \\
20 \% O H=17.25^{\prime \prime}\end{array}$}} & \multicolumn{3}{|c|}{ For $\mathrm{S}=\mathbf{8 . 6 2 5}$} & \multicolumn{3}{|c|}{ For $\mathrm{S}=10.0625^{\prime}$} & \multicolumn{3}{|c|}{ For $S=11.5^{\prime}$} \\
\hline & & & & & & & & & \multicolumn{3}{|c|}{$20 \% \mathrm{OH}=20.7^{\prime \prime}$} & \multicolumn{3}{|c|}{$20 \% \mathrm{OH}=24.15^{\prime \prime}$} & \multicolumn{3}{|c|}{$20 \% \mathrm{OH}=27.6^{\prime \prime}$} \\
\hline & & & & & & \multicolumn{3}{|c|}{$25 \% \mathrm{OH}=21.5625^{\prime \prime}$} & \multicolumn{3}{|c|}{$25 \% \mathrm{OH}=25.875^{\prime \prime}$} & \multicolumn{3}{|c|}{$25 \% \mathrm{OH}=30.1875^{\prime \prime}$} & \multicolumn{3}{|c|}{$25 \% \mathrm{OH}=34.5^{\prime \prime}$} \\
\hline & & & & & & \multicolumn{3}{|c|}{$33 \% \mathrm{OH}=28.75^{\prime \prime}$} & \multicolumn{3}{|c|}{$33 \% \mathrm{OH}=34.5^{\prime \prime}$} & \multirow{2}{*}{\multicolumn{3}{|c|}{$\frac{33 \% \mathrm{OH}=40.25 "}{\text { od and varie d parameters) }}$}} & \multicolumn{3}{|c|}{$33 \% \mathrm{OH}=46^{\prime \prime}$} \\
\hline \multicolumn{3}{|c|}{ Constant Parameters } & & & & \multicolumn{6}{|c|}{ Exte rior Girder Distribution Factors (organized by me thod and varied parame ters) } & & & & \multirow{2}{*}{\multicolumn{3}{|c|}{ Spe cial Analys is }} \\
\hline \multirow{2}{*}{$\mathbf{L}$ (ft) } & \multirow{2}{*}{$\mathbf{S}(\mathbf{f t})$} & $\mathbf{N}$ & & Ilings $/ Y$ & & & ini/Fred & & & ever R & & $\mathbf{A A s}$ & ITO Mo & ified & & & \\
\hline & & $\mathbf{N}_{\mathrm{b}}$ & $20 \%$ & $25 \%$ & $33 \%$ & $20 \%$ & $25 \%$ & $33 \%$ & $20 \%$ & $25 \%$ & $33 \%$ & $20 \%$ & $25 \%$ & $33 \%$ & $20 \%$ & $25 \%$ & $33 \%$ \\
\hline 100 & 7.1875 & 4 & 0.500 & 0.517 & 0.545 & 0.397 & 0.413 & 0.440 & & & & 0.457 & 0.479 & 0.518 & 0.500 & 0.526 & 0.576 \\
\hline 100 & 7.1875 & 5 & 0.471 & 0.486 & 0.511 & 0.385 & 0.400 & 0.425 & & & & 0.457 & 0.479 & 0.518 & 0.597 & 0.617 & 0.650 \\
\hline 100 & 8.625 & 4 & 0.541 & 0.562 & 0.597 & 0.443 & 0.463 & 0.496 & & & & 0.540 & 0.571 & 0.623 & 0.666 & 0.696 & 0.746 \\
\hline 100 & 8.625 & 5 & 0.502 & 0.522 & 0.557 & 0.421 & 0.441 & 0.473 & & & & 0.540 & 0.571 & 0.623 & 0.711 & 0.731 & 0.764 \\
\hline 100 & 10.0625 & 4 & 0.620 & 0.644 & 0.684 & 0.508 & 0.531 & 0.568 & & & & 0.626 & 0.666 & 0.734 & 0.788 & 0.818 & 0.868 \\
\hline 100 & 10.0625 & 5 & 0.580 & 0.604 & 0.644 & 0.487 & 0.510 & 0.546 & & & & 0.626 & 0.666 & 0.734 & 0.792 & 0.812 & 0.846 \\
\hline 100 & 11.5 & 4 & 0.673 & 0.701 & 0.748 & 0.557 & 0.583 & 0.626 & & & & 0.715 & 0.766 & 0.851 & 0.880 & 0.910 & 0.960 \\
\hline 100 & 11.5 & 5 & 0.638 & 0.666 & 0.713 & 0.539 & 0.565 & 0.607 & & & & 0.715 & 0.766 & 0.851 & 0.853 & 0.873 & 0.907 \\
\hline 150 & 7.1875 & 4 & 0.509 & 0.525 & 0.551 & 0.454 & 0.471 & 0.499 & & & & 0.440 & 0.462 & 0.498 & 0.500 & 0.526 & 0.576 \\
\hline 150 & 7.1875 & 5 & 0.485 & 0.498 & 0.519 & 0.440 & 0.455 & 0.479 & & & & 0.440 & 0.462 & 0.498 & 0.597 & 0.617 & 0.650 \\
\hline 150 & 8.625 & 4 & 0.578 & 0.596 & 0.626 & 0.523 & 0.542 & 0.574 & & & & 0.519 & 0.549 & 0.599 & 0.666 & 0.696 & 0.746 \\
\hline 150 & 8.625 & 5 & 0.539 & 0.554 & 0.581 & 0.496 & 0.513 & 0.543 & & & & 0.519 & 0.549 & 0.599 & 0.711 & 0.731 & 0.764 \\
\hline 150 & 10.0625 & 4 & 0.634 & 0.654 & 0.688 & 0.579 & 0.601 & 0.638 & & & & 0.602 & 0.641 & 0.706 & 0.788 & 0.818 & 0.868 \\
\hline 150 & 10.0625 & 5 & 0.588 & 0.607 & 0.639 & 0.547 & 0.568 & 0.602 & & & & 0.602 & 0.641 & 0.706 & 0.792 & 0.812 & 0.846 \\
\hline 150 & 11.5 & 4 & 0.683 & 0.707 & 0.746 & 0.630 & 0.655 & 0.696 & & & & 0.687 & 0.736 & 0.818 & 0.880 & 0.910 & 0.960 \\
\hline 150 & 11.5 & 5 & 0.637 & 0.660 & 0.698 & 0.597 & 0.621 & 0.661 & & & & 0.687 & 0.736 & 0.818 & 0.853 & 0.873 & 0.907 \\
\hline 200 & 7.1875 & 4 & 0.513 & 0.530 & 0.557 & 0.476 & 0.494 & 0.523 & & & & 0.442 & 0.464 & 0.501 & 0.500 & 0.526 & 0.576 \\
\hline 200 & 7.1875 & 5 & 0.495 & 0.508 & 0.529 & 0.464 & 0.479 & 0.504 & & & & 0.442 & 0.464 & 0.501 & 0.597 & 0.617 & 0.650 \\
\hline 200 & 8.625 & 4 & 0.588 & 0.606 & 0.636 & 0.550 & 0.570 & 0.604 & & & & 0.522 & 0.553 & 0.603 & 0.666 & 0.696 & 0.746 \\
\hline 200 & 8.625 & 5 & 0.553 & 0.568 & 0.593 & 0.523 & 0.541 & 0.570 & & & & 0.522 & 0.553 & 0.603 & 0.711 & 0.731 & 0.764 \\
\hline 200 & 10.0625 & 4 & 0.648 & 0.668 & 0.701 & 0.611 & 0.634 & 0.671 & & & & 0.605 & 0.645 & 0.710 & 0.788 & 0.818 & 0.868 \\
\hline 200 & 10.0625 & 5 & 0.602 & 0.620 & 0.650 & 0.575 & 0.596 & 0.630 & & & & 0.605 & 0.645 & 0.710 & 0.792 & 0.812 & 0.846 \\
\hline 200 & 11.5 & 4 & 0.699 & 0.721 & 0.758 & 0.664 & 0.689 & 0.730 & & & & 0.691 & 0.741 & 0.823 & 0.880 & 0.910 & 0.960 \\
\hline 200 & 11.5 & 5 & 0.649 & 0.670 & 0.704 & 0.624 & 0.648 & 0.686 & & & & 0.691 & 0.741 & 0.823 & 0.853 & 0.873 & 0.907 \\
\hline 250 & 7.1875 & 4 & 0.514 & 0.531 & 0.558 & 0.480 & 0.499 & 0.529 & & & & $0.444^{*}$ & $0.466 *$ & $0.503^{*}$ & 0.500 & 0.526 & 0.576 \\
\hline 250 & 7.1875 & 5 & 0.498 & 0.511 & 0.533 & 0.469 & 0.484 & 0.510 & & & & $0.444 *$ & $0.466^{*}$ & $0.503 *$ & 0.597 & 0.617 & 0.650 \\
\hline 250 & 8.625 & 4 & 0.592 & 0.610 & 0.641 & 0.558 & 0.578 & 0.612 & & & & $0.525^{*}$ & $0.555^{*}$ & $0.605^{*}$ & 0.666 & 0.696 & 0.746 \\
\hline 250 & 8.625 & 5 & 0.558 & 0.573 & 0.599 & 0.530 & 0.548 & 0.578 & & & & $0.525 *$ & $0.555^{*}$ & $0.605^{*}$ & 0.711 & 0.731 & 0.764 \\
\hline 250 & 10.0625 & 4 & 0.654 & 0.674 & 0.708 & 0.620 & 0.643 & 0.681 & & & & $0.608^{*}$ & $0.647^{*}$ & $0.713^{*}$ & 0.788 & 0.818 & 0.868 \\
\hline 250 & 10.0625 & 5 & 0.609 & 0.626 & 0.656 & 0.583 & 0.603 & 0.638 & & & & $0.608 *$ & $0.647^{*}$ & $0.713^{*}$ & 0.792 & 0.812 & 0.846 \\
\hline 250 & 11.5 & 4 & 0.707 & 0.729 & 0.766 & 0.675 & 0.700 & 0.742 & & & & $0.694 *$ & 0.744 * & $0.827 *$ & 0.880 & 0.910 & 0.960 \\
\hline 250 & 11.5 & 5 & 0.655 & 0.675 & 0.709 & 0.631 & 0.655 & 0.694 & & & & $0.694 \%$ & 0.744 * & $0.827 *$ & 0.853 & 0.873 & 0.907 \\
\hline
\end{tabular}




\begin{tabular}{|c|c|c|c|c|c|c|c|c|c|c|c|c|c|c|c|c|c|}
\hline \multirow{4}{*}{\multicolumn{6}{|c|}{$\begin{array}{l}\text { Comparison of the Effect of Deck Overhang (OH) } \\
\text { (bending moment, three lanes loaded) }\end{array}$}} & \multirow{2}{*}{\multicolumn{3}{|c|}{$\begin{array}{c}\text { For } \mathbf{S}=\mathbf{7 . 1 8 7 5}^{\prime} \\
20 \% O H=17.25^{\prime \prime}\end{array}$}} & \multicolumn{3}{|c|}{ For $S=8.625^{\prime}$} & \multicolumn{3}{|c|}{ For $\mathrm{S}=10.0625^{\prime}$} & \multicolumn{3}{|c|}{ For $S=11.5^{\prime}$} \\
\hline & & & & & & & & & \multicolumn{3}{|c|}{$20 \% \mathrm{OH}=20.7^{\prime \prime}$} & \multicolumn{3}{|c|}{$20 \% \mathrm{OH}=24.15^{\prime \prime}$} & \multicolumn{3}{|c|}{$20 \% \mathrm{OH}=27.6^{\prime \prime}$} \\
\hline & & & & & & \multicolumn{3}{|c|}{$20 \% \mathrm{OH}=17.25$} & \multicolumn{3}{|c|}{$25 \% \mathrm{OH}=25.875^{\prime \prime}$} & \multicolumn{3}{|c|}{$25 \% \mathrm{OH}=30.1875^{\prime \prime}$} & \multicolumn{3}{|c|}{$25 \% \mathrm{OH}=34.5^{\prime \prime}$} \\
\hline & & & & & & \multicolumn{3}{|c|}{$33 \% \mathrm{OH}=28.75^{\prime \prime}$} & \multicolumn{3}{|c|}{$33 \% \mathrm{OH}=34.5^{\prime \prime}$} & \multicolumn{3}{|c|}{$33 \% \mathrm{OH}=40.25^{\prime \prime}$} & \multicolumn{3}{|c|}{$33 \% \mathrm{OH}=46^{\prime \prime}$} \\
\hline \multicolumn{3}{|c|}{ Constant Parameters } & & & & \multicolumn{9}{|c|}{ Exte rior Girder Distribution Factors (organized by me thod and varied parame ters) } & & & \\
\hline \multirow{2}{*}{$\mathbf{L}$ (ft) } & \multirow{2}{*}{$\mathbf{S}(\mathbf{f t})$} & $\mathbf{N}$ & & lings $/ 1$ & & TaI & ni/Fred & & & ver Ru & & AAS & ITO Mo & ified & \multicolumn{3}{|c|}{ Special Analysis } \\
\hline & & $N_{b}$ & $20 \%$ & $25 \%$ & $33 \%$ & $20 \%$ & $25 \%$ & $33 \%$ & $20 \%$ & $25 \%$ & $33 \%$ & $20 \%$ & $25 \%$ & $33 \%$ & $20 \%$ & $25 \%$ & $33 \%$ \\
\hline 100 & 7.1875 & 4 & & & & & & & & & & & & & & & \\
\hline 100 & 7.1875 & 5 & & & & & & & & & & & & & & & \\
\hline 100 & 8.625 & 4 & & & & & & & & & & & & & & & \\
\hline 100 & 8.625 & 5 & & 0.579 & 0.616 & & 0.489 & 0.524 & & & & & 0.571 & 0.623 & & 0.577 & 0.620 \\
\hline 100 & 10.0625 & 4 & & & & & & & & & & & & & & & \\
\hline 100 & 10.0625 & 5 & 0.656 & 0.676 & 0.720 & 0.545 & 0.574 & 0.616 & & & & 0.626 & 0.666 & 0.734 & 0.706 & 0.731 & 0.774 \\
\hline 100 & 11.5 & 4 & 0.761 & 0.794 & 0.848 & 0.632 & 0.663 & 0.714 & & & & 0.715 & 0.766 & 0.851 & 0.723 & 0.761 & 0.825 \\
\hline 100 & 11.5 & 5 & 0.714 & 0.746 & 0.799 & 0.609 & 0.639 & 0.689 & & & & 0.715 & 0.766 & 0.851 & 0.822 & 0.847 & 0.890 \\
\hline 150 & 7.1875 & 4 & & & & & & & & & & & & & & & \\
\hline 150 & 7.1875 & 5 & & & & & & & & & & & & & & & \\
\hline 150 & 8.625 & 4 & & & & & & & & & & & & & & & \\
\hline 150 & 8.625 & 5 & & 0.640 & 0.672 & & 0.592 & 0.628 & & & & & 0.549 & 0.599 & & 0.577 & 0.620 \\
\hline 150 & 10.0625 & 4 & & & & & & & & & & & & & & & \\
\hline 150 & 10.0625 & 5 & 0.693 & 0.711 & 0.749 & 0.635 & 0.665 & 0.706 & & & & 0.602 & 0.641 & 0.706 & 0.706 & 0.731 & 0.774 \\
\hline 150 & 11.5 & 4 & 0.800 & 0.829 & 0.877 & 0.738 & 0.769 & 0.820 & & & & 0.687 & 0.736 & 0.818 & 0.723 & 0.761 & 0.825 \\
\hline 150 & 11.5 & 5 & 0.749 & 0.776 & 0.820 & 0.702 & 0.731 & 0.779 & & & & 0.687 & 0.736 & 0.818 & 0.822 & 0.847 & 0.890 \\
\hline 200 & 7.1875 & 4 & & & & & & & & & & & & & & & \\
\hline 200 & 7.1875 & 5 & & & & & & & & & & & & & & & \\
\hline 200 & 8.625 & 4 & & & & & & & & & & & & & & & \\
\hline 200 & 8.625 & 5 & & 0.656 & 0.688 & & 0.625 & 0.661 & & & & & 0.553 & 0.603 & & 0.577 & 0.620 \\
\hline 200 & 10.0625 & 4 & & & & & & & & & & & & & & & \\
\hline 200 & 10.0625 & 5 & 0.718 & 0.735 & 0.771 & 0.675 & 0.705 & 0.746 & & & & 0.605 & 0.645 & 0.710 & 0.706 & 0.731 & 0.774 \\
\hline 200 & 11.5 & 4 & 0.822 & 0.850 & 0.898 & 0.781 & 0.812 & 0.864 & & & & 0.691 & 0.741 & 0.823 & 0.723 & 0.761 & 0.825 \\
\hline 200 & 11.5 & 5 & 0.777 & 0.802 & 0.844 & 0.746 & 0.775 & 0.821 & & & & 0.691 & 0.741 & 0.823 & 0.822 & 0.847 & 0.890 \\
\hline 250 & 7.1875 & 4 & & & & & & & & & & & & & & & \\
\hline 250 & 7.1875 & 5 & & & & & & & & & & & & & & & \\
\hline 250 & 8.625 & 4 & & & & & & & & & & & & & & & \\
\hline 250 & 8.625 & 5 & & 0.661 & 0.694 & & 0.631 & 0.668 & & & & & $0.555^{*}$ & $0.605^{*}$ & & 0.577 & 0.620 \\
\hline 250 & 10.0625 & 4 & & & & & & & & & & & & & & & \\
\hline 250 & 10.0625 & 5 & 0.727 & 0.743 & 0.780 & 0.683 & 0.714 & 0.756 & & & & $0.608 *$ & $0.647 *$ & $0.713^{*}$ & 0.706 & 0.731 & 0.774 \\
\hline 250 & 11.5 & 4 & 0.830 & 0.859 & 0.906 & 0.791 & 0.823 & 0.876 & & & & 0.694 * & $0.744 \%$ & $0.827 *$ & 0.723 & 0.761 & 0.825 \\
\hline 250 & 11.5 & 5 & 0.788 & 0.813 & 0.854 & 0.757 & 0.785 & 0.832 & & & & $0.694 *$ & $0.744 *$ & $0.827 *$ & 0.822 & 0.847 & 0.890 \\
\hline
\end{tabular}




\section{APPENDIX D: COMPARISON OF PROPOSED EQUATIONS}

The following appendix lists in tabular form the comparison of distribution factors calculated from the finite element models of Parametric Variation \#2 discussed in Section 6.3 and the equations derived form that data (Equation 7-1 and Equation 7-2) in Chapter 7. For the reader's convenience, this data has been organized such that each table has the comparison for each equation listed next to its comparable distribution factor obtained from Parametric Variation \#2. These tables are then further discretized based on the number of lanes loaded.

It should be noted that these distribution factors will differ from those listed in Appendix $\mathrm{C}$ as each value has been multiplied by the appropriate multiple presence factor (described in Section 3.3.1).

In these tables, the following nomenclature is used.

- $\mathrm{S}=$ girder spacing (feet)

- $\mathrm{L}=$ span length (feet)

- $\mathrm{N}_{\mathrm{b}}=$ number of beams

- $\mathrm{OH}=$ overhang width (inches) 


\begin{tabular}{|c|c|c|c|c|c|c|c|c|}
\hline \multicolumn{9}{|c|}{ Comparis on of Proposed Equations } \\
\hline \multicolumn{5}{|c|}{ Varied Parame ters } & \multicolumn{4}{|c|}{ Exterior Girder DFs } \\
\hline \multirow{2}{*}{ L (ft) } & \multirow{2}{*}{$S$ (ft) } & \multirow{2}{*}{$\mathbf{N}_{\mathbf{b}}$} & \multicolumn{2}{|c|}{ OH (in) } & \multicolumn{2}{|c|}{ One Lane } & \multicolumn{2}{|c|}{ Multiple Lanes } \\
\hline & & & $\%$ & Value & FEA & Eq. 7-1 & FEA & Eq. 7-2 \\
\hline 100 & 7.1875 & 4 & $20 \%$ & 17.25 & 0.441 & 0.443 & 0.500 & 0.495 \\
\hline 100 & 7.1875 & 4 & $25 \%$ & 21.5625 & 0.454 & 0.458 & 0.517 & 0.514 \\
\hline 100 & 7.1875 & 4 & $33 \%$ & 28.75 & 0.475 & 0.477 & 0.545 & 0.539 \\
\hline 100 & 7.1875 & 5 & $20 \%$ & 17.25 & 0.409 & 0.412 & 0.471 & 0.466 \\
\hline 100 & 7.1875 & 5 & $25 \%$ & 21.5625 & 0.421 & 0.425 & 0.486 & 0.484 \\
\hline 100 & 7.1875 & 5 & $33 \%$ & 28.75 & 0.441 & 0.443 & 0.511 & 0.507 \\
\hline 100 & 8.625 & 4 & $20 \%$ & 20.7 & 0.477 & 0.485 & 0.541 & 0.558 \\
\hline 100 & 8.625 & 4 & $25 \%$ & 25.875 & 0.494 & 0.501 & 0.562 & 0.579 \\
\hline 100 & 8.625 & 4 & $33 \%$ & 34.5 & 0.523 & 0.522 & 0.597 & 0.607 \\
\hline 100 & 8.625 & 5 & $20 \%$ & 20.7 & 0.450 & 0.451 & 0.502 & 0.525 \\
\hline 100 & 8.625 & 5 & $25 \%$ & 25.875 & 0.468 & 0.465 & 0.522 & 0.545 \\
\hline 100 & 8.625 & 5 & $33 \%$ & 34.5 & 0.496 & 0.485 & 0.557 & 0.571 \\
\hline 100 & 10.0625 & 4 & $20 \%$ & 24.15 & 0.522 & 0.523 & 0.620 & 0.617 \\
\hline 100 & 10.0625 & 4 & $25 \%$ & 30.1875 & 0.540 & 0.540 & 0.644 & 0.640 \\
\hline 100 & 10.0625 & 4 & $33 \%$ & 40.25 & 0.569 & 0.563 & 0.684 & 0.671 \\
\hline 100 & 10.0625 & 5 & $20 \%$ & 24.15 & 0.497 & 0.486 & 0.580 & 0.581 \\
\hline 100 & 10.0625 & 5 & $25 \%$ & 30.1875 & 0.515 & 0.502 & 0.604 & 0.602 \\
\hline 100 & 10.0625 & 5 & $33 \%$ & 40.25 & 0.545 & 0.524 & 0.644 & 0.631 \\
\hline 100 & 11.5 & 4 & $20 \%$ & 27.6 & 0.561 & 0.559 & 0.673 & 0.673 \\
\hline 100 & 11.5 & 4 & $25 \%$ & 34.5 & 0.582 & 0.577 & 0.701 & 0.698 \\
\hline 100 & 11.5 & 4 & $33 \%$ & 46 & 0.615 & 0.602 & 0.748 & 0.732 \\
\hline 100 & 11.5 & 5 & $20 \%$ & 27.6 & 0.541 & 0.519 & 0.638 & 0.633 \\
\hline 100 & 11.5 & 5 & $25 \%$ & 34.5 & 0.562 & 0.536 & 0.666 & 0.657 \\
\hline 100 & 11.5 & 5 & $33 \%$ & 46 & 0.596 & 0.559 & 0.713 & 0.689 \\
\hline
\end{tabular}

\begin{tabular}{|c|c|c|c|c|c|c|c|c|}
\hline \multicolumn{9}{|c|}{ Comparis on of Proposed Equations } \\
\hline \multicolumn{5}{|c|}{ Varied Parameters } & \multicolumn{4}{|c|}{ Exte rior Girder DFs } \\
\hline \multirow{2}{*}{$\mathbf{L}$ (ft) } & \multirow{2}{*}{$S$ (ft) } & \multirow{2}{*}{$\mathbf{N}_{\mathbf{b}}$} & \multicolumn{2}{|c|}{ OH (in) } & \multicolumn{2}{|c|}{ One Lane } & \multicolumn{2}{|c|}{ Multiple Lanes } \\
\hline & & & $\%$ & Value & FEA & Eq. $7-1$ & FEA & Eq. 7-2 \\
\hline 150 & 7.1875 & 4 & $20 \%$ & 17.25 & 0.435 & 0.438 & 0.509 & 0.507 \\
\hline 150 & 7.1875 & 4 & $25 \%$ & 21.5625 & 0.446 & 0.452 & 0.525 & 0.526 \\
\hline 150 & 7.1875 & 4 & $33 \%$ & 28.75 & 0.464 & 0.471 & 0.551 & 0.552 \\
\hline 150 & 7.1875 & 5 & $20 \%$ & 17.25 & 0.399 & 0.407 & 0.485 & 0.477 \\
\hline 150 & 7.1875 & 5 & $25 \%$ & 21.5625 & 0.409 & 0.420 & 0.498 & 0.495 \\
\hline 150 & 7.1875 & 5 & $33 \%$ & 28.75 & 0.426 & 0.438 & 0.519 & 0.519 \\
\hline 150 & 8.625 & 4 & $20 \%$ & 20.7 & 0.473 & 0.479 & 0.578 & 0.571 \\
\hline 150 & 8.625 & 4 & $25 \%$ & 25.875 & 0.485 & 0.495 & 0.596 & 0.592 \\
\hline 150 & 8.625 & 4 & $33 \%$ & 34.5 & 0.507 & 0.516 & 0.626 & 0.621 \\
\hline 150 & 8.625 & 5 & $20 \%$ & 20.7 & 0.436 & 0.445 & 0.539 & 0.538 \\
\hline 150 & 8.625 & 5 & $25 \%$ & 25.875 & 0.448 & 0.460 & 0.554 & 0.558 \\
\hline 150 & 8.625 & 5 & $33 \%$ & 34.5 & 0.468 & 0.479 & 0.581 & 0.585 \\
\hline 150 & 10.0625 & 4 & $20 \%$ & 24.15 & 0.507 & 0.517 & 0.634 & 0.632 \\
\hline 150 & 10.0625 & 4 & $25 \%$ & 30.1875 & 0.521 & 0.534 & 0.654 & 0.655 \\
\hline 150 & 10.0625 & 4 & $33 \%$ & 40.25 & 0.545 & 0.556 & 0.688 & 0.687 \\
\hline 150 & 10.0625 & 5 & $20 \%$ & 24.15 & 0.472 & 0.480 & 0.589 & 0.594 \\
\hline 150 & 10.0625 & 5 & $25 \%$ & 30.1875 & 0.486 & 0.496 & 0.607 & 0.617 \\
\hline 150 & 10.0625 & 5 & $33 \%$ & 40.25 & 0.509 & 0.517 & 0.639 & 0.646 \\
\hline 150 & 11.5 & 4 & $20 \%$ & 27.6 & 0.539 & 0.552 & 0.683 & 0.689 \\
\hline 150 & 11.5 & 4 & $25 \%$ & 34.5 & 0.555 & 0.570 & 0.707 & 0.715 \\
\hline 150 & 11.5 & 4 & $33 \%$ & 46 & 0.581 & 0.594 & 0.746 & 0.749 \\
\hline 150 & 11.5 & 5 & $20 \%$ & 27.6 & 0.507 & 0.513 & 0.637 & 0.648 \\
\hline 150 & 11.5 & 5 & $25 \%$ & 34.5 & 0.524 & 0.530 & 0.660 & 0.673 \\
\hline 150 & 11.5 & 5 & $33 \%$ & 46 & 0.549 & 0.552 & 0.698 & 0.705 \\
\hline
\end{tabular}




\begin{tabular}{|c|c|c|c|c|c|c|c|c|}
\hline \multicolumn{9}{|c|}{ Comparis on of Proposed Equations } \\
\hline \multicolumn{5}{|c|}{ Varied Parameters } & \multicolumn{4}{|c|}{ Exterior Girder DFs } \\
\hline \multirow{2}{*}{ L (ft) } & \multirow{2}{*}{$\mathbf{S}(\mathbf{f t})$} & \multirow{2}{*}{$\mathbf{N}_{\mathbf{b}}$} & \multicolumn{2}{|c|}{ OH (in) } & \multicolumn{2}{|c|}{ One Lane } & \multicolumn{2}{|c|}{ Multiple Lanes } \\
\hline & & & $\%$ & Value & FEA & Eq. 7-1 & FEA & Eq. 7-2 \\
\hline 200 & 7.1875 & 4 & $20 \%$ & 17.25 & 0.441 & 0.434 & 0.513 & 0.516 \\
\hline 200 & 7.1875 & 4 & $25 \%$ & 21.5625 & 0.452 & 0.448 & 0.530 & 0.535 \\
\hline 200 & 7.1875 & 4 & $33 \%$ & 28.75 & 0.471 & 0.467 & 0.557 & 0.561 \\
\hline 200 & 7.1875 & 5 & $20 \%$ & 17.25 & 0.405 & 0.403 & 0.495 & 0.485 \\
\hline 200 & 7.1875 & 5 & $25 \%$ & 21.5625 & 0.415 & 0.417 & 0.508 & 0.503 \\
\hline 200 & 7.1875 & 5 & $33 \%$ & 28.75 & 0.431 & 0.434 & 0.529 & 0.528 \\
\hline 200 & 8.625 & 4 & $20 \%$ & 20.7 & 0.479 & 0.475 & 0.588 & 0.581 \\
\hline 200 & 8.625 & 4 & $25 \%$ & 25.875 & 0.491 & 0.490 & 0.606 & 0.602 \\
\hline 200 & 8.625 & 4 & $33 \%$ & 34.5 & 0.512 & 0.511 & 0.636 & 0.632 \\
\hline 200 & 8.625 & 5 & $20 \%$ & 20.7 & 0.440 & 0.441 & 0.553 & 0.547 \\
\hline 200 & 8.625 & 5 & $25 \%$ & 25.875 & 0.451 & 0.456 & 0.568 & 0.567 \\
\hline 200 & 8.625 & 5 & $33 \%$ & 34.5 & 0.470 & 0.475 & 0.593 & 0.594 \\
\hline 200 & 10.0625 & 4 & $20 \%$ & 24.15 & 0.512 & 0.512 & 0.648 & 0.642 \\
\hline 200 & 10.0625 & 4 & $25 \%$ & 30.1875 & 0.526 & 0.529 & 0.668 & 0.666 \\
\hline 200 & 10.0625 & 4 & $33 \%$ & 40.25 & 0.549 & 0.552 & 0.701 & 0.698 \\
\hline 200 & 10.0625 & 5 & $20 \%$ & 24.15 & 0.472 & 0.476 & 0.610 & 0.604 \\
\hline 200 & 10.0625 & 5 & $25 \%$ & 30.1875 & 0.485 & 0.492 & 0.624 & 0.627 \\
\hline 200 & 10.0625 & 5 & $33 \%$ & 40.25 & 0.506 & 0.513 & 0.655 & 0.657 \\
\hline 200 & 11.5 & 4 & $20 \%$ & 27.6 & 0.542 & 0.547 & 0.699 & 0.701 \\
\hline 200 & 11.5 & 4 & $25 \%$ & 34.5 & 0.557 & 0.565 & 0.723 & 0.727 \\
\hline 200 & 11.5 & 4 & $33 \%$ & 46 & 0.582 & 0.589 & 0.763 & 0.762 \\
\hline 200 & 11.5 & 5 & $20 \%$ & 27.6 & 0.503 & 0.509 & 0.660 & 0.659 \\
\hline 200 & 11.5 & 5 & $25 \%$ & 34.5 & 0.518 & 0.525 & 0.682 & 0.684 \\
\hline 200 & 11.5 & 5 & $33 \%$ & 46 & 0.541 & 0.548 & 0.717 & 0.717 \\
\hline
\end{tabular}

\begin{tabular}{|c|c|c|c|c|c|c|c|c|}
\hline \multicolumn{9}{|c|}{ Comparis on of Proposed Equations } \\
\hline \multicolumn{5}{|c|}{ Varied Parameters } & \multicolumn{4}{|c|}{ Exte rior Girder DFs } \\
\hline \multirow{2}{*}{$\mathbf{L}(\mathbf{f t})$} & \multirow{2}{*}{$S$ (ft) } & \multirow{2}{*}{$\mathbf{N}_{\mathbf{b}}$} & \multicolumn{2}{|c|}{ OH (in) } & \multicolumn{2}{|c|}{ One Lane } & \multicolumn{2}{|c|}{ Multiple Lanes } \\
\hline & & & $\%$ & Value & FEA & Eq. 7-1 & FEA & Eq. 7-2 \\
\hline 250 & 7.1875 & 4 & $20 \%$ & 17.25 & 0.445 & 0.431 & 0.514 & 0.522 \\
\hline 250 & 7.1875 & 4 & $25 \%$ & 21.5625 & 0.457 & 0.445 & 0.531 & 0.542 \\
\hline 250 & 7.1875 & 4 & $33 \%$ & 28.75 & 0.476 & 0.464 & 0.558 & 0.568 \\
\hline 250 & 7.1875 & 5 & $20 \%$ & 17.25 & 0.409 & 0.401 & 0.498 & 0.492 \\
\hline 250 & 7.1875 & 5 & $25 \%$ & 21.5625 & 0.419 & 0.414 & 0.511 & 0.510 \\
\hline 250 & 7.1875 & 5 & $33 \%$ & 28.75 & 0.435 & 0.431 & 0.533 & 0.535 \\
\hline 250 & 8.625 & 4 & $20 \%$ & 20.7 & 0.484 & 0.472 & 0.592 & 0.588 \\
\hline 250 & 8.625 & 4 & $25 \%$ & 25.875 & 0.497 & 0.487 & 0.610 & 0.610 \\
\hline 250 & 8.625 & 4 & $33 \%$ & 34.5 & 0.518 & 0.508 & 0.641 & 0.640 \\
\hline 250 & 8.625 & 5 & $20 \%$ & 20.7 & 0.444 & 0.438 & 0.558 & 0.554 \\
\hline 250 & 8.625 & 5 & $25 \%$ & 25.875 & 0.455 & 0.453 & 0.573 & 0.574 \\
\hline 250 & 8.625 & 5 & $33 \%$ & 34.5 & 0.474 & 0.472 & 0.599 & 0.602 \\
\hline 250 & 10.0625 & 4 & $20 \%$ & 24.15 & 0.517 & 0.509 & 0.654 & 0.651 \\
\hline 250 & 10.0625 & 4 & $25 \%$ & 30.1875 & 0.531 & 0.526 & 0.674 & 0.675 \\
\hline 250 & 10.0625 & 4 & $33 \%$ & 40.25 & 0.554 & 0.548 & 0.708 & 0.707 \\
\hline 250 & 10.0625 & 5 & $20 \%$ & 24.15 & 0.475 & 0.473 & 0.618 & 0.612 \\
\hline 250 & 10.0625 & 5 & $25 \%$ & 30.1875 & 0.488 & 0.489 & 0.632 & 0.635 \\
\hline 250 & 10.0625 & 5 & $33 \%$ & 40.25 & 0.509 & 0.509 & 0.663 & 0.666 \\
\hline 250 & 11.5 & 4 & $20 \%$ & 27.6 & 0.546 & 0.544 & 0.707 & 0.710 \\
\hline 250 & 11.5 & 4 & $25 \%$ & 34.5 & 0.561 & 0.561 & 0.730 & 0.736 \\
\hline 250 & 11.5 & 4 & $33 \%$ & 46 & 0.586 & 0.585 & 0.770 & 0.772 \\
\hline 250 & 11.5 & 5 & $20 \%$ & 27.6 & 0.504 & 0.505 & 0.670 & 0.668 \\
\hline 250 & 11.5 & 5 & $25 \%$ & 34.5 & 0.518 & 0.522 & 0.691 & 0.693 \\
\hline 250 & 11.5 & 5 & $33 \%$ & 46 & 0.541 & 0.544 & 0.726 & 0.726 \\
\hline
\end{tabular}

